\title{
Aspectos éticos de la comunicación de la Investigación e Innovación Responsable (RRI) en la universidad
}
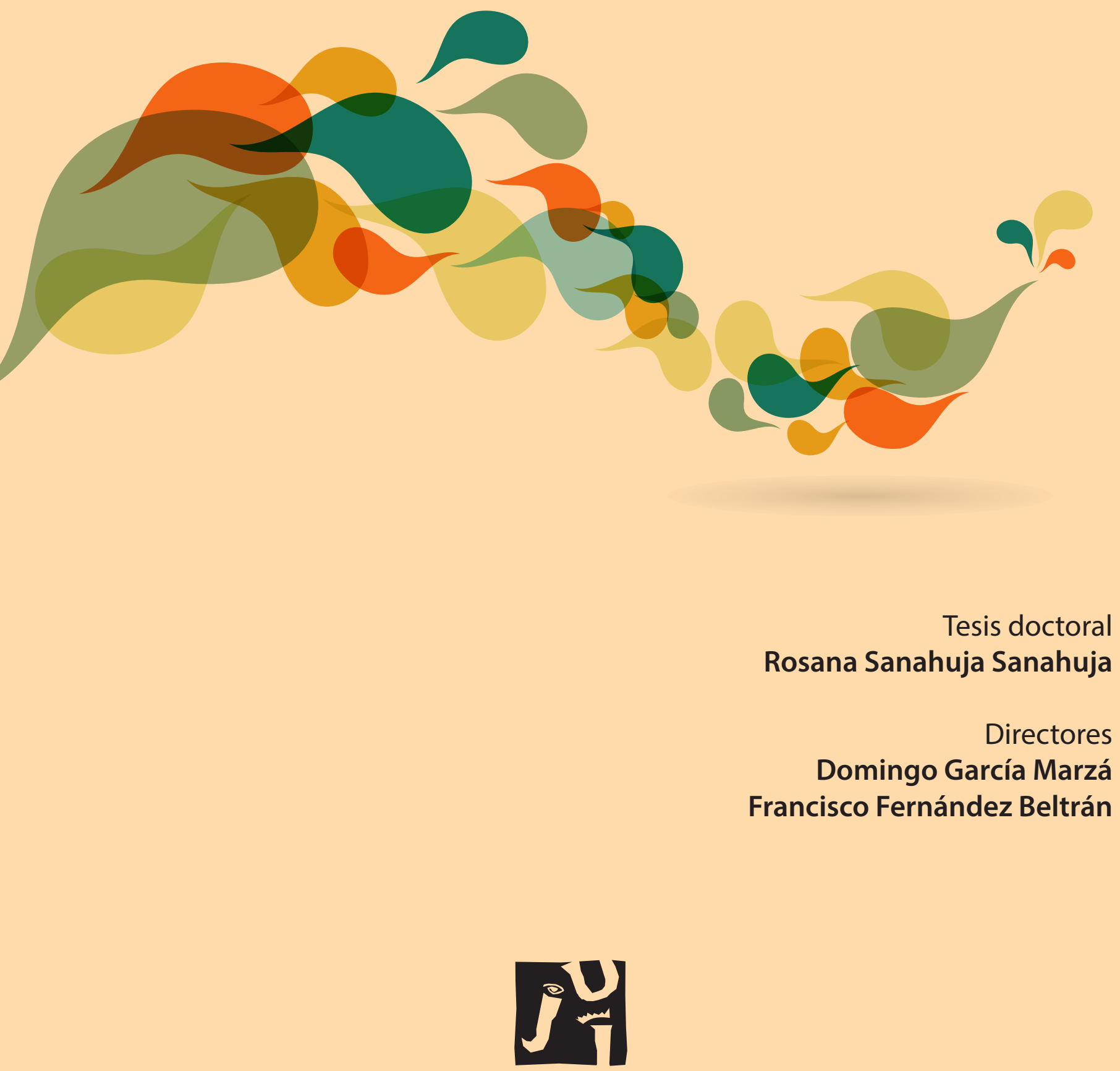

UNIVERSITAT

JAUME•I 


\section{Aspectos éticos de la comunicación de la Investigación e Innovación Responsable (RRI) en la universidad}

TESIS DOCTORAL

Rosana Sanahuja Sanahuja

Directores:

Domingo García Marzá

Francisco Fernández Beltrán

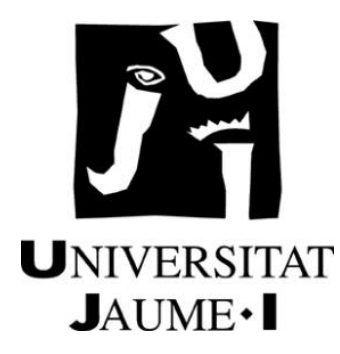

Facultad de Ciencias Humanas y Sociales Departamento de Ciencias de la Comunicación Castellón, diciembre de 2015 
Aspectos éticos de la comunicación de la Investigación e Innovación Responsable (RRI) en la universidad

Doctoranda: Rosana Sanahuja

Directores: Domingo García Marzá y Francisco Fernández Beltrán

Universitat Jaume I, 2015

*Diseño de cubiertas Alicia Andrés a partir de imagen diseñada por Freepik.com 


\section{Dedicatorias y agradecimientos}

A mis padres, por la educación y los valores que nos han dado, por haber sido y ser un ejemplo.

A Josep, por la confianza, por ser una ayuda y un aliado indispensable, pels somriures.

A mis hermanas, cuñadas, cuñados, a Júlia y Anna, a Vicenta, a mis sobrinas y sobrinos, por estar siempre dispuestos a echar una mano, por ser una familia de la que sentirse orgullosa.

A Paco y a Domingo, por animarme a emprender nuevos caminos personales y profesionales, por contar conmigo, por guiarme en esta aventura.

A las compañeras del trabajo, por ser más que compañeras.

A Alicia, Elsa, Patrici y Lauren, por la ayuda con la tesis.

A todos los que han participado en las encuestas, grupos de discusión y panel de expertos.

A los miembros del tribunal.

Y especialmente, a Martí y Manel, por impulsarme a mejorar, por transformarlo todo. 



\section{ÍNDICE}

I. PRESENTACIÓN Y CONTEXTUALIZACIÓN DE LA INVESTIGACIÓN..................... 9

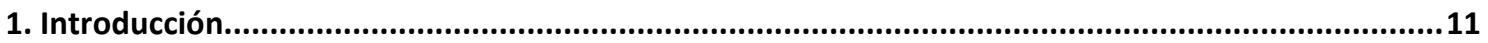

2. Interés del tema y motivación .......................................................................................................15

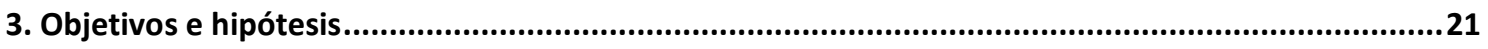

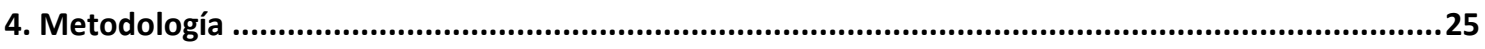

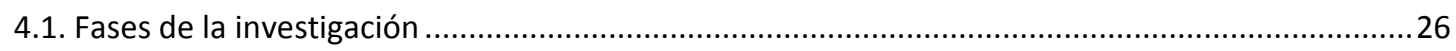

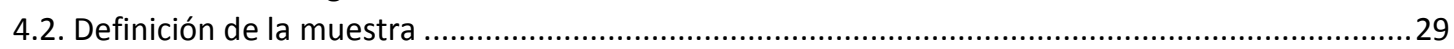

4.3. Técnicas e instrumentos de la investigación .............................................................................

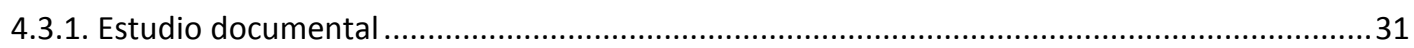

4.3.2. Cuestionario a los responsables de comunicación de la ciencia en el ámbito universitario

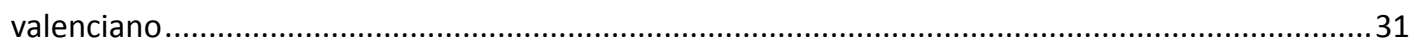

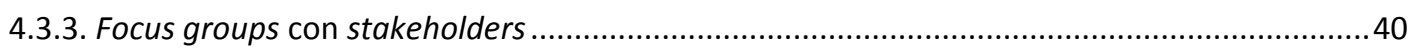

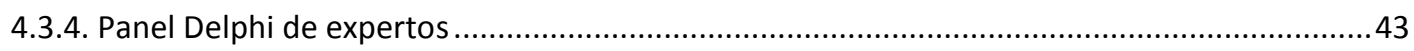

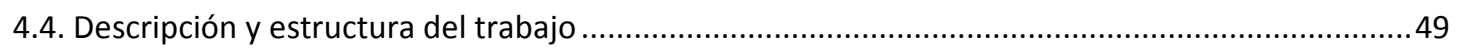

\section{EL MARCO ÉTICO DE LA INVESTIGACIÓN E INNOVACIÓN RESPONSABLE}

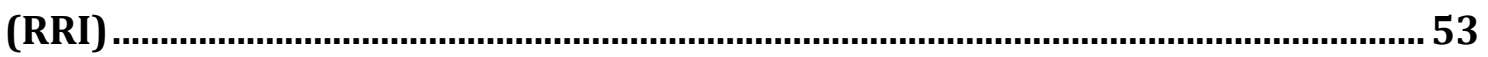

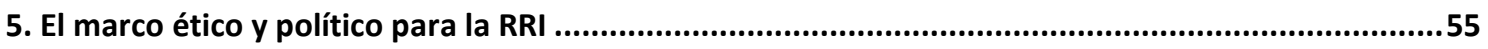

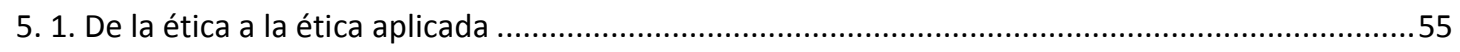

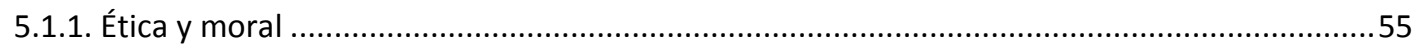

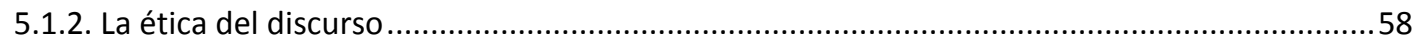

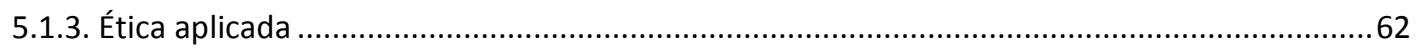

5.1.4. La ética aplicada a la ciencia y a su comunicación...........................................................66

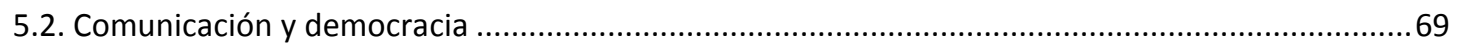

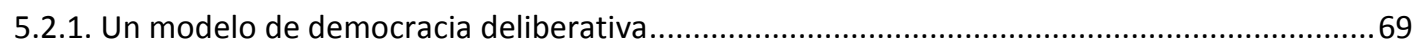

5.2.2. Aplicación de la ética del discurso al ámbito económico .....................................................74

5.2.3. Aplicación de la ética del discurso al ámbito político .......................................................76

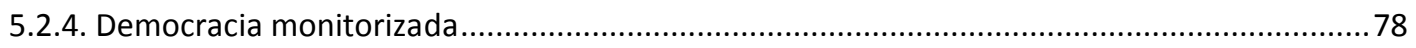

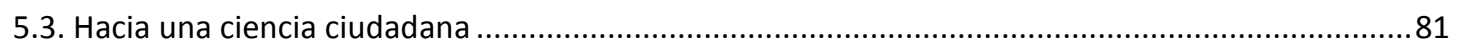

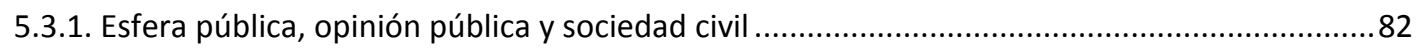

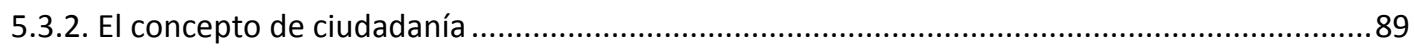

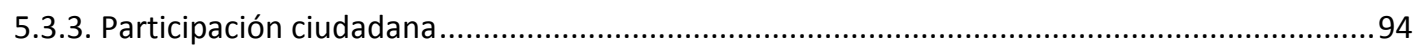

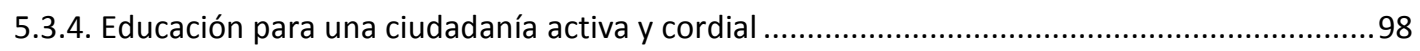

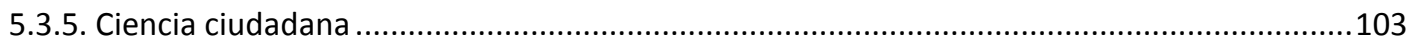

6. Innvestigación e Innovación Responsable: Una aproximación al concepto ..................................107

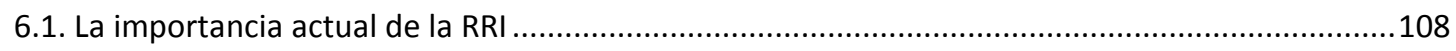

6.2. La Responsabilidad Social Empresarial como referente ...........................................................111

6.2.1 Una aproximación a la historia de la RSE........................................................................112

6.2.2. El concepto de responsabilidad ....................................................................................... 119

6.2.3. Ética y RSE desde la perspectiva de la Escuela de Valencia ................................................123

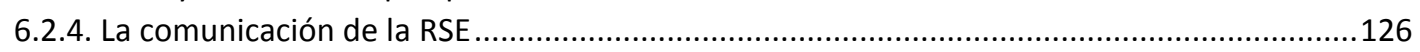

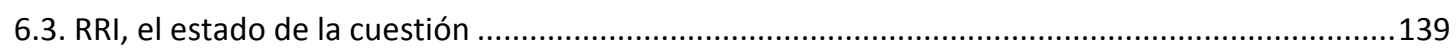

6.3.1. El estado de la cuestión, planteamientos teóricos ............................................................144 


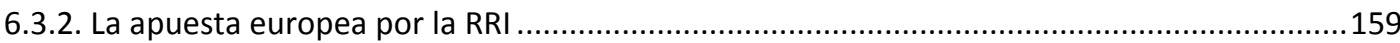

6.3.2. Ejemplos de buenas prácticas.................................................................................... 164

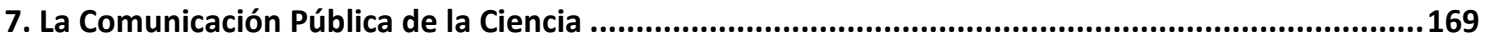

7.1. Comunicación de la ciencia: Una apuesta por la responsabilidad ...........................................170

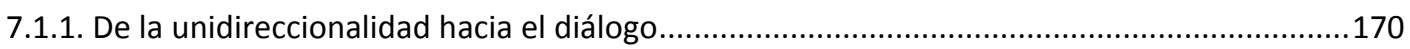

7.1.2. Razones y reflexiones en torno a la comunicación de la ciencia ........................................177

7.1.3. Percepción y actitudes hacia la ciencia...............................................................................189

7.1.4. Cultura científica: la gestión de la participación .............................................................197

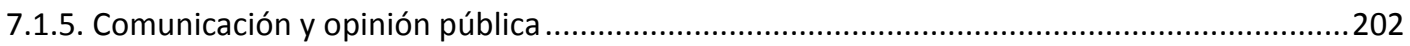

7.2. La explosión de la comunicación de la ciencia ............................................................................205

7.2.1. La explosión del periodismo en la nueva galaxia mediática ....................................................206

7.2.2. La explosión de la comunicación de la ciencia en España: avances y retos .........................219

7.3. La comunicación de la ciencia como parte de la función de las universidades ............................2232

7.3.1. Comunicación y transmisión de la ciencia, funciones de la Universidad.............................233

7.3.2. Retos a superar en la comunicación y formación universitaria ..............................................238

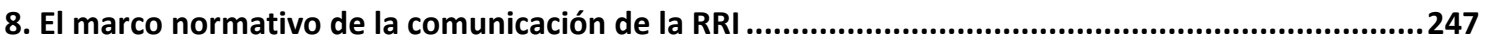

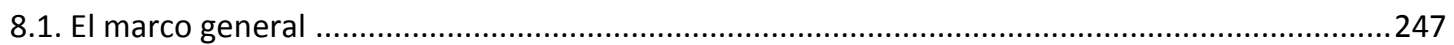

8.1.1. Carta de Derechos Fundamentales de la Unión Europea ...................................................248

8.1.2. Tratado de la Unión Europea .............................................................................................249

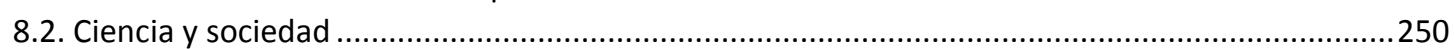

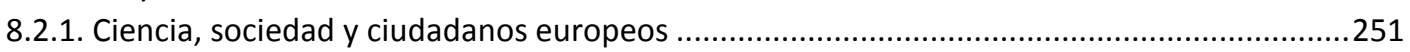

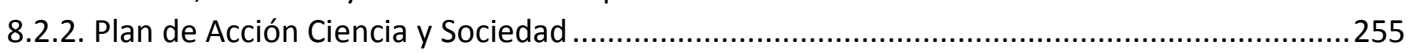

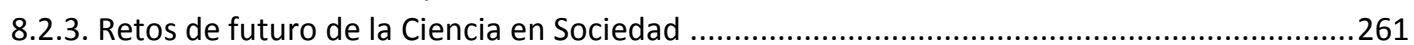

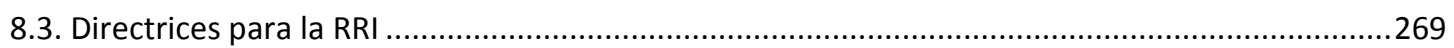

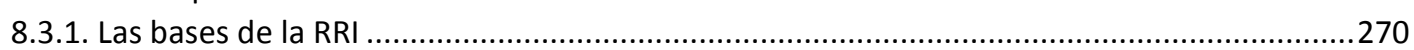

8.3.2. La RRI como respuesta a los retos de la sociedad ................................................................273

8.3.3. "Ciencia con y para la Sociedad" y RRI en Horizonte 2020 .................................................2 274

\section{UNA PROPUESTA DE MODELO DE COMUNICACIÓN ÉTICA DE LA RRI EN LA UNIVERSIDAD ................................................................................................. 281}

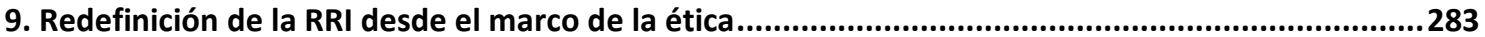

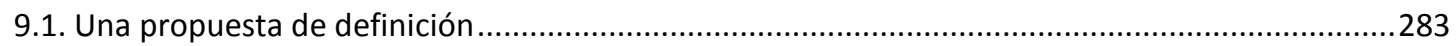

9.2. Los grupos de interés de la ciencia .............................................................................................294

9.2.1. Desarrollo de un mapa de stakeholders de la RRI ............................................................294

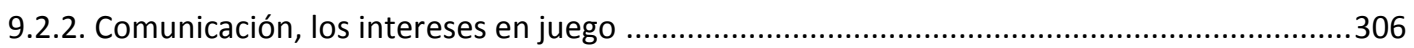

10. Un modelo de comunicación de la RRI para la universidad .....................................................319

10.1. Un modelo ético de comunicación para el diálogo y la acción ...................................................319

10.2. Respuestas para la responsabilidad y la comunicación de la ciencia .........................................331

\section{PRESENTE Y FUTURO DE LA COMUNICACIÓN DE LA RRI EN LA}

UNIVERSIDAD ................................................................................................ 339

11. La comunicación de la ciencia en la universidad. El caso de las universidades valencianas ..........341

11.1. Análisis de las acciones de comunicación de la ciencia de las universidades valencianas ..........341

11.1.1. Estructura y valoración de la comunicación de la ciencia ....................................................342

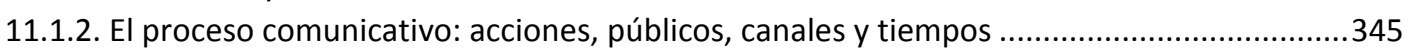

11.1.3. Ética y responsabilidad en la comunicación de la ciencia...................................................382

11.2. Consideraciones sobre la comunicación actual de la ciencia respecto al modelo propuesto .....388 
12. La visión de los stakeholders sobre la comunicación ética de la RRI en la universidad

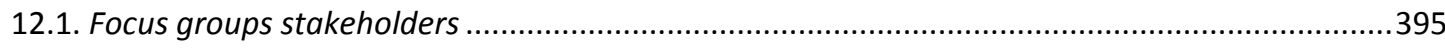

12.1.1. Receptores de la comunicación de la ciencia .................................................................395

12.1.2. Emisores de la comunicación de la ciencia ..................................................................405

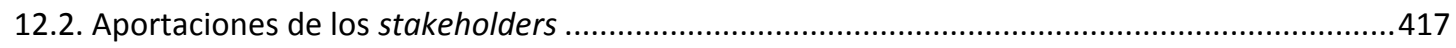

12.2.1. Visión de los stakeholders de la comunicación de la ciencia en las universidades..............417

12.2.2. Aportaciones al modelo de comunicación de la RRI ......................................................420

13. La visión de los expertos sobre la comunicación ética de la RRI en la universidad.......................425

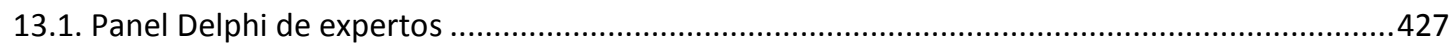

13.2. Aportaciones de los expertos al modelo de comunicación de la RRI ......................................441

14. Validación del modelo, pautas para su desarrollo ..................................................................445

V. CONCLUSIONES ........................................................................................... 453

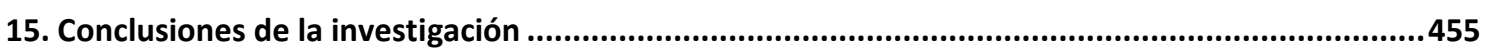

16. Implicaciones del estudio: un modelo de comunicación para favorecer la RRI en la universidad .475

17. Limitaciones y futuras líneas de trabajo

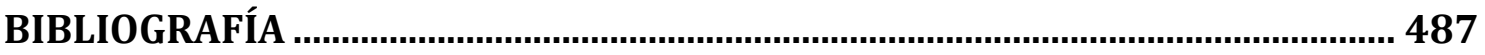





\section{PRESENTACIÓN Y}

CONTEXTUALIZACIÓN DE LA INVESTIGACIÓN 



\section{Introducción}

La Investigación e Innovación Responsable (RRI por sus siglas en inglés Responsible Research and Innovation) es un concepto emergente que ha ido adquiriendo un peso creciente en la Unión Europea. Desde que en el año 2001 el Programa Marco incorporara el Plan de Acción "Ciencia en sociedad" con el fin de establecer una estrategia común para mejorar la conexión entre la ciencia y la ciudadanía, el concepto de RRI ha adquirido una presencia cada vez más significativa en las convocatorias europeas que definen las líneas a financiar en materia de investigación. El actual programa Horizonte 2020 destaca incluso la necesidad de incorporar la RRI como una acción transversal en cualquier proceso de investigación.

El desarrollo de la RRI ha llevado a que en un espacio muy corto de tiempo afecte ya incluso a los mecanismos de gestión y financiación de la investigación y a los sistemas de control de calidad. La transparencia, la rendición de cuentas, la eficiencia y la productividad se han convertido en objetivos importantes de la política científica marcada por las instituciones europeas, especialmente por la Comisión Europea, y sus marcos de apoyo a la investigación han tenido una gran influencia en este sentido. Respecto a este peso creciente de la RRI, la Comisaria Europea de Investigación, Innovación y Ciencia, Máire Geoghegan-Quin, afirmaba en 2012 que nunca antes había sido tan importante establecer un diálogo entre la ciencia y el resto de la sociedad ante la necesidad de que los avances en ciencia e innovación respondan a sus necesidades y aspiraciones, reflejando sus valores y siendo responsables (Geoghegan-Quin, 2012).

El concepto de responsabilidad, también en el ámbito de la investigación e innovación, se encuentra estrechamente ligado al de ética. Para que el desarrollo científico pueda ser considerado responsable debe contar con un marco ético que marque el norte a seguir. El presente proyecto plantea el modelo de la ética del discurso de Jürgen Habermas como el marco más adecuado para la RRI al tener en cuenta los intereses de todos los posibles afectados presentes y futuros a través de la participación y el diálogo. La Escuela de Valencia lleva la ética del discurso de Habermas al campo de las éticas aplicadas con el fin de facilitar una orientación normativa que permita buscar soluciones a los problemas desde una voluntad común. Este marco ético conlleva además un marco político, basado en el modelo de democracia deliberativa, modelo que se ha consolidado como el más utilizado desde las perspectivas críticas que parten del 
"deber ser" como factor clave de legitimidad. La participación de la ciudadanía es un aspecto fundamental en este marco ético y político, siendo también un fenómeno ampliamente estudiado.

Si bien la RRI es un fenómeno relativamente reciente, puede encontrar en la Responsabilidad Social de la Empresa (RSE) un claro referente con más de medio siglo de desarrollo y un amplio corpus teórico. "Cualquier entidad cuyas decisiones tengan consecuencias sociales debe asumir su responsabilidad social pública por ellas" (Cortina, 1997a:23), argumenta la filósofa valenciana en relación a la responsabilidad de las empresas. Del mismo modo, la labor desarrollada por las entidades vinculadas a la investigación e innovación tiene unas evidentes consecuencias sociales y requiere de legitimación. En este sentido, Cortina destaca el hecho de que las organizaciones para tener legitimidad han de proporcionar unos bienes a la sociedad para ser aceptados por ella. La sociedad tiene derecho a reclamar estos bienes y, en el caso de que no se produzcan, a deslegitimar a la institución.

Desde esta visión, el modelo ético de la RSE desarrollado por la Escuela de Valencia en base a la ética del discurso y la teoría de los stakeholders ofrece interesantes aportaciones que pueden ser trasladadas al campo de la investigación e innovación responsables, adaptándolas a las características específicas de estas actividades y sus grupos de interés.

Por otra parte, las diferentes aproximaciones a la RRI coinciden en la importancia de la comunicación como elemento imprescindible para alcanzar una investigación e innovación que puedan ser consideradas responsables, tesis que mantiene la presente investigación. La Comunicación Pública de la Ciencia cuenta con un extenso desarrollo teórico, estando sobradamente argumentadas las razones para difundir la ciencia y su aportación al desarrollo de una sociedad más informada y democrática. En la actualidad, la comunicación de la investigación y la innovación debe hacer frente a la nueva realidad mediática surgida a partir de las nuevas Tecnologías de la Información y la Comunicación (TIC), que abre nuevos retos y oportunidades. Esto se produce en un momento en el que la comunicación de la ciencia está viviendo un importante auge respaldado por la profesionalización del sector. Todo ello despierta el interés por reflexionar sobre la adaptación de los modelos de comunicación de la investigación y la innovación existentes a esta nueva realidad. 
Entre los centros que llevan a cabo investigación e innovación cabe destacar el papel preponderante de la universidad, en cuya comunicación de la ciencia se centra la presente tesis. Entre las funciones de la misma se encuentra, según se contempla en el Artículo 1 del Título Preliminar de la Ley Orgánica de Universidades (LOU, 2001), "la creación, desarrollo, transmisión y crítica de la ciencia, de la técnica y de la cultura", así como "la difusión, la valorización y la transferencia del conocimiento al servicio de la cultura, de la calidad de la vida, y del desarrollo económico". Estas funciones de la universidad aparecen claramente vinculadas a la comunicación de la investigación e innovación y a la necesidad de trabajar desde los campus por una mayor cultura científica de la sociedad que contribuya a mejorar nuestra democracia.

El presente estudio busca por tanto aproximarse al fenómeno de la RRI desde la doble perspectiva disciplinar de la Ética y la Comunicación. Por una parte, desde el ámbito de la Ética se analiza el fenómeno teniendo en cuenta aspectos como responsabilidad, marco político, participación y ciudadanía con el fin de avanzar hacia un marco ético de la RRI. A partir de este marco, se plantea una aproximación a la Investigación e Innovación Responsable desde el ámbito de la Comunicación, poniendo el foco en la Comunicación Pública de la Ciencia y, especialmente, en la desarrollada desde el ámbito universitario y el impacto de las TIC en la misma. 



\section{Interés del tema y motivación}

Las consideraciones sobre el papel de la ciencia en la sociedad y sus responsabilidades no son nuevas, pero en los últimos años el debate en torno a las mimas se ha visto incrementado gracias al auge de la Investigación e Innovación Responsable. Como hemos visto se trata de un fenómeno relativamente reciente que en poco más de una década ha cobrado un papel fundamental en las políticas de gestión y financiación de la ciencia, especialmente en el ámbito de la Unión Europea.

Al tratarse de un concepto emergente, la definición de la RRI está todavía evolucionando, por lo que resulta de interés reunir las diferentes aproximaciones teóricas al término y plantear nuevas propuestas que tengan en cuenta disciplinas como la Ética y la Comunicación. De este modo, la presente investigación busca abordar la RRI desde una perspectiva interdisciplinar que permita dotarla de un marco ético y avance en un modelo de comunicación adaptado al nuevo modo de entender la investigación y la innovación desde la responsabilidad y al nuevo escenario mediático.

Para la Comisión Europea, la RRI busca la implicación de los diferentes actores de la sociedad en el proceso de investigación con el fin de alinear mejor los procesos y resultados con los valores, necesidades y expectativas de la sociedad europea (European Commission, 2012). El presente trabajo pretende profundizar en las condiciones en las que se debe producir esta implicación de los actores sociales en el proceso de investigación, dotándolas de un marco ético; así como concretar quiénes deberían ser estos actores sociales, dibujando el mapa de stakeholders de la RRI desde el punto de vista ético, además de definir un modelo de comunicación.

Se busca de este modo analizar y tratar de cubrir, desde la perspectiva ética de la Escuela de Valencia, algunos vacíos teóricos existentes en torno a la Investigación e Innovación Responsable y establecer los aspectos éticos de su comunicación como requisito moralmente imprescindible para la misma.

El desarrollo de la RRI viene acompañado por una creciente preocupación por el papel de la ciencia, por su legitimidad, por la incertidumbre que conlleva y sus riesgos asociados (Beck, 1992). La globalización y la transición hacia economías basadas en el conocimiento han vinculado la investigación y la innovación a las expectativas de desarrollo y competitividad. Sin embargo, autores como Owen, Macnaghten y Stilgoe 
advierten de las claras limitaciones de las políticas existentes para hacer frente a áreas éticamente problemáticas de la ciencia y la innovación y a sus impactos. Estas circunstancias han generado una mayor disposición a nivel político, social y académico a debatir los modelos de investigación e innovación existentes, así como el propio contrato social con la ciencia.

Ante esta situación, la RRI reivindica la necesidad de involucrar a la sociedad a lo largo de todo el proceso de investigación e innovación. Una implicación que requiere de una ciudadanía informada para poder participar en condiciones adecuadas en los diálogos sobre ciencia. La comunicación y divulgación de la ciencia desde las universidades tiene un papel fundamental en este incremento de la cultura científica.

Desde la Escuela de Valencia, Adela Cortina viene a ratificar la necesidad de que sean los afectados los que tomen las decisiones en materia de ciencia, tecnología e innovación. La autora argumenta que éstas no pueden dejarse en manos de la industria ni de los países ricos. Tampoco pueden ser decisiones políticas, ya que el juego de la política no es en realidad el de lo universal sino el de los intereses particulares. A diferencia de lo que pueda creerse, señala que tampoco corresponde a los expertos en investigación e innovación tomarlas, ya que "hay expertos en medios pero los fines sólo pueden determinarlos los afectados por la puesta en marcha de una ciencia, porque son ellos los que mejor conocen en qué consiste ese bien". Por ello, afirma que son los afectados los que deben tomar decisiones morales objetivas en materia de ciencia e innovación, con el debido asesoramiento de los expertos y teniendo en cuenta no sólo sus intereses individuales sino los universalizables (Cortina, 1993).

La investigación planteada parte del interés de establecer mecanismos que contribuyan a avanzar en esta toma de decisiones por parte de los afectados para lo que resultan claves aspectos como la participación y la comunicación, siempre desde una perspectiva ética. En este sentido, entendemos que el modelo de Responsabilidad Social Empresarial desarrollado por la Escuela de Valencia y apoyado en la ética del discurso y la teoría de los stakeholders puede suponer una interesante contribución al desarrollo de un modelo de RRI desde el campo de la ética. La apuesta de la Escuela de Valencia por las éticas aplicadas ha permitido además llevar a la práctica su modelo de RSE, contando con notables experiencias de implantación del mismo en entidades 
empresariales y organizaciones ${ }^{1}$. Este carácter práctico entendemos que resulta especialmente interesante para el desarrollo de un modelo de RRI con una verdadera vocación de implantación en el sistema investigador e innovador.

Del marco ético y político de la RRI planteado en la presente tesis se deriva también un modelo de comunicación de la misma. Como veremos a lo largo del presente trabajo, el ámbito de la Comunicación Pública de la Ciencia ha vivido también en las últimas décadas un importante auge, marcado en la actualidad por la profesionalización de la comunicación y la ruptura que ha supuesto la nueva galaxia mediática surgida a raíz de la aparición de las Tecnologías de la Información y la Comunicación y el fenómeno de la web 2.0 o web participativa y social.

Desde el punto de vista de la comunicación, el interés de la investigación radica principalmente en buscar un modelo de comunicación de la investigación y la innovación que responda a las características de la nueva forma de entenderlas y gestionarlas que supone la RRI. La responsabilidad en el desarrollo de la ciencia obliga a establecer mecanismos de comunicación con los diferentes grupos de interés para conocer sus expectativas e intereses legítimos y para responder de las acciones realizadas. Esto supone incorporar nuevos planteamientos al modelo más tradicional de la comunicación de la ciencia, basado fundamentalmente hasta la fecha en la información a la sociedad sobre los resultados alcanzados en materia de investigación e innovación, pasando del denominado "modelo del déficit" (Bodman, 1985; Miller, 2001) al modelo comunicativo de "ciencia y sociedad" (European Comission, 2002; Sinue et al, 2009). En este punto, entendemos que resultan asimismo de interés las aportaciones que se puedan realizar a partir del modelo de comunicación de la RSE desarrollado por la Escuela de Valencia.

En el lenguaje encontramos un nexo común entre las dos disciplinas desde las que el presente trabajo aborda el concepto de RRI, Ética y Comunicación. "El lenguaje no es el espejo del mundo, sino que nos abre un acceso a él" afirma Habermas (2006:23), y a través de este acceso resulta necesario fomentar la cultura científica para que, desde él, los afectados tomen la palabra para llegar a alcanzar normas legítimas.

\footnotetext{
${ }^{1}$ El Grupo de Ética y responsabilidad Social Empresarial GERSE, vinculado a la Escuela de Valencia, ha realizado trabajos para empresas como Mercadona, Unión de Mutuas, Bancaja, Aceralia, ONCE, Intercoop , ATOS ORIGIN España y Grupo UBE, entre otras.
} 
En cuanto a la motivación del presente trabajo desde el punto de vista personal, ha sido en esta perspectiva interdisciplinar de la Comunicación y la Ética en la cual se ha ido configurando mi desarrollo formativo y profesional. En terreno formativo completé mis estudios de Periodismo en la Universidad Autónoma de Barcelona con el Programa de Doctorado “Comunicación Empresarial e Institucional” impartido por el Departamento de Ciencias de la Comunicación de la Universitat Jaume I a través del que accedí posteriormente al Máster en Nuevas Tendencias y Procesos de Innovación en Comunicación de esta misma universidad. Más adelante, complementé esta formación en el campo del Periodismo y la Comunicación con estudios en el ámbito de la Ética y la Filosofía. Para ello cursé el Máster Interuniversitario en Ética y Democracia de la Universitat Jaume I y la Universitat de València. El aprendizaje desarrollado a través de ambos másteres dio paso al trabajo de investigación en el que se encuentra el germen de la presente tesis, defendido en noviembre de 2014 bajo el título de "Un marco ético para una investigación responsable".

Por lo que respecta al terreno profesional, mi trayectoria ha estado y está vinculada a ambas disciplinas, desarrollándose principalmente en el ámbito de la comunicación pero también en los últimos años en el campo de la ética y la responsabilidad social. Mis primeros pasos como profesional de la comunicación me permitieron adquirir una rica experiencia en los medios de comunicación y el periodismo, trabajando como redactora en televisiones locales, emisoras de radio y revistas (Burrriana Televisión, Planavisió, cadena COPE Castellón, Poble,...). No obstante, fue en la prensa diaria en la que acumulé una mayor experiencia como periodista, trabajando durante siete años en la redacción del diario El Mundo Castellón al Día. También en el ámbito de la comunicación he tenido la oportunidad de trabajar como periodista "al otro lado de la trinchera", expresión utilizada en el ámbito de la comunicación corporativa para aquellos profesionales que trabajamos en gabinetes de comunicación de empresas o instituciones. En concreto, desde el año 2005 he desempeñado mi trabajo en el Área de Comunicación y Relaciones Informativas de la Universitat Jaume I, lo que me permite conocer de primera mano la función de la comunicación por parte de las universidades, abordada también en el presente trabajo. En este sentido, cabe señalar mi pertenencia a AUGAC, la Asociación de Profesionales de Gabinetes de Comunicación de las Universidades Españolas, públicas y privadas, y Centros de Investigación, que me ha posibilitado compartir experiencias con 
profesionales de otras universidades y asistir a jornadas formativas muy enriquecedoras, algunas de ellas centradas en el campo de la comunicación científica como la celebrada en 2013 en Burgos.

La comunicación de la ciencia ha sido precisamente mi principal actividad profesional desde el año 2011, momento en el que la UJI puso en marcha la Unidad de Cultura Científica y de la Innovación (UCC+i), hasta julio de 2015, momento en el que pasé a ocupar una plaza de Periodista del Servicio de Comunicación y Publicaciones de esta Universidad. Esta experiencia me ha permitido conocer de primera mano la evolución que ha vivido en los últimos años la Comunicación Pública de la Ciencia, además de participar en el desarrollo de cuatro proyectos anuales financiados en convocatoria competitiva por la Fundación Española de Ciencia y Tecnología (FECYT). La labor profesional de intermediación entre investigadores, medios de comunicación y sociedad en su conjunto, se ha visto además enriquecida con la asistencia a jornadas y congresos como los Campus Gutenberg organizados anualmente por el Observatorio de Comunicación de la Ciencia de la Universidad Pompeu Fabra o los congresos Comcired, Comunicar Ciencia en Red organizados por la FECYT y en los que se dan cita las diferentes UCC+i españolas.

La experiencia y conocimientos adquiridos me han posibilitado además ampliar mi actividad profesional como profesora asociada del Grado de Periodismo de la Universitat Jaume I, en el que he impartido desde 2011 asignaturas de Diseño Periodístico y Ciberperiodismo. A esto se une la participación en conferencias y talleres de diferente índole que van desde ponencias sobre comunicación de la ciencia en jornadas como Comcired a talleres de comunicación de la ciencia dirigidos a investigadores e investigadoras, pasando por clases sobre divulgación de la ciencia en la Escuela de Doctorado de la UJI.

Por lo que respecta a la vinculación profesional al ámbito de la ética, esta es mucho más reciente y ha venido dada gracias a la oportunidad de colaborar como investigadora en el grupo de Gestión de la Ética y de la Responsabilidad Social Empresarial (GERSE) de la Universitat Jaume I. La participación en este grupo me ha permitido acercarme a la labor investigadora y poder colaborar en proyectos relacionados con la implantación de políticas de Responsabilidad Social para empresas como Grupo UBE y Unión de Mutuas. 
El perfil adquirido gracias a mi trayectoria formativa y profesional supone una importante motivación para avanzar en una investigación como la presente en la que confluyen los diferentes ámbitos en los que he tenido la oportunidad de participar como es el Periodismo, la Comunicación Corporativa desde las Universidades, y más específicamente, la Comunicación de la Ciencia, y la investigación en el ámbito de la Ética y la Responsabilidad Social.

Por tanto, la motivación para emprender esta tesis parte de la voluntad de seguir avanzando en mi trayectoria investigadora con un trabajo que englobe ambas disciplinas, tratando de contribuir al desarrollo de una investigación e innovación socialmente responsables y a trazar un modelo de comunicación de la misma desde las universidades, avanzando de este modo hacia un nuevo contrato social para la ciencia. 


\section{Objetivos e hipótesis}

La Declaración de Santo Domingo de 1999, documento preparatorio de la cumbre sobre ciencia de la UNESCO/ICSU, recogía las sensibilidades de lo que debería ser un nuevo contrato social para la ciencia. En ese documento se distinguen tres formas de entender el desafío de una democratización de la ciencia. Un primer sentido de democratización se refiere a «llevar la ciencia a los ciudadanos», es decir, a la alfabetización científico-tecnológica. Un segundo está relacionado con la reorientación de las políticas públicas de ciencia y tecnología hacia la demanda social, hacia las sensibilidades sociales. Y un tercero hace referencia a la apertura de las políticas en materia de ciencia y tecnología a las opiniones y participación de los ciudadanos.

Dado que se trata de tres desafíos que continúan vigentes y que aparecen estrechamente relacionados con el surgimiento de la Investigación e Innovación Responsable, y a partir de lo expuesto en la Introducción, los objetivos de la presente investigación pasan por plantear caminos para hacer frente a estos retos a través del desarrollo de un marco ético para la RRI basado en la ética del discurso y la teoría de los stakeholders y de un modelo de comunicación ética de la misma desde las Universidades. Además de este objetivo general que ampliamos a continuación, la tesis busca alcanzar una serie de objetivos específicos encaminados a confirmar la hipótesis de partida.

\section{Objetivo general:}

La tesis “Aspectos éticos de la comunicación de la Investigación y la Innovación Responsable en la Universidad" tiene como principal objetivo definir una serie de aspectos normativos que guíen la comunicación de la ciencia realizada por las universidades hacia una comunicación ética de la Investigación y la Innovación Responsable. Para ello será necesario definir previamente el concepto de investigación responsable desde un marco ético que posibilite esta gestión responsable de la comunicación de la ciencia. 


\section{Objetivos específicos:}

Los objetivos específicos de la investigación pueden dividirse en cuatro grandes grupos que serán asimismo los que conformen los bloques de desarrollo de la tesis y que expondremos más ampliamente en el apartado sobre descripción y estructura del trabajo.

1. Desarrollo del marco ético. En un primer momento se prevé alcanzar los siguientes objetivos:

- Desarrollar un marco ético y político para la RRI.

- Realizar una aproximación al estado de la Comunicación Pública de la Ciencia en España y a la misión de las universidades respecto a la misma.

- Conocer el estado de la cuestión sobre la RRI, las diferentes aportaciones a la misma y la apuesta europea.

- Extraer las posibles aportaciones a la RRI del modelo de Responsabilidad Social desarrollado por la Escuela de Valencia, incluida su propuesta en el campo de la comunicación.

- Analizar las actuales normativas en materia de comunicación de la RRI en el ámbito de la Unión Europea.

2. Elaboración de propuestas. El desarrollo de estos objetivos permitirá plantear tres propuestas específicas que determinan los siguientes objetivos:

- Proponer una nueva definición de Investigación Responsable y del proceso de RRI que es necesario llevar a cabo para alcanzarla desde un marco ético.

- Trazar el mapa de stakeholders de la RRI, definiendo las expectativas comunicativas de cada uno de los grupos.

- Desarrollar un modelo normativo de comunicación ética de la Investigación e Innovación Responsable en la universidad.

3. Análisis de la realidad y validación. En tercer lugar, los objetivos de la tesis pasan por: 
- Conocer la situación de la ciencia en la universidad y sus debilidades y fortalezas respecto al modelo de comunicación de la RRI desarrollado.

- Validar el modelo de comunicación de la RRI planteado mediante diálogos con los stakeholders y con expertos en ética y en comunicación universitaria.

4. Propuesta final. Las conclusiones alcanzadas a través de los objetivos anteriores permitirán:

- Realizar una propuesta final de modelo ético de comunicación de la RRI para las universidades.

- Confirmar la hipótesis de partida que exponemos a continuación.

\section{Hipótesis de trabajo}

Desde el ámbito de la ética, el presente trabajo busca avanzar en la propuesta de horizontes de normas morales para la RRI. Como veremos, el desarrollo de la responsabilidad social de la investigación y la innovación supone buscar la aceptabilidad de sus procesos y resultados por parte de todos los afectados presentes y futuros en un proceso abierto de diálogo en condiciones simétricas de participación. La hipótesis de trabajo de la presente tesis parte de la idea de que la comunicación ética es un requisito moralmente necesario en este proceso de RRI. De este modo, a partir de una visión interdisciplinar desde los campos de la Ética y la Comunicación, la tesis parte de la siguiente hipótesis:

\section{HIPÓTESIS:}

La comunicación ética de la ciencia es un requisito moralmente imprescindible para el desarrollo de un modelo de gestión de la Investigación e Innovación Responsable en las Universidades. 



\section{Metodología}

La metodología utilizada en el presente estudio combina una perspectiva fundamentalmente cualitativa con la utilización de algunas técnicas cuantitativas con el fin de responder en profundidad al planteamiento del problema. En este sentido, la utilización de análisis cuantitativos basados en un análisis numérico de determinados indicadores y variables viene a reforzar las aproximaciones cualitativas al objeto de estudio con el fin de conocer con mayor profundidad la realidad de la comunicación de la ciencia en la universidad y validar el modelo de comunicación de la RRI a desarrollar. El estudio parte de una perspectiva cualitativa entendida como:

Un proceso de indagación de un objeto al cual el investigador accede a través de interpretaciones sucesivas con la ayuda de instrumentos y técnicas, que le permiten involucrarse con el objeto para interpretarlo de la forma más integral posible (Orozco, 1996:83).

De este modo, los métodos cualitativos nos guiarán hacia el análisis de un marco ético y político de la RRI; el estudio del estado de la cuestión sobre la RRI y la situación de la Comunicación Pública de la Ciencia. Todo esto, en torno a un trabajo exploratorio y descriptivo desde el abordaje de aspectos particulares con el objetivo de responder en profundidad al planteamiento general del problema. "Los estudios cualitativos se fundamentan más en un proceso inductivo, exploran y describen, y luego generan perspectivas teóricas, van de lo particular a lo general” (Samperi et al, 2013:15). Este proceso inductivo permitirá avanzar hacia el desarrollo de un modelo de comunicación ético de la RRI.

Asimismo, autores como Taylos y Bogdan (1987:20) definen la metodología cualitativa como "la investigación que produce datos descriptivos" a partir de las propias palabras de las personas, ya sean escritas o habladas, y de la conducta observable. Desde esta perspectiva, la investigación recoge las palabras de los actores claves entorno a la RRI como son los grupos de interés que se derivarán del mapa de stakeholders de la RRI y los expertos en comunicación universitaria y en ética. También se observará la conducta de las universidades determinadas en el universo de estudio en materia de comunicación de la ciencia.

Como hemos indicado, el estudio cualitativo se complementará con un análisis cuantitativo de datos entendidos estos como cada uno de los elementos de información recogidos durante el desarrollo de la investigación a partir de los que, una vez 
sintetizados, podrán extraerse conclusiones de relevancia en relación al problema inicial planteado (Sabino, 1992:89). Se considera que, en este camino, se deben analizar aspectos concretos para luego ponerlos en contexto con la situación general de las distintas dimensiones del fenómeno en la búsqueda de la elaboración de un estudio que dé cuenta de la realidad actual de la comunicación de la ciencia en las universidades y analice sus fortalezas y debilidades respecto al modelo de RRI desarrollado, a la vez que busca la validación del mismo.

Este marco metodológico establecido permitirá avanzar hacia la obtención de los objetivos marcados, tanto a nivel general como específico. De este modo, al análisis del estado de la cuestión de la RRI desde los ámbitos de la ética y la comunicación se sumarán técnicas de análisis y recopilación de datos como cuestionarios, encuestas, focus groups y un panel Delphi. Todo ello nos permitirá indagar sobre las acciones de comunicación de la investigación e innovación por parte de las universidades y aproximarnos a las posturas de los principales actores vinculados a la RRI sobre la misma y su comunicación. Definiremos más ampliamente estas técnicas e instrumentos para la investigación en los siguientes apartados, pero antes nos detendremos en las fases en las que se estructura la investigación.

\subsection{FASES DE LA INVESTIGACIÓN}

Las fases en las que se articula la presente investigación se articulan tomando como referente el modelo propuesto por Rodríguez, Gil y García (1999:63), que plantea un proceso continuo en el que cada fase, a su vez, cuenta con varias etapas. Los autores distinguen cuatro fases en el proceso de investigación: Preparatoria, Proceso de campo, Analítica e Informativa. Entendemos que este modelo se adapta de forma adecuada a las características y necesidades de la investigación que nos ocupa y cuyo proceso se articula, por tanto, de la forma que detallamos a continuación:

1. Fase preparatoria: Esta fase incluye una primera etapa reflexiva y una segunda de diseño.

- Etapa reflexiva: Se trata del punto de partida de la investigación que supone una reflexión en torno al tema seleccionado para el estudio, algo que los autores definen como el "tópico de interés" y que se vincula a las motivaciones y condiciones del propio investigador. En el caso que nos ocupa, las motivaciones personales para abordar el 
fenómeno de la RRI desde la perspectiva de la ética y la comunicación han sido abordadas en el segundo apartado del presente capítulo. Rodríguez, Gil y García plantean cómo, una vez elegido el tema a tratar, el investigador suele buscar toda la información posible sobre el mismo, buscando conocer el estado de la cuestión desde una perspectiva amplia. De este modo, en un primer momento se realizó una amplia revisión bibliográfica del tema y un estudio documental sobre las principales aportaciones teóricas sobre el fenómeno de la RRI, así como sobre las posibles aproximaciones a este concepto desde el ámbito de la ética y la comunicación. Todo ello ayudó a delimitar el objeto de la investigación en base al interés del tema y sus posibles aportaciones.

En nuestro caso, la fase de reflexión y recopilación bibliográfica se ha visto respaldada por la realización del Máster en Ética y Democracia y el desarrollo, como trabajo final del mismo, de un estudio sobre "Un marco ético para una investigación responsable”. Este estudio sentó las bases de una primera reflexión y el desarrollo del marco teórico de partida, surgiendo del mismo diferentes propuestas de continuidad, entre las que se consideró como más interesante la abordada finalmente en la presente tesis.

A partir de este punto se amplió el estudio bibliográfico y documental a través de libros, artículos científicos, normativas y directivas europeas, webs y proyectos relacionados con los temas abordados. Todo ello permitió dibujar el Marco Teórico que queda recogido en el segundo bloque de la presente tesis y a partir del que se desarrollan las propuestas de aportaciones propias en torno al fenómeno de la RRI recogidas en el tercer bloque y que incluyen una definición de la RRI desde un marco ético y el mapa de stakeholders que de ésta se deriva, además un modelo de comunicación ética de la RRI desde las universidades.

El trabajo desarrollado en esta fase resulta fundamental para orientar el proceso de recogida y análisis de datos, un proceso que Rodríguez, Gil y García denominan como etapa de diseño.

- Etapa de diseño: Tras el proceso de reflexión teórica, llega el momento de planificar las actuaciones a partir de la elección de los métodos y la determinación de las técnicas e instrumentos de recogida de datos. El desarrollo de un marco ético, político y normativo para la RRI y la propuesta de un modelo de comunicación ética de la misma posibilitaron el diseño de los diferentes cuestionarios, grupos de trabajo y 
paneles a partir de unos objetivos concretos. De este modo, en esta fase se diseñó en un primer momento un cuestionario para conocer la actividad en comunicación de la ciencia de las universidades valencianas, así como diversos aspectos relacionados con la ética y la responsabilidad. El planteamiento del cuestionario buscó además poner en relación estas políticas comunicativas con el modelo de comunicación de la RRI planteado en el presente trabajo, con el objetivo de conocer las debilidades y fortalezas que presentan de cara a su posible implantación.

En esta etapa de diseño se dibujó la composición y el contenido de los diferentes focus groups con los que se buscaba conocer la opinión de los grupos de interés definidos en el mapa de stakeholders de la RRI respecto a la gestión responsable de la investigación y la innovación y al modelo de comunicación ético desarrollado.

Finalmente, se diseñó el panel Delphi a través de la reflexión sobre el perfil de los expertos más adecuados para su configuración, así como el establecimiento de las rondas que se realizarían y el contenido de los cuestionarios. Las herramientas desarrolladas en esta etapa de diseño fueron aplicadas en la fase de trabajo de campo que abordamos a continuación.

2. Trabajo de campo. Al igual que la primera fase, esta segunda está integrada a su vez por dos etapas, una primera de acceso al campo y una segunda de recogida productiva de los datos obtenidos.

- Acceso al campo. El primer paso de acceso al campo consiste en identificar a los informantes. En nuestro caso, se trató de identificar a los responsables de comunicación de la ciencia de las universidades públicas y privadas de la Comunidad Valenciana de cara a la realización de los cuestionarios sobre la difusión de la investigación y la innovación en el entorno universitaria. Por otra parte, para la organización de los focus groups se estableció las personas más adecuadas para participar en las reuniones para dar voz a los diferentes stakeholders, contactando con ellos y organizando la celebración de los encuentros en las fechas y lugares que se entendieron más idóneos para favorecer la participación y el buen desarrollo de la investigación. Finalmente, por lo que respecta al panel Delphi, se concretó el perfil de los expertos participantes en nombres del ámbito de la comunicación universitaria y científica y de la ética, planteándoles su participación en el proyecto. 
- Recogida productiva de datos. Esta segunda etapa se inicia en "un proceso de recogida de aquellos datos que realmente interesan al desarrollo de la investigación" (Rodríguez et al, 1999:74). Este proceso de recogida de datos está compuesto por el envío de los cuestionarios tantos a los responsables de la comunicación de la ciencia en el ámbito universitario valenciano como a los expertos incluidos en el Panel Delhi. Asimismo, incluyó el desarrollo de los focus groups.

3. Fase analítica. En esta fase se realiza, mediante un trabajo cuantitativo y cualitativo, al análisis de todos los datos obtenidos a raíz de las respuestas a los cuestionarios sobre la comunicación de la ciencia en las universidades valencianas, las reflexiones aportadas por los expertos a través de las diferentes rondas del panel Delphi y los resultados de los focus groups con los stakeholders de la RRI. Los resultados alcanzados fueron analizados, interpretados y valorados individualmente y puestos en relación entre sí con el fin de avanzar hacia la obtención de resultados.

4. Fase informativa. Se trata de la fase final del trabajo en la que a partir de los resultados obtenidos a lo largo del proceso en las diferentes fases de la investigación, se realiza la síntesis del estudio con la elaboración de las conclusiones finales de la tesis doctoral.

\subsection{DEFINICIÓN DE LA MUESTRA}

A la hora de plantear la metodología de la investigación, Sabino alude a la necesidad de hacer operativa la muestra, lo que significa delimitar un universo de estudio que permita alcanzar información relevante. Nos encontramos así ante técnicas cuantitativas que, en nuestro caso, se complementarán también con la determinación de indicadores cualitativos, tal y como señala el autor.

La operacionalización del universo consiste en reducir a proporciones factibles de investigar al conjunto de las unidades que nos interesan, en otras palabras, en la tarea de encontrar una forma de obtener información relevante sin necesidad de acudir a la medición de todo el universo posible de datos. Es el aspecto cuantitativo de la operacionalización y, para resolverlo, habrá de apelarse entre otras disciplinas a la estadística, mediante técnicas de muestreo. La operacionalización de las variables es, por lo contrario, de naturaleza básicamente cualitativa, y tiene por objeto encontrar los indicadores a través de los cuales se expresa concretamente el comportamiento de las mismas (Sabino, 1992:88). 
En nuestro caso, a la hora de analizar la situación de la comunicación de la ciencia en la universidad, optamos por limitar la muestra a las universidades valencianas por entender que resultan suficientemente representativas dado sus diferentes perfiles. Para delimitar el universo de estudio escogimos a las universidades valencianas que componen en la actualidad la Red de Universidades Valencianas para el fomento de la Investigación, el Desarrollo y la Innovación (RUVID), organización creada en diciembre de 2001 a través de un convenio de colaboración entre las cinco universidades públicas valencianas a la que posteriormente se sumaron dos universidades privadas. El interés por el desarrollo de la ciencia y la innovación que ha llevado a estas siete universidades a formar parte de RUVID justifica la adecuación de la muestra. Se trata además de un universo de estudio lo suficientemente variado en el que encontramos universidades de diferente tamaño y producción investigadora, de titularidad pública y privada, y con diversos modos de entender y gestionar la comunicación de la investigación y la innovación. De este modo, la muestra quedaba configurada por: Universitat de València, Universitat Politècnica de València, Universidad de Alicante, Universitat Jaume I de Castellón, Universidad Miguel Hernández de Elche, Universidad CEU Cardenal Herrera y Universidad Católica de Valencia "San Vicente Mártir".

Por lo que respecta a los focus groups, la muestra vino configurada por el mapa de stakeholders de la RRI propuesto en la presente investigación y que viene a coincidir con los grupos de interés de la ciencia responsable apuntados por la mayoría de autores. Para el desarrollo de los focus group se optó por reunir en un primero a los receptores tradicionales de la comunicación de la ciencia y en un segundo, a los emisores, buscando la participación de personas con perfiles diversos con el fin de enriquecer el debate con diferentes perspectivas. De este modo, los participantes en el primer focus group fueron representantes de la sociedad civil, Administración Pública y empresas, mientras que el segundo contó con miembros de la comunidad científica y profesionales de la comunicación de las universidades y parques científicos.

Finalmente, para la conformación del panel Delphi se consideró que la muestra necesaria para alcanzar los objetivos planteados de validación del modelo de comunicación ética de la RRI en la Universidad desarrollado, pasaba por incluir a expertos en la materia desde las dos disciplinas que guían el presente trabajo: Ética y Comunicación. 


\subsection{TÉCNICAS E INSTRUMENTOS DE LA INVESTIGACIÓN}

En el presente apartado realizaremos una enumeración y descripción de las técnicas de investigación e instrumentos utilizados en este trabajo y a los cuales hemos hecho ya referencia en los apartados anteriores:

\subsubsection{Estudio documental}

El estudio documental incluye la detección, recopilación, clasificación y lectura crítica de la bibliografía que abarca el ámbito de la Ética, haciendo especial hincapié en aspectos como la ética del discurso, la democracia deliberativa y la participación ciudadana; la Comunicación Pública de la Ciencia, abordando también aspectos como la nueva galaxia mediática o el modelo comunicativo de la Responsabilidad Social, entre otros; y, por supuesto, todo aquello relativo al fenómeno de la RRI y su vinculación a los conceptos de responsabilidad desde la perspectiva de la ética, además de las directrices y normativas existentes.

También se ha recurrido a documentación de diversa índole que aporta información necesaria para avanzar con la investigación como páginas web, estudios estadísticos, etc. Todos los documentos consultados se citan en la bibliografía de este trabajo y son el fruto de la labor de recopilación de información sobre estas materias desarrollada a lo largo de más de cuatro años.

\subsubsection{Cuestionario a los responsables de comunicación de la ciencia en el ámbito universitario valenciano}

Para conocer la situación de la comunicación de la ciencia y la innovación en el ámbito universitario valenciano, así como algunos aspectos relacionados con la gestión ética, se diseñó un cuestionario de recolección de datos y valoraciones, dirigido a los profesionales responsables de este ámbito en las universidades públicas y privadas valencianas.

Casas define el cuestionario como el documento que recoge en forma organizada los indicadores de las variables implicadas en el objetivo de la encuesta, señalando que para su desarrollo deben tenerse en cuenta, además de los objetivos del mismo, las características de las personas que lo cumplimentarán y el sistema de aplicación que va 
a ser empleado, ya que estos aspectos son decisivos para determinar el tipo de preguntas, el número, el lenguaje y el formato de respuesta (Casas et al, 2003:528). En la etapa de diseño se plantearon asimismo las cuestiones a preguntar, seleccionado el tipo de preguntas que se requería para cada cuestión, el número final de preguntas y su orden y disposición.

Los cuestionarios fruto de esta labor fueron enviados a finales de mayo de 2015, completándose la recogida de los mismos a mediados de junio a excepción de la Universidad de Alicante que a pesar de las reiteradas solicitudes no respondió el cuestionario. Se optó por realizar el cuestionario utilizando la herramienta de Google Drive para cuestionario con el fin de facilitar la realización de los mismos por parte de los participantes, así como de cara a facilitar el análisis posterior de los datos recogidos. A continuación recogemos el cuadro con los profesionales que respondieron el cuestionario así como las imágenes del mismo.

\begin{tabular}{|c|c|c|}
\hline UNIVERSIDAD & NOMBRE & CARGO \\
\hline $\begin{array}{l}\text { Universitat de } \\
\text { València }\end{array}$ & Maria Josep Picó & $\begin{array}{l}\text { Periodista Cátedra de Divulgación } \\
\text { Científica }\end{array}$ \\
\hline $\begin{array}{l}\text { Universitat Politècnica } \\
\text { de València }\end{array}$ & Luis Zurano & $\begin{array}{l}\text { Periodista Unidad de Cultura Científica y } \\
\text { de la Innovación }\end{array}$ \\
\hline $\begin{array}{l}\text { Universidad Miguel } \\
\text { Hernández de Elche }\end{array}$ & José Juan López* & Director de Comunicación \\
\hline $\begin{array}{l}\text { Universidad CEU } \\
\text { Cardenal Herrera }\end{array}$ & Elisa Marco Crespo & $\begin{array}{l}\text { Servicio de Comunicación Corporativa. } \\
\text { Unidad de Comunicación Científica. }\end{array}$ \\
\hline $\begin{array}{l}\text { Universidad Católica } \\
\text { de Valencia "San } \\
\text { Vicente Mártir" }\end{array}$ & David Prada Moreno & Director de Comunicación \\
\hline Universitat Jaume I & Luz Blanco & $\begin{array}{l}\text { Periodista Área de Relaciones } \\
\text { Informativas y Unidad de Cultura } \\
\text { Científica y de la Innovación }\end{array}$ \\
\hline $\begin{array}{l}\text { Universidad de } \\
\text { Alicante }\end{array}$ & Sin respuesta & \\
\hline
\end{tabular}

* Respuesta al cuestionario por vía telefónica. 


\section{Cuestionario sobre comunicación de la ciencia en las universidades valencianas}

El presente cuestionario busca conocer algunos aspectos relacionados con la comunicación de la ciencia y la innovación en las universidades valencianas y se incluye en la investigación de la tesis doctoral "Aspectos éticos de la comunicación de la investigación e innovación responsable en la Universidad". Muchas gracias por su colaboración.

* Necessari

Universidad: *

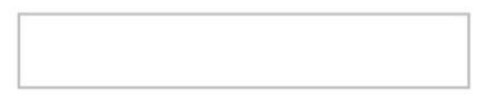

Nombre y cargo/función de la persona que responda este cuestionario:

Valore la importancia que otorga su Universidad a la comunicación de la ciencia. Siendo 0-nada, 1-poca, 2-algo, 3-bastante y 4-mucha.

$\begin{array}{lllll}0 & 1 & 2 & 3 & 4\end{array}$

$\bigcirc \bigcirc \bigcirc \bigcirc \bigcirc$

Indique los motivos de esa importancia otorgada a la comunicación de la ciencia en su Universidad

¿Qué servicio/s o unidad/es gestiona/n la comunicación de la ciencia y la innovación? 
Otras unidades u oficinas que colaboran/apoyan la gestión de la comunicación de la ciencia y la innovación:

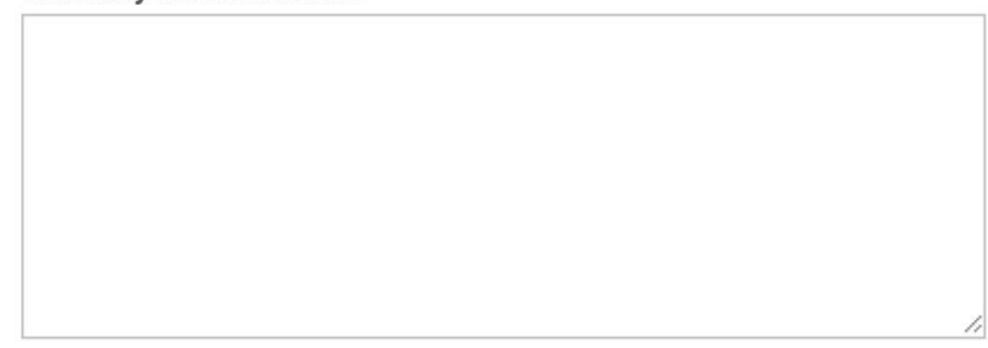

¿Cuál es su organigrama y/o dependencia orgánica dentro de la Universidad?

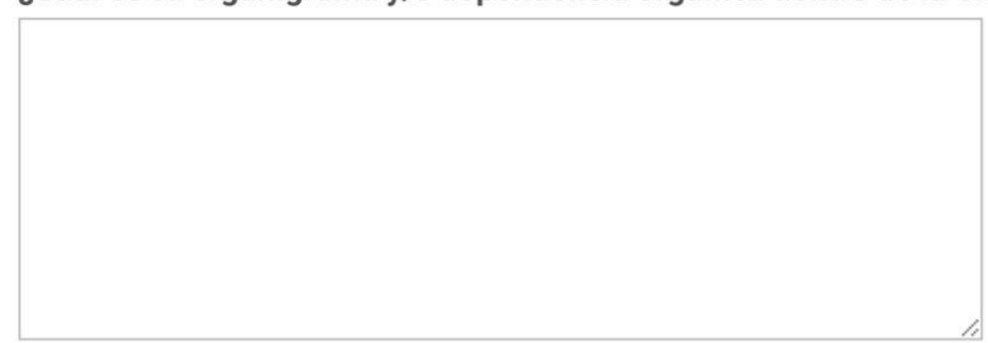

Número de personas dedicadas exclusivamente a comunicación de la ciencia y la innovación:

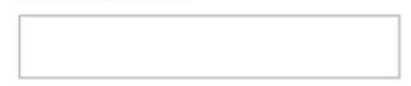

Número de personas dedicadas parcialmente a comunicación de la ciencia y la innovación:

¿Qué tipos de acciones de comunicación de la ciencia y la innovación son las que se realizan principalmente en su Universidad? Valore la frecuencia de las mismas. *

Nada Poca Algo Bastante Mucha $\begin{gathered}\text { No sabe / } \\ \text { No } \\ \text { contesta }\end{gathered}$

Elaboración de

productos

informativos para

su envío a medios

de comunicación

(notas de prensa,

vídeos, etc...)

Convocatoria de

ruedas de prensa

Atención a las

peticiones de los

medios

Elaboración de

contenidos para la

web de la

Universidad

Elaboración de

contenidos para

revista de la

Universidad 
(impresa o digital)

Elaboración de

contenidos para la

radio de la

Universidad

Elaboración de

contenidos para la

televisión de la

Universidad

Gestión de blogs

de la Universidad

sobre

ciencia/innovación

Relaciones con

blogs externos

especializados en

ciencia

Otras

O

○

○

○

○

○

O

Valore la importancia que considera que tienen para la Universidad las acciones de comunicación anteriores. *

\begin{tabular}{|c|c|c|c|c|c|c|}
\hline & Nada & Poca & Algo & Bastante & Mucha & $\begin{array}{l}\text { No sabe / } \\
\text { No } \\
\text { contesta }\end{array}$ \\
\hline $\begin{array}{l}\text { Elaboración de } \\
\text { productos } \\
\text { informativos para } \\
\text { su envío a medios } \\
\text { de comunicación } \\
\text { (notas de prensa, } \\
\text { vídeos, etc...) }\end{array}$ & $\bigcirc$ & $\bigcirc$ & O & 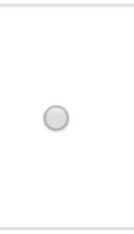 & $\bigcirc$ & $\bigcirc$ \\
\hline $\begin{array}{l}\text { Convocatoria de } \\
\text { ruedas de prensa }\end{array}$ & $\bigcirc$ & $\bigcirc$ & $\bigcirc$ & $\bigcirc$ & $\bigcirc$ & 0 \\
\hline $\begin{array}{l}\text { Atención a las } \\
\text { peticiones de los } \\
\text { medios }\end{array}$ & $\bigcirc$ & $\bigcirc$ & $\bigcirc$ & $\bigcirc$ & $\bigcirc$ & $\bigcirc$ \\
\hline $\begin{array}{l}\text { Elaboración de } \\
\text { contenidos para la } \\
\text { web de la } \\
\text { Universidad }\end{array}$ & $\mathrm{O}$ & O & $\bigcirc$ & $\mathrm{O}$ & $\bigcirc$ & $\bigcirc$ \\
\hline $\begin{array}{l}\text { Elaboración de } \\
\text { contenidos para la } \\
\text { revista de la } \\
\text { Universidad } \\
\text { (impresa o digital) }\end{array}$ & $\bigcirc$ & $\bigcirc$ & $\mathrm{O}$ & $\mathrm{O}$ & $\bigcirc$ & O \\
\hline $\begin{array}{l}\text { Elaboración de } \\
\text { contenidos para la } \\
\text { radio de la } \\
\text { Universidad }\end{array}$ & $\bigcirc$ & $\bigcirc$ & $\bigcirc$ & O & $\bigcirc$ & $\bigcirc$ \\
\hline $\begin{array}{l}\text { Elaboración de } \\
\text { contenidos para la } \\
\text { televisión de la } \\
\text { Universidad }\end{array}$ & $\bigcirc$ & $\bigcirc$ & $\bigcirc$ & $\bigcirc$ & $\bigcirc$ & $\bigcirc$ \\
\hline $\begin{array}{l}\text { Gestión de blogs } \\
\text { de la Universidad } \\
\text { sobre } \\
\text { ciencia/innovación }\end{array}$ & $\bigcirc$ & $\bigcirc$ & $\bigcirc$ & $\bigcirc$ & $\bigcirc$ & $\bigcirc$ \\
\hline
\end{tabular}


especializados en

ciencia

O

$\bigcirc$

○

O

Otras

$\bigcirc$

$\bigcirc$

$\bigcirc$

$\bigcirc$

$\bigcirc$

○

En el caso de que exista alguna acción que a pesar de tener una importancia alta se realice con poca frecuencia ¿puede explicar las causas?

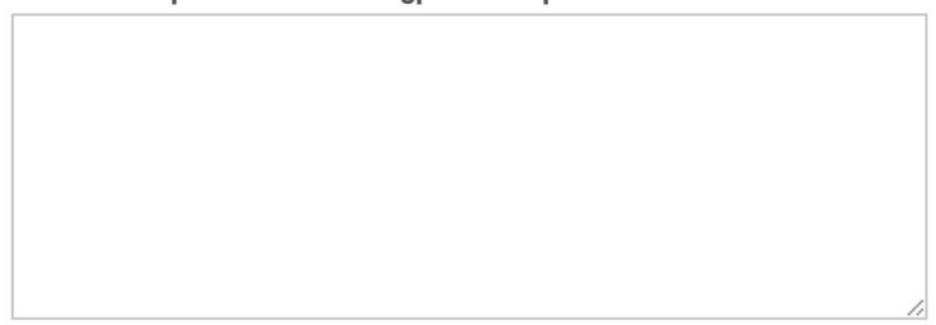

Respecto a los públicos destinatarios de las acciones de comunicación, valore cuáles de los siguientes son los más frecuentes. *

\begin{tabular}{|c|c|c|c|c|c|c|}
\hline & Nunca & Poco & Algo & Bastante & Mucho & $\begin{array}{c}\text { No sabe / } \\
\text { No } \\
\text { contesta }\end{array}$ \\
\hline $\begin{array}{l}\text { Sociedad del } \\
\text { entorno de la } \\
\text { Universidad }\end{array}$ & 0 & 0 & ○ & 0 & 0 & $\bigcirc$ \\
\hline $\begin{array}{l}\text { Sociedad a nivel } \\
\text { global }\end{array}$ & ○ & $\bigcirc$ & 0 & 0 & 0 & 0 \\
\hline $\begin{array}{l}\text { Administración } \\
\text { pública } \\
\text { local/provincial }\end{array}$ & $\bigcirc$ & $\bigcirc$ & 0 & $\bigcirc$ & ○ & $\bigcirc$ \\
\hline $\begin{array}{l}\text { Administración } \\
\text { pública } \\
\text { autonómica }\end{array}$ & 0 & 0 & ○ & 0 & 0 & 0 \\
\hline $\begin{array}{l}\text { Administración } \\
\text { pública nacional }\end{array}$ & $\bigcirc$ & $\bigcirc$ & ○ & $\bigcirc$ & ○ & 0 \\
\hline $\begin{array}{l}\text { Administración } \\
\text { pública europea }\end{array}$ & ○ & $\bigcirc$ & 0 & 0 & ○ & 0 \\
\hline $\begin{array}{l}\text { Comunidad } \\
\text { científica interna } \\
\text { de la Universidad }\end{array}$ & 0 & $\bigcirc$ & 0 & 0 & 0 & 0 \\
\hline $\begin{array}{l}\text { Comunidad } \\
\text { científica externa }\end{array}$ & 0 & $\bigcirc$ & 0 & $\bigcirc$ & $\bigcirc$ & $\bigcirc$ \\
\hline $\begin{array}{l}\text { Medios de } \\
\text { comunicación a } \\
\text { nivel } \\
\text { local/regional }\end{array}$ & 0 & $\bigcirc$ & 0 & 0 & 0 & 0 \\
\hline $\begin{array}{l}\text { Medios de } \\
\text { comunicación a } \\
\text { nivel nacional }\end{array}$ & 0 & $\bigcirc$ & 0 & 0 & 0 & $\bigcirc$ \\
\hline $\begin{array}{l}\text { Medios de } \\
\text { comunicación a } \\
\text { nivel internacional }\end{array}$ & 0 & $\bigcirc$ & 0 & ○ & 0 & 0 \\
\hline
\end{tabular}

¿Qué importancia considera que tienen para la comunicación de la ciencia de la Universidad cada uno de estos públicos? * 


\begin{tabular}{|c|c|c|c|c|c|c|}
\hline & Nada & Poca & Algo & Bastante & Mucha & $\begin{array}{c}\text { No sabe / } \\
\text { No } \\
\text { contesta }\end{array}$ \\
\hline $\begin{array}{l}\text { Sociedad del } \\
\text { entorno de la } \\
\text { Universidad }\end{array}$ & 0 & ○ & 0 & $\bigcirc$ & 0 & 0 \\
\hline $\begin{array}{l}\text { Sociedad a nivel } \\
\text { global }\end{array}$ & 0 & $\bigcirc$ & 0 & 0 & $\bigcirc$ & 0 \\
\hline $\begin{array}{l}\text { Administración } \\
\text { pública } \\
\text { local/provincial }\end{array}$ & 0 & 0 & 0 & 0 & 0 & 0 \\
\hline $\begin{array}{l}\text { Administración } \\
\text { pública } \\
\text { autonómica }\end{array}$ & 0 & 0 & 0 & 0 & 0 & 0 \\
\hline $\begin{array}{l}\text { Administración } \\
\text { pública nacional }\end{array}$ & $\bigcirc$ & 0 & 0 & 0 & 0 & 0 \\
\hline $\begin{array}{l}\text { Administración } \\
\text { pública europea }\end{array}$ & 0 & 0 & 0 & 0 & 0 & 0 \\
\hline $\begin{array}{l}\text { Comunidad } \\
\text { científica interna } \\
\text { de la Universidad }\end{array}$ & $\bigcirc$ & 0 & 0 & 0 & 0 & 0 \\
\hline $\begin{array}{l}\text { Comunidad } \\
\text { científica externa }\end{array}$ & $\bigcirc$ & 0 & 0 & 0 & 0 & 0 \\
\hline $\begin{array}{l}\text { Medios de } \\
\text { comunicación a } \\
\text { nivel } \\
\text { local/regional }\end{array}$ & 0 & 0 & 0 & 0 & 0 & 0 \\
\hline $\begin{array}{l}\text { Medios de } \\
\text { comunicación a } \\
\text { nivel nacional }\end{array}$ & 0 & 0 & 0 & 0 & 0 & 0 \\
\hline $\begin{array}{l}\text { Medios de } \\
\text { comunicación a } \\
\text { nivel internacional }\end{array}$ & 0 & 0 & ○ & 0 & 0 & 0 \\
\hline
\end{tabular}

Valore la promoción por parte de la Universidad de los siguientes canales/acciones para conocer los intereses y expectativas sobre la ciencia y la innovación de sus públicos. *

\begin{tabular}{|c|c|c|c|c|c|c|}
\hline & Nada & Poco & Algo & Bastante & Mucho & $\begin{array}{c}\text { No sabe / } \\
\text { No } \\
\text { contesta }\end{array}$ \\
\hline Correo electrónico & $\bigcirc$ & $\bigcirc$ & ○ & $\bigcirc$ & $\bigcirc$ & $\bigcirc$ \\
\hline Redes sociales & $\bigcirc$ & $\bigcirc$ & $\bigcirc$ & $\bigcirc$ & 0 & $\bigcirc$ \\
\hline $\begin{array}{l}\text { Buzón de } \\
\text { sugerencias }\end{array}$ & $\bigcirc$ & $\bigcirc$ & $\bigcirc$ & $\bigcirc$ & O & ○ \\
\hline $\begin{array}{l}\text { Peticiones directas } \\
\text { vía registro }\end{array}$ & $\bigcirc$ & $\bigcirc$ & ○ & ○ & ○ & ○ \\
\hline Consultas/encuestas & $\bigcirc$ & $\bigcirc$ & ○ & ○ & $\bigcirc$ & ○ \\
\hline Grupos de discusión & 0 & $\bigcirc$ & $\bigcirc$ & $\bigcirc$ & $\bigcirc$ & $\bigcirc$ \\
\hline Otros & 0 & $\bigcirc$ & ○ & $\bigcirc$ & O & ○ \\
\hline
\end{tabular}

Valore el nivel de respuesta de la Universidad a las peticiones/intereses en materia de ciencia que le llagan a través de estos canales/acciones* 
Aspectos éticos de la comunicación de la RRI en la universidad

\begin{tabular}{|c|c|c|c|c|c|c|}
\hline & Ninguno & Poco & Algo & Bastante & Mucho & $\begin{array}{c}\text { No sabe } \\
\text { No } \\
\text { contesta }\end{array}$ \\
\hline Correo electrónico & $\mathrm{O}$ & $\bigcirc$ & $\bigcirc$ & $\bigcirc$ & $\bigcirc$ & $\mathrm{O}$ \\
\hline Redes sociales & $\bigcirc$ & $\bigcirc$ & $\bigcirc$ & $\bigcirc$ & $\mathrm{O}$ & $\mathrm{O}$ \\
\hline $\begin{array}{l}\text { Buzón de } \\
\text { sugerencias }\end{array}$ & $\bigcirc$ & $\bigcirc$ & $\bigcirc$ & $\mathrm{O}$ & $\bigcirc$ & $\bigcirc$ \\
\hline $\begin{array}{l}\text { Peticiones directas } \\
\text { vía registro }\end{array}$ & $\bigcirc$ & $\bigcirc$ & $\bigcirc$ & $\mathrm{O}$ & $\bigcirc$ & \\
\hline Consultas/encuestas & O & $\bigcirc$ & $\bigcirc$ & $\mathrm{O}$ & $\bigcirc$ & $\bigcirc$ \\
\hline Grupos de discusión & $\mathrm{O}$ & $\bigcirc$ & $\bigcirc$ & $\bigcirc$ & $\bigcirc$ & $\bigcirc$ \\
\hline Otros & $\bigcirc$ & $\bigcirc$ & $\bigcirc$ & $\bigcirc$ & O & $\bigcirc$ \\
\hline
\end{tabular}

¿En qué momento suele realizarse la comunicación de las investigaciones e innovaciones? *

\begin{tabular}{|c|c|c|c|c|c|c|}
\hline & Nunca & $\begin{array}{l}\text { Pocas } \\
\text { veces }\end{array}$ & $\begin{array}{l}\text { Algunas } \\
\text { veces }\end{array}$ & $\begin{array}{l}\text { Bastantes } \\
\text { veces }\end{array}$ & Siempre & $\begin{array}{l}\text { No sabe / } \\
\text { No } \\
\text { contesta }\end{array}$ \\
\hline $\begin{array}{l}\text { En el inicio de la } \\
\text { investigación/innovación }\end{array}$ & 0 & 0 & $\bigcirc$ & 0 & ○ & 0 \\
\hline $\begin{array}{l}\text { En el desarrollo de la } \\
\text { investigación/innovación }\end{array}$ & 0 & 0 & ○ & 0 & 0 & 0 \\
\hline $\begin{array}{l}\text { En el momento de la } \\
\text { obtención de resultados }\end{array}$ & 0 & O & 0 & $\bigcirc$ & 0 & 0 \\
\hline $\begin{array}{l}\text { Tras la publicación de } \\
\text { resultados/patente de } \\
\text { innovación }\end{array}$ & 0 & ○ & ○ & 0 & ○ & 0 \\
\hline
\end{tabular}

La presente investigación entiende la función ética de la comunicación en el ámbito de la ciencia y la innovación como un medio para conocer las expectativas de los públicos, negociar con ellos los compromisos de la Universidad e informar del grado de cumplimiento de los mismos. En este sentido, indique con qué frecuencia considera que realiza su Universidad acciones en cada uno de estos ámbitos. *

$\begin{array}{ccccc}\text { Nunca } & \begin{array}{c}\text { Pocas } \\ \text { veces }\end{array} & \begin{array}{c}\text { Algunas } \\ \text { veces }\end{array} & \begin{array}{c}\text { Bastantes } \\ \text { veces }\end{array} \text { Siempre } & \begin{array}{c}\text { No sabe / } \\ \text { No } \\ \text { contesta }\end{array}\end{array}$

$\begin{aligned} & \text { Conocer las } \\ & \text { expectativas/intereses } \\ & \text { de los públicos }\end{aligned}$
$\begin{aligned} & \text { Negociar } \\ & \text { compromisos con los } \\ & \text { públicos }\end{aligned}$
$\begin{aligned} & \text { Informar sobre el } \\ & \text { cumplimiento de los } \\ & \text { compromisos }\end{aligned}$

¿Cree que su Universidad tiene en cuenta criterios de ética y responsabilidad social en la gestión de la investigación y la innovación (compromiso social, atención a las 
necesidades sociales, transparencia en sus acciones, igualdad, etc.)?

Valore la respuesta en una escala de 0-nada, 1-poco, 2-algo, 3-bastante y 4-mucho.

$\begin{array}{lllll}0 & 1 & 2 & 3 & 4\end{array}$

$\bigcirc \bigcirc \bigcirc \bigcirc \bigcirc$

¿Están estos criterios éticos o de responsabilidad en la gestión de la investigación y la innovación recogidos en algún documento oficial (Estatutos, Código Ético, comisión deontológica, etc.)? En caso afirmativo, indique en cuál/es.

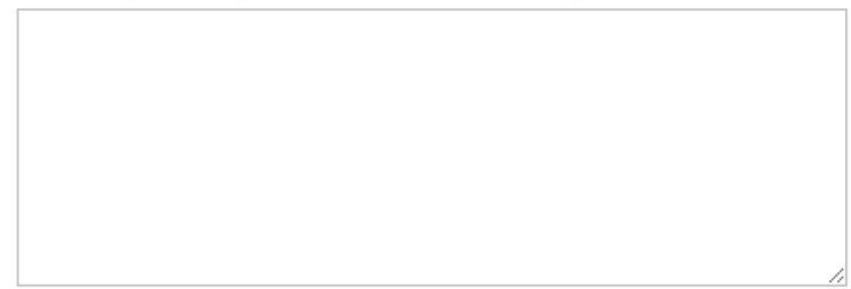

¿Considera que en la gestión de la comunicación de la investigación y la innovación se tienen en cuenta aspectos de ética y responsabilidad social (atención a las expectativas ciudadanas, transparencia, participación, etc.)?

Valore la respuesta en una escala de 0-nada, 1-poco, 2-algo, 3-bastante y 4-mucho.

$\begin{array}{lllll}0 & 1 & 2 & 3 & 4\end{array}$

$\bigcirc \bigcirc \bigcirc \bigcirc$

Comentarios y observaciones que considere de interés.

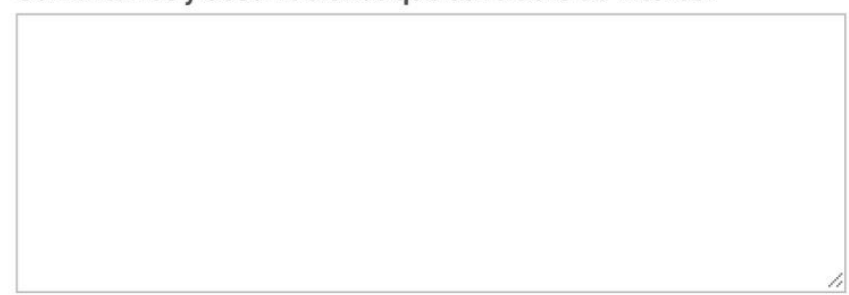

\section{Envia}

No envieu mai contrasenyes a través de Formularis de Google.
Ho heu aconseguit, heu emplenat e $100 \%$ 


\subsubsection{Focus groups con stakeholders}

Un focus group es un tipo de técnica de investigación cualitativa que implica discusiones y entrevistas en grupo en el que un asesor entrenado dirige la discusión de temas o ideas para generar la información significativa. $\mathrm{Su}$ función es obtener información sobre sus opiniones, actitudes y experiencias o incluso explicitar sus expectativas con respecto a esta política o esta intervención (Comisión Europea, 2006). Los participantes, habitualmente entre 6 y 8, se reúnen en un ambiente cómodo y permisivo para promover la discusión mutua y obtener impresiones, ideas nuevas y soluciones a problemas.

Las características del focus group ofrecían a la presente investigación un medio para recopilar rápidamente información y puntos de vista de los diferentes grupos de interés establecidos en el mapa de stakeholders de la RRI. De este modo, el focus group se planteaba como una herramienta útil para analizar y confrontar la información, ayudando a comprender la actitud de los participantes, su comprensión y su percepción de una intervención, lo que no sería posible partiendo de una base individual. La situación de grupo nos permitía además obtener diversos puntos de vista y percepciones estimulados por la interacción.

Como se ha indicado al hablar de las fases de la investigación, el proceso para el desarrollo de los focus groups incluyó el diseño y planificación de los mismos, la selección y reclutamiento de la muestra, la búsqueda de días y horarios ajustados a las diferentes agendas, la realización de las reuniones y el análisis de los resultados.

Para garantizar el correcto desarrollo de los focus groups se realizó una tabla preparatoria en la que se marcaron las diferentes fases de la reunión con sus correspondientes tiempos de duración, objetivos, desarrollo y, en su caso, materiales necesarios. También se preparó una parrilla con el calendario y el desarrollo específico de cada una de las reuniones. Incluimos a continuación ambas tablas, además de un cuadro con los participantes de cada uno de los focus group y sus cargos, en el que queda patente la búsqueda de diferentes perfiles con el fin de enriquecer el debate. 
- Cuadro preparatorio del focus group

\begin{tabular}{|c|c|c|c|}
\hline Tiempo & Objetivo & Desarrollo & Material necesario \\
\hline $15^{\prime}$ & $\begin{array}{l}\text { Acogida y } \\
\text { presentación del } \\
\text { proyecto }\end{array}$ & $\begin{array}{l}\text { - } \quad \text { Agradecimiento asistencia } \\
\text { - } \quad \text { Presentación del proyecto global } \\
\text { incluyendo conceptos de RRI, } \\
\text { Responsabilidad Social y ética dialógica. } \\
\text { - Explicación del modelo de comunicación } \\
\text { de la RRI para universidades }\end{array}$ & 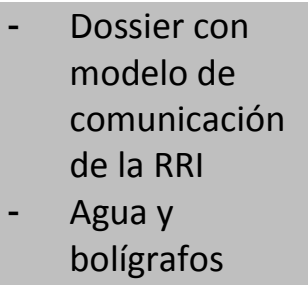 \\
\hline $70^{\prime}$ & Debate & $\begin{array}{l}\text { - Primera ronda de palabra de todos los } \\
\text { asistentes } \\
\text { - Debate dirigido por el coordinador/a del } \\
\text { focus group }\end{array}$ & \\
\hline $5^{\prime}$ & $\begin{array}{l}\text { Cierre y } \\
\text { agradecimiento }\end{array}$ & $\begin{array}{l}\text { - Agradecimiento por las aportaciones } \\
\text { - Cierre de la sesión }\end{array}$ & \\
\hline
\end{tabular}

- Desarrollo de los gocus group

\begin{tabular}{|c|c|c|c|}
\hline REUNIÓN & Objetivos & Stakeholders & Dinamizadores \\
\hline $\begin{array}{l}\text { Fecha: } 9 \text { de junio } \\
\text { Lugar: Rectorado } \\
\text { Universitat Jaume I } \\
\text { Hora: 12:30 a 14:00 } \\
\text { Duración: } 1 \text { h y } 30 \text { m }\end{array}$ & $\begin{array}{l}\text { - Focus Group de debate de } \\
\text { los stakeholders } \\
\text { tradicionalmente receptores } \\
\text { de la comunicación de la } \\
\text { ciencia. }\end{array}$ & $\begin{array}{l}\text { - Sociedad Civil } \\
\text { - Empresas } \\
\text { - Administración Pública }\end{array}$ & $\begin{array}{l}\text { - Dinamizador: } \\
\text { Francisco } \\
\text { Fernández } \\
\text { Beltrán } \\
\text { (codirector de la } \\
\text { tesis) } \\
\text { - Asistente: } \\
\text { Rosana Sanahuja } \\
\text { (doctoranda) }\end{array}$ \\
\hline $\begin{array}{l}\text { Fecha: } 17 \text { de junio } \\
\text { Lugar: Sede de } \\
\text { RUVID, Instituto } \\
\text { INTRAS de la } \\
\text { Universitat de } \\
\text { València } \\
\text { Hora: } 12: 30 \text { a } 14: 00 \\
\text { Duración: } 1 \text { y y } 30 \text { m }\end{array}$ & $\begin{array}{l}\text { - Focus Group de debate de } \\
\text { los stakeholders } \\
\text { tradicionalmente emisores } \\
\text { de la comunicación de la } \\
\text { ciencia. }\end{array}$ & $\begin{array}{l}\text { - Comunidad científica } \\
\text { (especial presencia de } \\
\text { investigadores/as y } \\
\text { periodistas de } \\
\text { comunicación científica } \\
\text { de las universidades y } \\
\text { parques científicos) }\end{array}$ & $\begin{array}{l}\text { - Dinamizadora: } \\
\text { Rosana Sanahuja } \\
\text { (doctoranda) } \\
\text { - Asistente: } \\
\text { Patrici Calvo } \\
\text { (investigador del } \\
\text { Grupo de Ética y } \\
\text { Responsabilidad } \\
\text { Social Empresarial } \\
\text { GERSE) }\end{array}$ \\
\hline
\end{tabular}


- Participantes focus group receptores de la comunicación de la ciencia. Se señala en un color más claro la persona que finalmente no pudo asistir por un problema de agenda a última hora.

\begin{tabular}{|l|l|l|}
\hline STAKEHOLDER & Nombre & Cargo \\
\hline Sociedad civil & Carlos Laguna & $\begin{array}{l}\text { Presidente de la Confederación Española de } \\
\text { Personas con Discapacidad Física y Orgánica } \\
\text { (COCEMFE) de la Comunidad Valenciana }\end{array}$ \\
\hline Sociedad civil & Carmen Ferrete & $\begin{array}{l}\text { Profesora de Educación Secundaria y profesora } \\
\text { asociada del Departamento de Filosofía y } \\
\text { Sociología de la UJI }\end{array}$ \\
\hline Sociedad civil & Sixto Barberá & $\begin{array}{l}\text { Vicepresidente de la Asociación Contra el Cáncer } \\
\text { de Castellón }\end{array}$ \\
\hline Sociedad Civil & Gemma Escrig Gil & Técnica de la Fundación Isonomía \\
\hline Empresas & Pablo Cruz & Corporate Manager UBE España \\
\hline Empresas & Carlos Cabrera & Gerente Cerámicas Cabrera \\
\hline $\begin{array}{l}\text { Administración } \\
\text { pública }\end{array}$ & Eva Alcón & $\begin{array}{l}\text { Diputada de las Cortes Valencianas y catedrática } \\
\text { de Filología Inglesa de la UJl. }\end{array}$ \\
\hline $\begin{array}{l}\text { Administración } \\
\text { pública }\end{array}$ & Ángeles Pellicer* & $\begin{array}{l}\text { Subdirectora de Universidad, Estudios } \\
\text { Superiores y Ciencia }\end{array}$ \\
\hline
\end{tabular}

* Ausencia por problemas de agenda de última hora

- Participantes focus group emisores de la comunicación de la ciencia.

\begin{tabular}{|l|l|l|}
\hline STAKEHOLDER & Nombre & Cargo \\
\hline $\begin{array}{l}\text { Comunidad Científica } \\
\text { (periodista) }\end{array}$ & Olga Denia & $\begin{array}{l}\text { Responsable Comunicación Parque Científico } \\
\text { Universitat de València (UV) }\end{array}$ \\
\hline $\begin{array}{l}\text { Comunidad Científica } \\
\text { (periodista) }\end{array}$ & Lauren Wickman & $\begin{array}{l}\text { Responsable comunicación RUVID, Red de } \\
\text { Universidades Valencianas para la } \\
\text { Investigación, Innovación y Tecnología }\end{array}$ \\
\hline $\begin{array}{l}\text { Comunidad Científica } \\
\text { (órganos } \\
\text { gobierno/investigador) }\end{array}$ & Pedro Carrasco & $\begin{array}{l}\text { Ex vicerrector de Investigación de la UV y } \\
\text { Titular Universidad de Bioquímica y Biología } \\
\text { Molecular }\end{array}$ \\
\hline $\begin{array}{l}\text { Comunidad Científica } \\
\text { (periodista) }\end{array}$ & Luis Zurano & $\begin{array}{l}\text { Periodista UCC+i y Parque Científico de la } \\
\text { Universitat Politècnica de València (UPV) }\end{array}$ \\
\hline
\end{tabular}




\begin{tabular}{|l|l|l|l|l}
$\begin{array}{l}\text { Comunidad Científica } \\
\text { (investigación/innovación) }\end{array}$ & Sandra Boni & $\begin{array}{l}\text { Investigadora del área Humanidades del } \\
\text { Departamento de Proyectos de Ingeniería de } \\
\text { la UPV }\end{array}$ \\
\hline $\begin{array}{l}\text { Comunidad Científica } \\
\text { (investigador/periodista) }\end{array}$ & $\begin{array}{l}\text { José Antonio } \\
\text { Solves Almela }\end{array}$ & $\begin{array}{l}\text { Investigador del Departamento } \\
\text { Comunicación e Información Periodística de } \\
\text { la Universidad Cardenal Herrera CEU }\end{array}$ \\
\hline $\begin{array}{l}\text { Comunidad Científica } \\
\text { (investigador) }\end{array}$ & Francisco Alonso & $\begin{array}{l}\text { Investigador de Instituto INTRAS de Tráfico y } \\
\text { Seguridad Vial perteneciente al área de } \\
\text { Psicología }\end{array}$ \\
\hline $\begin{array}{l}\text { Comunidad Científica } \\
\text { (investigadora) }\end{array}$ & $\begin{array}{l}\text { Sara Garcia Gil- } \\
\text { Perotín }\end{array}$ & $\begin{array}{l}\text { Médico e Investigadora de la Unidad Mixta } \\
\text { del Hospital Universitario La Fe-UV }\end{array}$ \\
\hline
\end{tabular}

\subsubsection{Panel Delphi de expertos}

La metodología Delphi es una técnica de comunicación estructurada, localmente desarrollada como un método de predicción sistemático interactivo, que se basa en un panel de expertos. Su objetivo es la consecución de un consenso basado en la discusión entre expertos a través de un proceso repetitivo. $\mathrm{Su}$ funcionamiento se basa en la elaboración de un cuestionario que ha de ser contestado por los expertos. Una vez recibida la información, se realiza una segunda ronda en la que el resumen de los juicios de los expertos se envía a los participantes con el fin de que puedan reevaluar sus opiniones a la luz de esta información, de modo que se tienda a avanzar hacia un consenso de grupo.

En la presente investigación se optó por el panel Delphi ante las posibilidades que ofrece de avanzar hacia conclusiones consensuadas a partir de los argumentos de los expertos. Esta metodología nos permitía además mantener el anonimato de los intervinientes entre ellos y conseguir una retroalimentación controlada.

En cuanto al desarrollo del mismo, una vez delimitad el contexto y el horizonte temporal en el que se deseaba realizar, se pasó a la selección de los expertos en materia de comunicación universitaria y de ética, alcanzando su compromiso de colaboración. En cuanto a la ejecución, se optó por dos rondas, realizadas durante los meses de junio y julio, de forma que en la segunda los expertos pudieron comparar sus contestaciones anteriores con las de los demás, para, a la vista de ello, mantener su opinión o 
modificarla, argumentándola libremente. Por último, se pasó a la fase de análisis de los datos definitivos.

En cuanto a los expertos participantes del panel Delphi, se buscó contar con personas que destacan como referentes en las diferentes áreas relacionadas con la tesis como son la ética, la comunicación universitaria, la comunicación de la ciencia y la Investigación e Innovación Responsable. A continuación incluimos el cuadro con el listado de participantes en el panel Delphi, incluyendo los cuatro ámbitos en los que se buscó colaboración, el nombre de la persona y el cargo que ocupa y que muestra su relevancia en los respectivos campos. A continuación se incluye el cuestionario que se les envió en la primera oleada.

\begin{tabular}{|l|l|l|}
\hline Ámbito & Nombre & Cargo \\
\hline Ética & Jesús Conill & $\begin{array}{l}\text { Catedrática de Filosofía Moral y Política de la } \\
\text { Universitat de València y asesor técnico de la } \\
\text { Fundación ÉTNOR para la Ética de los Negocios y } \\
\text { las Organizaciones }\end{array}$ \\
\hline $\begin{array}{l}\text { Comunicación de la } \\
\text { ciencia y universitaria }\end{array}$ & Antonio Marín & $\begin{array}{l}\text { Director de Mecenazgo de la Universidad de } \\
\text { Granada donde también ha sido Director de } \\
\text { Comunicación, especializado en comunicación } \\
\text { de la ciencia. }\end{array}$ \\
\hline $\begin{array}{l}\text { Comunicación de la } \\
\text { ciencia y RRI }\end{array}$ & Gemma Revuela & $\begin{array}{l}\text { Subdirectora del Observatorio de la } \\
\text { Comunicación de la Ciencia de la Universitat } \\
\text { Pompeu Fabra de Barcelona y miembro del } \\
\text { Grupo Europeo de Expertos en RRI }\end{array}$ \\
\hline $\begin{array}{l}\text { Investigación e } \\
\text { Innovación } \\
\text { Responsable (RRI) }\end{array}$ & $\begin{array}{l}\text { Guillermo } \\
\text { Santamaría }\end{array}$ & $\begin{array}{l}\text { Content manager del proyecto europeo RRI } \\
\text { Tools y comunicador científico del Área de } \\
\text { Ciencia y Medio Ambiente de la Fundació La } \\
\text { Caixa }\end{array}$ \\
\hline
\end{tabular}




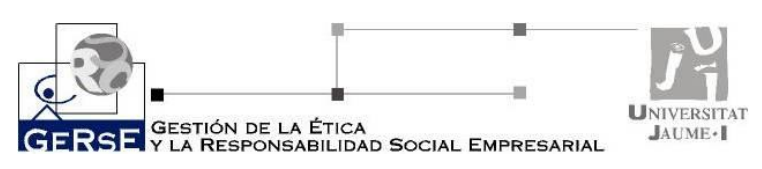

\title{
Aspectos éticos de la comunicación de la investigación e innovación responsable en la universidad
}

\author{
Grupo de Ética y Responsabilidad Social GERSE \\ Universitat Jaume I
}

\section{Instrucciones}

Le agradecemos su colaboración en este estudio con el que se pretende proponer un modelo de comunicación ética de la Investigación e Innovación Responsable para las universidades.

Para ello, necesitaremos que responda este cuestionario en dos ocasiones:

1을 Responda como experto a esta batería de preguntas de forma individual. Las cuestiones que se plantean incluyen una valoración del modelo de desarrollo propuesto y cinco cuestiones de valoración sobre aspectos relacionados con la ética y la comunicación en las universidades.

20 Fase: El cuestionario será devuelto a los expertos indicando los valores promedio obtenidos en las preguntas y un informe general sobre la valoración del modelo de comunicación. De esta forma, podrá reconsiderar sus respuestas y modificarlas, o no, en base a la visión global del conjunto de expertos que componen el panel.

Usted tendrá, por tanto, que responder a esta encuesta en dos ocasiones, una primera, basándose en su única experiencia, y una segunda, donde la opinión del resto de expertos puede hacerle reformular las respuestas que ofreció en la primera oleada.

A continuación presentamos de forma breve los principales aspectos del proyecto de investigación realizado por el Grupo de Ética y Responsabilidad Social GERSE de la Universitat Jaume I sobre "Aspectos éticos de la comunicación de la investigación e innovación responsable en la universidad", dirigido por el catedrático de Ética Domingo García Marzá y el director del Servicio de Comunicación y Publicaciones de la UJI, Francisco Fernández Beltrán. Tras la exposición del modelo ético de comunicación de la RRI propuesto, encontrará el cuestionario sobre el mismo.

\section{Un modelo ético de comunicación de la RRI para las universidades}

La Investigación e Innovación Responsable (RRI, por sus siglas en inglés) es un concepto emergente que ha cobrado fuerza en la última década especialmente en el ámbito europeo, incluyéndose en la convocatoria Horizonte 2020 como un objetivo transversal. Para la Unión Europea la RRI hace referencia a que los actores de la 
sociedad trabajen juntos durante todo el proceso de investigación e innovación con el fin de alinear mejor los procesos y sus resultados con los valores, necesidades y expectativas de la sociedad europea.

Desde el Grupo de investigación de Ética y Responsabilidad Social GERSE de la Universitat Jaume I planteamos un marco ético de la RRI basado en la ética dialógica, que establece la necesidad de entablar diálogos en condiciones de igualdad por parte de todos los posibles afectados presentes y futuros de cara a alcanzar acuerdos con pretensiones validez moral. El marco propuesto se basa asimismo en el ámbito de la Responsabilidad Social Corporativa que cuenta con una amplia trayectoria de aplicación en empresas y organizaciones. En concreto, partimos del enfoque de la Responsabilidad Social planteado por la Escuela de Valencia basado, además de en la ética dialógica, en la teoría de los stakeholders, grupos de interés cuyas expectativas legítimas que deben ser tenidas en consideración y satisfechas.

A partir de este marco teórico, proponemos un modelo ético de comunicación de la RRI para las universidades en el que la comunicación de la investigación y la innovación se sitúa como elemento central, al entender que la comunicación inicia y mejora la gestión de la RRI. Alrededor de este núcleo se establecen los objetivos a alcanzar por la universidad como son plantear las opciones que ofrece a los grupos de interés en materia de investigación e innovación, conocer las expectativas de los mismos, adquirir compromisos y evaluar resultados. En un tercer nivel se sitúan las acciones de comunicación específicas necesarias para alcanzar estos objetivos y dotarlos de validez que pasan por la información proactiva a los públicos sobre las opciones que brinda la universidad; el establecimiento de mecanismos de participación, diálogo y negociación, y el desarrollo de acciones de comunicación pública y transparencia tanto para dar a conocer los compromisos como los resultados alcanzados.

En el modelo propuesto tienen cabida dos formas de entender la comunicación de la ciencia que consideramos que resultan complementarias. Por una parte, se mantiene el modelo tradicional de la comunicación, de carácter unidireccional, entendida como transferencia de resultados y de informaciones sobre investigación e innovación, al entender que estas acciones comunicativas contribuyen a incrementar la cultura científica de los grupos de interés favoreciendo una participación informada en el diálogo. Por otra, siguiendo las directrices de los programas de Ciencia y Sociedad de la Unión Europea, se busca avanzar en un modelo de comunicación bidireccional que incremente la participación y el diálogo con todos los grupos de interés de la ciencia.

Este modelo de comunicación de la RRI para las universidades requeriría para su desarrollo de la implicación de los órganos de gobierno, la dotación de recursos suficientes y su concreción a través de un Plan de Comunicación. 


\section{Modelo ético de comunicación de la RRI en la Universidad}

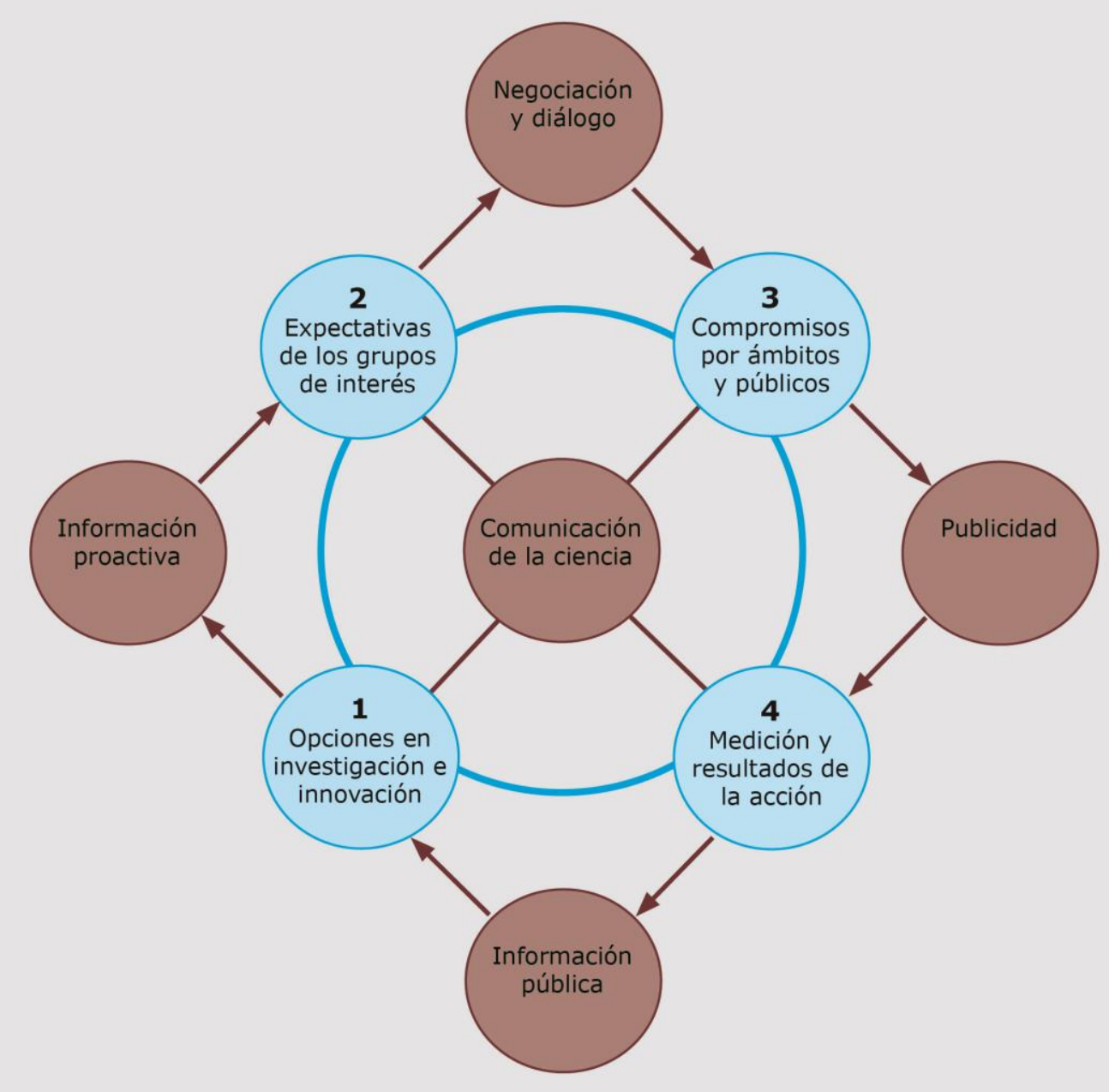

\section{CUESTIONARIO}

1. ¿Cómo valora el modelo de comunicación de la Investigación e Innovación Responsable propuesto para las universidades? ¿Qué oportunidades y riesgos considera que presenta? Responda con la extensión que considere oportuna. 
2. ¿Cuál considera que debe ser la importancia de la comunicación en el desarrollo de una Investigación e Innovación Responsable en las universidades?

Indique su valoración marcando una de las siguientes casillas.

\begin{tabular}{|c|c|c|c|c|}
\hline 0 Nada & 1 Algo & 2 Poco & 3 Bastante & 4 Mucho \\
\hline & & & & \\
\hline
\end{tabular}

3. ¿Cuál considera que debe ser la importancia del papel de las universidades como puente en la transmisión de intereses y necesidades de unos grupos de interés a otros (por ejemplo, de la sociedad a la Administración o la empresa)?

Indique su valoración marcando una de las siguientes casillas.

\begin{tabular}{|c|c|c|c|c|}
\hline 0 Nada & 1 Algo & 2 Poco & 3 Bastante & 4 Mucho \\
\hline & & & & \\
\hline
\end{tabular}

4. En nuestra propuesta agrupamos a los stakeholders de la RRI en cuatro grandes grupos: Comunidad Científica, Sociedad Civil, Administración Pública y Empresas ¿En qué medida considera que es importante el diálogo con estos stakeholders a la hora de establecer los fines de la investigación e innovación?

Indique su valoración marcando una de las siguientes casillas.

\begin{tabular}{|c|c|c|c|c|}
\hline 0 Nada & 1 Algo & 2 Poco & 3 Bastante & 4 Mucho \\
\hline & & & & \\
\hline
\end{tabular}

5. ¿En qué medida considera que las universidades españolas tienen en cuenta criterios de ética y responsabilidad social en la gestión de la investigación y la innovación (compromiso social, atención a las necesidades sociales, transparencia en sus acciones, igualdad, etc.)? Indique su valoración marcando una de las siguientes casillas

\begin{tabular}{|c|c|c|c|c|}
\hline 0 Nada & 1 Algo & 2 Poco & 3 Bastante & 4 Mucho \\
\hline & & & & \\
\hline
\end{tabular}

6. ¿En qué medida considera que en la gestión de la comunicación de la investigación y la innovación desde las universidades se tienen en cuenta aspectos de ética y responsabilidad social (atención a las expectativas ciudadanas, transparencia, participación, etc.)? Indique su valoración marcando una de las siguientes casillas.

\begin{tabular}{|c|c|c|c|c|}
\hline 0 Nada & 1 Algo & 2 Poco & 3 Bastante & 4 Mucho \\
\hline & & & & \\
\hline
\end{tabular}

7. Otras cuestiones que considere de interés:

Muchas gracias por su colaboración 


\subsection{DESCRIPCIÓN Y ESTRUCTURA DEL TRABAJO}

Para alcanzar los objetivos establecidos el trabajo se estructura en cinco bloques. El primero se dedica a presentar y contextualizar la investigación. El segundo bloque aborda el Marco Teórico de la tesis a partir de cuatro pilares: el marco ético y político de la RRI; el concepto mismo de Investigación e Innovación de la Ciencia; la Comunicación Pública de la Ciencia, y las normativas y directrices existentes en la actualidad en material de RRI y su comunicación. A partir de las conclusiones extraídas del marco teórico y las directrices existentes, el tercer bloque propone una definición de RRI desde un marco ético, un mapa de stakeholders de la RRI y un modelo ético de comunicación de la RRI en la Universidad. La validación de este modelo es el objetivo del cuarto bloque de la tesis, para lo que se recurre a la visión de expertos y de los propios stakeholders, además de a un análisis de la realidad actual de la comunicación de la ciencia en las universidades. Las conclusiones alcanzadas, incluidas en el quinto y último bloque, permitirán reformular y mejorar el modelo de comunicación ética de la RRI planteado previamente y establecer unos criterios normativos para su desarrollo. Mostramos a continuación más detalladamente la estructura y objetivos de cada uno de estos bloques.

Entendemos que el desarrollo de un marco ético de la RRI y su comunicación debe partir de una aproximación teórica a los conceptos de Ética y Moral, para posteriormente sentar las bases éticas en las que se asentará el marco a desarrollar y que, en esta caso, se apoyan en la ética del discurso y la ética aplicada, siguiendo la línea desarrollada por la Escuela de Valencia. Como hemos indicado, buscaremos definir un marco ético y también político para la RRI. Por tanto, el segundo punto de este capítulo se centrará en la democracia deliberativa partiendo de la ética del discurso de Habermas para acabar con algunas propuestas que suponen un avance de este modelo como es el caso de la democracia radical como democracia comunicativa planteada por Adela Cortina. Este primer apartado se cierra con una aproximación al concepto de ciudadanía que pone el acento en el desarrollo de una ciudadanía activa y participativa y que nos conduce hacia el fenómeno de la ciencia ciudadana, un concepto emergente que hace referencia precisamente a una ciudadanía participativa en el campo de la investigación y la innovación.

Continuando con el marco teórico del trabajo, un segundo capítulo está dedicado íntegramente al concepto emergente de RRI. Una vez expuestas las razones de la 
creciente importancia de la RRI, abordaremos cómo la Responsabilidad Social Empresarial, ampliamente desarrollada desde mediados del siglo $\mathrm{XX}$, sirve como referente para la Investigación e Innovación Responsable. En este sentido, y siguiendo con la línea teórica propuesta, se pone el acento en el modelo de ética y RSE desarrollado por la Escuela de Valencia basado en la teoría ética discursiva de Habermas y en la teoría de los stakeholders, así como en su modelo comunicativo. El capítulo se completa con una amplia aproximación a la RRI desde las diferentes definiciones y aproximaciones teóricas existentes y un análisis de la evolución y auge de este concepto en la Unión Europea, los principales proyectos que se están llevando a cabo en materia de RRI y algunos ejemplos de prácticas de Investigación e Innovación Responsable desarrollados a nivel nacional e internacional.

El marco teórico cuenta con un tercer capítulo centrado en la Comunicación Pública de la Ciencia que aborda aspectos como las razones por las que la difusión de la investigación es importante y necesaria; la necesidad de potenciar una mayor participación ciudadana; la evolución de un modelo unidireccional de la comunicación científica hacia una mayor bidireccionalidad, y el modo en el que actualmente se realiza la comunicación de la ciencia teniendo en cuenta los nuevos medios sociales. Llegados a este punto resulta de interés conocer cómo la explosión del periodismo generada por las nuevas tecnologías ha afectado a la ciudadanía mediática, dibujando un nuevo panorama que alcanza también a la comunicación de la ciencia. Asimismo, se aborda la comunicación de la ciencia como parte de las funciones de las universidades.

Una vez establecido el marco teórico desde la ética, la Investigación e Innovación Responsable y la comunicación de la ciencia, el último capítulo de este bloque recoge el marco normativo actual de la comunicación de la RRI. De este modo, el análisis de directrices y normativas europeas respecto a la RRI hace especial hincapié en todo lo referente a su comunicación y a los mecanismos de relación y participación de los stakeholders y, especialmente, en todo lo relativo a su comunicación y a las relaciones de diálogo entre los diferentes stakeholders

El trabajo desarrollado en estos dos primeros bloques permitirá plantear algunas propuestas propias que tengan en cuenta el marco ético establecido y las directrices existentes. Así, en el tercer bloque se plantea una propuesta normativa desde la ética para establecer cuándo una investigación puede considerarse responsable y se define la RRI como el proceso necesario para alcanzarlo. Dado el peso que cobran en este 
planteamiento los grupos de interés, se hace necesario desarrollar una propuesta de mapa de stakeholders y un análisis de los intereses de cada uno de ellos en materia de comunicación. El bloque se completa con la propuesta de un modelo de comunicación ética para la RRI en las universidades que tenga en cuenta los intereses de los stakeholders y las características de la comunicación de la ciencia como función de las universidades.

El cuarto bloque de la tesis busca la validación del modelo a través de una reflexión sobre el presente y el futuro de la comunicación de la RRI. Para ello, se analiza la realidad de la comunicación de la ciencia por parte de las cinco universidades públicas y privadas valencianas con el fin de poder establecer sus debilidades y fortalezas respecto a un modelo ético de comunicación de la RRI. Dado que la Investigación e Innovación Responsable es un concepto emergente que todavía no se ha implantado en la realidad universitaria valenciana, ni española en su conjunto, es de prever que la comunicación de la RRI tampoco se haya desarrollado. Por ello, en una segunda parte se busca conocer la opinión sobre el modelo planteado de los diferentes stakeholders de la RRI a través de focus groups y de los de expertos en ética y en comunicación universitaria y científica mediante un panel Delphi.

Las conclusiones alcanzadas a partir del análisis de la realidad y la valoración de expertos y grupos de interés permitirán reformular y mejorar el modelo de comunicación ética de la RRI en la universidad y establecer unos criterios normativos para su desarrollo. Este es el tema que centra el quinto bloque con el que se cierra la presente tesis doctoral. 



\section{EL MARCO ÉTICO DE LA}

INVESTIGACIÓN E INNOVACIÓN RESPONSABLE (RRI) 



\section{El marco ético y político para la RRI}

El presente capítulo aborda en un primer apartado el marco ético para la RRI en base a la ética del discurso de Habermas y las éticas aplicadas. El segundo punto se centra en el marco político y, en concreto, en el modelo de democracia deliberativa derivado de la ética del discurso. En este apartado se abordan también otras perspectivas de interés para la investigación como la ética económica o los conceptos de democracia radical y democracia monitorizada. Finalmente, el capítulo se cierra con un apartado centrado en el papel de la ciudadanía, abordando para ello los conceptos de esfera pública, opinión pública y sociedad civil, además del propio término de ciudadanía. La participación y el auge de la denominada ciudadana cierran este tercer apartado.

\section{1. DE LA ÉTICA A LA ÉTICA APLICADA}

El primer paso para definir el marco ético para una investigación responsable pasa por abordar los conceptos de "moral" "ética", "ética del discurso" y "ética aplicada" en los que se encuentra la base de la presente tesis. Este primer punto aborda estos términos partiendo de la perspectiva de la Escuela de Valencia de la mano de autores como Adela Cortina y Domingo García Marzá. Se avanza así desde el concepto de moral y de ética hacia la ética del discurso y la aplicación de la misma en las diferentes actividades sociales, incluida la investigación y la comunicación de la ciencia. Es precisamente una aproximación a la ética aplicada en estos dos últimos ámbitos la que cierra el presente punto introductorio.

\subsection{1. Ética y moral}

Para acercarnos al término "moral" partimos de la aproximación realizada por Adela Cortina en su obra Ética. En ella, la autora destaca que el término moral puede tener diferentes significados en función de su uso. Así, como sustantivo puede utilizarse para referirse a un modelo de conducta socialmente establecido en una sociedad concreta (la moral vigente); a un conjunto de convicciones morales personales; a tratados sistemáticos sobre las cuestiones morales (Moral); a disposiciones de ánimo producidas por el carácter y actitudes adquiridos por una persona o grupo (estar alto de 
moral); o a la dimensión de la vida humana por la cual nos vemos obligados a tomar decisiones y a dar razón de ellas (lo moral) (Cortina y Martínez, 1996).

Cuando el término moral se utiliza como adjetivo, en la mayoría de ocasiones tiene relación con la ética, haciendo referencia a la dimensión de la vida humana que llamamos moralidad. La autora destaca dos significados muy distintos que puede adoptar el término moral como adjetivo. Es el caso de "moral" como opuesto a "inmoral", en el que tiene un significado valorativo en el sentido de que algo es moralmente correcto o incorrecto. Este uso presupone la existencia de un código moral que es el que sirve como referencia para poder emitir un juicio moral. El segundo de los significados destacados de "moral" como adjetivo es como opuesto a "amoral". En este caso no supone una evaluación sino que describe una situación, es decir, si se pueden considerar responsables de sus actos o no. Así, solo puede ser calificado como "moral" o "inmoral" en el primer sentido aquello que se pueda considerar como "moral" en el segundo sentido.

Cortina se detiene también en los significados del término moralidad, que en ocasiones se utiliza como sinónimo de "moral" en el sentido de una concepción moral concreta. También puede ser utilizado como sinónimo de "lo moral" y en un sentido netamente filosófico que consiste en contraponer "moralidad" a "eticidad".

Por lo que respecta al término "ética", se utiliza en muchas ocasiones como sinónimo de la moral, en el sentido de un conjunto de principios, normas, preceptos y valores que rigen la vida de las personas. Ambos términos confluyen etimológicamente en un significado casi idéntico. Según señala Cortina: todo aquello que se refiere al modo de ser o carácter adquirido como resultado de poner en práctica unas costumbres o hábitos considerados buenos. A pesar de que en el ámbito cotidiano ambos términos pueden ser intercambiables en numerosas ocasiones, en el ámbito académico el término "Ética" hace referencia a la Filosofía moral, manteniéndose el término "moral" para hacer referencia a los distintos códigos morales concretos. Esta distinción permite establecer dos niveles de reflexión diferentes, dos niveles de pensamiento y lenguaje acerca de la acción moral.

Así, llamamos "moral" a ese conjunto de principios, normas y valores que cada generación transmite a la siguiente en la confianza de que se trata de un buen legado de orientaciones sobre el modo de comportarse para llevar una vida buena y justa. Y llamamos "Ética” a esa disciplina 
filosófica que constituye una reflexión de segundo orden sobre los problemas morales (Cortina, 1996:21-22).

Por tanto, la Ética como Filosofía moral no se identifica, en principio, con ningún código moral determinado. No obstante, la autora señala que tampoco puede permanecer neutral ante los distintos códigos morales puesto que sus propios métodos y objetivos la comprometen con ciertos valores y la obligan a denunciar a algunos códigos morales como incorrectos.

Por lo que respecta a las funciones de la Ética, Cortina le atribuye tres:

1. Aclarar qué es lo moral y cuáles son sus rasgos específicos.

2. Fundamentar la moralidad.

3. Aplicar a los distintos ámbitos los resultados obtenidos en las dos primeras funciones, de manera que se adopte en esos ámbitos sociales una moral crítica; es decir, una moral racionalmente fundamentada.

Es de esta tercera función de la que surge la ética aplicada a la que haremos referencia más adelante.

De forma esquemática, resulta de interés hacer una breve aproximación a algunos de los principios éticos más relevantes que han ido surgiendo a lo largo de la historia en la tarea de la fundamentación, como es:

- El utilitarista, en el que los principios pasan por lograr el mayor placer del mayor número.

- El kantiano, basado en tratar a las personas como fines en sí mismas y no como simples medios

- El dialógico, consistente en no tomar como correcta una norma si no la deciden todos los afectados por ella tras un diálogo celebrado en condiciones de simetría.

Esta última será la que tomemos como referente en el presente trabajo.

Cerramos este punto sobre el concepto de "Ética" con la respuesta de Adela Cortina a la cuestión sobre su utilidad, una respuesta que aporta una visión práctica del resultado final que se puede alcanzar gracias a la misma, y que entendemos que afecta también a la gestión de la investigación y la innovación y a su comunicación: 
"¿Para qué sirve la ética? Para abaratar costes en dinero y sufrimiento en todo aquello que depende de nosotros, e invertirlo en lo que vale la pena, sabiendo priorizar" (Cortina, 2013:26).

\subsubsection{La ética del discurso}

Como adelantábamos en el punto anterior, la ética del discurso será la que tomaremos como referente en el presente trabajo por entender que supone un marco ético adecuado para la RRI al fomentar la participación de todos los posibles afectados a través de un proceso dialógico. En este punto abordaremos de forma breve los postulados de la Escuela de Frankfurt, en concreto de Jürgen Habermas, para defender el interés de la ética del discurso en la comunicación de la ciencia y la investigación e innovación responsables. El uso comunicativo del lenguaje se encuentra en la base de las teorías de Habermas, que parte de la Teoría de los Actos de Habla de Austin y Searle y del lenguaje como el medio a través del cual pueden estructurarse las redes de reconocimiento recíproco, en las que aprendemos a relacionarnos con los demás y con nosotros mismos. Habermas distingue, en función de la voluntad de los actores en el uso del lenguaje, entre acciones estratégicas y acciones comunicativas. Estas últimas, caracterizadas por la orientación del actor hacia el entendimiento, son las que nos interesan (García Marzá, 1992).

De cara a abordar los aspectos relacionados con la comunicación de la ciencia y la investigación e innovación responsable, es importante tener en cuenta que un acto de habla con pretensiones de validez en la acción comunicativa debe cumplir, según Habermas, los siguientes presupuestos: inteligibilidad, sinceridad, verdad y justicia. Estas dos últimas variables son las que permiten la argumentación. El concepto de verdad como resultado del diálogo y del acuerdo, desvinculado de la realidad, resulta especialmente interesante en el campo de la ciencia y la tecnología, campos en los que los conocimientos no son neutros y las verdades son el resultado de un diálogo históricamente construido. Volveremos a estos presupuestos a la hora de definir el modelo comunicativo de la RRI en las universidades.

Cuando en el proceso de comunicación no hay acuerdo en los presupuestos de verdad o justicia entre los interlocutores, se entra en un proceso de argumentación. García Marzá explica cómo el proceso de argumentación se plantea así como una posibilidad cuando no existe acuerdo: "En caso de que se ponga en duda nuestra 
pretensión de verdad, y de nada sirva el recurso a la experiencia, tenemos aún la posibilidad de argumentar, de dar razones -explicaciones teóricas- de que efectivamente tiene lugar lo afirmado" (García Marzá, 1992:50). De este modo, el discurso teórico permite restablecer la interacción comunicativa mediante los acuerdos alcanzados.

Pero para que el discurso tenga validez ética debe cumplir los principios de sinceridad, inclusión, reciprocidad y simetría. De esta forma, las condiciones formales del discurso en una situación ideal del habla deben ser tales que aseguren a todos los participantes una completa igualdad. Llegamos así al principio moral básico que deben cumplir toda acción, también la investigación y la innovación y la comunicación de las mismas. Habermas da un paso más hacia el principio de universalización a partir de la ética del discurso, señalando que una norma, acción o decisión o una institución pueden ser consideradas correctas o justas cuando pudieran encontrar el consenso de todos los afectados, tras un cálculo de consecuencias, en un discurso práctico en condiciones de igualdad (Habermas, 2000).

De esta forma, para Habermas, en la ética del discurso lo moral está en el diálogo y en la posibilidad de alcanzar el acuerdo, para lo que resulta necesaria la comunicación. Y a pesar de las dificultades para que se cumplan todos los principios, marca un horizonte de actuación, señala el norte al que dirigirnos, es un criterio de justicia y validez. El contenido normativo universal de estas estructuras lingüísticas es lo que las dota de un valor moral. García Marzá recoge esta idea de Habermas de forma precisa, destacando el valor moral de los acuerdos alcanzados de forma argumentativa y ligados, por tanto, a los intereses de los diferentes afectados.

El discurso práctico permite una solución moral siempre y cuando la norma pueda ser considerada como justa o correcta, esto es, cuando pueda entenderse como fruto de un acuerdo argumentativo. La cuestión moral tiene que ver, por tanto, con la 'fundamentación y utilización de normas que determinan los derechos y obligaciones recíprocos'. Lo cual significa, que tiene que ver con los intereses comunes a todos los afectados (García Marzá, 1992:55).

Desde esta perspectiva, la reflexión ética adquiere la forma de una lógica de la argumentación práctica. La finalidad del discurso radica en buscar interpretaciones de nuestras necesidades con las que también puedan afectarse el resto de afectados en el conflicto, algo perfectamente extrapolable a los avances científicos y tecnológicos, que se encuentran directamente relacionados con las necesidades en numerosas ocasiones de 
la humanidad en su conjunto. Así, Habermas defiende que mediante el discurso ético como hilo conductor se puede desarrollar la idea formal de una sociedad, en la que todos los procesos potenciales importantes de decisión política estén unidos a las formas institucionales de la formación discursiva de la voluntad. De esta forma, ética y política se vinculan con la necesidad de que todos los procesos políticos de decisión, incluidos los relacionados con la ciencia y la tecnología, deben estar sometidos a la consideración de todos los afectados. La igualdad política se vincula así a la posibilidad de tomar parte en las decisiones por parte de los afectados. En palabras de García Marzá: "Igualdad política significará entonces la igual posibilidad de participación en todas las decisiones de alcance político" (García Marzá, 1992:173).

Hemos visto la importancia, por tanto, de la participación. Profundizando un poco más en este concepto, vemos como aparece estrechamente vinculado al de conocimiento como condición necesaria para alcanzar esta participación. García Marzá defiende que para alcanzar la "ideal participación" es necesario partir del conocimiento moral que se requiere para que los diferentes afectados puedan actuar autónomamente. Para que esta actuación y participación autónoma se dé en el terreno de la investigación y la innovación responsable, resulta fundamental establecer una cultura científica de base que permita a los afectados tomar parte en el discurso con criterio propio. Pero la participación no puede limitarse a que cada individuo reflexione sobre una cuestión y deposite su voto, la validez le viene dada por la argumentación real en la que participen de un modo cooperativo los afectados. $Y$ es que "los discursos espolean a los participantes a adoptar también las perspectivas de los demás” (Habermas, 2006: 25), lo que puede llevar incluso a cambiar las propias opiniones. Esto supone que no es suficiente con promover una cultura científica, sino que es necesario establecer los mecanismos necesarios para favorecer la argumentación y discusión entre los afectados. Habermas establece las condiciones en las que debe llevarse a cabo este discurso, entre las que resulta clave la participación de todos los posibles afectados:

Solo bajo los presupuestos comunicativos de un discurso universalmente ampliado en el que participen todos los posiblemente afectados y en el que, en actitud hipotética, pudiesen tomar posturas mediante argumentos respecto de las pretensiones de validez de las normas y modos de actuar que en cada caso hayan llegado a ser problemáticos, se constituye la intersubjetividad, de más alto nivel, de una imbricación de la perspectiva de cada uno con las perspectivas de todos (Habermas, 2000:121). 
A partir de la ética del discurso se pueden alcanzar normas con validez moral. Para García Marzá el principio ético-discursivo constituye así un procedimiento para garantizar la imparcialidad del juicio moral y un punto normativo de referencia para la formación de la voluntad tanto individual como colectiva, representa un criterio de corrección para la decisión posible sobre la justicia de una acción, norma o institución (García Marzá, 1992:29). En el terreno de la ciencia y la innovación, en numerosas ocasiones surgen diferencias sobre el camino a seguir y la legislación a aplicar. Así, la aplicación del principio ético-discursivo, que garantizaría la participación de todos los afectados o sus representantes en condiciones de igualdad y de forma autónoma, dotaría de valor moral estas decisiones. "Sabemos quienes hablan en nombre de las naciones, pero ¿quién habla en nombre de la especie humana?, ¿quién defiende a la Tierra?", se preguntaba el divulgador científico Carl Sagan. En este caso, la ética del discurso nos llevaría a decir que todos los afectados; es decir, toda la humanidad. De ahí la importancia de establecer mecanismos de formación, comunicación de la ciencia y deliberación para abordar conflictos que a todos nos afectan. Cómo hacerlo posible nos llevará a la democracia deliberativa y al valor de la opinión pública.

A la hora de llevar a la práctica la teoría de la ética del discurso de Habermas, desde la Escuela de Valencia autores como Adela Cortina y García Marzá defienden la necesidad de aunar teoría y praxis. Así, resaltan las potencialidades de aplicación del principio ético-discursivo, asegurando García Marzá que es precisamente en el nivel de la realización práctica donde mejor se pueden comprobar las capacidades y límites de este procedimiento ético. No obstante, el autor resalta que estas reglas que definen el discurso práctico no determinan el resultado. "Son reglas pragmáticas que establecen las condiciones de participación, no prescripciones normativas acerca de qué convicciones debemos modificar o aceptar” (García Marzá, 1992:159). En el terreno de la aplicación, Habermas destaca además la necesidad de tener en cuenta el contexto, basándose en un principio de adecuación.

La aplicación de normas exige una aclaración argumentativa específica. En ella la imparcialidad del juicio no puede estar garantizada a su vez por un principio de universalización; en lo que respecta a las cuestiones de aplicación sensible al contexto la razón práctica tiene que hacerse valer más bien como un principio de adecuación (Habermas, 2000:122).

La aplicación de las decisiones sobre ciencia tendrá que tener también en cuenta este principio de adecuación en función de situaciones complejas. Lo que parece 
resultar claro es el interés de la aplicación de una ética del discurso a la hora de abordar tanto la gestión de la ciencia como su propia comunicación, ya que la elección de los aspectos de la ciencia que se comunican y se divulgan y la forma en que se hace no son tampoco neutrales. De este modo, la ética del discurso nos da el marco ético para el desarrollo de un modelo de comunicación de la RRI.

La ética del discurso enlaza también con un modelo político, el de la democracia deliberativa, que abordaremos más ampliamente en el segundo punto centrado en el marco político de la RRI. Previamente, trataremos de completar el marco ético de la misma a través de la ética aplicada.

\subsection{3. Ética aplicada}

La Escuela de Valencia se caracteriza por proponer una renovación de la ética del discurso que, entre otros temas, insiste en la posibilidad y necesidad de una ética aplicada. Como hemos visto, entre las tareas de la Ética se encuentra no sólo la aclaración de lo que es la moralidad y la fundamentación de la misma, sino también la aplicación de sus descubrimientos a los distintos ámbitos de la vida social, averiguando cómo los principios éticos pueden ayudar a orientar actividades que tienen exigencias morales y valores propios de cada una. Fue en los años sesenta y setenta del siglo XX cuando surgió el concepto de ética aplicada ante la necesidad de dar respuesta a los problemas de la vida cotidiana según explica Cortina.

En aquel tiempo el problema de la fundamentación de lo moral seguía siendo el tema estrella de la ética, pero junto a él empezaba a ganar terreno la necesidad de aplicar a la vida cotidiana lo ganado en el proceso de fundamentación, la necesidad de diseñar una ética aplicada a las distintas esferas de la vida social, que daría lugar a las distintas "ética aplicadas" (Cortina, 2003:13).

Las éticas aplicadas nacieron por tanto, más que por un imperativo filosófico, "por imperativo de una realidad social que la necesitaba en sociedades moralmente pluralistas" (Cortina, 2003:13). En este sentido, Cortina destaca como las sociedades habían tomado conciencia de su pluralismo moral, por lo que no podían abordar las cuestiones morales desde un único código moral al albergar a distintas éticas de máximos. Fue en este contexto en el que surgieron y se consolidaron las éticas aplicadas para hacer frente a cuestiones como las biotecnologías, el desarrollo de los pueblos, la 
estructura de los medios de comunicación, la construcción de la paz, las consecuencias de las nuevas tecnologías, etc.

Para Domingo García Marzá, el fin de las éticas aplicadas pasa por favorecer la búsqueda de soluciones a los problemas desde una voluntad común partiendo de las capacidades morales que poseemos como individuos. Así, para el autor el gran reto de las éticas aplicadas pasa por:

Facilitar una orientación normativa que nos permita buscar soluciones a los problemas desde una
voluntad común. Soluciones que si bien se dan dentro de un marco jurídico, no pueden reducirse
ni identificarse con los procedimientos legales. Las éticas aplicadas se dirigen hacia las
capacidades morales que poseemos como individuos y que nos permiten asumir compromisos
responsables para la solución de los conflictos de acción (García Marzá, 2003:160).

En cuanto a la función de la ética aplicada, Cortina señala la necesidad de averiguar cuáles son los bienes internos que cada una de las actividades sociales debe aportar a la sociedad y qué valores y hábitos es preciso incorporar para alcanzarlas. Este trabajo debe realizarse en colaboración con los expertos de cada campo por lo que la ética aplicada es necesariamente interdisciplinar. Además, una ética aplicada a los ámbitos sociales propios de una sociedad pluralista moderna tiene que tener en cuenta la moral cívica que rige en este tipo de sociedades. Por tanto, la ética aplicada ha de hacer referencia a un método propio, a los valores cívicos de la sociedad y a los valores propios de cada actividad:

En síntesis, un planteamiento correcto de la ética aplicada -a nuestro juicio- tiene que aclarar cuál es su método propio (cómo se relaciona el plano de los principios éticos y el de las decisiones correctas), cuál es el marco de valores cívicos que ha de tener en cuenta, y cuáles son los valores propios de cada actividad (Cortina, 2003).

El método propuesto por Cortina es el de una hermenéutica crítica, que plantea “descubrir en los distintos campos la peculiar modulación del principio común" (Cortina, 1996:152), para lo que se requiere un trabajo interdisciplinar. El método planteado señala además la necesidad de tener en cuenta los diferentes modelos éticos en el momento oportuno, aunque tomando como elemento coordinador a la ética del discurso, al hundir ésta sus raíces en la acción comunicativa y en la subsiguiente argumentación, que constituye el medio de coordinación de las restantes actividades humanas. Así, aparece la idea de sujeto como interlocutor válido como elemento común a las distintas esferas, ya que en todas es el afectado quien está legitimado, en último 
término, para exponer sus intereses, y por eso sólo deben considerarse legítimas aquellas normas que satisfagan los intereses universalizables.

Los ámbitos de la ética aplicada son las actividades sociales realizadas por sujetos humanos como, según señala Cortina (1996), el sanitario, la investigación biotecnológica, la economía, la empresa, la ecología, los medios de comunicación, las organizaciones e instituciones sociales y las actividades profesionales y oficios. Cada una de estas actividades tienen su propio bien interno, por ejemplo, en el caso de la sanidad el bien del paciente o, en el de las biotecnologías, la investigación en pro de una humanidad más libre y feliz. De esta forma, la meta viene dada y es la que presta a la acción sentido y legitimidad social, por lo que, según señala la autora, únicamente se puede deliberar sobre los medios ya que los fines últimos ya vienen dados. Para articular una ética aplicada en torno a una de estas actividades sociales, Cortina considera que sería necesario recorrer los siguientes pasos (Cortina, 1996):

- Determinar claramente el fin específico, el bien interno por el que cobra su sentido y legitimidad social.

- Averiguar cuáles son los medios adecuados para producir ese bien en una sociedad moderna.

- Indagar qué virtudes y valores es preciso incorporar para alcanzar el bien interno.

- Descubrir cuáles son los valores de la moral cívica de la sociedad en la que se inscribe y qué derechos reconoce esa sociedad a las personas.

- Averiguar qué valores de justicia exige realizar en ese ámbito el principio de la ética del discurso, propio de una moral crítica universal, que permite poner en vigor normas vigentes.

- Dejar la toma de decisión en manos de los afectados que, con la ayuda de instrumentos de asesoría, ponderarán las consecuencias sirviéndose de criterios tomados de distintas tradiciones éticas.

Por su parte, desde la Escuela de Valencia también García Marzá señala las dificultades que surgen a la hora de llevar a la práctica la teoría filosófica, indicando que para superarlas es necesario comprender que la relación entra la teoría y la praxis no 
puede realizarse desde una perspectiva dual ya que el punto de vista moral está incrustado en el sentido mismo de la realidad social. Para el autor, se debe evitar tanto un enfoque correctivo que marque de forma deductiva cuáles son los límites externos de toda actividad, praxis o institución; como un enfoque funcional que considere a la ética como una estrategia para el logro de objetivos. El enfoque adecuado para García Marzá es el que parte de que el estatuto de las éticas aplicadas "debe basarse en el carácter integrativo que posee la misma realidad social, en la que no es posible separar vigencia y validez, hechos y valores". La ética del discurso puede servir de nuevo para definir los pasos necesarios para configurar la ética aplicada como una ética integrativa (García Marzá, 2003).

García Marzá parte de Habermas para establecer tres niveles para delimitar la estructura de una ética aplicada derivada de una ética discursiva: el nivel de justificación, el nivel de adecuación y el nivel de respuesta (García Marzá, 2003). En el primero de estos niveles se sitúa el principio de diálogo en una situación de igualdad basado en lo que Habermas denomina un discurso práctico, dónde solo las razones aducidas pueden producir un consenso. Para ello, y como veremos más ampliamente en el siguiente punto, el diálogo debe estar basado en los principios de sinceridad, inclusión, reciprocidad y simetría.

Por lo que respecta al nivel de adecuación, hace referencia a la capacidad de utilizar el saber alcanzado en la etapa anterior en situaciones concretas, a la adecuación a la realidad. En este punto se requiere de la interdisciplinariedad para conocer la lógica interna de cada una de las actividades y también la complementación con otras teorías como, por ejemplo, la teoría de los stakeholders que abordaremos más adelante. En este caso, García Marzá señala que ambas teorías pueden complementarse ya que la ética discursiva ofrece a la teoría de los stakeholders una fundamentación normativa acorde con la pluralidad y universalidad de los contextos actuales; y la teoría de los grupos de interés ofrece a la ética del discurso un acceso metodológico a las diferentes estructuras de la sociedad civil, sacándola de su excesiva abstracción. La presente tesis parte de la complementariedad de ambas teorías para dotar de un marco ético a la RRI y a su comunicación.

Finalmente, siguiendo la ética del discurso, el nivel de resolución estará siempre en manos de los propios afectados. Si bien ningún ético, por si mismo, puede decidir la validez moral de una actuación o institución, si puede ayudar a sentar las bases 
adecuadas para el diálogo, así como avanzar y concretar propuestas para su discusión. De este modo, para García Marzá, la ética aplicada:

(...) debe ofrecer para la discusión orientaciones y posibilidades de acción y de participación que ayuden en la resolución consensual de los conflictos de acción. Debe hacer propuestas y avanzar en la definición de las condiciones en que pueden aplicarse los recursos morales. Siempre, por supuesto, como contenido para la discusión libre y pública entre todos los afectados (García Marzá, 2003:184).

Para cerrar este punto, dado que en el siguiente profundizaremos más ampliamente sobre la ética del discurso y la propuesta de ética aplicada desarrollada por la Escuela de Valencia, cabe concluir que las éticas aplicadas permiten, en palabras de García Marzá, "la orientación de la acción y, con ella, posibilitan una coordinación social apoyada en la fuerza de convicción de las buenas razones" (García Marzá, 2003:190). Por lo que respecta a la red de éticas aplicadas derivadas de la ética discursiva, como es el caso de la propuesta por los autores de la Escuela de Valencia y en la que se basa la presente tesis doctoral, comparten el discurso práctico como mecanismo para esta coordinación de la acción.

\subsubsection{La ética aplicada a la ciencia y a su comunicación}

El ámbito de la ciencia no se ha mantenido ajeno a las consideraciones de la ética aplicada. En este sentido, Cortina hacía ya referencia en 1993 a los recelos de los investigadores e investigadoras ante la ética, señalando la necesidad de la misma para marcar el sentido de los avances:

La ética nada tiene que frenar de cuanto potencie el impulso creador por el que la humanidad se hace más humana, y que no es sino la moral del científico - su ethos- el que le marca ese camino ¿Un camino sin límites? No los hay sin ellos, pero lo que importa es la flecha indicadora del sentido (Cortina, 1993:252).

Ante un proyecto de investigación, Cortina considera que se generan dos preguntas. Por un lado, cuáles son los fines últimos de la investigación y quienes están legitimados para tomar decisiones sobre estos asuntos. Sobre la primera cuestión, señala que no existe un fin dado de antemano, "el fin nos lo damos a nosotros mismos" (Cortina, 1993:258). Por tanto, lo realmente relevante es el sujeto ético de la decisión. Las decisiones en materia de ciencia, tecnología e innovación no se pueden dejar en manos de los países ricos o de las industrias. Tampoco pueden ser decisiones políticas 
ya que sería peligroso porque el juego de la política no es en realidad el de lo universal sino el de los intereses particulares. A diferencia de lo que puede tenderse a pensar, tampoco deben recaer en manos de los expertos porque no hay expertos en fines, "hay expertos en medios pero los fines sólo pueden determinarlos los afectados por la puesta en marcha de una ciencia, porque son ellos quienes mejor conocen en qué consiste ese bien" (Cortina, 1993: 260). El papel de los expertos consiste entonces en asesorar y la decisión recae en manos de los afectados. Y es que nadie puede sustraer a los individuos la toma de decisiones en un asunto que les afecta directamente.

Hoy en día la posibilidad de tomar decisiones morales objetivas -intersubjetivas- pasa por la toma de decisiones responsables por parte de los afectados que, con el debido asesoramiento de los expertos, han de optar teniendo en cuenta no sólo sus intereses individuales, sino los universalizables (Cortina, 1993: 262).

Alcanzarlo exige, según Cortina, al menos una triple tarea. En primer lugar, lograr que los expertos comuniquen sus investigaciones a la sociedad, que las acerquen al público, de modo que éste pueda codecidir de forma autónoma, contando con la información necesaria para ello (Cortina, 1993). Es en esta tarea en la que cobra un especial protagonismo la comunicación y divulgación de la ciencia. Una segunda tarea pasa por concienciar a los individuos de que son ellos quienes han de decidir, saliendo de su habitual apatía en estos asuntos. Por último, es necesario educar moralmente a los individuos en la responsabilidad a la hora de tomar decisiones que pueden implicar, no sólo a individuos, sino incluso a la especia. Los afectados han de asumir la responsabilidad de informarse, dialogar y asumir las decisiones desde intereses universalizables, si es que desean que los intereses satisfechos por la investigación científica no sean unilaterales sino humanos (Cortina, 1993). De esta forma, la autora sienta algunos de los pilares que fundamentan la importancia y necesidad de la difusión de la ciencia y de la participación ciudadana en materia de investigación y tecnología.

Como ejemplo de un ámbito vinculado en gran medida a la investigación y la innovación encontramos la biotecnología, una rama relacionada con las ciencias de la salud y las biotecnologías sobre la que Cortina ofrece interesantes reflexiones desde la perspectiva de ética aplicada, reflexiones que serían extensibles a todas las ciencias de la salud. Así, entre los principios de la biotecnología la autora considera que existe un amplio consenso en señalar los de autonomía, beneficencia y justicia. Se trata de principios que entienden como válidos para servir de orientación en las cuestiones 
bioéticas, pero fundamentándolos filosóficamente mediante el concepto de persona entendida como interlocutor válido para apreciar plenamente su validez intersubjetiva. Se trata además de principios prima facie, es decir, que se han de seguir siempre que no entren en conflicto y que se han de ponderar cuando esto ocurra (Cortina, 1996).

Para cerrar el presente punto, en el ámbito de la ética aplicada, entendemos que son también de gran interés las aportaciones realizadas por Cortina por lo que respecta a las profesiones, señalando la necesidad de tender a la excelencia, que es además el único modo de hacer justicia a la naturaleza de estas actividades sociales (Cortina, 1997b:146). Así, resulta necesario que los profesionales tomen conciencia de que es un deber moral ejercer la propia profesión con pleno rendimiento, siendo este el caso tanto de los investigadores como de los profesionales de la comunicación científica.

El ejercicio de una profesión exige emplearse en esa causa social que trasciende a quien la sirve, integrándose en un tipo de actividad que tiene ya sus rasgos específicos. Los fines de la profesión, su bien último, no varía, pero el tipo de relaciones humanas para alcanzarlo ha cambiado en función de la conciencia moral de cada época. De ahí la importancia de establecer los hábitos y actitudes necesarios para alcanzar los fines últimos.

Por eso conviene ir dilucidando qué hábitos concretos han de ir incorporando los profesionales para alcanzar los fines de la profesión, qué actitudes han de ir apropiándose para realizar el bien interno, habida cuenta de que nos encontramos en sociedades que han accedido al nivel postconvencional en el desarrollo de su conciencia moral (Cortina, 1997b:157).

El virtuoso en una profesión es el que pretende alcanzar en ella la excelencia. El problema es cuando se olvidan los bienes internos y se cambian por los externos (dinero, prestigio o poder), de forma que los profesionales se corrompen, señala la autora. Para ejercerse con dignidad, una actividad profesional precisa contar con al menos dos tipos de ciudadanos: los que desde una opinión pública crítica le plantean exigencias, al recordarles cómo esperan los beneficiarios que la profesión les proporcione el bien por el que la consideran legítima, y los ciudadanos que desde dentro están dispuestos a ejercer su profesión de una forma excelente (Cortina, 1997b). Para alcanzar una ética profesional es necesaria una remoralización desde dentro de las profesiones ya que la moral, a diferencia del derecho, no puede imponerse sino que debe ser asumida desde dentro, siendo este el caso también de los profesionales en los que se 
centra de manera especial el presente trabajo como son los investigadores e investigadoras y los especialistas en comunicación de la ciencia.

Una vez definida la propuesta de marco ético para la RRI basada en una ética aplicada del discurso, abordaremos en el siguiente punto el modelo democrático derivado del mismo, un modelo que supone a su vez una propuesta de marco político para la investigación e innovación responsable y su modelo comunicativo.

\subsection{COMUNICACIÓN Y DEMOCRACIA}

En el presente punto abordaremos el modelo de democracia deliberativa desarrollado por Habermas a partir de la ética del discurso y en el que cabe destacar, entre otros muchos aspectos, el planteamiento de una democracia participativa de doble vía. En la última parte se desarrollarán algunas de las aportaciones realizadas desde la Escuela de Valencia al modelo de Habermas, en aspectos como la ética económica o la evolución de una democracia deliberativa hacia una democracia radical como democracia comunicativa. Finalmente, analizaremos la aportación que supone para el modelo deliberativo el concepto de democracia monitorizada posibilitado por las nuevas tecnologías.

\subsubsection{Un modelo de democracia deliberativa}

La ética del discurso lleva a Habermas a plantear el modelo de democracia deliberativa, que se ha consolidado como el más utilizado desde las perspectivas críticas que parten del deber ser como factor clave de legitimidad. Habermas mantiene la perspectiva crítica y la participación cómo núcleo de la democracia, de forma que el principio democrático es que todos aquellos que puedan sufrir las consecuencias tengan capacidad de decidir. Para el autor, la política tiene que ver con el poder como capacidad de construir un orden, con cómo podemos construir una voluntad común (Habermas, 1998).

De este modo, frente a los modelos de democracia liberales -que el autor considera que ofrecen una visión excesivamente estratégica a pesar de defender la necesidad de respetar los derechos individuales- y a los modelos republicanos -que ve 
excesivamente idealistas dada la complejidad de alcanzar una voluntad común en un mundo globalizado-, Habermas plantea el modelo deliberativo. En cualquier caso, para el autor, los modelos son discutibles y lo importante es cómo se deliberan, cómo se construyen. El interés general se basa en los procedimientos por los cuales discutimos entre todos qué intereses queremos satisfacer. Este proceso deliberativo resulta de especial interés en el caso de los avances científicos y tecnológicos en los que el número de afectados es muy amplio y los intereses pueden estar contrapuestos, y a pesar de ello los procesos de decisión suelen permanecen alejados de un proceso deliberativo.

Habermas no descarta las aportaciones liberales de defensa de los intereses privados, ni las republicanas en su apuesta por el interés común, sino que las pasa por el filtro del discurso moral en el que debe participar la sociedad civil. Esta red de discursos morales conforma, para Habermas, el proceso democrático y es el paso previo a los discursos jurídicos. La sociedad civil tiene el poder comunicativo que deriva del poder del acuerdo, un poder que García Marzá califica de "poder moral”. Mientras Kant aboga por ponerse en el lugar del otro, del afectado, Habermas da un paso más y defiende la participación del propio afectado. El aprendizaje moral pasa porque yo me siento implicado y afectado, en eso se basa la democracia deliberativa.

En "Tres modelos normativos de democracia", capítulo incluido en La inclusión del otro, Habermas defiende las ventajas del modelo deliberativo frente a los tradicionales modelos liberal y republicano (Habermas, 1999). Para el autor, estos dos modelos tradicionales pueden compenetrarse y complementarse de forma racional si están suficientemente institucionalizadas las correspondientes condiciones de comunicación y de los procedimientos que prestan su fuerza legitimadora a la formación institucionalizada de la opinión y de la voluntad común. Este tercer modelo de democracia tiene su base en las condiciones del discurso. En palabras de Habermas, la democracia deliberativa "se apoya en las condiciones comunicativas bajo las cuales el proceso político tiene para sí la presunción de producir resultados racionales porque se lleva a cabo en toda su extensión de un modo deliberativo" (Habermas, 1999:239).

Si para la concepción liberal el proceso de formación democrática de la voluntad solo se lleva a cabo en forma de compromiso entre intereses; y para la republicana se logra mediante la autocomprensión ética; la teoría discursiva asume elementos de ambas partes y los integra en el concepto de un procedimiento ideal para la deliberación y la toma de resoluciones. Este procedimiento democrático genera una conexión interna 
entre negociaciones, discursos de autocomprensión y discursos referentes a la justicia, y cimenta la presunción de que bajo tales condiciones se alcanzan resultados racionales o equitativos.

La teoría del discurso asocia al proceso democrático connotaciones normativas más fuertes que el modelo liberal y más débiles que el republicano. Toma elementos de ambas y los articula de una manera distinta. En concordancia con el republicanismo, coloca el proceso de formación de la voluntad y de la opinión política en el punto central, pero sin entender como algo secundario la constitución en términos del Estado de derecho; más bien, concibe los derechos como fundamentales y los principios del Estado de derecho como una respuesta consecuente con la cuestión de cómo pueden ser institucionalizados los exigentes presupuestos comunicativos del procedimiento democrático (Habermas, 1999).

Para Habermas, los procedimientos y presupuestos comunicativos de la formación democrática de la opinión y de la voluntad funcionan como las más importantes esclusas para la racionalización discursiva de las decisiones de un gobierno y de una administración sujetos al derecho y a la ley. Racionalización significa más que mera legitimación (modelo liberal) pero menos que constitución de poder (modelo republicano).

La teoría discursiva no hace depender la realización de una política deliberativa de una ciudadanía capaz de actuar colectivamente, sino de la institucionalización de los procedimientos correspondientes. Cuenta con la intersubjetividad de orden superior que representan los procesos de entendimiento que se llevan a cabo, por una parte, en la forma institucionalizada de deliberaciones en las cámaras parlamentarias y, por otra parte, en la red de comunicación de la esfera política de la opinión pública (Habermas, 1999: 242), conformando lo que se ha venido a denominar democracia de doble vía. Estas comunicaciones realizadas en el interior o en el exterior de las asambleas programadas para la toma de resoluciones, configuran escenarios donde pueden tener lugar una formación más o menos racional de la opinión y de la voluntad común sobre temas importantes para la sociedad o que requieren regulación.

La formación informal de la opinión desemboca en decisiones electorales institucionalizadas y en resoluciones legislativas por las que el poder producido comunicativamente se transforma en poder utilizable administrativamente (Habermas, 1999:242-243). 
El modelo democrático deliberativo diferencia así entre el Estado y la sociedad civil. En este modelo, el sistema político es un subsistema especializado en la toma de decisiones colectivamente vinculantes ya que las estructuras comunicativas del espacio público conforman una red de sensores que reaccionan ante la presión de los problemas que afectan a la sociedad en su conjunto, entre los que se encuentran los temas relacionados con la ciencia, y que además estimulan la generación de opiniones de mucha influencia (Habermas, 1999:244). La legitimidad de este procedimiento democrático se apoya para Habermas en dos componentes, la participación igualitaria de todos los ciudadanos y el proceso deliberativo.

Por un lado, a la participación política igualitaria de los ciudadanos, que garantiza que los destinatarios de las leyes puedan también entenderse a sí mismos al mismo tiempo como los autores de esas leyes; y, por otro lado, a la dimensión epistémica de las formas de discusión y de acuerdo dirigidas deliberativamente, que justifican la presunción de resultados racionalmente aceptables (Habermas 2006: 128).

Para que se den estas formas de discurso y acuerdo el Estado de derecho puede institucionalizar formas de deliberación, mientras que los espacios públicos pueden movilizarse culturalmente. Como en el modelo liberal, se respetan los límites entre Estado y sociedad, pero aquí la sociedad civil, como base social de una esfera pública autónoma, se diferencia tanto del sistema económico de acción como de la administración pública (Habermas, 1999:245). En este punto, la Escuela de Valencia introduce una discrepancia, al reivindicar la aplicación de la ética del discurso, y con ella de la democracia deliberativa, en el campo de la economía, un aspecto que dada su relevancia, trataremos más adelante en este mismo capítulo.

Únicamente el sistema político puede "actuar" en el sentido de que es un subsistema especializado en la toma de decisiones colectivamente vinculantes, mientras que las estructuras comunicativas de espacio público conforman una red ampliamente expandida de sensores que reaccionan ante la presión de los problemas que afectan a la sociedad en su conjunto y que además estimulan la generación de opiniones de mucha influencia. La opinión pública transformada en poder comunicativo mediante procedimientos democráticos no puede "mandar" ella misma, sino sólo dirigir el uso del poder administrativo hacia determinados canales.

La soberanía popular surge de las interacciones entre la formación de la voluntad común, institucionalizada con técnicas propias del Estado de derecho, y los espacios 
públicos movilizados culturalmente, que por su parte hallan una base en las asociaciones de una sociedad civil alejada por igual del Estado como de la Economía.

La interpretación de la democracia realizada en términos de la teoría discursiva enlaza para Habermas con una distanciada consideración científico-social, según la cual el sistema político no es ni el centro ni la cúspide, ni tan siquiera el modelo de la sociedad que acuñara las estructuras de ésta, sino tan sólo un sistema de acción entre otros.

La política deliberativa se puede llevar a cabo mediante procedimientos formales de formación institucionalizada de la voluntad y de la opinión, o bien de modo informal en las redes de espacios públicos. Autores como Adela Cortina destacan esta democracia de doble vía como una de las grandes aportaciones del modelo deliberativo de Habermas. Por una parte, tenemos la vía de los procesos formales, que corresponden a la dimensión política y que llevan a resoluciones. La clave política es institucionalizar jurídicamente los procesos para que las deliberaciones informales influyan de modo indirecto en las decisiones institucionalizadas. Por la otra, está la vía de los procesos informales, de la sociedad civil, que se convierte en una pieza clave de la democracia radical. La clave social es fomentar los procesos de deliberación en la opinión pública a través, por ejemplo, de asociaciones. La opinión pública es el lugar de descubrimiento de nuevas exigencias y problemas y sus deliberaciones no tienen pretensiones de justificación (Cortina, 2010a).

No obstante, para Cortina, la doble vía establecida por Habermas obvia una fuerza que ya existe y que actúa de forma eficaz, como son las instancias éticas intermedias (comités de bioética, departamentos de responsabilidad social, colegios profesionales, conferencias de ciudadanos), que es una esfera institucionalizada de la sociedad civil que no es sólo un lugar de descubrimiento, sino también de formación del juicio y de toma de decisiones racionalmente justificadas. La autora habla así de la fenomenización de la ética cívica: "Existe ya ese denso mundo moral que va expresando esa ética pública que no se identifican con el derecho pero tampoco con redes informales de crítica y protesta. Se ha producido ya la fenomenización de una ética cívica que debe convencer con razones si pretende obligar moralmente" (Cortina, 2010a:90).

Además, esa institución en distintos niveles permite hacer frente, según Cortina, a otras posiciones teóricas que consideran que la gente corriente no es capaz de una 
deliberación racional. Sin embargo, estas comisiones y comités, pertenecientes a la sociedad civil, sí son capaces de tomar decisiones recurriendo a una deliberación no egoísta y racional.

Las aportaciones de los autores de la Escuela de Valencia a la ética del discurso y al modelo de democracia deliberativa van más allá de la fenomenización de la ética cívica a la que hace referencia Adela Cortina. A continuación abordaremos dos de las que consideramos más interesantes de cara a sentar las bases de un marco ético y político para una investigación e innovación responsable. Por una parte, la aplicación de la teoría ética del discurso al modelo económico y, por otro, la evolución de la democracia deliberativa hacia una democracia radical o comunicativa.

\subsubsection{Aplicación de la ética del discurso al ámbito económico}

No es posible hablar de democracia sin abordar también la economía. Así, si bien no es objeto de la presente tesis doctoral abordar de forma exhaustiva la ética económica, entendemos que sí es necesario realizar una referencia a la misma dado que la economía está presente en todo modelo político y, en el caso que nos ocupa, en la gestión de la investigación y la innovación. Son muchos los autores que reclaman cada vez más el componente ético desde los propios planteamientos de la teoría económica después de que se haya producido, según denuncia desde la Escuela de Valencia Jesús Conill, "una escisión entre lo ético y lo técnico en la economía, que constituye un problema social, al que todavía no hemos sabido dar una solución, ni en la teoría ni en la práctica" (Conill, 2004:25). El autor recuerda que tanto en sus orígenes antiguos como modernos la economía había tenido una vinculación intrínseca con el enfoque ético. Esta voluntad de hacer valer los valores y normas morales en las condiciones de la economía moderna no es indiferente a la gestión y comunicación de la ciencia, la tecnología y la innovación, que no deja de estar movida en numerosas ocasiones por intereses económicos y depende en gran medida de financiación necesaria para su desarrollo.

También desde la Escuela de Valencia, Adela Cortina resalta que el mundo económico forma parte de la sociedad civil y necesita legitimación comunicativa para llevar a delante su quehacer. No cabe por tanto excluirlo del proceso de comunicación 
(Cortina, 2010a). Llevado al mundo de la empresa, Cortina plantea en Justicia cordial la existencia de tres modelos de comprensión del mundo de la organización empresarial.

Por una parte, el modelo economicista, para el que el único objetivo de la empresa es maximizar el beneficio de los accionistas o directivos, pensando que la única motivación es el incentivo económico, pero la autora considera que esto solo podría ser así en un "Estado de naturaleza", un Estado sin ley en el que se satisfacen las preferencias del más fuerte, pero no en un Estado de derecho.

Un segundo modelo sería el modelo institucional, que entiende las empresas como lo que son, instituciones que nacen del contrato sellado entre aquellos que invierten en ellas trabajo, dinero, servicios y consumo. De ahí que los firmantes del pacto tengan unos derechos, a los que corresponden deberes por parte de las organizaciones.

Finalmente, se encuentra el que la autora denomina modelo de los afectados, ya que el número de afectados por las actuaciones de una empresa excede con creces a los que han sellado el pacto, por lo que cabría pensar que lo más inteligente y justo sería satisfacer las expectativas legítimas de todos, los firmantes del pacto y los que no lo han hecho pero se ven afectados. En el marco de este modelo, la autora define las empresas éticas como aquellas que "se forjan un buen carácter, eligen buenas metas y se esfuerzan por alcanzarlas, y tienen por protagonistas de la actividad empresarial a los afectados por ella" (Cortina, 2010a:93). Sale a la luz un contrato no escrito, un contrato moral con todos los afectados, que firma implícitamente la empresa prudente y justa, como una obviedad (García Marzá, 2004). Lo que late en el fondo es el reconocimiento de una obligación moral, de que existe ya un vínculo con todos los afectados por la empresa que no puede ser pactado porque ya existe.

Por otra parte, entre las diferentes aportaciones a la ética económica aplicada, cabe destacar también la planteada por Peter Ulrich, quien busca lograr una "economía social en virtud de un nuevo fundamento normativo, no utilitarista ni contractualista, sino discursivo, entendido en la práctica como 'control democrático' por parte de los afectados" (Conill, 2004:68). Este desarrollo de una ética económica de la comunicación tiene su base, al igual que la ética del discurso, en el principio de universalización de Kant. El mínimo deontológico de toda ética racional está determinado en el criterio, especificado por Kant como imperativo categórico, de la generalización de estas exigencias personales fundamentales (principio de 
universalización). "Este momento deontológico tiene que fundamentarse ético económicamente como éticamente racional por delante de cualquier cálculo económico" (Ulrich, 1993:38).

Las consideraciones éticamente racionales pasan, según Ulrich, por "la conservación de la compatibilidad social y medioambiental de la acción económica bajo el horizonte de la idea regulativa de la exigibilidad y capacidad de consenso generales de todos los afectados" (Ulrich, 1993:43). Se trata de un criterio formal y procedimental que, al igual que en la ética del discurso, obliga a contar con la participación de todos los afectados. Desde esta perspectiva, las decisiones económicas también en materia de avances en investigación han de estar sujetas a esta capacidad de consenso y búsqueda de una compatibilidad social y medioambiental.

Para Ulrich, "la ética económica moderna no puede ser una mera ética interna del sistema económico, más bien es fundamentalmente una ética política, al igual que la economía es fundamentalmente una economía política" (Ulrich, 1993:48). Esto mismo ocurre con la investigación y la innovación, que entendemos que no pueden desarrollarse ni entenderse separadas de la ética, la economía y la política.

\subsubsection{Aplicación de la ética del discurso al ámbito político}

La segunda de las aportaciones de la Escuela de Valencia al modelo de democracia deliberativa a la que hacíamos referencia, es su evolución hacia una "Democracia radical como democracia comunicativa", nombre que da título a un capítulo de Cortina en Justicia cordial. Democracia radical, entendiendo por "raíz" de la política la voluntad de los sujetos que se reconocen recíprocamente el derecho a decidir sobre las normas comunes, porque reconocen su autonomía personal y la necesidad de normas justas que la protejan y potencien. La democracia radical no es una democracia participativa directa, "porque en sociedades complejas resulta imposible aplicar de forma directa el principio ético a la forma de organización política" (Cortina, 2010a:74). Lo que propone Cortina, al igual que los defensores de la ética del discurso, es una política deliberativa, en forma discursiva o en forma comunicativa.

La autora opta por la denominación democracia comunicativa porque entiende que el proceso comunicativo incluye tanto el momento de la deliberación como el del discurso, tanto las distintas formas de comunicación como el momento argumentativo y 
por tanto habla de democracia comunicativa como una forma peculiar de democracia deliberativa. A pesar de que el modelo surge a partir de la teoría del discurso, Cortina descarta la denominación democracia discursiva al entender que si el principio del discurso se aplicara directamente a la política, la participación de los afectados (no sólo los ciudadanos) debería entenderse como autogobierno, en el sentido de ejercicio directo del poder, algo imposible en las sociedades complejas. Una denominación más extendida y que utilizamos también en el presente trabajo es la de democracia deliberativa, ya que la deliberación incluye formas de comunicación distinta a los argumentos, y el discurso solo atiende a los argumentos.

Ante la imposibilidad de llevar a cabo en las actuales sociedades complejas una democracia participativa directa, Cortina defiende la democracia representativa como modelo adecuado siempre que los ciudadanos puedan hacer llegar sus propuestas al debate parlamentario a través de diversos mecanismos como debates en la opinión pública, referéndums, etc. En este sentido, recuerda que la clave está en el proceso por el que se forman las mayorías. Dewey escribía ya en 1927 que la regla de las mayorías de por sí no tiene porqué ser positiva y que lo importante es el proceso por el que se llegan a formar las mismas. Todo depende de este proceso:

La regla de las mayorías es tan absurda como sus críticos le acusan de serlo [...]. Lo importante es el medio por el que una mayoría llega a serlo: los debates antecedentes, la modificación de las perspectivas para atender a las opiniones de las minorías [...]. La necesidad esencial, en otras palabras, es la mejora de los métodos y condiciones de debate, discusión y persuasión (Dewey, 1927:207).

Cortina defiende que, a pesar de que no creamos que la voz de la mayoría sea la voluntad general, no hemos encontrado un mecanismo mejor. Por lo tanto hay que mejorar al máximo el proceso por el que se llegan a formar las mayorías. Este es la clave de una sociedad democrática, más aún que el procedimiento por el que se toman las decisiones últimas.

Existen autores que consideran que la democracia deliberativa no es un modelo de democracia distinto, sino el proceso por el que debe formarse la voluntad en una sociedad democrática, a partir de la existencia de desacuerdos.

A la hora de formar las mayorías, Cortina distingue entre democracias deliberativas frente a agregativas. En esta última los ciudadanos forman sus intereses y preferencias en privado y la misión del mecanismo democrático es sumarlos y atender a 
los intereses de la mayoría. Se trata de un modelo incapaz de percibir la capacidad transformadora de los procedimientos democráticos. Sin embargo, en la democracia deliberativa los desacuerdos se afrontan intentando transformarlos mediante deliberación. Las preferencias e intereses se forman socialmente y no en privado. Por tanto, la deliberación es un método racional para transformar públicamente las diferencias, más que para agregarlas. "La esencia de la legitimidad democrática descansa en la capacidad de los individuos, sujetos a una decisión colectiva, de entrar en una deliberación auténtica sobre la decisión que se debe tomar" (Cortina, 2010a:80).

La deliberación tiene capacidad para transformar las preferencias iniciales y modular una voluntad que en principio puede ser autocentrada. Si la democracia es el gobierno del pueblo, los ciudadanos deben ejercer su autonomía política no sólo eligiendo a sus representantes, sino también tomando parte activa en esas decisiones a través de la deliberación. "Las leyes y decretos tienen que ser racionalmente aceptables por sus destinatarios, y por eso deben ser éstos, de algún modo, sus autores" (Cortina, 2010a:82).

\subsubsection{Democracia monitorizada}

Una vez planteado el modelo de democracia deliberativa o comunicativa y antes de cerrar el presente punto, consideramos de interés hacer referencia a un nuevo concepto que entendemos que aparece estrechamente vinculado a los modelos basados en la ética del discurso. Se trata del concepto de democracia monitorizada planteado por John Keane, como una nueva propuesta de democracia participativa posibilitada por el cambio que han supuesto las nuevas tecnologías y la nueva galaxia de medios de comunicación. Ramón Feenstra, también de la Escuela de Valencia, considera que el término aúna los conceptos de seguimiento y control (monitorización) y el hecho de que se haga mediante múltiples aparatos audiovisuales (monitores). Para este autor, "en una era marcada por el creciente distanciamiento de la ciudadanía y la clase política, por las movilizaciones ciudadanas y por la incertidumbre, la democracia monitorizada se presenta como un concepto capaz de explicar algunas de las transformaciones que se producen actualmente" (Feenstra, 2012).

La democracia monitorizada supone el paso de la que fue la demanda central en la lucha por la democracia representativa "una persona, un voto, un representante" a un 
nuevo principio: "una persona, numerosos intereses, numerosas voces, múltiples votos, múltiples representantes" (Keane, 2009:5). Lo que distingue a este nuevo modelo es el modo por el cual todos los campos de la vida política y social, incluida la ciencia y la tecnología, vienen a ser escudriñados por todo tipo de organismos independientes, extraparlamentarios y frecuentemente no elegidos, que operan tanto dentro como fuera de las fronteras de los Estados territoriales. En este sentido, se trata de un modelo transfronterizo.

La aparición de la web 2.0, en la que se apoya esta nueva galaxia de medios, ha puesto de manifiesto la preocupación pública en cuestiones de sociedad civil y en temas de escrutinio público que antes fueron considerados como no políticos, una preocupación que, en opinión de Keane, sólo se encuentra en la era de la democracia monitorizada. Así, el propio autor señala que son motivo de escrutinio temas relacionados con la ciencia, como el desarrollo de iniciativas para garantizar que el futuro desarrollo de la nanotecnología y de las cosechas genéticamente modificadas "sean gobernadas públicamente en el interés de la mayoría, y no de la minoría -los esfuerzos por llevar la democracia 'corriente arriba', entrando en los afluentes de investigación científica y desarrollo técnico-son más ejemplos de la misma tendencia" (Keane, 2009:14).

El autor defiende asimismo la eficacia de esta labor de escrutinio, aludiendo al hecho de que las grandes cuestiones públicas que han irrumpido en el mundo desde 1945 (derechos civiles, armas nucleares, reducción de la pobreza y del calentamiento global,...) han sido generadas no desde las instituciones del Estado, sino principalmente por "redes monitoras de poder que actúan paralelamente a $-\mathrm{y}$ a menudo, posicionadas contra- los mecanismos ortodoxos de la representación basada en los partidos políticos" (Keane, 2009:19).

Especialmente interesante nos parece el papel que juega en esta democracia monitorizada la nueva galaxia de medios, ya que ésta influye también sin duda, y de forma determinante, en todo lo referente tanto a la comunicación pública de la ciencia como a la deliberación sobre cuestiones científicas. Keane destaca el carácter global, multimedia y accesible de esta nueva galaxia de medios sin precedentes históricos:

Simbolizado por uno de sus componentes claves, internet, es un nuevo sistema mundial de dispositivos de medios solapados e interconectados que por primera vez en la historia de la humanidad integran textos, sonido e imágenes y posibilita que la comunicación tenga lugar a 
través de múltiples puntos de uso, en el momento elegido, ya sea en directo o en diferido, dentro de redes modularizadas y a la larga o en última instancia globales que son asequibles y accesibles a muchos cientos de millones de personas dispersos a lo largo del globo (Keane, 2009:22).

Esta galaxia de medios supone una herramienta de gran utilidad para llevar a cabo la comunicación de la ciencia, desde la perspectiva de un periodismo bien entendido en sus funciones, al que Keane alude como un "periodismo vigoroso" que “ayuda a mantener vivas viejas utopías que pretenden arrojar luz al poder, establecer la libertad de la información, el gobierno de la claridad y una mayor transparencia en la toma de decisiones (...) Gracias al periodismo y los nuevos medios de la abundancia comunicativa las cosas se mueven" (Keane, 2009:26). Además de afectar al papel de la comunicación de la ciencia y del periodismo en su conjunto, esta labor de monitorización desde la nueva galaxia de medios, obliga a cambiar las actitudes de las estructuras de poder, presionando para una mayor transparencia y una continua rendición de cuentas, también en el terreno de la ciencia y la tecnología.

Pero este proceso, capaz de ampliar los procesos políticos más allá del momento de las votaciones y que se cree cada vez más presente en los sistemas democráticos, no es por sí sólo suficiente. Feenstra defiende que la monitorización se convierte en un proceso que acompaña a la representación, logra ampliar las posibilidades de participación política de la sociedad civil y altera las dinámicas políticas. Sin embargo, entiende que no es suficiente esta capacidad sancionadora o correctora, sino que es necesaria también un demos participativo destinado a crear o formular nuevas demandas. Esto permitiría un acercamiento entre una clase política que atendiera realmente a las demandas ciudadanas y una ciudadanía que vería como adquiere una mayor influencia efectiva. Feenstra argumenta la necesidad de, más allá del voto, dar voz a la ciudadanía en un sentido amplio:

La ciudadanía y los actores de la sociedad civil deben ver como además de la capacidad por escudriñar al poder, también adquieren peso y relevancia política procesos como la deliberación. (...) Desde mi punto de vista, estas dos formas de participación -una encaminada a contener los abusos del sistema y la otra dirigida a construir o influir en la toma de decisiones políticas-son necesarias para consolidar una democracia fortalecida, en la cual la base ciudadana del sistema político adquiera no sólo voto sino también voz en sentido amplio. Esto conlleva tener en cuenta tanto al sistema político como a la sociedad civil (Feenstra, 2012). 
Entendemos pues que democracia deliberativa y monitorizada vienen a complementar el concepto de participación, que engloba desde la labor de escrutinio y monitorización hasta la implicación en los discursos y deliberaciones para la toma de decisiones con valor moral. Para ambas tareas es necesaria, en el caso de la ciencia, el fomento previo de la comunicación, la divulgación y la cultura científica.

Participación ciudadana y cultura científica aparecen de nuevo ligados como requisitos previos y fundamentales. Para abordarlos de forma adecuada analizaremos en el siguiente punto el concepto de una ciudadanía activa adecuadamente formada y responsable a la hora de exigir transparencia y control sobre la ciencia.

\subsection{HACIA UNA CIENCIA CIUDADANA}

La democracia deliberativa ha sido el modelo defendido por la mayoría de los denominados participacionistas desde los años 90, lo que viene a mostrar de nuevo la estrecha relación entre este modelo de democracia y la participación ligada a una ciudadanía activa que debe ejercerse con relación a la política estatal pero también en muchos otros ámbitos de la sociedad civil, incluido el científico.

En el presente punto analizaremos en primer lugar los conceptos en los que se enmarca la ciudanía como son esfera pública, opinión pública y sociedad civil, para dar paso a la definición del propio concepto de ciudadanía y sus diferentes tipos en base a la catalogación establecida por Adela Cortina. La idea de participación resulta asimismo clave para entender la importancia de la implicación ciudadana en materia de ciencia y tecnología, por lo que abordaremos tanto el mismo concepto de participación como algunas propuestas para fomentarla, entre las que destaca la educación. Sobre esta última vemos especialmente interesante la propuesta de Cortina de desarrollar una educación para una ciudadanía activa y cordial con valores morales. Llevado al ámbito de la ciencia, los aspectos desarrollados a lo largo del capítulo darán paso al concepto de ciencia ciudadana, un concepto emergente que pone de manifiesto el papel de una ciudadanía activa y participativa en el ámbito de la ciencia. 


\subsubsection{Esfera pública, opinión pública y sociedad civil}

Antes de abordar el concepto de ciudadanía en sí mismo, entendemos que es necesario hacer referencia a los espacios en los que se enmarca a través de los conceptos de esfera pública, opinión pública y sociedad civil que abordaremos a continuación.

\section{- Espacio público}

El concepto de espacio público presenta diferentes perspectivas según el modelo democrático desde el que se mire. Mientras que el modelo liberal subsume lo público en lo político y supone que todo aquello sobre lo que no alcancemos consenso quede relegado a lo privado; el modelo republicano entiende que la forma de vida buena ha de entrar dentro del argumentario del espacio público, lo que conlleva el problema de que parece que toda decisión privada tenga que considerarse si alcanzaría el consenso.

Para Habermas, la esfera pública debería ser el espacio en el que abordar los temas conflictivos y todo eso es lo que va a permitir que se pase después a una nueva esfera que denomina política. El espacio público es pues la esfera en la que debe darse cita una opinión pública adecuadamente formada que busca la verdad y en la que se produce una deliberación que, una vez avanzada y argumentada, pasa al espacio parlamentario. Habla así, por tanto, del espacio público como espacio preparlamentario. La legitimidad de la legislación de una sociedad se basa precisamente en esa deliberación en el espacio público. Es a este espacio público de deliberación y elaboración de las razones de lo cultural, de lo que nos conviene, de la eficiencia, al que deben llegar también los temas relacionados con la ciencia y la tecnología.

En algunas ocasiones Habermas emplea también el concepto de espacio públicopolítico como una estructura aunada por la comunicación que queda enraizada en el mundo de la vida a través de la base que para ella representa la sociedad civil, un espacio capaz de percibir y alertar de posibles problemas.

El espacio público-político lo hemos descrito como caja de resonancia para problemas que han de ser elaborados por el sistema político porque no pueden ser resueltos en otra parte. En esta medida el espacio público-político es un sistema de avisos con sensores no especializados, pero que despliegan su capacidad perceptiva a lo largo y ancho de toda la sociedad (Habermas, 1998:439). 
Habermas confronta además la idea de espacio público con el de escena pública a la que se suben aquellos que alcanzan notoriedad en la sociedad de medios y que está formada por un público de oyentes, y no de hablantes y receptores que se rebaten unos a otros como es el caso de la esfera pública. "Se trata de un intercambio de razones, no de una convergencia de miradas" (Habermas, 2006:19). Habermas define así el espacio público como la red para la comunicación de contenidos y toma de posición, esto es, de opiniones, que se reproducen a través de la acción comunicativa. De esta forma, es el espacio en el que se perciben y tematizan los problemas.

El espacio público sólo puede, empero, cumplir su función de percibir problemas concernientes a la sociedad global y de tematizarlos, en la medida en que esté compuesto de los contextos de comunicación de los potencialmente afectados. Es sustentado por un público que se recluta de la totalidad de los ciudadanos (Habermas: 1998, 445).

\section{- Opinión pública}

Hemos aludido a que el espacio público es la esfera en la que se genera opinión pública, pero vale la pena detenerse en este concepto. Sartori lo define como "un público, o una multiplicidad de públicos, cuyos estados mentales difusos (opiniones) interactúan con los flujos de información sobre el estado de la cosa pública" (Sartori, 1992:151). De esta forma, el público no es sólo el sujeto, sino también el objeto de la expresión. "Una opinión se denomina pública no sólo porque es del público (difundida entre muchos, o entre los más), sino también porque afecta a objetos y material que son de naturaliza pública: el interés general, el bien común, y en esencia, la res pública" (Sartori, 1992:149). Por tanto, para el autor una opinión se denomina pública cuando conjuga dos características: la difusión entre públicos y la referencia a la cosa pública. Por este último aspecto la teoría de la opinión pública se convierte en parte constituyente de la teoría de la democracia y también en un aspecto fundamental a la hora de abordar la comunicación y gestión de la investigación y la innovación. En este sentido, los asuntos de ciencia no sólo generan un estado de opinión entre los públicos, sino que afectan directamente a la "cosa pública".

Por su parte, Habermas entiende la opinión pública como el resultado de controversias, informaciones y razones, más allá de la suma de opiniones individuales. Para el autor, como mejor puede describirse el espacio de la opinión pública es como una red para la comunicación de contenidos y tomas de postura. 
Al igual que el mundo de la vida en su totalidad, también el espacio de la opinión pública se reproduce a través de la acción comunicativa, para la que basta con dominar un lenguaje natural; y se ajusta a la inteligibilidad general de la práctica comunicativa cotidiana (Habermas, 1998:440).

El hecho de que la opinión pública sea el resultado de un procedimiento supone, para Habermas, que su calidad es medible al tratarse de una magnitud empírica. "Considerada normativamente, funda o establece una medida de la legitimidad de la influencia que las opiniones públicas ejercen sobre el sistema político" (Habermas, 1998:443).

Respecto a la formación de la opinión pública, Sartori encuentra válidos tanto el denominado modelo Bubble-up, en el que la opinión pública se forma como un rebullir del cuerpo social que sale hacia lo alto; como, por otra, el Cascade Model, de Deutsch, que contempla una serie de procesos descendientes cuyos saltos son contenidos a intervalos por contenedores en los cuales se vuelven a mezclar otra vez, estableciendo cinco niveles: élites económicas y sociales; élites políticas y de gobierno; redes de comunicación de masas; líderes de opinión a nivel local; y públicos de masas. Sartori considera además que las opiniones derivan en gran medida de los grupos de referencia (familia, trabajo, partido, religión, etc.). "Decimos entonces que las opiniones provienen de dos fuentes; de mensajes informadores, pero también de identificación" (Sartori, 1992:156). El primer contexto es el que nos interesa de cara a la comunicación de la ciencia ya que en él nos encontramos con opiniones que interactúan con informaciones, lo que, por sí mismo, no las convierte en opiniones informadas pero sí en opiniones expuestas e influidas por flujos de noticias. Este es, por tanto, el campo en el que puede trabajar la comunicación de la ciencia. Respecto a la formación de la opinión pública, Sartori concluye que la forman todos, en el sentido de muchos y en lugares y modos distintos, y ninguno, en el sentido de ninguno en particular.

A la hora de tratar el concepto de opinión pública resulta necesario abordar también la influencia y el papel de los medios de comunicación. Partiendo de la ética, Habermas considera que estos medios han de entenderse como mandatarios de un público ilustrado, cuya disponibilidad al aprendizaje y capacidad de crítica presuponen, invocan y a la vez refuerzan. El papel de los medios como informadores y formadores en ciencia entraría dentro de esta función. Asimismo, "entra dentro de sus obligaciones hacer suyas de forma imparcial las preocupaciones, intereses y temas del público y, a la 
luz de esos temas y contribuciones, exponer el proceso político a una crítica reforzada y a una coerción que lo empuje a legitimarse" (Habermas, 1998:460).

Por otra parte, cabe señalar que la definición de Sartori alude asimismo al concepto de flujo de la información dirigida a la totalidad y con voluntad de objetividad:

Se caracteriza como información en cuanto que está dirigida, dentro de los límites de la imperfección humana, a la totalidad y a la objetividad. No se pretende, obviamente, que estos requisitos se satisfagan por cada una de las voces. Es la polifonía la que proporciona una relativa totalidad; y es el policentrismo el que corrige, dentro del conjunto, la subjetividad, unilateralidad e incluso falsedad de los mensajes de fuentes particulares. (...) Y, por lo tanto, se puede hablar legítimamente de una información que es, en las democracias occidentales, relativamente completa y relativamente objetiva (Sartori, 1992:160).

A pesar de esta visión relativamente positiva, advierte del riesgo de opinión pública heterónoma, prefabricada, en este sentido señala la necesidad de distinguir entre la opinión en el público de la del público. La capacidad de generar opiniones autónomas se ve agravada para Sartori en la sociedad actual por una descorazonadora "falta de atención, desinformación, distorsión perceptiva y, finalmente, total ignorancia de los públicos de masas. Sólo un 10 o 20 por ciento de la población adulta merece la calificación de informada o suficientemente informada" (Sartori, 1992:165). En materia de ciencia esta ignorancia y desinformación parece ser aún más evidente, lo que supone un problema al que sólo puede hacerse frente desde el fomento de la cultura de la ciencia. Es necesario aumentar la formación de la opinión pública, también en el ámbito de la ciencia, ya que cuanto la democracia más deliberativa es, más obliga a la gente a formarse e informarse.

Para Sartori se encuentra en la base de la democracia que el consenso que soporta a los gobiernos parta de públicos con opiniones autónomas, para lo que es necesario que estén informados. Y considera que éste es el problema de base. Hablando de política, entiende que el estrato de los relativamente informados está constituido, fundamentalmente, por los sectores más instruidos, algo que se reproduce igual en ámbitos como el de la ciencia. Introduce asimismo un concepto que nos parece especialmente interesante, el del umbral que es necesario alcanzar para reducir el coste de informarse. 
Para quien no está informado, el coste de comprender y digerir la información política se replantea todos los días y ya no se convierte en gratificante. Lo que explica dos cosas. Primero, explica por qué encontramos el salto que enfrenta a quien está informado y a quien no lo está, es decir, una distribución discontinua. Segundo. Explica por qué los límites entre las distintas zonas o especialidades de información son verdaderamente unos límites, y por lo tanto también por qué la cuota de una especialidad puede convertirse en muy grande, mientras que la cuota de otra puede seguir siendo exigua (Sartori, 1992:173).

Estas reflexiones resultan asimismo aplicables a la ciencia, dónde una vez alcanzado un cierto umbral de conocimiento, resulta mucho más asequible acceder a nuevas informaciones. Sin embargo, sin una base suficiente, las noticias sobre investigaciones pueden suponer un reto que puede descorazonar a una gran parte del público. Es labor de los profesionales de la comunicación hacer la información accesible para la mayoría de la audiencia, pero sin duda, cualquier información resultará más interesante para un público con una mínima base de conocimiento científico.

Dando un paso más, Sartori señala que la información por sí solo no es suficiente, es necesario llegar a transformarla en conocimiento. "Si para la democracia electiva basta para la transformación de la información en opinión, la democracia refrendaria necesita la trasformación de la información en saber, en conocimiento" (Sartori, 1992: 174). Esto supone, destaca, un salto que debe ser verdaderamente cualitativo. Este es también el salto que entendemos que requiere una democracia deliberativa que aborde con garantías los avances en ciencia y tecnología.

\section{- Sociedad civil}

Para cerrar el presente apartado abordaremos un concepto clave para la democracia deliberativa y participativa, el de sociedad civil. García Marzá afirma que una teoría de la democracia debe incorporar en su análisis no sólo al Estado sino también a la sociedad civil y a los recursos que le son propios. Pasamos pues a ocuparnos de estos conceptos. En los diferentes autores que han abordado el tema de la sociedad civil aparecen dos características recurrentes: la autonomía individual y la asociación voluntaria. "Siempre nos encontramos con ambas características y un referente único: su posición 'frente' al estado. La sociedad civil necesita al estado para poder funcionar, pero es independiente en sus iniciativas, propuestas y capacidad organizativa" (García Marzá, 2008:30). 
La teoría política recuperó en los años 80 del pasado siglo el concepto de sociedad civil. Desde entonces, esos aspectos decisivos centran la temática de lo que se denomina la second wave, según recoge García Marzá en su artículo "Sociedad civil: una concepción radical” (García Marzá, 2008). En primer lugar, la interdependencia global de la mayoría de las relaciones sociales contemporáneas, de forma que la sociedad civil pierde su único referente claro hasta entonces: el Estado. En segundo lugar, indica que los trabajos sobre la sociedad civil hacen ahora mayor hincapié en los problemas de institucionalización, en la realización fáctica de esta voluntad compartida, debido a la proliferación de asociaciones y organizaciones que para nada derivan de un acuerdo libre y voluntario, ni tampoco fomentan las virtudes de tolerancia, respeto o civilidad. A partir de la reflexión sobre estas cuestiones, García Marzá establece una nueva definición de sociedad civil que aúna libertad individual y unión para alcanzar unos determinados objetivos. En concreto, la define como:

El ámbito de interacciones estructurado en torno a una red de asociaciones y organizaciones posibles gracias al libre acuerdo de todos los participantes, con el fin de alcanzar conjuntamente la satisfacción de determinados intereses y la resolución consensual de posibles conflictos de acción (García Marzá, 2008:40).

No existe en esta definición diferencia alguna entre sociedad civil y sociedad civil global, puesto que las fronteras de la sociedad civil, su ámbito de actuación, vienen determinadas sólo y exclusivamente por la dimensión de los conflictos que se quieren solucionar de forma dialógica y razonada, argumenta el autor. Asimismo, introduce la perspectiva hermenéutica al querer dar razón de la diversidad de las diferentes esferas de la sociedad civil. Tanto para García Marzá como para Adela Cortina, en el terreno de la sociedad civil la exigencia moral de una participación igual y efectiva debe combinarse con la lógica propia de cada una de las esferas de la sociedad civil, con las estrategias necesarias para el logro de un determinado bien social (García Marzá, 2008:39).

Como señalábamos al empezar a hablar del concepto de sociedad civil, es necesario asimismo aludir a los recursos morales con los que cuenta. Para García Marzá, "son recursos porque nos permiten realizar acciones, en este caso interacciones, y coordinar nuestros planes de acción con los planes de otros actores, sean individuales o corporativos. Son morales porque remiten a nuestra razón práctica, a nuestra capacidad de guiarnos por juicios morales" (García Marzá, 2008:43). Del mismo modo, 
indica como característica básica de este saber moral la universalidad ya que afecta por igual a todas las personas, sea cual sea su cultura e identidad. Los recursos morales son intangibles, en tanto que no se pueden tocar. El autor añade que tampoco se deben tocar ya que sólo funcionan si no son instrumentalizados. Se trata, en definitiva, de una fuerza de motivación racional que de forma universal nos conduce a saber que estamos actuando correctamente. Estos recursos morales se relacionan así con intangibles ampliamente analizados desde el campo de la comunicación y estrechamente relacionados entre ellos como la responsabilidad, la reputación y la generación de confianza y legitimidad. "Es precisamente como generadora del capital de legitimación como le llamará Beck, donde radica este contrapoder de la sociedad civil” (García Marzá, 2008:42).

Dado que el presente trabajo parte de la teoría crítica de Habermas, consideramos de interés conocer asimismo su visión de sociedad civil como una trama asociativa de carácter voluntario y separada de las esferas estatal y económica:

\footnotetext{
Su núcleo institucional lo constituye esta trama asociativa no-estatal y no-económica, de base voluntaria, que ancla las estructuras comunicativas del espacio de la opinión pública en la componente del mundo de la vida que (junto con la cultura y con la personalidad) es la sociedad. La sociedad civil se compone de esas asociaciones, organizaciones y movimientos surgidos de forma más o menos espontáneo que recogen la resonancia que las constelaciones de problemas de la sociedad encuentran en los ámbitos de la vida privada, la condensan y elevándola, por así decir, el volumen o voz, la transmiten al espacio de la opinión pública-política (Habermas, 1998:447).
}

El autor considera así que la periferia que es la sociedad civil posee una mayor sensibilidad para la percepción e identificación de nuevos problemas que los centros de poder, como confirma que de ella hayan partido la mayoría de los grandes cambios sociales de las últimas décadas, como ya veíamos al hablar de la democracia monitorizada. En cuanto a la labor de la sociedad civil, para Habermas tiene la función de un asedio continuo al Estado sin voluntad de conquista, una idea que en cierta forma comparte Keane al afirmar que la sociedad civil debe ser la espina clavada en el flanco político.

La principal objeción al concepto de sociedad civil de Habermas la encuentra García Marzá en su "delimitación a los espacios públicos no deformados, a la comunicación no distorsionada y a los intereses universalizables" al entender que consigue mermar la fuerza crítica del concepto (García Marzá, 2008:34). No obstante, 
entendemos que es interesante para cerrar el presente apartado ver cómo Habermas entrelaza los conceptos abordados de espacio de la opinión pública y sociedad civil como pilares del concepto de democracia deliberativa.

El entrelazamiento y juego entre un espacio de opinión pública basado en la sociedad civil, por un lado, y la formación de la opinión y la voluntad políticas en el complejo parlamentario, institucionalizado en términos de Estado de derecho (y también la práctica de las decisiones judiciales), por otro, constituyen un buen punto de arranque par la traducción sociológica del concepto de política deliberativa (Habermas, 1998:452).

Una vez abordados los conceptos de esfera pública, opinión pública y sociedad civil, continuamos avanzando hacia el planteamiento de una ciencia ciudadana. Para ello, previamente debemos detenernos en el concepto mismo de ciudadanía.

\subsubsection{El concepto de ciudadanía}

Desde los años 90 del pasado siglo ha existido una profunda reflexión sobre el concepto de ciudadanía. El ciudadano se sabe perteneciente a una ciudad, a una comunidad política, como recuerdan los comunitaristas, pero quiere que esa ciudad sea justa, según destacan los liberales, y al final es una mezcla de ambas con un sesgo más hacia una u otra (Cortina, 2007:28). Partiendo del concepto de ciudadanía planteado por Adela Cortina en Ciudadanos del mundo, podemos destacar que ciudadanía es una síntesis de justicia y pertenencia, aúna la parte de la razón y la del sentimiento. La razón de una sociedad que debe ser justa para que sus miembros le den legitimidad y el sentimiento de pertenencia a algo que forma parte de nuestra identidad. (Cortina, 1997b:33).

El concepto de ciudadano para el pensamiento liberal se relaciona con un estatus determinado por la medida de los derechos subjetivos que tienen frente al Estado y frente a los demás ciudadanos; mientras que el pensamiento republicano entiende los derechos cívicos, principalmente los de participación y comunicación, como libertades positivas. La función del Estado es salvaguardar "un proceso inclusivo de formación de la opinión y de la voluntad común, en el que los ciudadanos libres e iguales se entienden acerca de las metas y normas que serían de interés común para todos. Con esto a los ciudadanos republicanos se les exige algo más que una orientación en función de sus propios intereses. (Habermas, 1999-234).

Cortina plantea cinco tipos de ciudadanía: política, social, económica, civil e intercultural, en los que vale la pena detenerse. 
- Ciudadanía política: La ciudadanía es primariamente una relación política entre un individuo y una comunidad política, en virtud de la cual el individuo es miembro de pleno derecho de esa comunidad y le debe lealtad permanente (Heather, 1990:246). El vínculo político constituye además un factor de identidad.

En el marco del ámbito político es interesante también analizar el concepto de autonomía, que es lo que capacita al sujeto para ser reconocido como persona, sujeto de derechos humanos. Además no es graduable, de modo que ningún grupo humano adulto puede ser exceptuado de su ejercicio. La autonomía implica reconocer que en el ámbito político los expertos han de comportarse como asesores y los políticos como gestores (Cortina, 1993: 140).

- Ciudadanía social. El concepto de ciudadanía de Thomas H. Marshall señala que la ciudadanía incluye, además de derechos civiles y políticos, derechos sociales como el derecho al trabajo, a la vivienda, a la salud, etc. El Estado Social tiene también como exigencia ética la satisfacción de nuestras necesidades básicas y la protección de los derechos de la segunda generación, es decir, los económicos, sociales y culturales (Cortina, 1997b:77).

Frente al denominado Estado del Bienestar, al que Cortina critica por haber devenido en un estado benefactor y paternalista que genera ciudadanos heterónomos y dependientes, introduce el concepto de Estado de la Justicia. Además, recuerda que el concepto de bienestar ligado a la idea de felicidad es un criterio personal. "Los mínimos de justicia son cosa de los Estados, mientras que el bienestar págueselo cada quien de su peculio", dice la autora (Cortina, 1997b:84). La cuestión es entonces delimitar las necesidades básicas que el Estado de la Justicia ha de garantizar como mínimos de justicia.

Cortina defiende el Estado Social en función de que los bienes de cualquier sociedad son bienes sociales, de los que participan los que en ella viven. Cada persona debe a la sociedad mucho de sus facultades y del producto de ellas. Por tanto, los bienes sociales han de garantizar que sus legítimos propietarios tengan acceso al menos a un mínimo.

- Ciudadanía económica. El concepto de ciudadanía social de Marshall ha sido criticado por generar una ciudadanía pasiva, por lo que muchos autores reclaman una ciudadanía más activa y participativa, de forma que se transite de la teoría de los derechos a la de las responsabilidades. Para Cortina actualmente resulta imposible el ejercicio de una ciudadanía económica, que alcance una participación significativa en 
las decisiones económicas. Sin embargo, defiende que no hay ciudadanía política sin ciudadanía económica.

- Ciudadanía civil. A pesar de que existe un mundo de asociaciones civiles muy variado, en determinados sectores de sociedad civil se encuentra un potencial ético universalizador (Cortina, 1997b:139). Es el impulso ético el que exige universalismo e incita a traspasar los límites individuales y grupales. Para la autora, este impulso tiene hoy su expresión como exigencia en tres lugares privilegiados: el tercer sector, las profesiones y la opinión pública.

- Ciudadanía intercultural. Un concepto pleno de ciudadanía integra un estatus legal (conjunto de derechos) y un estatus moral (conjunto de responsabilidades) y también una identidad por la que una persona se sabe y siente perteneciente a una sociedad. Los problemas aparecen en sociedades poliétnicas en las que conviven diferentes cosmovisiones, distintas formas de concebir el sentido de la vida, de la felicidad, de la justicia y de la organización social. Cortina propone una ética intercultural basada en las éticas discursivas para las que las normas son justas si son universalizables y tienen en cuenta a todos los afectados. Este dialogo exige comprensión de los diferentes bagajes culturales de los interlocutores, en la medida en que constituyen signos de su identidad (Cortina, 1997b:214).

En todas estas facetas de la ciudadanía es relevante el papel de la ciencia y, por tanto, el de los investigadores e innovadores y el de los profesionales de la comunicación científica. Tanto desde el ámbito político, mediante el respaldo a determinados programas políticos y normativas; pasando por la responsabilidad de los profesionales en el ámbito civil; sin olvidar los mínimos de justicia a cuya consecución puede contribuir de forma determinante la ciencia. A nadie escapa tampoco la relevancia económica de las investigaciones científicas y la necesidad de que la ética dirija el sentido hacia el que se encaminan avances e innovaciones.

Posteriormente, en Ética de los medios (2010), Cortina añade una nueva dimensión de ciudadanía, la ciudadanía mediática ya que, como argumenta, "si los ciudadanos deben ser los protagonistas de la vida pública, deben serlo en una sociedad mediática, en una sociedad que resulta incomprensible sin contar con los medios de comunicación como una de sus claves interpretativas esenciales" (Cortina, 2010b:12). 
Esta dimensión resulta especialmente interesante para el presente trabajo ya que pone el acento en la importancia de la comunicación de la ciencia por parte de los medios para alcanzar una investigación e innovación responsable, punto en el que profundizaremos más ampliamente en el tercer apartado de este primer bloque. Por el momento, entendemos que resulta de interés detenerse en la aproximación al concepto de ciudadanía mediática desarrollada por Cortina.

Para abordar la relación entre ciudadanía y medios de comunicación la autora recurre a cinco tradiciones filosóficas. En primer lugar, la liberal, que considera que es ciudadano quien no es súbdito, sino su propio señor. Esto supone que el cuerpo social debe proteger su derecho a ejercer un conjunto de las denominadas libertadas "civiles", algunas de ellas directamente relacionadas con el papel que en una sociedad pluralista tienen los medios de comunicación como son la libertad de expresión, de conciencia, de información y el derecho a la intimidad. Siguiendo con la tradición liberal, es también "su propio señor" aquel que puede influir en la toma de decisiones políticas, un aspecto en el que también son claves los medios de comunicación por su capacidad de influir en las decisiones de los votantes.

La segunda tradición a la que hace referencia Cortina es la republicana, según la cual es ciudadano todo aquel que participa en la vida pública, tanto en el ámbito estatal como en el de la sociedad civil, y en esta participación y en la formación de una opinión pública razonante, capaz de debatir sobre decisiones en ámbitos como el científico, vuelven a tener un papel protagonista los medios de comunicación.

Para el comunitarismo, tercera de las tradiciones filosóficas señalada por la autora, el ciudadano es responsable de su comunidad y los medios de comunicación deberían tener como centro la norma social, porque el rasgo fundamental de un ser humano es la comunidad. La misión de la noticia, desde esta perspectiva comunitarista, pasa por crear una ciudadanía activa en el seno de la comunidad, y por eso entiende que los códigos predominantes en las narraciones han de ser la justicia social, el vínculo común y la política participativa.

Desde la concepción socialdemócrata, se suman a los derechos civiles y políticos de la ciudadanía, los derechos sociales, como trabajo, educación, vivienda, salud, etc., que deben ser garantizados por un Estado social de derecho. Finalmente, la autora hace referencia al cosmopolitismo y la multiculturalidad, por la que distintas culturas deben ser tenidas en cuenta para ir componiendo la figura del ciudadano. En 
este sentido, Cortina señala la dificultad que supone alcanzar este fin cuando las empresas mediáticas pertenecen al denominado Primer Mundo y dan a conocer el Tercer y Cuarto mundo desde su óptica.

De cara a avanzar en el papel de la ciudadanía en este entorno mediático, la autora plantea la necesidad de trabajar en cinco ámbitos de distinto nivel: fomentar la poliarquía de los centros mediáticos; potenciar la creación de asociaciones de consumidores que expresen su opinión; forjar un ethos profesional y empresarial que permita que la actividad mediática esté a la altura de los dos principios de la ética moderna y alcance las metas que le son propias; desarrollar una ética a nivel de las organizaciones mediáticas y empresariales, más allá de la ética de sus miembros; y avanzar en la construcción de sujetos éticos que se conviertan en consumidores éticos. Volveremos a estas recomendaciones en el tercer apartado de este primer bloque, a la hora de abordar la comunicación de la ciencia teniendo en cuenta su relación con la ciudadanía.

Para cerrar el presente apartado sobre el concepto de ciudadanía, entendemos que resulta también necesario hacer referencia a la idea de virtud cívica, por estar estrechamente relacionado. En concreto, Javier Peña relaciona el concepto de virtud cívica con una vuelta a la tradición republicana que, frente al énfasis liberal en el individuo y en sus derechos subjetivos, concibe al hombre primordialmente "como ciudadano, es decir, como alguien que se define por su vinculación a la ciudad y para el que la garantía de su libertad estriba en el compromiso con las instituciones política y en el cumplimiento de sus deberes para con la comunidad" (Peña, 2008:293) ya que la libertad individual es inseparable de la libertad política. La capacidad de intervención activa de la ciudadanía viene acompañada por la demanda de lo que denomina virtud cívica, es decir, de una determinada disposición moral. Entendemos que esta virtud es asimismo necesaria para alcanzar una verdadera democracia deliberativa. Sin una actitud de la ciudadanía dispuesta a deliberar sobre aquello que le afecta, así como a formarse para poder argumentar en condiciones de autonomía, resultaría imposible entender el desarrollo de una democracia basada en la ética del discurso.

El republicanismo se basa en una ciudadanía vigorosa... considera necesario que los ciudadanos dediquen tiempo y esfuerzo a informarse de los asuntos públicos, a deliberar sobre ellos y a participar activamente en el espacio político. Lo que es tanto como decir, sirviéndonos del léxico republicano, que la democracia requiere virtud cívica (Peña, 2008:305). 
Una virtud cívica igualmente necesaria para establecer debates con validez moral en materia de ciencia y tecnología, una virtud cívica que, como aclara Peña, se refiere solamente a la actividad de los individuos como ciudadanos en el espacio público, sin incluir una concepción de la vida buena con sus propios valores.

Además de esta virtud cívica, Peña entiende que es necesario que se establezcan instituciones y mecanismos que propicien la búsqueda de la corrección de las decisiones gracias, sobre todo, a la deliberación. La participación es igualmente un requisito necesario. "La participación de los ciudadanos es la condición de una sociedad libre; la vigilancia y el control de los ciudadanos son indispensables para asegurar su libertad". Sin embargo, siendo una condición necesaria, Peña entiende que no puede considerarse suficiente. No basta con votar, "la buena democracia se asienta sobre la deliberación, es decir, sobre el intercambio de razones que persiguen alcanzar el acuerdo respecto a objetivos justos" (Peña, 2008:314). El autor recupera así la idea de participación de Habermas, para quien "sólo pueden llevarse a cabo regulaciones justas cuando los participantes aprenden a adoptar también las perspectivas de los otros. Y el procedimiento adecuado para este fin es la formación democrática de la voluntad constituida deliberativamente" (Habermas, 2006:128). En el próximo punto reflexionaremos más ampliamente sobre esta relación entre ciudadanía y participación.

\subsubsection{Participación ciudadana}

Como hemos visto, a la hora de abordar el concepto de ciudadanía activa es necesario hacer referencia a la participación. De hecho, para autores como Escámez, la ciudadanía consiste "ante todo, en la participación activa en las diferentes asociaciones que constituyen la sociedad civil, la cual se entiende como un ámbito de acción social, como un espacio público distinto del Estado y del mercado" (Escámez, 2003: 192).

Son muchos los estudiosos que destacan la existencia actual de un periodo de desencanto o de falta de interés por la participación en la mayoría de ámbitos de la vida social. A pesar de que en España, al igual que en la mayoría de países democráticos, los cauces o estructuras técnicas para la participación están creados, para Escámez estamos lejos de vivir la cultura de la participación entendida como una forma compartida por los ciudadanos de percibir los asuntos comunes y tomar parte en las deliberaciones, decisiones y gestiones de lo público. 
Deteniéndonos en el propio concepto de participación, cabe destacar diferentes concepciones. La primera, relacionada con la concepción de libertad de los antiguos, considera que el hombre realiza del modo más pleno su naturaleza en una sociedad democrática, en cuya vida se dé una amplia y vigorosa participación social. Adela Cortina señala que la participación es así entendida como modelo de vida feliz, que los ciudadanos deben incorporar en la vida pública. Para Cortina la segunda forma de entender la participación es como un medio para defender la independencia o las libertades democráticas en las sociedades que las tienen implantadas (Cortina, 2001: 7879). Esta concepción de la participación como independencia se relaciona con la concepción liberal de la libertad, y en ella la noción fundamental de la vida política es la libertad como no dominación, de forma que nadie tenga que temer la intervención arbitraria de los poderosos en sus vidas. Amartya Sen introduce una nueva concepción de libertad que se refiere tanto a los procesos que hacen posible la libertad de acción y decisión (la libertad como no dominación) como a las oportunidades reales que tienen los individuos, dadas sus circunstancias personales y sociales (la libertad como expansión de las capacidades personales).

De entre los indudables beneficios que genera la participación en la sociedad civil, Escámez destaca cuatro que le parecen especialmente importantes como son, en primer lugar, la elección compartida de las prioridades sociales, un aspecto especialmente relevante en lo que se refiere a ciencia. Un segundo beneficio sería el ejercicio de la autonomía responsable, beneficio que incide en la responsabilidad de la ciudadanía a la hora de actuar y participar, alejándose de una posición pasiva.

La ética de la responsabilidad nos obliga a la acción, que es la única facultad que tenemos para producir los cambios sociales necesarios, junto con otros, formando asociaciones o participando en instituciones, para que nuestras decisiones tengan posibilidades de éxito (Escámez, 2003:198).

La formación de capital social es el tercer beneficio destacado por Escámez, argumentando al respecto que la premisa central de la teoría del capital social se resume en la afirmación de que las conexiones sociales y el compromiso cívico influyen tanto en nuestra vida pública como en los proyectos privados, de forma que en una sociedad con capital social es más fácil vivir. Finalmente, la participación favorece el desarrollo económico de los pueblos. El ejercicio de las libertades políticas mediante la participación social, como demuestra Sen, lima las desigualdades y obliga a los 
responsables del gobierno a responder a las necesidades económicas de los ciudadanos (Sen, 2000:191).

Escámez plantea una serie de propuestas centradas en la participación en la sociedad civil porque considera que es en ese espacio donde se encuentra el problema de las deficiencias en participación ciudadana, que es necesario resolver para el mantenimiento y fortalecimiento de la democracia. La formación se presenta como un aspecto fundamental para fomentar la participación.

Como hay graves obstáculos y fuerzas poderosas en su contra, es necesario tomarse el asunto de la formación para la participación en serio y para ello se requieren proyectos de actuación política, cívica, ética y educativa (Escámez, 2003:199).

Las propuestas se centran en la legitimación democrática de las leyes, de forma que los ciudadanos las perciban como una intervención legítima en la vida civil, para lo que se requiere que antes de su aprobación y promulgación sea explicada y debatida, algo que en el caso de la normativa científica requiere asimismo la labor divulgativa por parte de investigadores y comunicadores científicos. Otra propuesta pasa por la civilización de la economía global, lo que requiere tres tipos de acciones por parte del gobierno: su cooperación con otros estados para promover una legislación internacional que regule la economía global; la decisión de recuperar la política para decidir lo que se produce y cómo; y la protección de las vinculaciones que puedan tener las asociaciones de la sociedad civil para constituir una sociedad civil mundial.

La tercera propuesta de Escámez radica en la promoción de movimientos sociales para el servicio voluntario a la comunidad social; mientras que una cuarta propuesta se refiere al desarrollo del sentimiento de pertenencia a la comunidad propia. Una democracia ciudadana sólo puede funcionar si la mayoría de sus miembros están convencidos de que su comunidad política es una empresa común de considerable transcendencia, y que la importancia de esta empresa es tan vital, que están dispuestos a participar en todo lo posible para que siga funcionando como una democracia (Escámez, 2003:203). La teoría de las Esferas de Afecto de M. Walzer defiende que es necesario el compromiso solidario con el círculo social más próximo para ampliar ese sentimiento de fraternidad a nuevos grupos de personas y finalmente a todas las personas. En este sentido, cada ser humano pertenece a dos comunidades, la local, con unas leyes y costumbres propias; y la comunidad universal, de todos los hombres. Para pasar de una a otra, Cortina propone educar en un cosmopolitismo arraigado: la enseñanza de los 
valores y actitudes de las comunidades familiar, vecinal, religiosa, escolar, política, para ir aprendiendo a degustar en ellas los valores que nos permiten acondicionar la vida para hacerla más habitable a todas las personas (Cortina, 2001:124-130).

Por otra parte, una propuesta que nos resulta especialmente interesante para la presente tesis, y que abordaremos más ampliamente en el cuarto apartado del presente punto, es la de una educación en los valores de la ética cívica. Para Escámez, los valores morales recogidos en la Constitución configuran el contenido propio de la educación e impone la finalidad hacia la que ésta ha de tender y, al tiempo, integra todas las normas internacionales, como evolución de los Derechos Humanos, que la preocupación por el pleno desarrollo de la personalidad humana ha ido generando. Los valores son nuestro capital axiológico con el que contamos y determinan que una sociedad esté más o menos a la altura de la dignidad humana.

La participación en la gestión de los centros educativos es otra de las propuestas ya que los individuos sólo pueden aprender a comprenderse a sí mismos como personas democráticas, cuando son miembros de una comunidad democrática en la cual se resuelven los problemas de la vida social a través de deliberaciones colectivas y de un compartido interés por el bien común. Se requiere por tanto que las escuelas proporcionen un entorno en el cual se estimule al estudiantado a resolver problemas morales y sociales prácticos, a través de actividades conjuntas y de una toma de decisiones en común.

Finalmente, la última de las propuestas planteada por Escámez para favorecer la participación es la formación de competencias para un discurso público y civilizado. La participación responsable en la sociedad civil exige que los ciudadanos adquieran las competencias necesarias para pedir razones y darlas, deliberar y decidir. Escámez entiende por discurso público "el ejercicio de dar y pedir razones o argumentos a los demás sobre asuntos de los que se derivan efectos públicos" (Escámez, 2003:207). Formar parte de la voz de la sociedad civil es un derecho y una obligación para todos. Además, el autor destaca la importancia de que el discurso público deje de ser vertical para ser lateral, produciéndose en condiciones de igualdad entre todos los afectados. Y para que esto se dé es necesario que las instituciones lo fomenten y los ciudadanos alcancen las competencias adecuadas. 


\subsubsection{Educación para una ciudadanía activa y cordial}

Una de las críticas planteadas por Adela Cortina al modelo de democracia deliberativa de Habermas es el hecho de que no trate de responder a una pregunta que la autora entiende cómo central para todo el proceso: ¿por qué los ciudadanos van a estar interesados por entrar en los procesos de deliberación?, ¿por qué les va a interesar argumentar en serio sobre la validez de las normas? La política deliberativa no parece reparar en que es preciso construir sujetos cordiales, sujetos con voluntad de justicia, dispuestos a dialogar en serio, a detectar qué intereses son universalizables y a decidirse por ellos. No solo es necesario que tengan capacidad de argumentar, también han de tener la capacidad de querer lo justo.

Educar para una ciudadanía democrática, capaz de reconocer a los otros en su dignidad y en su vulnerabilidad, capaz de interesarse por descubrir lo justo a través de una deliberación comunicativa, es entonces una pieza central del edificio (Cortina, 2010a:94).

A ser ciudadano se aprende no por ley ni por castigo sino por degustación, afirma Adela Cortina. “Ayudar a cultivar las facultades (intelectuales y sintientes) necesarias para degustar los valores ciudadanos es educar en la ciudadanía local y universal" (Cortina, 1997b: 219). Para educar en esta ciudadanía es necesario educar en los valores morales, unos valores que se especifican por al menos estos factores: dependen de la libertad humana por lo que no pueden atribuirse a otros seres vivos; y una vida sin ellos está falta de humanidad, por eso los universalizaríamos, estamos dispuestos a defender que cualquier persona debería intentar realizarlos sino quiere perder en humanidad (Cortina, 1997b:225). Los valores morales progresan a la largo de la historia, de forma que se mantienen los anteriores pero se consideran insuficientes. Se trata de un progreso moral. El camino que tomen los avances científicos y su contribución en humanidad dependerá del haber en valores alcanzado por la sociedad afirma Adela Cortina.

Sin duda los avances técnicos son valiosos, pero se pueden dirigir en diferentes sentidos, se pueden encaminar hacia la libertad o la opresión, hacia la igualdad o la desigualdad, y es la dirección que les damos lo que los convierte en valiosos o rechazables. De ahí que podemos afirmar que nuestro "capital axiológico", nuestro haber en valores es nuestra mayor riqueza (Cortina, 1997b: 230).

Adela Cortina establece una serie de valores morales principales que articulan al resto y que son: 
- Libertad. Que puede entenderse como participación, como derecho a tomar parte en las decisiones comunes; y también como independencia, en referencia a un espacio, el de la vida privada, en el que todos los individuos pueden moverse sin interferencias; y finalmente, la libertad entendida como autonomía, que entiende que libres son las personas capaces de darse sus propias leyes, lo que exige hacer el esfuerzo de ver lo que nos humaniza y seguirlo.

- Igualdad. Todas las personas son iguales en dignidad, hecho por el cual merecen igual consideración y respeto.

- Respeto activo. Este valor moral supone no sólo respetar que otros piensen de forma distinta, sino tener un interés positivo por comprenderlos.

- Solidaridad. No grupal sino universal, lo que implica actuar pensando en los intereses de todos los afectados por las acciones. Para Cortina hay valores que requieren solidaridad universal como son la paz, el desarrollo de los pueblos menos favorecidos y el medio ambiente.

- Diálogo. El diálogo compromete a la totalidad de la persona que se introduce en él para convertirse en protagonista de una tarea compartida que se bifurca en dos ramales: la búsqueda compartida de lo verdadero y lo justo; y la resolución justa de los conflictos que van surgiendo a lo largo de la vida (Cortina, 1997b: 248).

En Ética de la razón cordial Cortina plantea además la necesidad de avanzar hacia una ciudadanía cordial, dado que nuestro contacto con la realidad es afectivo, sabemos de la realidad a través de una inteligencia sentiente, emocional y afectiva, a través de una razón cordial. Para que la vida compartida funcione bien y para que sea alto el nivel moral de una sociedad, importa que los ciudadanos tengan virtudes bien arraigadas y se propongan metas comunes desde el respeto mutuo y desde la amistad cívica, desde una ciudadanía cordial que es necesario educar. Antes de abordar los hábitos en los que Cortina recomienda educar para alcanzar la ciudadanía cordial, es oportuno detenerse aunque sea brevemente en el concepto de ética cordial propuesto por la autora. Se trata de lo que denomina una "versión cálida" de la ética del discurso, preocupada no sólo por los aspectos epistémicos del vínculo comunicativo, sino también por los aspectos cordiales que lo convierten en una auténtica comunicación (Cortina, 2007:221). 
Cortina fija cinco principios de la ética cordial, de los cuales los cuatro primeros surgen del reconocimiento cordial de la igual dignidad y el quinto se refieren a la relación de los seres humanos con la naturaleza no humana. Haremos referencia a continuación a cada uno de estos principios:

- No instrumentalizar a las personas, lo que supone no ponerlas al servicio de fines que no han elegido, así como respetar la autonomía tanto ajena como la propia. "El límite de la actividad política, económica, científica, es la no manipulación" (Cortina, 2007:224). Este principio lleva implícito el de no dañar.

- Principio de las capacidades, que implica empoderar a las personas. En este punto se pone de manifiesto la importancia de promover una cultura científica. La sociedad está obligada, como una cuestión de justicia, a fortalecer el poder de empoderar a las personas para que sean sujetos agentes de sus vidas. Para poder serlo, en muchas ocasiones es imprescindible contar con unos conocimientos científicos que permitan elegir sobre la forma de vida. No se trata sólo de no manipular, sino también de empoderar, de actuar positivamente para potenciar las capacidades de las personas, de forma que puedan llevar adelante los planes de vida que elijan, siempre que con ellos no dañen a otras (Cortina, 2007:225).

- Principio de justicia distributiva. En la distribución equitativa de los recursos la dificultad principal estriba en establecer los mínimos de igualdad. Cortina plantea como solución el modelo de justicia del "interlocutor válido" que consiste en empoderar a las personas para que puedan ser interlocutores válidos como un primer mínimo decente, a partir del que pueden decidir qué consideran básico mediante el diálogo, ya que lo básico es lo que expresa intereses universalizables (Cortina, 2007:236). Este planteamiento supone dos ventajas: concreta lo necesario para que las gentes puedan participar en los diálogos defendiendo sus propios intereses; y compromete a la sociedad a diseñar las instituciones de modo que las gentes puedan participar realmente en los diálogos. Además, el motor de esta voluntad de justicia es el reconocimiento cordial de que todos somos iguales en dignidad.

- Principio dialógico. "Tomar como fuente de la obligación moral el reconocimiento recíproco exige tener en cuenta los intereses de los afectados por las decisiones, y que sean ellos quienes, en la medida de lo posible, expresen 
esos intereses a través del diálogo" (Cortina, 2007: 237). No es extraño que la participación dialógica de los afectados vaya siendo una constante en distintas esferas de la vida social, como los stakeholders en la Responsabilidad Social Empresarial, y cada vez más también en el ámbito de la ciencia a través del impulso de la RRI, como veremos más adelante. Al respecto de las actividades científicas, Cortina señala que cada vez necesitan más el refrendo público para llevarse a cabo como ocurre, por ejemplo, en el caso de actividad biotecnológica. En concreto, respecto a la importancia de este principio en relación con la ciencia, señala que

Ampliar la información y crear plataformas para la participación es un requisito indispensable de respeto a la libertad y la dignidad, así como la única forma de llegar a las decisiones más justas posibles, pero además es una medida de prudencia (Cortina, 2007:239).

- Principio de responsabilidad por los seres indefensos no humanos. En este punto hace referencia al Principio de Responsabilidad de Hans Jonas que establece la obligación de proteger aquello que es internamente valioso y vulnerable. Este principio resulta de especial interés para la RRI, ya que lo que Jonas plantea es la problemática de la responsabilidad humana frente a las consecuencias del desarrollo científico tecnológico y del ilimitado poder que han alcanzado los seres humanos sobre el mundo natural y social. Ante esta situación, el autor pone de manifiesto la necesidad de plantear y analizar la problemática de la responsabilidad por la vida futura de la humanidad, formulando el siguiente imperativo ético: "Obra de tal modo, que las consecuencias de tu acción sean compatibles con la permanencia de una verdadera vida humana sobre la tierra" (Jonas, 1996).

Una vez definidos los principios de una ética cordial, a los que volveremos en el tercer apartado dedicado a la comunicación pública de la ciencia, abordaremos con Cortina los hábitos que es necesario desarrollar a través de la educación para alcanzar una ciudadanía activa y cordial. Se trata de conocimiento; prudencia para llevar adelante una vida feliz y sabiduría moral. El primero de ellos, el conocimiento, es importante, además de para el desarrollo profesional, porque una sociedad bien informada tiene mayor capacidad de aprovechar sus recursos naturales y es además menos permeable al 
engaño (Cortina, 2007:254). Contar con información fiable, también por supuesto en el terreno de la investigación y la innovación, es imprescindible para formarse un juicio moral, de lo contrario actúan los prejuicios.

Por ello, explica Cortina que se necesitan expertos que estén dispuestos a diseñar en cada uno de sus campos alternativas humanizadoras y viables; a presentar sus propuestas a los poderosos; y a llevar sus conocimientos y opiniones a la esfera de la opinión pública, a ese ámbito en el que los ciudadanos de las sociedades pluralistas deliberan sobre lo justo y lo injusto (Cortina, 2007:256). Así, en una "república moral" en la que el peso de la deliberación pública resulta decisivo, que profesionales y expertos informen adecuadamente es imprescindible, de ahí la importancia de concienciar a los científicos de la necesidad de fomentar la vertiente divulgadora de su trabajo. En este sentido, cabe destacar la reivindicación desde distintos ámbitos, incluido el de los profesionales de la comunicación científica, para que la divulgación pase a ser valorada en el currículum de los investigadores.

Por lo que respecta a la prudencia, Aristóteles ya la recomendaba para determinar la bondad de los fines, que es lo que hace buena o mala la técnica y el conocimiento. Contar con ciudadanos y gobiernos prudentes es necesario para organizar las sociedades atendiendo a los criterios de calidad de vida y no de cantidad de bienes. Solo desde esa visión prudencial tiene sentido el enfoque de sostenibilidad de los recursos (Cortina, 2007:259).

Pero educar en la búsqueda de calidad de vida es insuficiente para formar a una persona en el pleno sentido de la palabra. La calidad de vida es inevitablemente excluyente ya que excluye a cuanto no entra en el cálculo prudencial de su bien. Educar en el sentido de justicia exige siempre ir más allá del cálculo y de la prudencia. Cortina llega así al tercer hábito, el de la sabiduría moral, que la autora de la Escuela de Valencia relaciona además con los que denomina bienes de gratuidad, aquellos bienes que los comparten quienes los regalan por la abundancia del corazón.

En definitiva, vemos como la información y la formación se encuentran en la base de la educación para una ciudadanía activa y cordial:

Educar para el siglo XXI sería formar ciudadanos bien informados, con buenos conocimientos y asimismo prudentes en lo referente a la cantidad y la calidad. Pero es también, en gran medida, en una enorme medida, educar personas con corazón, con un profundo sentido de la justicia y un profundo sentido de la gratuidad (Cortina, 2007:263). 


\subsubsection{Ciencia ciudadana}

Los conceptos desarrollados a lo largo del presente capítulo nos llevan a plantear la necesidad de una ciudadanía activa y participativa para una investigación e innovación responsables, siendo la ciencia ciudadana un claro exponente de lo que puede generar una ciudadanía activa en este ámbito. Se entiende por ciencia ciudadana la investigación científica llevada a cabo por una suma de colaboradores entre los que se encuentran investigadores y personas con una formación no especializada en ciencia. El Libro Verde de la Ciencia Ciudadana resalta la capacidad de ésta para involucrar al público general en actividades científicas y fomentar la contribución activa de los ciudadanos en el proceso investigador aportando su esfuerzo intelectual, su conocimiento general o sus herramientas y recursos. Se trata de crear una nueva cultura científica gracias a la aportación de unos y otros, creando un escenario abierto y trasdisciplinar para favorecer una investigación más democrática, según destaca el libro desarrollado en el marco del proyecto europeo Socientize, proyecto incluido en el $7^{\circ}$ Programa Marco que busca coordinar a todos los agentes implicados en el proceso de la ciencia ciudadana con el fin de sentar las bases para este nuevo paradigma de la ciencia abierta.

Citizen Science refers to the general public engagement in scientific research activities when citizens actively contribute to science either with their intellectual effort or surrounding knowledge or with their tools and resources. Participants provide experimental data and facilities for researchers, raise new questions and co-create a new scientific culture. While adding value, volunteers acquire new learning and skills, and deeper understanding of the scientific work in an appealing way. As a result of this open, networked and trans-disciplinary scenario, sciencesociety-policy interactions are improved leading to a more democratic research based on evidence-informed decision making (Socientize Consortium, 2013).

La ciencia ciudadana supone la colaboración de personas que no son profesionales de la ciencia y que aportan sus recursos intelectuales o materiales de forma consciente y voluntaria. A pesar del auge que está viviendo la ciencia ciudadana como concepto en los últimos años, se trata de un fenómeno que no es nuevo. Los fanáticos de las estrellas, los apasionados de los avistamientos de aves o los voluntarios que desde hace décadas cuentan con estaciones meteorológicas más o menos avanzadas en sus casas, son solo algunos ejemplos de aportaciones voluntarias al desarrollo de la ciencia a lo largo de la historia y hasta nuestros días. 
El auge actual de este fenómeno se ha visto favorecido por diferentes factores, entre los que destacan las posibilidades que abren las nuevas tecnologías. La sociedad digital permite, entre otras cuestiones, las comunicaciones inmediatas, los datos compartidos masivamente, el conocimiento abierto o el desarrollo de la denominada $e$ ciencia, ciencia basada en grandes recursos computacionales y equipos multidisciplinares en red. Todos estos avances generan infinidad de posibilidades de colaboración ciudadana en el avance de la ciencia.

En función del tipo de colaboración, se habla de tres modelos de ciencia ciudadana (Medialab Prado, 2014):

- Recolección de datos (volunteer sensing). En este caso la colaboración consiste en la búsqueda de datos. Así, existen numerosas herramientas disponibles para la toma de datos gracias a voluntarios distribuidos por todo el mundo. Páginas como Publiclaboratory.org permiten desarrollar una comunidad internacional para la recogida de datos y la investigación sobre temas, en este caso, ambientales. La web proporciona el software, el hardware y los planos necesarios para que cualquier persona pueda crearse sus propios kits de sensores para la realización de fotografías aéreas, espectrómetros o fotografías infrarrojas. Los datos recogidos a través de estos sensores son puestos en común a través de la web y utilizados con fines científicos.

- Computación voluntaria (volunteer computing). Los voluntarios y voluntarias aportan la capacidad de computación de sus ordenadores personales conectados a internet, planteando una alternativa barata y sencilla para poder llevar a cabo supercomputación. El precursor de esta modalidad de ciencia ciudadana fue el proyecto SETI@home lanzado en 1999 por la Universidad de California en Berkeley. Se trataba de un experimento científico que utiliza ordenadores conectados a internet para la búsqueda de inteligencia extraterrestre (SETI: Search for Extraterrestrial Intelligence). Para posibilitar la computación voluntaria y la computación en red se desarrolló el software BOINC que, ante el éxito de la iniciativa, pasó a ser de código abierto. Actualmente proyectos como Einstein@Home y centros como el World Community Grid de IBM o el CERN utilizan este software para procesar, analizar y estudiar diferentes problemas científicos. A través de programas como BOINC, cada usuario decide cómo 
colaborar, en qué proyectos y la capacidad de computación que quiere donar, sin ver incrementado más de un $10 \%$ el consumo de su ordenador.

- Inteligencia distribuida (volunteer thinking). Este tercer modelo de colaboración es el que requiere una mayor implicación por parte del voluntario ya que en este caso lo que dona son ciclos de su conocimiento para resolver problemas científicos reales. Uno de los proyectos pioneros en este campo es Galaxy Zoo, proyecto a través del que los voluntarios ayudan clasificando galaxias por sus formas siguiendo unas sencillas indicaciones.

En la actualidad comienzan a crearse proyectos que hibridan estas tres categorías, de forma que los colaboradores y colaboradoras recopilan datos, realizan análisis computacionales de los mismos y participan en su supervisión y validación.

En el caso de España, cabe destacar la creación en 2011 de la Fundación Ibercivis con el fin de potenciar la computación voluntaria y la ciencia ciudadana. La Fundación Ibercivis da soporte a personal investigador de diferentes áreas cuyas necesidades de cálculo y recogida de datos son elevadas; organiza recursos y el trabajo a realizar; hace de intermediario entre la comunidad científica y la comunidad de voluntarios, y da soporte en la comunicación y difusión de los proyectos.

Cabe señalar el beneficio que supone la ciencia ciudadana para investigadores y voluntariado. Así, por un lado, el científico aprovecha las contribuciones de los colaboradores lo que le permite reducir tiempos, costes y mejorar sus procesos. Por el otro, el ciudadano voluntario se mejora a sí mismo mientras ayuda a mejorar a los demás, conoce la realidad investigadora de primera mano y aumenta su cultura científica y sus capacidades científico-tecnológicas (Serrano, 2013).

En relación al marco ético y al papel de la ciudadanía planteados en el presente trabajo, cabe señalar como este concepto se relaciona con algunos de los principios de la ética cordial establecidos por Cortina y expuestos en el punto anterior. Es el caso del principio de no instrumentalizar a las personas, respetando su autonomía, algo que garantiza la ciencia ciudadana gracias a su carácter voluntario y a la posibilidad de elegir los proyectos en los que se colabora. También favorece el principio de las capacidades, ya que la implicación en los proyectos conlleva un empoderamiento de las personas en las áreas científicas en las que colaboran. Desde el marco ético de la RRI, el principio dialógico debería ser asimismo clave en el ámbito de la ciencia ciudadana, de 
forma que la participación no se limitara a una aportación determinada, sino que incluyera también una defensa de los intereses de todos los posibles afectados a través del diálogo en las diferentes fases del proyecto. Sobre este punto volveremos en el segundo apartado del presente bloque, dedicado a la Investigación e Innovación Responsable.

A lo largo de este capítulo hemos visto la relación de la ética con la ciencia y la comunicación científica, y hemos abordado la apuesta por una ética del discurso como un norte a seguir en el camino hacia una gestión de la ciencia deliberativa al dar voz a todos los afectados en condiciones de igualdad para hacer frente a personalmente involucrado. Una apertura de la ciencia hacia la ciudadanía es sin duda necesaria y positiva para la democracia, pero también para la propia ciencia. En cualquier caso, parece que en primer lugar, cada uno de nosotros, debemos asumir el papel de ciudadanos con virtud cívica, es decir, dispuestos a formarnos, informarnos, deliberar, participar y exigir transparencia y control. 


\section{Innvestigación e Innovación Responsable: Una}

\section{aproximación al concepto}

La Investigación e Innovación Responsable (RRI por sus siglas en inglés) es un concepto emergente en el campo de la ciencia gracias a la apuesta de organismos internacionales como la Unión Europea para definirlo y favorecer su implantación. En el presente capítulo buscaremos ofrecer una aproximación a este concepto desde diferentes frentes, partiendo de un análisis de algunas de las causas que han llevado al auge, tan consistente como rápido, que ha experimentado.

La presente tesis tiene entre sus puntos de partida la idea de que el modelo de Responsabilidad Social desarrollado por empresas y organizaciones a lo largo del siglo XX puede realizar interesantes aportaciones al desarrollo de la RRI y de su comunicación. Será éste el tema que centrará el segundo apartado, partiendo de un repaso del surgimiento y evolución del concepto de la Responsabilidad Social Empresarial (RSE), también llamada Responsabilidad Social Corporativa (RSC). Para poder comprenderlo y trasladarlo a la RRI, entendemos asimismo que resulta necesario detenerse en el propio concepto de responsabilidad desde la perspectiva de la ética. Precisamente, siguiendo el marco ético trazado en el capítulo con el que abríamos el presente bloque, abordaremos en este apartado la ética y la RSE desde la perspectiva de la Escuela de Valencia, perspectiva que nos permitirá llevar la teoría al ámbito de la aplicación también a la hora de establecer modelos de comunicación de la Responsabilidad Social.

El capítulo sobre la RRI se completará con un apartado en el que se recogerán las principales aproximaciones teóricas a este novedoso concepto. Para ello abordaremos las diferentes definiciones planteadas desde el ámbito académico y también por parte de la Unión Europea, organismo que, como veremos, ha resultado clave en la consolidación de la RRI. En este último apartado incluiremos también algunos ejemplos de prácticas que nos permitan entender mejor qué se ha venido considerando en Europa como acciones de investigación y de innovación responsables y cómo han ido evolucionando. 


\subsection{LA IMPORTANCIA ACTUAL DE LA RRI}

Las consideraciones sobre el lugar de la ciencia en la sociedad y sus responsabilidades no son nuevas, pero en los últimos años el debate y la investigación sobre estos temas se han implementado de forma mucho más amplia, especialmente en Europa.

El desarrollo de la RRI viene precedido por una creciente preocupación por el papel de la ciencia, por su evolución, por su legitimidad, así como por la incertidumbre que conlleva y sus riesgos asociados (Beck, 1992). A partir de estas preocupaciones se generó un campo de investigación académico ligado al estudio de las relaciones entre la ciencia, la tecnología y la sociedad, cobrando además cada vez un peso mayor las políticas científicas y tecnológicas (Bloch y Mejlgaard, 2012: 695)

La globalización y la transición hacia economías basadas en el conocimiento han vinculado la ciencia a las expectativas de desarrollo y competitividad. En opinión de autores como Bloch y Mejlgaard, tecnologías estratégicas como las Tecnologías de la Información y la Comunicación (TIC), la biotecnología o la nanotecnología, que tienen un alcance global y un desarrollo trasdisciplinar en una sociedad del conocimiento intersectorial, han desempeñado un papel fundamental en el avance de la preocupación por la responsabilidad de la ciencia. Los sistemas de innovación en los que se desarrollan estas tecnologías se basan en la colaboración entre investigadores e industria y su interacción con los responsables políticos.

Entre las causas que han favorecido el impulso de la RRI, Owen, Macnaghten y Stilgoe destacan también el reconocimiento de las limitaciones de las políticas existentes a principios del siglo XXI para hacer frente a áreas éticamente problemáticas de la ciencia y la innovación, como los organismos modificados genéticamente, la biología sintética, la geoingeniería o las TIC, entre otras. A esto se une, para estos autores, una creciente conciencia profunda, global e intergeneracional de los impactos que la innovación y la investigación tienen en la sociedad contemporánea. Estas circunstancias han llevado a una mayor disposición a nivel político a debatir y cuestionar los modelos de la investigación y la innovación y el propio contrato social con la ciencia.

These have catalysed an increasing willingness at a policy level to discuss, challenge and rethink linear models of science and innovation policy and the social contract for science (in which scientific freedom is exchanged for the promise or expectation of socially-beneficial impacts) 
and risk-based regulation as a predominant innovation governance paradigm (Owen et al, 2012:752) .

La creciente preocupación por el valor público de la ciencia, la necesidad de demostrar el impacto de las investigaciones y la voluntad de dirigir la ciencia hacia fines socialmente deseables, son aspectos que han favorecido la RRI.

Al inaugurar el primer taller sobre RRI celebrado por la Unión Europea (UE) en 2011, Octavi Quintana, director del Espacio Europeo de Investigación (EEI), manifestaba la necesidad de involucrar a la sociedad a lo largo del proceso de investigación.

\footnotetext{
After several years of research on the relation between science and society, we evidenced that we need to involve civil society very upstream to avoid misunderstanding and difficulties afterwards. We cannot guarantee the social acceptability for anything but the more we have dialogue the easier it is to understand the potential obstacles and to work on them (Owen et al, 2012: 752).
}

Entre los factores específicos que han dado lugar a la actual preocupación en Europa por la RRI, otros autores como Sutcliffe destacan también la necesidad de aprender de los errores del pasado y potenciar el uso de nuevas tecnologías para resolver problemas apremiantes para la sociedad a pesar de sus posibles riesgos; la preocupación por que el desconocimiento de la sociedad no bloquee la competitividad investigadora; y la voluntad de evitar que se repitan efectos negativos fruto de la innovación tratando de avanzarse a las consecuencias negativas. A estos motivos añade la cada vez mayor presión de nuevos inversores socialmente responsables y de la ciudadanía en su conjunto.

La pérdida de la confianza de la sociedad generada por la crisis financiera unida al potencial de monitorización y control que suponen las nuevas tecnologías y la web 2.0 está dando paso a una ciudadanía más crítica y la RRI se convierte en un elemento fundamental para abrir diálogos entre todos los actores con el fin de construir confianza en torno a los procesos y productos de la investigación y la innovación. La globalización y la necesidad de avanzar en investigación, pero de forma sostenible, es otra de las causas que ha impulsado la RRI. En este sentido, la RRI no pretende ser una barrera a la innovación, sino un estímulo para el éxito. Desde Europa se toma conciencia de que el crecimiento basado en la verdadera innovación llevará al desarrollo de un tipo de vida sostenible en el que se favorezca la participación de la sociedad. 
Pero favorecer la participación supone además partir de un público informado, con una comprensión básica de la ciencia y el proceso científico que le capacite para realizar "mejor" los juicios. En este sentido, cobra especial protagonismo el papel de la Comunicación Pública de la Ciencia, básica para contar con una opinión pública formada e informada. En este sentido, señala Sutcliffe que uno de los retos más importantes de la RRI es considerar cuidadosamente qué tipo de información y de participación quiere y necesita la gente para ayudarles a formarse una opinión informada, y entregársela con claridad y eficacia (Sutcliffe, 2011:12). Volveremos a este punto con mayor profundidad en el próximo capítulo, dedicado a la Comunicación Pública de la Ciencia.

Para finalizar el presente apartado sobre la importancia del auge actual de la RRI, resulta de interés hacer referencia al hecho de que el movimiento de la RRI no parte de cero ya que el desarrollo científico ha estado siempre ligado a planteamientos éticos y de derecho. En este sentido, los especialistas reunidos en el primer workshop de la Unión Europea sobre RRI destacaban la posibilidad de partir de los valores europeos recogidos en documentos como el Tratado de la Unión Europea y la Carta de Derechos Fundamentales de la Unión Europea, documentos que abordaremos en el capítulo dedicado al marco normativo de la comunicación de la RRI.

Además, existen numerosas actividades consolidadas para desarrollar una supervisión eficaz, adaptable y sensible del desarrollo de la ciencia, la tecnología y la innovación como mecanismos voluntarios de rendición de cuentas, iniciativas de gestión de riesgos, reglamentos de evaluación, comités científicos, entidades comerciales de rendición de cuentas (Global Reporting Initiative, Global Compact, AA1000), etc. Asimismo, son destacables algunas iniciativas dirigidas a incrementar la apertura y la transparencia, principio que sustenta la RRI, como códigos de conducta como el desarrollado en Europa para la Investigación en Nanociencia y Nanotecnología, el fallido intento de Reino Unido de desarrollar un plan voluntario de presentación de informes para los nanomateriales artificiales o el Walking with Stakeholders Project para entender cómo las compañías pueden responder a las expectativas del público. Aludiendo al concepto de meta-responsabilidad de Carsten, que abordaremos ampliamente más adelante, se trata ahora de coordinar y alinear estas acciones encaminadas a garantizar la responsabilidad de la investigación y la innovación. 
Una vez analizadas algunas de las razones de la actual importancia de la RRI, volveremos sobre este concepto más adelante para analizar con mayor amplitud el estado de la cuestión sobre el mismo. Antes, entendemos que resulta necesario profundizar en el propio concepto de responsabilidad y en el precedente que supone la Responsabilidad Social Empresarial y que es un referente a tener muy en cuenta de cara al desarrollo de una investigación e innovación realmente responsables.

\subsection{LA RESPONSABILIDAD SOCIAL EMPRESARIAL COMO}

\section{REFERENTE}

Para aproximarnos al concepto de RRI tomaremos entendemos que resulta de gran interés tomar como referente un campo que cuenta ya con una amplia y consolidada tradición teórica y aplicada como es la Responsabilidad Social Empresarial (RSE), partiendo de la idea de que los avances alcanzados en esta materia serán de utilidad para el desarrollo de una responsabilidad social en el ámbito de la ciencia. Al igual que desde mediados del siglo XX las empresas han ido tomando conciencia de la necesidad de hacer compatibles su tradicional papel con nuevas expectativas sociales, también los centros y organismos de investigación e innovación, así como los propios científicos y científicas, han de desarrollar su labor teniendo en cuenta las expectativas de sus stakeholders. La viabilidad de la investigación, su sostenibilidad futura, estará ligada a la capacidad que tenga de ser y mostrarse socialmente responsable.

Con el fin de profundizar en estos aspectos, abordaremos en un segundo punto el concepto mismo de responsabilidad, apoyándonos en la tradición ética hispánica. También nos centraremos en la evolución histórica y en el propio concepto de RSE, así como en los mecanismos y herramientas para su implantación. El presente trabajo hace hincapié asimismo en el modelo de responsabilidad social desarrollado desde una perspectiva ética por la Escuela de Valencia y apoyado tanto en la teoría de los stakeholders como en el modelo discursivo de Habermas. Finalmente, cerraremos el capítulo poniendo el foco en la comunicación de la Responsabilidad Social con el fin de, a partir de estas aproximaciones teóricas, poder extrapolar aspectos de interés para el desarrollo de una propuesta de modelo comunicativo de la RRI. 


\subsubsection{Una aproximación a la historia de la RSE}

El nacimiento y la evolución del movimiento de la Responsabilidad Social de la Empresa (RSE) aparecen ligados a la necesidad que las empresas tienen de justificar el uso que realizan del gran poder que desde mediados del siglo $\mathrm{XX}$ fueron adquiriendo. Josep Maria Lozano, a la hora de abordar la historia de la RSE, pone de manifiesto que en todas las épocas se ha reflexionado sobre la misión de las empresas y su relación con la sociedad y ya desde principios del siglo XX hay publicaciones que abordan la responsabilidad de los empresarios, pero es a partir de los años 50 cuando proliferan los artículos sobre la responsabilidad de los empresarios más allá de los beneficios económicos (Lozano, 2007).

En una etapa previa, en la primera mitad del siglo XX, se puede hacer referencia a una RSE ligada únicamente a la idea de filantropía o de caridad. Pero el nacimiento del concepto de RSE tal y como lo entendemos hoy en día se sitúa en Estados Unidos en los años 50, momento en el que, más allá del comportamiento voluntarista o filantrópico de la empresa, se entiende que hay una necesidad de que ésta justifique su poder y se legitime así ante la sociedad. Esta nueva posición significa que la empresa para responder del poder que tiene -y que la sociedad le permite o autoriza a utilizar- tendrá que preocuparse por averiguar de qué es responsable. La RSE se considera como una obligación entre otras que tiene la empresa frente a la sociedad de justificar, de dar explicación de sus valores y objetivos, de mostrar cómo y de qué forma utiliza la capacidad de actuar y que les legitima cada día (González, 2007). De este modo, en este momento encontramos ya aspectos básicos que estructurarán el debate de la RSE como son la no-reducción a su función económica, la atención a todos los grupos incluidos en la actividad empresarial y la implicación en la solución de los problemas sociales (Lozano, 1999:84).

En esta segunda mitad del siglo XX proliferen también las críticas a la RSE, especialmente aquellas que consideran que se trata únicamente de un mecanismo de legitimación del poder. Sin embargo, autores como K. Davis responden a estas críticas señalando que son los diferentes grupos de interés quienes otorgan el poder a las empresas. "La sociedad concede legitimidad y poder a la empresa. En el largo plazo, aquellos que no usan ese poder de un modo que la sociedad considera responsable tienden a perderlo", enuncia la Ley de Hierro de la Responsabilidad de este autor (Davis 1977:37). De esta forma, se entiende que la empresa queda legitimada para usar su 
poder siempre y cuando haga uso del mismo dentro de unas normas sociales aceptadas por todos los miembros de su comunidad local o sociedad concreta, así como por todos los grupos de interés.

En los 70 surge el término stakeholders y las reflexiones sobre el nuevo capitalismo basado en grandes multinacionales, y es en los 80 cuando se empieza a ver la necesidad de convertir las responsabilidades sociales en oportunidades de negocio. Sin embargo, para Lozano es a finales de los 90 y principios del siglo XXI cuando la RSE cobra un verdadero auge en respuesta a factores sociales y geopolíticos muy diversos como, por ejemplo, la ola de privatizaciones, la reestructuración de las relacionales sociales que supone la globalización, y que en los últimos años se ha visto acrecentada por las redes sociales de la web 2.0, la creciente importancia económica y política de las grandes corporaciones que escapan a las leyes del estado-nación al ser transnacionales y la falta de mecanismos de rendición de cuentas de esas transnacionales (Lozano, 2007). Otro de los factores determinantes en el impulso de la RSC según Lozano ha sido la presión de crecientes movimientos sociales, sobretodo medioambientalistas.

En el siglo XXI el debate se traslada a la esfera pública ante la necesidad de integrar lo económico, los social y lo medioambiental. La RSE se ve como una solución, pero no todos están de acuerdo en cuál es el concepto. La ONU lanzó en 2002 el Pacto Mundial con diez principios de comportamiento ético al que se han incorporado numerosas empresas. Tanto la ONU como la OCDE asocian el concepto de RSE a la lucha contra la corrupción y la promoción del diálogo entre las empresas y los stakeholders.

Por su parte, la Unión Europea ha sido pionera en abanderarla. Ya en la cumbre de Lisboa de 2000 realizó un llamamiento al sentido de responsabilidad social de las empresas y en 2001 publicó el Libro Verde, promoviendo un marco europeo de la responsabilidad social con el objetivo de "convertirse en la economía basada en el conocimiento más competitiva y dinámica del mundo, capaz de crecer económicamente de manera sostenible con más y mejores empleos y con mayor cohesión social" (COM 2001). La Unión Europea no aboga por la reglamentación, manteniendo el carácter voluntario que caracteriza la RSE. Además, en 2002 se creó un foro Multi-stakeholder europeo sobre la RSE en el que están presentes distintas voces e interlocutores relacionados con las actividades empresariales como empresarios, trabajadores, 
sindicatos y organizaciones cívicas y académicas. El objetivo en este caso es converger en la adopción de enfoques comunes y soluciones únicas y universales, en la medida de lo posible.

Continuando en esta línea, en 2006 se lanzó una propuesta de Alianza Europea para la RSE, una plataforma política desde la que las empresas europeas voluntariamente trabajen asociativamente para que se desarrollen diferentes áreas prioritarias que Europa se ha marcado en materia de RSE y entre las que se encuentran también aspectos relacionados con la ciencia como fomentar la innovación y el espíritu empresarial en las tecnologías sostenibles, productos y servicios que respondan a necesidades de la sociedad y avanzar en la innovación en el sector ambiental. También se recogen aspectos relacionados con la comunicación como seguir abordando los retos de la transparencia y la comunicación para hacer que los resultados no financieros de las empresas y organizaciones sean más comprensibles para todos los interesados y estén mejor integrados en sus resultados financieros.

Por lo que respecta al caso de España, el Congreso de los Diputados ha editado un Libro Blanco de la RSE y ha creado una subcomisión para promoverla. Además, en 2005 se constituyó el Foro de Expertos sobre RSE y en 2008 se creó el Consejo Estatal de RSE, cuya labor pasa por analizar la situación en esta materia y asesorar al Gobierno. En 2014 el Ministerio de Empleo y Seguridad Social presentaba la "Estrategia Española de Responsabilidad Social de las Empresas" que recoge la estrategia diseñada a nivel nacional para el periodo 2014-2020 dirigida a empresas, administraciones públicas y el resto de organizaciones con el fin de avanzar hacia una sociedad y una economía más competitiva, productiva, sostenible e integradora.

Tras esta breve aproximación histórica, que nos permite poner en contexto la RSE, nos centraremos en lo que resta del presenta punto en una aproximación conceptual al mismo, partiendo de diferentes reflexiones sobre los estados o niveles de desarrollo de la responsabilidad. En este sentido, Simon Zadek establece cinco estados según el grado de implantación de la misma en una empresa o institución.

- Defensa ante posibles o certeros riesgos que surgen de su actuación.

- Cumplimiento de las leyes.

- Gestión. Introducción de aspectos de justicia social, responsabilidad económica y cuidado por el medioambiente en sus operaciones. 
- Estrategia. RSE como elemento de competitividad, lo que supone integrar la voz de los stakeholders en la toma de decisiones.

- Fase civil. En la que la empresa se preocupa de la sociedad en la que vive y abandera el cambio social.

Otro autor que analiza los niveles de responsabilidad social es Archie B. Carroll, estableciendo una pirámide de niveles de responsabilidad de la empresa, en la que el primero corresponde a la responsabilidad económica ya que, como institución económica, su primera obligación es ser rentable. Las segundas son las responsabilidades legales, es decir, obedecer las normas; y las terceras, las responsabilidades morales, lo que supone cumplir las expectativas sobre las que existe un acuerdo entre los diferentes grupos implicados. El cuarto nivel sería la responsabilidad voluntaria o filantrópica a través de la contribución con recursos a la comunidad. Esa última es la única que no es exigible sino deseable para Carroll. Así, "la empresa socialmente responsable debe esforzarse por conseguir un beneficio, obedeciendo la ley, siendo ética y siendo un buen ciudadano corporativo" (Carroll, 1993:35).

Justo Villafañe plantea la necesidad de sustituir en la pirámide de Carroll la responsabilidad filantrópica por la responsabilidad con los stakeholders, con un comportamiento corporativo comprometido, desde una posición más europea de la RSE (Villafañe, 2004). Por su parte, Domingo García Marzá (2004) considera que el error de Carroll es centrarse en el cálculo de consecuencias por parte de la dirección frente al resto de grupos, desde una perspectiva utilitarista. Frente a esta, señala que se ha de pasar a una perspectiva dialógica, en la que el criterio para delimitar el ámbito y los contenidos de la responsabilidad es el acuerdo entre todas las partes implicadas. La responsabilidad constituiría así, según García Marzá, "un continuo que abarca tres niveles que siempre se dan juntos en la realidad empresarial: económico, legal y moral" (García Marzá, 2004:90). El económico y legal quedan claros en la pirámide de Carroll, mientras que el nivel de responsabilidad moral remitiría, según el modelo en el que profundizaremos en el tercer bloque de la tesis, al diálogo y acuerdo de todos los grupos de interés acerca de qué responsabilidades puede y debe adoptar la empresa y en qué grado. 
Lo que importa no es tanto el contenido de la responsabilidad como las condiciones procedimentales para el diálogo ya que solo la inclusión de todos en condiciones de igualdad asegurará la justicia del acuerdo. García Marzá realiza así una distinción entre responsabilidad moral y responsabilidad social. La primera atañe a este nivel procedimental para establecer un diálogo justo o moral, mientras que la responsabilidad social se refiere al conjunto de acciones, decisiones y políticas que conforman la respuesta de cada organización ante las demandas y exigencias de sus grupos de interés. Así, una hace referencia a los criterios de acción y la otra a las conductas.

El autor responde así a una de las principales críticas de Milton Friedman a la RSE como es la falta de criterios intersubjetivos a la hora de definirla. La defensa del modelo funcionalista de Friedman, que defiende que la empresa no tiene ninguna obligación más allá de obtener beneficios dentro de un contexto de libertad y competencia abierta, se encuentra en la base de los principales argumentos realizados en contra de la RSE.

Tan sólo existe una responsabilidad social por parte de las empresas, el emplear sus recursos e involucrarse en actividades diseñadas para incrementar sus beneficios siempre y cuando se sigan las reglas del juego, esto es, se involucren en una competencia libre y abierta sin decepciones ni fraudes (Friedman, 1979:10).

Frente al modelo funcionalista de Friedman, diferentes autores defienden el modelo de permiso social que parte de la base de que la empresa existe y actúa por el permiso de la sociedad para hacerlo, de forma que el comportamiento corporativo es legítimo sólo si sirve al propósito social. Las diferentes corrientes que abarca este modelo (teorías de la concesión social, teorías del contrato social y teorías de la ciudadanía) se apoyan en el argumento fundamental que afirma que no se puede separar la argumentación y la realidad económica de la argumentación moral y la realidad ética.

Si para Friedman no se les puede exigir responsabilidad moral a las empresas ya que no son personas sino entidades jurídicas artificiales, y "tan sólo la gente tiene responsabilidades" (Friedman, 1979:1), para los defensores del modelo del permiso social las empresas poseen conciencia moral en el sentido de que son sujetos colectivos o agentes morales y sus acciones, según recuerda Cortina, tienen consecuencias sociales: 
Cualquier entidad cuyas decisiones tengan consecuencias sociales debe asumir su responsabilidad social y pública por ellas, cosa que ocurre claramente en el caso de las empresas, cuyas decisiones tienen inevitablemente repercusiones sociales y, por lo tanto, son responsables de ellas ante la sociedad a la que afectan (Cortina, 1997a:25-26).

Lo mismo consideramos que ocurre en el caso de las instituciones de investigación e innovación, la repercusión social de cuyas acciones es indudable. Cortina va más allá en su reflexión sobre la responsabilidad de las organizaciones, afirmando que solo pueden estar legitimadas si proporcionan bienes a la sociedad:

A diferencia de las personas, cuya existencia no necesita legitimación, las organizaciones han de proporcionar unos bienes a la sociedad para ser aceptados por ella. Y, lógicamente, en el caso de que no los produzcan, la sociedad tiene derecho a reclamárselos y, por último, a deslegitimarlas (Cortina., 2005:22-23).

Racionalidad empresarial y racionalidad social y moral se encuentran entretejidas en el modelo empresarial del permiso social, de modo que es imposible separar completamente el ámbito de la ética y el de la empresa, cuyas actuaciones deberán responder tanto de los objetivos que se fija como de los medios que utiliza para alcanzarlos y tal respuesta estará referida a los valores y normas no sólo legales y económicos sino también sociales y morales (González, 2012).

Otro de las críticas de Friedman hace referencia a la confusión entre público y privado, señalando que el objetivo de las empresas es ganar dinero y no ocuparse de asuntos públicos introduciendo elementos políticos en la economía. En este sentido, García Marzá señala que las empresas no son actividades privadas porque implican a diversos grupos de interés y las consecuencias de sus acciones siempre son públicas, criticando también la confusión entre responsabilidad pública y responsabilidad estatal (García Marzá, 2004:87).

El tercero de los principales argumentos de crítica de Friedman, autor en el que posteriormente se han apoyado muchas otras voces contrarias, es la motivación última de la empresa al aplicar esta política, considerándola un fraude al perseguir otros fines, generalmente beneficios económicos, por lo que considera hipócritas estas prácticas. García Marzá responde a ello con el principio de publicidad, señalando que "toda adopción de medidas de responsabilidad social y ecológicas exige que la empresa sea capaz de hacer públicos sus esfuerzos realizados, de realizar una justificación pública como parte del contrato moral que tiene con la sociedad y que es la base de la confianza” (García Marzá, 2004:92). 
De esta forma se consigue evitar la crítica de engaño ya que la acción hipócrita no resiste la exigencia de publicidad. Entonces, la confianza es directamente proporcional a la capacidad de la empresa para hacer pública su responsabilidad. García Marzá destaca diferentes elementos para dar publicidad como:

- Los códigos éticos, que han de establecer un conjunto de valores que guíen la conducta y orientación en la toma de decisiones, la definición del posicionamiento frente a la responsabilidad social y la ecología y no un conjunto de normas. Los códigos éticos son una herramienta ampliamente extendida que en muchas ocasiones genera desconfianza por su uso instrumental.

- Comités de ética como implicación en la gestión ética de los diferentes intereses sociales con el objetivo de asesorar, supervisar y proponer.

- Auditoría ética como instrumento de evaluación del cumplimiento de la responsabilidad y también de gestión para la mejora de las buenas prácticas empresariales.

Estos mecanismos de publicidad forman parte del contrato moral que se establece entre empresa y sociedad ya que la empresa requiere una serie de recursos materiales, técnicos y humanos y, a cambio, la sociedad espera una serie de bienes que no se reducen al beneficio económico. Estas expectativas se generan tanto en los grupos internos como externos afectados por la compañía.

La RSE no es un recurso estratégico para alcanzar fines, como denostaba Friedman y como muchas veces se malinterpreta perdiendo así credibilidad, sino un recurso moral para el logro de las condiciones óptimas para la generación y mantenimiento de la confianza. Y para ello la responsabilidad social ha de ir ligada a la comunicación ya que, como hemos visto, responsabilidad es responder. Para García Marzá la responsabilidad social consiste desde esta perspectiva en decir lo que se hace y en hacer lo que se dice (García Marzá, 2005).

Desde la perspectiva de la comunicación y del management, la RSE se presenta por tanto como uno de los principales intangibles de la empresa vinculado estrechamente a la reputación de la misma. En este sentido, autores como Villafañe resaltan que sólo la RSE entendida como el compromiso de una empresa de mantener un comportamiento corporativo autoexigente con todos sus stakeholders le supondrá un 
incremento de su reputación corporativa. Por el contrario, la acción filantrópica entendida como "peaje social" no perjudica la reputación pero tampoco la beneficia (Villafañe, 2004). Así, desde el ámbito de la comunicación corporativa Villafañe resalta la ética como una nueva frontera de legitimidad tan importante como los resultados económicos porque es un requerimiento para obtenerlos. Trasladando estas reflexiones al ámbito de la investigación y la innovación, consideramos que es igualmente necesario que los centros de investigación estén legitimados por la sociedad para desarrollar su trabajo, para lo que es necesario aplicar también en estas instituciones el valor de los recursos intangibles, siendo la confianza el ejemplo más claro de estos recursos. La confianza es para García Marzá “directamente proporcional a la capacidad de las empresas para hacer públicas y justificar discursivamente sus acciones, estrategias y políticas. En definitiva, de hacer pública su responsabilidad” (García Marzá, 2006:93). En este sentido, el autor resalta el hecho de que además se trate de un tipo de recurso que aumenta más cuanto más se utiliza.

En los siguientes puntos profundizaremos en el concepto mismo de responsabilidad y en la propuesta de la Escuela de Valencia para llevar a la práctica de forma efectiva y eficiente el desarrollo de la RSE en diferentes organismos a partir de la ética del discurso de Habermas y la teoría de los stakeholders.

\subsubsection{El concepto de responsabilidad}

Con el fin de aproximarnos a la responsabilidad tanto empresarial como en el campo de la investigación y la innovación, resulta de interés tener en consideración las bases ético filosóficas del concepto de responsabilidad, palabra que en sus orígenes romanos y griegos hace referencia a las respuestas, justificaciones, explicaciones y razones que los seres humanos dan de sus actos ante alguien. También son elementos constituyentes de la responsabilidad la libertad del ser humano, una realidad de la que se responde y la necesidad de dar razón de las decisiones que se toman desde tal libertad. Para aproximarse a cada uno de estos elementos resulta recomendable acudir a la tradición ética hispana iniciada por Ortega y Gasset y continuada por X. Zubiri y J.L.L. Aranguren.

Para Ortega y Gasset la libertad tiene que ver con el proceso que se produce en los agentes morales, de hacerse cargo de la realidad, de conocerla e incorporarla a su 
propia existencia, de forma que como agentes morales que son, tanto los individuos como las empresas, poseen espacios de libertad dentro de las circunstancias que les rodean. En este sentido, el autor define la circunstancia como un conjunto de posibilidades determinadas y limitadas. Zubiri, como discípulo de Ortega y Gasset, profundiza en la idea de que los seres humanos somos inevitablemente morales por ser inevitablemente libres, y analiza el modo en que el sujeto se relaciona con su propia circunstancia. Tal modo de relacionarse posee dos aspectos clave, por un lado, el sujeto tiene que entender y comprender su circunstancia y, por otro, tiene que elegir y decidir para configurar su propia relación con el entorno (responsabilidad como ajustamiento por apropiación). Zubiri aborda asimismo el término justificación relacionándolo con el hecho de dar razón de un acto que ha realizado un ser humano.

Por su parte, Aranguren señala que cualquier decisión llevada a cabo por el ser humano, tanto individual como colectivamente, se realiza con relación a criterios morales o inmorales. Cada sujeto tiene libertad dentro de su circunstancia concreta para apropiarse de aquellas posibilidades que irán creando su ethos o segunda naturaleza (responsabilidad como ajustamiento por justeza), de las que tendrá que dar cuentas o razón de la posibilidad elegida entre las diferentes existentes.

Los elementos constitutivos de la responsabilidad son, por tanto, la circunstancia como conjunto de posibilidades determinadas y limitadas; la libertad del sujeto definida como la capacidad para autodeterminar sus propias acciones y respuestas; la autoderminación que se producirá por elección, decisión y apropiación de posibilidades de su entorno; y la justificación de la apropiación y ajustamiento realizado, que apunta tanto a explicar la posibilidad que se ha elegido como a las razones que han conducido a elegir y decidir tal respuesta. En definitiva, las normas y criterios en función de los que se ha ajustado el sujeto a su entorno, que cuando tienen pretensión de deber o 'justeza' apunta a normas que pueden ser de distinta índole y permite hablar de una estructura propia de la responsabilidad.

La estructura más sencilla de la responsabilidad es la planteada por O. Höffe, que supone una triple relación: la atribución de tareas asumidas, por tanto, la calidad de ser responsables de ellas; la atribución de la propia acción u omisión a determinadas personas; y los atributos de carácter al rendir cuentas ante una instancia. Por su parte, M. Kettner habla también de una triple relación en la estructura de la responsabilidad social entre el sujeto con respecto a sí mismo, el objeto de responsabilidad y la instancia 
ante la que debe responder. La estructura ha de estar asimismo ligada a los elementos constituyentes de la responsabilidad, de forma que sólo se podrá atribuir e imputar responsabilidad moral a aquel sujeto que ha actuado a partir de su propia circunstancia desde la libertad. Ingarden también introduce la necesidad de distinguir sobre si el sujeto asume su responsabilidad y obra en consecuencia con ésta o es hecho responsable por otro sujeto, pero no es responsable de aquello que se le atribuye.

Por su parte, Elsa González señala que para conocer la estructura de la responsabilidad y su funcionamiento se deben analizar tanto sus elementos (el sujeto, de qué es responsable, frente a qué instancia o persona), como las variantes de tal estructura dependiendo de la situación concreta en la que se manifieste la responsabilidad. Es decir, si el sujeto es responsable, asume su responsabilidad, es hecho responsable y/u obra responsablemente. Para llevar a cabo el análisis de la estructura de la responsabilidad la autora plantea un esquema de cinco preguntas básicas: ¿quién es responsable?, ¿cuál es la situación en la que se plantea la pregunta de la responsabilidad?, ¿de qué es responsable?, ¿en nombre de qué? y ¿ante quién tiene que responder? (González, 2002). Estas preguntas nos resultarán de utilidad para acercarnos a la estructura de la responsabilidad en cualquiera de sus ámbitos, incluido el científico, llevándonos a plantear cuestiones básicas sobre la responsabilidad tanto del investigadores a nivel individual como de los centros de investigación e innovación como instituciones.

Cabe matizar que al hablar de en nombre de qué es una persona o institución responsable hacemos referencia a los criterios o normas por las que el sujeto es responsable de algo, pudiéndose distinguir entre cuatro tipos de normas: legales, sociales, morales y religiosas, que derivan por tanto en cuatro tipos de responsabilidad diferente. Del análisis de esta estructura de la responsabilidad se puede apreciar, en términos tanto empresariales como institucionales, que la responsabilidad de una empresa o de una universidad o centro de investigación está referida al ajustamiento que hace con su entorno y a los criterios o normas a los que se refiere para realizar tal ajustamiento. Así se puede hablar de los tres tipos de responsabilidades más importantes: responsabilidad moral, responsabilidad jurídica y responsabilidad social (Cortina, 2001:145-156).

En nuestro caso nos interesa profundizar en el ámbito de las normas morales, entendiendo que la responsabilidad moral remite a normas posconvencionales con 
pretensiones de universalidad, incondicionalidad y autoobligación. Entendemos en este sentido que el principio de universalización "establece que una decisión es moralmente correcta cuando puede o podría ser aceptada por todos los afectados presentes y futuros" (González, 2007:211). En este sentido, González señala que, si bien la tradición hispana permite desentrañar los elementos constitutivos de la responsabilidad, resulta necesario esclarecer el tipo de norma moral a la que deberá ajustarse el comportamiento del sujeto para poder ser calificado no solamente de socialmente responsable, sino también de moralmente responsable. Para la autora, esta tarea se podría llevar a cabo desde la posición de la ética discursiva, formal y deontológica puesto que desde ella se ofrece un criterio que lejos de ser sustantivo es procedimental y cognitivista. En este sentido, la responsabilidad moral sería aquella que respetara un principio de actuación de tal clase que asegurara la incondicional, universal y auto-obligación del ámbito moral.

En esta tesis abordaremos la responsabilidad social como una parte de la ética empresarial, que es mucho más amplia. Para ello, y continuando con el ámbito de lo moral, hacemos referencia a lo que desde la Escuela de Valencia entienden por ética empresarial, partiendo de la concepción de la moral de Ortega y Gasset en el sentido que adquiere cuando se dice que alguien está desmoralizado. "La empresa, como la universidad o como cualquier persona, puede estar alta de moral o desmoralizada, y cuando está alta de moral es cuando se halla en su quicio y en su vital eficacia", señala Adela Cortina (2005:14). Para la autora, un clima ético se genera en una organización cuando sus distintos niveles saben que las decisiones suelen tomarse atendiendo a unos valores y existe la convicción generalizada de que eso es así.

Cortina alude asimismo al contrato moral que establecen las empresas y organizaciones con la sociedad, considerando que también además de ser responsables deben ser "responsivas", en el sentido de dar respuesta a las expectativas de los afectados, alcanzando así un reconocimiento recíproco:

Ya que quien pone en marcha una empresa tiene una serie de afectados con sus respectivas expectativas y que, si muestran ser legítimas, la empresa no tiene que actuar solamente con responsabilidad, sino con 'responsividad', es decir, tratando de responder a dichas expectativas. Desde la ética empresarial no pensamos sólo en el contrato legal, sino que vamos hacia el contrato moral y el reconocimiento recíproco (Cortina, 2005:15). 
La ética de la empresa trataría, pues, para la autora, de la adquisición del carácter necesario para responder a las expectativas legítimas de los afectados por ella de manera excelente.

Una vez realizada esta primera aproximación a la responsabilidad desde el marco de la ética, incluida de forma breve la ética empresarial, profundizaremos en el siguiente apartado en la perspectiva de la RSE de la Escuela de Valencia al entender que ofrece un modelo ya consolidado que puede servirnos de guía y referente para el desarrollo de la responsabilidad en el ámbito de la investigación y la innovación.

\subsection{3. Ética y RSE desde la perspectiva de la Escuela de Valencia}

Como hemos ido viendo a lo largo del presente trabajo, desde la Escuela de Valencia, autores como Adela Cortina, Domingo García Marzá y Elsa González proponen un modelo de RSE basado en la teoría ética discursiva de Habermas y en la teoría de los stakeholders. Esta última, surgida a partir de la obra Strategic Management. A stakeholder approach publicada por Richard Edward Freeman en los años 80, parte de una nueva visión empresarial en la que la empresa mantiene una relación de retroalimentación con todos los grupos de interés con los que se relaciona (proveedores, propietarios, trabajadores, clientes, etc.) en definitiva, "cualquier grupo o individuo que puede afectar o ser afectado por el logro de los objetivos de la empresa" (Freeman, 1984).

El modelo de RSE desarrollado a partir de la ética del discurso y de la teoría de los stakeholders se basa en el diálogo entre ellos y el conocimiento de sus valores e intereses:

Una corporación que quiera gestionar su responsabilidad debe tener presente que tal responsabilidad se define a partir del diálogo con todos sus stakeholders tratando de averiguar en tal diálogo qué intereses y valores son comunes a todos ellos y por tanto universalizables; qué intereses y valores son propios de cada grupo o de alianzas grupales y cuáles son simplemente intereses y valores particulares (González y García Marzá, 2006:162).

Asimismo, los diálogos que se establezcan deberán atender a los cuatro principios establecidos por Habermas en su ética del discurso como son el principio de sinceridad de los interlocutores; el principio de inclusión de todos los afectados como solución a los conflictos -o en su defecto los representantes-, potenciales, presentes y 
futuros; el principio de reciprocidad entre los participantes, y el principio de simetría entre todos los intereses planteados (Habermas, 2000). De esta forma, "el acuerdo será considerado siempre como un proceso y no como un hecho, y la valoración ética del mismo dependerá del alejamiento o cercanía respecto a la inclusión de los múltiples stakeholders, las condiciones del diálogo y del posible acuerdo” (González 2007:211).

A la hora de aplicar la teoría de los stakeholders a la RSE, una cuestión clave es diferenciar a los grupos de interés que poseen un poder de comunicación, es decir, que tienen capacidad de comunicación, y expectativas urgentes y legítimas. Para Elsa González estos son stakeholders centrales, mientras que los demás serían latentes (González, 2007:210).

Partiendo de este enfoque ético, desde la Escuela de Valencia entienden que una empresa podrá considerarse que está dando una respuesta adecuada a su RSE cuando encuentre el acuerdo de todos los implicados. Para mantener esta respuesta adecuada, el diálogo ha de estar en constante revisión. De este modo, para institucionalizar la RSE plantean implementar herramientas como las siguientes: definición e implantación de un código ético; establecimiento de un comité de ética corporativo; desarrollo de planes de comunicación interna y externa del código ético y del funcionamiento del comité de ética; elaboración de informes de RSE que incluyan un triple balance con los resultados económicos, sociales y ecológicos de la empresa (que pueden seguir modelos ya consolidados como el Global Reporting Initiative o la reciente ISO 26000); y establecimiento de una auditoría ética. Para el desarrollo de un modelo de investigación e innovación responsable entendemos que se trata de herramientas igualmente útiles, siempre que se realice la necesaria traslación y adecuación de las mismas a las características específicas de los organismos científicos.

En definitiva, desde la Escuela de Valencia Elsa González plantea la aplicación de la teoría de los stakeholders y de la ética del discurso para el desarrollo de una ética organizacional que busca avanzar hacia una sociedad "que quiera organizarse teniendo en cuenta a los individuos que pueden y deben exigir los derechos de ciudadanía económica, social y política” (González, 2007:207). En este sentido, la autora va más allá y plantea una revisión de los sistemas económico, político y social desde el concepto de stakeholding que supondría la voluntad de apostar por cuatro principios: la inclusión, la cooperación, la participación y la responsabilidad. De esta forma el stakeholding se perfila como un concepto capaz de mediar entre la perspectiva 
individualista y colectiva pues supone que cada individuo se sienta poseedor de un "stake" (en el sentido de tener un interés) en la sociedad de la que es miembro, de forma que se sienta motivado a cooperar, participar y contribuir a que se le pueda pedir responsabilidad. El desarrollo de esta sociedad de ciudadanos activamente implicados consideramos que resulta asimismo clave para su participación en las decisiones sobre ciencia, tecnología e innovación.

Por su parte, también desde la Escuela de Valencia, Adela Cortina propone el marco por el que debe regirse una empresa ética (Cortina, 1997a:112-113), que consideramos extrapolable a un centro de investigación. De este modo, para desarrollar su actividad de forma legítima e inteligente y generar una cultura de la confianza deben atender al menos a cuatro puntos de referencia:

- Las metas sociales por las que cobra su sentido y que consisten en satisfacer con calidad necesidades humanas de grupos de afectados.

- Los mecanismos adecuados para alcanzarlas, que en el caso de las empresas serían competencia, mercado y búsqueda de beneficios, aspectos que son mecanismos pero no metas.

- El marco jurídico-político, que no ha de responder a intereses sectoriales sino universalizables.

- Las exigencias de la conciencia moral crítica alcanzada por esa sociedad, punto que nos devuelve al marco ético desarrollado en el primer bloque del trabajo y que es claramente extrapolable al campo de la ciencia y la innovación.

Recapitulando y a modo de conclusión del presente punto, recogemos la reflexión de Domingo García Marzá sobre cuándo una institución es responsable en base a la aplicación del modelo pragmático desarrollado a partir de la ética del discurso y de la teoría de los stakeholders.

Una institución es responsable cuando las decisiones, acciones y políticas que adopta, así como las consecuencias y efectos de las mismas respecto a los intereses en juego, pudieran ser aceptadas por todos los implicados y/o afectados presentes y futuros en un diálogo abierto en condiciones simétricas de participación (García Marzá, 2006:91). 


\subsubsection{La comunicación de la RSE}

El modelo de RSE de la Escuela de Valencia expuesto conlleva a su vez una determinada forma de entender la gestión de la comunicación. En el presente punto abordaremos el modelo de comunicación de la RSE desarrollada por la Escuela de Valencia y que conlleva un proceso cíclico de comunicación que incluye como acciones centrales el diálogo con los stakeholders, la publicidad de los compromisos alcanzados y la publicación de los resultados. Trataremos también los retos y oportunidades que ofrece este modelo, así como términos ligados a la comunicación de la RSE como accountability y reporting. Sobre este último, incidiremos en la labor del Global Reporting Initiative como referente en la elaboración del triple informe de la RSE en materia económica, ambiental y social. Para finalizar, llevaremos los aspectos desarrollados al terreno de lo práctico, aproximándonos a experiencias empresariales de comunicación de la RSE.

Desde la perspectiva de la RSE de la Escuela de Valencia, Francisco Fernández Beltrán (2008) plantea la comunicación como el nexo de unión entre las expectativas de los grupos de interés que rodean a la firma y su comportamiento, siendo la materia prima desde la que han de construirse las políticas de Responsabilidad Social. La comunicación se sitúa de este modo como principio, y no únicamente como fin, de los procesos de RSE.

Desde este planteamiento, la comunicación inicia y mejora el proceso. Siguiendo este modelo, la organización requiere en primer lugar conocer las aspiraciones y expectativas legítimas de los grupos de interés para iniciar una negociación y adquirir un compromiso de satisfacción. Este proceso obliga por tanto a establecer procesos de comunicación bidireccional entre los stakeholders y la organización. Posteriormente, la comunicación resulta también imprescindible para que la organización dé cuenta del grado cumplimiento de sus compromisos.

Se establecen así algunas de las claves para la gestión de la comunicación. En primer lugar, siguiendo a García Marzá (2004), la definición de los mecanismos de participación y diálogo, así como de comunicación y transparencia, que permita la intervención igual de todos los afectados en la toma de decisiones. En segundo, la publicación de los diferentes compromisos que la empresa u organización asume ante 
todos los intereses en juego como paso previo para el diálogo y posterior acuerdo. Y finalmente, la rendición de cuentas a través de la comunicación de los resultados.

La comunicación se plantea de este modo como una herramienta al servicio de la RSE que debe ser gestionada adecuadamente. Por otra parte, la RSE no se puede supeditar a la comunicación. Pero no podemos obviar que tiene una influencia determinante en la imagen y reputación de la organización y por tanto debe ser puesta en valor. Siguiendo este modelo planteado por la Escuela de Valencia, Francisco Fernández Beltrán desarrolla el siguiente esquema de comunicación de la RSE.

\section{MODELO PARA LA COMUNICACIÓN DE LA RSE}

Francisco Fernández Beltrán, 2008

Compromisos por ámbitos y públicos
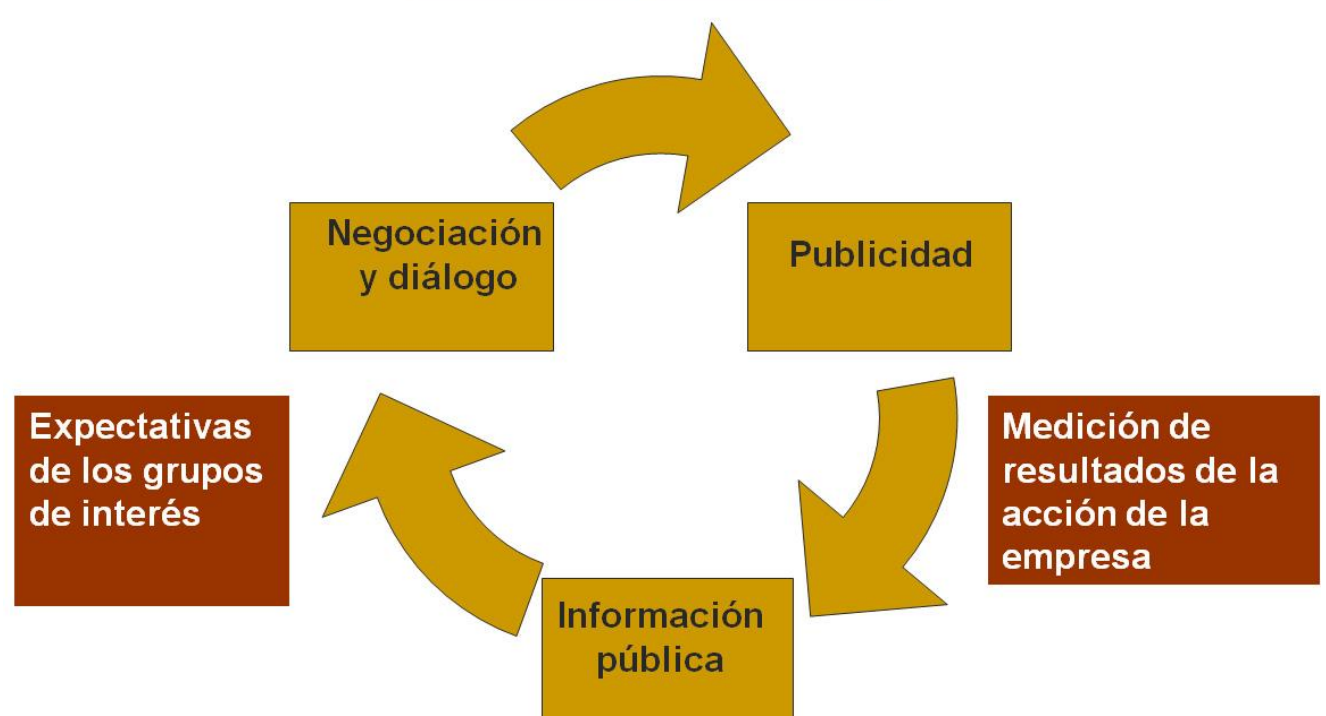

El modelo de comunicación de la RSE planteado por Fernández Beltrán (2008) parte de la incorporación de las preocupaciones de los grupos de interés a la estrategia general de la empresa. Esta incorporación implica, para Agüero, Martínez y Domínguez (2011), “el establecimiento de una relación sustentada en un proceso comunicativo fluido, flexible, adecuado a cada uno de ellos en cuanto a sus mensajes, canales e iniciativas”. Resulta asimismo necesario, para Fernández Beltrán, el establecimiento de 
un proceso de negociación y diálogo que permita a la organización, conjuntamente con cada uno de sus stakeholders, determinar las expectativas legítimas a incorporar y fijar unos compromisos asumibles, concretos y públicos con los diferentes grupos de interés.

Una nueva fase en la gestión de la comunicación de la RSE vendrá dada por la comunicación pública de los compromisos alcanzados con los stakeholders. Pero no será suficiente con que estos se queden en buenas intenciones ya que, para completar el círculo, resultará necesario que la organización realice un informe de resultados en el que quede patente el grado de cumplimiento de los compromisos alcanzados y responda de ellos haciéndolos asimismo públicos, justificando en todo caso las razones por las que no se han cumplido cuando así haya sido.

Como refleja el esquema planteado por Fernández Beltrán, la gestión de la comunicación no se cierra con la presentación de la memoria de RSE o el informe de resultados, sino que se trata de un proceso continuo, de forma que la comunicación del balance de RSE dé pie a nuevos diálogos en los que los stakeholders puedan, a partir de los resultados alcanzados, replantear sus expectativas e incorporar nuevos intereses que, a través del diálogo y la negociación, se conviertan en nuevos compromisos por parte de la organización.

Tal y como hemos visto, la propuesta de RSE planteada y, por tanto, la gestión de su comunicación, requiere como paso previo el establecimiento claro de sus stakeholders para así poder establecer los canales más adecuados de comunicación con los mismos.

La empresa establece una política concreta de comunicación, dibujando un mapa de stakeholders de la empresa y valorando las necesidades de información de cada uno de ellos. En este sentido, es clave definir no sólo la información sino los canales a través de los que desarrollar dicha comunicación (Vilanova et al, 2006).

Un paso fundamental para la comunicación de la RSE será por tanto la identificación y priorización de los stakeholders de la empresa, paso imprescindible para establecer una política de diálogo que constituye en sí misma una estrategia de comunicación. Agüero, Martínez y Domínguez (2011) señalan que esta estrategia de comunicación, como el resto de la comunicación estratégica desarrollada por la empresa, persigue unos objetivos, se orienta y adecúa a unos públicos prioritarios y debe disponer de un presupuesto y unos recursos específicos. 
Con el fin de avanzar en una adecuada gestión de la comunicación, estos autores señalan la necesidad de jerarquizar los grupos de interés, realizando el diagnóstico del estado de la relación con cada uno de ellos, incluyendo la detección de los canales de contacto y la periodicidad de la comunicación. Asimismo, resulta necesario definir los objetivos y expectativas de la organización respecto a cada uno de ellos y fijar el modelo deseado de relación y los recursos humanos y técnicos destinados a este objetivo. El diálogo establecido con los grupos debe asimismo ser adecuadamente comunicado.

El desarrollo de iniciativas a partir de la retroalimentación recogida en el proceso de diálogo con los grupos de interés no sólo demuestra la proactividad de la empresa sino que constituye el principal agente motivacional para el mantenimiento de dicho diálogo. De ahí la importancia de comunicar estas iniciativas a los públicos respectivos como una consecuencia directa de su participación en el proceso de diálogo (Agüero et al, 2011:13).

Más allá de los posibles planes de comunicación corporativa de las organizaciones, Agüero, Martínez y Domínguez defienden que el Plan de Comunicación de RSE debe ser único a nivel de estrategia, contenidos, mensajes clave, audiencias (en clave de grupos de interés), canales e indicadores de seguimiento. Esta especificidad de la comunicación de la RSE viene dada, en opinión de estos autores, cuando la empresa ha integrado la RSE transversalmente en su modelo de negocio, y sus actuaciones son coherentes con este compromiso, de modo que su comunicación se vuelve un aspecto más de dicha responsabilidad, como factor fundamental para la transparencia. Esto lleva también a situar al responsable de comunicación a nivel de la Alta Dirección con la consecuente responsabilidad sobre el logro de los objetivos de negocio.

El desarrollo de un Plan de Comunicación de la RSE debe tener en cuenta asimismo que se requiere establecer un diálogo entre la organización y los stakeholders que en ocasiones resulta complejo. Entre los principales problemas a los que debe enfrentarse, Fernández Beltrán destaca en primer lugar las derivadas del flujo de comunicación desde los grupos de interés hacia la organización. En este sentido, señala las dificultades para el envío de mensajes y la complejidad de establecer una comunicación a demanda, lo que obliga a buscar fórmulas de expresión alternativas. El flujo de comunicación en sentido inverso, desde la organización hacia los stakeholders, plantea también diversos retos, como el hecho de que se trata de una audiencia amplia y dispersa, lo que dificulta el establecimiento de mecanismos de comunicación directa. 
Asimismo, al tratarse de grupos con intereses diferentes se requiere una personalización de la comunicación.

Además de los problemas para establecer estos flujos de comunicación bidireccionales, la comunicación de la RSE se enfrenta también a dificultades internas y externas. Entre estas, Fernández Beltrán destaca a nivel interno el hecho de que se otorgue menor importancia a la comunicación de la Responsabilidad Social que a la esencia del negocio; la voluntad de mantener la confidencialidad de determinados datos y la complejidad de conjugar lo interno y lo externo. A nivel externo, entre los retos a superar el autor considera que se encuentran la escasa receptividad de los medios de comunicación de masas a los temas de responsabilidad, la dificultad de convertir ideas en noticias y el desconocimiento social sobre este tipo de cuestiones.

Como hemos visto en el punto anterior, la RSE cuenta ya con un extenso desarrollo, lo que ha permitido la puesta en marcha de diferentes herramientas de comunicación. En este sentido, desde la Escuela de Valencia González y García Marzá (2006) destacan el interés de hacer extensibles a otros grupos de interés las herramientas de comunicación que ya se han demostrado útiles en la relación entre las empresas y los accionistas. Se trata de mecanismos de comunicación como la memoria financiera y los informes trimestrales, las webs específicas, el correo electrónico, el teléfono de información, el Club del accionista, el envío de una revista interna o incluso de una publicación específica, las visitas a las instalaciones por grupos de accionistas o los programas de encuentros con directivos. Todas estas herramientas, que se han venido destinando únicamente a la comunicación con un grupo de interés concreto como son los accionistas, pueden resultar de utilidad para establecer mecanismos de comunicación con los restantes stakeholders.

A estas herramientas se unen nuevas vías y mecanismos que buscan favorecer los canales de diálogo con los stakeholders y la rendición de cuentas por parte de la empresa. Es el caso, por ejemplo, de la memoria de sostenibilidad; la realización de presentaciones; los anuarios de empresas Responsable y Sostenible; los foros; la publicación de índices éticos, sociales y de sostenibilidad; las entidades de evaluación y calificación, y las acciones de Relaciones Públicas. En cualquier caso, las herramientas de comunicación a utilizar en cada caso dependerán de numerosos aspectos como los compromisos alcanzados por la organización y sus grupos de interés, las características de cada stakeholder, etc. 
Entre las herramientas de comunicación de la RSE cabe destacar, no obstante, el avance del denominado reporting. Este tipo de informes de datos y resultados permite establecer indicadores objetivos que pueden ser comparados entre anualidades y también entre organizaciones. Además, la información sobre los hechos se establece como la mejor comunicación para los medios de comunicación y para los grupos de interés.

Más allá del reporting, Vilanova, Lozano y Dinares (2006) recuerdan que las empresas siempre han tenido que presentar informes y rendir cuentas, señalando que tradicionalmente se ha utilizado el término accountability para hacer referencia al "final de un proceso en el cual se juzga o evalúa el resultado de acciones previamente realizadas". En la actualidad, el concepto de accountability ha ido cobrando relevancia en la gestión de la RSE. Si en el enfoque tradicional (shareholder) se tomaba como único público a los accionistas, caracterizándose por ser un proceso en el cual las empresas debían responder por sus acciones y consecuencias; en el enfoque actual, centrado en los stakeholders, el proceso está basado en la responsabilidad que amplía sus ámbitos y grupos de interés, entendiéndose que cada individuo que se sienta o pueda verse afectado por las acciones de la empresa, puede demandar la responsabilidad de esta.

Para los citados autores, en este nuevo enfoque, el accountability se concibe como un proceso dinámico, en el cual los stakeholders pueden participar en todos los niveles de toma de decisiones de la empresa y pueden exigirle responsabilidad. Frente a esta realidad, uno de los retos que se presenta, como hemos visto, es el de la rendición de cuentas a diferentes públicos, con diversos intereses y perfiles, los cuales en ocasiones son casi desconocidos para la organización. Este enfoque de accountability requiere, por tanto, de una estructura de poder clara en la empresa, para poder definir, medir y ejercer este proceso de rendición de cuentas y evaluación de resultados (Vilanova et al, 2006).

De este modo, sitúan el marco de accountability como elemento central del diálogo entre actores sociales que adoptan diferentes estrategias para llegar a un mismo objetivo: el desarrollo sostenible dentro de un contexto de globalización. En este sentido, definen accountability como un proceso basado en la responsabilidad ante los stakeholders de la empresa, tengan o no poder sobre la misma, y que sería deseable que 
constara de algún tipo de proceso de participación de estos stakeholders. Los autores ilustran este proceso con el siguiente cuadro:

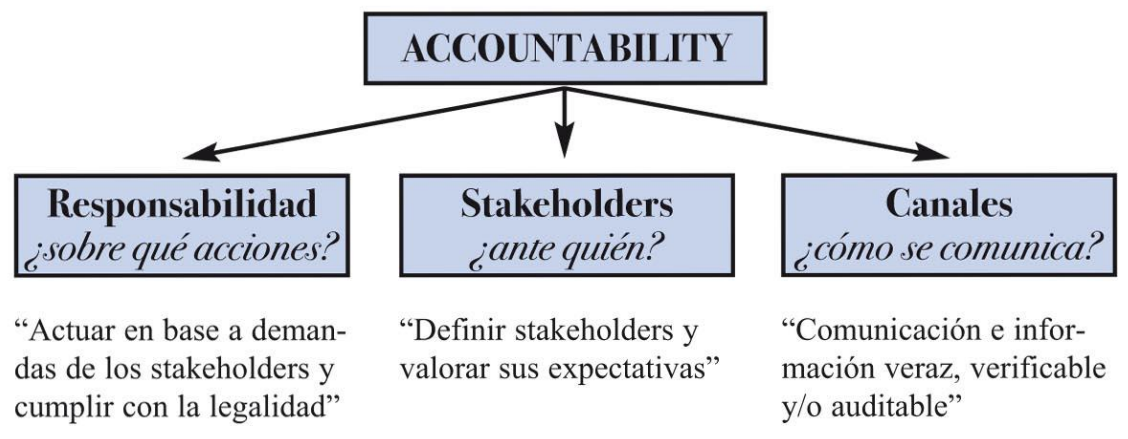

Marc Vilanova y Josep María Lozano (2005)

Según esta propuesta, el accountability implicaría implementar la RSE, definir el mapa de stakeholders y gestionar la comunicación.

El accountability implica en primer lugar implementar procesos de RSE en la empresa, en segundo lugar definir el mapa de stakeholders de la organización, y en tercer lugar establecer canales de relación, diálogo y -eventualmente- participación con dichos stakeholders (Vilanova et al, 2006:25).

Se defiende así que el proceso de accountability va mucho más allá de la preparación de un informe, y que el desarrollo adecuado del proceso requiere un alto grado de transformación de las estrategias, políticas y prácticas de la empresa. Para su desarrollo, proponen una serie de recomendaciones que en el apartado de comunicación pasan por "definir e implantar una estrategia de transparencia y comunicación creíble y acorde con el modelo de RSE y posicionamiento en relación al desarrollo sostenible”.

El modelo de accountability planteado por Vilanova, Lozano y Dinares presenta importantes puntos en común con la propuesta de gestión y comunicación de la RSE que el presente trabajo toma como referente. En cualquier caso, partiendo del término reporting o accountability, lo que parece quedar claro es que el proceso de comunicación de la RSE debe incluir la rendición de cuentas sobre las acciones desarrolladas. En este terreno, la Memoria de Sostenibilidad desarrollada por el Global Reporting Initiative (GRI) se ha posicionado como el principal estándar de información pública en materia de RSE, por lo que consideramos de interés detenernos en el mismo. 
El GRI se presenta como una organización sin ánimo de lucro cuyo fin es impulsar la elaboración de memorias de sostenibilidad en todo tipo de organizaciones. Actualmente el GRI produce un completo marco para la elaboración de memorias de sostenibilidad, cuyo uso está muy extendido en todo el mundo y que incluye la guía para la elaboración de memorias y establece los principios e indicadores que las organizaciones pueden utilizar para medir y dar a conocer su desempeño económico, ambiental y social, dando lugar al denominado como triple informe. El GRI fue fundado por CERES y el Programa de las Naciones Unidas para el Medio Ambiente (PNUMA) en el año 1997 en Estados Unidos, contando en la actualidad con oficinas regionales y una red de más de 30.000 personas en todo el mundo (Global Reporting Initiative, 2015). Los principios en los que se inspira el GRI se dividen en cuatro grupos:

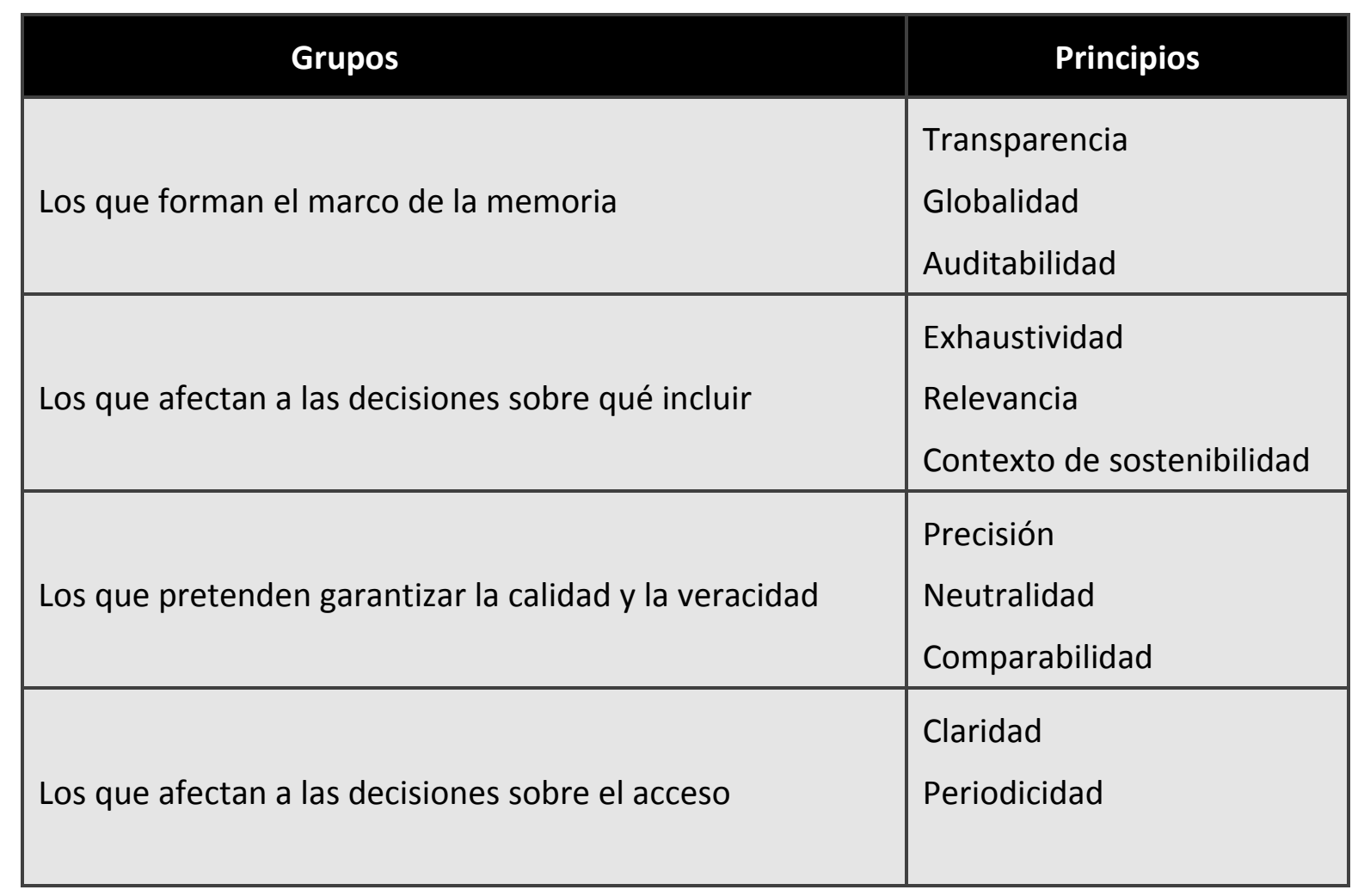

Dada la preponderancia de este tipo de memorias, y su utilidad como mecanismo para rendir cuentas ante los grupos de interés, consideramos de interés detenernos brevemente en cada uno de estos principios. Así, el principio de transparencia hace referencia a la exposición completa de los procesos, procedimientos y supuestos implicados en la elaboración de la memoria, entendiendo que esta transparencia resulta esencial para la credibilidad del informe. Al hablar de globalidad se hace referencia a la 
necesidad de que toda organización informante implique a sus partes interesadas en la ayuda al enfoque y la mejora continua de la calidad de sus memorias. También como marco de la memoria, el principio de auditabilidad supone que los datos y la información presentes en la misma deberían recopilarse, analizarse y divulgarse de modo que los auditores internos o los encargados de la verificación externa puedan avalar su veracidad.

Por lo que respecta a los principios que afectan a las decisiones sobre qué incluir en la memoria, encontramos en primer lugar el de exhaustividad, lo que supone que toda la información esencial para la evaluación por parte de los usuarios del desempeño económico, ambiental y social de una organización informante debería aparecer en la memoria de una forma coherente con el marco temporal, el alcance y los límites manifestados. La relevancia es el grado de importancia asignado a un aspecto, indicador o dato concreto, y constituye el umbral en el cual la información adquiere la suficiente trascendencia como para presentarse. Este grupo se completa con el principio de contexto de sostenibilidad, que alude a la necesidad de que las organizaciones informantes intenten situar su actuación en el más amplio contexto de restricciones o límites ecológicos, sociales o de otro tipo, en aquellos casos en los que ese contexto añada un significado importante a la información presentada.

Precisión, neutralidad y comparabilidad son los principios requeridos para garantizar la calidad y veracidad de la memoria. El objetivo del principio de precisión es el de conseguir que la información presentada ofrezca la mayor exactitud y el menor margen de error posibles, para que los usuarios puedan tomar sus decisiones con un alto grado de confianza. En cuanto a la neutralidad, desde la Guía del GRI señalan que en toda memoria deberían evitarse los sesgos en la selección y exposición de la información, y se debería tratar de ofrecer un informe equilibrado sobre la actuación de la organización informante. Por lo que respecta a la comparabilidad, establece que toda organización debería mantener la coherencia en lo referente a los límites y el alcance de sus memorias, dar a conocer cualquier cambio y volver a exponer la información presentada anteriormente.

Los principios de claridad y periodicidad marcan las decisiones sobre el acceso a la memoria. En referencia a la claridad, desde la Guía del GRI se destaca que toda organización informante debería mantenerse al corriente de las distintas necesidades y experiencias de sus partes interesadas, y poner la información a disposición de los 
usuarios de manera que resulte inteligible para el mayor número posible de éstos, manteniendo un adecuado nivel de detalle. Este principio aparece estrechamente ligado a la necesidad de establecer diálogos con los stakeholders para conocer sus expectativas y llegar a acuerdos. Finalmente, se establece que toda memoria debería ofrecer información con una periodicidad que se adapte a las necesidades de los usuarios y a la naturaleza de los datos.

Además de las memorias del GRI, el auge de la RSE ha llevado a la proliferación de diversos indicadores y normas sobre la misma a nivel internacional como es el caso del Pacto Mundial, la AA1000 AccountAbility, la SA 8000, la Norma SGE 21 o la ISO 26000. No es motivo del presente trabajo analizar cada una de ellas, más allá de la breve aproximación planteada al GRI como informe pionero y de referencia en este ámbito.

La publicación sobre La medición y la comunicación de la RSE: Indicadores y Normas, recogida en los Cuadernos de la Cátedra "la Caixa" de Responsabilidad Social de la Empresa y Gobierno Corporativo (Strandberg, 2010), alerta de que, ante el auge de este tipo de informes no financieros, "puede parecer que el foco de la RSE está en la publicación de memorias, cuando en realidad ésta sólo forma parte del proceso de integración de la RSE”. En este sentido, se hace hincapié en que el punto principal es el diálogo con los stakeholders, ratificando una vez más el punto de partida del modelo de comunicación de la RSE planteado por Fernández Beltrán. No obstante, las memorias tienen también un papel clave en la gestión de la RSE como mecanismo de rendición de cuentas y también como orientadoras para un diálogo renovado, según se destaca en el informe sobre indicadores y normas de la RSE.

En este proceso, el diálogo con los grupos de interés es parte decisiva: ellos son los afectados por las actividades de la empresa y quienes pueden afectarlas. Además, son ellos los que usarán la información publicada en las memorias. Entre los diferentes grupos, los empleados tienen un papel crucial respecto (...) Las normas tienen un valor añadido para la empresa, porque ofrecen un punto de partida para empezar a reflexionar sobre los temas sociales y medioambientales. Al mismo tiempo, pueden orientar a la empresa en la medición de la información no financiera, la elaboración de una memoria de RSE y en el diálogo con los grupos de interés (Strandberg, 2010:21).

Llevando la comunicación de la RSE al terreno de la práctica, vemos como se ratifican algunas de las consideraciones puestas de manifiesto a lo largo del presente punto. Podemos tomar como ejemplo las reflexiones realizadas por Valentín Alfaya, 
director Corporativo de Calidad, Prevención y Medio Ambiente de Ferrovial, en el marco de un Curso de Verano organizado por Foroética (Alfaya, 2006). En ellas, destacaba tres aspectos claves en la comunicación de la empresa, en particular en la comunicación que se refiere a los aspectos de la RSE: adecuación en la gestión de la comunicación, compromisos públicos verificables y prudencia.

En primer lugar, Alfaya señala que la estrategia de comunicación tiene que ser adecuada, en el sentido de adquirir la capacidad para entablar un "proceso de comunicación inteligente" con los grupos de interés. En este sentido, señala que la comunicación no puede ser un fin en sí misma "para justificar que me estoy comunicando con los grupos de interés y que hablo con ellos y les mando cuestionarios, sino un proceso de comunicación en el que ambos saquemos beneficios. Porque si no la comunicación no tiene sentido". Adecuada supone entonces que se presta a ese fin, pero también que los medios y canales de comunicación que se establecen con los grupos de interés son los más eficaces y "amables” para quien tiene interés en transmitir algún aspecto.

Desde el punto de vista de la práctica empresarial, Alfaya considera además de vital importancia la existencia de unos compromisos públicos que puedan ser verificables por terceros con el fin de asegurar que la información que se ofrece es rigurosa, "y que se cuenta todo: lo bueno y lo malo. La veracidad e integridad de la información se convierte así en un aspecto fundamental y en una ventaja”, asegura. Por último, el directivo de Ferrovial considera como un tercer aspecto igualmente fundamental la prudencia, en el sentido de ser realista y plantear unos compromisos alcanzables.

El papel de la comunicación como elemento fundamental para contribuir a una gestión más responsable se hace extensible a otros campos, más allá de la empresa. Es el caso, por ejemplo, de la comunicación ambiental, como ponen de manifiesto Olga Roger y Pilar Buil en el Manual de comunicación ambiental (2014).

Gracias a los procesos de comunicación se puede contribuir a una gestión más responsable por parte de las organizaciones y de los ciudadanos en materia de medio ambiente. En este sentido, la comunicación ambiental recurre a distintas estrategias y técnicas de comunicación con el fin de llegar a los distintos stakeholders de la organización (Roger y Buil, 2014:181).

Partiendo de estas reflexiones, a la hora de llevar a la práctica la comunicación de la RSE, resulta asimismo interesante para el presente trabajo conocer algunos de los 
proyectos en los que se ha aplicado el modelo de RSE desarrollado por la Escuela de Valencia a través del grupo de investigación "Éticas aplicadas y democracia" que aglutina a investigadores de la Universitat de Valencia, la Universitat Jaume I, la Universitat Politécnica de Valencia, la Universidad de Murcia y la Fundación ÉTNOR para la Ética de los Negocios y de las Organizaciones. Desde este grupo de investigación se ha prestado asesoría a organizaciones en materias como la identificación de los stakeholders; la definición de los procesos de diálogo con los grupos de interés centrales y latentes; la determinación del universo de valores e intereses en juego, tanto universalizables, como grupales y particulares; el diseño de estrategias frente a cada uno de los stakeholders; el desarrollo de códigos éticos corporativos; el diseño y puesta en marcha de comités éticos corporativos; la elaboración y difusión del informe de RSC; la definición y elaboración de auditorías éticas; el diseño y desarrollo de planes de formación internos referentes al código ético de la organización y de la apuesta por la RSC, y el diseño e implantación de sistemas de comunicación internos y externos en materia de ética y RSC (González y García Marzá, 2006:166).

En un artículo publicado por Elsa González y Domingo García Marzá para una revisión crítica de la RSE desde la ética empresarial (2006), se incluyen dos de los ejemplos de experiencias con empresas desarrolladas por este grupo de investigación: Unión de Mutuas y Mercadona. En el caso de Unión de Mutuas, empresa dedicada a la prestación de servicios sanitarios para empresas, la labor de asesoría incluyó en un primer momento el desarrollo de un plan integral de ética y RSC que permitió definir los stakeholders de la corporación, delimitar las expectativas en juego y diseñar e implementar el código ético de Unión de Mutuas que fue comunicado interna y externamente y en el que se formaron todos los mandos intermedios de la organización. A partir del trabajo realizado, la empresa pasó a contar con un comité de ética, informes de RSC y auditorías éticas. El código ético de Unión de Mutuas está estructurado en tres principios, diez valores y ocho compromisos revisables y actualizables. Un comité de ética se encarga de supervisar y asesorar acerca de cualquier conflicto que pudiera surgir en la práctica diaria de la empresa con respecto al contenido del código ético, así como de cualquier conflicto planteado por los stakeholders.

Las acciones recogidas en este artículo de 2006 respecto al desarrollo de un proceso de RSE tienen su continuidad en la actualidad con nuevas acciones que 
permiten seguir avanzando en el proceso circular del modelo de comunicación de la RSE planteado. En este sentido, cabe señalar el desarrollo en 2015 del proyecto "Diálogo con los Grupos de Interés para determinar la materialidad de los impactos en materia Ética y RSE en Unión de Mutuas”. Entre los objetivos de este proyecto, en el que he tenido la oportunidad de participar como investigadora, se encuentra, en primer lugar, dialogar con los Grupos de Interés para determinar el grado de materialidad que le dan a los aspectos evaluados como relevantes en Unión de Mutuas en un proyecto previo. Para establecer este diálogo se ha recurrido a la técnica de focus group con los principales stakeholders. Un segundo objetivo del proyecto pasa por revisar la materialidad de Unión de Mutuas en materia de Ética y RSE dando lugar a una base para la toma de decisiones en materia de RSE alineadas con su Plan Estratégico 20142016, su Plan de RSC 2014-2016 y sus Grupos de Interés.

Otra empresa con la que ha trabajado en materia de RSE el grupo de investigación es la cadena de supermercados Mercadona (González y García Marzá, 2006). Su modelo de gestión se basa en la creencia de que el cliente es el principal stakeholder, y para darle satisfacción es fundamental que la empresa dé apoyo, en este orden de prioridad, a los trabajadores, los proveedores, la comunidad local y el capital de la empresa. En el año 2002 la empresa consideró que era necesario evaluar si sus apuestas en materia de valores y de responsabilidad social estaban siendo percibidas positivamente por sus stakeholders por lo que el grupo de investigación desarrolló una auditoría ética con el objetivo de reflejar el grado de cumplimiento de las diferentes expectativas sociales de las que depende la confianza depositada en la empresa. "La auditoría ética fue para la empresa Mercadona todo un proceso de aprendizaje acerca de su gestión de la RSC así como de su relación con los distintos stakeholders", un proceso que ha mantenido asimismo en años posteriores.

Volveremos al modelo de RSE y de su comunicación propuesto por la Escuela de Valencia en el tercer bloque de la tesis, como referentes a la hora de establecer una propuesta de definición de la RRI desde la ética, así como para sentar las bases para un modelo de comunicación de la Investigación e Innovación Responsable. 


\subsection{RRI, EL ESTADO DE LA CUESTIÓN}

Como hemos visto, el concepto de RRI ha surgido con fuerza en el ámbito de la ciencia y la innovación en los últimos años, especialmente en la Unión Europea, dónde el programa Horizonte 2020 considera ya que se trata de una acción transversal que debe estar presente a lo largo de todo el proceso.

En un primer momento realizaremos un repaso a las principales definiciones que hasta la fecha se han realizado de la RRI. Posteriormente se analizan las razones que han favorecido el auge de la RRI en la última década y se presentan las principales contribuciones teóricas desarrolladas por autores como Stilgoe, Carsten y Owen. En un apartado sobre la RRI no puede faltar tampoco un completo análisis sobre el papel que ha jugado la Unión Europea en su desarrollo, así como algunos ejemplos de políticas de RRI llevadas a cabo, aspectos con los que se cerrará el presente apartado.

La Unión Europea señalaba en las conclusiones del encuentro celebrado en Bruselas en 2011 con el fin de potenciar la Investigación y la Innovación Responsable que "la RRI hace referencia a intentar mejorar y anticipar los problemas, teniendo en cuenta factores sociales, éticos y medioambientales y ser capaz de crear sistemas flexibles y adaptables para hacer frente a estas consecuencias no deseadas". Podemos considerar que este Research Workshop on Responsible Research and Innovation in Europe celebrado en 2011 fue un paso fundamental a la hora de sentar las bases del ámbito de la RRI y de su futuro en Europa.

Como veremos, el papel de la Unión Europea ha sido clave en el desarrollo y definición del concepto de RRI. Pero previamente, entendemos que resulta de interés conocer algunas de las definiciones planteadas por diversos autores. A partir del taller celebrado en mayo de 2011, en el que expertos y políticos reflexionaron entorno a la RRI, Hilary Sutcliffe realiza un informe en el que señala que el concepto de RRI hace referencia a cuestiones como los avances en investigación e innovación para alcanzar un beneficio social o medioambiental; la necesidad de potenciar la participación de la sociedad en todo el proceso de investigación; la evaluación de los efectos, riesgos y oportunidades de los avances de la ciencia para el presente y el futuro; el desarrollo de mecanismos de supervisión capaces de anticiparse y de responder con rapidez; la apertura y la transparencia como componentes integrales del proceso de investigación y la innovación (Sutcliffe, 2011). 
Por su parte Gilles Laroche, jefe de la Unidad de Gobierno y de Ética de la Dirección General de Investigación e Innovación de la Unión Europea, considera que la definición de RRI hace referencia a cuestiones como los resultados o productos, en términos de sostenibilidad, seguridad y aceptabilidad ética; los procesos y su calidad, teniendo en cuenta la participación de los interesados en base a los principios de rendición de cuentas y transparencia; y la recomendación de utilizar métodos participativos y multidisciplinares (Laroche, 2011).

En las jornadas EscoLab sobre Investigación e Innovación Responsable se definía la RRI como un proceso transparente e interactivo en el que los actores sociales y los innovadores participan activamente en la construcción de conocimiento y dialogan en términos de aceptabilidad ética, sostenibilidad y conveniencia social de la investigación, la innovación y sus productos comercializables (Cresa.cat, 2014).

Una de las definiciones más completa y consolidadas es la desarrollada por Schomberg en la que se hace hincapié en la necesidad de aceptabilidad y deseabilidad de los procesos de investigación por parte de los diferentes actores sociales:

\footnotetext{
Un proceso transparente e interactivo mediante el cual los actores sociales y los innovadores se vuelven solidarios entre sí con vistas a la (ética) la aceptabilidad, la sostenibilidad y la deseabilidad social del proceso de innovación y sus productos negociables (con el fin de permitir una inclusión adecuada de los avances científicos y tecnológicos en nuestra sociedad) (Schomberg, 2011).
}

La definición de Schomberg apunta a que la RRI se refiere al proceso y el producto de la innovación y su objetivo es lograr resultados aceptables e incluso deseables. Para lograr esto, la RRI necesita comprometerse con las posibles consecuencias de la investigación y la innovación a través de procesos de prospectiva y evaluación. Parte de la definición incluye el compromiso público de los diferentes grupos de interés, entre los que se incluyen investigadores y financiadores de investigación, así como la sociedad civil y los responsables políticos (Carsten, 2013).

Para los investigadores del proyecto RRI Tools, la definición de Schomberg destaca también como la transparencia y la interactividad son características importantes de un proceso de investigación e innovación responsables. Por otra parte, los actores involucrados deben tener sensibilidad mutua. El propósito del proceso y por lo tanto el resultado de la RRI serán entonces procesos y productos aceptables y socialmente deseables (RRI Tools, 2015). Abordaremos más ampliamente la perspectiva planteada 
por Schomberg más adelante, cuando nos detengamos en algunas de las principales aproximaciones teóricas a la RRI.

Por su parte, Stilgoe pone el acento en los procesos políticos y administrativos de la ciencia, tomando como punto de partida la participación colectiva para alcanzar un desarrollo futuro exitoso.

La innovación responsable significa cuidar del futuro a través de la administración colectiva de la ciencia y la innovación en el presente (J. Stilgoe et al., 2013:1570).

Bernd Carsten Stahl aporta una nueva visión al definir la RRI como una responsabilidad de alto nivel o meta-responsabilidad, encaminada a formar, mantener, desarrollar, coordinar y alinear los procesos, actores y responsabilidades existentes y nuevos relacionados con la investigación y con la innovación, con el fin de garantizar los resultados de investigación deseables y aceptables .

This paper defines RRI as a higher-level responsibility or meta-responsibility that aims to shape, maintain, develop, coordinate and align existing and novel research and innovation-related processes, actors and responsibilities with a view to ensuring desirable and acceptable research outcomes (Carsten, 2013:708).

Como veremos posteriormente de forma más amplia, Carsten considera que hay una gran cantidad de actividades, actores y normas que ya están configurados en relaciones de responsabilidad, por lo que defiende que la RRI no es tanto un nuevo tipo de responsabilidad como una meta-responsabilidad, es decir, una responsabilidad para el mantenimiento, desarrollo y coordinación de las responsabilidades existentes.

Desde el proyecto RRI Tools, que como veremos más adelante trata de desarrollar herramientas para la gestión y desarrollo de la RRI, consideran ésta como un concepto "paraguas", que incluye una amplia gama de nociones encontradas en la literatura académica y los informes oficiales. Lo que estas nociones tienen en común es que todos se esfuerzan por crear prácticas responsables en la investigación e innovación. Así, a expensas de continuar con el trabajo de indagación y deliberación entorno a este concepto, señalan que la RRI puede ser también entendida como el cambio de las responsabilidades individuales a las colectivas.

Por lo tanto, la RRI se puede entender como un cambio de responsabilidad: el cambio de pensar en términos de responsabilidad individual y sobre las consecuencias, a pensar en procesos y responsabilidad repartidas y colectivas (RRI Tools, 2015). 
Entrando en la visión que la Comisión Europea ha desarrollado de la RRI, cabe hacer referencia a la definición recogida en la publicación Responsible Research and Innovation. Europe's ability to respond to societal challenges editada en 2012. Según la misma, la Investigación e Innovación Responsable hace referencia a que los actores de la sociedad trabajen juntos durante todo el proceso de investigación e innovación con el fin de alinear mejor los procesos y sus resultados con los valores, necesidades y expectativas de la sociedad europea. El organismo europeo reconoce que se trata de un reto ambicioso que requiere de la participación de los diferentes actores sociales.

\footnotetext{
Responsible Research and Innovation means that societal actors work together during the whole research and innovation process in order to better align both the process and its outcomes, with the values, needs and expectations of European society. RRI is an ambitious challenge for the creation of a Research and Innovation policy driven by the needs of society and engaging all societal actors via inclusive participatory approaches (Publications Office, UE, 2012).
}

Para la Unión Europea, y según queda recogido en esta misma publicación, la RRI se fundamenta en seis elementos clave: la participación pública, la educación científica, la igualdad de género, el acceso abierto a la información científica, la ética y el buen gobierno. Para comprender el concepto de RRI desde la perspectiva de la UE resulta de interés analizar la visión que ofrece de cada una de estas claves.

- Participación pública: Elegir juntos. La primera clave es el compromiso de todos los actores sociales, incluidos los investigadores, la industria, los responsables políticos y la sociedad civil, y la articulación de su participación en los procesos de innovación e investigación, de acuerdo con el valor de la inclusión recogido en la Carta de Derechos Fundamentales de la Unión Europea. Para la UE, el desarrollo de un marco sólido para la excelencia en la Investigación e Innovación implica que los retos sociales se enmarquen en una amplia representación social. Esto requiere del desarrollo de prácticas acordadas conjuntamente para desarrollar Investigación e Innovación Responsable que haga frente a los problemas y las oportunidades de la sociedad.

- Igualdad de género: Desbloquear el potencial. La segunda clave es la igualdad de género, entendiendo que compromiso significa que todos los actores, mujeres y hombres, estén implicados. Para ello debe abordarse la baja representación de las mujeres, de forma que la dimensión de género debe estar integrada en el proceso de RRI. 
- Educación científica: El aprendizaje creativo. Europa no sólo debe aumentar su número de investigadores, sino que también tiene que mejorar el sistema educativo actual para dotar a los futuros investigadores y a los demás miembros de la sociedad de los conocimientos y las herramientas necesarias para participar plenamente y tomar decisiones responsables respecto a los procesos de innovación e investigación. La publicación europea destaca la necesidad urgente de aumentar el interés de la infancia y la juventud por la ciencia y la tecnología para que puedan llegar a ser los investigadores e investigadoras del mañana y contribuir a la alfabetización científica de la sociedad. Como veremos en el siguiente capítulo, esta necesidad de contribuir a una mayor cultura científica que capacite a la ciudadanía en la toma de decisiones es precisamente una de las principales razones aducidas por científicos, comunicadores y teóricos para potenciar la Comunicación Pública de la Ciencia.

- Acceso abierto a la información científica: Compartir los resultados para avanzar. La UE deja claro que para ser responsable, la investigación y la innovación deben ser transparentes y accesibles. Por ello, la cuarta clave que establece es que el acceso abierto sea una realidad. Esto significa ofrecer on line y sin coste alguno el acceso a los resultados de las investigaciones realizadas con financiación pública, tanto a las publicaciones como a los datos resultantes. Esto permitirá incrementar las posibilidades de uso de los resultados científicos por parte de todos actores sociales.

- Ética: Realizar el pensamiento correcto y hacer las cosas bien. La quinta clave es la Ética. La publicación de la UE resalta el hecho de que la sociedad europea se basa en compartir valores. Con el fin de responder de manera adecuada a los retos sociales, la investigación y la innovación deben respetar los derechos fundamentales y los más altos estándares éticos. Más allá de los aspectos legales de obligado cumplimiento, se debe garantizar la relevancia social y la aceptabilidad de los resultados de investigación e innovación. Así, se destaca que la ética no debe ser percibida como una restricción, sino más bien como una forma de garantizar resultados de alta calidad.

In order to adequately respond to societal challenges, research and innovation must respect fundamental right sand the highest ethical standards. Beyond the mandatory legal aspects, this aims to ensure increased societal relevance and acceptability of 
research and innovation outcomes. Ethics should not be perceived as a constraint to research and innovation, but rather as a way of ensuring high quality results (Publications Office, UE, 2012).

- Buen gobierno: Diseñar la ciencia para y con la sociedad. La última dimensión, la gobernanza, supone un paraguas para todas las anteriores. En este punto, la UE hace hincapié en la responsabilidad de las autoridades a la hora de evitar desarrollos perjudiciales o poco éticos en la investigación y la innovación.

Más allá de las definiciones del concepto de RRI, para conocer el estado de la cuestión resulta asimismo de interés analizar algunas de las aproximaciones teóricas que entendemos de mayor relevancia respecto a la RRI y a las que dedicaremos el siguiente punto.

\subsubsection{El estado de la cuestión, planteamientos teóricos}

El auge de la RRI ha llevado a que en los últimos años hayan surgido una serie de aproximaciones teóricas a este fenómeno que aportan perspectivas de gran interés para seguir profundizando en un concepto sobre el que todavía no parece existir un consenso general, pero que en cualquier caso tiene en la ética, la participación, la comunicación y la búsqueda de resultados socialmente aceptables algunas de sus claves. A continuación nos detenemos en los planteamientos teóricos desarrollados por autores como Stilgoe, Carsten, Owen, Macnaghten o Schomberg que están ayudando a sentar las bases teóricas de la RRI. Finalizaremos el presente apartado con una referencia al proyecto europeo RRI Tools en su búsqueda de una aproximación a la RRI desde la que avanzar en el desarrollo de herramientas para su gestión.

\section{- La RRI como reto para la democracia}

Jack Stilgoe destaca la gobernanza de la ciencia y la innovación como un reto importante para la democracia, reto que se enmarca para el autor en los esfuerzos encaminados hacia la innovación responsable. En "Developing a framework for responsible innovation" Stilgoe, Owen y Macnaght (2013) parten de la base de que las concepciones de la responsabilidad deberían basarse en la comprensión de que la 
ciencia y la tecnología no están constituidas sólo técnicamente, sino también social y políticamente. Las preocupaciones públicas entorno a la ciencia no pueden reducirse únicamente a cuestiones de riesgo, sino que deben abarcar una gama de preocupaciones relacionadas con los fines y motivaciones de la investigación, uniéndose a una corriente de debate de las políticas sobre las direcciones de la innovación.

Los autores señalan entre las dimensiones de la RRI la anticipación en la gobernanza, la reflexividad de agentes e instituciones, la inclusión de nuevas voces y la capacidad de respuesta en los sistemas de innovación. Para Stilgoe, Owen y Macnaght, a pesar de los esfuerzos actuales en la ampliación de la participación, las formas de regular la gobernanza de la ciencia ofrecen poco margen para una amplia reflexión ética sobre los propósitos de la ciencia o la innovación (Stilgoe et al, 2013:1569), consideración que viene a reforzar la importancia de trabajos como el que nos ocupa, que plantea precisamente una reflexión sobre el marco ético de la Investigación e Innovación Responsable.

\section{- La RRI como meta-responsabilidad}

Carsten realiza una interesante aproximación al concepto de RRI como una metaresponsabilidad que engloba responsabilidades ya existentes junto a otras nuevas. El autor señala entre las razones originarias del surgimiento de la responsabilidad de la ciencia, la necesidad de abordar los riesgos de la investigación y evitar los resultados negativos, destacando que posteriormente la RRI adoptó un mandato más amplio. Para el autor, las sociedades se apoyan en la investigación y la innovación para resolver sus problemas, pero al mismo tiempo son conscientes de la necesidad de tener en cuenta las consecuencias futuras de las mismas. Las incertidumbres futuras y los retos que tratan de abordar la investigación y la innovación son de naturaleza global. Carsten considera que la razón del crecimiento exponencial de la RRI se encuentra en el incremento de la importancia de la investigación y la innovación unida a la disminución de la capacidad de los gobiernos para dirigirlas (Carsten, 2013).

El autor hace hincapié en la multiplicidad de componentes de la RRI, planteando la Investigación e Innovación Responsable como un espacio constituido por tres dimensiones: las actividades, los actores y las normas, que representa gráficamente a través de la siguiente figura. 
Different Attempts to Graphically Represent the Space of RRI.
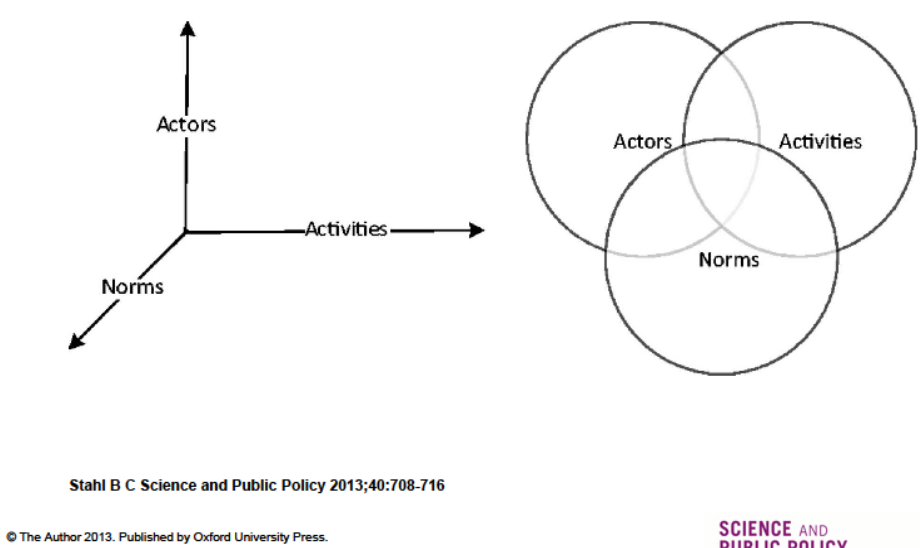

SCIENCE AND
PUBLIC POLICY

(Carsten, 2013)

En la dimensión de actividades, el autor resalta que existen una amplia gama de procesos y actividades que ya están establecidas como los códigos éticos o la formación en valores. Es el caso también, por ejemplo, de diferentes mecanismos de evaluación de la responsabilidad como la evaluación de riesgos integrada en algunas investigaciones, que supone además un mecanismo de gobernabilidad (Owen y Goldberg, 2010); o la denominada Evaluación Tecnológica, una corriente que abarca la evaluación de impacto entre otros aspectos. Las evaluaciones ponen el foco en numerosas ocasiones en los sucesos futuros, teniendo por tanto un carácter prospectivo. Respecto a la dimensión de actividades, el autor también recoge la necesidad de implicar a todos los afectados y a lo largo de todo el proceso, lo que permite recurrir a numerosas actividades y es en este punto en el que la democracia deliberativa encuentra su conciliación con la RRI (Schomberg, 2012). Para ser responsables, las actividades de investigación tienen que estar además abiertas al escrutinio externo, lo que incluye el sometimiento a revisiones éticas, cumplimiento de estándares de integridad, etc., apostando por una reflexividad interna. En este sentido, el autor señala que para comprender los problemas éticos y explorar las consecuencias de la investigación, resulta conveniente integrar de forma explícita los mecanismos de reflexión en los proyectos.

Research activities, in order to count as responsible, need to open up to external scrutiny. Some aspects of the processes related to RRI are open to external aims and thus to scrutiny by bodies independent of the actual research. This refers to activities such as ethics reviews which are normally done by external bodies as well as standards of research integrity, which govern research in many areas. In addition to such external scrutiny, research needs to develop internal 
reflexivity. In order to understand ethical issues and explore the assumptions and consequences of research, it is desirable to integrate mechanisms of explicit reflection into projects (Carsten, 2013).

En la segunda dimensión, referente a los actores, el autor destaca la amplitud de los mismos, planteando una serie de grupos que veremos más ampliamente en el apartado correspondiente a stakeholders. Carsten pone el foco en el hecho de que las diferentes actuaciones requieren la participación de diferentes actores, poniendo como ejemplo el caso de la educación.

Education, for example requires the individual researcher's engagement, it requires a legal framework, often supported by professional bodies and is implemented by educational organisations. Thus, there is a complex relationship between actors and their activities (Carsten, 2013).

Por lo que respecta a la dimensión de las normas, señala que para poder evaluar si un determinado tipo de investigación es deseable o aceptable, la RRI necesita unos principios normativos fundamentales. Sin embargo, esto choca con el problema de la fragmentación de la autoridad moral. La globalización, el liberalismo y el mayor desarrollo de las sociedades occidentales durante el siglo XX han eliminado cualquier consenso moral que las sociedades pudieran haber tenido en el pasado, asegura Carsten. El autor hace referencia a algunas de las normas existentes en las que se puede asentar la RRI, como los tratados europeos en el ámbito de la UE o los Derechos Humanos a nivel global. Como marco más amplio, señala que la fuente más obvia de las normas para la RRI se encuentra en la tradición milenaria de la ética filosófica y sus desarrollos más actuales que pueden ser aplicables a la Investigación e Innovación Responsable. En nuestro caso esta tradición filosófica se concreta en la ética del discurso, siguiendo la línea argumental planteada en el primer capítulo de este bloque.

El principio fundamental de gobierno que informa a los principios y procesos de RRI es el de la democracia (Gutan, 2011). Para Carsten la referencia a la democracia explica aspectos clave de la RRI como son la participación pública, el énfasis en los grandes retos o el principio de rendición de cuentas. Además conlleva principios de administración pública de relevancia para la RRI como son la transparencia. En un análisis más profundo, el autor señala que sería necesario determinar qué modelo de gobierno democrático puede conducir al acuerdo sobre bases normativas. En este sentido, resalta que existe un acuerdo casi unánime sobre la necesidad de que la 
participación en los procesos de investigación e innovación forme parte de la RRI pero permanece abierta la pregunta de por qué esto es así y la forma en que se puede lograr.

For example, there is almost unanimous agreement that participative activities in research and innovation should form part of RRI. At the same time the question of why this is so and how it can be achieved remains open. Participation as a mechanism of research and innovation governance can run counter to established mechanisms of representative democracy. On a practical level, it is not clear how participation in research and innovation is to be organised (e.g. should it happen on a project level, on a programme level, who is responsible for it), who should participate or how participation is to be evaluated (Carsten, 2013).

La existencia previa de actividades, actores y normas configurados en relaciones de responsabilidad lleva a Carsten a definir la RRI como una meta-responsabilidad para el mantenimiento, desarrollo y coordinación de las responsabilidades existentes. Su novedad radica para el autor en el hecho de que coordina las responsabilidades existentes y mejora las condiciones para un mejor desarrollo. Por tanto, se trata de poner en relación las diferentes responsabilidades ya existentes, como la responsabilidad de la fuente de financiación para la asignación eficiente de los recursos o la responsabilidad del investigador de mantener la integridad de la investigación, etc., alineándolas con nuevas responsabilidades para atender a los retos sociales más amplios que pretende abordar la RRI (Carsten, 2013).

Entre los problemas a los que se enfrenta la RRI, el autor destaca las posibles resistencias por parte de algunos grupos de interés o las posturas contradictorias entre los mismos que puedan resultar imposibles de mediar, por lo que subraya que la RRI tampoco puede ser vista como la panacea. Así, advierte que no será capaz de prevenir las consecuencias negativas de la investigación, ni eliminará la controversia de los debates. En este sentido, señala la necesidad de ver la RRI como una manera de tomar mejores decisiones sobre cuestiones controvertidas, poniendo el foco en el proceso de discusión, tal y como se defiende a lo largo del presente trabajo.

\footnotetext{
It is therefore important to stress that RRI is no panacea. It will not be able to prevent all the negative consequences of research and innovation. It will not remove the need to have controversial debates about desirable futures and the role that research and innovation can play in them. [...] RRI should be seen as a way to make better decisions on contested questions. In this spirit, RRI will be a resource of creativity that will allow stakeholders to improve the quality of debate and thereby contribute to better and more standardised decisions about contested developments. (Carsten, 2013)
} 
Finamente, entre las aportaciones del autor cabe destacar, además de la concepción de la RRI como una meta-responsabilidad, la defensa de que ésta debe ser de naturaleza reflexiva, de modo que parte de la RRI incluye considerar y reflexionar sobre sus propios supuestos, presupuestos y consecuencias.

\section{- De la ciencia en sociedad a la ciencia con y para la sociedad}

De cara a avanzar en el conocimiento del estado de la cuestión de la RRI, resulta también de interés acercarse a la aproximación planteada por Owen, Macnaghten y Stilgoe sobre el paso de la ciencia en sociedad a la ciencia con y para la sociedad. En el artículo "Responsible research and innovation: From science in society to science for society, with society" (2012), los autores destacan la rápida evolución del concepto de RRI sobre el que se mantienen importantes ambigüedades en cuando a la motivación, la conceptualización teórica y la traducción a la práctica. No obstante, y a pesar de las incertidumbres de esta primera etapa, señalan que se pueden identificar ya algunas características distintivas de la RRI entre las que destacan tres: la democratización de la gobernanza de la intención, la institucionalización de la sensibilidad y el replanteamiento de la responsabilidad (Owen et al, 2012:754).

La primera característica, la democratización de la gobernanza de la intención, pone el acento en la ciencia "para" la sociedad y tiene que ver con los efectos de la ciencia y la innovación, y las motivaciones subyacentes de las mismas. Se trata de la decisión de qué se quiere que se haga. Los autores destacan éste como un punto de partida importante para la RRI, que plantea cómo identificar los objetivos de forma ética, incluyente, de manera democrática y equitativa. Se pide la deliberación inclusiva en relación con la dirección en la que ha de avanzar la ciencia y la innovación con el fin de que se oriente desde un principio hacia fines socialmente deseables. Esto puede generar una tensión entre el principio de participación y el de libertad científica, que no es nueva, pero que en la RRI cobra una especial relevancia. Si bien el interés social ha sido habitualmente tenido en cuenta en la financiación de los proyectos, ahora se pide la participación de los públicos y los interesados en la formulación de los grandes retos, desarrollando un marco de gobernanza más generalizada. En cualquier caso, los autores defienden que la negociación sobre los impactos adecuados de la ciencia es intrínsecamente una decisión política, que implica consideraciones de poder, de democracia y de valores. Así, para los autores la RRI no puede ser disociada de su 
contexto político, requiriendo de procesos de reflexión inclusiva y de democracia deliberativa (Owen et al, 2012: 754), lo que viene a reafirmar el marco ético y político de la RRI propuesto en la presente tesis.

Como segunda característica, los autores señalan lo que denominan la institucionalización de la sensibilidad que recoge la idea de ciencia "con" la sociedad. En este punto se hace hincapié en la integración e institucionalización de los mecanismos establecidos de anticipación, reflexión y deliberación inclusiva alrededor de los procesos de investigación e innovación. Esta dimensión recoge en primer lugar la necesidad de anticipar las posibles consecuencias. En segundo lugar, el tener que reflexionar sobre los propósitos subyacentes, las motivaciones, los impactos potenciales, lo que se conoce y lo que no se sabe, las incertidumbres asociadas, los riesgos, las preguntas y los dilemas éticos. En tercer lugar, destacan la necesidad de abrir esta reflexión a la deliberación colectiva a través de procesos de diálogo con las diferentes partes interesadas. A pesar de que estos aspectos tomados por separados no son nuevos, la aportación de la RRI radica en su acoplamiento integrado (Owen et al, 2012: 754).

El replanteamiento de la responsabilidad es la tercera característica señalada. Los científicos y científicas ya tienen responsabilidades, incluidas las asociadas con los conceptos de integridad de la investigación. Sin embargo, la RRI les confiere nuevas responsabilidades (Douglas, 2003). Y no sólo al colectivo científico, sino también a otros actores como las universidades, los innovadores e innovadoras, las empresas, los responsables políticos y los financiadores de investigación. Se trata de reevaluar el concepto de responsabilidad y de repensar las funciones de cada uno de los diferentes actores, aspectos en los que el presente trabajo busca realizar aportaciones que puedan resultar de interés desde el marco de la ética del discurso.

This is prompting a re-evaluation of the concept of responsibility as a social ascription in the context of innovation as a future oriented, uncertain, complex and collective endeavour. This, in turn, is challenging scientists, innovators, business partners, research funders and policy-makers to reflect on their own roles and responsibilities, acknowledging that the irresponsibility in innovation is a manifestation of the ecosystem of innovation and requires a collective, institutionalized response, if this is indeed possible (Owen et al, 2012: 754).

De este modo, la propuesta de los autores pasa por poner el énfasis en la ciencia para la sociedad, centrándose en la investigación e innovación enfocada a los mayores retos y los "impactos adecuados", respaldada por una democracia deliberativa. Además, 
la ciencia con la sociedad, pone el acento en la necesidad de que la deliberación y la reflexión se unan a la acción, para lo que resulta necesaria asimismo una adecuada capacidad de respuesta institucional. El artículo enmarca además la responsabilidad en un contexto de investigación e innovación como actividades colectivas con consecuencias inciertas e impredecibles, retando a científicos, innovadores, socios empresariales, financiadores de investigación y responsables políticos a reflexionar sobre sus propios roles y responsabilidades.

\section{- Productos y procesos: dimensiones interrelacionadas}

Schomberg (2013) plantea en "A vision of Responsible Research and Innovation" una definición y un marco normativo de la RRI que parte en gran medida de una prospectiva de la política europea en esta materia. Para el autor la RRI debe entenderse como una estrategia para que los interesados en materia de ciencia e innovación respondan mutuamente, compartiendo la responsabilidad ante las respuestas a los grandes retos de nuestro tiempo.

Para el desarrollo de un marco para la RRI, Schomberg parte de dos preguntas que considera claves: ¿Podemos definir los resultados e impactos correctos de la investigación y la innovación? ¿Posteriormente, podemos conseguir tener éxito en dirigir la innovación y la investigación hacia esos resultados si lo hacemos poniéndonos de acuerdo sobre los mismos?

De cara a articular los "impactos correctos" que permitan guiar los programas de investigación públicos en el ámbito europeo, Schomberg considera que se puede encontrar una base para los mismos en el Tratado de la Unión Europea cuyos objetivos normativos han sido democráticamente acordados y proporcionan por tanto una base legítima para un marco público de los programas de investigación europeos. Del artículo 3 de este tratado se pueden derivar algunos aspectos clave, como que la Unión Europea trabajará para un desarrollo sostenible de Europa basado en el equilibrio del crecimiento económico y la estabilidad de precios, una economía social de mercado altamente competitiva, con el objetivo de alcanzar el pleno empleo y el progreso social, y un alto nivel de protección y mejora de la calidad del medio ambiente. Asimismo, se establece que se promoverá el progreso científico y tecnológico 
El artículo 3 establece también que la UE combatirá la exclusión social y la discriminación y fomentará la justicia social y la protección, la igualdad entre mujeres y hombres, la solidaridad entre las generaciones y la protección de los derechos del niño. Incluye además entre los objetivo de la UE el de promover un desarrollo armonioso, equilibrado y sostenible de las actividades económicas, un alto nivel de empleo y de protección social, la igualdad entre hombres y mujeres, un crecimiento sostenible, un alto grado de competitividad y de convergencia de los resultados económicos, un alto nivel de protección y mejora de la calidad del medio ambiente, la mejora del nivel y la calidad de vida y la cohesión y solidaridad económica y social entre los Estados miembros.

Para Schomberg, el Tratado ofrece puntos de anclaje normativos en la búsqueda de "impactos correctos" y la relación mutua entre ellos entiende que proporciona una base legítima para definir el tipo de impactos, o los impactos legítimos, que la investigación y la innovación deben perseguir. Se trata además de aspectos de base normativos que tienen impacto más allá del ámbito de la UE ya que los compromisos de la Unión a la hora de promover los derechos humanos y demostrar solidaridad con los más pobres en la tierra tienen su reflejo necesariamente en sus políticas internacionales. Llevado al terreno de la investigación e innovación internacionales, supone abordar el tema de las "brechas tecnológicas" entre países y la necesidad de buscar ampliar el beneficio compartiendo el avance científico y tecnológico. Schomberg recoge estos puntos de anclaje normativos establecidos por el Tratado de la Unión Europea en la figura que incluimos a continuación.

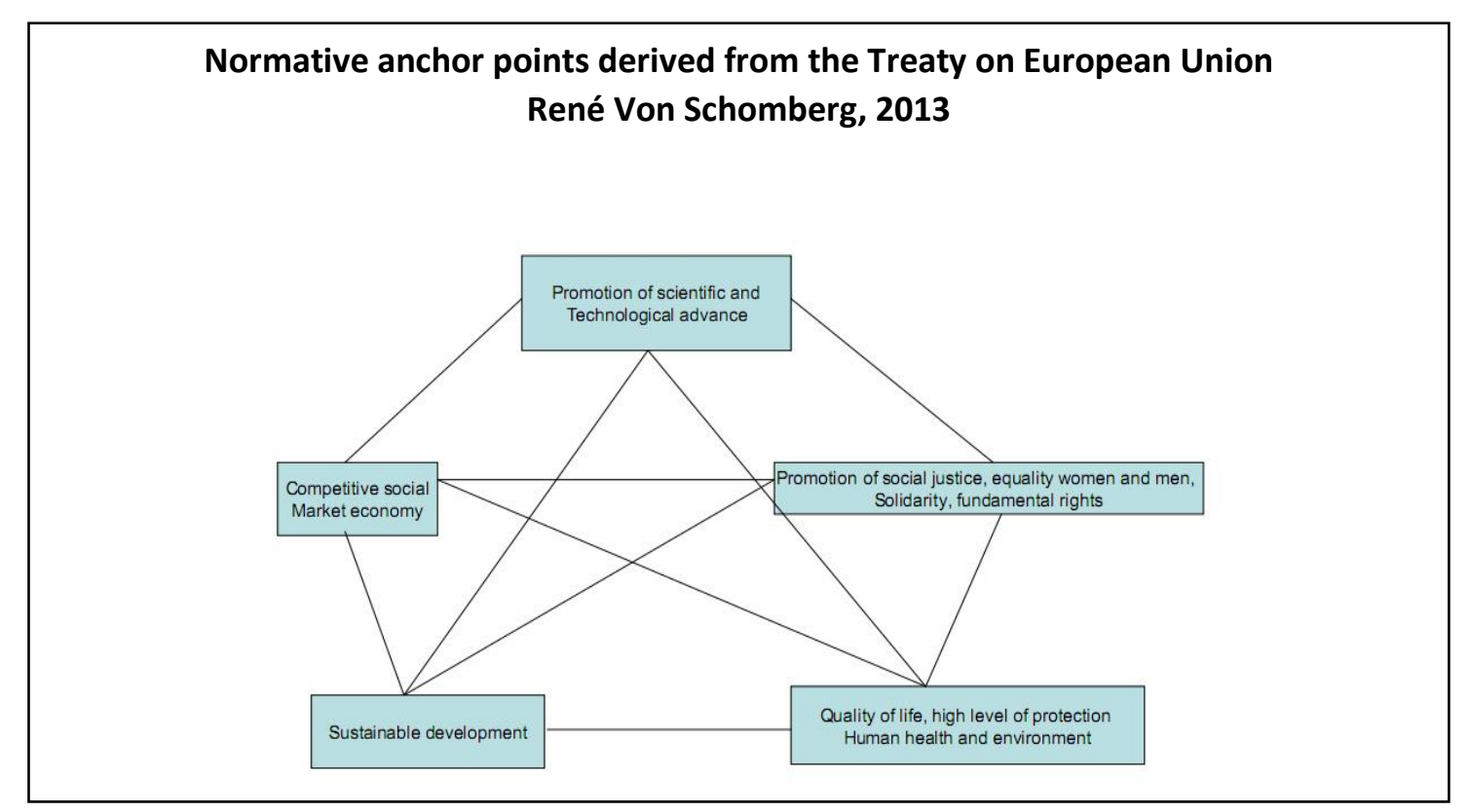


Por lo que respecta a la organización de la responsabilidad colectiva en la RRI, el autor destaca que debe tenerse en cuenta el hecho de que los impactos de la investigación y la innovación tecnológica son difíciles de predecir y de que raramente un único autor puede considerarse responsable de su utilización, incluso por parte de otros. En este sentido, señala que a menudo las consecuencias negativas no son ni previsibles ni intencionales. Entiende por tanto que una creación como Frankestein ya no puede ser en nuestros días el resultado de la locura de un científico, pero si el de la consecuencia imprevista de una acción colectiva.

The fear of a mad scientist creating a Frankenstein is not appropriate in the context of modern innovation- where knowledge is co-produced by many "authors". Modern "Frankenstein's" are not intentionally created by a single actor, but, if they arise, are more likely the unforeseen side effects of collective action. Indeed, techno-scientific applications can remain ethically problematic even in cases where scientists and engineers have the best possible intentions and users have no conscious intention to misuse or abuse. This situation constitutes the major ethical challenge we face today. An ethics focused on the intentions and/or consequence of actions of individuals is not appropriate for the innovation. There is a collective responsibility both for the right impacts and negative consequences, whether these impacts are intentional or not. This is why I have argued for the necessity of knowledge assessment procedures (Schomberg, 2013:13).

Vemos por tanto como, incluso siendo buenas las intenciones de investigadores y usuarios, los resultados pueden ser problemáticos, constituyendo esta situación un gran reto para la ética. En el actual sistema de ciencia e innovación no es suficiente, para el autor, con una ética de los individuos centrada en las intenciones o consecuencias de las acciones, sino que hay que aludir a una responsabilidad colectiva.

A partir de estas reflexiones, Schomberg plantea la siguiente definición que, como veíamos al inicio del presente apartado, se ha convertido en referente a la hora de abordar el concepto de RRI.

Responsible Research and Innovation is a transparent, interactive process by which societal actors and innovators become mutually responsive to each other with a view to the (ethical) acceptability, sustainability and societal desirability of the innovation process and its marketable products (in order to allow a proper embedding of scientific and technological advances in our society) (Schomberg, 2013:19).

La definición pone así el acento en dos dimensiones interrelacionadas: la del producto, en términos de objetivos globales y específicos; y la de los procesos, que para el autor debe estar enmarcada una democracia deliberativa. 
Centrándonos en primer lugar en la dimensión del producto, establece en su definición los siguientes puntos de anclaje normativos:

- (Éticamente) aceptable. Para el autor, en el contexto de la UE, esto hace referencia al cumplimiento de los valores fundamentales establecidos en la Carta de la UE sobre los Derechos Fundamentales (derecho a la privacidad, etc.) y al nivel de protección de seguridad establecido por la Unión, una seguridad que también debe hacer referencia al desarrollo de productos en términos de riesgos aceptables. A pesar de que las evaluaciones de riesgos son actualmente parte de los procesos de innovación, entiende que la cuestión de la seguridad debe abordarse desde una perspectiva más amplia.

- Sostenible. Schomberg hace en este punto referencia a que la dimensión de los productos tenga en cuenta la necesidad de contribuir al objetivo del desarrollo sostenible de la UE. La Unión sigue la definición de desarrollo sostenible establecida por la ONU en 1997, basada en la mutua dependencia entre las dimensiones económicas, sociales y ambientales.

- Socialmente deseable. En este apartado entiende que quedan recogidos los anclajes normativos que hemos visto que quedan establecidos en el Tratado de la Unión Europea como la calidad de vida o la igualdad entre hombres y mujeres, entre otros. La inclusión sistemática de estos referentes en el desarrollo y evaluación de productos permitiría, en opinión del autor, ir más allá de la búsqueda de rentabilidad del mercado. Para Schomberg, la RRI no requiere por tanto de nuevas directrices políticas, sino de la aplicación coherente de los fundamentos de la UE recogidos en el Tratado de la Unión Europea en el ámbito de la investigación y la innovación. El autor concluye a partir de estas reflexiones que los productos deben ser diseñados y evaluados con el fin de atender a estos puntos de anclaje normativos que pasan por un alto nivel de protección al medio ambiente y la salud humana, la sostenibilidad, y la conveniencia social.

Por lo que respecta a la dimensión del proceso, para Schomberg el reto en este caso pasa por alcanzar una gestión más responsable, adaptativa e integrada de los 
procesos de innovación, un proceso multidisciplinar y participativo que permita avanzar hacia resultados socialmente deseables.

A multidisciplinary approach with the involvement of stakeholders and other interested parties should lead to an inclusive innovation process whereby technical innovators become responsive to societal needs and societal actors become co-responsible for the innovation process by a constructive input in terms of defining societal desirable products (Schomberg, 2013: 21).

Las dimensiones de producto y de proceso están interrelacionadas, estableciendo Schomberg cinco mecanismos para su implementación que recogemos de forma resumida a continuación:

- Evaluación y prospectiva tecnológica. El uso de este tipo de evaluaciones tiene como objetivo anticipar impactos positivos y negativos o, siempre que sea posible, definir los impactos deseables de la investigación y la innovación. En este punto, el autor entiende que el establecimiento de las prioridades e impactos de la investigación debe ser supervisado por la sociedad, lo que implica una ampliación en la revisión de las propuestas de investigación que vaya más allá de la excelencia científica e incluya los impactos sociales.

- Aplicación del principio de precaución. Este principio se encuentra en la legislación comunitaria y se aplica sobre todo a los procedimientos de autorización de productos. El autor destaca que el principio de precaución funciona como un incentivo a la hora de desarrollar productos seguros y sostenibles y permite a los organismos gubernamentales intervenir en las decisiones sobre gestión de riesgos siempre que sea necesario, con el fin de evitar los impactos negativos.

- Gobernanza de la innovación. En este punto establece la necesidad de la participación de los stakeholders, el uso de códigos de conducta y la adopción de estándares, certificaciones y autoregulaciones. Dada la clara relación de este punto con el marco ético y político de la RRI propuesto, así como con el modelo comunicativo del mismo, nos detendremos a continuación en cada uno de estos tres aspectos:

- Participación de stakeholders. Schomberg considera que la RRI debe reunir a los grupos de interés del ámbito de la empresa, la sociedad civil y la ciencia para definir conjuntamente un plan de implementación para 
el desarrollo responsable de un producto en particular desarrollado dentro de un campo de investigación o innovación específico. El autor destaca en este terreno la necesidad de que los actores no se centren exclusivamente en aspectos particulares, sino que aborden todos los aspectos del proceso de innovación.

- Códigos de conducta. El autor considera que los códigos de conducta permiten la creación de una comunidad científica proactiva que identifica e informa sobre los riesgos y beneficios en una etapa temprana. Así, entiende que estos documentos son especialmente útiles cuando los riesgos son inciertos, además de ayudar a la identificación de objetivos sociales. El autor señala como ejemplo la recomendación de la Comisión Europea en el ámbito de la nanotecnología para que los estados miembros utilicen los códigos de conducta como un instrumento para fomentar el diálogo entre responsables políticos, investigadores, industria, comités de ética, organizaciones de la sociedad civil y la sociedad en general, así como parta compartir experiencias y revisar el Código de Conducta desarrollado a nivel europeo.

- Adopción de estándares, certificación y autorregulación. La adopción de normas y estándares resulta un requisito fundamental para permitir el desarrollo responsable, afirma Schomberg. El uso de estándares, certificaciones y acreditaciones constituye una nueva forma de gobernanza que el autor considera que juega un papel clave en la RRI.

- Ética como factor de "diseño" de la tecnología. En este punto, el autor pone el acento en la necesidad de que la ética no sea vista únicamente como una restricción a los avances tecnológicos al entender que la incorporación de los principios éticos en el proceso de diseño de la tecnología puede llevar a que estos avances sean aceptados por la sociedad. En este sentido, considera el aumento de la reflexión ético-social en las prácticas de la ciencia y la innovación un mecanismo necesario para el desarrollo de las dimensiones de producto y resultado.

- Mecanismos deliberativos que permitan la retroalimentación con los legisladores. En este ámbito, el autor hace énfasis en la necesidad de desarrollar 
modelos que permitan avanzar hacia una gobernanza responsable a través del compromiso y el debate público. Para Schomberg, los modelos de gobernanza responsable deben asignar los roles de la responsabilidad de todos los actores involucrados en el proceso de innovación. Idealmente, esto debería conducir a una situación en la que los actores puedan resolver los conflictos e ir más allá de sus funciones tradicionales que, para el autor, pasan por empresas centradas principalmente en aspectos sobre los beneficios y Organizaciones No Gubernamentales que abordan mayoritariamente cuestiones relacionadas con los riesgos. La corresponsabilidad implicaría aquí que los actores actuaran de forma solidaria, de forma que las empresas adoptarán una perspectiva que fuera más allá de la competitividad de mercado inmediata y las ONG reflexionarán sobre el papel constructivo de las nuevas tecnologías para el desarrollo de productos sostenibles.

Como veremos a continuación a través del proyecto RRI Tools, la visión teórica planteada por Schomberg sirve de base para nuevas consideraciones en torno a la RRI y su desarrollo futuro en el ámbito europeo.

\section{- Responsabilidad colectiva y distribuida}

Como hemos visto a la hora de aproximarnos al concepto de RRI, desde el proyecto europeo RRI Tools se señala que la RRI puede entenderse como un cambio en la responsabilidad que supone pasar de pensar en términos de nociones individualistas y consecuencialistas de responsabilidad a pensar en términos de responsabilidad colectiva y distribuida.

Para los investigadores de RRI Tools, en el ámbito de la investigación y de la innovación responsable confluyen una amplia gama de ideas recogidas en la literatura académica y en los informes políticos, que van desde las teorías sobre el buen gobierno, al compromiso del público desde el inicio de los procesos de desarrollo de nuevas tecnologías, pasando por consultas a través de focus group, los códigos de conducta o los mecanismos de acceso abierto al conocimiento. A pesar de las diversas formas de aplicar la responsabilidad a la investigación, entienden que todas las aproximaciones 
tienen en común su fuerte componente ético, poniendo el acento en el desarrollo de prácticas responsables en investigación e innovación.

We might even say that the variety of concepts that could be labelled as a responsible R\&I practice is as wide as the variety of ideas about how R\&I practices can become responsible. But what these notions have in common -more than anything- is their strong ethical component. They all strive to create responsible practices in research and innovation (RRI Tools, 2015).

El proyecto europeo RRI Tools plantea el desarrollo de herramientas para la gestión de la RRI sobre un marco teórico que, como explican a través de su portal web, está todavía en fase de elaboración. No obstante, señalan que, a partir de una primera impresión sobre qué se puede extraer de las definiciones actuales, se puede establecer ya una primera aproximación operacional de la RRI que especifique los requisitos tanto de los procesos como de los resultados de los procesos de innovación e investigación responsables.

Desde la perspectiva teórica desarrollada a través del proyecto, y basada principalmente en las definiciones de RRI de Stilgoe y Schomberg que hemos visto en el presente punto, los resultados de la RRI se pueden dividir en tres:

- Resultados de aprendizaje: públicos comprometidos, actores responsables e instituciones responsables

- Resultados de investigación e innovación: investigación e innovación éticamente aceptables, investigación e innovación sostenibles e investigación e innovación socialmente deseables.

- Resultados sociales: soluciones a grandes retos.

En cuanto a los requisitos de los procesos de la RRI, consideran que la investigación y la innovación responsables deben comprender cuatro dimensiones integradas (las cuatro primeras) y tres requisitos procesuales (los tres últimos):

- Anticipación, en el sentido de prever el futuro y comprender cómo las actuales dinámicas de promesa lo moldean.

- Reflexividad, que ocurre como aprendizaje de primer, segundo y tercer orden.

- Inclusión, que supone la participación de una amplia gama de agentes, como usuarios, ONGs, etc. en el desarrollo inicial de ciencia y tecnología. 
- Sensibilidad mutua, ligada a responder a los conocimientos, perspectivas, puntos de vista y estándares que surgen en el proceso.

- Diversidad, criterio que se considera clave para la evaluación de los procesos interactivos de formular políticas.

- Apertura significativa, que supone una reformulación del concepto de transparencia a un ámbito más amplio.

Transparency is an often-mentioned criterion for policy-making processes involving multiple stakeholders. We propose to rephrase transparency as 'meaningful openness', since insight into process structure, agenda-setting and outcomes also needs to make sense in the context of the content and the process at hand (RRI Tools, 2015).

- Cambio adaptativo, en referencia a la necesidad de describir cómo un proceso RRI debe dejar espacio para la adaptación.

Finalmente, el marco teórico del proyecto hace asimismo referencia a los seis ámbitos de la RRI establecidos en la Unión Europea -implicación social o participación, igualdad de género, educación científica, libre acceso, ética y gobernanza- y a los que ya hacíamos referencia en el punto anterior.

\subsubsection{La apuesta europea por la RRI}

La RRI ha ido adquiriendo un peso creciente en la agenda europea, desde que en 2001 se pusiera en marcha el Plan de Acción “Ciencia y Sociedad” para establecer una estrategia común que mejorara la conexión entre la ciencia y los ciudadanos europeos. En 2010 el VII Programa Marco (7PM) habla ya de un marco para la Investigación e Innovación Responsable y establece "Ciencia y Sociedad (SiS)" como una de las modalidades de financiación. Desde 2010 el foco de SiS ha sido el desarrollo de un marco para la RRI, un concepto con el que se busca responder a las aspiraciones y las ambiciones de los ciudadanos europeos. La UE destacaba en 2012 que los grandes retos sociales que tiene Europa por delante tendrán muchas más posibilidades de ser abordados con éxito si todos los actores de la sociedad trabajan de forma conjunta.

Since 2010 the focus of $\mathrm{SiS}$ has been to develop a concept responding to the aspirations and ambitions of European citizens: a framework for Responsible Research and Innovation (RRI). The grand societal challenges that lie before us will have a far better chance of being tackled if 
all societal actors are fully engaged in the coconstruction of innovative solutions, products and services (Publications Office UE, 2012).

La comisaria europea de Investigación, Innovación y Ciencia Máire GeogheganQuinn afirmaba en 2012 que el diálogo entre la ciencia y el resto de la sociedad nunca ha sido tan importante como en estos momentos, destacando el avance alcanzado en los últimos años en este campo y la importancia de que la ciencia responda a las necesidades y aspiraciones de la sociedad, reflejando sus valores y siendo responsable.

The dialogue between science and the rest of society has never been more important. As the Europe 2020 Strategy makes clear, to overcome the current economic crisis we need to create a smarter, greener economy, where our prosperity will come from research and innovation. Science is the basis for a better future and the bedrock of a knowledge-based society and a healthy economy. After ten years of action at EU level to develop and promote the role of science in society, at least one thing is very clear: we can only find the right answers to the challenges we face by involving as many stakeholders as possible in the research and innovation process. Research and innovation must respond to the needs and ambitions of society, reflect its values, and be responsible. To my mind, there are a number of keys to doing this (GogheganQuinn M., 2012).

Es en 2012 cuando la Unión Europea publica Responsible Research and Innovation. Europe's ability to respond to societal challenges, documento que aporta una nueva reflexión sobre la RRI y en el que se establecen, como hemos visto, los seis ejes que centran la política europea entorno a la misma: implicación social, igualdad de género, educación científica, libre acceso, ética y gobernanza. Es a partir de este documento, en el que la UE pone el acento en la RRI como un proceso que permite a los agentes sociales trabajar juntos durante todo el proceso de investigación e innovación para alinear mejor tanto el proceso como sus resultados con los valores, necesidades y expectativas de la sociedad Europea. Se trata, señalan, de un reto ambicioso para la creación de una política de Investigación e Innovación impulsada por las necesidades de la sociedad que involucran a todos los agentes sociales a través de enfoques inclusivos y participativos.

En 2014 la Unión Europea creó el Grupo Europeo de Expertos para el estudio de Indicadores Sociopolíticos de Investigación e Innovación Responsables con el objetivo de ayudar a la Comisión Europea a identificar los indicadores existentes y proponer nuevos que puedan medir el impacto de las actividades encaminadas hacia el concepto de RRI. En particular, el grupo tiene como fin asistir en el diseño e implementación de indicadores cualitativos y cuantitativos fiables y válidos. Además, para satisfacer la 
necesidad de elaborar políticas basadas en la evidencia, el grupo de expertos reflexiona sobre la RRI, las iniciativas en torno a este concepto y la concreción de objetivos SMART (por las siglas en inglés de específicos, mesurables, alcanzables, relevantes y oportunos). A nivel europeo, tales objetivos están vinculados al Programa Marco Horizonte 2020 (Observatori 2.0, 2014).

El grupo de expertos está coordinado por Roger Strand, profesor y director del Centre for the Study of the Sciences and the Humanities de la University of Bergen (Noruega), e integrado por cinco miembros, entre los que se encuentra Gema Revuelta, directora adjunta del Observatorio de la Comunicación de la Ciencia de la Universitat Pompeu Fabra.

Por otra parte, Horizonte 2020, el programa para la Investigación y la Innovación en la Unión Europea para el periodo 2014-2020, incluye "Ciencia con y para la sociedad" como una acción transversal de cualquier investigación. En la convocatoria se destaca como objetivo de este programa la construcción de una cooperación eficaz entre la ciencia y la sociedad para reclutar nuevos talentos para la ciencia y para vincular la excelencia científica con la conciencia y responsabilidad social. Se busca que todos los actores sociales (investigadores, ciudadanos, responsables políticos, empresas, organizaciones del tercer sector, etc.) trabajen juntos durante todo el proceso de investigación e innovación con el fin de alinear mejor el proceso y sus resultados con los valores, necesidades y expectativas de los la sociedad europea, siguiendo el enfoque de la RRI (Horizon 2020, ec.europa.eu).

En palabras de Philippe Galiay, jefe de Unidad en la Dirección General de Investigación de la Comisión Europea, durante la reunión de lanzamiento del proyecto RRI Tools "la iniciativa 'Ciencia por y para la sociedad', que forma parte de Horizonte 2020, es la evolución natural del programa 'Ciencia y sociedad' del 7PM, mientras que la RRI es un tema transversal en todo Horizonte 2020” (López, 2014a).

A pesar de la apuesta por la RRI impulsada por la Comisión Europea, existía un gran desconocimiento sobre las políticas y actividades en materia de ciencia y sociedad llevadas a cabo por cada uno de los países miembros. Para llenar este vacío, la UE puso en marcha el proyecto Monitoring Policy and Research Activities on Science in Society in Europe (MASIS). El proyecto incluyó el desarrollo de una metodología de monitoreo de 27 estados miembros de la UE y 11 países asociados a través del Programa Marco, con la intención de proporcionar datos nacionales sólidos y comparables. El objetivo era 
ofrecer una amplia visión de conjunto de la investigación y las políticas sobre ciencia y sociedad en cada país, así como una base de datos de información internacionalmente comparable que permitiera análisis temáticos entre los países. MASIS incluyó la recolección de datos por parte de corresponsales nacionales encargados de elaborar informes que fueron supervisados por grupos de expertos y validados por un especialista nombrado por la Comisión Europea. El contenido de estos informes nacionales configura una amplia base de datos sobre las políticas nacionales en materia de investigación y actividades relacionadas con la ciencia en la sociedad (Bloch y Mejlgaard, 2012:696-697). Las conclusiones alcanzadas por los expertos participantes y las recomendaciones planteadas por los mismos, recogidas en el informe Challenging Futures of Science in Society Emerging Trends and cutting-edge issues (Sinue, 2009) dibujan el marco normativo de la comunicación de la RRI, que abordaremos ampliamente en el capítulo que cierra el presente bloque.

Desde el ámbito europeo, cabe destacar asimismo la puesta en marcha del proyecto RRI Tools para el desarrollo de las herramientas formativas necesarias hacia una investigación e innovación responsables que cuenta con un presupuesto de 7 millones de euros y 26 socios divididos en 19 núcleos que cubren 30 países. El Área de Ciencia y Medio Ambiente de la Obra Social "la Caixa" lidera y coordina el proyecto, ganado en convocatoria competitiva del VII Programa Marco. IrsiCaixa, el Instituto de Investigación del Sida, se encarga de la coordinación adjunta y del centro de actividad español de RRI Tools.

El proyecto, lanzado el 20 y 21 de enero de 2014 en Bruselas, tiene como objetivo desarrollar una serie de herramientas - incluidos recursos digitales y acciones prácticas- destinadas a la sensibilización, formación, difusión y aplicación de la RRI en Europa. Entre los miembros del consorcio se encuentran fundaciones, universidades y centros educativos, centros de investigación, museos y centros de ciencia, redes paneuropeas, representantes del mundo empresarial y empresas tecnológicas. Su objetivo último es establecer una comunidad que reúna a todas las personas e instituciones que trabajan en esta nueva visión del desarrollo científico y social para desarrollar un proyecto colaborativo e inclusivo, cuyo objetivo es aumentar la creatividad y la propiedad compartida del proceso.

La participación de los distintos actores en el desarrollo y difusión del conjunto de herramientas será facilitada por los nodos nacionales que promoverán la RRI entre 
los diferentes actores implicados a nivel local y nacional. Además, RRI Tools abarca las seis claves de la RRI marcada por la UE: la participación pública, la educación formal e informal, la igualdad de género, la ética, el libre acceso a los resultados científicos y de investigación, y la propia gobernanza de la I+i.

Ignasi López Verdeguer, coordinador del proyecto, se muestra confiado en que RRI Tools contribuirá a cumplir con la estrategia Europa 2020 que establece que el crecimiento social debe ser inteligente, a través de inversiones más eficaces en la educación, la investigación y la innovación; además de sostenible, y que la sociedad tiene que ser incluyente, poniendo especial énfasis en la creación de empleo y reducción de la pobreza.

The Europe 2020 strategy states that the growth of our societies must be smart, through more effective investments in education, research and innovation. It also says that society must be sustainable, thanks to a decisive move towards a low-carbon economy. And that society has to be inclusive, with a strong emphasis on job creation and poverty reduction. We are confident that RRI Tools will contribute to the realisation of this strategy. In doing so, it will contribute to transform Research and Innovation in Europe into a process targeted at the grand challenges of our time-science for society-where deliberation and reflection are coupled with actionscience with society (López Verdeguer, 2014a).

Fermín Serrano, responsable asimismo del proyecto, en un artículo publicado a raíz de la primera reunión de trabajo del proyecto RRI Tools, destaca la dificultad de alcanzar acuerdos ante la diferencia de criterio de los diferentes países, por ejemplo, a la hora de entender lo que es responsable y lo que es sostenible, así como sobre los temas que preocupan en cada territorio. El consenso, señala Serrano, fue más fácil a la hora de definir una "herramienta" como un formato y guía. También, en el caso de RRI Tools, se busca hacer referencia a una herramienta de evaluación que determine la calidad de RRI de los proyectos de investigación propuestos (Serrano, 2014b).

El reto, según lo planteado en este primer encuentro, pasa por reunir un conjunto representativo de buenas prácticas y normas de RRI, a la vez que estas se adaptan a las diferentes características locales de los territorios europeos. El proceso de elaboración del conjunto de herramientas pretende ser colaborativo e integrador. Una vez las herramientas estén diseñadas, se formará a las personas responsables de implantarlas de forma efectiva con el fin último de incrementar la participación de los grupos de interés en la toma de decisiones. 
RRI Tool is a very ambitious project, which will only help map out RRI capabilities across Europe, through the creation of a tookit. Once this toolkit is available, the project will instruct trainers, who are responsible for ensuring that the tools are used effectively by RRI stakeholders. Ultimately, the project aims to increase the participation of society and stakeholders in making relevant decisions concerning research and innovation (Serrano, 2014b).

Serrano destaca el hecho de que, en última instancia, el objetivo de RRI Tools es promover la transformación del sistema científico hacia una ciencia más democrática, para lo que resulta necesario facilitar la participación activa de los ciudadanos en la investigación. La formación de la ciudadanía en materia de ciencia y el dotar de un nuevo sentido a los conceptos de iniciativa y propiedad entiende que son algunos de los factores claves.

\footnotetext{
Ultimately, we are aiming to promote the transformation of the scientific system towards more democratic science. This means facilitating the active involvement of citizens in research. In the process, citizens will be educated on the current state of scientific research and gain digital skills. In addition, being associated with research in such a way will provide citizens with a greater sense of initiative and ownership. We hope that the contributions from citizens will become a new driving force for addressing global challenges, such as sustainable development and inclusive growth (Serrano, 2014b).
}

\subsubsection{Ejemplos de buenas prácticas}

Para finalizar el presente apartado, resulta de interés analizar algunos ejemplos de RRI. Como hemos visto, la apuesta europea por la Investigación Responsable ha posibilitado la puesta en marcha de diversos proyectos con mayor o menor éxito como vemos a continuación:

- Science Shops, el caso de Bonn. El Centro Nacional para el desarrollo del proyecto RRI Tools en Alemania es un ejemplo RRI. Se trata de la Science Shop Bonn. El responsable de la misma, Norbert Steinhaus (2014), explica que en Alemania hace ya más de tres décadas que empezaron a plantearse soluciones para fomentar una investigación más participativa, pero ha sido en los últimos cinco años cuando ésta implicación de la sociedad civil ha cobrado mayor fuerza. Uno de los mecanismos más efectivos para interactuar mejor con los ciudadanos han sido las denominadas Science Shops, pequeños organismos, a menudo vinculados a universidades, cuyo objetivo es poner en relación a los centros de investigación con las organizaciones de la sociedad 
civil. Todos los Science Shops están interconectados a través de la red Living Knowledge y entre sus finalidades se encuentra la búsqueda colectiva de soluciones, lo que favorece la generación de un nuevo conocimiento o al menos la adaptación y modificación del conocimiento existente. Además, a través de sus contactos, Steinhaus destaca que las Science Shops cumplen una función de gran utilidad como antena de recepción de las demandas actuales y futuras de la sociedad en materia de ciencia.

\footnotetext{
The fact that Science Shops respond to civil society's needs for expertise and knowledge is a key element that distinguishes them from other knowledge transfer mechanisms. In practice, civil society organisations contact Science Shops, when seeking research support. They then engage in a collective search for a solution. This leads to new knowledge being generated, or at least existing knowledge being combined and adapted. This process takes the form of a true partnership without science prevailing in any way. Through their contacts, Science Shops provide a unique antenna function for society's current and future demands on science (Steinhaus, Euroscientis, 2014).
}

Desde la experiencia adquirida en las Science Shops, el director de este centro en Bonn destaca la importancia de la participación del público en todos los niveles de la investigación, desde la recopilación de datos al desarrollo de escenarios, con el fin de identificar soluciones prácticas y favorecer el desarrollo de la RRI. Steinhaus señala como ejemplo de éxito el caso de la "tienda de la ciencia" de Bonn puesta en marcha en 1984 y que a finales del siglo XX contaba ya con numerosas actividades de investigación multidisciplinar e importantes resultados de difusión y educación a nivel local, regional y nacional, participando además en diversos proyectos europeos como SCIPAS (Study \& Conference on Improving Public Access to Science through Science Shops), CIPAST (Citizen Participation in Science and Technology), EFSUPS (Exploring the Ground: Fostering Scientific Understanding in Primary Schools) o PERARES (Public Engagement with Research and Research Engagement with Society), entre otros.

- Neuro-enchancement: Responsible Research and Innovation (NERRI). Es un proyecto de tres años de duración (2013-15) financiado por la Comisión Europea en el VII Programa Marco cuyo objetivo es aplicar el concepto de Investigación e Innovación Responsable al campo de la "neuromejora", un área de investigación centrada en la búsqueda de tratamientos y aplicaciones para mejorar las capacidades cognitivas de las personas sanas. El proyecto está liderado por Ciencia Viva, la principal 
red portuguesa de comunicación científica y en él participan 18 organismos de 11 países distintos, incluido el Observatorio de Comunicación de la Ciencia de la Universitat Pompeu Fabra.

El proyecto ha conllevado además la creación del Comité Español de Apoyo a la Investigación e Innovación Responsable en el marco de la Neuromejora constituido el 25 de noviembre de 2013 en un evento en el que participaron representantes de diferentes centros y asociaciones y en el que se definió el grado de implicación de cada uno de ellos en las actividades de movilización y aprendizaje mutuo que se están desarrollando durante 2014 en el marco del proyecto NERRI (Observatori 2.0, 2013).

- Engineering and Physical Sciences Research Council (EPSRC). Un ejemplo anterior de participación exitosa de la sociedad en la toma de decisiones sobre qué líneas de investigación han de recibir financiación respecto a otras es, por ejemplo, el resultante de la iniciativa puesta en marcha por el EPSRC de Reino Unido en 2008 con la apertura de un proceso de diálogo público que influyó claramente en la concesión de ayudas a la investigación. La iniciativa consistió en decidir conjuntamente con diferentes agentes sociales qué líneas de investigación en nanotecnología y salud se financiaban de entre seis áreas posibles. El diálogo contribuyó a establecer prioridades llegando así a un proceso de toma de decisiones más completo y más sólido desde el punto de vista del impacto social de la investigación, con cierto grado de corresponsabilidad sobre los posibles impactos de futuro (López, 2014).

- Voices for Innovation. Otro ejemplo significativo de participación es Voices for Innovation, un proyecto europeo que permitió oír las voces de mil ciudadanos en materia de residuos urbanos como recurso, tema elegido para el proyecto. En total se redactaron 27 informes de países de la UE y un informe global detallando las esperanzas, miedos, preocupaciones e ideas de este millar de ciudadanos. Los análisis no solo confirmaron una serie de prioridades para la investigación europea actual, sino que también plantearon nuevas propuestas para ajustar y fortalecer el programa de investigación europeo. Los informes Voces se han utilizado para elaborar una serie de convocatorias de investigación para el programa de financiación de la UE Horizonte 2020. Además, los resultados del proyecto y la metodología de consulta Voces se 
pueden aplicar más ampliamente, para que las voces de los ciudadanos y las partes interesadas en la investigación tengan cabida. En este sentido, la metodología consistió en la creación de un centenar de grupos de discusión, de tres horas de duración, en los que se involucró a los ciudadanos y se recogieron sus opiniones e ideas acerca de la investigación y la innovación en 2013. Las consultas se llevaron a cabo por parte de centros de ciencia y museos coordinaros por la Red Europea de Centros y Museos de Ciencias ECSITE (voicesforinnovation.eu).

- Agenda Ciudadana de Ciencia e Innovación. A nivel europeo, podemos destacar también como ejemplo de iniciativa para escuchar las voces de la ciudadanía la denominada Agenda Ciudadana de Ciencia e Innovación, una acción de sensibilización puesta en marcha en 2010, y gestionada en España por la Fundación Española para la Ciencia y la Tecnología (FECYT), en la que los ciudadanos europeos pudieron hacer llegar a los máximos representantes de ciencia e innovación en Europa qué retos consideraban que se debían afrontar en estos dos ámbitos en el horizonte 2030. La FECYT defendía esta campaña como una acción de sensibilización innovadora porque unía en una misma iniciativa a científicos e innovadores, políticos y ciudadanos para hablar de ciencia e innovación, en un "ejercicio de debate público que permite implicarse y construir más Europa con los ciudadanos" (http://www.reto2030.eu). El formato participativo consistía en votar por uno de los 14 retos planteados y explicados a través de vídeos y otros materiales por expertos. Posteriormente se han repetido este tipo de iniciativas de agenda ciudadana en otros ámbitos como Iberoamérica o en países como México.

El presenta capítulo nos ha permitido conocer el estado de la cuestión en torno a la RRI, deteniéndonos en las principales aproximaciones teóricas surgidas hasta el momento. También hemos podido profundizar en el concepto mismo de responsabilidad y en su desarrollo y aplicación en el campo de las empresas y las organizaciones, haciendo especial hincapié en el modelo de RSE desarrollado por la Escuela de Valencia y en el que encontramos un interesante referente de cara al desarrollo de una nueva propuesta de definición de la RRI desde la perspectiva de la ética dialógica. Por otra parte, en el trabajo desarrollado hasta el momento queda patente la importancia de la Unión Europea en el desarrollo y consolidación del fenómeno de la RRI. Precisamente, 
buscaremos en este ámbito europeo el marco normativo para la RRI y su comunicación que recogeremos en el octavo capítulo. Antes, abordaremos la Comunicación Pública de la Ciencia. 


\section{La Comunicación Pública de la Ciencia}

Como hemos visto en los apartados previos, la consolidación de una cultura científica resulta básica para que los afectados por temas de ciencia, tecnología e innovación estén capacitados para participar de forma autónoma en las deliberaciones sobre los avances en esta materia, de forma que se puedan alcanzar decisiones y normas dotadas de valor moral. Pero para alcanzar este necesario grado de autonomía es imprescindible llevar a cabo una mayor comunicación y divulgación de la ciencia. Sólo desde una opinión pública informada, los ciudadanos pueden estar capacitados para llegar a comprender las consecuencias de unas políticas científicas que afectan a todos y ejercer tanto las labores de deliberación como de monitorización. La Comunicación Pública de la Ciencia (CPC) es un instrumento para la democracia porque facilita a todos el conocimiento para poder opinar sobre los avances de la ciencia y compartir con los demás grupos de interés la capacidad de tomar decisiones. Pero además la comunicación es una herramienta clave, como veremos, para establecer un diálogo con la sociedad y los grupos de interés de la ciencia.

Para que las condiciones de participación en los procesos de deliberación sean válidas, es necesario realizar una apuesta clara por la comunicación y divulgación de la ciencia ya que tan sólo una sociedad formada en este terreno será capaz de participar en condiciones adecuadas en el discurso. Asimismo, la comunicación de la labor investigadora cierra el círculo de la responsabilidad por parte de los científicos ya que estos deben responder de la misma, rindiendo cuentas de su trabajo y haciendo públicos tanto los procesos de investigación como sus resultados.

En el presente apartado abordaremos en un primer momento la CPC, su evolución, las razones para comunicar y sus riesgos, vinculándola a cuestiones como la participación y la opinión pública. En el segundo apartado trataremos la explosión de la comunicación de la ciencia, por una parte, a raíz de la nueva galaxia mediática, y por otro, como consecuencia de los avances de la comunicación de la ciencia como un sector cada vez más profesionalizado que se enfrenta a nuevos retos. 


\subsection{COMUNICACIÓN DE LA CIENCIA: UNA APUESTA POR LA}

\section{RESPONSABILIDAD}

La comunicación y divulgación de la ciencia cuentan con una extensa trayectoria, que ha ido ganando peso en los últimos años, y una amplia bibliografía. En el presente apartado trataremos de realizar una completa aproximación a las mismas, partiendo de la historia y deteniéndonos en el desarrollo de los dos modelos de comunicación de la ciencia que coexisten en la actualidad. Resulta asimismo fundamental tratar las razones por las que es importante la comunicación de la ciencia que, como veremos, van desde responder a los propios intereses de la comunidad científica a cumplir un deber y una responsabilidad de cara a la sociedad. Precisamente, en la percepción y las actitudes de la sociedad española y europea de cara a la ciencia nos detendremos en el tercer punto.

La necesidad de favorecer la participación ciudadana en materia de ciencia a partir de un marco normativo basado en los principios para una ética cordial de Cortina es la perspectiva de la que parte el cuarto punto, en el que también veremos cómo autores como López Cerezo defienden cómo la participación puede favorecer asimismo el desarrollo de una cultura científica, variando el tradicional esquema lineal de difusión expertos-comunicadores-ciudadanos, por un modelo interactivo en el que el periodista científico ejerce como mediador activo entre unos y otros. Para finalizar esta reflexión sobre la comunicación de la ciencia como una apuesta por la responsabilidad resulta asimismo de interés aproximarse a la relación de la CPC con la opinión pública, punto con el que cerraremos el presente apartado.

\subsubsection{De la unidireccionalidad hacia el diálogo}

La actual comunicación de la ciencia es la herencia de una sólida tradición histórica de la divulgación cultural y social de las ciencias que tiene su origen en la práctica artística, científica, naturalista y humanista del Renacimiento y que a su vez posee sus raíces más lejanas en el naturalismo griego. Así lo explica De Semir en el trazado que ofrece sobre la historia del periodismo y la comunicación científico en su obra Decir la ciencia y a partir de la que recogemos a continuación algunos de los principales aspectos de la evolución de lo que llamamos Comunicación Pública de la Ciencia (De Semir, 2014). 
Entre los siglos XVII y XIX se fragua en toda Europa una tendencia naturalista y divulgadora. Encontramos ya en éste periodo científicos con una inquietud divulgadora. Es el caso, por ejemplo, de Galileo Galilei que en 1632 publicaba su obra Dialogo sopra i due massimi sistemi del mondo, tolemaico e copernicano en italiano, en lugar de en latín, abriéndola así a la sociedad. Poco después aparece en París una publicación con un claro carácter divulgador como es Le Journal des Savants y en 1686 Bernard de Fontenelle publica su Entretiens sur la pluralité des mondes. Entre las publicaciones que ejemplifican con mayor claridad la voluntad de hacer llegar a toda la sociedad el conocimiento cabe destacar la gran Encyclopédie (1750-1772) de Diderot.

La historia de la comunicación y la divulgación de la ciencia vive asimismo una edad de oro a finales del siglo XIX con la aparición de la británica Nature en 1869, fundada por el astrónomo Norman Lockyer y el editor McMillan y la aparición solo unos años después, en 1872, de la estadounidense Popular Science, todavía vigente. A esto se une la proliferación de conferencias, libros, revistas, exposiciones, planetarios, museos, observatorios, jardines botánicos y zoológicos como canales y herramientas de la divulgación del conocimiento científico.

Pero es en el siglo XX cuando la necesidad de explicar y compartir se desarrolla intensamente en paralelo a los grandes avances científicos y tecnológicos que se suceden con una intensidad sin precedentes en la historia de la humanidad. Gran parte de estos avances son consecuencia de las dos guerras mundiales, especialmente de la segunda, que marcó un hito en la capacidad tecnológica del ser humano y de sus consecuencias, plasmada en la consecución de la bomba atómica que supuso un reto científico y unos resultados de destrucción sin precedentes.

En el siglo XX se refuerza asimismo la conciencia del papel divulgador de los científicos. Así, uno de los principales referentes de la ciencia del pasado siglo como es Albert Einstein cuenta con una extensa bibliografía con un claro carácter divulgador: Sobre la teoría de la relatividad especial y general (1917), El significado de la relatividad (1921), La evolución de la física (1938), Mi visión del mundo (1934) o Mis ideas y opiniones (1954), son algunos ejemplos de ello. La divulgación alcanza además una amplia repercusión social, llegando a convertirse en auténticos best sellers obras como Historia del Tiempo de Stephen Hawking, Los Dragones del Edén, premio Pulitzer 1978, de Carl Sagan, impulsor a su vez de una serie de televisión pionera en la divulgación científica como fue Cosmos. 
Es en la época de la guerra fría cuando se produce la consolidación definitiva del periodismo científico moderno, en un escenario en el que los medios de comunicación y la propaganda fueron el campo de batalla en el que los dos grandes bloques ideológicos competían por un mayor desarrollo-científico y tecnológico escenificado en la carrera espacial. De Semir señala que es en este contexto en el que Estados Unidos impulsó, en 1957, la primera encuesta sobre comprensión pública de las ciencias por la National Association of Science Writters que concluía que los americanos tenían, en general, una actitud positiva hacia la ciencia, aunque sus conocimientos sobre estas materias eran escasos. Ante la amenaza soviética, el Gobierno de Estados Unidos se movilizó para que la sociedad adquiriera el nivel científico y tecnológico necesario para asegurar un país competente y líder en el concierto mundial. Precisamente el mismo año de la llegada del hombre a la Luna, en 1969, se creó el que está considerado como primer centro contemporáneo del mundo para la divulgación de las ciencias, el Exploratorium de San Francisco.

La estrategia puesta en marcha desde finales de los años 50 en Estados Unidos para fomentar la divulgación, el periodismo científico y la alfabetización pública de las ciencias culminó, señala De Semir, en 1985 con la puesta en marcha por parte de la American Association for the Advancement of Sciences del Proyecto 2061 (año en el que volverá a pasar el cometa Halley) que tiene por objetivo ayudar a todos los norteamericanos a alcanzar una adecuada instrucción en cencías, matemáticas y tecnología.

Esta apuesta por el desarrollo de la cultura científica tuvo también su traslación al ámbito europeo, donde la tradición histórica de divulgación cultural de las ciencias que se consolidó durante el siglo XIX se desarrolló intensamente en el último tercio del siglo XX en paralelo a los grandes avances científicos y tecnológicos. En este tiempo la promoción de la cultura científica fue adquiriendo naturaleza de estrategia política también en España. Una muestra de ello, señala De Semir, es la eclosión de los denominados centros de ciencia, instalaciones como el CosmoCaixa de Barcelona, la Casa de las Ciencias de La Coruña, el Aquarium Finsterrae, la Ciudad de las Artes y las Ciencias de Valencia o el Parque de las Ciencias de Granada, entre otros.

A partir de los años 80 también el periodismo científico fue ganando terreno en los medios de comunicación. En 1982 La Vanguardia insertaba las primeras páginas semanales especializadas en ciencia de la prensa española contemporánea, que en 1987 
pasaron a convertirse en el suplemente "Ciencia y Medicina". Otros periódicos y medios de comunicación siguieron esta línea hasta consolidar la presencia de información especializada en ciencia como un contenido habitual en prensa, radio y televisión, posicionándose incluso la revista de divulgación Muy Interesante como la más vendida a nivel nacional en la categoría de publicaciones mensuales.

De Semir destaca otras iniciativas surgidas en los años 80 que muestran la consolidación de una inquietud por la promoción de la cultura científica. Es el caso, por ejemplo, en el ámbito editorial, de la aparición de colecciones de divulgación como la Biblioteca Científica de Editorial Salvat y la Biblioteca de Divulgación Científica Muy Interesante de Ediciones Orbis. En el ámbito político, la Generalitat de Cataluña creó en 1988 una Comisión para el Estímulo de la Cultura Científica que desarrolló hasta 1996 una notable labor para que la ciencia se integrara en el mundo de la cultura.

Otro de los momentos que han marcado el desarrollo de la Comunicación Pública de la Ciencia en España fue la celebración en 2007 del Año de la Ciencia con la organización de más de 4.000 actos en todo el país. Pero más allá de los actos conmemorativos, lo que realmente contribuyó a cambiar el panorama de la comunicación de la ciencia fue la creación de una serie de estructuras estables que han tenido continuidad como la Agencia de Información y Noticias Científicas SINC y el establecimiento de un programa de ayudas en tres ámbitos: el de las universidades y centros de investigación, el local y el museístico. Se creaban así la Red de Unidades de Cultura Científica y la Innovación, la Red de Agentes Locales de Cultura Científica y la Red Nacional de Museos de Ciencia y Tecnología. Como veremos más ampliamente en el siguiente apartado estas acciones han resultado claves para avanzar en la profesionalización de la comunicación de la ciencia en España.

La forma de entender la promoción de la cultura científica y las relaciones entre ciencia y sociedad también ha ido avanzando en las últimas décadas, produciéndose cambios importantes que han afectado al modelo comunicativo. En un primer momento, que De Semir sitúa a mediados de los años 80 del pasado siglo, la atención se centra en la necesidad de que la ciudadanía adquiera mayores conocimientos científicos en una sociedad cada vez más compleja. Se empieza a habar así de la importancia de que tanto los políticos como la ciudadanía cuenten con conocimiento científico y tecnológico a la hora de planificar y tomar decisiones. También es una etapa en la que se empieza a 
insistir en el papel de los científicos como comunicadores, promoviéndose actuaciones para formarlos y dotarlos de herramientas.

A partir de estas premisas se establecen acciones de comunicación de carácter unidireccional, dirigidas desde las universidades y centros de investigación hacia el público. También se fomenta la formación en comunicación por parte de investigadores e investigadoras a través de programas de entrenamiento en comunicación de la ciencia, premios, inclusión de criterios de divulgación en proyectos de investigación, etc.

En el plano académico, los estudios se centran en valorar los conocimientos del público, el grado de información percibido y el interés por la ciencia. Son términos habituales en los documentos publicados en este periodo los anglosajones public understanding of science, science literacy y citizen competence in science. Precisamente, entre los documentos más representativos de este enfoque se encuentra The Public Understanding os Sciencie (Bodmer, 1985).

Entre las principales críticas a este enfoque se encuentra el hecho de que se base en un modelo de comunicación de la ciencia unidireccional, de arriba hacia abajo, en el que, según critica Miller (2001), "los científicos - con toda la información requerida deben llenar a su antojo el vacío de conocimiento del público científicamente analfabeto". Además, sus detractores le acusan de partir de la visión simplista de que cuanto mayor sea el conocimiento e información sobre ciencia y tecnología mayor será el aprecio a los avances derivados de las mismas. En este sentido, De Semir defiende que sí existen relaciones entre el conocimientos y las actitudes de la ciudadanía "aunque son mucho más complejas y sofisticadas de lo que el modelo lineal puede presuponer" (De Semir, 2014:115).

A partir de mediados de los 90 surge una nueva corriente como alternativa a este modelo denominado de forma peyorativa "de déficit" (déficit model). Se trata de un nuevo enfoque que pone el acento en el diálogo y la participación, pasando por tanto a un modelo de comunicación de la ciencia bidireccional. En el enfoque denominado "ciencia y sociedad", en el que se enmarcaría el modelo presentado en esta tesis, se destaca la necesidad de establecer un diálogo entre la comunidad científica y la ciudadanía y de tener en cuenta las valoraciones, expectativas, opiniones y conocimientos de los ciudadanos y ciudadanas. Se reconoce además la necesidad de que la ciudadanía participe realmente en el proceso de la ciencia, siendo esta participación un derecho y un deber democrático. En este reconocimiento, como hemos visto, se 
encuentra la base del auge de la RRI. "En contraposición al deficit model, en esta etapa se expone un modelo de interpretación entre ciencia y sociedad contextual. Es decir, una aproximación en la que el contexto social y el conocimiento ciudadano juegan un papel importante en el propio desarrollo de la ciencia y la tecnología" (De Semir, 2014:116). Como actividades y resultados propios de este modelo el autor destaca las consultas ciudadanas, el auge de herramientas participativas como las conferencias de consenso, los referéndums, acciones de divulgación más participativas como los cafés científicos, las science shops, etc.

Por lo que respecta a las investigaciones, en esta época se incorporan a los estudios sobre los conocimientos de la ciudadanía, otros aspectos como la percepción del riesgo, la confianza en diferentes fuentes o sectores o cuestiones de especial relevancia para el presente trabajo como la aceptabilidad moral. Son conceptos que cobran fuerza a partir de esta corriente: public engangement in science, public awareness, science dialogue, citizen paticipation, local knowledge, contextual approach, ascientific citizenship y scientific cultura. Entre los documentos que marcaron el inicio de esta tendencia se encuentra el informe realizado por el Comité de Ciencia y Tecnología de la House of Lords de Gran Bretaña que comienza afirmando: "La relación de la ciencia en la sociedad se encuentra en una fase crítica (...) Esta crisis de confianza es de gran importancia tanto para la sociedad británica como para la ciencia británica" (The House of Lords Reports Science and Society, 2000). El informe llegaba después de que buena parte de la sociedad británica, y europea en su conjunto, hubiera perdido en gran medida su confianza en la ciencia tras el escándalo de las “vacas locas" que alcanzó su auge mediático en 1996.

El informe de los lores británicos ponía de manifiesto la existencia de una crisis de confianza en la ciencia y la puesta en duda de muchos de sus valores debido, entre otras razones, a la existencia de una reticencia del público sobre la autoridad científica. Entre las razones de esta desconfianza el informe señalaba el hecho de que la mayoría de la información que recibe la ciudadanía una vez superada la escuela está determinada por la creación de una realidad deformada por los medios de comunicación, principalmente la televisión, a los que señalaba como uno de los principales responsables de la banalización de los mensajes culturales que se estaban produciendo. Para hacer frente a esta situación el informe recomendaba establecer un diálogo directo con el público. 
El informe de los lores británicos seguía así la línea establecida en la Declaración sobre la Ciencia y el Uso del Conocimiento Científico surgida a raíz de la conferencia mundial celebrada en 1999 en Budapest (Hungría) bajo el título de "La ciencia para el siglo XXI: un nuevo compromiso", auspiciada por la Unesco y el International Council for Science. La Declaración incluía el compromiso de "promover el diálogo entre la comunidad científica y la sociedad y consolidar la cultura científica y su aplicación con fines pacíficos en el mundo". A partir de esta Declaración se fueron generalizando en Europa los estudios y acciones encaminados a aumentar la sensibilización pública en general a favor de la interacción entre ciencia y sociedad.

Entre estas acciones cabe destacar la publicación por parte de la Comisión Europea de dos documentos claves en el desarrollo del modelo de comunicación de la ciencia que pone el acento en el diálogo entre ciencia y sociedad: Science and Society Action Plan (2002) y el Challenging Futures of Science in Society Emerging Trends and cutting-edge issues (Sinue et al, 2009). Ambos sientan las directrices de la comunicación entre ciencia y sociedad en las que se basa la RRI, por lo que volveremos a ellos en el próximo capítulo dirigido a trazar el marco normativo europeo de la comunicación de la RRI.

El modelo de comunicación "ciencia y sociedad" no está exento de críticas. La principal de ellas hace referencia al hecho de que muchos programas y acciones que dicen fomentar la participación ciudadana no llegan finalmente a cumplir su propósito, puesto que las opiniones y demandas de la ciudadanía no son tenidas realmente en cuenta en los niveles de decisión. En este sentido, se señala que no llega a tratarse de un modelo realmente bidireccional. La propuesta de un modelo de comunicación de la RRI que plantearemos en el siguiente bloque tiene en cuenta esta crítica, buscando garantizar la adopción de compromisos públicos por parte de los centros de investigación a la hora de atender las expectativas de los grupos de interés.

Si bien se trata de dos tendencias diferentes a la hora de abordar la relación entre ciencia y sociedad, que comportan acciones de comunicación diferentes, ambas han coexistido en el tiempo. En este sentido, entendemos que, siendo necesario establecer acciones de diálogo entre ciudadanía e investigadores, esto no resta valor a la continuidad de las acciones de comunicación de la ciencia dirigidas al público y a la labor comunicadora de los investigadores. 
En este sentido, cabe recoger las reflexiones de Olga Roger y Pilar Buil (2014) respecto a la comunicación ambiental, claramente extrapolables a la comunicación de la ciencia en general, resaltando que resulta necesario tanto informar como comunicar; entendiendo que informar es "dar a conocer un hecho, un acontecimiento o transmitir unas ideas", mientras que al hablar de comunicación "nos referimos a una actividad relacional, a una realidad dialógica", tratándose por tanto de un proceso bidireccional, que va más allá de la simple transmisión de información.

\footnotetext{
Informar es básico para comunicar, pero la transmisión de esta información, por sí misma, no suele ser suficiente para concienciar y conseguir el entendimiento que lleve a actuar en un determinado sentido. Sólo en ciertos casos, como por ejemplo, en grupos de población que están concienciados pero no saben cómo actuar, la información puede ser suficiente al proporcionar los mecanismos o conocimientos necesarios para que la ciudadanía pueda participar (Roger y Buil, 2014:23,24).
}

Vemos como información y comunicación son necesarias, en la práctica totalidad de los casos, para favorecer la participación y la concienciación. En este sentido, consideramos que ambas formas de entender la relación entre científicos y públicos y la comunicación de la ciencia se complementan y enriquecen.

\subsubsection{Razones y reflexiones en torno a la comunicación de la ciencia}

En la Declaración de la Ciencia y el Uso del Conocimiento Científico adoptada en la Conferencia Mundial de la Ciencia de 1999, auspiciada por la UNESCO, a la que hacíamos referencia en el anterior apartado, se establecía que: el conocimiento científico debe ser compartido; se necesita que exista una auténtica cooperación entre gobiernos, sociedad civil, sector empresarial y científicos; y los investigadores deben regirse por los estándares éticos correspondientes. De nuevo vemos como se hace referencia a la necesidad de un marco ético para la ciencia y la labor de los investigadores e investigadoras, y se pone el acento en la necesidad de compartir y cooperar entre los diferentes grupos de interés. Una Comunicación Pública de la Ciencia responsable resulta imprescindible para compartir el conocimiento científico y alcanzar unas relaciones de cooperación fructíferas. En el presente apartado abordaremos algunas de las razones para comunicar la ciencia y la innovación esgrimidas por científicos, profesionales de la comunicación y académicos, así como sus reflexiones sobre sus riesgos, posibilidades y retos. 
Para el director del Observatorio de la Comunicación de la Ciencia de la Universitat Pompeu Fabra y uno de los principales teóricos españoles sobre la materia, Vladimir De Semir, se pueden encontrar diferentes motivos para comunicar públicamente la ciencia según quien sea el que resulte beneficiado (De Semir, 2011:19). Así, para cada uno de los individuos, la comunicación de la ciencia aumenta su conocimiento del mundo, así como su capacidad para tomar decisiones informadas y utilizar las nuevas aplicaciones derivadas de la ciencia de una manera eficiente. Para la sociedad en general también resulta beneficiosos "puesto que la difusión pública del conocimiento, especialmente si ha sido generado a partir de la inversión pública, es un elemento imprescindible de la democracia"; y además porque "el conocimiento del conocimiento" puede contribuir al bienestar y al desarrollo económico de los países. Cuando el beneficiario es la ciencia y la cultura en general, el autor destaca cómo el conocimiento que no queda limitado a unos pocos se expande y genera nuevas preguntas de investigación tanto en su campo como en otros. Finalmente, en el caso de la comunidad científica, asegura que ésta es la primera beneficiaria de un mayor conocimiento público sobre la ciencia y sus procesos ya que la opacidad genera temor, mientras que la transparencia genera confianza entre el público.

Son muchas las voces de científicos y profesionales de la comunicación que han dado razones de la importancia de la CPC, entre ellos Carl Sagan, uno de los pioneros y referente en el campo de la divulgación científica. El astrónomo tuvo que hacer frente a las críticas de algunos de sus colegas que consideraban discutible su labor para tratar de hacer accesible y popular la ciencia. El divulgador salía al paso de las mismas argumentando que existen al menos dos razones por las que los científicos tienen la obligación de explicar lo que hacen:

La primera es un simple y llano interés propio: la mayor parte de la financiación de la ciencia procede del público, y el público tiene el derecho a saber cómo gastamos su dinero. Si los científicos sabemos incrementar el interés del público por la ciencia, hay muchas posibilidades de que acabemos teniendo mayor apoyo social. Y la otra es que es tremendamente estimulante poder comunicar a los otros la propia excitación que genera el conocimiento (Sagan, 2005:15).

También en la actualidad son muchos los investigadores que reivindican la necesidad de comunicar la ciencia y su influencia no sólo en el desarrollo de una ciudadanía más formada y comprometida, sino también incluso en su papel para que seamos mejores personas. Así lo señalaba el biólogo y director de la colección de 
divulgación Ciencia que ladra, Diego Golombek, en la entrevista publicada por la Revista Digital Cabal.

La ciencia no es ciencia hasta que no se comparte, hasta que no se comunica. Por un lado, está la comunicación a los colegas (en forma de congresos y papers científicos), pero no alcanza: es necesario poner en común el conocimiento - aún cuando sea sin los detalles técnicos- con la sociedad que nos abraza... y nos paga. Comunicar la ciencia te ayuda a aclarar las ideas, a hacerte preguntas básicas que de otra manera quedan debajo de la alfombra. Por un lado, el público necesita tener acceso a las ideas y logros de la ciencia. Por otro, la riqueza de una sociedad o de una región está ligada al conocimiento científico, y muchas elecciones ciudadanas se tienen que basar en saber de qué se trata. (...) Pero, y tal vez de manera más importante, compartir el pensamiento científico y racional, libre de prejuicios, de mitos, de pensamiento mágico y del principio de autoridad, no sólo sirve para futuras generaciones de científicos o ciudadanos más comprometidos. Sirve, sobre todo, a que seamos mejores personas (Golombeck, 2015).

La justificación de las inversiones realizadas con dinero público en investigación e innovación, las oportunidades que supone la divulgación de la ciencia para captar recursos o la importancia de transferir los resultados alcanzados a la sociedad y el mundo empresarial son razone asimismo argumentadas por investigadores concienciados de la importancia de la CPC. Es el caso, por ejemplo, de Pere-Joan Cardona, (2014) investigador de la Unidad de Tuberculosis Experimental del Hospital Germans Trias i Pujol de Badalona (Barcelona), quien reivindica la capacidad comunicadora y divulgadora de los investigadores e investigadoras a la hora de justificar las inversiones públicas "ante una sociedad cada vez más exigente y ávida de transparencia y de información". El investigador destaca asimismo la necesidad, ante los recortes actuales, de que la comunidad científica intente captar dinero, así como de transferir los conocimientos alcanzados para poder generar "nuevas empresas tecnológicas, y con ello el valor añadido para nuestra sociedad con el fin de cerrar el círculo de inversión y retorno". En este sentido, Cardona pone el acento en la importancia del público empresarial, un público que considera que requiere un tipo de explicaciones muy específicas y un esfuerzo comunicador muy particular para poder generar un modelo de éxito y de esperanzas comerciales.

Jana Gregory y Steven Miller reflexionan en Science in Public (1998) sobre los motivos que llevan a los científicos a comunicar la ciencia a la sociedad, agrupándolos en cinco propósitos o razones: 
- Entusiasmo. Como hemos visto ya entre los argumentos de los investigadores, el científico siente pasión por el ámbito en el que trabaja y quiere compartirla con otros.

- Mejorar las capacidades de los receptores, razón que en el presente trabajo vinculamos a la necesidad de contar con públicos suficientemente preparados para poder opinar en los asuntos de ciencia e innovación que les afectan.

- Profundizar en los procesos democráticos existentes o ayudar a crear nuevos cuando estos no existen. Entendemos que este propósito aparece directamente vinculado al modelo de democracia deliberativo expuesto en la presente tesis.

- Prevenir la alienación de determinados sectores de la sociedad.

- Servir a los intereses de la comunidad científica y las entidades que la financian.

En un estudio realizado en España entre miembros del Consejo Superior de Investigaciones Científicas (CSIC) que habían participado en acciones de divulgación entre 2001 y 2004, se observó que los investigadores de alto nivel reconocían en mayor medida un sentimiento de deber, asumiendo que el comunicar ante el público formaba parte de sus obligaciones, mientras que los más jóvenes decían sentir con mayor frecuencia satisfacción personal y disfrutar al realizar estas actividades (Martín Sempere et al., 2008).

Tampoco han faltado las voces de periodistas y comunicadores a la hora de reivindicar la importancia de la comunicación de la ciencia y de dar razones para potenciarla. Entre estas voces cabe destacar como especialmente representativa la de Manuel Calvo Hernando, doctor en Ciencias de la Información y presidente durante más de 30 años de la Asociación Española de Periodismo Científico y secretario general de la Asociación Iberoamericana de Periodismo Científico. Calvo Hernando destacaba la importancia y las dificultades de la divulgación de la ciencia en un momento histórico en el que la distancia entre las enseñanzas que se reciben en la escuela y los progresos del conocimiento durante la vida del ser humano se han disparado.

Estamos en presencia de un fenómeno histórico que podría formularse cuantitativamente: hubo una época en que los adelantos de la ciencia durante la vida de un hombre representaban un $10 \mathrm{o}$ un 20 por ciento suplementario sobre la masa de conocimientos que esa persona adquiría en su edad escolar; hoy, la relación puede ser de varios cientos por cientos (Calvo Hernando, 2005:22). 
A esta realidad del momento histórico se une la creciente y decisiva influencia de la ciencia y la tecnología en la vida cotidiana. Para el autor, si los medios de comunicación deben reflejar e informar sobre esa vida cotidiana, parece claro que el periodismo científico está llamado a ser "una de las estrellas informativas del milenio en el que acabamos de entrar, una de las especialidades informativas de nuestro tiempo más cargadas de contenido y... de emoción” ya que, como argumenta Calvo Hernando, el periodismo científico comunica a todos los descubrimientos que están cambiando las vidas y la estructura social de una parte de la humanidad.

Calvo Hernando vinculaba también la comunicación de la ciencia con la democracia al facilitar a todos el conocimiento para poder opinar sobre los avances de la ciencia, y compartir con los políticos y los científicos la capacidad de tomar decisiones en las graves cuestiones que plantea a la humanidad del desarrollo científico y tecnológico. "El periodismo científico tiene la obligación social de hacer lo posible porque la ciencia y la tecnología no sirvan sólo para el enriquecimiento cultural y el beneficio práctico de algunas naciones o ciertas sociedades privilegiadas", según defendía el autor.

En el paradójico y fascinante contexto de nuestro tiempo, surgen unos profesionales de la información cuya misión, cercana a la utopía, es explicar el universo, que es -puede decirseinexplicable. Cada día adquiere más fuerza la convicción de que los periodistas juegan un papel esencial en la comunicación al público de los avances de la ciencia. La democracia requiere que todo ciudadano ilustrado pueda conocer el estado de los conocimientos y de los desconocimientos, y también de sus aspectos éticos. Hacer partícipe a la mayoría de los descubrimientos de la minoría, en un ejercicio plenamente democrático, nos impone a los divulgadores, seamos periodistas o no, una serie de obligaciones, la primera de las cuales es tratar de crear una conciencia pública sobre el valor de la ciencia en nuestro tiempo (Calvo Hernando, 2005:37).

Para el autor, el funcionamiento de un democracia exige un mínimo de armonía y comprensión entre la mayoría de sus miembros, requisitos que no pueden cumplirse si la divulgación "no consigue modificar este estado de espíritu que excluye a la ciencia de la cultura general".

La participación de la sociedad en la ciencia debe tener también un papel fundamental en el camino hacia el que se dirijan las aplicaciones de la ciencia y la tecnología. En este sentido, Calvo Hernando recuerda que todas las disciplinas científicas pueden engendrar tanto milagros como catástrofes y "es la sabiduría del ser 
humano y de la sociedad la que tiene la obligación de evitar sus efectos perniciosos, tanto en la energía nuclear como en los automóviles".

Sobre los problemas a los que se enfrenta el periodismo científico, el periodista hace referencia a los enunciados ya en 1990 al inaugurar el Congreso Nacional de Periodismo Científico, entre los que se encuentran la necesidad de formación del periodista científico, el acceso a las fuentes, la actualización de vocabularios especializados y la sensibilización a los medios para que cuenten en sus plantillas con al menos un periodista capaz de seguir la actualidad científica y tecnológica.

Para llevar a cabo una más adecuada información pública de la ciencia, el periodista y divulgador, establece además la necesidad de tener en cuenta una serie de consideraciones que creemos interesante recoger (Calvo Hernando, 2002).

- La demostración científica no tiene un valor absoluto, sino que ha de ser entendida, como cualquier otro discurso, dentro de un contexto y una situación.

- Es necesario elaborar más y mejores elencos de vocabulario científico y técnico.

- Hay que estimular a los científicos para que cada vez más sean capaces de proferir tanto el lenguaje de la ciencia como el de la divulgación científica, que son discursos distintos.

- Para el caso de aquellos científicos que no quieran o no sepan hacerlo, hay que propiciar la existencia de mediadores capaces de traducir de un discurso a otro.

- Por lo demás, el informador debe acercarse al campo de la ciencia como a cualquier otro: con honradez, rigor y la máxima competencia posible. Para hablar sobre ciencia se posee el mismo instrumento que para hablar de cualquier otra cosa: la lengua común.

- Hay que desmitificar la ciencia: no es una panacea para los problemas del ser humano ni una religión. Como todo instrumento, se puede emplear para el bien o para el mal.

- Se debe hacer propaganda de la ciencia: expande los límites del conocimiento humano y proporciona bienestar.

- Las ciencias y las humanidades forman parte de la cultura: no es aceptable una ciencia sin humanismo, ni lo son unas humanidades al margen de la ciencia. 
Las reflexiones de Manuel Calvo en obras posteriores (2005) avanzan además hacia la necesidad de un trabajo en equipo entre diferentes grupos de interés y el establecimiento de un diálogo sobre ciencia. En concreto, el autor destaca cómo va tomando cuerpo la consideración de que la divulgación del conocimiento científico y del desarrollo tecnológico es una tarea común en la que parece necesario trabajar en equipo entre científicos, periodistas, escritores, docentes $\mathrm{y}$, en general, todas las personas e instituciones preocupadas por incrementar el conocimiento del público. Asimismo, el diálogo se presenta como el gran reto para este tercer milenio, teniendo en la comunicación de la ciencia una herramienta clave:

El periodismo científico y la divulgación de la ciencia constituyen elementos básicos del futuro del siglo XXI que son necesarios para un desarrollo ponderado y actual de individuos y sociedades. Las sociedades del Tercer Milenio se enfrentan con un objetivo importante, y de cuyo incumplimiento se pueden derivar graves daños. Se trata de la urgencia de hacer partícipe a la sociedad del valor del conocimiento científico, de sus beneficios y de sus riesgos, y de promover un diálogo razonable entre quienes tiene a su cargo la actividad científica y el resto de ciudadanos (Calvo Hernando, 2005:42-43).

El foro europeo de periodismo científico celebrado en Madrid en 2010 con el nombre de Media for Science Forum y organizado por la Fundación Española para la Ciencia y la Tecnología (FECYT) en el marco de la Presidencia española de la Unión Europea reunió a numerosos profesionales del ámbito de la comunicación de la investigación y la innovación, planteando reflexiones de gran interés para el presente apartado que fueron recogidas por De Semir en la obra Meta análisis: comunicación científica y periodismo científico publicada por la FECYT. Los expertos reunidos en el foro concluyeron "que la ciencia constituye la más importante aportación histórica de Europa a la civilización moderna" y que es actualmente el soporte más sólido con el que cuenta la humanidad para mejorar el bienestar de los ciudadanos, combatir la pobreza, afrontar los retos del cambio climático y hacer posibles nuevas metas para el desarrollo de los pueblos". Ante esta realidad, destacan la necesidad de que la ciudadanía reconozca la contribución del conocimiento científico y de que la comunidad científica renueve su compromiso con la sociedad que la financia y la apoya. La comunicación científica tiene un papel fundamental en esta relación entre ciencia y sociedad.

Para que esta relación entre la comunidad científica y los ciudadanos sea fructífera es imprescindible potenciar la extensión de la cultura científica, el acceso a la información 
científica y tecnológica y la participación de los ciudadanos en las decisiones científicas desde una perspectiva informada, habilitando para ello los marcos sociales y jurídicos adecuados (De Semir, 2011:51-52).

Los expertos reunidos en el Forum coincidieron también en destacar la importancia de los profesionales de la comunicación de la ciencia como nexo de unión entre ciencia y sociedad. Es a través de la comunicación pública de la ciencia como se deben acercar a la ciudadanía los avances y descubrimientos científicos; y son los periodistas y comunicadores científicos los que deben asumir la responsabilidad de facilitar la comprensión de los procesos de la investigación, la relevancia de los marcos institucionales en los que se produce el conocimiento y las implicaciones sociales, culturales y políticas que tiene la ciencia, afirmaban. No obstante, para alcanzar una adecuada CPC, apelaban asimismo a la necesaria implicación de los centros de investigación, la Administración Pública y las empresas de comunicación, destacando la necesidad de una gran alianza entre la comunidad científica, los medios de comunicación, los periodistas científicos y las autoridades responsables de la política científica en Europa para potenciar la cultura científica de la población. Para alcanzar estos fines se propusieron diez medidas que resumimos a continuación (De Semir, 2011:52-54):

- Los gobiernos deben adoptar medidas de apoyo eficaces a la difusión pública de la ciencia, el ejercicio del periodismo científico y a la extensión de la cultura científica, desarrollándolas como actividades complementarias e inseparables de la propia investigación científica y tecnológica.

- Promover, especialmente desde el sector público, iniciativas de conocimiento abierto, facilitando el acceso universal a los resultados de la investigación.

- Los poderes públicos deben promover programas específicos de divulgación e información científica a través de los medios de comunicación masivos y de los nuevos medios basados en las tecnologías de la información y las comunicaciones.

- Medios de comunicación, investigadores y administración deben aprovechar e incentivar el uso de los recursos asociados a las nuevas tecnologías de la información y las comunicaciones, como herramientas clave a la hora de involucrar la participación activa de la ciudadanía en la comunicación y divulgación de la ciencia, desde una perspectiva crítica e interactiva. 
- Medios de comunicación, centros de investigación y administración deben favorecer la identificación por parte de la ciudadanía de las capacidades científicas y tecnológicas ubicadas en el entorno geográfico próximo, situando dichas actividades y herramientas en el contexto globalizado de producción del conocimiento.

- Debe impulsarse y apoyarse el papel de las asociaciones de periodismo científico, las cuales han probado ya su compromiso con el desarrollo de una profesión especializada e independiente.

- Las universidades deben incluir en los programas de formación de expertos en comunicación cursos específicos de periodismo científico. De la misma manera se hace necesario el diseño de programas formativos que faciliten a científicos e investigadores la adquisición de las habilidades y herramientas comunicativas básicas para acercar al público los resultados y metodologías propios de su actividad.

- Impulsar líneas de investigación en ciencias sociales y de la información que contribuyan a mejorar el conocimiento científico en el ámbito de la comunicación, la percepción pública de la ciencia y el periodismo científico.

- La comunidad científica debe seguir abriéndose a las demandas de información científica de interés cívico y asumir como una responsabilidad propia la tarea de facilitar la extensión de la cultura científica, la información periodística sobre sus actividades de investigación y el acercamiento del público a las controversias científicas.

- Las instituciones científicas deben dotarse de instrumentos especializados en difusión pública de la ciencia y personal especializado en periodismo y divulgación científica.

Como vemos, las recomendaciones de los expertos parecen poner el acento en medidas dirigidas hacia un modelo de comunicación de la ciencia todavía con un carácter claramente unidireccional. Más recientemente, en 2014, De Semir ponía el acento en las razones y la importancia de llevar la comunicación de la ciencia a un verdadero diálogo entre ciencia y sociedad, destacando que: informa al gran público 
sobre cuestiones relacionadas con la ciencia y la tecnología; informa a la ciencia acerca de las percepciones y expectativas sociales; pone la experiencia científica a disposición del público; tiene un impacto en el diseño de políticas y en la creación de programas; afecta a la legitimidad de la investigación y desempeña una función destacada en el gobierno de la ciencia, la tecnología y el riesgo potencial.

Pero esta comunicación basada en el modelo "ciencia y sociedad" implica también algunos riesgos. Entre ellos, el autor destaca la vulnerabilidad a los malentendidos y los abusos, ante el riego de caer en modelos y conceptos excesivamente simplificados de cómo la ciencia y la sociedad se comunican. También alerta de la creación de expectativas poco realistas acerca de ambas partes en relación con los beneficios de la comunicación, así como los riesgos que suponen formas de comunicación que aumentan la distancia entre la ciencia y sus audiencias extracientíficas en lugar de captarlas. Ante estos riesgos, De Semir destaca la necesidad de tener siempre presente que el objetivo de la comunicación de la ciencia a través del diálogo pasa por posibilitar que la sociedad haga el mejor uso posible del conocimiento científico.

La comunicación científica debe ser útil para establecer una forma de interrelación transparente y abierta que contribuya a definir la función de la ciencia en la sociedad, y fundamentalmente para posibilitar que la sociedad haga el mejor uso posible del conocimiento científico (De Semir, 2014: 109).

Tras una aproximación a las voces de investigadores y divulgadores sobre las razones, riesgos y retos de la comunicación de la ciencia, cabe detenerse en algunas reflexiones académicas sobre la importancia y los motivos de la CPC. En un influyente artículo publicado en 1987, Thomas y Durant se preguntaban ¿por qué deberíamos promover la comprensión pública de la ciencia? (Thomas y Durant, 1987). La revista Public Understanding of Science (PUS) reunía en 2014 a varios autores para tratar de analizar las respuestas actuales a esta cuestión. Entre las conclusiones extraídas de estas aportaciones, destacan la necesidad de dar respuesta a la acusación de que la participación de los argumentos sociales en la prescripción, ejecución y evaluación del compromiso público con la ciencia se limita al argumento de que "the technical is political, the political should be democratic and the democratic should be participatory" (Moore, 2010:793). En este sentido, Stilgoe destaca la necesidad de desarrollar nuevas líneas de argumentación y análisis, reconociendo más abiertamente 
que el compromiso público tiende a convertirse en una respuesta procedimental a un desafío político.

If we, as social scientists, are going to continue a normative commitment to the idea of public engagement, we need to develop new lines of argument and analysis. The first thing to acknowledge more openly is that public engagement has typically become a procedural response to a more fundamental political challenge (Stilgoe, 2014:11).

Trabajos como el que presentamos buscan sumar argumentos a la necesidad de una participación efectiva de la opinión pública en la ciencia desde una perspectiva ética, de forma que esta participación no se quede en una mera cuestión procedimental. Como hemos visto en el apartado anterior sobre RRI y corroboran diversos autores, a través de diferentes proyectos se ha comprobado el potencial de la participación del público para generar sorprendentes y productivas discusiones sobre la política y los objetivos de la ciencia. También hemos visto como las instituciones cada vez se toman estas cuestiones más en serio, como demuestra la apuesta por la RRI. No obstante, autores como Stilgoe alertan de que, en ocasiones, el compromiso público irreflexivo ha sido utilizado para cerrar debates en áreas complejas. Por ello plantean la necesidad de reflexionar sobre el interés de preguntarse, además del ¿por qué?, el ¿cuándo debemos promover el compromiso público con la ciencia? (Stilgoe et al, 2014:11).

Desde el ámbito académico, cabe destacar por otra parte la publicación de estudios que vienen a sumar a las razones para comunicar la ciencia, la del propio prestigio del los científicos. En este sentido, el estudio desarrollado por el Department of Life Sciences Communication de la University os Wisconsin-Madison (Yeo et al, 2014) vincula el compromiso de los científicos con el público fuera del ámbito académicos a mayores tasas de citación en revistas académicas. "Nuestros resultados destacan la importancia de la comunicación pública, especialmente si incluye múltiples actividades, en el alcance académico de los investigadores", explica la coautora del estudio Dominique Brossard. A medida que los investigadores se acercan más a los medios de comunicación, los límites entre los contextos académicos y públicos son más borrosos, señala el estudio, alcanzando mejores índices h (indicador que mide el impacto de la actividad investigadora publicada) aquellos que mantienen una relación más fluida con los mismos y una actitud más activa en las redes sociales, especialmente en Twitter. Los autores del estudio destacan también la posibilidad de que esta relación se deba a las mayores posibilidades de presencia en los medios de aquellos 
investigadores de prestigio. En cualquier caso, parece claro que la comunicación de la ciencia contribuye a mejorar el prestigio de los investigadores e investigadoras tanto entre la sociedad como a nivel de sus iguales. En una sociedad globalizada en la que la investigación requiere del trabajo colaborativo entre grupos y equipos de investigación, alcanzar un mayor prestigio parece también clave de cara a poder establecer relaciones más fructíferas también con los pares.

A lo largo de este apartado hemos visto un amplio número de razones apuntadas por científicos, divulgadores, periodistas y académicos para comunicar la ciencia. Algunas de ellas aparecen vinculadas a los propios beneficios que supone para los investigadores y la ciencia en general. Es el caso del aumento del prestigio y la confianza en la comunidad científica, la mayor legitimación y apoyo a la ciencia, el posible apoyo para la captación de recursos o el simple gozo de transmitir el entusiasmo por su trabajo. Otras tienen que ver con la necesidad de rendir cuentas a una sociedad ante la que se debe justificar el gasto público y que exige cada vez mayores niveles de transparencia e información. Esta demanda de la ciudadanía tiene que ver también con la responsabilidad de la ciencia, lo que nos lleva a una serie de razones vinculadas al marco ético de la RRI planteado en el presente trabajo. Es el caso de la importancia de aumentar el conocimiento y la comprensión ciudadana de la ciencia, vinculando este conocimiento a una mayor capacidad para la toma de decisiones. En este punto, son muchos los autores que, como hemos visto, señalan la comunicación de la ciencia como un requisito imprescindible para mejorar la salud democrática de las sociedades. Más allá del ámbito político, la transmisión del conocimiento aparece también como una contribución al bienestar de las personas, al desarrollo económico de las sociedades a través de la transferencia y a la expansión del propio conocimiento.

Entre las razones para comunicar la ciencia encontramos también una que resulta especialmente significativa para el presente trabajo, como es el conocer las expectativas en materia de ciencia de la sociedad. Entendemos que este conocimiento requiere establecer un verdadero diálogo entre ciencia y sociedad, que vaya más allá de la comunicación unidireccional de la ciencia. A buscar un modelo de comunicación para este diálogo dedicaremos el tercer bloque de la tesis. Antes, entendemos que resulta de interés conocer cómo los ciudadanos perciben la ciencia y a través de qué fuentes acceden a la información científica. 


\subsubsection{Percepción y actitudes hacia la ciencia}

A la hora de analizar las razones por las que comunicar la ciencia, nos encontramos también con una razón muy positiva de cara a potenciar la participación de la sociedad civil en el ámbito de la investigación. Se trata del hecho de que la ciencia y la información sobre la misma interesan a la ciudadanía. Así lo demuestran los estudios y encuestas ciudadanas realizadas por diferentes instituciones. Según el informe sobre Indicadores del Sistema Español de Ciencia y Tecnología de 2013 realizado por la FECYT $^{2}$, el interés no ha dejado de subir en los últimos años, situándose en un 3,12 sobre 5, mientras que otros temas con una presencia mucho mayor en los medios de comunicación, como es el caso de la política, solo alcanzaban un 2,67.

Para realizar un bosquejo sobre las opiniones de los españoles en materia de ciencia es necesario acercarse a las Encuestas de Percepción Social de la Ciencia y la Tecnología realizadas bienalmente por la FECYT desde 2002. Los resultados de la séptima y última encuesta, presentados el 23 de abril de 2015, nos ofrecen un interesante panorama tanto de la evolución como de la situación actual de la comunicación de la ciencia y la percepción de la ciudadanía sobre la misma, por lo que consideramos de interés detenernos en ellos (FECYT, 2015a).

Los datos de la última encuesta muestran como la imagen que los ciudadanos tienen sobre la ciencia ha mejorado en los últimos dos años. Un 59,5\% afirma que ésta tiene más beneficios que perjuicios frente a un 53\% en 2012, lo que supone un aumento del $12,2 \%$. El estudio señala que el interés por la ciencia y la tecnología ha ido en aumento en los últimos años y actualmente se mantiene estable en un $15 \%$ de los españoles (15\% en 2014 frente a 15,6\% en 2012).

\section{EVOLUCIÓN DEL INTERES ESPONTÁNEO POR LA CIENCIA Y LA TECNOLOGÍA}

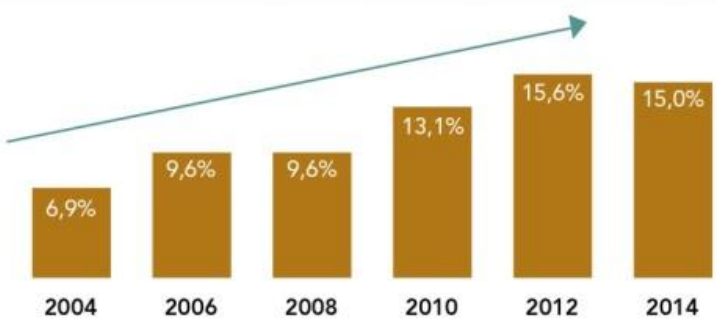

Fuente: VII Encuesta de Percepción Social de la Ciencia (2014), FECYT.

\footnotetext{
${ }^{2}$ El informe Indicadores del Sistema Español de Ciencia, Tecnología e Innovación 2013 es el último publicado que recoge datos sobre cultura científica ya que estos no aparecen en el informe de 2014.
} 
El interés por la ciencia es mayor entre los más jóvenes y mayor también en hombres que en mujeres: 20,9\% frente al 9,9\%. Esta brecha de género se mantiene en todos los tramos de edad, incluso en los más jóvenes.

\section{INTERÉS ESPONTANEO POR LA CIENCIA Y TECNOLOGÍA SEGÚN SEXO Y EDAD EN 2014}

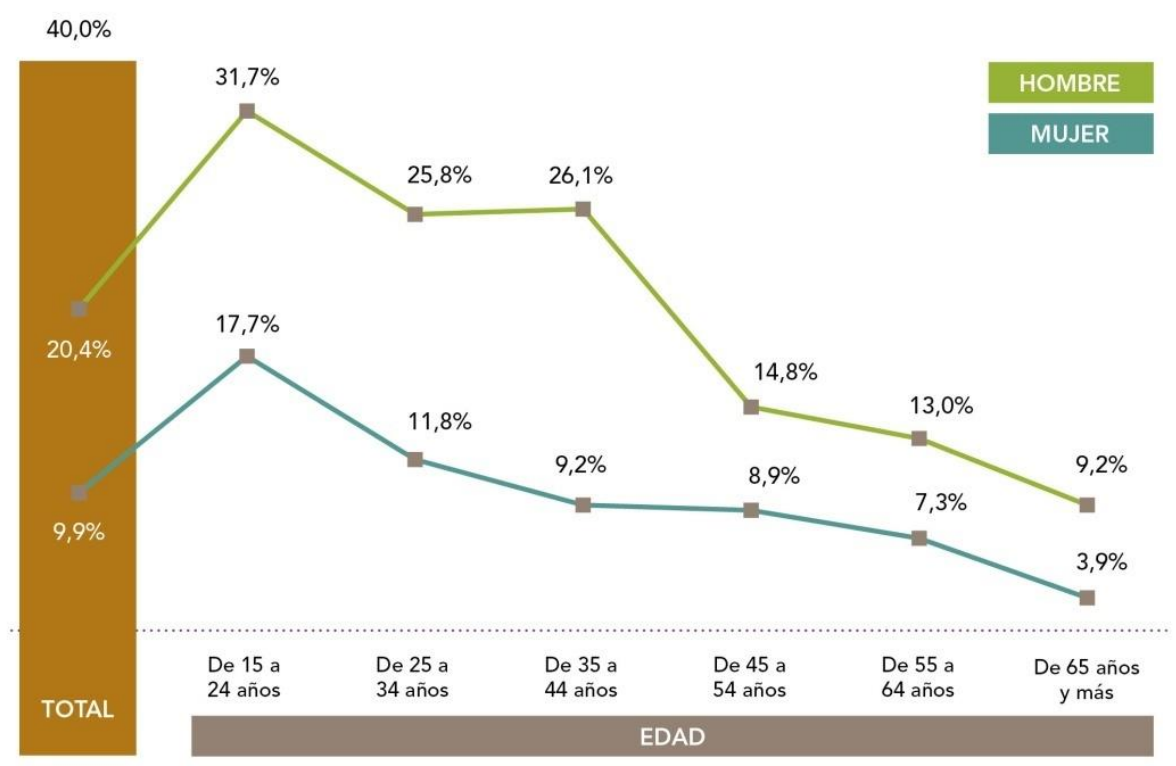

Fuente: VII Encuesta de Percepción Social de la Ciencia (2014), FECYT.

Otro de los datos destacados del estudio revela que uno de cada cuatro españoles no está interesado en ciencia, fundamentalmente porque no la entiende, aunque este porcentaje desciende ligeramente respecto a 2012, del 25\% al 24,3\%. En relación a la imagen social de la ciencia, los científicos vuelven a ser la segunda profesión más valorada con un 4,40 sobre 5 (subiendo respecto al 4,24 de 2012), solo por detrás de los médicos $(4,55)$. A continuación se sitúan profesores $(4,28)$ e ingenieros $(4,14)$.

En cuanto a la alfabetización en materia de ciencia y tecnología, los ciudadanos perciben un déficit en formación científica y aumentan al 47,1\% los que consideran que su educación científica es baja o muy baja (41,5\% en 2012), superando a los que la califican de normal (41,6\%). Esta percepción mejora respecto a 2004 pero desciende en los dos últimos años. Destaca que los jóvenes de 15 a 24 años perciben una mejor educación científica que la media, pues solo el 31,4\% la califica de baja o muy baja, 16 puntos menos que la media. En 2014 se incluyó por segunda vez en estas encuestas una pregunta sobre conocimientos científicos concretos y la nota media de los entrevistados se ha situado en 7,2 sobre 10 . Comparando los resultados con las nueve preguntas 
idénticas que se hicieron en 2006 hay una notable mejoría, del 5,84 de entonces al 7,04 de 2014.

Por lo que respecta a la percepción sobre la información de ciencia y tecnología difundida en los medios, respecto a años anteriores, se acentúa el déficit de información científica percibido, pues existe una diferencia entre el nivel de información (2,82 sobre $5)$ y el grado de interés (3,25 sobre 5) de un 0,43. Los ciudadanos, según se desprende de los datos de la encuesta, consideran que internet es el único medio que presta suficiente atención a la información científica $(61,5 \%)$, mientras que la mayoría percibe que televisión, radio y diarios y revistas no incluyen suficiente información sobre estos temas.

En cuanto a los medios de acceso, internet es ya la primera fuente de información científica para un 39,8\% de los ciudadanos, pero es la televisión la fuente más consultada cuando se citan tres medios para estar informado de ciencia $(72,1 \%)$ e internet se sitúa en segundo lugar con el 56,7\%.

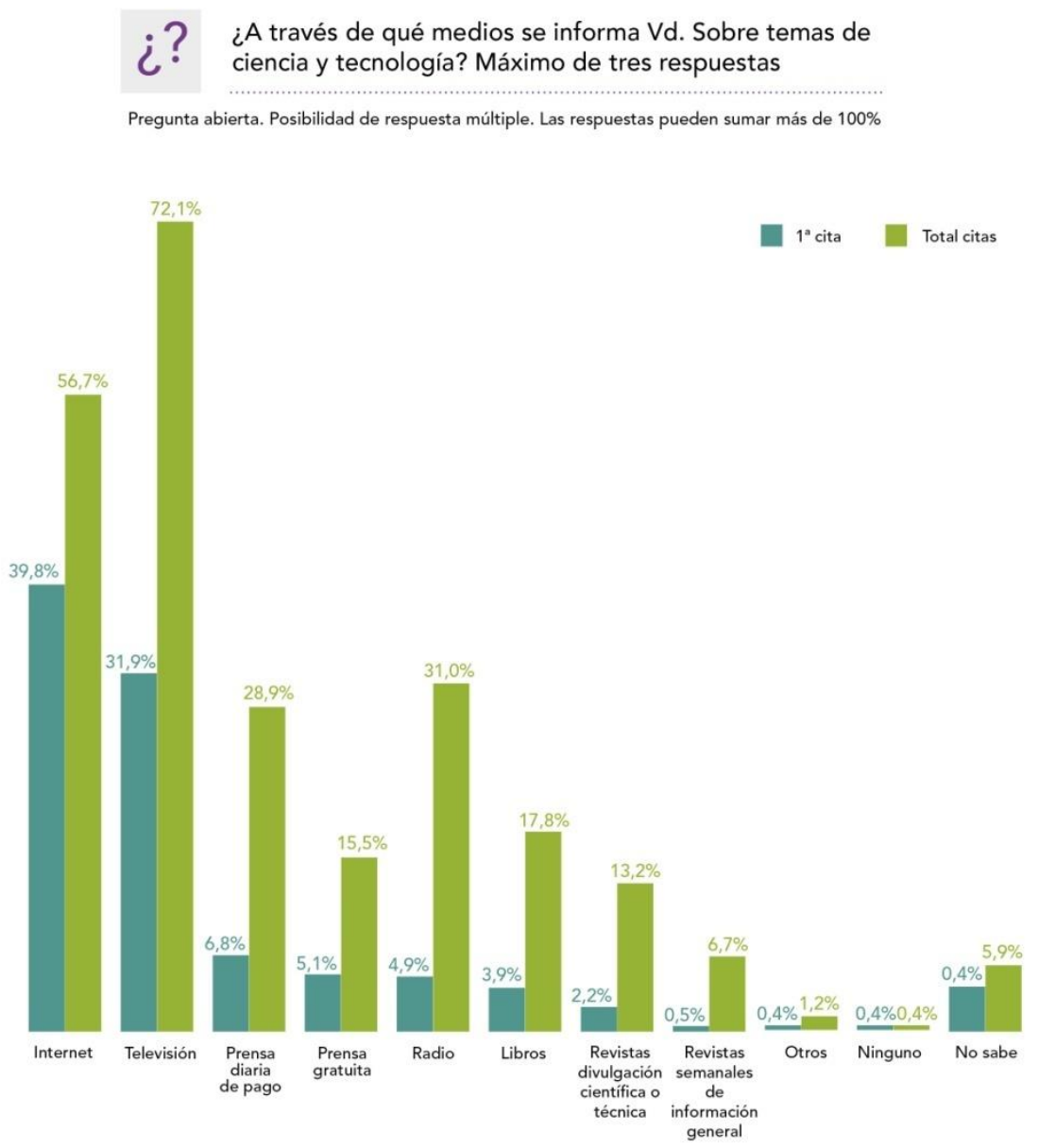

Fuente: VII Encuesta de Percepción Social de la Ciencia (2014), FECYT. 
Los jóvenes utilizan mayoritariamente internet para informarse de ciencia: un $84,4 \%$ de penetración en jóvenes de 15 a 24 años y un 78,4\% en los de 25 a 34 años. Wikipedia es la primera fuente de información científica en internet $(32,7 \%)$, seguida muy de cerca por los medios digitales generalistas $(31,5 \%)$ y de las redes sociales (30,8\%). Después están los vídeos de ciencia para el 29,7\%, los blogs $(25,4 \%)$ y los medios de comunicación especializados en ciencia (22,8\%). Entre el 30,7\% de los ciudadanos que usan las redes sociales como canal de información sobre ciencia, el 91,8\% lo hace por Facebook, el $47,7 \%$ por Twitter y el $21,5 \%$ por Instagram. La encuesta bianual aborda también la percepción de la ciudadanía en materia de políticas de apoyo a la ciencia y tecnología. Las prioridades de gasto público de los españoles se concentran en sanidad y educación (por encima del 80\%) seguidas de pensiones (46,6\%) y desempleo (42,9\%). Como primer ámbito después de los sectores básicos se sitúa la ciencia y tecnología con un $23,4 \%$ de ciudadanos que la eligen entre sus cuatro prioridades de gasto público. La ciencia obtiene mayor apoyo entre los jóvenes $(27,5 \%)$ y personas con estudios universitarios (35\%). Tres de cada cuatro españoles considera además que en un contexto de recorte de gasto público los distintos gobiernos deberían invertir más en ciencia y tecnología. Este apoyo ciudadano ha crecido sustancialmente pasando del 53,7\% de apoyo a mayor inversión en I+D en 2010 al 79,8\% de 2014, en el caso del gobierno central. Dos de cada tres ciudadanos españoles $(64,7 \%)$ estarían dispuestos además incluso a donar a la ciencia, frente a un 57,1\% en 2012, aunque más de la mitad matiza que ahora no tiene posibilidades para hacerlo. Están más dispuestos a incluir a la ciencia entre sus donaciones los hombres mayores de 34 años y las personas con educación secundaria de segundo ciclo y universitaria. Se observa que a mayor interés por la ciencia aumenta la disponibilidad a donar de forma altruista a la ciencia.

Asimismo, en 2014 por primera vez son mayoría los ciudadanos que consideran que deberían desempeñar un papel más importante en las decisiones sobre ciencia y tecnología que les afectan. Un 53,1\% de los ciudadanos están muy o bastante de acuerdo en 2014 con tener un papel más importante en la ciencia frente al 40,4\% de 2012. Este dato resulta especialmente significativo para el presente estudio ya que demuestra el interés de la sociedad como grupo de interés de la ciencia e innovación en que sus voces sean oídas y sus expectativas tenidas en cuenta. En este sentido, ante la afirmación: "Los ciudadanos deberían desempeñar un papel más importante en las decisiones sobre ciencia y tecnología que les afectan directamente", en una escala del 1 
al 5 -de nada a mucho- los encuestados puntuaron en 2008 con un 3,18; en 2012 con un 3,39 y en la encuesta de 2014 la puntuación se eleva ya a un 3,60, continuando así una tendencia ascendente.

Los estudios desarrollados por la FECYT se enmarcan en los denominados Public Understanding of Science, estudios sobre la percepción social de la ciencia que, como hemos visto, comenzaron a realizarse a mediados del siglo XX en Estados Unidos y posteriormente en otros países, incluidos los europeos. Este tipo de estudios contemplan en su mayoría indicadores que tradicionalmente pueden dividirse en cinco grupos: el conocimiento público sobre ciencia y tecnología; el acceso a la información; la comprensión sobre la ciencia y sus procedimientos; las actitudes y las opiniones de la sociedad hacia la ciencia y sus procedimientos; y la confianza en los científicos o en las entidades encargadas de la regulación de sus actividades (Revuelta, 2012:118).

Entre este tipo de estudios cabe destacar a nivel nacional los realizados por la FECYT, a los que ya hemos hecho referencia, y los sondeos del Centro de Investigaciones Sociológicas (CIS), que recogen las actitudes de los españoles mayores de 18 años frente a la ciencia y la técnica recabadas a lo largo de las últimas dos décadas, de forma monográfica o como parte de cuestionarios más extensos. A nivel europeo, cabe destacar los Eurobarómetros elaborados por la Comisión Europea que miden la opinión y conocimientos de los europeos sobre una gran variedad de temas, incluidos ciencia, tecnología e innovación. En 2014 el Grupo de Estudios Avanzados de Comunicación de la Universidad Rey Juan Carlos, liderados por Luis Pablo Francescutti (2014), realizaba una recopilación y análisis de todos estos informes con el fin de ofrecer un completo mapa sobre la atención prestada a la ciencia por la ciudadanía en España y Europa y sus actitudes antes determinados aspectos de la actividad científica.

Del análisis de las encuestas del CIS y la FECYT, el estudio dirigido por Francescutti confirma que en los últimos 20 años se ha registrado en España un aumento generalizado del interés manifiesto por la ciencia y la tecnología. En paralelo, los españoles dicen sentirse cada vez más informados al respecto. En el seno de esta tendencia ascendente se aprecian fluctuaciones, pues en ocasiones el porcentaje de personas muy interesadas retrocede respecto de la cota alcanzada en mediciones anteriores, sin retornar a los niveles iniciales.

A la vista de los datos, el estudio establece que el interés no se distribuye de modo uniforme por edades, como viene a ratificar la última encuesta de la FECYT, 
posterior al estudio de Francescutti. En casi todas las encuestas, los jóvenes de 15 a 24 años de edad se muestran como los más interesados, y los mayores de 55 años, los menos. Este dato que podría arrojar cierta esperanza de cara a la evolución del interés futuro, debe ponerse en relación con los datos evolutivos arrojados por el Eurobarómetro para no alimentar falsas expectativas de futuro.

Este rasgo recurrente puede alimentar esperanzas en que el relevo generacional garantice un aumento continuo de la implicación, a medida que los jóvenes (mejor escolarizados y más interesados) sustituyan a sus mayores (peor escolarizados y menos interesados). Pero esta expectativa debe ser ponderada a la luz del Eurobarómetro, cuyo estudio longitudinal advierte de que no siempre las nuevas generaciones se interesan más por la ciencia y la tecnología que las anteriores: en Francia, el interés sufre un declive intergeneracional, en Alemania y en Portugal crece, y en Italia y el Reino Unido experimenta altibajos (Francescutti, 2014:14).

El sexo es otra variable influyente. Tanto en España como en Europa, los porcentajes de hombres interesados por la ciencia duplican a los de mujeres, y la diferencia se mantiene a lo largo del periodo estudiado, pese al incremento del interés femenino. Este dato vuelve a ser de nuevo corroborado por el último estudio de la FECYT, por lo que no parece que existan motivos para esperar que la preponderancia masculina en los públicos de la ciencia vaya a desaparecer en el corto plazo. De ahí también la importancia de la introducción de aspectos de género en el desarrollo de la RRI planteada por la Unión Europea como una cuestión prioritaria en la consecución de una investigación e innovación más responsables.

A pesar de que todas las encuestas muestran un creciente interés por la ciencia, éste sigue siendo inferior al expresado por otros temas como la medicina. Lo mismo ocurre con el atractivo de los contenidos científicos de los medios, situado todavía muy por detrás del manifestado por los deportes o los espectáculos. La ciencia interesa cada vez más pero, para los autores del estudio, “continúa sin despertar entusiasmo. De todos modos, que dicho interés no es meramente declarativo lo prueba la asistencia a los museos de ciencia y técnica, y de ciencias naturales, que creció de modo exponencial hasta frenarse a partir de 2006". La encuesta de la FECYT de 2010 atribuye un cierto descenso del contacto ciudadano con la ciencia tecnología a la crisis económica que afecta, por ejemplo, a la visita a museos que cobran entrada. Pero, en opinión de Francescutti, la crisis económica no explica por qué, “en el mismo periodo en que cae la asistencia a los museos científicos, los artísticos baten récords de público”. El autor considera que, de no deberse a la economía, habría que buscar sus causas en dinámicas 
culturales no tenidas en cuenta como, por ejemplo, la finalización de los estudios obligatorios, en los cuales la enseñanza científica tiene carácter prescriptivo, y el ingreso en una fase de mayor autonomía y exploración de gustos vinculados a la cultura juvenil.

Por lo que respecta a las fuentes de información a través de las que la ciencia llega a la ciudadanía, del análisis de las encuestas realizadas a nivel nacional, los datos indican que, hasta recientemente, la televisión era la principal fuente de divulgación con el documental como género más popular. Los datos certifican además que, como confirma la encuesta de la FECYT de 2014, en los últimos años, la pequeña pantalla ha cedido el testigo a internet, la fuente que los encuestados consideran más fiable después de las revistas de divulgación. Los demás medios han perdido audiencia, incluso dichas publicaciones, que hasta 2008 venían ganando lectores. En este cambio en los canales por los que la información sobre ciencia y tecnología llega a la ciudadanía sin duda ha tenido un gran peso el cambio de paradigma que ha supuesto la nueva galaxia mediática y que abordaremos ampliamente en el siguiente apartado.

Los datos de las encuestas también ponen de manifiesto que los contenidos científicos de los medios figuran entre los últimos de las preferencias de los españoles, lideradas por los deportes, la salud y la cultura (datos de 2004). El porcentaje de quienes buscan aquellos contenidos no supera el 12\% (datos de 2007), cifra muy alejada del $36 \%$ de los encuestados que dicen tener un interés "destacado" por la ciencia y la tecnología, y más próxima al 15,6\% de muy interesados por esas informaciones.

Algunas encuestas, como las de la FECYT, sugieren una demanda informativa insatisfecha, resultado de la brecha entre la información científica recibida y la deseada; otras señalan un empate entre quienes la consideran suficiente y quienes la creen insuficiente; y otras detectan una opinión mayoritaria a entremedias de ambos extremos. Para Francescutti, “dilucidar este punto importa sobremanera, pues de ello depende que se conozca con certeza la magnitud del público potencial de la comunicación de la ciencia" (Francescutti, 2014).

Entre los estudios sobre percepción social de la ciencia, entendemos necesario hacer también referencia al realizado por la Fundación BBVA en once países, diez europeos y Estados Unidos, sobre las percepciones y la actitud de la opinión pública en ciencia y tecnología (Fundación BBVA, 2012). Al igual que en las encuestas que hemos ido viendo, el estudio refleja que la visión de la ciencia es altamente positiva, 
considerando la ciudadanía que la ciencia es el motor de progreso, que tiene efectos positivos en la salud de las personas, la cultura de la sociedad y la forma de entender el mundo. Los médicos y científicos son percibidos como los grupos profesionales que más contribuyen al bienestar y al avance de la sociedad, mientras que las universidades y las asociaciones profesionales de médicos son las que obtienen un mayor nivel de confianza sobre la información científica que aportan a la sociedad.

El estudio tiene también en cuenta el papel de la religión y la ética respecto a la ciencia. En este sentido, resulta especialmente significativa la existencia de un amplio consenso en los Estados Unidos (69\%) y en Europa (72\%), respecto a que la religión no debe poner límites a los avances científicos. Este porcentaje se eleva al $80 \%$ en el caso de España. Por el contrario, alrededor de la mitad de la población piensa que la ética sí debería poner límites a los avances: el $49 \%$ en Estados Unidos y el 54\% de media en Europa. En el caso de España, la ciudadanía se diferencia del promedio europeo con un $47 \%$ que cree que la ética no debería poner límites a los avances científicos y un $41 \%$ que cree que sí.

El estudio se cuestiona además la colisión potencial en áreas concretas entre conocimiento científico y credos religiosos. En este sentido, resulta sorprendente que la visión científica del origen y evolución de los seres humanos a partir de especies animales anteriores es considerada como verdadera por un $64 \%$ de la ciudadanía europea, un 65\% en el caso de España. Sin embargo, en Estados Unidos predomina la visión opuesta, elevándose a un $61 \%$ el porcentaje de ciudadanos que cree que Dios creó a los seres humanos más o menos con su forma actual, negando así la teoría de la Evolución de las Especies.

Con respecto al nivel de cultura científica, España se sitúa en la parte baja de los países analizados en conocimientos científicos. El estudio de la Fundación BBVA revela un importante déficit en las dimensiones simbólicas de la cultura científica, como el conocimiento de las instituciones científicas y las grandes figuraras históricas. Sólo un 5\% nombró entre los científicos famosos españoles a Ramón y Cajal y no llega al $3 \%$ los que mencionaron a Severo Ochoa. Por el contrario, el estudio evidencia que en países como Polonia, Francia o Italia sus científicos más relevantes son ampliamente conocidos por la ciudadanía. En este sentido, cabe señalar que el estudio refleja como a mayor nivel de conocimiento científico, de cercanía a la ciencia y nivel educativo, se produce un menor nivel de reservas ante la ciencia. 
Una vez planteada esta aproximación a través de diferentes estudios y encuestas a la percepción y las actitudes de la ciudadanía ante la ciencia, profundizaremos a continuación en la necesidad de avanzar hacia una ciudadanía más activa y participativa.

\subsubsection{Cultura científica: la gestión de la participación}

Como hemos visto hasta ahora y como destacan numerosos autores, el conocimiento científico tiene un papel central en el mundo actual, como factor crucial de la productividad, la Administración Pública e incluso la experiencia personal (Castells, 1996). Además, se ha producido una politización de la ciencia debida, entre otras cosas, a la visibilidad de los impactos negativos para la salud y el medio ambiente. Este es un fenómeno relativamente reciente, pues tradicionalmente la ciencia y la tecnología eran consideradas actividades al margen de la esfera política, aunque motor de modernización social. "Esta situación ha llevado a la ciencia y la tecnología al centro de la arena pública, haciéndola objeto del debate político y el conflicto social” (López Cerezo, 2010:353). Para autores como López Cerezo, la consecuencia de esta creciente importancia pública de la ciencia y la tecnología, así como su politización, ha generado una preocupación institucional por la alfabetización científica de la ciudadanía, tanto en la educación formal como a través de otros canales.

Por otra parte, el creciente protagonismo ciudadano y la vertebración social del mundo contemporáneo está en la base de que la participación ciudadana en las políticas públicas relacionadas con la ciencia y la tecnología (la discusión de programas, proyectos y reglamentos, así como la regulación de impactos y riesgos tecnológicos) sea frecuentemente defendida como un principio democrático básico y una condición de gobernanza (Renn, Webler y Wiedemann, 1995). Esta demanda de participación viene impulsada por el incremento del activismo social desde los años 60 del pasado siglo.

A la hora de abordar esta participación de la ciudadanía y la formación de una cultura científica, consideramos de interés recuperar los principios fijados por Cortina para el desarrollo de una ética y una ciudadanía cordial. De este modo, la búsqueda de una participación ciudadana debe respetar el principio de no instrumentalizar a las personas, respetando en todo momento su autonomía y evitando cualquier tipo de manipulación. A este respecto entendemos que la comunicación de la ciencia resulta 
clave para que las personas puedan actuar de forma informada y autónoma. Esta necesidad de información está asimismo relacionada con el principio de las capacidades, que implica empoderar a las personas para que sean sujetos agentes de sus vidas. Lograr este empoderamiento es una cuestión de justicia a la que la sociedad está obligada, recuerda la autora. El tercer principio planteado por Cortina, el principio de justicia distributiva, también está relacionado con este empoderamiento, ya que para la autora el mínimo decente es el del "interlocutor válido" que consiste en empoderar a las personas para que puedan ser interlocutores válidos como un primer mínimo a partir del que pueden decidir qué consideran básico mediante el diálogo, ya que lo básico es lo que expresa intereses universalizables (Cortina, 2007).

Un principio que entendemos de especial relevancia para el tema que nos ocupa y que se desprende del marco ético propuesto en el presente trabajo es el principio dialógico, que obliga a tomar como fuente de la obligación moral el reconocimiento recíproco, de forma que deben tenerse en cuenta los intereses de los afectados por las decisiones para que sean ellos quienes, en la medida de lo posible, expresen esos intereses a través del diálogo (Cortina, 2007). En el caso de la ciencia, recordemos que la autora considera un requisito indispensable para llegar a decisiones justas la ampliación de la información y la creación de plataformas de participación. Así, la necesidad de una comunicación que favorezca una cultura científica y el fomento de la participación vuelven a aparecer como necesarias para el desarrollo de una ciencia responsable.

Finalmente, a la hora de hablar de cultura científica y participación resulta asimismo necesario no perder de vista la importancia de garantizar el futuro de la naturaleza y de la vida humana, lo que enlaza con el principio de responsabilidad por los seres indefensos no humanos.

Los principios de Cortina nos ofrecen un marco normativo para la participación en materia de ciencia y el desarrollo de una cultura científica. Ligada a estos dos fenómenos, el de la alfabetización para una mayor cultura científica y el de la participación ciudadana, encontramos también interesante hacer referencia a la propuesta de López Cerezo que plantea un cauce de unión entre ambos a través de la denominada formación participativa (López Cerezo, 2010). Así, existen casos en los que la implicación en un asunto social, relacionado con la innovación tecnológica o intervención ambiental, genera conocimiento entre los involucrados; y otros en los que 
es el conocimiento disponible y su apropiación social lo que genera implicación cívica y participación. Existe así un bucle de retroalimentación entre conocimiento y participación. "La generación de cultura científica en la vida ciudadana no sólo no es independiente de la participación social sino que se hallan estrechamente vinculadas como procesos en paralelo mutuamente realimentados" (López Cerezo, 2010:353).

El autor revisa el concepto de cultura científica, señalando que la idea básica que subyace a la mayoría de las propuestas de alfabetización científica es que, puesto que numerosas decisiones políticas están relacionadas con la ciencia y la tecnología, es necesario que los ciudadanos posean ciertos conocimientos mínimos sobre dichas actividades.

El concepto de cultura científica presupuesto es el de una comprensión mínima de los principales resultados de la ciencia y la tecnología y también del llamado «método científico» (...). Se supone, siguiendo el modelo del déficit cognitivo, que si la ciencia y la tecnología se han convertido en objeto de controversia social es debido principalmente al desconocimiento por la ciudadanía de algunos aspectos técnicos implicados en el tema objeto de debate, por ejemplo, la energía nuclear, la telefonía móvil o los alimentos transgénicos (López Cerezo, 2010:353).

Para López Cerezo se trata de un modelo erróneo por varios motivos entre los que destaca cuatro. En primer lugar, defiende que las actitudes hacia la ciencia y la tecnología no dependen exclusivamente del nivel de conocimiento científico. Además, considera que se subestima el conocimiento de los impactos negativos, riesgos e incertidumbre en ciencia y tecnología, a pesar de que estos temas tienen una creciente visibilidad pública en los medios de comunicación y son motivo frecuente de conflictos sociales. En tercer lugar, señala que no suelen incluirse contenidos de las ciencias sociales, conocimiento sobre la ciencia y no únicamente de ciencia y tecnología. Es decir, conocimiento sobre los usos políticos del conocimiento científico, sobre el valor económico de la innovación tecnológica, sobre los dilemas éticos de algunas tecnologías, etc. Finalmente, para el autor otro de los problemas de este modelo es que no tiene en cuenta el importante papel de la confianza y las actitudes en la modulación de la apropiación del conocimiento científico por parte de los ciudadanos. Para López Cerezo, mejor oferta formativa no implica mayor volumen de apropiación ciudadana puesto que las actitudes negativas o la desconfianza en las fuentes o canales de la oferta puede llevar al fracaso en la generación de cultura científica.

En definitiva, considera que esta concepción, basada en el modelo lineal de difusión (expertos-comunicadores-ciudadanos), maneja una visión pasiva y muy pobre 
del proceso de enculturación que desatiende consideraciones de calidad, comportamentales e idiosincrásicas en el proceso de apropiación (López Cerezo, 2010:354). Para enriquecer el concepto de cultura científica y avanzar hacia nuevas posibilidades de democratización de la gestión y las políticas públicas, plantea un modelo interactivo que no contempla a los ciudadanos como receptores pasivos de los elementos cognitivos generados por expertos y posibilitados por comunicadores, ni a éstos como un mero canal de transmisión que se limita a traducir la información técnica en un lenguaje accesible. En el modelo interactivo el periodista científico debe actuar "como mediador activo entre legos y científicos, trasladando inquietudes, valores e información en un sentido, y conocimiento, incertidumbre y también valores en el otro" (López Cerezo, 2010:356).

Siguiendo este modelo, la cultura científica no puede medirse sin atender a su calidad, entendiendo que:

Una cultura científica de calidad es una cultura crítica y responsable, es conocimiento no sólo de las potencialidades de la ciencia sino también de sus incertidumbres, de sus riesgos, y de los interrogantes éticos que plantea (...) Es ser capaz de hacer uso de esa información al tomar decisiones de compra en el supermercado o en la exposición a una tecnología médica, como consumidor, como padre, como empresario o como trabajador (López Cerezo, 2010:357).

Este tipo de cultura de calidad, personalmente valiosa, no lo proporcionan sin más los medios de comunicación. Requiere con frecuencia de una base sólida en la educación reglada, y sobre todo asimilar significativamente esa información en el enriquecimiento de la propia vida, lo cual suele presuponer experiencia individual a través de la vivencia personal, con frecuencia por la implicación en procesos de participación.

"No podemos, como con frecuencia ocurre, concebir la cultura científica como un prerrequisito para la participación, como una tarea a desarrollar antes de dar el paso de la democratización” (López Cerezo, 2010: 357). Para el autor, hacerlo supondría, además de desplazar sine die este último desafío, cerrar las puertas a algunas de las formas de promoción de la cultura científica que mejores resultados pueden dar, no sólo en alfabetización sino también en el desarrollo de una actitud de responsabilidad cívica que acompañe a esa alfabetización. Más aun, López Cerezo resalta el interés de que los diferentes modelos que puede asumir la participación pública sean evaluados de acuerdo 
con su capacidad para que el proceso de participación genere aprendizaje social en relación con la ciencia y la tecnología, y por lo tanto, cultura científica en la ciudadanía.

López Cerezo habla de diferentes tipos de participación a través de la cultura científica alejadas de las concepciones más clásicas como, por ejemplo, distintas formas de protesta social a nivel individual o comunitario, el consumo diferencial informado y consciente, la colaboración con otros usuarios de internet en la generación de conocimiento, la implicación personal a través del activismo en grupos de interés, etc. También existen otros formatos más clásicos de participación como el referéndum, la gestión negociada o un comité asesor, que requieren asimismo del aprendizaje social.

Existen iniciativas emprendidas según un modelo más interactivo de gestión que han generado una ciencia más relevante, enriquecida por la experiencia de afectados e interesados, una mayor legitimidad en el proceso de gestión política y el aprendizaje social, asegura el autor, citando como ejemplos el National Research Council estadounidense (1996) o las denominadas conferencias de consenso, una técnica de participación que genera cultura científica y debate social, adoptada inicialmente en Dinamarca y actualmente extendida a numerosos países. Se trata de adoptar un modelo de jurado, con ciudadanos representativos de la población general, que debaten durante unos tres días, con asesoría de expertos aportados por los grupos de interés implicados, sobre un asunto social relacionado con el impacto de los avances científicos. Se trata de reuniones abiertas al público y los medios de comunicación, que pretenden estimular el debate social, mejorando la comprensión y el conocimiento público sobre una cuestión política particular. El objetivo es informar a los ciudadanos sobre las diferentes opciones políticas y las consecuencias potenciales de tales opciones. Al final se elabora un informe de evaluación de alternativas que se hace público y, en algunos casos, puede tener influencia sobre el proceso de toma de decisiones.

Otro ejemplo novedoso son las Sciencie shops, vistas en el capítulo anterior al hablar de ejemplos de acciones de RRI. Se trata de un servicio de asesoramiento especializado para aquellos agentes sociales que, sin recursos propios, requieren conocimiento experto para adoptar una postura o involucrarse en un debate sobre algún reglamento o actuación en materia de ciencia o tecnología. Son mecanismos potencialmente abiertos a todos los ciudadanos o colectivos de una comunidad, que ofrecen un asesoramiento puntual que puede tener duración variable. Se han desarrollado experiencias en numerosas universidades holandesas y de otros países. El 
community-based research es un mecanismo desarrollado en EEUU y Canadá, variante de las tiendas de la ciencia, en el que el trabajo de investigación es realizado por los estudiantes universitarios como parte de su formación académica, en colaboración con colectivos o comunidades locales.

Se trata de ejemplos en los que a partir de la participación se genera formación, de forma que la cultura científica no se plantea únicamente como necesidad previa. En cualquier caso e independientemente de cuál se dé primero, entendemos que participación y cultura científica mantienen una estrecha vinculación en la que la comunicación no deja de tener un papel clave. En el siguiente punto abordaremos por tanto cómo esta comunicación llega a la opinión pública.

\subsubsection{Comunicación y opinión pública}

Más allá de proyectos específicos y acciones de participación como las planteadas en el punto anterior, la Comunicación Pública de la Ciencia llega a la opinión pública hasta fechas recientes mayoritariamente a través de los medios de comunicación de masas. Si bien una parte reducida de la ciudadanía mantiene una actitud activa en la búsqueda de información sobre ciencia, acudiendo a los medios especializados -sobre los que plantearemos un análisis más amplio en el siguiente capítulo-, la mayor parte de la población solo recibe la información sobre ciencia a través de los medios generalistas, junto con los restantes contenidos informativos sobre otras materias. Por ello, en el presente apartado trataremos de profundizar, entre otros aspectos, en la respuesta de la opinión pública a la CPC y el perfil de la ciudadanía respecto a este tipo de información de la ciencia, así como el papel de los medios de información generalistas y la revolución que ha supuesto internet en el papel de los mismos.

Antes de entrar en estas cuestiones, resulta de interés tener en consideración el hecho de que en la educación, información y formación de la opinión pública en torno a las ciencias son múltiples los agentes culturales que intervienen como maestros, profesores, comunicadores institucionales, gestores culturales, políticos. Sin embargo, De Semir (2014) destaca el papel protagonista por encima de cualquier otro actor de los científicos y de los comunicadores de ciencia. "Contrariamente a lo que es una suposición común, la mayor parte de la educación científica de una persona se hace 
fuera de un ambiente formal: menos del 5\% de la vida de una persona se invierte en la educación reglada", señala el autor. Por tanto, la mejor manera de aumentar el conocimiento público de la ciencia está en el $95 \%$ restante de su vida. En este aprendizaje los medios de comunicación tienen un papel fundamental, pero también pueden tenerlo otros mecanismos de divulgación de la ciencia. Para comprender el papel de los medios resulta de interés detenerse en algunos estudios publicados al respecto.

En el estudio correspondiente a la Encuesta de Percepción Social de la Ciencia de 2010 de la FECYT, las profesoras de la Universidad Pompeu Fabra Gema Revuelta y Cristina Corchero analizaron si había o no distintos tipos de comportamiento en el acceso a la información y, en caso afirmativo, en qué se caracterizaban los ciudadanos pertenecientes a los distintos tipos o patrones encontrados. El estudio concluyó que entre la población española hay dos patrones de comportamiento diferenciados en relación al acceso a la información sobre ciencia y tecnología. Una forma de acceder a dicha información es a través de la recepción pasiva, sin requerir más esfuerzo que estar en contacto con medios de comunicación generalistas (televisión, radio, prensa, medios electrónicos generalistas, libros en general y revistas no especializadas en ciencia). Una segunda forma es a través de la búsqueda de información en medios de comunicación que exigen un proceso de búsqueda activa y selectiva (buscadores electrónicos, blogs, revistas especializadas en ciencia, etc.) o un componente de participación (redes sociales, foros). Es decir, hay un patrón de Recepción Pasiva y otro de Búsqueda Activa en cuanto al acceso a la información sobre ciencia y tecnología entre la población española. Un 50\% de los encuestados combinaban ambos perfiles, un 44,3\% eran solo receptores pasivos y únicamente un $3,8 \%$ se podía interpretar que eran totalmente buscadores activos. El estudio también concluyó que las personas más activas en relación a la búsqueda de información eran mayoritariamente las que tenían un nivel de estudios medio o superior, los menores de 44 años, las personas con más ingresos económicos, las que se consideraban políticamente como de izquierda o centro izquierda y los ateos y agnósticos o indiferentes en materia religiosa (Revuelta, 2012).

En la actual sociedad de la información, a la hora de hablar tanto de medios de comunicación generalistas como especializados es necesario distinguir entre los medios tradicionales y aquellos basados en internet, a pesar de que en la actualidad 
prácticamente todos los medios, independientemente de su soporte original (prensa escrita, radio y televisión), tienen también presencia en internet.

El Libro Blanco de las Unidades de Cultura Científica $(U C C+i)$-entidades sobre las que volveremos en el próximo apartado- reflexiona sobre el papel de ambos tipos de medios en la difusión de la ciencia (2012), señalando que los medios tradicionales entendidos como medios de comunicación social han sido y siguen siendo el canal más habitual para difundir informaciones de actualidad científica. Los medios impresos tienen como principal ventaja el hecho de que el espacio informativo es más amplio, sin embargo, hoy en día los medios audiovisuales son los que tienen una mayor hegemonía. El Libro Blanco también incluye en el apartado de medios tradicionales a las agencias de noticias científicas como la española SINC, la europea Alphagalielo o la anglosajona EurekAlert, a pesar de que todas ellas tienen en internet su principal soporte. Estas dos últimas agencias difunden contenidos de actualidad a cientos de miles de periodistas de todo el mundo, siendo claves para la internacionalización de la información. Los contenidos divulgativos, menos ligados a la actualidad, tienen también presencia en los medios tradicionales como es el caso de revistas, radios y televisiones. Este tipo de contenidos resultan de gran utilidad para incrementar la cultura científica de la sociedad gracias a su capacidad para llegar a un público más amplio.

Por lo que respecta a internet, es evidente que la Red se ha consolidado como uno de los principales canales de información, como hemos visto que ha venido a confirmar la última encuesta de la FECYT. El Libro Blanco de las UCC+i destaca el hecho de que muchos contenidos que no tienen cabida en los formatos tradicionales encuentran su espacio en las versiones digitales de estas mismas radios, diarios o televisiones. Además, la web permite a los centros de investigación convertirse en emisores de sus contenidos, estableciendo una relación directa con el público destinatario. A esto se unen las posibilidades de multiplicar los impactos de la comunicación científica a través de las redes sociales, que permiten además la interacción con los usuarios.

Tanto los materiales periodísticos como divulgativos multiplican su impacto si van acompañados por el uso de las redes sociales, en especial Facebook y Twitter. La presencia de las UCC+i en las redes sociales es esencial para comunicar la ciencia. Desde ellas se crean lazos con el público y se aumenta la visibilidad ante los periodistas y medios (Libro Blanco UCC+i, 2012:29). 
El estudio "El videoblog multilingüe como oportunidad ante los nuevos retos de la comunicación científica: el caso Ciència UJI TV”, dirigido por Francisco Fernández Beltrán y en el que tuve la oportunidad de participar, viene a confirmar el potencial de las redes sociales en la comunicación de la ciencia y la importancia que el audiovisual cobra en las mismas. Así, el estudio concluye que la producción audiovisual incrementa en más de un $38 \%$ la interacción con la audiencia. El estudio también puso de manifiesto el papel de las redes sociales como Facebook, Twitter y YouTube para difundir los contenidos de ciencia, más allá de los blogs sobre ciencia, así como la importancia de internacionalizar los contenidos a través de su traducción al inglés (Fernández Beltrán et al, 2012).

El papel de las redes sociales y de la web 2.0 resulta fundamental también para incrementar la divulgación de la ciencia realizada a través de los medios de comunicación convencionales. En este sentido, el estudio realizado por Lucía Casajús sobre "Radios universitarias y redes sociales" pone de manifiesto que el desafío para de estas emisoras puedan extender y potenciar su presencia pasa por "aumentar la actividad en redes sociales, mostrarse interactivos en ellas, ofrecer en los portales web una extensión de las mismas, e incorporar las redes sociales a la gestión integral de las emisoras mediante una planificación específica” (Casajús, 2014).

Estudios y encuestas como los expuestos muestran cómo resulta fundamental destacar las posibilidades que ofrecen las nuevas tecnologías de la comunicación y la web 2.0 y su utilidad de cara a llevar el conocimiento científico a la opinión pública y a potenciar la interacción entre los diferentes grupos de interés de la ciencia al permitir establecer mecanismos de discusión y comunicación. La revolución que ha supuesto la nueva galaxia mediática y la explosión del periodismo que ha generado, incluido el periodismo científico, es el tema con el que abrimos el próximo apartado.

\subsection{LA EXPLOSIÓN DE LA COMUNICACIÓN DE LA CIENCIA}

La nueva galaxia mediática ha modificado las tradicionales estructuras comunicativas, generando nuevos paradigmas que afectan también a la comunicación de la ciencia. En un primer punto abordaremos cómo estos cambios han afectado, en primer lugar, al concepto mismo de ciudadanía mediática, haciendo necesaria una educación crítica para que la sociedad pueda hacer frente a la sobreinformación 
generada por las Tecnologías de la Información y la Comunicación (TIC). De la mano de autores como Vicent Gozálveze e Ignasi Ramonet avanzaremos en la nueva realidad a la que se enfrenta el periodismo ante la nueva galaxia mediática, para finalmente analizar cómo la irrupción de las TIC ha afectado y afecta a la comunicación de la ciencia.

En este nuevo panorama se produce además lo que podemos considerar una explosión en la propia comunicación de la ciencia con un notable avance hacia la profesionalización del sector y la aparición de nuevos retos. Una especialización y profesionalización en la que ha sido clave a nivel nacional el papel jugado por la Fundación Española para la Ciencia y la Tecnología (FECYT) a través de acciones como el impulso de una red de Unidades de Cultura Científica y de la Innovación en centros de investigación y universidades o la creación de SINC, la primera agencia nacional de noticias científicas. Estos serán algunos de los aspectos que trataremos en un segundo punto.

\subsubsection{La explosión del periodismo en la nueva galaxia mediática}

Para abordar correctamente la cuestión de la comunicación de la ciencia entendemos que es necesario detenerse en el concepto de ciudadanía en relación con los medios, así como conocer la situación de cambio a la que se enfrenta el periodismo tradicional y, de forma específica, el periodismo científico. En el presente punto profundizaremos en un primer momento en esta ciudadanía mediática desde la perspectiva de la nueva situación en la que se encuentran los medios de comunicación, y para ello tomaremos como referente algunas obras que analizan tanto el contexto social de los medios como el papel de la ciudadanía como quinto poder que debe actuar como necesario contrapoder de los medios: Ciudadanía mediática. Una mirada educativa, de Vicent Gozálvez (2013); y La explosión del periodismo. De los medios de masas a la masa de medios, de Ignacio Ramonet (2011).

El periodismo tradicional está viviendo tiempos difíciles ante el desarrollo de las nuevas tecnologías de la comunicación, que suponen una amenaza para los medios tradicionales, pero también un reto y una oportunidad de renovarse para la profesión. A lo largo del presente punto se analizan algunos de los principales problemas que atraviesa el periodismo, pero también se pone de manifiesto su importancia para 
contribuir a una verdadera democracia deliberativa. Pero para ello, es necesario contar además con una ciudadanía crítica y formada, consciente de las fortalezas y las debilidades de los medios, del contexto de la profesión periodística y del poder de los grupos mediáticos. Es necesario, en suma, una ciudadanía mediática cuyas características abordamos a continuación.

El humanismo crítico, sin abandonar el terreno de lo escrito que le ha caracterizado, se involucra también en la cultura de los nuevos medios y las nuevas tecnologías propias de los nuevos tiempos. Desde esta perspectiva, Vicent Gozálvez señala que la comunicación se puede quedar en entretenimiento y mensajes vacíos, en charlatanería que esclavice en vez de liberar o invitar a la reflexión. Los medios, y de forma especial los medios audiovisuales, tienen ese potencial, por ello es importante educar en un buen uso de los mismos.

Algunos problemas que presenta la actual situación mediática en opinión del autor son la sensación de miedo incentivada por los medios, ya que el miedo es un negocio para las cadenas, para las empresas vinculadas a la venta de armas, para guerras y para políticos. El exceso de violencia generado por los medios fomenta además la cultura de la hostilidad, pero el autor se plantea cómo y por qué limitarla si es negocio y hay libertad de expresión. Otro de los problemas del actual panorama mediático pasa por la hibridación de las funciones tradicionales de los medios, especialmente en el caso de la televisión, de forma que se ofrece la información adaptada al estilo de espectáculo info-show, que poco aporta a la edificación de la autonomía cívica. De esta forma, los noticiarios buscan rentabilidad, lo que provoca un fenómeno de estandarización y una tendencia al sensacionalismo. Al final, lo que se ofrece no es realmente lo que el público desea sino lo que es más barato y más rentable de producir. Todos estos problemas vienen unidos, y responden en muchos casos, al oligopolio de las empresas mediáticas, según este mismo autor.

Ante esta situación se requiere un quinto poder que, como señala Ignacio Ramonet, ejerza de contrapoder desde una ciudadanía crítica. Esto requiere una educación para la ciudadanía mediática ya que el ejercicio de la libertad se despliega en relación directa a la que puede acceder cada persona, afirma Gozálvez. El problema para este quinto poder son las dificultades de acceso a una información de calidad y las carencias en la educación mediática. Desde los medios, los oligarcas de lo mediático educan a la ciudadanía en los valores que les interesan. 
Por otra parte, el autor señala que el individualismo moderno retrocede a favor de un individualismo cívico, un individualismo propiciado por la red y planteado como satisfacción del deseo sin responsabilidad ni restricción, como ocurre, por ejemplo, en el caso de los blogs escritos para uno mismo, lo que conduce a un autismo electrónico.

El civismo posmoderno consiste en un civismo de baja intensidad, de personas integradas en la sociedad pero despechadas de ella, que viven y dejan vivir reducidas en su mundo particular, indiferentes. Para Lipovetsky las sociedades postmodernas se caracterizan por el individualismo y narcisismo hedonista, por un minimalismo ético que genera una moral indolora. Este minimalismo ético está compuesto más de valores negativos (no hacer o que no me hagan) que positivos (tú debes). Las TIC son el puntal de este minimalismo, favoreciendo el individualismo. Para Gozálvez, en la construcción del individualismo moderno, las TIC nos permiten tener experiencias desconectadas del momento del encuentro, experiencias que no anulan sino que complementan las experiencias comunicativas directas y tradicionales. De este modo, las nuevas tecnologías constituyen el soporte para el avance socio-político y moral al intensificar las vías de entrada y salida en la esfera de una opinión pública racional.

Asimismo, resalta la idea de que los medios de comunicación de masas dan voz y rostro a aquellos que, si no, no la tendrían. "Pensar que la era mediática es indefectiblemente la era de la homogenización supone ignorar la importancia de los medios en la lucha por la visibilidad y en la creación de un nuevo espacio público" (Gozálvez, 2013:124). Esto supone identificar los medios, especialmente los audiovisuales, exclusivamente con lo sensible y oponerlo a lo inteligible, como hiciera Sartori. En definitiva, considera que los media constituyen un instrumento crucial para la formación de juicios razonados sobre cuestiones públicas a partir de informaciones, argumentaciones, réplicas... y la exposición de puntos de vista ante los que seriamos prácticamente ciegos sin el concurso de tales medios. Al entender del autor, la comunicación audiovisual a gran escala ha de ser valorada y entendida como un complemento a la comunicación dialogada. La calidad de lo comunicado no depende del medio sino del uso, no hay determinismo mediático.

Respecto a los límites posmodernos a la ciudadanía mediática, Vicent Gozálvez argumenta que el problema de fondo no es la tecnología, sino considerar que la enseñanza de valores cívicos es algo demodé, prejuicio posmoderno que se traduce en lo que llama charlatanería comunicacional. Esta situación hace que se apele a los derechos 
modernos como la libertad de expresión pero socavando otros derechos fundamentales. Se limita la moral al ámbito privado, se busca el éxito personal por encima de las consideraciones cívicas. Sin embargo, lo moral es también un asunto público y el ciudadano responsable para con la sociedad se resiste a desaparecer.

En esa resistencia reside uno de los desafíos más importantes de la educación como servicio público. Los centros educativos no pueden, en opinión de Gozálvez, dejar pasar la oportunidad de ofrecerse a la sociedad como modelo y referente de ciudadano mediático. Deteniéndonos en este concepto, para el autor ciudadanía mediática es aquella capaz de:

- Distinguir informaciones contrastadas y las opiniones razonables.

- Contribuir a una opinión pública ponderada, basada en la deliberación argumentada.

- Hacer un buen uso de la libertad de expresión.

- Promover en el ámbito del ciberespacio una interacción responsable y respetuosa.

- Seleccionar e interpretar sensatamente el inmenso flujo de contenidos.

- Detectar las intenciones y valores de los productores mediáticos, constituyendo un quinto poder.

- Conocer y utilizar los recursos tecnológicos que mejoran el proceso de aprendizaje.

- Entender las emociones suscitadas por los medios para gestionarlas mejor.

- Vivir los contenidos de entretenimiento inteligentemente, sin renunciar a los componentes del juicio crítico.

- Interpretar las necesidades y deseos creados por la publicidad comercial de un modo selectivo.

¿Quién ha de empoderar a la ciudadanía ante los medios? Para el autor, en respuesta a esta pregunta la escuela tiene un papel fundamental, pero también los profesionales de los medios y en última instancia la propia ciudadanía. La educación 
desde todos estos ámbitos es por tanto clave para alcanzar una ciudadanía mediática capaz de ser autónoma y crítica a la hora de entender los productos mediáticos. Así lo entiende Gozálvez:

La nueva ciudadanía moderna y cosmopolita ha de apuntar hacia la autonomía ligada y coaligada de los ciudadanos, levantada por cada persona desde los procesos educativos adecuados y desde la intersubjetividad inscrita en el mismo lenguaje. Al fin y al cabo, no puede haber ciudadanía crítica sin la formación en un buen uso de los medios, ni puede haber ciudadanía mediática sin la interpretación crítica de los contenidos que estos nos ofrecen (Gozálvez, 2013:147).

Como hemos visto, la ciudadanía ha de hacer frente a una nueva realidad mediática a la que trataremos de aproximarnos a continuación. La nueva galaxia mediática ha supuesto lo que autores como Ignacio Ramonet han dado en llamar la explosión del periodismo. Ante esta nueva situación, el autor plantea la necesidad de un quinto poder que domine el poder de algunos grandes grupos mediáticos que llegan a actuar en contra de la ciudadanía después de haberse convertido en latifundios mediáticos. Son aparatos ideológicos de la globalización que actúan como partidos políticos y se alzan como posición ideológica, como lo ocurrido, por ejemplo, en el caso del complejo mediático de Silvio Berlusconi en Italia. Un problema que evidencia la necesidad de este quinto poder es asimismo "la endogamia entre políticos y medios, con periodistas dominantes en su papel de estrellas en estado de levitación”, señala.

Esta situación se produce además después de que la globalización económica haya hecho que los medios hayan perdido su papel de cuarto poder, entendido como función de contrapoder gracias a su sentido cívico. La necesidad de un quinto poder viene dada asimismo, en opinión de Ramonet, por la fusión de tres esferas antes diferenciadas, sobre todo gracias al desarrollo de internet, como son la cultura de masas, la comunicación y la información.

También existe un problema de fiabilidad de los medios por distintos factores, como la obsesión por la rapidez frente a la reflexión. El exceso de información genera asimismo falta de credibilidad. De esta forma, se produce un problema de sobreinformación que a menudo genera información contaminada. Las mentiras evidenciadas, como el caso de las armas de destrucción masiva en Irak, agravan esta falta de credibilidad. Ante esta situación, el autor afirma que "resulta urgente exigir a los grandes medios que permitan a sus periodistas actuar en función de su libertad de conciencia y no en función de los intereses de los grupos" (Ramonet, 2011:65). 
Por estos y otros motivos, el periodismo tradicional se encuentra al borde del precipicio por razones tecnológicas, ideológicas y deontológicas. La necesidad de un quinto poder viene dada además de por la situación del sector, por el hecho de que los medios de comunicación siguen siendo, en los Estados de Derecho, el único poder sin contrapoder, lo que en opinión de Ramonet crea un desequilibrio perjudicial para la democracia.

Cabe aquí hacer un inciso para indicar algunos de los problemas del actual periodismo señalados asimismo por la Federación de Asociaciones de Periodistas de España (FAPE), como la precariedad laboral y salarial que coloca a los periodistas en una situación de indefensión ante las presiones; la expulsión de periodistas veteranos, con fuentes y con criterio; la connivencia con los poderes, a la que considera uno de los factores principales de la pérdida de credibilidad y prestigio del periodismo; las trabas a la libertad de expresión, como muestran las ruedas de prensa sin preguntas; el aumento de las presiones hacia los medios y periodistas que, con independencia y rigor, investigan los abusos de poder, especialmente los ligados a la corrupción; y la reforma de la Ley de Enjuiciamiento Criminal, que presenta serios límites a los derechos de información y a la libertad de expresión. Problemas que, de uno u otro modo, también afectan al periodismo científico.

Ante esta situación, la FAPE ha elaborado un manifiesto bajo el lema "Sin periodistas no hay periodismo. Sin periodismo, no hay democracia", en el que defiende que los periodistas seguirán siendo necesarios "para jerarquizar las noticias, confirmar su veracidad, contrastarlas y difundirlas bajo un paraguas ético y deontológico, como garantes que somos del derecho fundamental de los ciudadanos a recibir información libre y veraz".

La importancia del papel de la labor de los periodistas la ponía ya de manifiesto Joseph Pulitzer a principios del siglo XX:

Nuestra República y su prensa triunfarán o se hundirán juntas. Una prensa capaz, desinteresada y solidaria con la sociedad, intelectualmente entrenada para conocer lo que es correcto y con el valor para conquistarlo y defenderlo, conservará esa virtud pública sin la cual un gobierno popular es una farsa y una burla. En cambio, una prensa mercenaria, demagógica y corrupta producirá, con el tiempo, un pueblo tan vil como ella. El poder de moldear el futuro de la República está en las manos de los periodistas de las futuras generaciones (Pulitzer, 1904). 
En el panorama actual de la prensa se abren paso también casos de innovaciones y éxitos que ponen de manifiesto que la prensa sigue ejerciendo su papel. Así, Ramonet destaca algunos ejemplos de buen periodismo que hace frente a las difíciles circunstancias. Es el caso, por ejemplo, del periodismo sin ánimo de lucro, que apuesta por la calidad y la independencia gracias a la financiación de mecenas o de sistemas de crowfunding. Este es el caso también de los diarios y radios promovidos por asociaciones surgidos inicialmente en EEUU.

Otro ejemplo de éxito son las webs que combinan el trabajo de periodistas on line profesionales con el de expertos, blogueros e internautas como, por ejemplo, The Huffington Post, medio que funciona como un agregador de contenidos informativos a los que suma crónicas de especialistas. Otro caso interesante es el de Politico.com, web de éxito que hace seguimiento del Congreso de EEUU y que ha lanzado incluso una versión de pago. En opinión de Ramonet, el periodismo de base de datos ofrece más transparencia, pero también tiene sus límites y riesgos, como es el caso de las listas de sueldos, de delincuentes, etc.

Mención aparte requiere el caso de Wikileaks, cuyo promotor, Julianna Assange, mantiene una visión crítica del periodismo y sostiene que la democracia no debe ocultar nada. Esta plataforma vive de donaciones y publica lo que le llega sin importar cómo se ha obtenido, pero verificando siempre la información. Cualquier persona sensible a temas que considera que deberían conocerse por parte de la opinión pública posee una infraestructura para difundirlos. En algunos casos, desde Wikileaks se ha utilizado para la publicación de temas el filtro de cinco grandes periódicos internacionales, incluido $E l$ País, que elimina nombres y selecciona datos de interés general.

Para Ramonet "el verdadero escándalo es que tras las revelaciones de Wikileaks no haya pasado nada", a excepción de la revolución tunecina, en la que una filtración sobre las prácticas corruptas ejerció de catalizador. También cabe destacar la respuesta del movimiento ciudadano Anonymous, consistente en la manifestación ciudadana digital bloqueando webs.

Por otra parte, el autor se plantea hacia qué modelo de rentabilidad nos dirigimos, preguntándose si lo que importa a los medios son los compradores o los lectores. "Antes vendían información y entretenimiento a los ciudadanos, ahora prefieren vender ciudadanos a los anunciantes", asegura. 
Ante las nuevas tecnologías, internet es el soporte del futuro y del presente, pero los medios todavía no han encontrado un modelo de rentabilidad en la red. Por el momento, el precio de la publicidad en internet aún no compensa las pérdidas. Respecto al pago por el acceso a contenidos, supone siempre un descenso excesivo de audiencia. Por ejemplo, en el caso de The Times, su audiencia pasó de 22 millones a menos de 200.000 al establecer el pago. No obstante, algunos creen que esta audiencia cualificada es buena para los anunciantes. Otra modalidad con la que se experimenta es el Freemium, una parte libre y otra más exclusiva de pago. También se ha planteado el iPad como tableta de salvación, con contenidos como la revista The Project y diarios de pago adaptados. Otro modelo de negocio son las que Ramonet denomina fábricas de información lowcost con contenidos de freelance en masa, un sistema que permitió a un periódico de Quebec mantenerse durante una huelga de 23 meses de sus periodistas.

Pero el trabajo del periodista tiene, entre otros valores, los de seleccionar y jerarquizar las informaciones, como defendía un editorial de El País:

La gente nos paga por nuestro criterio. Hay una diferencia entre lo que dice la Wikipedia y The New York Times: la gente va a la Wikipedia sabiendo lo que quiere; pero viene a The New York Times, o la BBC sin saber qué es lo que buscan, vienen a ver qué les cuenta gente inteligente y bien formada, para que les cuenten qué pasó, qué importa y qué significa eso; nadie tiene tiempo de hacer eso por su propia cuenta (El País, 25 de julio de 2010).

Ante el panorama descrito y las dificultades para encontrar modelos rentables, Ramonet se pregunta si sobrevivirá el periodismo y su respuesta es sí. El autor cree incluso que es un momento favorable para ser periodista ante un mayor acceso a la información y a la audiencia. Se trata de una revolución que requiere una adaptación a un nuevo contexto, y para conseguirlo propone que cada medio se centre en su saber hacer específico con rigor y seriedad, así como aprender a elaborar la información para su difusión en diversos formatos. Considera Ramonet que el futuro de la profesión pasa por un periodismo de profundización y orientación, más que de información. La ventaja para el periodismo ante cualquier circunstancia es que la gente buscaba y sigue buscando información útil, de calidad y fiable.

El periodismo científico puede encontrar en esta especialización defendida por Ramonet un escenario adecuado, ofreciendo la información de calidad que la ciudadanía requiere en un contexto de sobreinformación. El concepto de ciudadanía mediática al que aludía Gozálvez, capaz de distinguir informaciones contrastadas y contribuir a una 
opinión pública ponderada, basada en la deliberación argumentada, resulta asimismo clave en el campo de la comunicación científica que abordaremos en el siguiente punto.

El terremoto al que está sometido el mundo de las noticias afecta también a la comunicación de la ciencia. Para comprender la situación en la que se encuentra el periodismo científico en España y los desafíos a los que se enfrenta en esta nueva galaxia mediática, resulta de gran interés el Meta Análisis: comunicación científica y periodismo científico, realizado por Vladimir De Semir (2011) de cara a la celebración en Madrid del fórum internacional Media For Science Forum en 2010 al que hemos hecho referencia anteriormente. El análisis fue editado un año después en español por la FECYT. De Semir advertía en este estudio del cambio en el acceso a la información ante la irrupción de nuevos soportes como webs, blogs, podcasts, google news, redes sociales, etc., a los que hemos dado en llamar la nueva galaxia mediática, así como del cambio de actitud del público respecto a la forma de consumir información. El autor advierte de la crisis de los medios y la pérdida de calidad de sus contenidos, señalando que el declive del mundo de la información "no sólo pone en peligro la generación de una sociedad suficientemente capacitada y escéptica para poder ser culta y crítica sino que compromete la propia democracia" (De Semir, 2011:10).

Para combatir este fenómeno, De Semir resalta, al igual que lo hacía Gozálvez, la importancia del papel de la educación como herramienta clave para desarrollar la necesaria capacidad crítica que permita a la ciudadanía discernir entre los contenidos que ayuden realmente a combatir la desinformación y permitan el acceso a una cultura adecuada para ser miembros activos de la sociedad del conocimiento. Y en esta tarea educativa, considera que los nuevos medios de comunicación surgidos de las TIC tienen un papel fundamental ya que permiten a las personas "llegar a buena información en un sistema cooperativo en el que participan expertos y no expertos" en la que denomina como computación social que posibilita a los usuarios ser participantes activos, coproducir contenidos, decidir la reputación y reforzar los efectos de la red.

La computación social impulsada por la innovación y la colaboración está creando nuevos recursos que podrían ser utilizados por los gobiernos, los políticos, la sociedad civil, los intermediarios y los ciudadanos, para trabajar en la consecución de los objetivos de las políticas públicas en múltiples áreas, incluido el del acceso a la educación directa y también indirectamente por mediación del nuevo sistema comunicativo en red (De Semir, 2011:11). 
La adecuada comunicación de la ciencia en este escenario de sobreinformación cobra todavía mayor trascendencia. En este sentido, el autor destaca la necesidad de que exista una mejor contextualización del discurso científico que permita una mayor comprensión pública. El hecho de que la $\mathrm{I}+\mathrm{D}+\mathrm{i}$ se haya consolidado como un eje vertebrador de la sociedad del conocimiento ha dotado a la comunicación pública de la ciencia de una relevancia estratégica, afirma De Semir, por lo que propone sumar a la tradicional fórmula de la $\mathrm{I}+\mathrm{D}+\mathrm{i}$ la $\mathrm{C}$ de comunicación científica, de cultura científica y de una ciudadanía creativa y capaz que nos convierta en una comunidad adecuadamente preparada y competente. Así, en la fórmula $\mathrm{I}+\mathrm{D}+\mathrm{i}+\mathrm{C}$, esta última supondría "el indispensable fortalecimiento de la comunicación y difusión pública de las ciencias, que permita alcanzar una adecuada cultura científica para devenir una sociedad preparada y competente". Para el autor, el futuro de la sociedad depende del nivel que la ciudadanía llegue a tener en el campo de la cultura científica ya que supone la única forma de que pueda participar en el modelo de sociedad hacia el que se avanza. En este sentido, recuerda que muchos de los problemas planteados en el siglo XXI requieren soluciones científicas como es la gestión de recursos naturales, la energía, el cambio climático, los problemas éticos relacionados con las nuevas tecnologías médicas, etc.

Respecto al papel de los periodistas, considera que las nuevas tecnologías han puesto fin a su necesaria intermediación. Canales como Futuruty, puesto en marcha por centros de investigación y universidades de Estados Unidos o Canadá, son un ejemplo de cómo está cambiando el escenario de la comunicación de la ciencia, con vías que permiten al mundo de la ciencia "saltarse la ineluctable colaboración o - para algunos el obstáculo que representan los medios de comunicación en el objetivo de difundir su información entre el público general" y éste a su vez puede ir a buscar información directamente a las fuentes especializadas (De Semir, 2011:14).

La “desintermediación” de la información científica puede ser positiva en el sentido de que permite un acercamiento entre las fuentes de información y la sociedad. Pero el autor advierte también de los riesgos de la institucionalización de la información, que hace que se pierda el papel regulador que debería tener el periodismo en su búsqueda de la verdad y de la mayor objetividad posible. En este sentido, y coincidiendo con la visión planteada por Ramonet, De Semir abre también la puerta al optimismo al plantear que el nuevo escenario puede llevar incluso a una búsqueda de un periodismo de mayor calidad y más accesible a toda la ciudadanía. 
En una obra posterior, De Semir profundizaba en el cambio que suponen las nuevas tecnologías y las posibilidades que abren a la comunicación de la ciencia.

Hoy la comunicación entre los científicos y el público está cambiando por las nuevas formas de diseminar y de acceder a la información, y con toda seguridad este fenómeno va a mejorar - por lo menos así debería ser - la percepción colectiva de las ciencias y sus aplicaciones. Los motivos más importantes de este cambio son la rápida evolución de internet, ahora en su versión web 2.0, con una abundancia de sitios para compartir videos, blogs y redes sociales... plataformas de plena ubicuidad que además facilitan la fusión de la comunicación individual y la pública. Las nuevas infraestructuras que dan acceso casi instantáneo a la información han roto barreras técnicas y económicas en los tradicionales sistemas de comunicación. Esta interactividad entre los participantes de la comunicación en línea trasciende potencialmente el modelo tradicional de comunicación de masas y naturalmente tiene efectos en el público (De Semir, 2014:117-118).

Entre las consecuencias de este desarrollo para la comunicación científica, el autor destaca el hecho de poder utilizar canales de comunicación y formatos que involucren mejor al público. También considera que abren puertas a la participación y a una mayor interactividad, posibilidades que por sí solas no conducen automáticamente a una mejora del diálogo público entre ciencia y sociedad pero que abren sin duda posibilidades para que los ciudadanos o las partes interesadas puedan influir en la gobernanza de la ciencia.

El autor amplía asimismo la mirada a los efectos de la nueva galaxia tiene en los propios investigadores e investigadoras, señalando que, para muchos, blogs y wikis siguen constituyendo distracciones de su verdadero trabajo, considerándolos una versión virtual de las charlas de cafetería, "un ruido de fondo que va en contra del espíritu de la información erudita y académica evaluada por pares”. En cambio, los científicos activos en la web 2.0 piensan de manera muy distinta, considerando que la jerarquía dinámica de los enlaces y las recomendaciones generadas por los blogs crea un filtrado colaborativo muy intenso e interesante.

El autor señala que muchos investigadores, "la mayoría seguramente", todavía consideran las publicaciones de literatura científica formal como el medio principal de comunicación científica, sobre todo porque a menudo estas publicaciones son la base de la carrera profesional, además de entender que garantizan una memoria científica. Sin embargo, De Semir destaca que existe una corriente de partidarios de una mayor utilización de las TIC que afirman que se deben plantear foros en internet que permitan un debate más amplio y complementario del sistema tradicional de revistas evaluadas 
por homólogos (peer review), avanzando hacia lo que podríamos considerar una Ciencia 2.0 en la que el proceso de revisión no sea sólo interpares sino abierto a toda la comunidad científica e incluso a la sociedad. Esto podría suponer una mejora de la comunicación científica "tanto antes de las publicaciones, al generarse las ideas, como tras la publicación, al debatirse los resultados”. Esta visión resulta especialmente interesante por las posibilidades de diálogo que abre no solo entre investigadores, sino también con los diferentes grupos de interés de la ciencia y la innovación.

Como hemos visto en el apartado anterior, las encuestas vienen a confirmar la consolidación de internet como principal fuente de información en materia de ciencia y tecnología. El papel de la web 2.0 tiene también un claro reflejo en la evolución de los blogs científicos. ScienceBlog, uno de los portales de redes sociales más destacados en la categoría de ciencia, con más de 130 blogs acreditados, ha registrado un crecimiento de dos dígitos en su tráfico (al mensos el 50\%) todos los años desde su creación en 2006, contando en 2014 con una audiencia de más de dos millones de visitantes únicos al mes. Para el director del Observatorio de la Comunicación Científica de la Universitat Pompeu Fabra, "la actual blogosfera científica está plantando la semilla de una profunda renovación futura" (De Semir, 2014:218).

Esta explosión de la blogosfera científica y de otras iniciativas 2.0 lleva a que en la actualidad el consumidor pueda encontrar, gracias a internet, más información sobre ciencia y tecnología que nunca, pero la desaparición de la desintermediación periodística nos devuelve a la necesidad, ya planteada a lo largo del capítulo, de unas aptitudes críticas por parte de la audiencia para saber cómo obtener información fiable y útil, y capacidad para identificar las fuentes de información de confianza. Precisamente, para el autor, una de las características más importantes de la era de la información es una ciudadanía mucho más activa, que reclama que se tenga en cuenta su capacidad de opinar e implicarse en las decisiones y las acciones.

De Semir entiende que la sobreinformación de la nueva galaxia mediática hace más necesario que nunca formar a los ciudadanos en el sentido crítico y de la responsabilidad, de forma que la capacitación (empowerment, en inglés) se añada a los valores democráticos tradicionales construidos y reclamados por la sociedad desde la Revolución Francesa como un factor clave para hacer ciudadanos libres.

Esta necesidad de ciudadanos críticos se hace aún más evidente si se tiene en cuenta que la nueva galaxia mediática abre las posibilidades de comunicación a todas 
las voces y perspectivas, poniéndolas al mismo nivel y ofreciéndoles las mismas posibilidades para competir en lo que algunos han empezado a denominar la comunicación científica en la era digital postexperta, es decir, la era de la opinión generalizada en la que vale lo mismo la voz experta que la que no lo es (Luers y Kroodsma, 2014).

Como hemos visto con De Semir y Ramonet, tampoco faltan las voces que, ante este escenario de sobreinformación, reivindican el papel de los periodistas científicos como intermediarios necesarios. Para David Rowan, editor de la influyente revista Wired, el periodismo de ámbito científico es el que más se beneficia de las nuevas herramientas que ofrece internet para el acceso a la información y el conocimiento, asegurando que hoy más que nunca se necesitan periodistas científicos informados y de mente articulada. En este sentido, resalta la presencia diaria de noticias que requieren del conocimiento científico para su comprensión, la gran demanda sobre este tipo de informaciones y la oportunidad que supone esto para los periodistas que cuentan con la especialización necesaria.

And thanks to the internet, and its culture of sharing, of openness, there's more, and better, science writing easily available than ever before. And there's a huge demand for it (...) So let's start by being optimistic. Congratulations: you, the science journalist, have an expertise, a skillset, for which there's huge public demand (Rowan, 2010).

Desde foros de expertos se ha buscado asimismo analizar la influencia que han tenido las nuevas tecnologías en la web 2.0 en la comunicación científica. Es el caso del debate del seminario "La ética, esencia de la comunicación científica y médica" (Fundació Víctor Grifols i Lucas, 2010) en el que el papel de la web 2.0 se convirtió en uno de los ejes de la jornada, tal y como analiza la periodista y consultora de comunicación Cristina Aced. En el marco del debate, los expertos destacaron las nuevas oportunidades que abren las plataformas 2.0 para llegar directamente al público, sin necesidad de intermediarios ni de pasar por el filtro de los medios. Estas herramientas también permiten dar voz a los ciudadanos, con iniciativas como PatientsLikeMe.com que facilitan a los pacientes compartir sus experiencias con otras personas en su misma situación. La periodista considera que este tipo de iniciativas muestran la existencia de necesidades no cubiertas, "de ahí que los usuarios aprovechen estas herramientas para crear y compartir lo que no encuentran en otras plataformas". Esta necesidad y las ganas 
de compartir son precisamente las claves del éxito del 2.0 y de las iniciativas participativas.

Es fácil crear una red virtual, tecnológicamente hablando, puesto que existen plataformas gratuitas que lo permiten; lo verdaderamente difícil de conseguir es crear una comunidad, un sentimiento de pertenencia entre los miembros que forman parte de ella. Esto último no se puede forzar, sino que debe surgir de forma natural, y debería ser el punto de partida de cualquier comunidad virtual (Aced, 2010:93).

En este sentido, los participantes en el debate destacaron la necesidad de, antes de poner en marcha iniciativas 2.0 de comunicación de la ciencia, tener claro el público al que se dirigen y los objetivos de las mismas. Aced considera que la comunicación de la ciencia debe aprovechar las oportunidades que abre la web 2.0, convirtiéndose en agentes activos a la hora de impulsar el diálogo sobre ciencia, tecnología y medicina en la red. Se trata, para la periodista:

(...) de ser proactivos en la gestión de nuestra reputación y participar en la red. No podemos evitar que otras personas hablen de nosotros, pero sí contribuir con nuestras aportaciones y nuestro punto de vista a la conversación, aunque siempre de forma transparente, veraz y respetuosa, tal y como ya hacemos en el mundo offline. Al fin y al cabo, la red no es tan distinta de la calle y actuar con sentido común es la mejor forma —y la más segura- de moverse por internet (Aced, 2010:94).

La apuesta por la proactividad y la calidad en la comunicación de la ciencia, a cuya necesidad hacían referencia Aced y De Semir, entendemos que se encuentra directamente ligada a la profesionalización del sector. En este sentido, cabe señalar como dato positivo el hecho de que el auge de la comunicación de la ciencia en las últimas décadas haya favorecido el incremento del número de profesionales especializados en comunicación de la ciencia, así como de los medios y canales de comunicación dedicados a la misma, muchos de ellos a través de internet. A analizar este fenómeno dedicamos el siguiente apartado.

\subsubsection{La explosión de la comunicación de la ciencia en España: avances y retos}

En el caso de España, a la hora de analizar la profesionalización y el avance de la comunicación de la ciencia, es necesario hacer referencia al papel de la Fundación Española para la Ciencia y la Tecnología (FECYT), dependiente en la actualidad del 
Ministerio de Economía y Competitividad, por lo que respecta a la creación de algunos de los pilares actuales de la CPC en España como son la Red de Unidades de Cultura Científica y de la Innovación (Red UCC+i), el congreso anual Comcired o la Agencia de Noticias Científicas SINC. Nos detendremos a continuación en cada uno de ellos para después abordar algunos de los retos a los que se enfrenta la comunicación de la ciencia tras estos avances.

Como hemos adelantado, la Red UCC+i dio sus primeros pasos con motivo de la publicación de la Convocatoria de Ayudas para la realización de actividades de difusión y divulgación científica y tecnológica del Año de la Ciencia 2007 que promovió la creación y el fortalecimiento de este tipo de Unidades en universidades y centros de investigación. Según destacan desde la FECYT, las UCC+i son hoy en día uno de los principales agentes en la difusión y divulgación de la ciencia y la innovación en España, y constituyen un servicio clave para mejorar e incrementar la formación, la cultura y los conocimientos científicos de los ciudadanos. Entre los objetivos de la Red de UCC+i se encuentran "fomentar el intercambio experiencias y la búsqueda de sinergias entre entidades lo que mejora la calidad de los productos y servicios de las UCC+i y promueve la optimización de recursos" (www.comcired.fecyt.es).

Paralelamente se crearon a partir de la celebración en 2007 del Año de la Ciencia otras dos redes vinculadas a la comunicación y divulgación de la ciencia: la Red de Agentes Locales de Cultura Científica y la Red Nacional de Museos de Ciencia y Tecnología. Desde la FECYT argumentan que, si bien desde cualquier nivel de la Administración General del Estado se debe fomentar la divulgación de la ciencia y la innovación, son las entidades locales, por ser las que se encuentran más cerca de la sociedad, las que son más conscientes de las inquietudes y necesidades de los ciudadanos, las que deben implicarse de un modo más directo en esta tarea. La red, que actualmente ha pasado a denominarse Red Local de Divulgación de la Ciencia y la Innovación, está formada por los Ayuntamientos que han obtenido financiación a través de la Convocatoria de Ayudas de FECYT en esta modalidad, así como por aquellos de la Red INNPULSO que desean pasar a formar parte de la misma.

Por lo que respecta a la Red Nacional de Museos de Ciencia y Tecnología, encuentra sus orígenes en la reunión celebrada en 1997 en A Coruña entre representantes de la mayor parte de los centros de ciencia para debatir problemas comunes y coordinar actividades, elaborando un manifiesto conjunto. A partir de 
entonces se han venido celebrando reuniones anuales que han permitido crear una comunidad que se presta apoyo mutuo, comparte experiencias, intercambia exposiciones y ofrece una voz común para dar fuerza a sus reivindicaciones. La Red de museos está conformada por museos, planetarios y centros de ciencia de todo el territorio del Estado Español.

Dado el interés de su ámbito de actuación y su relación con la comunicación de la ciencia desde las universidades, nos detendremos más ampliamente en la Red de UCC+i, Unidades cuyo objetivo no es sólo acercar el conocimiento nuevo, sino hacerlo de manera innovadora, de forma que sea fácilmente comprensible para todo tipo de públicos y, al mismo tiempo, atractivo e interesante.

Con el fin de acreditar que las UCC+i cumplían con los objetivos establecidos para las mismas, la FECYT constituyó en 2013 el registro oficial de Unidades, en el que en julio de 2014 constaban un total de 42 UCC $+\mathrm{i}$ pertenecientes a centros de investigación y universidades de toda España. La "Convocatoria de ayudas para el fomento de la cultura científica, tecnológica y de la innovación" que cada año realiza la FECYT cuenta en 2015 con una dotación de 700.000 euros para la Línea de actuación "Redes de divulgación y comunicación de la ciencia y la innovación" en la que se incluyen las modalidades: "Red de Unidades de Cultura Científica y de la Innovación $(\mathrm{UCC}+\mathrm{i})$ ", a través de la que se da apoyo al programa de actividades de las UCC+i registradas; y "Red de Museos de Ciencia y Tecnología".

En 2012 la FECYT editaba el Libro Blanco de las UCC+i en el que se destaca que estas unidades son hoy en día uno de los principales agentes en la difusión y divulgación de la ciencia y la innovación en España, y constituyen un servicio clave para mejorar e incrementar la formación, la cultura y los conocimientos científicos de los ciudadanos.

Las UCC+i han adquirido un papel fundamental en la transmisión social del conocimiento generado en los centros de investigación, universidades y otras instituciones. Asimismo, desempeñan una labor de gran importancia para el fomento de la cultura científica y de la innovación, tanto en la sociedad civil como en el tejido productivo; en este último aspecto contribuyen a impulsar la transferencia de conocimiento y a generar un nuevo modelo productivo más competitivo (FECYT, 2012:5).

Más allá de su papel como comunicadores profesionales, las UCC+i se presentan además como intermediarios entre los investigadores y los periodistas de los medios de 
comunicación. Así, las Unidades colaboran con los medios de comunicación en la elaboración de contenidos que resulten interesantes y comprensibles para la sociedad, sin que se desvirtúe el mensaje que hay detrás de ella; y están al servicio de los investigadores para asesorarles sobre cómo comunicar sus proyectos y resultados, cómo atender a los periodistas, ofreciéndoles pautas acerca de la dinámica de los medios, sus tiempos de trabajo, necesidades, etc. El trabajo de las Unidades está además contribuyendo a la concienciación de la comunidad científica y los órganos de gobernanza de la investigación y la innovación sobre la importancia de acercar la ciencia a la sociedad (Libro Blanco UCC+i, 2012:6).

Atendiendo a sus líneas de actuación, se establecen cuatro modalidades de UCC+i en función de si realizan acciones de divulgación de la ciencia y la innovación, acciones de comunicación de resultados, formación en materia de comunicación de la ciencia o si desarrollan investigación (Comcired.es, 2014). Las acciones de comunicación de resultados de $\mathrm{I}+\mathrm{D}+\mathrm{i}$, según recoge el Libro Blanco, son todas aquellas asociadas a la difusión de informaciones y contenidos que cumplen determinados criterios de noticiabilidad. En concreto, que sean novedosos y de actualidad, y que estén asociados directamente a resultados producidos en los centros de investigación a los que pertenece la UCC+i.

Por actividades de divulgación del conocimiento científico y tecnológico se entienden todas aquellas orientadas a difundir informaciones y contenidos que no necesariamente sean novedosos o de actualidad, pero que contribuyan a aumentar el nivel de cultura científica y tecnológica de la ciudadanía. Así, entre las acciones de divulgación que han ido consolidándose en los últimos años se encuentran, por ejemplo, cafés de la ciencia en los que los investigadores se acercan de una forma más próxima al público, acciones concretas para personas discapacitadas con publicaciones y audiovisuales adaptados, todo tipo de competiciones y campus para los más jóvenes, páginas webs con recursos educativos, concursos de fotografías, juegos, videojuegos, etc.

En cualquier caso, desde la FECYT destacan el hecho de que todas las UCC+i, con independencia de su enfoque, trabajan por y para que la sociedad se sienta cada vez más atraída por la ciencia, estimulando su curiosidad por este ámbito de la cultura; y contribuyen a sensibilizar a la opinión pública sobre la importancia y beneficios de los avances desarrollados desde el ámbito de la I+D+I (Libro Blanco UCC+i, 2012:7). 
Por otra parte, a raíz de la celebración en 2007 del Año de la Ciencia, se puso en marcha otra de las acciones desarrolladas por la FECYT con el objetivo de fortalecer el impulso de la comunicación de la ciencia en España. Se trata de la puesta en marcha en 2008 del Servicio de Información y Noticias Científicas (SINC), la primera agencia pública de ámbito estatal especializada en información sobre ciencia, tecnología e innovación en español. El equipo de SINC produce noticias, reportajes, entrevistas y materiales audiovisuales (vídeos, fotografías, ilustraciones e infografías). La agencia ofrece su servicio a periodistas, científicos y ciudadanos para dar a conocer los últimos desarrollos de la ciencia más relevante, con especial énfasis sobre los trabajos españoles. Muchos medios de comunicación, tanto locales como nacionales, especializados y generalistas, utilizan los contenidos de SINC como fuente de información. La agencia también se ha consolidado como una referencia de información científica entre la comunidad investigadora (García Molina, 2012:73). Además de contar con un equipo de periodistas especializados que cubren la actualidad diaria nacional e internacional, la agencia bebe de las noticias subidas por los centros de investigación registrados que pueden cargar sus informaciones, siendo estas posteriormente revisadas, editadas y aprobadas por los responsables del SINC para su publicación.

La última encuesta de valoración de los usurarios publicada en el Anuario SINC de 2013, en la que participaron 303 periodistas y 309 responsables de comunicación de centros de investigación y universidades, recogía que el $98 \%$ de los periodistas consideraba que SINC era una fuente útil para su trabajo y el $82 \%$ la tenía como una de sus principales fuentes, mientras que el $78 \%$ de las instituciones consideraba que SINC era útil para difundir sus noticias (SINC, 2013:156). En cuanto a audiencia, según los datos actualizados en el Anuario SINC de 2014, la web superó los 3,2 millones de visitantes únicos y los 6,3 millones de páginas vistas. Por lo que respecta a usuarios registrados, cuenta con 679 instituciones y 889 periodistas (SINC, 2014).

En definitiva, el propósito de la agencia SINC es potenciar la comunicación de la ciencia para lo que consideran necesaria la intermediación de profesionales especializados, según explicaba Esperanza García Molina, redactora jefe de la agencia, en un congreso sobre Comunicación Social de la Ciencia:

La culminación de nuestro propósito es visibilizar la ciencia que se hace en España, apoyar a los periodistas para que la voz de la ciencia se refleje en los medios, y, por último, penetrar día a día 
en los cerebros de los ciudadanos para aumentar la cultura científica de la sociedad. Para traducir los complejos resultados científicos a un lenguaje asequible para el lector de periódicos, contextualizar los resultados en el marco adecuado para poder interpretarlos, y, en definitiva, para lograr que los ciudadanos se interesen por la ciencia, necesitamos especialistas (García Molina, 2012:75).

La agencia SINC sigue el modelo de agencias de noticias científicas internacionales de referencia y con una extensa trayectoria como son Alphagalileo en el ámbito europeo y EurekAlert en el anglosajón.

En su estudio sobre Los públicos de la ciencia, Francescutti (2014) destaca el papel clave en España de agencias como SINC junto a los medios de comunicación públicos en la divulgación y comunicación de la ciencia.

El servicio público continúa siendo decisivo; sin el sostén de TVE2, RNE y algunas cadenas autonómicas, buena parte de la oferta inventariada desaparecería y sus audiencias se dispersarían. Vista la indiferencia del sector privado por la divulgación (salvo honrosas excepciones), los patrocinios de instituciones como la FECYT y otras agencias estatales cobran un valor estratégico (Francescutti, 2014:46).

Finalmente, destacaremos entre las iniciativas de la FECYT para la promoción de la CPC y el desarrollo de la cultura científica, la puesta en marcha del portal web ComCiRed, Comunicar Ciencia en Red, como "punto de encuentro para intercambio de información y recursos de los miembros de las redes de divulgación y comunicación coordinadas por FECYT y de todo aquel interesado en la ciencia y la innovación" (www.comcired.fecyt.es). ComCiRed da también nombre al congreso anual organizado por la FECYT y dirigido a la Red de UCC+i que en 2014 celebró su sexta edición en el Museo Nacional de Ciencia y Tecnología (MUNCYT) de Alcobendas (Madrid). A lo largo de los últimos seis años los participantes en el congreso han abordado temas como la ciencia ciudadana, las experiencias internacionales, el universo 2.0 al servicio de la divulgación y la promoción de vocaciones científicas, entre otros. ComCiRed sirve además de escenario para que las UCC+i compartan el trabajo que están llevando a cabo.

Más allá de la actuación de la FECYT, cabe señalar otras acciones dirigidas a incrementar la profesionalización del sector como son iniciativas de formación, entre las que se encuentra el Observatorio de la Comunicación de la Ciencia de la Universidad Pompeu Fabra que, a nivel académico, ofrece desde 1995 el Máster en Comunicación Científica, Médica y Ambiental (MCC), que en 2013 se amplió con una oferta on line. 
El Observatorio organiza además anualmente el Campus Gutemberg, con una intensa programación de dos días que tiene como objetivo consolidar un espacio abierto que muestre los diversos canales y formatos que se utilizan para impulsar el periodismo, la comunicación, la cultura y la divulgación científica desde todos los ámbitos, así como reflexionar en torno a los cambios que se están produciendo y las nuevas estrategias a seguir.

Los resultados de iniciativas como estas y de una mayor sensibilización por la comunicación de la ciencia a nivel internacional han favorecido importantes avances en la CPC y en las actitudes de sus actores. El estudio sobre la relación de los investigadores con el mundo de la comunicación y el periodismo realizado en 2008 por un grupo internacional de investigadores en comunicación científica dirigidos por Hans Peter Peters (2008) concluía que las relaciones entre los científicos y los periodistas son ahora más frecuentes y mucho más fluidas y satisfactorias de lo que cabría esperar. Para el estudio se entrevistaron a 1.354 investigadores e investigadoras de EEUU, Japón, Alemania, Reino Unido y Francia, sin que se encontraran diferencias importantes entre los participantes de los diferentes países (Peters, 2008).

El $69 \%$ de los encuestados había mantenido al menos un contacto con los medios en los últimos tres años, y de ellos, en el $30 \%$ de los casos los contactos superaban los cinco. En las interacciones con los medios, muchos indicaron que a menudo se sentían inseguros y faltos de control sobre el proceso comunicativo, identificando nueve de cada diez el "riesgo de ser citados de forma incorrecta" como un importante elemento disuasorio a la hora de establecer relaciones con los medios. También ocho de cada diez consideraban un problema la imprevisibilidad de los periodistas. A pesar de estas reticencias, el 57\% valoraban de forma positiva su última relación con los medios frente a un $6 \%$ que se mostraban más bien insatisfechos. En este sentido, también cabe destacar que el estudio apunta a que los científicos están cada vez más informados sobre las rutinas de producción de los periodistas, por lo que están más capacitados para colaborar con ellos.

Si en los inicios de la divulgación de la ciencia veíamos como la presión ejercida por los pares, que veían la divulgación como algo alejado del quehacer investigador, podía disuadir a los miembros de la comunidad científica de realizar acciones de comunicación, en la actualidad parece que ya no es así. En este sentido, el estudio realizado refleja un importante cambio en esta visión ya que únicamente un 34\% de los 
participantes identificó la incompatibilidad con la divulgación científica como una preocupación importante. Incluso un 39\% reconocían que un resultado importante de sus contactos con los medios era mejorar la reputación personal entre iguales. No obstante, las posibles reacciones críticas de sus compañeros seguían preocupando a un $42 \%$. En términos generales, el estudio muestra que la relación entre científicos y periodistas, tradicionalmente presidida por una cierta tensión e incluso desconfianza, es más fluida, frecuente y satisfactoria de lo que pudiera parecer, reflejando también un avance en la sensibilidad científica por comunicar y divulgar conocimientos.

Para la coautora del informe Dominique Brossard, "el estudio indica claramente que los científicos consideran necesaria la interacción con los periodistas. Ya no tenemos que convencer a los científicos. Hemos superado ese punto". Para los autores, lo que puede estar produciendo el cambio en la conducta de los científicos es la perspectiva de obtener recompensa. La ciencia que es más visible da la sensación de ser más creíble para los posibles financiadores y la cobertura periodística puede mejorar las perspectivas profesionales de los científicos. Asimismo, entiende que otra motivación para los investigadores e investigadoras es que consideran beneficioso que un público más amplio tenga conocimiento del sector científico a través de la cobertura periodística de sus investigadores, lo que viene a ratificar algunas de las razones expuestas ya en el apartado anterior.

Parece evidente que más allá de la profesionalización del sector de la comunicación científica, se ha de continuar avanzando en la sensibilización de la comunidad científica y también en su capacitación. En este campo, a los talleres y cursos de formación para investigadores e investigadoras impartidos cada vez por más centros de investigación y universidades, cabe añadir iniciativas internacionales como el proyecto ESConect desarrollado entre 2005 y 2008 en el marco del VI Programa Marco de la Unión Europea, que permitió el desarrollo de módulos formativos en abierto en materias como actores y razones para la comunicación, la escritura de la ciencia para los medios de comunicación, cómo hablar con los medios, ciencia pública en la web o cómo comunicar el riesgo, entre otros temas (EsConect, 2009).

También en el VII Programa Marco se incluyeron acciones de formación masiva en comunicación científica. Sin embargo, a pesar de esta y otras muchas acciones de formación, para autores como De Semir sigue siendo necesario aumentar el número de cursos de formación específica para profesionales especializados en comunicación 
científica. En este sentido, destaca el papel de las universidades, en las que considera que sigue habiendo importantes deficiencias en comunicación de la ciencia tanto en las carreras de Periodismo como en las licenciaturas científicas (De Semir, 2014:91).

La implicación de los investigadores parece clave si se tiene en cuenta además que los científicos son los interlocutores predilectos cuando se trata de saber e informarse sobre temas científicos, según se desprende del Eurobarómetro sobre "La investigación científica en los medios de comunicación” (2007).

De cara a avanzar en la Comunicación Pública de la Ciencia parece necesario que tanto los científicos como las organizaciones científicas, entre ellas las universidades, mejoren la comunicación del trabajo que llevan a cabo en materia de ciencia e innovación. Para De Semir, la comunicación más eficiente debe centrarse en el trabajo de los científicos, que por su parte han de participar personalmente en la iniciativa de comunicación. El autor considera además necesario que el periodismo científico tenga entre sus objetivos, además de informar, los de convencer y movilizar. También entiende que deber estar fomentado por universidades, museos, grupos de reflexión, fundaciones, sociedades profesionales $\mathrm{u}$ organizaciones vinculadas al Gobierno. Para De Semir, el nuevo contexto de la ciencia y de su comunicación obliga a replantear las acciones y relaciones entre investigadores y comunicadores.

La amalgama de los nuevos modos, formas, estilos y patrocinadores de la cultura científica implica que científicos y periodistas deben profundizar - y en su caso replantear - las orientaciones y definiciones estándar de objetividad y equilibrio informativo en su interrelación y protagonismo en la labor conjunta de involucrar al público en su interés por las ciencias y sus aplicaciones. Es un camino que hemos emprendido juntos desde hace unos relativamente pocos años y en el que hemos de profundizar a pesar de los recelos, crisis e intereses que nos envuelven (De Semir, 2014:96).

Mirando el futuro, y siguiendo el modelo de comunicación basado en una apuesta por el diálogo entre ciencia y sociedad, la comunicación de la ciencia de forma unidireccional hacia el público no será suficiente. Difundir la ciencia de manera útil y valiosa sigue siendo un reto tanto para la propia ciencia como para la sociedad, no solo porque el modelo deficitario, basado en educar a quien no sabe, subyace a la tendencia de fomentar la comprensión pública de la ciencia y mantener su arraigo entre científicos, responsables políticos y medios de comunicación. La solución no consiste en ofrecer más comunicación sobre ciencia, sino en una información y en un diálogo más eficaces (European Comision, 2009). 
Los avances en la CPC impulsados principalmente por la FECYT que hemos podido ver al inicio del presente apartado parece que siguen poniendo el foco en la comunicación de la ciencia desde una perspectiva unidireccional. En este sentido, las últimas convocatorias de ayudas para el fomento de la cultura científica, tecnológica y de la innovación buscan introducir la perspectiva de la participación ciudadana siguiendo las directrices establecidas por el Plan Estatal de Investigación Científica, Técnica y de Innovación 2013-2016. En concreto, la convocatoria de 2015 establece la necesidad de establecer sinergias con los objetivos del mismo:

El Plan Estatal de Investigación Científica, Técnica y de Innovación 2013-2016 tiene entre sus objetivos específicos incrementar la cultura científica, tecnológica e innovadora de la sociedad española así como incrementar la difusión de los resultados de investigación científico-técnica y de la innovación financiados con fondos públicos. De esta manera, busca fomentar e incentivar el acercamiento de la ciencia, la tecnología y la innovación a los ciudadanos acortando distancias entre el mundo científico y tecnológico y la sociedad en general, mejorando la educación científico-técnica de la sociedad en todos los niveles e impulsando la participación activa de la sociedad en los procesos de I+D+I, contribuyendo además de este modo a fomentar la construcción de una identidad colectiva e imagen de España como un país de ciencia e innovador (FECYT, 2015b:3).

Vemos así como queda recogida la necesidad de impulsar la participación de la sociedad en los procesos de ciencia e innovación. En el caso concreto de la modalidad dirigida a la Red de Unidades de Cultura Científica y de Innovación (Red UCC+i), la convocatoria alude asimismo a la necesidad de que estas Unidades actúen como "canal de comunicación entre los investigadores y la sociedad”.

A pesar de la voluntad de avanzar hacia la promoción de mecanismos de participación y diálogo, como veremos más adelante al abordar la comunicación de la ciencia desde las universidades, todavía la práctica de la comunicación de la investigación y la innovación mantiene un carácter predominantemente unidireccional, tanto con la intención de informar al público como para captarlo y motivarlo. Para De Semir, el objetivo "relativamente oculto" de este enfoque de la comunicación de la ciencia “es generar aceptación y fascinación por las ciencias, por lo que la comunicación pública constituye un tipo de marketing dominado por los intereses económicos y la promoción de la innovación”. El objetivo de este tipo de comunicación, en opinión del autor, se basa en la necesidad de que la sociedad acepte la ciencia, la tecnología y la innovación, y en la consecución de los ingenieros y científicos 
necesarios. En este sentido, considera que universidades y centros de investigación han desarrollado "unas aptitudes y unos equipos de comunicación eficaces, que hoy forman parte importante de un proceso comunicativo que ya no se circunscribe al binomio clásico entre científicos y periodistas (De Semir, 2014:102).

En este contexto, el director del Observatorio de la Comunicación de la Ciencia destaca cinco retos para alcanzar una verdadera interacción exitosa entre la ciencia y la sociedad. Veamos cada uno de ellos:

- Desechar el mito del público singular. La idea del público ha sido central en el desarrollo teórico del mundo de las noticias, pero hoy existen múltiples públicos, desde los escolares a la propia comunidad científica, y también múltiples fuentes que van desde los científicos y las organizaciones a los políticos y los periodistas. El reto consiste entonces en demandar diferentes mecanismos en diferentes momentos y con una formación diferente tanto para los proveedores como para los usuarios de la información, permitiéndoles escoger los medios de comunicación más apropiados. "Cada uno implica a muchos actores, por lo que una visión unidireccional de la ciencia hacia la sociedad y unidimensional del público es una simplificación y no dará resultado".

- Cambiar la percepción que los científicos tienen de la sociedad. En numerosas ocasiones, la comunidad científica considera a la sociedad como "un enorme ente irracional, desconocido y con aversión a corres riesgos, que en ocasiones se comporta de manera impredecible y negativa para sus investigaciones”, señala. La investigación, la evaluación tecnológica y las actividades con implicaciones éticas, legales y sociales son en ocasiones consideradas por la comunidad científica como un obstáculo para el progreso científico. Sin embargo, el autor considera que en los temas en los que se ha promovió la información y el debate social, como es el caso de la nanotecnología, los resultados han sido positivos.

- Superar la fuerte dependencia de las revistas científicas y de los comunicados de prensa que generan. La credibilidad y la facilidad que ofrecen las informaciones ya seleccionadas y revisadas por pares de las revistas de ciencia provoca que en muchas ocasiones los medios de comunicación se limiten a trasladar sus comunicados. Para De Semir, es importante que los periodistas vayan más allá y entiendan cómo se produce el conocimiento científico y cuáles 
son sus límites con el fin de transmitir estos aspectos. Para ello es necesario también que los periodistas diversifiquen sus fuentes y los investigadores adquieran destrezas en lo referido a las posibilidades y los límites de los diferentes medios de comunicación para comunicar a públicos distintos. También resulta necesario contar con audiencias capaces de entender el funcionamiento y los intereses de los medios y del mundo de la ciencia y la innovación.

- Responder a los derechos y responsabilidades de la ciencia y de la sociedad. En este sentido, el autor afirma que la comunicación científica "se ha convertido en un deber para los científicos y en un derecho para el público, el derecho a saber y el derecho a participar. Pero el deber no siempre es bienvenido y los derechos no siempre son ejercidos con entusiasmo". En este punto, como veremos a la hora de abordar las directivas en materia de comunicación de la RRI en el siguiente capítulo, el grupo de expertos que supervisó las actividades científicas en la sociedad a través del proyecto MASIS $^{3}$, recomienda hacer hincapié en la implicación del público con la ciencia desde el punto de vista de la comunicación, con unas responsabilidades claramente definidas para los actores. Para que esto sea eficaz, debe producirse una mayor comprensión de todas las partes acerca de la naturaleza de la ciencia como actividad evolutiva y debe situarse el conocimiento científico en el contexto social y económico para que la cada vez más abundante información sobre avances científicos no se convierta en pura anécdota.

- Superar el grado de especificidad cultural entre países en relación con la comunicación científica. Mientras que el conocimiento científico ha superado las fronteras políticas y lingüísticas, De Semir considera que desde el punto de vista de la comunicación siguen existiendo tradiciones y regulaciones muy diferentes en el grado de autonomía periodística y científica, diferencias que se dan tanto entre países del propio ámbito europeo como entre diferentes

\footnotetext{
${ }^{3}$ El proyecto Monitoring Policy and Research Activities on Science in Society in Europe (MASIS) de la UE tuvo como objetivo ofrecer una amplia visión de conjunto de la investigación y las políticas sobre ciencia y sociedad en Europa. Las conclusiones y recomendaciones fueron recogidas en el informe Challenging Futures of Science in Society Emerging Trends and cuttingedge issues (Sinue, 2009).
} 
continentes. "Estas tienen consecuencias y establecen diferentes modalidades en cómo se difunde la ciencia en cada comunidad o país y también de forma transnacional, que no deben ignorarse ni subestimarse", señala.

En cualquier caso, y más allá de estos cinco retos, De Semir destaca que el papel de la comunidad científica resulta clave. En un momento de recortes en los medios, que afectan también a la posibilidad de contar con periodistas especializados en ciencia, y en el que las reglas de la comunicación están cambiando, los científicos "pueden y deben ayudar a garantizar que la información sobre ciencia está siendo documentada y rigurosa". De un adecuado acceso al conocimiento científico se derivará la actitud hacia la ciencia y la innovación de la sociedad.

Está claro que la opinión pública depende directamente de la clase de información que pueda recibir, de la que se derivan reacciones en un sentido u otro - positivas, negativas -, según sea el conocimiento que la ciudadanía tenga sobre la implantación de determinadas nuevas tecnologías y sus aplicaciones. De ahí se deriva la importancia de que haya un acceso adecuado y una buena transmisión del conocimiento científico a la sociedad (De Semir, 2014:106).

Vemos como iniciativas como las que hemos abordado a lo largo del presente apartado ayudan a avanzar en la profesionalización de la comunicación de la ciencia, así como algunos de los retos a los que deberá hacer frente estos profesionales para convertir la comunicación en un verdadero diálogo entre ciencia y sociedad. Desde la perspectiva ética planteada, resulta de utilidad recuperar las consideraciones realizadas por Cortina para avanzar hacia una ciudadanía mediática y crítica, hacia una ciudadanía empoderada para poder participar con autonomía en la RRI. La autora señalaba en este sentido la necesidad de avanzar en cinco ámbitos en los que entendemos que también debe avanzar una comunicación de la ciencia cada vez más profesionalizada y que son:

- Fomentar la poliarquía de los centros mediáticos, incluidos los de ciencia.

- Potenciar la creación de asociaciones de consumidores que expresen su opinión.

- Forjar un ethos profesional y empresarial que permita que la actividad mediática esté a la altura de los principios de la ética moderna.

- Desarrollar una ética a nivel de las organizaciones mediáticas y empresariales.

- Avanzar en la construcción de sujetos éticos que se conviertan en consumidores éticos. 
Comunicación y ética se entrelazan, como señala el filósofo y antropólogo Georges Kutukdjian, durante años impulsor de los Derechos Humanos y director de la Unidad de Bioética de la UNESCO, para quien en el actual contexto histórico, cultural, social y científico, la ética debe ser la esencia de la comunicación. Según Kutukdjian, tres son las condiciones para poder considerar ética la esencia de la comunicación: verdad, transparencia y confianza. En este sentido, De Semir entiende que la consideración ética es especialmente aplicable a la comunicación del conocimiento científico y médico.

Ética y comunicación se conjugan en el avance de la RRI, volviendo desde el ámbito de la comunicación al concepto de la ética con el que abríamos el presente trabajo. Tras plantear en un primer momento un marco ético y político para la ciencia y concretarlo en un segundo capítulo en la Investigación e Innovación Responsable, en lo que llevamos de este tercer capítulo hemos abordado cómo el desarrollo de una Comunicación Pública de la Ciencia que tenga en cuenta tanto la capacitación de la ciudadanía como el establecimiento de un diálogo entre ciencia y sociedad resulta una premisa básica para alcanzarla. El recorrido planteado nos lleva a continuación a centrarnos en el caso de la comunicación de la ciencia desde las universidades.

\subsection{LA COMUNICACIÓN DE LA CIENCIA COMO PARTE DE LA}

\section{FUNCIÓN DE LAS UNIVERSIDADES}

A lo largo de los apartados anteriores hemos visto como ha evolucionado la comunicación de la ciencia y sus modelos, así como algunas de las razones de su importancia y los riesgos, retos y oportunidades a los que se enfrenta, entre los que se encuentra la nueva galaxia mediática y la profesionalización del sector. En el presente apartado centraremos el foco de la comunicación de la ciencia, la tecnología y la innovación en el ámbito de las universidades.

Para ello, trataremos en primer lugar de buscar entre las funciones de la Universidad aquellas relacionadas con la transferencia y comunicación del conocimiento científico, abordando asimismo la perspectiva de diversos autores que ponen el acento en la comunicación de la ciencia como una comunicación central en el ámbito de la comunicación universitaria. En un segundo punto trataremos de perfilar un análisis de la situación en la que se encuentra la comunicación universitaria en España, 
haciendo para ello referencia a diferentes declaraciones que recogen las recomendaciones de expertos para mejorar en éste ámbito. En este apartado, resulta asimismo especialmente interesante recoger la mirada de Antonio Marín, quien ha abordado a través de diversas publicaciones tanto la relación entre Universidad y medios de comunicación como la situación de la comunicación de la ciencia y la innovación desde los centros de enseñanza superior.

Estas aproximaciones nos ayudarán a conocer las funciones y objetivos de la comunicación de la ciencia, la tecnología y la innovación en la Universidad y a trazar una visión amplia de su evolución en los últimos años y de su situación actual.

\subsubsection{Comunicación y transmisión de la ciencia, funciones de la Universidad}

La comunicación de la ciencia y la innovación forma claramente parte de la misión de las universidades, tal y como queda recogido por la propia legislación española. Pero además, son muchas las voces que a nivel nacional e internacional destacan el potencial de los centros de enseñanza superior para transferir el conocimiento científico y tecnológico a la sociedad, a través de una comunicación que es a la vez un deber y una responsabilidad.

La Ley Orgánica 6/2001, de 21 de diciembre, de Universidades, conocida como la LOU, establece en su Título Preliminar que son funciones de la Universidad al servicio de la sociedad (LOU, 2001):

a. La creación, desarrollo, transmisión y crítica de la ciencia, de la técnica y de la cultura.

b. La preparación para el ejercicio de actividades profesionales que exijan la aplicación de conocimientos y métodos científicos y para la creación artística.

c. La difusión, la valorización y la transferencia del conocimiento al servicio de la cultura, de la calidad de la vida, y del desarrollo económico.

d. La difusión del conocimiento y la cultura a través de la extensión universitaria y la formación a lo largo de toda la vida. 
Vemos como ya en la primera de las funciones atribuidas a la Universidad aparece la transmisión de la ciencia y la tecnología como misión fundamental de los centros de enseñanza superior. La comunicación de la ciencia y la innovación desde la Universidad aparece asimismo estrechamente vinculada a la tercera de las funciones, que incluye la difusión y transferencia del conocimiento al servicio de la cultura, de la calidad de la vida, y del desarrollo económico. A partir de lo expuesto en capítulos anteriores, entendemos que la comunicación de la ciencia aparece ligada a la mejora democrática de la sociedad, y con ella, a la calidad de vida de sus ciudadanos y ciudadanas.

Más allá de la legislación española, desde una perspectiva global, independientemente de las diferencias existentes en el ámbito universitario respecto al desarrollo histórico y sistemas de gobiernos y funcionamiento entre países, existe consenso en considerar a las universidades como "herramientas fundamentales para enfrentar los desafíos de la sociedad al tiempo que para formar ciudadanos capaces de construir una sociedad más justa, sustentada en la solidaridad, el respeto de los derechos humanos y el uso del conocimiento compartido" (Marín, 2005a:11). En este escenario la función comunicativa de las universidades está llamada a jugar un papel fundamental. En palabras del especialista argentino José Luis Coraggio:

Hoy el problema de las universidades no es el problema de un sector más. Es el problema del sector de actividad que tiene que asumir parte importante de la tarea de cerrar la brecha internacional en la rama más dinámica del sistema global: la producción autónoma y la difusión de conocimientos y la formación de las capacidades de la ciudadanía y las instituciones para participar en condiciones no subordinadas del proceso global del cambio (Corraggio, 2001:15).

Para el sociólogo Antonio Ariño, vicerrector de Cultura e Igualdad de la Universitat de València, la función de comunicar ciencia o saber establecida por la normativa universitaria, debe tener como objetivo "ayudar a las personas a interpretar su mundo de acuerdo con los conocimientos más avanzados en cada momento" (Ariño, 2014:63). Con este fin, el autor resalta la necesidad de comunicar la ciencia y la tecnología no únicamente en los sentidos restringidos que se dan a estos términos, sino ampliándolo también a las ciencias humanas y sociales ya que estas resultan necesarias para interpretar los problemas que vive actualmente nuestra sociedad como la pobreza, el reto del envejecimiento, las dificultades de inserción de las generaciones jóvenes, el terrorismo transnacional o las futuras guerras, entre otras. Para Ariño, la resolución de 
este tipo de problemas "requiere más ciencia y más tecnologías sociales. Y sobre todo más comunicación de estas ciencia".

En este sentido, cabe destacar que a la hora de hablar de ciencia e investigación, esta no se puede limitar al campo de las tecnologías y las ciencias experimentales. Los ámbitos jurídicos, económicos, humanísticos y sociales forman igualmente parte del conocimiento científico y sus investigadores e investigadoras trabajan para continuar avanzando en ellos. Asimismo, cuando hablamos de transmisión de noticias científicas, no cabe hablar sólo de aquellas relacionadas con novedades en el proceso del descubrimiento científico. Desde la Asociación Catalana de Comunicación Científica, Cristina Ribas señala que hay al menos tres tipos de ciencia que pueden ser comunicados: la ciencia cultural, la ciencia práctica y la ciencia social, poniendo el acento sobre los riesgos que corre en la actualidad la difusión de esta última.

Hay diversos tipos de ciencia susceptibles de ser comunicados. Para simplificar: la ciencia cultural que nos ayuda a entender el mundo, la ciencia práctica que nos da herramientas para el día a día y la ciencia social que nos capacita para valorar su papel en la sociedad. El boom de iniciativas de comunicación científica que han aparecido en las últimas décadas, propiciadas por la revolución digital, parece que garantizan la supervivencia de la ciencia cultural y de la ciencia práctica. Sin embargo la ciencia más social va disminuyendo dramática e inexorablemente a medida que se agudiza la crisis en los medios de comunicación (Ribas, 2014).

Además de tener en cuenta el ámbito de la ciencia a la que hacemos referencia al hablar de comunicación, Delia Crovi considera también de interés detenerse en el tipo de conocimiento. Alfred Schutz establece dos tipos de conocimiento: uno social, intuitivo, que circula con cierta libertad y pocas restricciones y el otro, aprobado socialmente, identificado con el saber científico. Entendemos que la comunicación de la ciencia y la innovación desde las universidades tienen que ver con este segundo tipo de conocimiento socialmente aprobado. Es precisamente el hecho de comunicar un conocimiento avalado lo que puede diferenciar a las universidades de la proliferación de otros emisores surgidos en la nueva galaxia mediática. De hecho, como veíamos en el estudio sobre la percepción de la ciencia de la Fundación BBVA (2012), las universidades son, junto con las asociaciones profesionales de médicos, las que obtienen un mayor nivel de confianza sobre la información científica que aportan a la sociedad.

Este aval universitario se hace extensible a otras webs y canales que, sin ser expresamente de la Universidad, implícitamente lo tienen como es el caso de las páginas creadas por profesores, por proyectos de investigación, por grupos de investigación o 
por los propios investigadores e investigadoras. Se trata de espacios "donde un usuario interesado en el conocimiento socialmente aprobado, sabe que puede navegar con seguridad y con el respaldo que da la casa de estudios, un respaldo y confiabilidad que no siempre es fácil de encontrar en la red" (Crovi, 2005:59). La diferencia por tanto con otros medios y emisores radica en la legitimidad del conocimiento que comunica y su prestigio. Se trata, entendemos, de una valor de suma importancia en la era, como veíamos, postexperta (Luers y Kroodsma, 2014), en las que son muchas las voces que hablan de ciencia en la red.

Por otra parte, más allá del conocimiento social y del conocimiento socialmente aprobado, Schutz distingue respecto a la capacidad de las personas para acercarnos a los conocimientos entre dos campos de significatividades: las intrínsecas, que son el resultado de los intereses que hemos elegido; y las impuestas, que son aquellas que recibimos pasivamente y que nos llegan sin nuestra intervención. Para Delia Crovi el tránsito desde las significatividades impuestas hacia las intrínsecas, libremente elegidas, debe ser uno de los propósitos de la relación medios-universidad en su función de distribución social del conocimiento para no caer en la difusión de informaciones al margen del interés colectivo.

(...) espacios de significación e interés por el contenido son los eslabones que la comunicación universitaria debe unir para vincular a los ciudadanos con el conocimiento (...) Si la comunicación universitaria no es capaz de facilitar estos tránsitos simbólicos, sobrevivirá el riesgo de emitir discursos y mensajes al margen del interés colectivo (Crovi, 2005:49).

Las universidades, como centros productores de saberes y como núcleos que concentran grupos y organismos de investigación, están llamadas a promover la comunicación científica, comenzando por su propia comunidad y continuando con el resto de la sociedad. Así lo defiende la periodista e investigadora Argelia Ferrer (2005:73), quien considera que la "mina de oro" que supone la Universidad para la comunicación de la ciencia se debe explotar con varios fines como son: fortalecer la imagen externa e interna de la universidad explicando cómo sus investigadores contribuyen al avance del conocimiento; contribuir con la educación no formal de los ciudadanos; estimular la participación de los investigadores en la difusión del conocimiento, a través de mecanismos de divulgación en los medios de comunicación, y contribuir con la discusión pública de temas de gran actualidad en los cuales los investigadores tienen mucho que aportar desde una perspectiva local o nacional. 
Para alcanzar estos objetivos, la autora señala que las universidades deben adoptar una actitud proactiva, fortaleciendo los servicios de prensa, a los que la autora otorga una importancia capital para la creación de una cultura científica en la comunidad. Así, los gabinetes de comunicación de las universidades tienen un papel fundamental a la hora de contar qué hacen los laboratorios y los centros de investigación, los proyectos en proceso, sus dificultades, las personas que los conforman y muchos otros aspectos vinculados con la cotidianidad del trabajo científico. La transmisión de esta información sirve, en opinión de Ferrer, "para que la comunidad conozca, se informe y se eduque en temas propios del periodismo científico".

Para la autora, la comunicación científica universitaria también puede tener una papel protagonista a la hora de acercar al público aquellos temas de la ciencia que pueden parecer lejanos, temas que pueden ser comentados, explicados y analizados por los investigadores de las universidades "que podrán hacernos más cercanos y comprensibles estos avances". Pero además de la comunicación externa, Ferrer destaca la importancia del papel de los gabinetes de comunicación universitarios en la comunicación interna. Su papel, señala, resulta fundamental "para vender dentro de las mismas universidades la idea de explotar la mina de oro de la información sobre ciencia y tecnología que está adentro". En definitiva, la autora sitúa la comunicación de la ciencia en el centro de la comunicación universitaria en su conjunto:

Consideramos que proyectar a la universidad y a la ciencia es el objetivo central de las
comunicaciones universitarias. Siempre debemos tener presente el sentido originario del verbo
comunicar: poner en común, hacer partícipes a los otros, comulgar, expandirnos. La política
comunicacional universitaria es el sustento conceptual del derecho de los universitarios y de toda
la comunidad de conocer qué se hace en los distintos ámbitos institucionales. Es la plataforma de
donde se expande e irradia la misión universitaria y se proyecta el enorme potencial que
tenemos, es también el soporte de la imagen institucional y el mecanismo de fomento de todos
los valores universitarios, en los que destaca ser vanguardia científica y social (Ferrer, 2005:84).
En la introducción del libro dedicado a analizar la situación de la Universidad y la comunicación social de la ciencia en el contextos iberoamericano (Marín, 2005b), la física y divulgadora de la Universidad Nacional Autónoma de México (UNAM) Guadalupe Zamarrón constata el hecho de que la comunicación en las universidades es una actividad cotidiana en la enseñanza, en los grupos de investigación y sobre todo en la extensión de la cultura y de los servicios. Asimismo, destaca la existencia de oficinas 
o gabinetes encargados de la comunicación interna y externa "y es ya frecuente que los gabinetes incluyan labores de comunicación de la ciencia", indicando que en estas unidades el propósito principal de esta actividad es el de informar sobre los quehaceres institucionales, por lo que la forma utilizada generalmente es la periodística.

La existencia de gabinetes de comunicación a los que se refiere Zamarrón, que incluyen entre sus funciones la comunicación de la ciencia, no parece ser garantía de que ésta se desarrolla de la forma más adecuada y se convierta en el centro de la comunicación universitaria al que aludía Ferrer. Veremos en el siguiente apartado algunas de las voces que denuncian un importante déficit de información científica en la comunicación de las universidades, así como declaraciones y recomendaciones de expertos que plantean medidas para hacerle frente y fomentar una mayor comunicación de la ciencia, la tecnología y la innovación como parte de función de las universidades.

\subsubsection{Retos a superar en la comunicación y formación universitaria}

Tras lo expuesto en el punto anterior, parece claro que entre las funciones de la Universidad se encuentra la de comunicar el conocimiento científico y tecnológico y mejorar la divulgación de la investigación y la innovación. Los déficits detectados por expertos y expertas en el cumplimiento de estas funciones han llevado a incluir en diversas declaraciones sobre comunicación de la ciencia recomendaciones específicas para la mejora de la misma por parte de las universidades.

Ya en 1994, la Declaración de Baeza de la Asociación Española de Periodismo Científico, surgida a partir de las reflexiones de los expertos reunidos en un curso de verano entorno al periodismo científico como reto de nuestro tiempo, recogía entre sus recomendaciones de forma expresa la necesidad de potenciar la comunicación de la ciencia desde las universidades. En concreto, recomendaba "plantear a las universidades la necesidad de crear gabinetes de divulgación científica que faciliten la difusión a la sociedad de los hallazgos, investigaciones y publicaciones de cada centro universitario" (Marín, 2005b:89).

Además de ésta, la declaración también recogía otras recomendaciones dirigidas a las universidades, como solicitar a las autoridades académicas que los trabajos de divulgación científica fuesen valorados en los baremos de currículo como méritos, así como instar a las facultades de Ciencias de la Información a que incluyesen las 
enseñanzas de periodismo científico en sus planes de estudio. La Declaración planteaba estas medidas ante la escasez de divulgación científica en el periodismo, llamando la atención sobre "el deber moral y cultural de informar sobre el valor y la rentabilidad de la investigación científica, teniendo en cuenta la influencia creciente en la vida cotidiana" (Marín, 2005b:90).

Como hemos visto en los apartados anteriores, los expertos reunidos en el Media for Science Forum organizado por la FECYT en 2010 incluían también entre sus recomendaciones algunas medidas dirigidas específicamente a los centros de enseñanza superior. En este sentido, ponían el acento en la función formativa de las universidades, tanto de cara a los comunicadores como para los investigadores e investigadoras. Así, indicaban que las universidades deben incluir cursos específicos de periodismo científico en los programas de formación de expertos en comunicación y diseñar programas formativos que faciliten a científicos e investigadores la adquisición de las habilidades y herramientas comunicativas básicas para acercar al público los resultados y metodologías propios de su actividad.

Estas declaraciones dejan patentes algunos de los déficits detectados por los expertos en el papel de la Universidad como promotor de la comunicación de la ciencia y la innovación entre los que destaca la creación de gabinetes de difusión de la ciencia y la innovación y el impulso de acciones formativas en CPC de cara tanto a los profesionales de la comunicación como al personal investigador. Sobre los déficits en comunicación de la ciencia en los centros de enseñanza superior ha profundizado uno de los principales teóricos españoles en materia de comunicación científica desde las universidades como es Antonio Marín ${ }^{4}$. El periodista resaltaba que en la práctica real en muchas ocasiones "el trabajo científico es transmitido más porque su financiación guarda una estrecha relación con la productividad de los investigadores, medida en artículos publicados en revistas científicas, que porque se quiera que la sociedad lo conozca" (Marín, 2009). En este sentido, alertaba de la crisis que supone para las instituciones universitarias la falta de un reconocimiento suficientemente de la divulgación periodística como una de sus prioridades, ya que de ella depende en buena medida su prestigio social.

\footnotetext{
${ }^{4}$ Antonio Marín ha participado en numerosas publicaciones que reflexionan sobre la comunicación universitaria y la comunicación de la ciencia, aportando la experiencia acumulada como director de Comunicación de la Universidad de Granada, donde actualmente ocupa el cargo de director de Mecenazgo.
} 
Más allá de la publicación en revistas científicas dirigidas a públicos especializados, Marín considera que las universidades y centros de investigación españoles dedican poco esfuerzo, en general, a divulgar la ciencia entre el gran público a través de los medios de comunicación. En este sentido, señala como apenas una de cada veinte de las noticias remitidas a los medios de comunicación en el día a día por esas instituciones guarda relación directa con lo que pudiera ser llamado divulgación de la ciencia. Esto resulta especialmente preocupante si se tiene en cuenta que la ciencia es una actividad clave para las universidades, principales responsable de su difusión en los medios.

En la percepción de quienes trabajan en los servicios de comunicación institucionales, los medios informativos circunscriben su interés por lo universitario a la crónica social, la extensión cultural, las reales o aparentes carencias académicas o de infraestructura y poco más. Justo sería esta la acusación de no pocos periodistas de medios informativos, que sólo ese tipo de actividades es comunicado por los gabinetes de prensa. De ahí que, estimamos, de que no haya más información científica en los medios informativos son tan responsables los propios medios como las universidades y los centros de investigación (Marín, 2009).

Cabe concretar que, por noticias de ciencia, Marín entiende aquellas que hacen referencia a resultados de investigación, a proyectos de investigación o a contratos de investigación suscritos con instituciones o empresas. En cuanto al papel de los profesionales de la comunicación científica en las universidades, el autor destaca entre sus funciones la de actuar de mediadores entre científicos y periodistas de los medios de comunicación, redactando las noticias, a partir de las fuentes de la propia institución académica-investigadora, y trasladándolas a los medios.

El problema principal radicaría en opinión de Marín en que, en el funcionamiento cotidiano de los servicios de comunicación universitarios, "no se ha previsto una reacción adecuada ante el hecho de que la producción científica propia es noticia relevante, que podría contribuir a mejorar la imagen interna y externa las instituciones a las que pertenecen”. Entre las razones que provocan este déficit en la comunicación de la ciencia por parte de las universidades, el autor señala la inercia a que se ve obligada en cierta medida toda instancia universitaria; la presión informativa interna, de la propia institución, acostumbrada a comunicar esencialmente actividades de extensión universitaria, convocatorias (cursos, seminarios, congresos, simposios, conferencias, inauguraciones, etc.); la presión que suponen los espacios informativos propios como revistas y boletines internos; o la presión de la información político- 
académica relacionada con la actividad de los equipos de gobierno de la institución y de sus centros. En este sentido, autores como Crovi, coinciden en advertir como en la comunicación universitaria "se da prioridad a contenidos vinculados con el quehacer político-administrativo de las instituciones, a veces en detrimento del saber científico y de la docencia" (Crovi, 2005:51).

Entre las razones de la reducida presencia de noticias sobre ciencia, Marín encuentra también causas relacionadas con los recursos disponibles y con la relación de los gabinetes con los medios. Así, destaca la limitación de medios humanos y materiales de los equipos de comunicación y la demanda de los medios de comunicación que en muchas ocasiones limita el tiempo disponible y hace difícil abordar notas de carácter científico, que precisan de mucho más tiempo para su desarrollo.

Frente a esta limitada presencia, Marín destaca las oportunidades que abre la ciencia para consolidar a las universidades como fuente de información de los medios, ocupando un lugar de privilegio al ofrecer contenidos "que a un tiempo se ajusten a los criterios de noticiabilidad, de calidad que la Universidad ha de exigir en todos sus ámbitos de actuación y sean, por ello, del gusto de los editores de los medios de comunicación" (Marín, 2005b:106). En este sentido, apunta el interés de consolidar a los investigadores e investigadoras de las universidades como fuente de referencia a la hora de buscar una opinión fundada, a través de la experiencia de expertos que desarrollan su trabajo docente e investigador sobre temáticas que son parte de la actualidad que más interesa socialmente: medioambiente, salud, educación, desempleo, violencia, vivienda y un largo etcétera.

Para conseguir esta presencia en los medios de la comunicación de la ciencia desde las universidades, el autor destaca la necesidad de una verdadera voluntad política por parte de las instancias de gobierno universitario y de una dotación de medios humanos y materiales suficiente. En este sentido, Marín resalta la capacidad del personal propio del servicio de comunicación, pero también de becarios o estudiantes en prácticas, para conocer qué es noticia en el ámbito universitario, qué noticias suscitan el interés de los medios de comunicación, dónde encontrar las fuentes informativas en el seno de las propias universidades, cómo acceder a ellas y elaborar las informaciones y cómo contrastarlas y difundirlas.

El déficit de noticias científicas tiene consecuencias claramente negativas para las universidades. Entre ellas, Marín apunta el hecho de que la sociedad no conozca y 
valore el quehacer investigador universitario, algo que permitiría mejorar la imagen pública de la universidad y contribuiría a la extensión social de la cultura científicotecnológica.

Esta situación genera que se mantenga en ocasiones la desconfianza entre investigadores y periodistas, "algo constatable, en términos generales, y que tiene su origen en la idea periodística de que el científico no se aviene a comunicar su labor a la sociedad y en la idea de los científicos de que los periodistas no tratarán con rigor la información que puedan ofrecerles". En este sentido, reivindica el papel de los profesionales de la comunicación científica en la universidad como agentes mediadores entre medios de comunicación social, "que difícilmente contarán con medios humanos para trabajar a fondo una información científica, y científicos, que no pueden renunciar a que su información sea aborda con el rigor que del ejercicio de su profesión se exige" (Marín, 2009).

Como hemos visto en los apartados anteriores, la creciente profesionalización de la comunicación de la ciencia y la apuesta de la FECYT por respaldar la creación de Unidades de Comunicación Científica y de la Innovación en universidades y centros de investigación, entendemos que ha venido a paliar la situación descrita por Marín. Veíamos incluso en este sentido estudios como el realizado por Peter Peters (2008) que demuestran que la relación entre científicos y medios es mejor de lo que se pudiera pensar. El propio Marín señala que también hay ejemplos claros en el panorama universitario español de un notable esfuerzo por mejorar la comunicación de la ciencia, así como acciones de formación en materia de comunicación científica a través de másters y cursos. En este sentido, señala que en muchas ocasiones las acciones de comunicación de la ciencia se sustentan en grandes compromisos personales, en situaciones de precariedad y en la dependencia de proyectos temporales. Por ello destaca que es hora de entender que la necesidad de comunicar la ciencia por parte de las universidades exige la existencia de estructuras estables de comunicación, y eso se consigue con instalaciones, personal propio, formación permanente y proyectos de trabajo, "con independencia de que haya que seguir contando con becarios, formando estudiantes y compitiendo por nuevos recursos”. De cara a esta mejora, Marín apunta el interés incluso de establecer partidas correspondientes a comunicación de los resultados científicos dentro de los mismos proyectos de investigación, algo que ya se viene haciendo como algo habitual en convocatorias europeas. 
También de cara a analizar el presente y el futuro de la comunicación de la ciencia en las universidades, resulta de interés detenerse en los retos y oportunidades que supone la nueva galaxia mediática que, como hemos visto en el apartado anterior, ha modificado las reglas de la comunicación. Estos cambios han afectado también a la comunicación desde las universidades, de forma que, siguiendo a Delia Crovi, pueden establecerse dos grandes momentos en la construcción de la relación mediosuniversidad: el de las comunicaciones masivas y el de las comunicaciones en red. Para la autora no se trata de momentos excluyente sino que implican la acumulación de recursos comunicativos obligando a repensar el vínculo comunicación-universidad.

En el momento de las comunicaciones masivas, la autora destaca cómo durante el siglo XX las instituciones de educación superior realizaron grandes esfuerzos para contar con sus propios medios; producir sus mensajes escritos, audiovisuales y sonoros para difundirlos en los medios y transformarse en fuente de información cualificada de procesos, actividades o hechos tratados por los medios. Crovi considera este último un factor clave "para la promoción de las actividades universitarias, pero también para la difusión del conocimiento científico, cultural y artístico" (Crovi, 2005:51).

Manteniendo estos objetivos en el ámbito de la comunicación, el momento de la comunicación en red introduce nuevos factores a tener en cuenta, entre los que destaca el favorecimiento de una comunicación horizontal, entre iguales, que rompe la verticalidad que caracteriza a lo masivo y que se caracteriza por la unidireccionalidad y por dirigirse a receptores anónimos, heterogéneos y masivos. La horizontalidad supone la superación de la división entre emisor y receptor e introduce las nociones de ida y vuelta y de participación. Pero además, las nuevas tecnologías permiten a las universidades convertirse directamente en fuentes de información de masas.

(...) es la primera vez que contamos a nivel social con la posibilidad tecnológica de emitir mensajes de manera sencilla y constante hacia públicos que pueden llegar a ser masivos y heterogéneos, al margen y en paralelo de las grandes corporaciones mediáticas (Crovi, 2005:54).

En el que Crovi denomina el momento de la comunicación en red, las universidades ponen en marcha nuevas estrategias como la creación de sus propios portales en internet, medios de comunicación digital y redes sociales que permiten interactuar directamente con sus públicos. Estos canales de comunicación se convierten asimismo en nuevas vías de comunicación y divulgación del conocimiento científico. 
En este panorama global que supone la nueva galaxia mediática, la autora considera que es necesario abrir los escenarios y ocupar todos los espacios posibles (prensa, radio, TV, internet, bases de datos, grupos de discusión, comunidades virtuales, etc.) con un conocimiento socialmente aprobado, legitimado por el prestigio científico de sus emisores. Las redes suponen un nuevo instrumento tecnológico y social para afrontar el problema de la relación universidad-sociedad. En el ciberespacio todo circula pero también todo puede ser puesto en tela de juicio, señala, destacando por ello la necesidad de que la comunicación de la universidad esté asociada al prestigio de la institución que lo genera y avala.

A pesar de las posibles mejoras en el panorama de la comunicación científica desde las universidades en los últimos años y de las oportunidades que abre internet y la web 2.0, entendemos que las recomendaciones establecidas en las declaraciones de Baeza y por los expertos del Media for Science Forum siguen teniendo vigencia en el caso de muchas universidades. El desarrollo de gabinetes de comunicación especializados en ciencia e innovación se ha incrementado gracias al respaldo de las UCC+i por parte de la FECYT, pero todavía son muchas las universidades que no cuentan con un servicio estable en este ámbito. También parece que queda mucho por hacer en formación de la CPC para profesionales de la comunicación y personal investigador. Asimismo, los problemas expuestos por Marín respecto al déficit de información científica en las acciones de comunicación de las universidades, y las consecuencias negativas derivadas del mismo, siguen siendo una constante en gran parte del panorama universitario español.

A partir de lo expuesto a lo largo del presente apartado y de la propia experiencia profesional en la comunicación universitaria y la comunicación de la ciencia, cabe pensar que existen todavía muchos retos por superar por parte de los centros de educación superior en este ámbito. Por una parte, cabría destacar la comunicación de la ciencia hacia el público, en la que, a pesar de los déficits que puedan seguir existiendo en muchos centros, entendemos que se ha producido un notable avance en los últimos años, con la consolidación de Unidades de Cultura Científica y de la Innovación, la labor de profesionales dedicados a este ámbito y el incremento de las informaciones sobre ciencia. Sin embargo, parece que el modelo de comunicación centrado en el diálogo ciencia y sociedad todavía queda distante del ámbito universitario. Ni las declaraciones de los expertos ni las voces de divulgadores y 
académicos parecen poner el foco en la necesidad del establecimiento de nuevos mecanismos de comunicación en las universidades que favorezcan la bidireccionalidad y hagan llegar a la Universidad las expectativas e intereses en materia de ciencia e innovación de la sociedad y los diferentes grupos de interés.

El análisis de las acciones de comunicación de la ciencia por parte de las universidades valencianas, tanto públicas como privadas, desarrollado en el cuarto bloque de la tesis, nos permitirá hacernos una idea más clara de la situación en la que se encuentra actualmente la comunicación de la ciencia, la tecnología y la innovación desde el ámbito universitaria. Asimismo, pretendemos que este análisis nos permita analizar sus fortalezas y debilidades respecto al modelo ético de comunicación de la RRI en la Universidad que desarrollaremos en el tercer bloque. Pero antes de ello, cerraremos este segundo bloque con un repaso a las directivas y normativas europeas que afectan a la comunicación de la RRI. 



\section{El marco normativo de la comunicación de la RRI}

Europa ha trazado a través de diferentes documentos y publicaciones el marco normativo de la RRI que establece asimismo las consideraciones de la Unión Europea respecto a las formas de entender la comunicación y la participación en el camino hacia una investigación y una innovación más responsable. El presente capítulo recoge las diferentes normativas y publicaciones, estructurándolas en tres apartados: marco general, ciencia y sociedad y RRI.

El movimiento de la RRI no parte de cero, ya que el desarrollo científico ha estado siempre ligado a planteamientos éticos y de derechos. En este sentido, los especialistas reunidos en el primer workshop de la Unión Europea sobre RRI destacaban la posibilidad de partir de los valores europeos recogidos en documentos como el Tratado de la Unión Europea y la Carta de Derechos Fundamentales de la Unión Europea. Estos documentos entendemos que conforman el marco general normativo de la RRI y su comunicación. La publicación en el año 2000 del documento Ciencia, sociedad y ciudadanos europeos sienta las bases de una nueva propuesta para abordar la relación entre la ciencia y la sociedad, abriendo la puesta a nuevas formas de entender la participación y la comunicación entre ambas. El segundo apartado se centra en los documentos surgidos alrededor del concepto de ciencia y/en sociedad, para dar paso en tercer lugar a las directrices específicas en materia de RRI, a partir de la publicación en 2011 del primer informe que recoge específicamente este término en el ámbito europeo.

\subsection{EL MARCO GENERAL}

En un primer momento, entendemos que resulta de interés detenerse en dos de los documentos en los cuales se asientan los valores y los fundamentos de la Unión Europea, como son la Carta de Derechos Fundamentales de la Unión Europea y el Tratado de la Unión Europea, para abordar su contenido en materia de comunicación y participación ciudadana, así como los valores de los que parte. 


\subsubsection{Carta de Derechos Fundamentales de la Unión Europea}

El Preámbulo de la Carta de Derechos Fundamentales de la Unión Europea pone el acento en la decisión de los pueblos de Europa de "compartir un porvenir pacífico basado en valores comunes". A pesar de que el presente capítulo se centra en el marco normativo en relación a la comunicación, entendemos que resulta interesante detenerse brevemente en este entendimiento de la UE como una Unión "fundada sobre los valores indivisibles y universales de la dignidad humana, la libertad, la igualdad y la solidaridad" y basada en los principios de la democracia y el Estado de Derecho. La Unión Europea “al instituir la ciudadanía de la Unión y crear un espacio de libertad, seguridad y justicia, sitúa a la persona en el centro de su actuación” (Unión Europea, 2010).

El Preámbulo establece asimismo el compromiso de la Unión de defender y fomentar estos valores comunes. La Carta busca precisamente reforzar la protección de lo que entiende como derechos fundamentales "a tenor de la evolución de la sociedad, del progreso social y de los avances científicos y tecnológicos”.

De esta forma, en la Carta se establecen los valores que conforman también el marco ético y político de la Unión Europea y que dan sentido al desarrollo de una ciencia y una innovación responsable.

Entrando en los artículos, en el ámbito de la información y la comunicación, cabe señalar que el Artículo 11, incluido en el Título 2 sobre Libertades, hace referencia a la Libertad de expresión y de información, señalando que:

1. Toda persona tiene derecho a la libertad de expresión. Este derecho comprende la libertad de opinión y la libertad de recibir o comunicar informaciones o ideas sin que pueda haber injerencia de autoridades públicas y sin consideración de fronteras.

2. Se respetan la libertad de los medios de comunicación y su pluralismo.

(Unión Europea, 2010)

La transparencia y el derecho al acceso a los documentos queda además recogida en el Título V sobre Ciudadanía, que en su Artículo 42 señala como "todo ciudadano de la Unión y toda persona física o jurídica que resida o tenga su domicilio social en un Estado miembro tiene derecho a acceder a los documentos de las instituciones, órganos y organismos de la Unión, cualquiera que sea su soporte”. 
Se refleja de este modo entre los derechos fundamentales, el de información y acceso a la documentación pública, aspectos que entendemos que resultarán fundamentales de cara a garantizar una adecuada gestión y comunicación de la RRI.

\subsubsection{Tratado de la Unión Europea}

Schomberg encontraba en el Tratado de la Unión Europea los valores que deben perseguir una investigación y una innovación responsable. Más allá de estos valores, abordados en el sexto capítulo, consideramos de interés detenernos aquí en las disposiciones sobre los principios democráticos recogidas en el Título II del Tratado, en cuyo Artículo 10 se establece que el funcionamiento de la Unión se basa en la democracia representativa, estableciendo que los ciudadanos estarán directamente representados en la Unión a través del Parlamento Europeo. Más allá de esta democracia representativa, el Tratado deja clara la voluntad de participación y deliberación por parte de la ciudadanía, señalando que "todo ciudadano tiene derecho a participar en la vida democrática de la Unión. Las decisiones serán tomadas de la forma más abierta y próxima posible a los ciudadanos" (Unión Europea, 2010), punto que en el caso que nos ocupa aparece vinculado a las decisiones sobre la gestión de la ciencia y la innovación y sobre sus posibles resultados.

El Artículo 11 hace hincapié en la necesidad de que las instituciones establezcan los cauces y mecanismos apropiados para la participación de ciudadanos y asociaciones, señalando la necesidad de mantener un diálogo abierto, transparente y continuo con los representantes de la sociedad civil, para lo que contempla también mecanismos como consultas.

1. Las instituciones darán a los ciudadanos y a las asociaciones representativas, por los cauces apropiados, la posibilidad de expresar e intercambiar públicamente sus opiniones en todos los ámbitos de actuación de la Unión.

2. Las instituciones mantendrán un diálogo abierto, transparente y regular con las asociaciones representativas y la sociedad civil.

3. Con objeto de garantizar la coherencia y la transparencia de las acciones de la Unión, la Comisión Europea mantendrá amplias consultas con las partes interesadas.

(Unión Europea, 2010) 
Estos mecanismos se establecen con el objetivo de contribuir a la finalidad de la Unión que, según se recoge en el Título I de Disposiciones Comunes, pasa por "promover la paz, sus valores y el bienestar de sus pueblos".

Entendemos que el impulso a la participación ciudadana y al diálogo abierto con la sociedad civil enlaza con la Declaración Internacional de Derechos Humanos, en cuyos valores se apoya también la UE. En la misma, el artículo 27 recoge explícitamente el derecho a participar en el progreso científico y en sus beneficios.

Toda persona tiene derecho a tomar parte libremente en la vida cultural de la comunidad, a gozar de las artes y a participar en el progreso científico y en los beneficios que de él resulten.

Además, en una aproximación general a las directrices europeas, cabe señalar que la Visión 2020 para el Espacio Europeo de Investigación, adoptada por el Consejo en diciembre de 2008, subrayó que este espacio debe estar firmemente arraigado en la sociedad y responder a sus necesidades y ambiciones en búsqueda del desarrollo sostenible. Asimismo, en julio de 2009, la Declaración de Lund pidió un nuevo acuerdo en la Investigación Europea que establece que la identificación de los Grandes Desafíos en materia de ciencia e innovación debe involucrar a las principales partes interesadas, incluyendo a las instituciones europeas, empresas, servicios públicos, las ONG y las comunidades científicas (Sinue, 2009).

Una vez trazado el marco general, pasaremos a detenernos en aquellos documentos que recogen el fenómeno denominado "ciencia y sociedad" en el que se encuentra el germen de la RRI.

\subsection{CIENCIA Y SOCIEDAD}

La publicación en el año 2000 del informe Ciencia, sociedad y ciudadanos europeos supone un avance hacia un modo de entender la ciencia más abierta y participativa, siendo el germen de lo que apenas una década después pasaría a denominarse RRI. En el presente apartado analizaremos, además de este documento, el Plan de Acción Ciencia y Sociedad que sentaba en 2002 las bases para el desarrollo de este nuevo modelo a nivel europeo, con la propuesta de 38 acciones específicas. Otro documento clave en la propuesta que en 2009 pasó a denominarse "Ciencia en Sociedad" fue el 
publicado por los expertos participantes en el proyecto MASIS, al que dedicaremos el último punto del apartado.

\subsubsection{Ciencia, sociedad y ciudadanos europeos}

El documento Ciencia, sociedad y ciudadanos europeos (European Commission, 2000:4) examina distintas cuestiones que se planteaban en el año 2000 bajo la denominación "Ciencia, sociedad y ciudadanos", al plantearse como objeto de preocupación creciente entre los ciudadanos y los responsables políticos aspectos como la elaboración de políticas de investigación que respondan a necesidades auténticas de la sociedad y la implicación de ésta en la ejecución del programa de investigación. También se planteaban cuestiones como la necesidad de tener en cuenta las consecuencias y los aspectos éticos del progreso tecnológico y, simultáneamente, los imperativos de la libertad de investigación y el acceso a los conocimientos; qué hacer para reforzar el diálogo entre ciencia y sociedad; cómo mejorar el conocimiento de la ciencia por parte de los ciudadanos y el interés de los jóvenes por las carreras científicas, así como qué hacer para reforzar la posición y el papel de las mujeres en las ciencias y la investigación.

Los objetivos de Ciencia, sociedad y ciudadanos europeos fueron tres. En primer lugar, la puesta en marcha de un debate sobre estas cuestiones a nivel europeo, ofreciendo un marco de referencia. En segundo, presentar, sobre la base de breves análisis, algunas sugerencias relativas a medidas que convendría adoptar o estudiar sobre los distintos temas, a nivel nacional, regional o europeo. Y en tercero, solicitar propuestas sobre nuevas pistas de reflexión que pudieran explorarse. De este modo, el texto se plantea como un documento de reflexión sobre la manera en que se pueden y deben abordar a nivel europeo y desde una perspectiva europea el conjunto de aspectos del tema "ciencia y sociedad".

Para la Comisión Europea, la importancia adquirida por las cuestiones de lo que se había dado en llamar "ciencia y sociedad" era producto de varias tendencias, entre las que cita la evolución del conocimiento y la tecnología y el cambio en las relaciones entre la ciencia, la tecnología y la sociedad, que se modifican desde lo que consideran una triple perspectiva: los cambios sociales que influyen sobre los programas de la investigación al suscitar la aparición de nuevas necesidades; los importantes intereses 
económicos, financieros y comerciales que están cada vez más asociados al progreso del conocimiento; y la aceleración del progreso que plantea a la sociedad el reto de seguir su ritmo y cuestiona cada vez más frecuentemente los valores y principios básicos de la vida social. Otra tendencia que favorecía el fenómeno de "ciencia y sociedad" para la Comisión Europea era la evolución general a nivel social y político, dado que una ciudadanía mejor informada e instruida tiene mayor capacidad para ejercer su espíritu crítico frente a unos acontecimientos que parecen escapar a su control. "Estas tendencias, y las tensiones resultantes, emplazan a científicos, autoridades políticas, responsables económicos e industriales y ciudadanos a establecer nuevas formas de relación mutua”, señala el documento (European Commission, 2000:4). Este cambio de escenario obliga a una reescritura del contrato establecido entre ciencia y sociedad que implique una nueva forma de entender las relaciones entre ambas.

La ciencia moderna se desarrolló sobre la base de un "contrato" tácito entre, por un lado, la ciencia y las instituciones que la asumen (la universidad, la industria, los Gobiernos), y por otro, la sociedad y los ciudadanos. Hacen falta unas relaciones nuevas, adaptadas a la nueva configuración de las relaciones entre la ciencia, la tecnología y la sociedad (European Commission, 2000:4).

En el ámbito de la innovación, se destaca asimismo la necesidad de fomentar un espíritu abierto a la misma a través del establecimiento de un diálogo entre investigadores, industriales, responsables políticos, grupos de interés y el conjunto de los ciudadanos. Así, el documento señala la necesidad de estructurar las políticas de investigación e innovación en torno a objetivos de la sociedad, dotándolas de principios estructuradores definidos en función de objetivos pertinentes para la sociedad y con sentido para la ciudadanía.

La administración del riesgo ocupa también un lugar destacado en este documento, el primero que aborda a nivel europeo el concepto "ciencia y sociedad", señalando la necesidad de favorecer un control social del tipo de riesgos que pasa por la combinación de varios elementos en distintas fases. Entre ellos, se señala la evaluación del riesgo, recurriendo al mejor asesoramiento científico disponible, en forma de dictámenes independientes y transparentes; la gestión del riesgo, mediante medidas políticas que permitan garantizar que se mantenga a un nivel aceptable por la sociedad y que el nivel de protección resulte suficiente; y la comunicación sobre el riesgo, por medio de nuevas formas de deliberación colectiva y debate democrático sobre los beneficios y los riesgos comparados que comporta la utilización de las tecnologías, 
componente central del diálogo ciencia-sociedad. Vemos aquí cómo la comunicación y la deliberación aparecen desde un primer momento como aspectos centrales de la relación entre ciencia y sociedad.

La utilización del proceso científico y tecnológico de manera responsable incluye, además de la administración del riesgo, otros aspectos entre los que cabe destacar la ética y la libertad de investigación. Respecto a la ética, el documento recuerda que no todo lo que es científicamente posible y tecnológicamente viable es necesariamente deseable o admisible. "Existen numerosos aspectos del progreso del conocimiento y la tecnología que cuestionan nuestros valores y nuestros principios fundamentales" (European Commission, 2000:13), indica el documento, señalando que, a pesar de que muchos de estos valores suscitan la adhesión a nivel europeo e incluso mundial, pueden existir discrepancias a la hora de valorar cómo conviene aplicarlos. Para atender estas discrepancias, se destaca cómo en los años precedentes se habían dado pasos importantes para crear unas condiciones favorables a la aproximación y el consensos sobre una serie de puntos: actividades legislativas del Consejo de Europa (y de la Unión en sus ámbitos de competencia), deliberaciones y dictamen del Grupo Europeo de Ética de las Ciencias y las Nuevas Tecnologías establecido para asesorar a la Comisión y acercamiento de los comités de ética nacionales bajo los auspicios de la Comisión o del Consejo de Europa.

Entre las iniciativas suplementarias que el documento establece que deberían preverse en este ámbito se encuentra el establecimiento de vínculos más estructurales entre los comités de ética que existen a nivel nacional y europeo; la mejora de la coordinación de las investigaciones, necesariamente pluridisciplinarias, sobre ética de las ciencias realizadas en Europa; la coherencia de los criterios de evaluación ética de los proyectos de investigación; el refuerzo de la enseñanza en este ámbito en Europa; el desarrollo de una función de "observatorio" de los problemas, prácticas y legislaciones en materia de ética de las ciencias y tecnologías; y, por último, la aproximación de las actividades legislativas del Consejo de Europa y de la Unión.

Por lo que respecta a la libertad de investigación, se recuerda que se trata de una de las expresiones de la concepción de la vida, la sociedad y el individuo que tienen los europeos. El documento entiende que puede producirse cierta tensión entre esta libertad y otros valores éticos, "pero se trata en cualquier caso de un elemento fundamental de nuestra concepción del mundo" (European Commission, 2000:14). Para la Comisión 
Europea, la cuestión de las relaciones entre ciencia y libertad reviste en realidad una doble forma: libertad de investigación y libertad de acceso a los conocimientos. Así, en los países democráticos europeos, los investigadores son formalmente libres, lo que no significa, sin embargo, que lo sean siempre materialmente, señalando la publicación que las limitaciones que impone la influencia cada vez más importante de las consideraciones económicas y los intereses industriales y comerciales en la investigación les dejan a menudo muy pocas posibilidades de elegir el objeto de su investigación y la manera de realizarla. El informe de la Comisión Europea considera aún más fundamental la cuestión de la libertad de acceso a los conocimientos, destacando la importancia de avanzar hacia la misma.

El informe dedica un capítulo a la necesidad de reforzar el diálogo entre ciencia y sociedad, señalando que el tratamiento de la cuestión del riesgo tecnológico y, más en general, de las cuestiones relativas a ciencia y sociedad, "exige el desarrollo, en particular a nivel europeo, de nuevas formas de diálogo entre investigadores, expertos, responsables políticos, industriales y ciudadanos" (European Commission, 2000:15). Entre las fórmulas con las que se ha experimentado, el documento destaca algunas como los jurados de ciudadanos o las conferencias de ciudadanos.

Para la Comisión Europea, el diálogo entre sociedad y ciencia ha de ser necesariamente un diálogo en los dos sentidos, en el que cada parte escucha a la otra en la misma medida en que se expresa. Sin embargo, pone también el acento en la alfabetización científica, al considerar que el diálogo de los ciudadanos con los investigadores y los expertos será más fértil, y más elevada su capacidad para debatir con conocimiento de causa las cuestiones relativas a "ciencia y sociedad", cuanto más profundos sean sus conocimientos y su comprensión de la ciencia y la tecnología, incluyendo los "hechos" de la ciencia, los resultados de la labor de investigación, el método científico y la forma en que funciona concretamente la investigación. "El objetivo no puede ni debe ser obtener de la población una actitud sistemáticamente favorable, sino crear las condiciones necesarias para un debate democrático con conocimiento de causa", se indica (European Commission, 2000:15). De cara a la adecuada información, el documento destaca el papel de los medios de comunicación y alerta del déficit de información en materia de ciencia en Europa.

Los europeos no ocupan actualmente el lugar que les correspondería en el mundo de la información y la comunicación científica. Y esta observación es válida tanto para la 
comunicación dentro de la comunidad científica como para la información destinada a la población en general (European Commission, 2000:16).

Por otra parte, el documento también aborda la perspectiva de género, asegurando que el desarrollo de unas relaciones nuevas entre ciencia y sociedad supone no solamente un refuerzo de la presencia de las mujeres en la vida científica, sino también una mejor incorporación de las necesidades específicas de las mujeres en el programa de la investigación y una mejor comprensión de las relaciones entre hombres y mujeres en la sociedad.

El documento concluye señalando que el debate iniciado a través del mismo y la aplicación de las actuaciones derivadas, debería permitir tener plenamente en cuenta las cuestiones relativas a "ciencia y sociedad" en la ejecución del Espacio Europeo de Investigación.

\subsubsection{Plan de Acción Ciencia y Sociedad}

El Plan de Acción Ciencia y Sociedad realizado por la Comisión Europea en 2002 supuso una iniciativa europea encaminada a crear una relación más estrecha y armoniosa entre el mundo de la ciencia y la sociedad en general. El plan propuso 38 actuaciones relativas al papel de la ciencia en la educación y en la cultura popular, la participación de los ciudadanos en la política científica, la igualdad entre hombres y mujeres, la ética y la gobernanza. Más allá del análisis de la ejecución de cada una de estas propuestas, el Plan de Acción ofrece el marco normativo de la forma de entender por parte de la Unión Europea esta relación entre ciencia y sociedad en la que la comunicación juega un papel básico.

El prefacio de Philippe Busquin, miembro de la Comisión Europea de Investigación, comienza señalando que en una sociedad del conocimiento, el buen gobierno democrático exige poner en manos de los ciudadanos los medios para que participen, con pleno conocimiento de causa, en la selección de las opciones que ofrece un progreso científico y tecnológico responsable.

Por lo que respecta al marco normativo que se desprende del Plan de Acción, cabe señalar en primer lugar que el término "ciencia" se utiliza, según se especifica, en referencia al conjunto de actividades públicas o privadas, de carácter científico y tecnológico, incluidas las ciencias sociales. Por lo que respecta al término "sociedad", 
abarca a todos los ciudadanos y sus asociaciones, así como a las empresas y administraciones públicas. Al hablar de "sociedad civil" se hace referencia a las organizaciones cuyos miembros se plantean objetivos y responsabilidades de interés general, y que actúan como mediadores entre las autoridades públicas y los ciudadanos. En este sentido, se indica que pueden ser sindicatos u organizaciones patronales (“interlocutores sociales"), organizaciones no gubernamentales, asociaciones profesionales, asociaciones benéficas, organizaciones de base, organizaciones de participación ciudadana en los asuntos municipales y locales, asociaciones, religiosas y parroquiales.

El documento comienza advirtiendo de cómo los riesgos industriales o las cuestiones éticas son ampliamente comentadas por los medios de comunicación, lo que suscita interrogantes entre el público y confirma su deseo de un mayor control del progreso. Algunos pueden tener la impresión, advierte, de que la ciencia y la tecnología cambian su modo de vida demasiado deprisa. El documento señala en este sentido la necesidad de fomentar una adecuada formación e información en materia de ciencia e innovación que favorezca a su vez la participación.

Europa ganaría, por lo tanto, instituyendo un marco de nivel comunitario en el que se reunieran los esfuerzos realizados en los Estados miembros para lograr que los ciudadanos europeos puedan juzgar con mayor conocimiento de causa los grandes fenómenos científicos y tecnológicos de su tiempo, y para despertar sus deseos de participar en la aventura científica (European Commission, 2002:7).

A partir de aquí, plantea una estrategia centrada en tres ámbitos:

- La promoción de la educación y la cultura científica en Europa, considerando que la ciencia y la tecnología deben convertirse en algo más familiar para los ciudadanos. "En esta perspectiva, será fundamental reforzar la presencia de la ciencia y la tecnología en los medios de comunicación y los ámbitos docentes europeos" de cara a "fomentar el diálogo entre la esfera de la ciencia y la de la sociedad, por ejemplo mediante la celebración a intervalos regulares de eventos importantes" (European Commission, 2002:7).

- La elaboración de políticas científicas más cercanas a los ciudadanos, señalando que la ciencia, la tecnología y la innovación deberán reconsiderar su contrato social y establecer su planificación en función de las necesidades y aspiraciones de los ciudadanos europeos. 
- La incorporación de una ciencia responsable en las distintas políticas, entendiendo que la mayoría de las políticas cuenta con una dimensión científica y tecnológica, y sus decisiones deben apoyarse en dictámenes transparentes y responsables basados en investigaciones que tengan en cuenta imperativos éticos. Por ello, se señala que es necesario reforzar la base ética de las actividades científicas y tecnológicas, así como detectar y evaluar los riesgos inherentes al progreso y encontrar soluciones responsables para éstos en función de experiencias pasadas.

Se trata, como vemos, de tres ámbitos que se encuentran en la base del surgimiento del fenómeno de la RRI, y en los que la comunicación y la participación juegan un papel clave. El Plan plantea el desarrollo de acciones en cada uno de estos ámbitos que abordaremos más detalladamente en las siguientes páginas.

En primer lugar, por lo que respecta a la promoción de la cultura científica, se pone el acento en la necesaria sensibilización e información del público, destacando el papel especialmente relevante de las universidades en esta comunicación del conocimiento científico y de su contexto.

Para que los progresos de la ciencia y la tecnología respondan a las necesidades de los ciudadanos europeos y cuenten con su adhesión, es necesario que dispongan de una información comprensible y de calidad, así como de un acceso libre a esta cultura específica. Los medios de comunicación, los investigadores, los organismos de investigación -y, en particular, las universidades, y también las empresas, deben desempeñar plenamente su papel de información al público. Deben ser capaces de comunicar y dialogar sobre temas de carácter científico de una forma profesional, a la vez rigurosa y atractiva, así como de exponer, en mayor grado que hasta el momento, en qué consiste la labor científica, con todo rigor y especificando sus límites (European Commission, 2002:9).

De cara a impulsar fuentes de información preparadas e independientes, se apunta el interés de desarrollar módulos de formación científica temáticos y multilingües destinados a los profesionales de la prensa o de los medios de comunicación audiovisuales. También se alude a la necesidad de establecer buenas relaciones entre la comunidad científica y los medios y a promover los contenidos de investigación e innovación en los mismos.

El documento pone el acento en la responsabilidad para con la sociedad de los investigadores y organismos de ciencia en cuanto a la comunicación de los avances alcanzados. El Plan de Acción resalta el papel de las universidades como los hábitats 
naturales de la ciencia, la educación y la transmisión de conocimientos, destacando el hecho de que en los últimos años se hayan enfrentado a una evolución profunda que afecta a su apertura y su interacción con la sociedad a todos los niveles, desde el local al mundial.

Por lo que respecta a los investigadores, se indica la necesidad que existen respecto a competencias tales como la gestión de la investigación, el derecho y la comunicación, en particular con el público, señalándolas como competencias que pueden resultar fundamentales para el ejercicio de la profesión.

También en el ámbito del fomento de la cultura científica, el Plan de Acción Ciencia y Sociedad indica que la comunicación unidireccional no resulta suficiente, aludiendo a la necesidad de establecer un verdadero diálogo.

La adquisición de una cultura científica y tecnológica básica entre los ciudadanos europeos, y la disponibilidad de información regular proveniente de expertos por parte del público no bastan, por sí mismos, para que se formen las opiniones. Es necesario que se instaure un verdadero diálogo entre la ciencia y la sociedad. Estos últimos años se han multiplicado las iniciativas en este sentido: conferencias de consenso, jurado de ciudadanos, consultas nacionales y regionales, foros electrónicos, programas prospectivos participativos, etc., que han pretendido satisfacer esta necesidad de comprensión mutua. Los Estados miembros y la Comisión deberán favorecer este tipo de diálogo a todos los niveles, europeo, nacional, regional y local (European Commission, 2002:14).

Para los expertos de la Comisión Europea, el establecimiento de un diálogo a nivel europeo supone una cooperación estrecha entre un gran número de partes interesadas de los ámbitos de las organizaciones de investigación, las autoridades públicas, los medios de comunicación, los ciudadanos, la sociedad civil, las empresas, etc., colectivos a los que en el próximo capítulo trataremos de dar forma a través de la propuesta de un mapa de stakeholders. En este contexto, se destaca cómo las esferas científicas y tecnológicas pueden desempeñar un papel esencial presentando temas de interés para el público en general y contribuyendo al debate.

Por lo que respecta a los niveles local y regional, se considera que son ámbitos que se prestan bien al diálogo "Ciencia y Sociedad" cuando los temas tratados son de interés directo para los ciudadanos, como medio ambiente, desarrollo sostenible, salud, seguridad, transportes urbanos, etc., de ahí que señalen la conveniencia de favorecer la participación de científicos en foros y audiciones de iniciativa local y regional. 
El segundo ámbito del Plan de Acción se centra en el desarrollo de una política de la ciencia más próxima a los ciudadanos. En este apartado, cabe destacar la búsqueda de una mayor participación ciudadana. Para ello, el documento incide en la importancia del fomento de la transparencia y la consulta entre las administraciones y la sociedad civil. Para que los ciudadanos y la sociedad civil se asocien de forma significativa en los debates en torno a la ciencia, la tecnología y la innovación en general, se indica que "no sólo deben estar informados, sino además tener la posibilidad de expresarse en los foros adecuados". Por ello, la Comisión apela a los Estados miembros para que fomenten el debate de las partes interesadas en torno a la innovación, permitiendo la participación de los científicos, la industria, los consumidores y las autoridades públicas.

Entre los métodos de participación, se señalan las conferencias de consenso o jurados de ciudadanos como experiencias que han mostrado su efectividad a la hora de proporcionar un espacio de análisis y propiciar un debate informado sobre temas importantes de interés común, sirviendo de marco de reunión de ciudadanos, grupos de interés y órganos de decisión, sirviendo de complemento para el proceso de toma de decisiones y pudiendo ser de gran valor para el establecimiento de políticas correctas. En la determinación de la política de investigación, el documento destaca que cada vez se han utilizado más mecanismos de participación. A nivel comunitario las partes interesadas, los usuarios y las esferas científicas han venido cooperando cada vez más en la determinación y puesta en práctica de la política de investigación, desarrollo y tecnología. En este sentido, se señala que la participación más sistemática y estructurada ha sido la desarrollada en torno a los grupos consultivos de expertos y a otros organismos consultivos. También se han utilizado acuerdos ad hoc tales como plataformas, talleres y otros mecanismos de diálogo en el que las partes interesadas puedan expresar su opinión. El Plan de Acción establece que "estas experiencias deben ahora ampliarse y profundizarse para dar cabida a otros sectores de la sociedad civil en todas las etapas" (European Commission, 2002:17).

El documento recoge asimismo el interés de la organización de actividades específicas de participación desde la Unión Europea, así como la necesidad de fomentar la igualdad entre hombres y mujeres, señalando en este ámbito, que si la sociedad en su conjunto desea identificar y comprender mejor la evolución de la ciencia y la tecnología, es necesario adoptar medidas específicas para solucionar tanto la 
representación insuficiente de las mujeres en la ciencia como la falta de atención que se presta a las diferencias entre hombres y mujeres en la investigación.

El tercer ámbito del plan hace referencia al impulso de una ciencia responsable como núcleo de las políticas científicas, incidiendo en este punto en la dimensión ética de la ciencia y las nuevas tecnologías. Para la Comisión Europea, el rápido ritmo que adquiere el progreso tecnológico puede dar lugar a serias cuestiones de carácter ético que conciernen a todos los europeos. Estas cuestiones pueden tener también implicaciones para las generaciones futuras. Por ello, se considera necesario que la investigación sea algo funcional y aceptado por todos los ciudadanos de los Estados miembros y de los países candidatos a la adhesión, respetando las diferencias que supone el entramado cultural que es la Unión Europea, compuesto por tradiciones éticas, religiosas, históricas y filosóficas divergentes.

En este ámbito, se destaca también la necesidad de una información más accesible, argumentando que Europa necesita un sistema de información sobre cuestiones éticas de índole científica más estructurado y que permita un acceso, en varias lenguas, a información sobre las legislaciones, códigos de conducta, mejores prácticas, y debates celebrados en los distintos países de Europa. Asimismo, se aborda la importancia de fomentar un diálogo público europeo sobre ética y ciencia, animando a investigadores, círculos empresariales, entidades de normalización e interlocutores sociales a que entren en un diálogo público entre Estados miembros y países candidatos en torno a las nuevas tecnologías punta desde el momento en que hacen su aparición. Ello permitiría que se tomaran unas decisiones responsables, respaldadas por unas políticas adecuadas, aplicadas en el momento preciso.

La dimensión ética de la ciencia y la tecnología desarrollada en el Plan de Acción Ciencia y Sociedad contempla también otros aspectos como una mayor sensibilización de los investigadores ante las buenas prácticas científicas, incluidas la dimensión ética, la integridad en la investigación y el cumplimiento, en lo fundamental, de la legislación, las convenciones y las prácticas vigentes en Europa. Para ello, se recomienda el desarrollo de iniciativas de formación en torno al tema de la ética en la ciencia y el fomento de los códigos de conducta. En esta misma dimensión, se señala el interés de facilitar los intercambios entre comités éticos tanto a nivel regional como entre naciones; el diálogo sobre ética con otras regiones del mundo; y la protección de los animales en la investigación. 
El impulso de una ciencia responsable como núcleo de las políticas científicas hace referencia también al tema de la gobernanza. Sobre la misma, el Plan de Acción se centra en la gobernanza en materia de riesgos, señalando que la innovación, que mejora nuestra calidad de vida y es esencial para el crecimiento económico, también puede suscitar ciertas inquietudes e incertidumbres y puede plantear nuevos riesgos para la salud o el medio ambiente. Por ello, se considera necesaria una labor científica que atienda a estos asuntos y ayude a determinar y evaluar el riesgo planteado por estos factores y a reducir la incertidumbre en torno a ellos. Para la Comisión Europea, "la gobernanza en materia de riesgo -que abarca la determinación del riesgo, su evaluación, su gestión y la comunicación- se ha convertido en un componente fundamental y altamente controvertido de la vida pública” (European Commission, 2002:23).

Finalmente, de cara a avanzar hacia una ciencia responsable, el documento señala asimismo la importancia de la utilización de los conocimientos, destacando la necesidad de que los expertos contribuyan a informar y asesorar de forma abierta y plural sobre cuestiones complejas y a menudo controvertidas.

El Plan de Acción Ciencia y Sociedad, independientemente del grado de cumplimiento de las 38 acciones específicas que planteó, sentó de este modo las bases para el avance del diálogo y la participación de la sociedad en la ciencia. Siete años más tarde, un grupo de expertos analizaba el camino andado y la situación de la ciencia en sociedad y planteaba una serie de recomendaciones y propuestas en el informe que abordamos en el siguiente punto.

\subsubsection{Retos de futuro de la Ciencia en Sociedad}

El proyecto Monitoring Activities of Science in Society (MASIS), que hemos visto en el sexto capítulo, supuso la publicación en 2009 de un amplio informe titulado Challenging the Future of Science in Society. Emerging trends and cutting-edge issues. The Masis Project, elaborado por un grupo de nueve especialistas en el área de "Ciencia en Sociedad", entre los cuales estaba Vladimir de Semir, bajo la dirección de Karen Sinue (Sinue et al, 2009). Los resultados de este documento aportaron una visión colectiva de tendencias y permitieron poner en debate la estrategia a seguir en el diseño y la difusión del área "Ciencia en Sociedad". 
A partir de las recomendaciones del informe, el proyecto MASIS se completó con la evaluación de las políticas y la investigación en Ciencia y Sociedad en un total de 38 países, de los cuales 27 pertenecían a la Unión Europea. En cada caso se solicitó a un especialista la redacción de un informe sobre el contexto social y político de la investigación y las actividades organizadas en torno al área "Ciencia en Sociedad", realizando esta labor en España Vladimir de Semir y Gema Revuelta, ambos del Observatorio de la Comunicación de la Ciencia de la Universitat Pompeu Fabra.

Entrando en el contenido del informe, cabe señalar en primer lugar la estructura del mismo, que comienza recogiendo el mandato para el grupo de expertos respecto al proyecto "Ciencia en Sociedad". En un segundo apartado se aborda el papel de la ciencia en sociedad, para tratar en tercer lugar los grupos de interés, cuestión en la que nos detendremos ampliamente a la hora de abordar la propuesta de un mapa de stakeholders de la RRI en el próximo capítulo. El informe profundiza en cuarto lugar en los avances en la gobernanza de la ciencia en la sociedad, poniendo de manifiesto que la presión a la que está sometida la gobernanza de las instituciones científicas ante el empuje por parte de los diferentes contextos de la gestión pública hacia la innovación, la democratización y la integridad científica. A este respecto, se incide en el surgimiento de nuevas formas de gobernabilidad, en las que hay que tener en cuenta el discurso sobre el desarrollo responsable, que incluye la perspectiva ética y el desarrollo de códigos de conducta; las formas interactivas de evaluación de la tecnología; y el compromiso público en las investigaciones.

El informe incluye también un apartado dedicado al fortalecimiento del potencial, en el que se incide tanto en cuestiones de género como en el fomento de las vocaciones científicas. El sexto capítulo está dedicado a la comunicación de la ciencia y las oportunidades que ofrece, completándose el informe con una aproximación a un posible modelo europeo de ciencia en sociedad que tenga en cuenta las diferencias entre países y culturas y a la vez unifique planteamientos y objetivos, y que ayude a situar a la UE a la cabeza en el desarrollo de políticas que favorezcan la participación de la sociedad en el desarrollo científico y tecnológico.

Dada la temática de esta tesis, consideramos de interés centrarnos, a la hora de abordar el informe, en la visión ofrecida de la comunicación de la ciencia, con el objetivo de conocer las directrices que establece y que pueden ser extrapolables a la comunicación de la RRI. El informe plantea que los medios de comunicación 
tradicionales siguen siendo el medio más importante para la definición de la agenda en materia de ciencia e innovación, elevando el conocimiento e implicando a ciudadanos que no estén, de entrada, particularmente interesados en cuestiones de ciencia. En este sentido, destacan las oportunidades de acceso que supone internet. Asimismo, se establece que si bien la transmisión de la información sigue siendo importante, el verdadero reto supone la construcción compartida del futuro a través de la participación y el diálogo.

El apartado sobre comunicación de la ciencia comienza destacando la importancia de la difusión de la ciencia y la tecnología y la participación del público en su desarrollo en una sociedad en una sociedad basada en el conocimiento en la que la ciencia y la tecnología son fundamentales. El informe hace hincapié en los cambios surgidos en la forma de entender la comunicación de la ciencia desde mediados del siglo $\mathrm{XX}$, momento en el que los gobiernos y las instituciones científicas empezaron a ver la necesidad de que el público comprendiera la ciencia para poder actuar de forma adecuada en un creciente número de contextos tecnocientíficos como trabajadores, consumidores y pacientes. En 1980, sitúan el origen de lo que hoy se conoce como Comprensión Pública de la Ciencia y que dio pie al "modelo del déficit" que hemos abordado en el capítulo anterior, basado en la transmisión de la ciencia a través de la educación y los medios de comunicación.

Como respuesta a este enfoque, el informe destaca el surgimiento de nuevos enfoques por parte de partidos políticos, organizaciones de la sociedad civil y pensadores. Entre ellos, recuerda la figura de Habermas, destacando cómo el filósofo ya comenzó a postular la participación pública en la definición de la agenda científica en los años 60. Desde este enfoque se entiende que las decisiones sobre la ciencia se habían vuelto demasiado sensibles para dejarla en manos de los expertos. Este giro democrático se ha traducido en un mayor esfuerzo para avanzar en el compromiso y el diálogo público en la ciencia.

El informe destaca las oportunidades que abre este nuevo enfoque que parte de la consideración de que científicos y sociedad pueden aprender unos de otros y de que ambos tienen valores políticos y normativos relevantes para la toma de decisiones en materia de ciencia e innovación, instando a avanzar en el diálogo, la deliberación y la interacción. 
This transaction model differs crucially from the transmission model in that it involves a more symmetric, though not necessarily more equal, notion of communication. The starting point is that scientists and the public can learn from each other, that both have access to knowledge as well as having political and normative values that are relevant for scientific choices. The model recognises that scientific knowledge is necessarily provisional and subject to change. So, this transaction is an ongoing exchange of information, debate and knowledge that becomes an interaction (Sinue, 2009:51).

El informe hace referencia a la necesidad de entender la ciencia en un sentido amplio, incluyendo también las ciencias sociales y las humanidades, ámbitos que entiende que han sido "profundamente descuidados". No obstante, destaca el hecho que en las cuestiones relacionadas con ciencias sociales, como la educación, los modelos sociales o la economía, existe una mayor apertura a la hora de abordar la cuestión de quién debe participar en los debates públicos "y la gente en general está bastante dispuesta a reclamar el derecho a participar". Sin embargo, en el ámbito de las ciencias naturales y las ingenierías, parece estar "mucho menos claro a quién se debe permitir participar y en qué términos". En este sentido, los expertos autores del informe recuerdan que en el mundo contemporáneo la ciencia está vinculada no sólo a la definición de los problemas científicos y sociales, sino también a la provisión de soluciones a esos problemas.

El informe establece unos objetivos claros de la comunicación entre la ciencia y la sociedad, estableciendo que estos pasan por "informar al público en general acerca de los problemas relacionados con la ciencia y la tecnología, e informar a la ciencia sobre las percepciones y expectativas de la sociedad". La comunicación de la ciencia hace visible públicamente la experiencia científica, establece la agenda de la formulación de políticas, afecta la legitimidad de la investigación, y juega un papel importante en la gobernanza de la ciencia, la tecnología y el riesgo. Asimismo, la comunicación puede ayudar a establecer una forma de relación bidireccional que contribuya a hacer más tranparentes las inversiones públicas en materia de ciencia, permita a los responsables políticos y a los investigadores conocer la percepción de la ciencia y favorezca el uso del conocimiento científico por parte de la sociedad.

Al mismo tiempo, los expertos advierten de cómo la comunicación es también en ocasiones una fuente de malentendidos y malos usos, como modelos excesivamente simples de cómo la ciencia y la sociedad se comunican; expectativas poco realistas respecto a los beneficios de la comunicación por ambas partes; o formas de 
comunicación que aumentan la distancia entre la ciencia y sus públicos más amplios en lugar de favorecer la participación. Como vemos, se trata de riesgos planteados por De Semir y abordador en el capítulo sobre comunicación de la ciencia, y a los que trataremos de responder a través de la propuesta de un modelo comunicativo de la RRI.

Los expertos de MASIS, como también recogía De Semir en una obra más reciente (De Semir, 2014), ya advertían de que la comunicación de la ciencia sigue siendo con demasiada frecuencia poco más que un ejercicio de relaciones públicas para la ciencia, "a menudo el despliegue de grandes promesas sobre los resultados futuros sin molestarse en ofrecer una visión más matizada de lo que la investigación científica y los conocimientos tecnológicos realmente pueden lograr".

A pesar de los riesgos y las dificultades a las que deba hacer frente, el informe reafirma la importancia de la comunicación de la ciencia en una economía cada vez más basada en el conocimiento, en la que se entiende que la ciudadanía debe tener un conocimiento en materia de ciencia y tecnología con el fin de ser empresarios, trabajadores y consumidores competentes. Por su parte, gobiernos, políticos y organizaciones de la sociedad civil también quieren que el público esté informado sobre nuevos desarrollos, señalan.

El informe aborda también la diversidad no solo de los públicos de la ciencia, sino también de sus emisores, que van desde los científicos a nivel individual a los grupos de investigación, los centros regionales, nacionales e internacionales de ciencia, las asociaciones disciplinarias, las empresas y las industrias basadas en la ciencia (por ejemplo, productos farmacéuticos), políticos, editores, escuelas y universidades. Los expertos destacan el papel de estas últimas, por un lado, como actores clave en la construcción del Espacio Europeo de Investigación a través de la investigación y la formación de las nuevas generaciones de investigadores. Por otro, destacan como las universidades se han convertido en lugares importantes desde los que los avances tecnocientíficos son comunicados en un sentido amplio.

Asimismo, el informe destaca el papel de los medios de comunicación de masas como actores clave. En este sentido, recoge el riesgo de trivialización de las noticias, de la imposición del "pensamiento rápido" impuesta a los medios de comunicación audiovisuales, independientemente del grado de dificultad en la presentación de conocimientos científicos complejos. Los autores entienden que la simplificación de la ciencia no tiene por qué ser negativa "si se hace con sensatez". Sin embargo, el impacto 
continuo de titulares en las noticias sobre descubrimientos asombrosos puede conducir a una percepción anecdótica del desarrollo de la investigación y la ciencia si esta información no es correctamente contextualizada, sobre todo si se tiene en cuenta la complejidad y la incertidumbre que es inherente a la investigación científica.

El estudio recoge también la transformación en el campo de la comunicación que ha supuesto internet y las nuevas tecnologías, y a la que no ha sido ajena la comunicación de la ciencia, como hemos visto en el sexto capítulo de la tesis. En este sentido, el informe destaca las posibilidades que abre internet para que investigadores y centros de investigación lleguen a grandes audiencias. El grupo de expertos del proyecto MASIS hace hincapié en que "no hay una escasez de información científica, especialmente desde la explosión de la World Wide Web". La red dispara las posibilidades de distribución y acceso a la información. El problema no es pues cómo aumentar el gran volumen de información que ya existe sino la forma de aumentar la capacidad de las personas para encontrar información útil, para juzgar lo que es fiable y relevante, para dar sentido a informaciones en ocasiones contradictorias y para participar en la comunicación y discusión cuando sea apropiado. Se trata, como decíamos al hablar de la nueva galaxia mediática, de fomentar la necesaria alfabetización mediática.

Para los expertos del proyecto MASIS, internet tiene el potencial de cambiar radicalmente la relación entre los proveedores de la información y los que buscan informarse, sin necesidad de pasar por la intermediación de los medios tradicionales. El estudio recoge asimismo, las reticencias que hemos visto de parte de la comunidad científica al uso de internet para la difusión de nuevos conocimientos, mientras que otra parte de los investigadores encuentra en la red nuevas formas de comunicar resultados y de relacionarse con los públicos. Los autores del estudio consideran que para mejorar la comunicación de la ciencia, los científicos podrían hacer un mayor uso de tecnologías de colaboración para exponer sus ideas antes de las publicaciones y para posteriormente, mostrar los resultados.

En el apartado de conclusiones, los expertos señalan que el reto de la comunicación para una ciencia en sociedad no pasa tanto por ofrecer más información como por proporcionar formas adecuadas para la comunicación y el diálogo.

Communicating science in ways that are useful and meaningful for both science and society remains a challenge not least because the deficit model underlying the public understanding of 
science remains very strong amongst (some) scientists, policy makers and the media. The solution is thus not to produce more information about science but to provide it in forms suitable for communication and dialogue (Sinue, 2009:60).

Como hemos visto al abordar la comunicación de la ciencia desde las universidades, el informe de 2009 advertía ya de que, a pesar de la proliferación de declaraciones en sentido contrario, la práctica de la comunicación de la ciencia se basa todavía principalmente en el modelo de transmisión, de modo que el enfoque de Comprensión Pública de la Ciencia sigue siendo predominante en gran parte de la comunicación de la ciencia que entiende que el objetivo de la misma para por informar al público en lugar de favorecer su participación en la misma. Como ya hemos visto con De Semir (2014), la ideología que puede estar escondida después de estos planteamientos es que la sociedad debe aceptar la ciencia, la tecnología y la innovación, y a su vez dar respuesta a la necesidad de aumentar las vocaciones para contar con los ingenieros y científicos que requiere una economía basada en el conocimiento. A través de este modelo, entienden que "la ciencia y la sociedad no se comunican (la comunicación es un proceso de dos canales), sino que la ciencia habla a la sociedad".

El informe identifica siete retos para avanzar en una relación de participación productiva entre la ciencia y la sociedad. Como veremos, cinco de ellos coinciden con los cinco retos recogidos por De Semir en otras publicaciones a los que ya hemos hecho referencia en el capítulo anterior, variando en ocasiones algunos de sus planteamientos, por lo que entendemos que resulta de interés recogerlos de nuevo en este punto. Los cinco primeros retos son los recogidos también por De Semir en obras posteriores, mientras que los dos que hemos situado al final aparecen únicamente en el informe del proyecto MASIS:

- Multiplicidad de públicos, de razones y de intermediarios. En este punto, señalan que existe una multiplicidad de audiencias (científicos, organismos financieros, políticos, periodistas, organizaciones no gubernamentales), una multiplicidad de razones para estar involucrado (educación, entretenimiento, deliberación/diálogo) y, por tanto, una multiplicidad de voces (profanas y expertas, experiencial y codificada), así como diferentes tipos de intermediarios (periodistas, maestros, organizaciones de la sociedad civil, etc.). El desafío consiste en este punto en utilizar diferentes mecanismos en diferentes momentos 
y diferentes formaciones para proveedores y usuarios de la información, lo que permitiría elegir el conjunto más adecuado en diferentes contextos.

- Reticencias de la comunidad científica hacia la sociedad. En este punto, se indica cómo los científicos suelen considerar al público como una masa irracional con aversión al riesgo. Asimismo, pueden ser muy críticos sobre el papel de los medios de comunicación, de la educación primaria y secundaria y de los responsables políticos. Las cuestiones éticas y de evaluación del riesgo son consideradas a veces por la comunidad científica como un obstáculo para el progreso científico o incluso como un peligro para la ciencia.

- Dependencia de la publicación en revistas científicas. En este sentido, se destaca la necesidad de incrementar la formación para acceder al conocimiento científico a través de fuentes más diversificadas, entendiendo cómo se produce el conocimiento científico y cuáles son sus limitaciones. Asimismo, el informe señala que los científicos deben conocer mejor las posibilidades y los límites de los diferentes medios de comunicación con los diferentes públicos.

- Derechos y responsabilidades de la ciencia y la sociedad. Como veíamos con De Semir, la comunicación de la ciencia se ha convertido en un "deber" para los científicos y un "derecho" para el público, un derecho a saber y un derecho a participar. "Pero el deber no siempre es bienvenido y los derechos no son siempre ejercidos con entusiasmo". El grupo de expertos sugiere la necesidad de hacer mayor énfasis en la participación pública en la ciencia desde el punto de vista de la comunicación con una clara definición de la responsabilidad de los actores, para lo que entienden que resulta necesario una mayor comprensión de la ciencia como una actividad en curso.

For this to be effective there needs to be greater understanding and reflexivity from all parties regarding the nature of science as an on-going activity. There are places to celebrate great scientists and amazing discoveries, but for effective public engagement there needs to be more attention to the choices to be made, the resources to be allocated and the work done by individual scientists as well as research organizations (Sinue, 2009:62).

- Superar las fronteras en la comunicación de la ciencia. En este punto se señala como, a diferencia del caso de los conocimientos científicos que han sabido trascender las fronteras de la política y el lenguaje, sigue habiendo un alto grado 
de especificidad cultural en relación con la comunicación de la ciencia. El informe señala la existencia de diferentes tradiciones y regulaciones con respecto a los medios de comunicación y la autonomía científica que afectan a la forma en que se comunica la ciencia dentro de los países y sus fronteras.

- Construir futuros potenciales. La comunicación de la ciencia desde la perspectiva planteada no se puede limitar a la transmisión de hallazgos científicos, sino que debe participar en la construcción de los posibles futuros vinculados al desarrollo científico. La investigación y la tecnología tienen responsabilidad en la planificación, negociación y transformación del futuro. Como artífices de este futuro, los científicos y también los profesionales de la comunicación de la ciencia son responsables de su papel en las gestiones que determinarán las creaciones futuras. Las promesas de futuro y las declaraciones sobre oportunidades tienen, para los expertos de MASIS, un claro componente ético. Es por ello que consideran necesario profundizar en los mecanismos de la "comunicación de futuros" en la comunicación de la ciencia y desarrollar enfoques que permitan una mejor deliberación y evaluación de esos futuros.

- Aprovechar las tecnologías de la web 2.0. En este punto, entienden que las nuevas tecnologías juegan un papel cada vez más destacado en la comunicación y la interacción, por lo que uno de los retos para la comunicación científica es apoderarse de estas herramientas e incorporarlas para el desarrollo de la Comprensión Pública de la Ciencia y sobre todo en el Compromiso Público con la Ciencia.

Una vez analizados las principales publicaciones e informes referentes al modelo ciencia y sociedad, pasamos en el siguiente apartado a abordar los textos referidos específicamente al concepto de RRI publicados por la UE a partir del año 2011.

\subsection{DIRECTRICES PARA LA RRI}

El presente apartado recoge tres documentos que dibujan el marco normativo de la RRI en la Unión Europea. Se trata en primer lugar del primer informe sobre RRI elaborado por Hillary Sutcliffe a partir principalmente de las conclusiones extraídas de la reunión 
de trabajo y del taller sobre RRI celebrados en 2011 en Bruselas y Londres, respectivamente. A pesar de ser un texto muy breve, entendemos que también es necesario recoger en este apartado el documento Responsible Research and Innovation. Europe's ability to respond to societal challenges, publicado en 2012 y en el que se recoge tanto la definición de qué entiende la UE por RRI como los seis ejes entorno a los que considera que se debe articular su desarrollo. Finalmente, el presente apartado se completa con los documentos correspondientes a la convocatoria Horizonte 2020 en el que la RRI se plantea como una acción transversal, además de ser el foco de atención de las acciones financiadas a través del programa "Ciencia con y para la Sociedad".

\subsubsection{Las bases de la RRI}

La Comisión Europea publicó en 2011 el informe sobre RRI elaborado por Hilary Sutcliffe en el que se recogen las conclusiones del Research Workshop on Responsible Research and Innovation celebrado en mayo de 2011 en Bruselas y el taller franco-británico realizado los días 23 y 24 de ese mismo mes de mayo en la Embajada de Francia en Londres. A lo largo de la tesis hemos hecho referencia a ambas acciones ya que en ellas se encuentra la base del enfoque de la RRI por parte de la Unión Europea. El informe ofrece una visión amplia de las conclusiones de ambos y sienta las bases de las directrices europeas entorno a la RRI.

El informe A report on Responsible Research and Innovation contempla aspectos que ya hemos abordado en el sexto capítulo, como la aproximación al concepto de RRI. En el presente punto buscaremos profundizar en las recomendaciones y directrices relacionadas con la comunicación de la RRI y la participación de los grupos de interés. Sobre esta última, el documento considera la participación de los actores sociales en los procesos y resultados de la investigación y la innovación como un componente "clave de RRI", a pesar de reconocer que todavía es objeto de discusión por parte de los expertos tanto el enfoque apropiado de esta participación como el momento y la forma. El documento alude asimismo a la necesidad de involucrar a los stakeholders en el desarrollo de soluciones beneficiosas para el bien común (Sutcliffe, 2011:8).

Entre las razones que se argumentan en el informe para justificar la necesidad de una mayor participación social se encuentran la necesidad de aceptación de las 
innovaciones y la responsabilidad moral de los gobiernos y otras organizaciones de dar voz a la ciudadanía a la hora de determinar los avances en investigación e innovación, argumento que se apoya en la gestión de los fondos públicos, pero también en la responsabilidad social de la investigación. Otros argumentos destacan el papel y la aportación de la ciudadanía como co-creadores de innovación, involucrándola en actividades de $\mathrm{I}+\mathrm{D}+\mathrm{i}$, mientras que otra razón responde a la idea de que la participación hace a la innovación más efectiva al alinearla con las necesidades de la sociedad.

RRI does not shut off options, but opens them up. If connections are what make inventions and innovation happen, RRI is a more deliberate way of making that happen. It is fundamentally about making better connections with more people to enrich our innovation process and create better, more sustainable products (Sutcliffe, 2011:12).

Por lo que respecta a quiénes están llamados a participar, a pesar de que el informe señala que el público abarca a todas las personas, que pueden ser seleccionadas para su participación de una forma representativa a través de técnicas demoscópicas, resalta que en la sociedad existen grupos y asociaciones que pueden jugar un papel activo como colegios profesionales, organizaciones de consumidores, organizaciones no gubernamentales y otros grupos intermediarios entre los gobiernos, las empresas y el público.

El informe señala como uno de los retos de la RRI ser más innovadora e inclusiva a la hora de alcanzar la participación efectiva de la ciudadanía en todas las etapas de la investigación y la innovación, determinando la manera más eficaz de articular el proceso.

RRI challenges each actor in the innovation process to play their part and it explores when and how best to involve the public and others stakeholders appropriately and effectively in their particular part of the process (Sutcliffe, 2011:12).

En este sentido, se indica la necesidad de transmitir a los participantes que su aportación se va a gestionar de forma rigurosa y profesional, y que su voz va a ser considerada y tenida en cuenta. El informen lamenta la notable ausencia de una retroalimentación con los participantes y la sociedad en general acerca de cómo se utilizan las aportaciones, cómo influyen en el proceso en discusión y las razones de las decisiones finalmente adoptadas, sobre todo si son contrarias a las opiniones suscitadas a través del proceso de participación. El modelo de comunicación de la RRI que 
plantearemos buscará precisamente dar respuesta a esta falta de retroalimentación, poniendo el acento en las acciones de diálogo, negociación e información pública.

El informe hace asimismo referencia a las teorías que defienden la necesidad de contar con un "público informado" para favorecer su adecuada participación, partiendo de la idea de que si el público tiene un conocimiento básico de la ciencia y de los procesos científicos podrá hacer juicios "mejores". En este sentido, destaca el papel de los medios de comunicación y especialmente de internet como vías de acceso a una gran cantidad de información. Sin embargo, alerta de que "la información no tiene por qué informar" en el sentido de que más información puede no ser mejor, señalando tanto los riesgos de una sobreinformación con artículos que pueden resultar incomprensibles para los públicos, como de una excesiva simplificación de la ciencia por parte de los medios. El excesivo ruido o la banalización pueden generar en la ciudadanía incertidumbre, preocupación, confusión o incluso aburrimiento y falta de compromiso. Por tanto, el informe señala que uno de los retos más importantes de la RRI es considerar cuidadosamente los canales de participación del público y la información que requieren y necesitan para facilitársela con claridad y eficacia.

One of the most signifcant challenges of RRI is to consider carefully how the public wish to participate and what information and engagement people want and need to help them become appropriately involved or give an informed opinion and deliver it clearly and effectively (Sutcliffe, 2011:15).

El documento recuerda asimismo la necesidad de promover la participación e involucrar a la sociedad en los procesos de investigación e innovación lo más al principio posible "aguas arriba" o, siguiendo el término anglosajón utilizado en ciencia sociales "upstream", con el fin de ayudar a dar forma al proceso desde su inicio. Asimismo, resalta la importancia de comunicar con claridad y eficacia las decisiones adoptadas y las influencias que llevaron a las mismas. De esta manera, el proceso de toma de decisiones podrá ser legítimo, inclusivo y transparente y construirá confianza en el proceso, incluso aun habiendo disconformidad con el resultado.

It also communicates clearly and effectively about the decisions taken and the influences which led to the chosen path. In this way the decision-making process is legitimate, inclusive, and transparent which will build confidence in the process even if we don't always agree with the outcome (Sutcliffe, 2011:15).

Respecto a cómo conseguir involucrar a los públicos, el informe recoge que son muchos los gobiernos, centros de investigación, empresas y grupos de la sociedad civil 
que están buscando nuevas formas de participación de los actores públicos en la evaluación y priorización de la investigación y la innovación. Como ejemplos señalan los jurados ciudadanos, eventos de tormentas de ideas (brainstorm), focus group o acciones de co-creación. Sin embargo, advierte de que muchos se quedan cortos en cuanto a alcanzar una verdadera participación ciudadana. Para lograrlo destaca la necesidad de suministrar la información necesaria en los procesos de participación a la ciudadanía, como un componente clave de la transparencia y la rendición de cuentas, de modo que la información es esencial para alcanzar una RRI eficaz. En este punto, el documento de la Unión Europea, viene a destacar la importancia de la comunicación, que en la hipótesis de la presente tesis se plantea como un requisito moralmente imprescindible para la gestión de la RRI.

It should be noted that the provision of information on their processes and products to citizens by government and business is a key component of transparency and accountability and though it is likely to be categorised as 'informing' it is essential to effective RRI (Sutclieffe, 2011:16).

\subsubsection{La RRI como respuesta a los retos de la sociedad}

En 2012 la Comisión Europea publica Responsible Research and Innovation. Europe's ability to respond to societal challenges, un documento muy breve, de tan solo cuatro páginas, pero que entendemos que resulta básico por recoger tanto la perspectiva de la UE del concepto de RRI como los seis puntos que a partir de ese momento se convierten en los seis aspectos claves entorno a los que gira el desarrollo de una investigación y una innovación más responsables en el ámbito europeo.

Los contenidos de este documento ya han sido recogidos en el sexto capítulo, por lo que en el presente punto nos limitaremos a considerar la relación de la comunicación de la RRI con cada uno de estos seis ejes centrales. El primero de ellos hace referencia a la participación pública, por lo que entendemos que la comunicación de la RRI debería buscar fomentar mecanismos para favorecer la participación de los diferentes actores sociales. Respecto a la igualdad de género, se trata asimismo de un tema a considerar también desde el ámbito de la comunicación de la ciencia, con el fin de garantizar que la información y la participación alcance realmente a las mujeres, integrando la dimensión de género tanto en el proceso de RRI como en su comunicación. 
La comunicación tiene asimismo un papel clave en la educación científica. En este punto, la publicación destaca la necesidad de fomentar las vocaciones y avanzar en la alfabetización científica de la sociedad. También aparece estrechamente vinculado a la comunicación, y de forma específica a la transparencia, el cuarto punto, referido al acceso abierto a la información científica, lo que significa ofrecer on line y sin coste alguno el acceso a los resultados de las investigaciones realizadas con financiación pública, tanto a las publicaciones como a los datos resultantes. Esto permitirá incrementar las posibilidades de uso de los resultados científicos por parte de todos actores sociales.

Ética y gobernanza centran los últimos dos ejes de la RRI establecidos por la UE. Por lo que respecta a la ética, se destaca como la innovación deben respetar los derechos fundamentales y los más altos estándares éticos, garantizando la relevancia social y la aceptabilidad de los resultados de investigación e innovación. En cuanto a la gobernanza, se plantea como un paraguas de todas las anteriores, poniendo el acento en el diseño de una ciencia para la sociedad pero también con la sociedad. Desde la perspectiva planteada en la presente tesis, la comunicación es un requisito moralmente imprescindible para conseguir una investigación e innovación ética y una gobernanza legítima.

\subsection{3. "Ciencia con y para la Sociedad" y RRI en Horizonte 2020}

La convocatoria Horizonte 2020 de la Unión Europea incluye el programa "Ciencia con y para la Sociedad" (SwafS - Science with and for Society) como sucesor del programa "Ciencia en Sociedad" del VII Programa Marco (SIS - Science in Society) con el objetivo de promover y facilitar la comprensión de la RRI. El Artículo 20 de la Propuesta del Reglamento del Parlamento y del Consejo por el que se establece Horizonte 2020, Programa Marco de Investigación e Innovación (2014-2020), señala:

Con el fin de profundizar las relaciones entre la ciencia y la sociedad, así como de reforzar la confianza pública en la ciencia, Horizonte 2020 debe favorecer una participación informada de los ciudadanos y de la sociedad civil, en las cuestiones relacionadas con la investigación y la innovación, mediante el fomento de la educación científica, haciendo más accesibles los conocimientos científicos, elaborando unas agendas de investigación e innovación responsables que atiendan las expectativas y preocupaciones de los ciudadanos y de la sociedad civil, y facilitando su participación en las actividades de Horizonte 2020 (Mesas, 2015). 
Como hemos visto y como queda recogido en la web de la convocatoria Horizonte 2020 (European Commission, 2013), la UE define la RRI como un enfoque que anticipa y evalúa las implicaciones potenciales y las expectativas de la sociedad con respecto a la investigación y la innovación, con el objetivo de fomentar el diseño de la investigación y la innovación inclusiva y sostenible.

Investigación e Innovación Responsable (RRI) implica que los actores sociales (investigadores, ciudadanos, responsables políticos, empresariales, organizaciones del tercer sector, etc.) trabajan juntos durante todo el proceso de investigación e innovación con el fin de alinear mejor el proceso y sus resultados con los valores, necesidades y expectativas de la sociedad (European Commission, 2013).

En la práctica, la RRI se implementa en la convocatoria Horizonte 2020 como un paquete que incluye múltiples actores y la participación pública en la investigación y la innovación, con el fin de permitir un acceso más fácil a los resultados científicos, la introducción de la perspectiva de género y la ética en el contenido y el proceso de la investigación y la innovación y el proceso, y la educación formal e informal de la ciencia.

La RRI es la acción clave de los objetivos del programa "Ciencia con y para la Sociedad”. Según se establece en la convocatoria, las acciones de RRI se promoverán en este programa a través de: acciones sobre elementos temáticos de la RRI (participación pública, acceso abierto, perspectiva de género, ética y educación la ciencia); y acciones integradas que, por ejemplo, promuevan el cambio institucional, para fomentar la introducción del enfoque de la RRI por parte de los interesados y las organizaciones. La RRI se plantea además como un tema transversal en Horizonte 2020, promoviéndose a lo largo de todos los objetivos de la convocatoria.

El programa "Ciencia con y para la Sociedad" destaca en su Introducción (European Commission, 2015) la importancia de la mejora en la cooperación entre la ciencia y la sociedad de cara a permitir un mayor apoyo social y político a la ciencia y a la tecnología en todos los Estados miembros, considerándolo como un elemento crucial, más aún en el actual contexto de crisis. En este sentido, se señala que la inversión pública en ciencia requiere un amplio apoyo social y político, la participación en sus procesos y la capacidad de reconocer sus aportaciones al conocimiento, a la sociedad y al progreso económico. De este modo, "Ciencia con y para la Sociedad" se plantea como una herramienta fundamental para hacer frente a los retos abordados en Horizonte 
2020 y para el desarrollo de nuevas formas de acercar la ciencia y la sociedad, todo ello de cara a hacer la ciencia más atractiva, favorecer la participación de los diferentes actores sociales a lo largo del proceso, y alinear mejor los resultados con las expectativas sociales, siguiendo el enfoque de la RRI.

'Science with and for Society' will be instrumental in addressing the European societal challenges tackled by Horizon 2020, building capacities and developing innovative ways of connecting science to society. It will make science more attractive (notably to young people), raise the appetite of society for innovation, and open up further research and innovation activities. It allows all societal actors (researchers, citizens, policy makers, business, third sector organisations etc.) to work together during the whole research and innovation process in order to better align both the process and its outcomes with the values, needs and expectations of European society. This approach to research and innovation is termed Responsible Research and Innovation (RRI) (European Commission, 2015:4).

En la práctica, el programa establece que la RRI consiste en el diseño y la implementación de políticas de investigación e innovación de cara a:

- Involucrar a la sociedad de manera más amplia en las actividades de investigación e innovación.

- Aumentar el acceso a los resultados científicos.

- Garantizar la igualdad de género tanto en el proceso de investigación como en el contenido de la misma.

- Tener en cuenta la dimensión ética.

- Promover la educación científica formal e informal.

Para los años 2014-2015, el programa "Ciencia con y para la Sociedad” incluye cuatro puntos, además de un apartado para "Otras acciones" y "Actividades horizontales". Los cuatro puntos (calls) son:

- Haciendo la educación científica y las carreras de ciencias atractivas para los jóvenes (SEAC).

- Promoviendo la igualdad de género en investigación e innovación (GERI).

- Integrando a la sociedad en la ciencia y la innovación (ISSIS). 
- Desarrollando la gobernanza para el avance de la investigación e innovación responsable (GARRI).

Entendemos que la convocatoria "Integrando a la sociedad en la ciencia y la innovación (ISSIS)" es la que aparece vinculada más directamente con la temática de la presente tesis y las directrices europeas en materia de comunicación de la ciencia y participación de los grupos de interés, por lo que nos detendremos a continuación en la misma. Esta convocatoria parte de la idea de que los intereses y valores de la ciudadanía deben integrarse mejor en la ciencia, la tecnología, las cuestiones relacionadas con investigación e innovación, las políticas y las actividades, con la idea de que esta integración aumentará la calidad, la pertinencia, la aceptación social y la sostenibilidad de la investigación y la innovación. Asimismo, señala que esta integración será posible gracias a la promoción de la RRI entendida como "la participación de los ciudadanos y la sociedad en la investigación y la innovación como un proceso de creación conjunta".

El programa "Ciencia con y para la Sociedad" plantea promover e incrementar la comprensión de la RRI mediante la combinación de diferentes acciones, en particular, con el objetivo de:

- Desarrollar el interés y la capacidad de los ciudadanos en materia de ciencia para permitirles participar activamente en diversas actividades científicas como, por ejemplo, exposiciones y cafés de ciencia, comunidades de reutilización creativa, mecanismos de asesoramiento online sobre políticas basada en el conocimiento, etc.

- Fomentar la difusión de información y buenas prácticas a través de Plataformas de Conocimiento Compartido (KSP, Knowledge Sharing Platform), incluyendo la creación de redes, monitoreo y la evaluación de iniciativas pertinentes.

- Apoyar el cambio estructural en los centros de investigación y las instituciones de educación superior para promover la RRI.

Estas actividades están dirigidas a los ciudadanos y sus asociaciones o agrupaciones, a investigadores e innovadores, centros de investigación, políticos y administraciones a nivel nacional, regional y local, centros de educación de primaria, 
secundaria y superior, museos de ciencia, bibliotecas, medios de comunicación, artistas, industrias creativas, etc. El resultado esperado de las acciones planteadas por la Comisión Europea es una mejora en la integración de la sociedad en la ciencia y la innovación.

Los temas (topics) planteados en la propuesta ISSIS incluyen la difusión pública paneuropea a través de la organización de exposiciones y cafés con ciencia que involucren a la ciudadanía en la ciencia; la participación de la ciudadanía y múltiples actores para la construcción de escenarios; el desarrollo de Plataformas de Conocimiento Compartido; la creación de mecanismos en línea para el asesoramiento sobre políticas basados en el conocimiento; y el apoyo a los cambios estructurales en los centros de investigación para promover la RRI.

Por otra parte, cabe señalar que el portal web de la convocatoria Horizonte 2020 aborda el concepto de Compromiso Público (PE, Public Engagement) en RRI, como un aspecto clave, señalando que se trata de crear conjuntamente el futuro con los ciudadanos y organizaciones de la sociedad civil, y también hacer partícipes a la diversidad más amplia posible de actores que normalmente no interactuar entre sí, en materia de ciencia y tecnología. Par la UE, el compromiso público conduce a múltiples beneficios:

- Contribuye a la construcción de una sociedad más alfabetizada científicamente que pueda participar activamente y apoyar los procesos democráticos en los desarrollos científicos y tecnológicos.

- Inyecta perspectivas diferentes y una mayor creatividad en el diseño de la investigación y sus resultados.

- Contribuye a fomentar unos resultados de la investigación y la innovación más relevantes y deseables socialmente para ayudar a hacer frente a los retos sociales.

El PE implica el establecimiento de diálogos multi-actores participativos, interactivos e inclusivos entre investigadores, responsables políticos, industria, organizaciones de la sociedad civil, ONG y ciudadanía. Asimismo, supone el fomento de la comprensión mutua y la creación conjunta de resultados de investigación e 
innovación y de agendas políticas eficaces en respuesta a los retos sociales, así como el fomento de una mayor aceptabilidad de los resultados.

La implementación del PE en la convocatoria Horizonte 2020 se articula a través de tres ejes.

- Desarrollo de acciones participativas de Investigación e Innovación. El PE puede integrarse voluntariamente en los proyectos de investigación presentados en la convocatoria con el fin de promover resultados relevantes y aceptables socialmente. En este sentido, la UE establece que lo ideal sería que este compromiso se integrara en el diseño de la investigación y en el proceso desde el principio de forma que la participación y los aprendizajes generados a partir de la misma pudieran contribuir a enriquecer el proceso y los resultados. En este sentido, señala que las acciones de ciencia ciudadana también podrían incluirse dentro de esta categoría.

- Fomentar aportaciones que puedan influir en la agenda política de Investigación e Innovación de la Unión Europea. En este punto se plantea el interés de lanzar iniciativas, similares al proyecto Voces que hemos abordado en el sexto capítulo, que favorezcan la participación ciudadana de forma presencial o en línea sobre temas previamente seleccionados. Estas iniciativas requerirían un elevado nivel de compromiso, la transparencia y la trazabilidad de los resultados, y la integración oportuna y legitima en los actuales mecanismos de Horizonte 2020 y la estrategia institucional de la UE.

- Apoyar el desarrollo y la implementación de políticas temáticas. Un objetivo importante de la política de Investigación e Innovación para la UE es proporcionar conocimientos y pruebas para apoyar el diseño e implementación de políticas temáticas (por ejemplo, medio ambiente, salud, transporte) a nivel nacional y regional, en particular en relación con los retos sociales.

Vemos así como el término compromiso público o public engangement juegan un papel clave en la RRI, un concepto que en poco más de una década ha pasado a jugar un papel clave en las políticas científicas de la Unión Europea. Una vez analizado el marco normativo de la RRI y en especial de su comunicación, establecido a través de las 
diferentes publicaciones de la Unión Europea, y trazado el marco ético de la RRI a través del análisis teórico de los ámbitos de la ética, la responsabilidad social y el concepto de RRI, y la comunicación de la ciencia, pasamos a plantear en el próximo bloque una propuesta de definición de RRI desde la ética dialógica, un mapa de stakeholders y un modelo ético de comunicación de la RRI para las universidades. 


\section{UNA PROPUESTA DE}

MODELO DE COMUNICACIÓN ÉTICA DE LA RRI EN LA UNIVERSIDAD 



\section{Redefinición de la RRI desde el marco de la ética}

El marco ético y normativo desarrollado en el primer bloque de la tesis nos da las claves para avanzar en una nueva aproximación al concepto de RRI desde la perspectiva de la ética dialógica. Entendemos que para abordar el concepto de RRI desde la ética resulta de gran interés tomar como referente el modelo de Responsabilidad Social desarrollado por la Escuela de Valencia en base a la ética del discurso de Habermas y la teoría de los stakeholder, siempre teniendo en cuenta las particularidades de los ámbitos de la ciencia y la innovación. Este modelo nos permitirá delimitar la definición y el alcance de la responsabilidad de la investigación y la innovación y aportar algunas orientaciones prácticas acerca de cómo puede operar este modelo en la práctica.

De este modo la aproximación que plantearemos tiene en cuenta los diferentes stakeholders y sus expectativas, así como los mecanismos de comunicación y debate necesarios para alcanzar acuerdos que tengan en cuenta los diferentes intereses legítimos. Para ello, y con el fin de garantizar una participación en condiciones adecuadas, será necesario establecer las acciones necesarias de comunicación de la ciencia y la innovación que permitan contar con interlocutores suficientemente formados y sentar las bases para el diálogo con los mismos. La propuesta desarrollada tendrá asimismo en cuenta las aproximaciones a la RRI planteadas por diferentes teóricos y por la Unión Europea. Una vez realizada la propuesta de definición analizaremos sus claves en base a las aportaciones teóricas.

\subsection{UNA PROPUESTA DE DEFINICIÓN}

Siguiendo el modelo de Responsabilidad Social desarrollado por la Escuela de Valencia y fundamentado en la teoría ético-discursiva y en la teoría de los stakeholders, entendemos que un centro de investigación o innovación que quiera gestionar su responsabilidad debe tener presente que esta responsabilidad ha de definirse a partir de un diálogo con todos los stakeholders que tenga como fin averiguar qué intereses y valores son comunes a todos ellos y por tanto universalizables; qué intereses y valores son propios de cada grupo o de alianzas grupales y cuáles son intereses y valores particulares. Al determinar tales valores e intereses, las universidades podrán diseñar y 
generar estrategias que traten de satisfacer los intereses considerados universalizables, dar una respuesta adecuada a valores grupales que no contradigan los anteriores y, en la medida de lo posible, satisfacer intereses y valores particulares. De este modo, se puede considerar que la gestión de la ciencia y la innovación conseguirá la legitimidad y credibilidad de sus stakeholders siempre y cuando sea capaz de dar respuesta sus expectativas legítimas universalizables (González y García Marzá, 2006). Cabe recordar que para Habermas una norma, acción o decisión puede ser considerada universalizable cuando pudiera encontrar el consenso de todos los afectados, tras un cálculo de consecuencias, en un discurso práctico en condiciones de igualdad (Habermas, 2000).

Siguiendo el modelo de Responsabilidad Social desarrollado por la Escuela de Valencia, el diálogo que nos llevará a conocer los intereses de los grupos de interés de la ciencia e innovación debe tener los siguientes rasgos (González y García Marzá, 2006):

- Los intereses deben poder ser cualificados y existen tres tipos: particulares, grupales y universalizables o generalizables. Una perspectiva ética del enfoque de los stakeholders debería adoptar los intereses universalizables o generalizables como guía para la definición de sus estrategias y de su RSE.

- Un stakeholder no será comprendido sólo como un afectado por la actividad de la ciencia y la innovación sino como un interlocutor válido. En este sentido los autores afirman que no es un simple reclamante pasivo sino que trata de influir en las decisiones y actividades. Con esta definición de los stakeholders se exige que todos los afectados por los procesos de investigación e innovación sean considerados como interlocutores válidos, cuyos intereses es preciso tener en cuenta en la toma de decisiones.

- Un stakeholder válido posee poder tanto de carácter estratégico o instrumental como comunicativo, es decir, generador de entendimientos y consensos acerca de intereses universalizables.

- El establecimiento de diálogos para la búsqueda de consensos acerca de las normas y procedimientos que respondan a intereses universalizables o generalizables para guiar la dirección de la ciencia y la innovación es una exigencia. Es decir, deberá existir un respeto obligado al principio de 
universalización que establece que una decisión es moralmente correcta cuando puede o podría ser aceptada por todos los afectados presentes y futuros.

- Los diálogos deberán atender a los cuatro principios establecidos por Habermas (2000): principio de sinceridad de los interlocutores; principio de inclusión de todos los afectados como solución a los conflictos -o en su defecto los representantes-, potenciales, presentes y futuros; principio de reciprocidad entre los participantes; y principio de simetría entre todos los intereses planteados.

Partiendo de este enfoque ético, podría considerarse que un centro de investigación o innovación está dando una respuesta adecuada a su RRI cuando encuentre el acuerdo de todos los implicados a través de un proceso dialógico que tenga en cuenta la inclusión de todos los grupos de interés identificados.

Este acuerdo será considerado siempre como un proceso y no un hecho, y la valoración ética del mismo dependerá del alejamiento o cercanía respecto a la inclusión de los múltiples stakeholders, las condiciones del diálogo y del posible acuerdo. El requisito mínimo, consecuentemente, es siempre la exigencia del diálogo entre todos aquellos stakeholders identificados (González y García Marzá, 2006:163).

Bajo esta perspectiva, se hace hincapié en que los seres humanos son capaces de alcanzar acuerdos intersubjetivos acerca de la corrección de las normas morales y, en el caso de la ciencia y la innovación, para la gestión de la RRI. Para que el acuerdo o consenso alcanzado sea considerado como moral deberá contar con la participación de todos los afectados por las cuestiones que se dirimen en el diálogo en condiciones iguales y simétricas de participación. Así pues, se considerarán stakeholders a incluir en los procesos de decisión y diálogo en materia de ciencia e innovación a todos aquellos que posean competencia comunicativa y cuyos resultados de tales diálogos puedan afectarles. Siguiendo a González y García Marzá, los derechos que les corresponden a los stakeholders válidos "podrían tener la calidad de ser expectativas legítimas”, por lo que serían sujetos a responsabilidad para la organización de ciencia e innovación y en este sentido se convierten en obligaciones para la misma. Es decir, cada stakeholder como interlocutor válido, desde este modelo procedimental para la RRI, tendría el derecho a participar en los diálogos que se planteen y cuyos resultados le afecten.

Cabe recordar que, siguiendo a Habermas, en la ética del discurso lo moral está en el diálogo y en la posibilidad de alcanzar el acuerdo. Y a pesar de las dificultades 
para que se cumplan todos los principios dialógicos, marca un horizonte de actuación, señala el norte al que dirigirnos, es un criterio de justicia y validez. El contenido normativo universal de estas estructuras lingüísticas es lo que las dota de un valor moral.

Así, el modelo de RRI planteado pone el acento en la participación a través del diálogo de los afectados y es, a través de este, como se pueden determinar los fines de la investigación y la innovación. En este punto, cabe recordar que, para Cortina, en materia de ciencia e innovación los fines sólo pueden determinarlos los afectados por las mismas, porque son ellos quienes mejor conocen en qué consiste ese bien (Cortina, 1993), de forma que el establecimiento de los fines no puede recaer en los expertos, que entiende que sí tendrían la función de asesorar y comunicar.

Hoy en día la posibilidad de tomar decisiones morales objetivas -intersubjetivas- pasa por la toma de decisiones responsables por parte de los afectados que, con el debido asesoramiento de los expertos, han de optar teniendo en cuenta no sólo sus intereses individuales, sino los universalizables (Cortina, 1993:262).

Alcanzarlo exige, según Cortina, al menos una triple tarea. En primer lugar, lograr que los expertos comuniquen sus investigaciones a la sociedad, que las acerquen al público, de modo que éste pueda codecidir de forma autónoma, contando con la información necesaria para ello (Cortina, 1993). Una segunda tarea pasa por concienciar a los individuos de que son ellos quienes han de decidir, saliendo de su habitual apatía en estos asuntos. Por último, es necesario educar moralmente a los individuos en la responsabilidad a la hora de tomar decisiones que pueden implicar, no sólo a individuos, sino incluso a la especia. El modelo de comunicación de la RRI que desarrollaremos tendrá en cuenta esta triple tarea a la hora de formar a los grupos de interés y fomentar su participación.

Continuando con Cortina, la gestión de la RRI debe tener presentes los principios de la ética cordial, que pasan por no instrumentalizar a las personas, no poniéndolas al servicio de fines que no han elegido y respectando su autonomía; el principio de las capacidades, que implica empoderar a las personas, punto en el que la comunicación y la divulgación de la ciencia tiene un papel clave; el principio de justicia distributiva, que plantea el modelo de justicia del "interlocutor válido" que consiste en empoderar a las personas para que puedan ser interlocutores válidos como un primer mínimo decente, a partir del que pueden decidir qué consideran básico mediante el 
diálogo; el principio dialógico, que supone tomar como fuente de la obligación moral el tener en cuenta los intereses de los afectados por las decisiones para que "sean ellos quienes, en la medida de lo posible, expresen esos intereses a través del diálogo" (Cortina, 2007:237); y el principio de responsabilidad por los seres indefensos no humanos, que establece la obligación de proteger aquello que es internamente valioso y vulnerable, así como la vida futura de la humanidad.

Una vez expuestas las consideraciones éticas que nos permitirán avanzar hacia una propuesta de definición de la RRI, nos detenemos ahora en algunos de los planteamientos expuestos por los teóricos de la RRI y la Unión Europea, así como en el marco normativo establecido por ésta. Así, en primer lugar, cabe resaltar como el Tratado de la Unión Europea deja clara la voluntad de participación y deliberación por parte de la ciudadanía, señalando que "todo ciudadano tiene derecho a participar en la vida democrática de la Unión. Las decisiones serán tomadas de la forma más abierta y próxima posible a los ciudadanos" (Unión Europea, 2010).

El marco normativo europeo dibujado a partir del fenómeno denominado “ciencia y sociedad” incide en la dimensión ética de la ciencia y la tecnología cuyos rápidos avances pueden tener también implicaciones para generaciones futuras. Por ello, el Plan de Acción Ciencia y Sociedad considera necesario que la investigación sea algo funcional y aceptado por todos los ciudadanos de los Estados miembros y de los países candidatos a la adhesión, respetando las diferencias que supone el entramado cultural que es la Unión Europea, compuesto por tradiciones éticas, religiosas, históricas y filosóficas divergentes (European Commission, 2002).

Posteriormente, el informe realizado por Hillary Sutcliffe a partir del grupo de trabajo organizado por la UE en torno a la RRI en 2011 pone el acento en aspectos que concuerdan con el marco teórico expuesto, destacando la importancia de la participación a lo largo de todo el proceso de investigación; valorando los efectos, riesgos y oportunidades de los avances en el presente y también en el futuro; y generando apertura y transparencia como componentes integrales del procesos de investigación e innovación (Sutcliffe, 2011). El informe señala la participación de los actores sociales en los procesos y resultados de la investigación y la innovación como un componente "clave de RRI", aludiendo a la necesidad de involucrar a los stakeholders en el desarrollo de soluciones beneficiosas para el bien común (Sutcliffe, 2011:8). Encontramos ya en esta primera aproximación alguna de las claves que centrarán 
nuestra propuesta de definición, como son la participación de los posibles afectados tanto presentes como futuros y la comunicación como herramienta de transparencia y apertura.

Por su parte Gilles Laroche, también desde el ámbito de la UE, considera que la RRI hace referencia a cuestiones como los resultados o productos, en términos de sostenibilidad, seguridad y aceptabilidad ética; los procesos y su calidad, teniendo en cuenta la participación de los interesados en base a los principios de rendición de cuentas y transparencia; y la recomendación de utilizar métodos participativos y multidisciplinares (Laroche, 2011). Vemos de nuevo en este caso como se pone el acento en la participación y en la aceptabilidad por parte de los afectados tanto de los procesos de la ciencia y la innovación como de sus resultados. La comunicación vuelve a estar presente como instrumento necesario tanto para la participación como para la rendición de cuentas y la transparencia.

Veíamos también como en las jornadas EscoLab sobre RRI se definía la misma como un proceso transparente e interactivo en el que los actores sociales y los innovadores participan activamente en la construcción de conocimiento y dialogan en términos de aceptabilidad ética, sostenibilidad y conveniencia social de la investigación, la innovación y sus productos comercializables (Cresa.cat, 2014). De nuevo la participación, la comunicación en forma de transparencia y la aceptabilidad de los procesos y sus resultados se repiten como aspectos claves, a los que se suma también el diálogo.

También la definición de Schomberg (2011) pone el acento en la necesidad de aceptabilidad y deseabilidad de los procesos y resultados de la investigación por parte de los diferentes actores sociales y su búsqueda a través de un proceso transparente e interactivo. La comunicación y la interacción son de este modo aspectos claves también para el autor.

La participación e interacción en forma de administración colectiva centra la propuesta de RRI de Stilgoe, para quien "la innovación responsable significa cuidar del futuro a través de la administración colectiva de la ciencia y la innovación en el presente" (J. Stilgoe et al., 2013:1570), poniendo así también el foco en los afectados presentes y futuros de la misma.

Para Bernd Carsten Stahl (2013) la RRI tiene como fin garantizar los resultados de investigación deseables y aceptables, entendiendo que hay una gran cantidad de 
actividades, actores y normas que ya están configurados en relaciones de responsabilidad, por lo que defiende que la RRI no es tanto un nuevo tipo de responsabilidad como una meta-responsabilidad, es decir, una responsabilidad para el mantenimiento, desarrollo y coordinación de las responsabilidades existentes.

La visión de la Comisión Europea más actual, recogida en la publicación Responsible Research and Innovation. Europe's ability to respond to societal challenges (European Commission, 2012), considera que la RRI hace referencia al trabajo conjunto de los actores de la sociedad durante todo el proceso de investigación e innovación con el fin de alinear mejor los procesos y sus resultados con los valores, necesidades y expectativas de la sociedad europea. Participación e interacción son así claves en esta perspectiva de la RRI que hace asimismo referencia a la necesidad de alcanzar la aceptabilidad y deseabilidad de los procesos y sus resultados al alinearlos con los valores, expectativas y necesidades.

Finalmente, cabe recordar que la convocatoria Horizonte 2020 de la Unión Europea parte de la idea de que los intereses y valores de la ciudadanía deben integrarse mejor en la ciencia, la tecnología, las cuestiones relacionadas con investigación e innovación, las políticas y las actividades, con la idea de que esta integración aumentará la calidad, la pertinencia, la aceptación social y la sostenibilidad de la investigación y la innovación. Asimismo, señala que esta integración será posible gracias a la promoción de la RRI entendida como "la participación de los ciudadanos y la sociedad en la investigación y la innovación como un proceso de creación conjunta".

A través de esta aproximación a las definiciones vemos como la aceptabilidad y deseabilidad de la ciencia y la innovación, tanto en sus procesos como en sus resultados, es un aspecto reiterado por diferentes autores. El papel de los afectados y actores sociales es otro de los puntos que se reitera, así como la necesidad de la participación y la interacción de los mismos. Por lo que respecta la comunicación, puede relacionarse con la necesidad de transparencia y apertura defendida en algunas de las diferentes propuesta teóricas analizadas.

La propuesta de modelo de RRI desarrollado en base al enfoque de la Responsabilidad Social de la Escuela de Valencia y las consideraciones de la ética discursiva, así como la lectura de las aproximaciones teóricas a la RRI, nos lleva a una propuesta de definición de la Investigación e Innovación Responsable que bebe directamente del concepto de institución responsable desarrollado por García Marzá 
(2006:91) a la hora de definir cuándo puede considerarse responsable una investigación o una innovación. En cuanto a la RRI entendida como proceso, supone desde este planteamiento desarrollar las condiciones necesarias para alcanzar estas investigaciones e innovaciones responsables, para lo que son necesarias acciones de participación, comunicación e interacción por parte de los diferentes grupos de interés:

\section{DEFINICIÓN:}

La Investigación y la Innovación serán Responsables cuando las decisiones sobre la aceptabilidad y deseabilidad de las mismas y sus resultados pudieran ser aceptadas por todas las personas afectadas y/o implicadas presentes y futuras en un diálogo abierto en condiciones simétricas de participación.

El proceso de Investigación e Innovación Responsable (RRI) supone establecer las condiciones de comunicación interacción y participación, por parte de los diferentes grupos de interés (stakeholders) necesarias para alcanzar dicha aceptabilidad.

La presente propuesta de definición desde la ética dialógica pone el acento en el diálogo como base para alcanzar decisiones sobre la aceptabilidad y deseabilidad de la ciencia y la innovación, tanto por lo que respecta a sus procesos como a sus resultados. Para que tenga un valor moral, en el diálogo deberían participar en condiciones simétricas todos los afectados y afectadas presentes y futuros, lo que introduce la necesidad de valorar los riesgos y oportunidades que tendrán más adelante los procesos de investigación e innovación.

De este modo, a la hora de definir cuándo la investigación y la innovación podrán ser consideradas responsables, se hace hincapié en las condiciones de aceptabilidad y deseabilidad a la que hacían referencia en estos términos o similares Laroche, Schomberg, Carsten o las publicaciones de la propia UE. Todos estos autores, a excepción de Carsten, afirman que la aceptabilidad y deseabilidad deben buscarse tanto en los procesos como en los resultados de la ciencia y la innovación.

Respecto a los actores del diálogo, la definición plantea que sean los afectados y/o implicados, un término que entendemos que abarca desde una perspectiva ética los 
actores a los que Laroche hace referencia como interesados; Shomberg y la Unión Europea en el documento de 2011, como actores sociales o de la sociedad o en la convocatoria de Horizonte 2020 como ciudadanos y sociedad; y Sutcliffe como sociedad. En sus aproximaciones autores como Sutcliffe y Stilgoe introducen asimismo la perspectiva de presente y también de futuro, recogida asimismo en la definición propuesta.

La definición aborda asimismo la RRI planteada como proceso, considerando que el mismo consiste en establecer las condiciones de participación por parte de los stakeholders o grupos de interés necesarios para alcanzar una Investigación e Innovación que pueda considerarse responsable. De este modo, los afectados vuelven a ser los actores del proceso, a partir del establecimiento de grupos de interés siguiendo la teoría de los stakeholders. En cuando a los pilares para alcanzar la investigación e innovación responsable, la definición plantea la comunicación, la participación y la interacción.

La interacción entre los actores sociales o afectados por la ciencia y la innovación es un aspecto que hemos visto reiterado en las aproximaciones teóricas de Shomberg, Stilgoe o la UE. Del mismo modo, la participación es un concepto repetido en la mayoría de aproximaciones a la RRI, como es el caso de Sutcliff, Stilgoe o en los diferentes documentos europeos, empezando por el propio Tratado de la Unión Europea.

Por lo que respecta a la comunicación, el término no aparece recogido con esta denominación en ninguna de las definiciones planteadas. Entendemos no obstante que guarda relación con los conceptos de transparencia y apertura recogidos por Sutcliffe, Shomberg y la UE. Como hemos señalado a lo largo del trabajo, la presente tesis entiende que la comunicación es un requisito moralmente imprescindible para la gestión de la RRI a partir de los principios de la ética dialógica, siguiendo a autores como Habermas, Cortina y García-Marzá; de ahí que consideremos indispensable su inclusión en la propuesta de definición de la RRI como mecanismo necesario para alcanzarla.

Por otra parte, cabe destacar que la definición permite abordar los seis elementos claves que para la Unión Europea conforman la RRI. En primer lugar, la participación pública en el sentido de elegir juntos que, como hemos visto, centra la propuesta de definición de la RRI desde el marco de la ética-dialógica, de forma que se articulen mecanismos de participación de todos los actores sociales. 
Por lo que respecta a la igualdad de género, se trata de una consideración a tener en cuenta a la hora de buscar la participación de todas las personas afectadas e interesadas, teniendo en cuenta la brecha de género que existe a todos los niveles, tanto en el ámbito de la ciencia como en el acceso a la información sobre investigación e innovación y en la sociedad en su conjunto. En este sentido, la dimensión de género debe integrase en cualquier procesos que busque avanzar en una Investigación e Innovación Responsable ya que no se puede dejar de escuchar las voces de las afectadas e interesadas en la ciencia y la innovación.

En cuanto a la educación científica como elemento clave, la necesidad de establecer un diálogo abierto en condiciones simétricas de participación que establece la definición como requisito moral, hace necesario dotar a los afectados y afectadas por la ciencia y la innovación del acceso al conocimiento suficiente para que puedan dialogar en condiciones adecuadas. Como ha quedado reflejado a lo largo de la tesis, la comunicación y divulgación de la ciencia tienen mucho que aportar al incremento de la cultura científica de la ciudadanía. En este sentido, la Unión Europea en su publicación sobre RRI (2011) destaca la necesidad de dotar a los miembros de la sociedad "de los conocimientos y las herramientas necesarias para participar plenamente y tomar decisiones responsables respecto a los procesos de innovación e investigación”. Pero además, desde la perspectiva de la ética y siguiendo a Cortina, resulta asimismo necesario educar en valores morales con el fin de que los participantes en el diálogo puedan buscar intereses universalizables.

El cuarto elemento clave de la RRI para la UE es el acceso abierto a la información científica, elemento que queda vinculada a la necesidad de transparencia y apertura que, como hemos visto, aparecía en las aproximaciones teóricas de diferentes autores, y que requiere de la comunicación para alcanzarse.

La ética es el quinto elemento destacado por la UE, siendo el elemento que sirve de marco a la definición planteada. La propia Unión Europea vincula en este punto la ética a la necesidad de ir más allá de los aspectos legales de obligado cumplimiento, debiéndose garantizar "la relevancia social y la aceptabilidad de los resultados de la investigación y la innovación", una deseabilidad y aceptabilidad que la definición plantea como condición necesaria para que estas puedan ser consideradas responsables. Desde esta perspectiva, la UE considera que la ética no debe ser percibida como una restricción, sino como una forma de garantizar resultados de alta calidad. 
Finalmente, la UE fija como una última dimensión, que sirve de paraguas para todas las anteriores, el buen gobierno, vinculándolo a la necesidad de diseñar la ciencia para y con la sociedad. La ciencia "para" la sociedad tiene que ver, siguiendo a Owen, Macnaghten y Stilgoe (2012), con los efectos de la ciencia y la innovación, y las motivaciones subyacentes de las mismas. Se trata de la decisión de qué se quiere que se haga. Los autores destacan éste como un punto de partida importante para la RRI, que plantea cómo identificar los objetivos de forma ética, incluyente, de manera democrática y equitativa. Se pide la deliberación inclusiva en relación con la dirección en la que ha de avanzar la ciencia y la innovación con el fin de que se oriente desde un principio hacia fines socialmente deseables. Por su parte, la idea de ciencia "con" la sociedad pone el foco en la necesidad de abrir esta reflexión a la deliberación colectiva a través de procesos de diálogo con las diferentes partes interesadas. En este sentido, la definición tiene en cuenta la participación de los afectados, el "con", a la hora de determinar los fines, el "para".

La definición responde asimismo al marco ético planteado, teniendo en cuenta los valores morales principales que articulan al resto y que, siguiendo a Cortina, son la libertad, entendida como participación, como derecho a tomar parte en las decisiones comunes, y también como independencia y como autonomía. En este sentido, la participación y el derecho a decidir en la búsqueda de procesos y resultados de ciencia e innovación aceptables se encuentra en la base de la definición planteada. La misma hace también referencia al principio de igualdad, como condición del diálogo, entendiendo con la autora que todas las personas son iguales en dignidad y merecen igual consideración. Del mismo modo, el diálogo requiere del respeto activo, valor que supone tratar de comprender a aquellos que piensan de forma distinta. La definición de RRI planteada responde asimismo a la solidaridad, no grupal sino universal, haciendo necesario pensar en los intereses de todos los afectados por las acciones. Finalmente, Cortina establece el diálogo como valor moral que compromete a la totalidad de la persona que se introduce en él para convertirse en protagonista de una tarea compartida que se bifurca en dos ramales: la búsqueda compartida de lo verdadero y lo justo; y la resolución justa de los conflictos que van surgiendo a lo largo de la vida (Cortina, 1997b:248). La definición propuesta sitúa al diálogo en el centro para avanzar en ambas direcciones. 
En la definición de RRI propuesta los grupos de interés son los actores fundamentales en los procesos hacia una investigación e innovación más responsables. Por tanto, para seguir avanzando en el desarrollo de la RRI desde el marco de la ética del discurso será necesario identificar quiénes son estos stakeholders. Para ello, a continuación daremos un paso más en esta aproximación al concepto planteado de RRI a través del desarrollo de una propuesta de mapa de stakeholders y la definición de sus posibles intereses en materia de comunicación.

\subsection{LOS GRUPOS DE INTERÉS DE LA CIENCIA}

El concepto de stakeholders ha venido repitiéndose a lo largo de la presente tesis, tanto desde la perspectiva ética de la Responsabilidad Social aportada por la Escuela de Valencia como desde las aproximaciones teóricas de diferentes autores al fenómeno de la RRI. La definición de RRI propuesta hace necesario tener en cuenta a los diferentes stakeholders, para lo que es imprescindible determinar quiénes son. En el presente apartado realizaremos una propuesta de mapa de stakeholders de la RRI partiendo de la literatura científica al respecto. Como hemos visto, la comunicación se entiende como una premisa necesaria para la RRI. Por ello, el presente trabajo pone el foco en la misma, avanzando en el segundo punto en los intereses que cada uno de los grupos de interés pueda tener en materia de comunicación.

\subsubsection{Desarrollo de un mapa de stakeholders de la RRI}

La propuesta de un mapa de stakeholders que planteamos parte del análisis de los grupos de interés determinados por diferentes autores que han abordado el concepto de RRI, así como de la visión de los mismos por parte de la Unión Europea. Pero, previamente, entendemos que resulta necesario detenerse en el análisis del propio concepto de interés en el que descansa el concepto de stakeholders.

Como señala García Marzá (2004), interés significa etimológicamente “estar entre", definiendo así una posición entre una necesidad o un deseo y el logro del bien que se persigue. Esta situación intermedia es la que el autor considera que hace más útil este concepto en relación a los stakeholders, ya que si lo que se tuviera en cuenta fueran las necesidades o deseos no habría forma de encontrar un punto de vista común entre 
todos los grupos. El concepto de interés se relaciona con el lenguaje, constituyendo una articulación lingüística de los deseos y necesidades que ya tienen así en cuenta los límites de la realidad y de las representaciones de los demás. Se añade así a los deseos una base racional. "El interés hace que nuestro mundo subjetivo se 'conecte' en una forma de vida coherente. Las normas se encargarán, por su parte, de definir qué intereses son o no relevantes, y harán posible así la coordinación de la acción", argumenta García Marzá (2004:201).

Este autor diferencia dos significados de interés que dan pie a dos comprensiones diferentes del significado de una empresa u organización ética y que serían extrapolables a un centro de investigación. Desde una visión liberal subjetiva, los intereses son aquello que las personas desean o prefieren y son ellos los que mejor lo conocen. Así, el interés del individuo es sencillamente lo que él dice que es y todos son igualmente válidos y respetables. Sin embargo, desde una visión deliberativa o intersubjetiva, la expresión de un interés, como en la visión liberal, es ya una razón para que se respete y se intente satisfacer, pero lo que convierte una razón en una "buena" razón va más allá de la perspectiva individualista. Para el autor, cabe tener en cuenta el hecho de que podemos estar equivocados sobre cuál es nuestro interés, lo que daría pie a intereses legítimos e ilegítimos.

Desde un enfoque deliberativo, y siguiendo a Morgan, un interés puede considerarse legítimo cuando responde a una "demanda o expectativa justificada que un grupo de individuos puede tener o elevar sobre las consecuencias o resultados de las acciones, políticas o procedimientos de las empresas" (Morgan, 1990:135). Esta definición de interés legítimo es perfectamente aplicable a las acciones, políticas o procedimientos de la ciencia y la innovación, desde un marco de la ética del discurso que remite a la necesidad del diálogo y del acuerdo. Será a través de estos como se pueda alcanzar un interés común, lo que, según García Marzá, no implica necesariamente renunciar a intereses particulares, si no encontrar interpretaciones que integren los intereses individuales dentro de un interés más amplio, capaz de recoger los deseos y necesidades de otras personas implicadas en el proyecto de empresa.

En el ámbito de la investigación y la innovación, al igual que en el empresarial, es posible diferenciar tres tipos de intereses: los intereses particulares, que remiten al mundo interno de cada actor y sólo cruzan el ámbito privado y pasan a convertirse en intereses comunes en el caso de que choquen con otros intereses; los intereses comunes, 
que hacen referencia a la participación de las personas en las diferentes instituciones y organizaciones con las que se estructura la vida social, siendo por tanto expectativas grupales; y los intereses generales, referidos a las expectativas, derechos y obligaciones que tenemos como personas y que son universalizables (García Marzá, 1990).

Una vez realizada esta aproximación al concepto de interés, cabe señalar que desde el planteamiento de la Escuela de Valencia un stakeholder es cualquier individuo o grupo que es afectado o puede ser afectado por la consecución de los objetivos de la organización y que posee expectativas, donde algunas de ellas son universalizables (González y García Marzá, 2006). La cuestión clave en la identificación de los diferentes stakeholders es conseguir diferenciar aquellos que poseen poder comunicativo -capacidad de interlocución- y expectativas urgentes y legítimas. A éstos González y García Marzá les denominan stakeholders centrales, mientras que al resto de stakeholders que poseen sólo dos de estos atributos les denominan latentes, puesto que en cualquier momento se pueden convertir en centrales para la determinación de las responsabilidades de la organización.

A partir de estas cuestiones teóricas, abordamos a continuación las aproximaciones al fenómeno de la RRI que nos ayudarán a realizan nuestra propuesta de grupos de interés de la RRI. La Unión Europea trazó un mapa de los públicos de la "Ciencia en Sociedad" en el informe Challenging the Future of Science in Society (Sinue et al, 2009) en el marco del proyecto Monitoring Activities of Science in Society (MASIS). Como hemos visto en el capítulo dedicado al marco normativo de la RRI, el proyecto MASIS marcó el punto de partida de la renovación del programa "Ciencia y Sociedad" ligado a la denominada estrategia de Lisboa iniciada en el año 2000 para convertir a Europea en una sociedad y economía competente en el siglo XXI. El informe fue elaborado por el grupo de nueve expertos que asesora a la Dirección General de Investigación de la Unión Europea liderados por Karen Sinue. Abordaremos en un primer momento la visión de los stakeholders planteada en el informe MASIS para posteriormente compararla con los grupos de interés establecidos por los diferentes teóricos de la RRI y, a partir de aquí, realizar una propuesta propia del mapa de stakeholders de la Investigación e Innovación Responsable.

Para los expertos del proyecto MASIS (Sinue et al, 2009), en el contexto de la ciencia en sociedad, los stakeholders se definen como aquellos grupos afectados por la interacción entre ciencia y sociedad, un planteamiento que requiere analizar las 
motivaciones de los diferentes grupos de interés. Para los responsables del estudio, en materia de ciencia las preocupaciones e intereses pueden encontrarse en el ámbito económico pero también en otros. En este sentido, señalan las preocupaciones éticas o morales planteadas por grupos religiosos y ONGs, así como la defensa de los Derechos Humanos. Otros grupos de interés están más preocupados por la calidad de vida, la salud o el medio ambiente por lo que respecta a la ciencia en sociedad. También existen los intereses y motivaciones políticos que guían en ocasiones a los gobiernos.

A pesar de entender que todos los miembros de la sociedad pueden ser afectados por la interacción entre ciencia y sociedad, el informe destaca la necesidad de agruparlos en stakeholders que tengan o puedan tener un papel activo. Como hemos visto a partir de la aproximación a la RRI, la participación de la ciudadanía en un sentido amplio ha estado en la agenda de la Unión Europea y en el debate sobre la gobernanza durante varios años, realizándose diferentes acciones de experimentación en participación ciudadana en materia de ciencia e innovación. A partir del estudio de estas y otras acciones realizado por el proyecto MASIS, sus autores plantean un sistema de grupos de interés superpuestos en el que destaca la interconexión y la difusión de los límites. Este mapa de stakeholders estaría formado por investigadores, universidades y centros de enseñanza, gobiernos y parlamentos, compañías privadas, medios de comunicación y museos, tal y como se establece en la figura que recogemos a continuación.

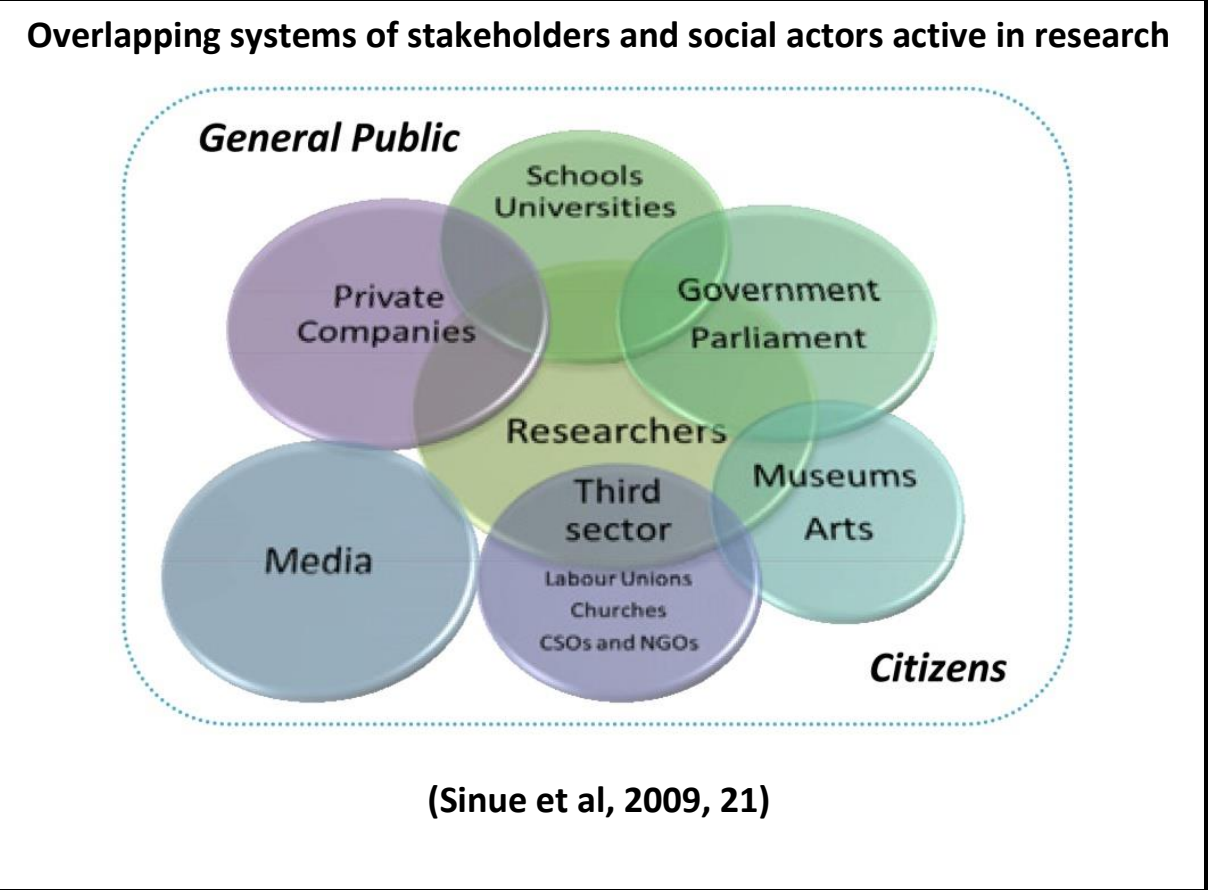


Los autores entienden que no se trata de un mapa completo y definitivo dado el incremento continuado en los últimos años de los stakeholders y la diversidad de sus intereses. Asimismo, destacan la dificultad de identificar a todos los grupos y conocer sus intereses dado que en ocasiones las motivaciones para comprometerse con la ciencia no se revelan públicamente, señalando como ejemplo accionistas o grupos de interés económico que puedan evitar intencionadamente hacer públicos sus intereses, tratándose además de grupos con un considerable poder económico.

Por ello, en el informe realizado en 2009 consideraban necesario el impulso de nuevos estudios que tengan en cuenta los cambios en los instrumentos de poder y cómo los actores perciben sus propios intereses y roles. El modelo de comunicación que se planteará a continuación busca proponer caminos para avanzar en el conocimiento de estos intereses desde un marco ético. Asimismo, de cara a los retos de futuro, los expertos participantes en el informe MASIS recomiendan también aumentar la transparencia respecto a los grupos de interés con el fin de evitar la desconfianza que a menudo genera de forma innecesaria el desafío de las acciones públicas de participación, una cuestión que también buscaremos abordar a través de un modelo que encuentra su base en la publicidad y la transparencia.

Más allá de los retos futuros y del reconocimiento de que no se trata de un mapa de stakeholders cerrado, entendemos que la propuesta de grupos de interés para la ciencia en sociedad encabezada por Karen Sinue resulta de interés para realizar una primera aproximación a los posibles stakeholders de la RRI. Profundizando en la bibliografía específica en materia de RRI, vemos como la mayoría de autores y organizaciones muestran una notable coincidencia a la hora de señalar cuáles son los grupos de interés de la ciencia.

Recuperando los grupos considerados como stakeholders de la ciencia y la innovación responsables por diferentes autores, vemos como Carsten incluye a la hora de hacer referencia a los stakeholders a investigadores, industria, administraciones políticas y sociedad civil (Carsten, 2013). Por su parte, Owen habla de científicos, innovadores, socios empresariales, financiadores de la investigación y administradores políticos (Owen et al, 2012:754).

La Unión Europea, en sus publicaciones oficiales sobre RRI, hace referencia a la participación de todos los actores sociales, incluyendo entre ellos a investigadores, industria, administraciones políticas y sociedad civil (Publications Office, UE, 2012). 
En la convocatoria Horizonte 2020 la Unión Europea incluye entre los actores también a las empresas, ciudadanos y organizaciones del tercer sector, correspondiéndose estos dos últimos con la sociedad civil contemplada en su conjunto en el documento anterior.

También en documentos previos, como el Plan de Acción Ciencia y Sociedad (European Commission, 2002), se señala que el establecimiento de un diálogo a nivel europeo supone una cooperación estrecha entre un gran número de partes interesadas, entre las que ya menciona a organizaciones de investigación, autoridades públicas, medios de comunicación, ciudadanos, sociedad civil, empresas, etc. Dos años antes, el documento Ciencia, sociedad y ciudadanos europeos (European Commission, 2000) recogía la necesidad de crear nuevas formas de relación mutua entre científicos, autoridades políticas, responsables económicos e industriales y ciudadanos.

Como vemos, existe una gran unanimidad a la hora de determinar los grupos de interés de la ciencia, a pesar de que puedan existir pequeños matices en la denominación, reiterándose por parte de los diferentes autores y organismos cuatro grupos claros:

- Investigadores, innovadores y comunidad científica en su conjunto.

- Responsables políticos, autoridades políticas y administración públicas.

- Industrias, empresas y compañías privadas.

- Sociedad en un sentido amplio, que iría desde el tercer sector hasta la ciudadanía.

También el planteamiento desarrollado en el proyecto MASIS contempla a los investigadores, los gobiernos y las compañías privadas como grandes grupos de interés. Respecto la sociedad civil, como argumentaremos más adelante, entendemos que aparece vinculada al stakeholder establecido por el informe como tercer sector. Por lo que respecta a los museos, centros de educación y otras instituciones culturales, consideramos que podrían incluirse asimismo en la sociedad civil entendida como gran grupo, más aún teniendo en cuenta que no aparecen como grupos diferenciados para ninguno de los demás autores que han abordado el tema de la RRI. Lo mismo ocurre con los medios de comunicación, establecidos en el informe MASIS como stakeholder. Entendemos que los medios de comunicación externos a los centros de investigación e innovación, tanto generalistas como especializados, forman parte de la sociedad civil y 
por lo tanto comparten sus intereses, independientemente de que puedan tenar una función comunicadora de especial relevancia. En el caso de los servicios y unidades de comunicación de los centros de investigación e innovación, formarían parte del grupo de la comunidad científica en su sentido amplio, siendo transmisores de la ciencia y la innovación a partir de sus respectivas organizaciones.

De este modo, la propuesta de mapa de stakeholders de la RRI de la presente tesis plantea establecer como grupos de interés de la Investigación e Innovación Responsable aquellos stakeholders en los que existe una mayor unanimidad, estando presentes de uno u otro modo en todas las aproximaciones teóricas a la RRI. Se establecen así cuatro stakeholders de la RRI que serían centrales al tener capacidad comunicativa e intereses legítimos y urgentes. Los stakeholders quedan agrupados bajo las denominaciones: comunidad científica, Administración pública, empresas y sociedad civil. Se trata de cuatro grandes grupos en los que, como desarrollaremos a continuación, tienen cabida diferentes perfiles. Al igual que ocurría en el sistema de grupos de interés planteado por el informe MASIS, entendemos que se trata de grupos de interés interconectados y cuyos límites pueden difuminarse en algunos puntos.

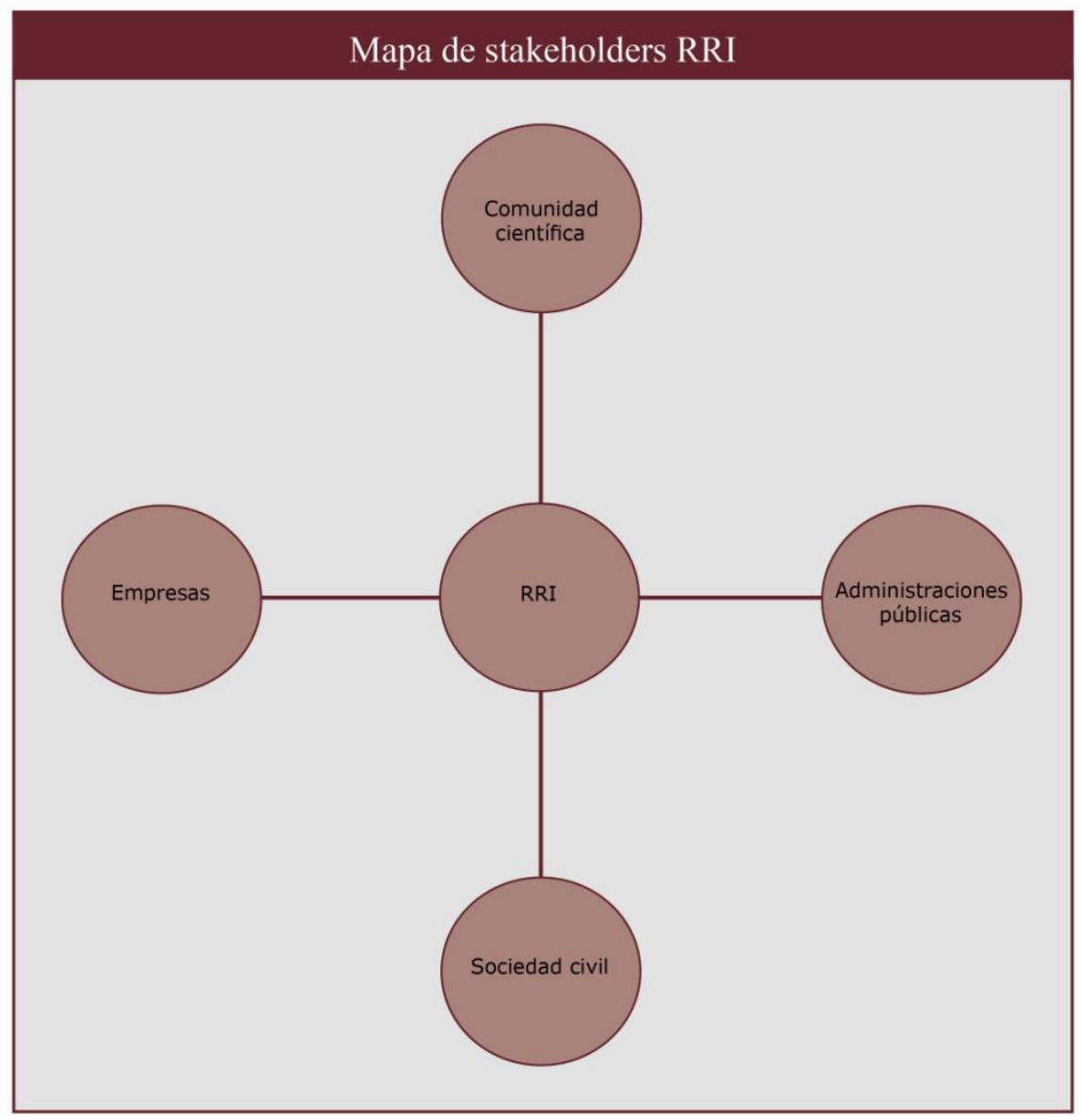


Vemos así como el mapa de stakeholders de la RRI queda establecido en base a cuatro grandes grupos de interés agrupados en torno a dos ejes en cuyo centro se encuentra la Investigación e Innovación Responsable, y que ponen en relación a la comunidad científica con la sociedad civil, las empresas y las Administraciones Públicas. Se trata de un mapa que define los stakeholders generales de la RRI, de forma que posteriormente cada universidad o centro de investigación e innovación deberá desarrollarlos y concretarlos en función de sus características y estructuras específicas.

A continuación abordaremos cada uno de estos grandes grupos en su papel de stakeholders de la RRI.

\section{- Comunidad científica}

La totalidad de autores y textos que tratan de definir los stakeholders de la ciencia hacen referencia a los investigadores (citándolos algunos como científicos) como principal actor de la ciencia. Si hablamos de Investigación e Innovación, en este segundo caso el actor principal serían los innovadores. En nuestro caso, agruparemos a este primer stakeholder bajo una denominación que consideramos más amplia como es comunidad científica, que incluye a todos sus miembros como agentes encargados de ejecutar el proceso de investigación e innovación. Dentro de la comunidad científica cabe diferenciar asimismo entre el personal propiamente investigador e innovador y los diferentes estamentos que incluyen figuras como responsables de grupos de investigación, de departamentos, de centros de investigación, etc. así como los diferentes órganos de gobierno de la investigación, que presentan características propias, no teniendo por qué estar constituidos necesariamente en su totalidad por personal investigador o innovador. Es el caso, por ejemplo, de los equipos de gobierno de Universidades, las Oficinas de Transferencia Tecnológica, los Parques Científicos y Tecnológicos, los profesionales de la comunicación y divulgación de la ciencia, etc. En este sentido, cada centro o universidad debería especificar los subgrupos de stakeholders dentro de la comunidad científica teniendo en cuenta sus especificidades.

La comunidad científica puede verse como el grupo de interés más directamente involucrado en la RRI. Sin embargo, desde el proyecto MASIS (Sinue, 2009) destacan como, a pesar de percibirse a sí mismos como los actores principales de la ciencia, sólo un número limitado de investigadores e investigadoras participa a nivel individual en las 
interacciones de la ciencia y la sociedad. Así, la participación del personal investigador e innovador en los temas de ciencia e innovación se produce más habitualmente a nivel asociativo o colectivo. En el caso de las universidades y centros de investigación, esta participación está además muy reglada por los estamentos establecidos (Sinue, 2009).

Los autores del informe MASIS reconocen asimismo el papel activo de las universidades en el ámbito de la ciencia y su comunicación, otorgándoles un papel fundamental. Para estos expertos, las universidades e instituciones de educación superior representan grupos de interés de la ciencia en la sociedad, en parte debido a su papel en la investigación, y en parte por su labor en el desarrollo de la educación institucional.

\section{- Empresas}

Bien sea con la denominación de industria, de empresa o de socios comerciales, todos los autores que han abordado la RRI hacen referencia a la participación de organismos económicos del sector privado como stakeholder que puede resultar beneficiario de los avances de la ciencia y la innovación y, en cualquier caso, deviene afectado por sus avances. Se trata por tanto de un segundo grupo de interés que recogemos bajo el paraguas genérico de empresas. En algunas ocasiones, las empresas son además financiadoras de la investigación y la innovación, ya sea a través de sus propias acciones o mediante la colaboración y financiación a terceros, variando en estos casos sus expectativas, objetivos y responsabilidades.

Desde el informe MASIS (Sinue, 2009), los expertos de la Unión Europea destacan como las empresas y sus asociaciones son un stakeholder muy activo en el campo de la ciencia en sociedad. En este sentido, resaltan como en ocasiones sus miembros adquieren un papel protagonista en los debates públicos sobre la política de investigación, se convierten en interlocutores de los medios de comunicación y desarrollan informes especiales con recomendaciones para nuevas iniciativas políticas.

Los expertos encabezados por Sinue entienden que la principal preocupación de este stakeholder es la necesidad de una mayor cooperación, la comunicación y la transferencia de la investigación producida en centros públicos de ciencia como las universidades y su uso por parte del sector privado. El papel de los stakeholders del sector empresarial ha ido cobrando cada vez mayor importancia a nivel europeo desde 
la Estrategia de Lisboa del año 2000 y, especialmente, a raíz del Acuerdo de Barcelona COM 2002, desde el que se instó a las empresas privadas de toda Europa a aumentar su inversión en investigación hasta alcanzar al menos el 2\% del PIB nacional. Como resultado de esta evolución, se ha incrementado el número de empresas que participan en proyectos de investigación con centros públicos.

Recientemente, incluso las pequeñas y medianas empresas (PYME) están ampliamente reconocidas como partes interesadas de la ciencia en sociedad, y su potencial en investigación e innovación está ganando importancia en la construcción de la sociedad del conocimiento (Sinue, 2009).

\section{- Administraciones públicas}

Los responsables políticos y administraciones públicas son asimismo un grupo que se repite en todas las aproximaciones a la RRI y que cobra especial relevancia como gestor y financiador público de la ciencia a nivel regional, nacional o internacional. Al igual que en el caso de las empresas, en numerosas ocasiones las administraciones son asimismo financiadoras de la $\mathrm{I}+\mathrm{i}$.

A la hora de analizar los intereses y motivaciones de este grupo de interés, el informe MASIS señala como, tradicionalmente, los gobiernos nacionales han sido los responsable de las inversiones públicas en investigación e innovación y del desarrollo de los centros nacionales de ciencia. Los autores del informe entienden que los gobiernos responsables de las políticas de ciencia, incluidos ministerios, Comisión Europea y gobiernos locales, tienen grandes expectativas y mucho en juego en la interacción entre ciencia y sociedad, señalando que las políticas científicas y de investigación se formulan cada vez más desde todos los niveles, desde el local y el regional al nacional y el europeo.

En el caso concreto de los organismos de gobierno europeo, cabe señalar su papel cada vez más importante como actores de los programas de ciencia en sociedad, posicionándose como un actor muy activo. El papel de la Unión Europea como organismo regulador de las políticas científicas y de las inversiones públicas se ha visto además reforzado a través de la implementación de los Programas Marco y actualmente con la convocatoria Horizonte 2020. 
Por lo que respecta a los ministerios de ciencia, el informe MASIS destaca su importancia en la gestión de la ciencia y el desarrollo de políticas de investigación con el fin de que las inversiones en $\mathrm{I}+\mathrm{D}$ se conviertan en un medio para el crecimiento económico. Por tanto, entienden que la mayoría de ministerios participan activamente en los debates públicos sobre ciencia y mantienen regularmente contactos con los medios de comunicación debido a su interés en el impacto de sus iniciativas y a su preocupación por su situación en el contexto europeo.

Por lo que respecta a los partidos políticos, en la mayoría de los estados miembros europeos han estado proponiendo planes más o menos específicos para las inversiones en centros de ciencia, abogando por una mayor inversión en actividades de investigación e innovación.

\section{- Sociedad civil}

Finalmente, el cuarto grupo presente en las diferentes aproximaciones y en el que hace especial hincapié el concepto de RRI desarrollado a partir de los programas "Ciencia en sociedad" de la Unión Europea es precisamente el de sociedad, a la que los diferentes autores hacen referencia a través de términos como sociedad civil, ciudadanos o ciudadanía. En nuestro caso, adoptaremos el término sociedad civil al entender que, como hemos visto en el segundo capítulo de la tesis, incluye tanto a la ciudadanía a nivel individual como al ámbito de interacciones estructurado en torno a una red de asociaciones y organizaciones (García Marzá, 2008:40).

De este modo, en este grupo de interés se incluirían las organizaciones del tercer sector a las que hacen referencia el programa Horizonte 2020 y el proyecto MASIS. Los expertos participantes en este último reconocen que la diversidad de las entidades que tienen cabida en el denominado tercer sector hace difícil su análisis, al utilizar tercer sector como término general para abarcar a diversos grupos de interés de la ciudadanía, que van desde las organizaciones de la sociedad civil y los sindicatos de trabajadores a las organizaciones religiosas y las redes informales de ciudadanos. Cada uno de estos grupos tiene motivaciones diferentes. En la actualidad, las organizaciones del tercer sector se encuentran a menudo involucradas en las acciones de ciencia en sociedad, ya sea debido a las preocupaciones morales, éticas e ideológicas que plantea la ciencia y la innovación o bien con el fin de representar ciertos intereses de los grupos de la 
sociedad. En este sentido, desde el proyecto MASIS destacan que la participación ciudadana no suele ser individual, sino que habitualmente se realiza a través de movimientos asociativos.

In general, some citizens are more concerned than others and may express their concern by participating actively in public debates. In reality though, very few people participate as individual citizens. Most of these citizens are organized in non-governmental organizations, being members of social organizations that reflect their interests or ideological ties (Sinue, 2009:23).

En el ámbito de la sociedad, los autores destacan el papel activo de los grupos religiosos en los procesos de deliberación de ciencia en sociedad, especialmente cuando se trata de debates que abordan cuestiones éticas o morales. En este sentido, señalan que la Iglesia Católica es excepcionalmente activa en el establecimiento de la agenda de debates éticos en temas como la investigación con células madres, los organismos genéticamente modificados y el desarrollo de otras tecnologías basadas en la ciencia.

Grupos de reflexión, redes ciudadanas y defensores de derechos civiles son también organizaciones sociales que se han vuelto asimismo más visibles e influyentes en la agenda pública de la ciencia, señalan, destacando la proliferación de estos grupos de interés organizados en redes virtuales o presenciales tanto a nivel nacional como internacional.

Por otra parte, otro colectivo destacado por los expertos del proyecto MASIS sería el formado por la comunidad educativa. Si bien entendemos que las universidades dada su función investigadora aparecen vinculadas al grupo de interés de la comunidad científica, cabe pensar que, junto con los demás centros de enseñanza, forman también parte de la sociedad civil, viendo de nuevo como los límites entre unos grupos y otros se difuminan. En este sentido, desde el informe se destaca el hecho de que el estudiantado de todas las instituciones educativas está directamente expuesto a la ciencia y al uso del conocimiento científico y sus resultados. Por ello, consideran que se trata de stakeholders cruciales en la interacción entre la ciencia y la sociedad en general. Por lo que respecta al caso concreto del profesorado de primaria y secundaria y sus asociaciones, señalan su importancia como actores en el campo de la sociedad, especialmente cuando se trata de la educación científica y la popularización de la misma. Por otra parte, añaden que su papel es también fundamental en la comunicación de los aspectos éticos de la ciencia. 
Dentro de la sociedad civil, consideramos que cabe también considerar que cuentan con una motivación muy específica aquellas personas o asociaciones que pueden resultar directamente beneficiadas por cada una de las investigaciones o innovaciones específicas. A pesar de que en algunos casos los beneficiarios puedan ser todos los miembros de la sociedad en su conjunto, en muchas ocasiones los beneficiarios directos dependerán del ámbito de actuación, por ejemplo, el estudio de una determinada enfermedad, de un cultivo o de una mejora social para un colectivo específico.

Como hemos señalado, los medios de comunicación externos a los centros de investigación son un perfil de especial relevancia dentro de la sociedad civil dado su papel en la transmisión de las informaciones sobre ciencia e innovación y también como altavoces de las expectativas, intereses y posturas de los demás grupos de interés como gobiernos, empresas, asociaciones o la propia comunidad científica. Desde el informe MASIS se destaca que si bien la función principal de los medios de comunicación sigue siendo la difusión de la ciencia para el desarrollo de la sociedad del conocimiento, siendo su labor esencial la difusión de los resultados de la ciencia y la investigación a la sociedad, en muchas ocasiones su función va más allá, jugando también un papel clave en el establecimiento de la agenda para el discurso de la ciencia en la sociedad.

Una vez establecido el mapa de stakeholders y abordado cada uno de los cuatro grupos, entendemos que resulta de interés dado el tema de la presente tesis aproximarnos en el siguiente punto a cada uno de ellos desde la perspectiva de la comunicación de la ciencia y la innovación.

\subsubsection{Comunicación, los intereses en juego}

La participación de los implicados a la que hacen referencia los diferentes autores que han abordado el fenómeno de la RRI tiene en la comunicación uno de sus principales pilares. Como hemos visto a lo largo del trabajo, la responsabilidad basada en la ética dialógica tiene como condición el diálogo entre los implicados en condiciones adecuadas, lo que requiere de la comunicación, aspecto que desarrollaremos ampliamente en el siguiente capítulo. No obstante, en el presente punto, entendemos que resulta de interés abordar las motivaciones, intereses y expectativas que 
cada uno de los cuatro stakeholders de la RRI establecidos tienen en materia de comunicación de la investigación y la innovación. A pesar de que para conocerlos la vía más adecuada será establecer un diálogo con los diferentes grupos, el estudio realizado hasta el momento, la documentación bibliográfica y la experiencia profesional en el campo de la CPC, nos permite realizar una aproximación a los mismos. Así, tras unas breves pinceladas teóricas que vienen a sumarse a los argumentos ya expuestos sobre la importancia del aspecto comunicativo en el desarrollo de la RRI, expondremos los posibles intereses en la CPC de cada uno de los stakeholders.

A la hora de hablar de grupos de interés, Carsten hace hincapié en cómo la RRI ha puesto de manifiesto que la investigación y la innovación deben ser beneficiosas para todas las partes interesadas y por lo tanto estas deben participar en todos los aspectos de la RRI a lo largo de todo el proceso.

One frequently cited aspect of RRI is that it moves beyond the researcher and expert-centred view of research and innovation and explicitly includes a broader set of stakeholders. This is based on the recognition that research and innovation need to be beneficial to all stakeholders, who should thus be involved in all aspects of RRI. This includes early (upstream) engagement as well as midstream and downstream activities (Carsten, 2013).

Autores como Andri W. Stahel apelan a situar el debate sobre el desarrollo tecnológico - que consideramos extrapolable al debate científico e innovador - en el marco de la razón comunicativa. Así, Stahel alerta de la preponderancia en los debates sobre ciencia actuales de los procedimientos propios de la razón instrumental, a diferencia de los desarrollados en las sociedades tradicionales que considera que se encontraban limitados por un marco cultural y ético más amplio.

Lo que podemos ver en la actualidad es que los procedimientos propios de la razón instrumental son claramente hegemónicos en estos debates. Se hacen así constantes llamadas a la legitimidad científica de los distintos discursos, más que referencia a sus componentes éticos (W. Stahel, 2004:60).

En detrimento de las valoraciones éticas, en la política moderna el autor considera que son cada vez más los criterios de eficiencia y de resultados los que pasan a ser empleados para valorar las distintas políticas. Stahel hace también referencia al empleo creciente de la persuasión y manipulación informativa como instrumento fundamental en el debate entre distintas opciones éticas y políticas. Por todo ello, defiende no limitar más la cuestión del desarrollo técnico al campo de la razón 
instrumental, sino situarla en el marco de la razón comunicativa, del debate dialéctico entre los distintos actores implicados y afectados. Al respecto, destaca que "esto no supone que en estas discusiones la razón instrumental no tenga cabida, sino que ésta asume un papel subordinado a los valores éticos y a las opciones sociales en ellos basadas" (W. Stahel, 2004:74), reflexiones que concuerdan con la utilidad de la ética del discurso como marco para la RRI y con la relevancia de la comunicación en este marco ético y político.

El autor hace hincapié en la necesidad de democratizar la información para poder entre todos, de forma colectiva, plantear los límites éticos. Se ha de abordar en este punto el derecho tanto a recibir información adecuada, transparente y fidedigna, como el derecho a tener voz.

Tras realizar esta breve aproximación teórica a la importancia de la comunicación en la relación con los grupos de interés, pasamos a abordar las posibles expectativas de los diferentes stakeholders de la RRI en materia de comunicación. Si bien la siguiente relación no cierra todos los intereses posibles de cada uno de los stakeholders y su relación con la comunicación de la ciencia y la innovación, sí recoge algunos que entendemos que se encuentran entre los principales:

\section{- Comunidad científica}

Los investigadores e innovadores y los centros en los que se inscriben tienen, como es obvio, una especial relevancia en la comunicación de la ciencia en primer lugar como primeros emisores del mensaje. Independientemente de que en la comunicación de la investigación y la innovación al público participen profesionales de la comunicación y la divulgación de la ciencia; el paso inicial siempre dependerá de los únicos que cuentan con el conocimiento científico y son conocedores del estado y los posibles resultados de las investigaciones. Sin su implicación, no es posible ninguna comunicación.

Más allá de la importancia de su papel como emisores, lo que los investigadores e innovadores pueden esperar de la comunicación de la ciencia es una correcta y adecuada información sobre su labor a los restantes grupos de interés. En este sentido, agentes de comunicación como las Unidades de Cultura Científica y de la Innovación promovidas por la FECYT, trabajan para eliminar los recelos que, como hemos visto, en 
muchas ocasiones la comunidad investigadora ha mantenido ante la difusión de informaciones erróneas. Por ello, el Libro Blanco de las UCC+i destaca la labor de los profesionales de la comunicación a la hora de concienciar y formar a la comunidad científica.

Tradicionalmente, los investigadores se han mostrado reticentes a compartir el resultado de su trabajo con los medios de comunicación por miedo a la publicación de información errónea o distorsionada. Esta actitud dificulta que la ciudadanía conozca la importante labor de generación de conocimiento que se realiza en los centros de investigación y sus múltiples aplicaciones en beneficio de la sociedad. Por tanto, parte del trabajo de las UCC+i como entidades de transmisión del conocimiento estará dirigido a concienciar, asesorar, formar e informar a la comunidad científica (FECYT, 2012:16).

La comunicación por parte de la comunidad científica en este sentido debe ser adecuada a los diferentes públicos, desde los más especializados a los menos. Esta comunicación será clave para que la interacción con los demás stakeholders resulte efectiva y provechosa. Precisamente la comunidad científica aparece como el primer destinatario de las UCC+i de cara a llevar a cabo una necesaria labor de concienciación sobre la necesidad de comunicar y con los que destaca la importancia de establecer una relación de colaboración para garantizar la calidad de las acciones.

$\mathrm{Al}$ abordar la Comunicación Pública de la Ciencia hemos visto también algunas de las razones e intereses que los investigadores e investigadoras pueden tener en la difusión de sus conocimientos y avances. Entre ellas se encuentran los propios beneficios que puede suponer gracias al incremento del prestigio y la posibilidad de generar una mayor confianza y apoyo a la comunidad científica y a la ciencia. Veíamos también entre las motivaciones de la comunidad científica la posible contribución que puede suponer la comunicación para la captación de recursos. Existen asimismo investigadores concienciados de la necesidad de rendir cuentas a una sociedad ante la que se debe justificar el gasto público, así como de la importancia de transferir los resultados alcanzados.

La comunicación científica basada en el enfoque de ciencia y sociedad puede servir además para que la comunidad científica conozca los valores, necesidades y expectativas de los restantes stakeholders y alinee a los mismos sus procesos y resultados. En el caso de los Órganos de Gobierno de los centros de investigación e innovación, su posición como responsables de la gobernanza lleva a que tengan un papel clave a la hora de respaldar la comunicación de la ciencia como uno de los pilares 
fundamentales y estratégicos de los centros de investigación, tanto de cara a hacer pública su gestión como para establecer canales de diálogo con los grupos de interés. Asimismo, su labor como gestores les convierte en públicos claves con los que establecer canales de comunicación adecuados.

Otros actores claves dentro de la comunidad científica serían los profesionales de comunicación de la ciencia propios de los centros de investigación e innovación, que actúan de transmisores de todo aquello relacionado con la ciencia y la innovación tanto a nivel interno como externo, llegando así a los diferentes grupos de interés. Desde la perspectiva de ciencia y sociedad, los expertos en comunicación de los centros tienen un papel fundamental a la hora de establecer canales bidireccionales que permitan hacer llegar a la comunidad científica las voces de todos los stakeholders.

\section{- Empresas}

Las empresas encuentran en la gestión de la comunicación de la ciencia y la innovación una fuente de información que puede resultarles de gran interés en su mejora y desarrollo. Asimismo, aquellas que realizan o financian acciones de $\mathrm{I}+\mathrm{D}+\mathrm{i}$ pueden servirse de la comunicación para dar a conocer sus avances y aportaciones sociales. De este modo contribuyen a alcanzar un conocimiento más abierto, siempre dentro de las limitaciones derivadas de ser resultados que responden a intereses privados. A la vez, dan a conocer una faceta de la empresa o industria que contribuye a mejorar su imagen ya que la investigación y la innovación es un valor añadido que mejora la reputación corporativa.

Como grupo de interés destinatario de la comunicación de la ciencia y la innovación, en Públicos para la ciencia Pere-Joan Cardona pone el acento en la importancia del público empresarial, un público que considera que requiere "un tipo de explicaciones muy específicas y un esfuerzo comunicador muy particular para poder generar un modelo de éxito y de esperanzas comerciales" (Cardona, 2014:67). En este sentido, parece evidente que el establecimiento de un diálogo adecuado con las empresas e industrias como grupo de interés puede ayudar a conocer sus intereses y demandas de cara al desarrollo de la ciencia y la innovación, además de favorecer la comunicación y la transferencia de los resultados alcanzados. 
Al igual que la comunidad científica, las empresas también se encuentran entre los destinatarios de las UCC+i según establece su Libro Blanco (FECYT, 2012:15-20). En este sentido, cabe destacar la coincidencia existente ente los grupos de interés establecidos en la propuesta de mapa de stakeholders de la RRI y los públicos destinatarios de las acciones de las UCC+i. En el caso concreto de las empresas, el Libro Blanco destaca la importancia de que cuenten con una información "correcta y suficiente".

\section{- Administración pública}

Si hay un grupo que domina la comunicación entre los stakeholders de la RRI, éste es probablemente el de los responsables políticos y la Administración que tienen en la comunicación una de sus estrategias y pilares fundamentales de relación con la ciudadanía. Por lo que respecta a la comunicación de la ciencia, los responsables políticos pueden encontrar en ella una fuente de información indispensable para conocer y estar al día sobre las acciones que se están llevando a cabo en materia de investigación e innovación. La comunicación de la ciencia contribuye a que políticos y gestores de las administraciones públicas aumenten su cultura científica, una alfabetización que resulta necesaria para una adecuada participación en los debates.

Además, como gestores y financiadores de políticas científicas, responsables políticos y administraciones tienen en la comunicación de la ciencia el canal necesario para hacer públicas sus actuaciones y mantener informados a los restantes stakeholders de la RRI. Asimismo, la comunicación debe establecer canales para que los responsable políticos puedan escuchar las posiciones de los restantes grupos de interés respecto a cuestiones de ciencia.

Como principales financiadores de la investigación, entre los intereses de administración en la comunicación de la ciencia se encuentra el hacer visibles las investigaciones e innovaciones que se están costeando, así como sus aportaciones de cara al desarrollo de la sociedad. Para favorecer la RRI es además determinante que aquellos que financian la investigación y la innovación estén dispuestos a establecer canales de comunicación con los demás stakeholders a la hora de abordar incluso en qué proyectos invertir, más aún si se tiene en cuenta que se trata de dinero público. En este sentido, autores como Stilgoe admite que el fomento de la participación puede suponer 
tanto un reto como un inconveniente para las instituciones que financian la investigación.

In the post-financial crisis period of austerity that Nowotny describes, we will hear the question 'is public engagement worth it?' increasingly often. This is almost impossible to answer, especially as the most important benefits of engagement may be those that are challenging and inconvenient for the institutions that fund it (Stilgoe et al, 2014:7).

Las administraciones públicas se encuentran también entre los destinatarios de las acciones de comunicación de las UCC+i, destacando el Libro Blanco su potencialidad dada la importancia de que sus órganos de gobierno conozcan la actividad investigadora para así poder fundamentar sus políticas científicas en datos más rigurosos y actualizados.

\section{- Sociedad civil}

Como se ha puesto de manifiesto a lo largo del presente trabajo, son cada vez más las acciones que buscan incrementar la participación ciudadana en las decisiones y procesos de investigación e innovación. Para que esta se dé en condiciones adecuadas es imprescindible la comunicación de la ciencia. En este sentido, lo que la sociedad civil, incluidos los diferentes organismos que defienden la protección de aspectos como los Derechos Humanos o la sostenibilidad medioambiental, puede esperar de la comunicación de la ciencia es que establezca los canales más adecuados para que la información llegue de forma adecuada, veraz y comprensible y favorezca a su vez la interacción. Sobre este último aspecto, resulta de gran interés que la comunicación de la ciencia establezca canales de retorno que faciliten la interacción con los diferentes stakeholders y de forma especial con la sociedad civil.

Respecto a las cuestiones a las que la sociedad civil espera que dé respuesta la comunicación de la ciencia y la innovación, resultan también de interés algunos estudios como el recogido por Stilgoe en base al análisis transversal realizado en Reino Unido sobre las preocupaciones del público en materia de innovación. Para su desarrollo se realizaron 17 grupos de diálogo, categorizándose posteriormente las preguntas según su relación con los productos, los procesos o los propósitos de la innovación. Reproducimos a continuación la tabla con los resultados obtenidos (Stilgoe, 2013:1570). 
Table 1

Lines of questioning on responsible innovation.

\begin{tabular}{lll}
\hline Product questions & Process questions & Purpose questions \\
\hline How will the risks and benefits be distributed? & How should standards be drawn up and applied? & Why are researchers doing it? \\
What other impacts can we anticipate? & How should risks and benefits be defined and measured? & Are these motivations transparent and in \\
& & the public interest? \\
How might these change in the future? & Who is in control? & Who will benefit? \\
What don't we know about? & Who is taking part? & What are they going to gain? \\
What might we never know about? & Who will take responsibility if things go wrong? & What are the alternatives? \\
\hline
\end{tabular}

(Stilgoe, 2013: 1570)

Como vemos, gran parte de las preguntas tienen que ver con los riesgos y beneficios que conlleva, así como con los impactos y los efectos que pudiera tener en un futuro. La ciudadanía también se pregunta sobre los agentes responsables: quién tiene el control, quién forma parte del proceso, quién asumirá las responsabilidades si las cosas no van bien y quiénes serán los beneficiarios. Respecto a los propósitos de la investigación y la innovación, los ciudadanos se cuestiona las razones que llevan a los científicos a realizarlas y si estas motivaciones son transparentes y responden al interés público, así como las posibles alternativas. Stilgoe propone hacer frente a estas preguntas mediante cuatro dimensiones de la innovación responsable que serían anticipación, reflexividad, capacidad de respuesta e inclusión.

A la hora de enfocar una comunicación de la ciencia que busque favorecer la participación de la ciudadanía en la toma de decisiones sobre el proceso investigador resultará necesario responder de forma eficaz y comprensible a estas y otras preguntas que se puedan plantear.

Como hemos indicado a la hora de establecer los grupos de interés de la RRI, los beneficiarios de la investigación son una parte de la sociedad civil que presenta algunas especificidades. Las personas y colectivos que se prevé que se beneficiarán de los resultados alcanzados por una investigación determinada, como miembros de la sociedad civil que son, comparten las mismas expectativas en líneas generales. No obstante, estas se ven afectadas por el hecho de esperar unos beneficios específicos del desarrollo científico, siendo directamente afectados por los resultados de la investigación. Así, cabe pensar que las demandas hacia la comunicación de la ciencia serán más elevadas ante el mayor interés por recibir una información suficiente y adecuada. El hecho de que les afecte directamente la investigación también los convierte en un colectivo con el que resulta necesario establecer canales de comunicación que pueden ser tanto presenciales como digitales a través de las nuevas tecnologías y que, en cualquier caso, deberían ser bidireccionales. 
Por otra parte, como grupo de interés que es también el principal destinatarios de las acciones de comunicación de la ciencia, cabe profundizar también en un acercamiento a su papel como público de la ciencia. En este sentido, el Libro Blanco de las UCC+i destaca la necesidad de establecer dentro de la sociedad diferentes colectivos a la hora de considerarlos como destinatarios de la ciencia ya que, como hemos visto, los Estudios de Percepción Social de la Ciencia de la FECYT, ponen de manifiesto importantes diferencias según la edad, género y nivel de estudios de los ciudadanos y ciudadanas ante determinadas cuestiones relacionadas con la cultura científica y tecnológica y su comunicación. Por ello, el Libro Blanco plantea la necesidad de segmentar de forma más detallada los públicos. Así, entre los destinatarios de la comunicación de la ciencia establecidos por las UCC+i y que entendemos que formarían parte del grupo de interés de la sociedad civil se encuentran (FECYT, 2010):

- Jóvenes y público infantil, destinatarios que destacan por su capacidad para interesarse, así como por ser un público clave de cara al futuro.

- Personal docente universitario y no universitario, resaltando su papel clave dada su capacidad de influencia en el alumnado.

- Las entidades de difusión cultural, como organizaciones que pueden proporcionar espacios, contenidos y actividades relacionados con la difusión de la ciencia y la cultura, el ocio y el entretenimiento.

- Colectivos sociales y políticos, sobre los que destaca su capacidad de generar opinión sobre otros colectivos y contribuir a determinar o participar en los procesos de tomas de decisiones políticas y sociales.

- Otros colectivos específicos que puedan resultar de interés como, por ejemplo, amas de casa, jubilados, desempleados, etc.

Desde la perspectiva planteada en la presente tesis, los medios de comunicación tendrían también un papel fundamental dentro de la sociedad civil. En este sentido, desde el Libro Blanco de las UCC+i se destaca su papel como intermediarios de estas Unidades con la sociedad, considerándolos "los socios imprescindibles para que prosperen sus actividades", de ahí la importancia de establecer relaciones de ayuda y colaboración. Los medios de comunicación tienen en la ciencia y la investigación, como 
hemos visto, una fuente de temas de interés para los restantes grupos de interés, además de una responsabilidad en su acción comunicativa.

En este punto, cabe preguntarse cuál es la capacidad real de los medios de comunicación como transmisores de la ciencia y la innovación. A pesar de los intentos realizados, por el momento parece imposible cuantificar el público de la ciencia en los medios de comunicación. Francescutti (2014) propone una aproximación a partir de diferentes datos de audiencia recogidos en el estudio Públicos para la ciencia que reúne las audiencias verificadas de varios espacios dedicados a la ciencia en medios de comunicación españoles.

Según los datos de este estudio, los periódicos con suplementos de ciencia o I+D suponen 4.141.000 lectores expuestos regularmente a contenidos de ciencia y tecnología. A las revistas de divulgación, el EGM les imputa unos cinco millones de lectores mensuales, aparte de los 1.764 .427 visitantes mensuales de sus ediciones digitales contabilizados por ComScore y OJD interactiva, cantidades que los autores del estudio consideran que se incrementarían en varios cientos de miles más con los lectores de las publicaciones no incluidas en dicho estudio. Las cadenas de televisión TVE2, Antena 3, TVE3 y Canal Sur reúnen 3.830.000 espectadores semanales para programas con contenidos científicos variables. Los programas radiofónicos dedicados a ciencia cuentan, por su parte, con 4.365.000 oyentes. En cuanto a las audiencias digitales, en base a los datos de ComScore, los blogs y sitios web especializados en este ámbito tendrían casi un millón de visitantes únicos.

El grupo de Estudios Avanzados de Comunicación de la Universidad Rey Juan Carlos responsable del estudio liderado por Francescutti considera que no tiene sentido sumar estas audiencias y decir que la ciencia cuenta en España con más de diez millones de seguidores en diversos canales de comunicación ya que resulta inevitable el solapamiento de personas que consumen ciencia a través de más de uno de estos canales. Por tanto solo se puede realizar un cálculo muy orientativo que puede acercarse a los resultados de algunas encuestas:

Igual de plausible resulta suponer que no todos se solapan, con lo que, descontando las personas repetidas, el público total de la ciencia se situaría por encima de los cinco millones de lectores de revistas y por debajo de la simple suma de las audiencias parciales, siendo imposible precisar a cuánta distancia de ambos extremos. Quizás ese valor hipotético no se aleje demasiado de las 5.997.849 personas que en 2012 visitaron museos científicos de todo tipo, o del 15,6\% de 
españoles de 15 años o más de edad que en esa fecha declararon su interés por la ciencia y la tecnología (equivalente a unas 6.240 .000 personas, sobre los 39.325.516 residentes mayores de 15 años censados por el INE en 2011) (Francescutti, 2014:43).

Como ya veíamos con la necesidad de segmentar destinatarios señalada por el Libro Blanco de las UCC+i, los datos de público recopilados en el estudio de Francescutti vienen a coincidir también con los que se desprenden de las encuestas sobre interés y percepción de la ciencia que hemos visto. De este modo, se mantiene una preponderancia de públicos masculinos y, por edades, prevalece la franja de 25 a 44 años. En lo referente al nivel educativo de los públicos, el estudio sobre las audiencias, verifica el mayor interés de las personas con formación universitaria consignado también en las encuestas, siendo el estrato dominante entre los lectores de revistas, blogs y publicaciones digitales. Su primacía da pie a pensar que los menos instruidos han dado la espalda a la divulgación, o en el mejor de los casos siguen los espacios científicos de la radio y la televisión, señalan, indicando que de confirmarse esta hipótesis significaría "que la difusión de internet, tan positiva en todo caso, tiene todavía más de función de comunicación de élites que de instrumento de mejora informativa y educativa del conjunto de la población” (Francescutti, 2014:43).

Otra disposición captada por las encuestas que la práctica mediática ha refrendado es la preferencia por la divulgación realizada por los propios científicos. En este sentido, hemos visto como internet y las TIC han favorecido la proliferación de investigadores como comunicadores.

El estudio pone además de manifiesto la existencia de un elevado porcentaje de población que en las encuestas señala sentirse interesada por la información científica, pero luego no lo concreta en una búsqueda de información a través de los medios disponibles. De este modo, el 36\% de los encuestados que manifestaban un interés destacado por los tópicos de ciencia e innovación equivaldría a algo más de 14 millones de residentes mayores de 15 años, un número muy superior al de las audiencias contabilizadas. Por tanto, entienden que el problema no es de falta de información.

Ciertamente, hoy, la persona motivada tiene a su alcance toda la actualidad científica expuesta en la prensa de pago, las ediciones digitales gratuitas y las noticias de la radio y la televisión, además de un abanico de revistas especializadas que no llegaban a los quioscos y ahora son accesibles a través de la red, por no hablar de los textos que circulan por las redes sociales. Quien sienta una curiosidad real por la ciencia cuenta para saciarla con ingentes recursos dispuestos en las más diversas presentaciones y niveles de complejidad; de ahí que achacar al 
sistema de medios su déficit informativo no sea enteramente justo. Otra cosa sería dilucidar si el interés declarado es consistente o choca con barreras comunicativas, cognitivas o culturales que impidan satisfacerlo, para lo cual haría falta una investigación cualitativa (Francescutti, 2014:43).

Más allá del acercamiento a los públicos que pudiéramos entender pertenecientes a la sociedad civil, el estudio de Francescutti nos ofrece también una interesante aproximación a los diferentes grupos de interés como públicos de la ciencia, en un planteamiento de "capas de interés" en el que los integrantes juegan el papel tanto de emisores como de receptores. Así, el autor propone imaginar a los públicos de la comunicación de la ciencia y la innovación repartidos como en las capas de una cebolla, de forma que en su capa exterior, la más amplia, se ubican los aficionados a la "ciencia popular" (curiosidades, hallazgos sensacionales, novedades tecnológicas, etc., difundidos en revistas, televisión y redes sociales); en la capa inmediatamente interior, estarían los seguidores de la actualidad científica cubierta por la prensa de papel y digital, los comentaristas radiofónicos, las webs divulgativas y los blogs especializados; más adentro, en una capa más pequeña, los adeptos a la "alta divulgación"; y por fin el pequeño corazón constituido por los expertos y profesionales consumidores de contenidos ultraespecializados, por lo común referidos a sus ámbitos de actuación (científicos, ingenieros, tecnólogos).

La transversalidad sería un rasgo fundamental en esta propuesta, señala el autor, ya que la misma persona puede ocupar dos o más posiciones en capas diferentes. A la hora de ubicar a algunos de los grupos de interés de la RRI en estas capas cabe acercarse a la propuesta de distribución en las mismas de cuatro colectivos diferenciados (Francescutti, 2014:45):

- Investigadores, tecnólogos, gestores de I+D, profesores y estudiantes de posgrado se ubicarían para Francescutti en la más interna. Encontramos por tanto representado en este nivel al stakeholder correspondiente a la comunidad científica, que actúa a su vez como emisor sobre ciencia pero también como receptor altamente interesado en las informaciones sobre investigación e innovación.

- Periodistas especializados y comunicadores ligados a los museos de ciencia, las UCC+i, las webs y los blogs, se situarían para el autor en la siguiente capa, junto también a otros científicos y estudiantes universitarios y titulados en ciencias no 
vinculados a la investigación. Encontramos aquí profesionales de la comunicación de la ciencia junto con miembros de la sociedad civil con una elevada formación.

- Aficionados (activistas ligados a las ciencias ambientales, miembros de asociaciones astronómicas, entusiastas de la informática) y titulados superiores en disciplinas no científicas se situarían en la capa inmediatamente superior.

- Personas con escasa o nula formación científica y bajo nivel educativo, atraídos por la innovación y los hallazgos sensacionales o con impacto práctico en su vida cotidiana se encontrarían según este planteamiento en la capa superior, de forma que para Francescutti "atraerlos a las capas interiores debería ser una meta prioritaria de la divulgación".

A partir del análisis realizado, entre los retos respecto a los públicos de la ciencia Francescutti destaca precisamente la necesidad de reducir esa capa externa, incorporando al 25,9\% de la ciudadanía que, según las encuestas de la FECYT, se confiesa poco interesada por la ciencia y la tecnología, porque estas no despiertan su interés o sencillamente no las entienden. En este punto, entendemos que resultan de interés las reflexiones de Esperanza García, de la Agencia SINC, sobre la necesidad de acercar a los públicos noticias que realmente sean de su interés:

No podemos pretender enseñar al público lo que debe interesarle. Al contrario. Entendamos qué interesa a la gente, en primer lugar, y después expliquemos a la sociedad lo que la ciencia aporta a esas cuestiones (García Molina, 2014:71).

La periodista destaca que la información sobre ciencia y el testimonio de los investigadores no puede limitarse solo a resultados científicos, sino que se ha de poner el conocimiento científico al servicio de informar sobre temas que interesen.

Los públicos de la ciencia planteados en estudios como el de Francescutti o en el Libro Blanco de las UCC+i parecen seguir respondiendo a un enfoque de la comunicación de la ciencia basa en el modelo unidireccional (del déficit). Avanzar hacia una comunicación que responda al enfoque ciencia y sociedad, favoreciendo el diálogo para conocer los intereses y expectativas de la ciudadanía, es la propuesta que plantearemos a continuación una vez expuestos el mapa de stakeholders de la RRI y los posibles intereses en juego de cada unos de los grupos en materia de comunicación. 


\section{Un modelo de comunicación de la RRI para la}

\section{universidad}

Siguiendo la propuesta de comunicación de la RSE de la Escuela de Valencia, el modelo comunicativo de la RRI para las universidades que planteamos sitúa a la comunicación como el nexo de unión entre las expectativas de los grupos de interés que rodean a la ciencia y la innovación y el comportamiento de la Universidad. Además, dadas las características propias de la ciencia y la innovación, la participación de los stakeholders requiere que la comunicación se sitúe como elemento central del que parte la transferencia del conocimiento previo y necesario para que se dé el diálogo y la interacción en condiciones adecuadas.

En un primer punto propondremos el modelo de comunicación ética de la RRI para las Universidades derivado de la definición desarrollada de Investigación e Innovación Responsable desde la perspectiva de la ética dialógica. Abordaremos asimismo cada una de las fases de este modelo y propondremos herramientas comunicativas para llevarlas a cabo. En un segundo punto abordaremos las respuestas que ofrece el modelo comunicativo planteado de cara al desarrollo de la responsabilidad de la investigación y la innovación de las universidades desde la ética dialógica y la teoría de los stakeholders. Trataremos además las respuestas que puede ofrecer a los retos de la comunicación de la ciencia y de la propia RRI.

\subsection{UN MODELO ÉTICO DE COMUNICACIÓN PARA EL DIÁLOGO}

\section{Y LA ACCIÓN}

La consideración de que la Investigación y la Innovación podrán ser valoradas como responsables cuando las decisiones sobre la aceptabilidad de sus procesos y resultados pudieran ser aceptadas por las personas afectadas en un diálogo abierto en condiciones simétricas de participación, conlleva la necesidad de plantear un modelo comunicativo que favorezca el desarrollo de este diálogo en las condiciones adecuadas como horizonte moral hacia el que dirigirse. El modelo comunicativo que planteamos para las universidades propone que sea la comunicación la que inicie y mejore el 
proceso de la RRI, convirtiéndose en la materia prima desde la que han de construirse las políticas de Responsabilidad Social de la ciencia y la innovación.

El esquema de comunicación planteado sitúa a la comunicación de la ciencia y la en el centro, como elemento necesario para alcanzar los objetivos de la Investigación e Innovación Responsable. Alrededor de este núcleo se establecen los objetivos a alcanzar la universidad como son conocer las expectativas, adquirir compromisos y evaluar resultados; y, en un tercer nivel, las acciones de comunicación específicas necesarias para alcanzarlos y dotarlos de validez como son la definición de los mecanismos de participación y diálogo y el desarrollo de acciones de comunicación pública y transparencia. De este modo, el proceso circular comienza con las acciones de comunicación necesarias para conocer las aspiraciones y expectativas legítimas de los grupos de interés que permitirá, mediante un proceso de comunicación bidireccional entre la organización y los stakeholders, establecer los compromisos por parte de la universidad de cara a satisfacer estos intereses. La acción comunicativa en este punto debe garantizar que los compromisos alcanzados se hagan públicos. El proceso continúa con la evaluación y medición de los resultados alcanzados y las acciones de comunicación necesarias para que la universidad dé cuenta del grado de cumplimiento de sus compromisos.

La comunicación de la ciencia, que abarca también la innovación, afecta a su vez a cada uno de los objetivos a alcanzar por la RRI, siendo condición necesaria para transmitir el conocimiento científico y fomentar una cultura que capacite a los stakeholders para el diálogo en condiciones adecuadas. El establecimiento de los temas de actualidad y debate por parte de los diferentes canales y medios de comunicación (agenda setting) afecta a su vez a los compromisos y a la rendición de cuentas por parte de la universidad. La relación entre estos objetivos y la comunicación es bidireccional, ya que las expectativas de los grupos de interés, los compromisos de la universidad y los resultados de sus acciones condicionan a su vez a la comunicación de la ciencia.

De este modo, el modelo de comunicación de la RRI para las universidades que proponemos desde la perspectiva de la ética dialógica quedaría reflejado en la siguiente figura: 


\section{Modelo ético de comunicación de la RRI en la Universidad}

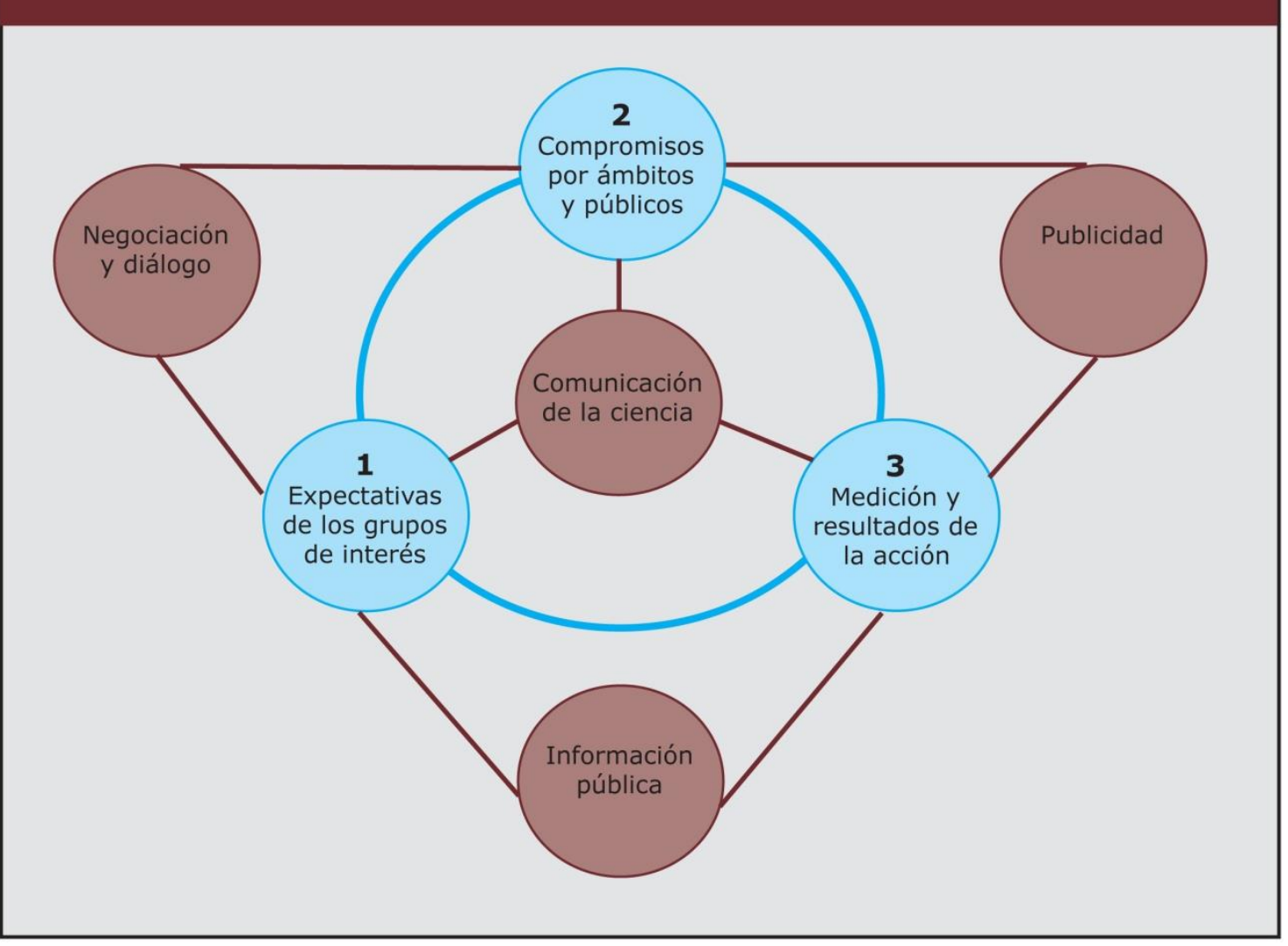

Como vemos, se trata de un modelo en el que la comunicación está al servicio de la RRI, planteándose como una herramienta que debe ser gestionada adecuadamente ya que, como cualquier tipo de comunicación realizada por parte de la Universidad, tiene una influencia determinante en la imagen y reputación de la misma. Para que la comunicación de la RRI sea adecuadamente puesta en valor, se requiere, al igual que ocurría en el caso de la comunicación de la RSE, una apuesta real de la institución lo que conlleva la necesaria implicación de los órganos de gobierno. En este sentido, y dada la estructura universitaria, entendemos que resulta especialmente significativo el apoyo del rectorado y de todos los vicerrectorados vinculados a ciencia, innovación y comunicación, así como de las oficinas y servicios relacionadas con las transferencia de resultados de investigaciones (habitualmente conocidas como OTRIS) y los servicios y unidades de comunicación tanto especializadas en ciencia, como son las UCC+i, como del ámbito general de la universidad.

La comunicación de la RRI por parte de la universidad, al igual que el resto de comunicación estratégica, persigue unos objetivos, se dirige a unos públicos y debe disponer de recursos específicos. De este modo, el modelo de comunicación de la RRI 
deberá concretarse en un Plan de Comunicación de RRI en el que estén claramente definidos los objetivos, estrategias, contenidos, audiencias en clave de grupos de interés, canales y acciones de comunicación e indicadores de seguimiento. Asimismo, para que llegue a buen puerto es necesario que disponga del presupuesto y los recursos humanos y materiales que precise $\mathrm{y}$, como hemos indicado, del respaldo institucional.

Antes de abordar cada una de sus etapas, cabe detenerse en algunos de los problemas a los que puede tener que hacer frente este modelo comunicativo. Entre ellos, la dificultad para que los stakeholders puedan hacer llegar sus mensajes a la universidad y la falta de canales adecuados para ello, lo que obliga a avanzar en el desarrollo de mecanismos eficaces para que las voces de los grupos de interés sean oídas y tenidas en cuenta. También la comunicación desde la organización hacia los stakeholders plantea dificultades, entre ellas, el hecho de que se trata de grupos con intereses diferentes y que, por tanto, requieren una comunicación específica. Esto se une al hecho de que en términos globales se trata a su vez de una audiencia amplia y dispersa, circunstancias que obligan a establecer un Plan de Comunicación que contemple unos canales y estrategias diferenciados y adecuados para cada uno de los grupos.

En el modelo desarrollado podemos establecer tres fases y un elemento central, cuestiones que abordamos a continuación.

\section{- Fase de negociación y diálogo}

El modelo de comunicación de la RRI se basa en la incorporación de las preocupaciones de los grupos de interés en materia de ciencia e innovación a la estrategia general de la universidad en estos campos. El conocimiento e incorporación de estas expectativas requiere del establecimiento de un proceso de negociación y diálogo entre la organización y cada uno de sus grupos de interés, que permita determinar las expectativas legítimas a incorporar y fijar unos compromisos concretos y públicos por parte de la universidad. En esta fase será clave el establecimiento de los mecanismos adecuados de participación y diálogo.

La fase de negociación y diálogo parte de la definición de los stakeholders de la universidad. Si bien en el mapa de stakeholders propuesto se plantean los grandes grupos de interés, resulta necesario que cada centro de enseñanza superior profundice en la estructura de cada uno de ellos en función de las especificidades de la organización. 
Un siguiente paso supondrá la realización de un diagnóstico del estado de la relación de la universidad con cada uno de sus stakeholders, incluyendo la detección de los canales de contacto y la periodicidad de la comunicación. De cara al establecimiento de las acciones de comunicación, será necesario definir los objetivos y expectativas de la organización respecto a cada uno de ellos y fijar el modelo deseado de relación y los recursos humanos y técnicos destinados a este objetivo (Agüero et al, 2011:13).

Como veíamos con Schomberg (2013), la participación y el diálogo con los stakeholders y el establecimiento de canales para conocer sus expectativas aparece directamente relacionado con la gobernanza de la investigación y la innovación, elemento central de la RRI para la UE. En este sentido, Schomberg considera que la RRI debe reunir a los grupos de interés para definir conjuntamente un plan de implementación para el desarrollo responsable de un producto en particular desarrollado dentro de un campo de investigación o innovación específico. El autor destaca en este terreno la necesidad de que los actores no se centren exclusivamente en aspectos particulares, sino que aborden todos los aspectos del proceso de innovación, que en el caso de las universidades se haría extensible a la investigación.

Para alcanzar esta participación, los canales de comunicación a establecer en cada una de las fases dependerán en gran medida de las características de cada universidad, de los canales de comunicación que ya tenga establecidos con sus públicos y de la relación que mantenga con cada uno de los grupos de interés. En cualquier caso, cabe tener en cuenta que en esta primera fase los canales tendrán que favorecer el diálogo y por tanto la bidireccionalidad. Las nuevas tecnologías y las redes sociales podrían ser una opción, pero también mecanismos presenciales de diálogo como encuentros, foros y focus groups. El correo electrónico, los teléfonos de información, las visitas a las instalaciones por grupos de interés, los programas de encuentros con miembros de los equipos de gobierno y responsables de la gestión de la investigación y la innovación y las acciones de relaciones públicas y relaciones informativas son asimismo herramientas que ya se han demostrado eficaces para establecer canales de comunicación bidireccionales entre las empresas y sus grupos de interés, especialmente los accionistas, y que pueden resultar interesantes para la comunicación interactiva entre la universidad y sus grupos de interés en materia de RRI. 


\section{- Fase de publicidad de los compromisos alcanzados}

La siguiente fase en la gestión de la comunicación de la RRI supone la comunicación pública por parte de la universidad de todos los compromisos alcanzados con cada uno de los stakeholders. En esta segunda fase, el elemento clave será el establecimiento de los compromisos, y a nivel comunicativo, la transparencia y la capacidad de la organización para establecer acciones de comunicación que garanticen una adecuada difusión de los mismos.

Al alcanzar compromisos con sus grupos de interés la universidad pasa a ser, como diría Cortina, "responsiva". La autora alude al contrato moral que establecen las organizaciones con la sociedad, considerando que además de ser responsables deben ser "responsivas", en el sentido de dar respuesta a las expectativas legítimas de los afectados, alcanzando así un reconocimiento recíproco.

De cara al establecimiento de los compromisos y a su publicación, una herramienta ampliamente utilizada en el campo de la Responsabilidad Social son los códigos éticos o de conducta, que pueden tener también su aplicación en el ámbito de la universidad en relación a la gestión de la investigación y la innovación. En el ámbito de la RRI, Shomberg (2013) considera que los códigos de conducta pueden permitir la creación de una comunidad científica proactiva que identifica e informa sobre los riesgos y beneficios en una etapa temprana. Así, entiende que estos documentos son especialmente útiles cuando los riesgos son inciertos, además de ayudar a la identificación de objetivos sociales. Otra herramienta ampliamente utilizada en el ámbito de la Responsabilidad Social y que podría asimismo resultar de interés para esta etapa son los comités de ética, encargados de velar por el cumplimiento de los códigos éticos y de atender los posibles conflictos o dudas que se puedan plantear.

De cara a hacer públicos y dar visibilidad a los compromisos alcanzados, puede ser de interés aprovechar los canales de comunicación ya consolidados en cada universidad como webs, medios de comunicación propios como televisiones, radios o boletines, envío de notas de prensa a los medios, envío de correos a listas, etc., sin dejar de lado tampoco las redes sociales, que favorecen en todo momento mantener la oportunidad de interactuar con los stakeholders. Asimismo, cabe plantearse en el caso de cada universidad la conveniencia de establecer canales específicos para la comunicación de la RRI como webs o revistas dedicadas a este ámbito. En el caso de que se opte por el desarrolló de códigos y comités de ética y RRI resulta indispensable 
que estos sean comunicados de forma adecuada y suficiente tanto a los públicos internos como externos, incluyendo acciones formativas sobre el código de conducta para los miembros de la universidad que se requiera.

\section{- Fase de reporting}

Como organización responsable, la universidad debe en esta tercera fase responder del grado de cumplimiento de los compromisos alcanzados con los stakeholders, mostrando las acciones desarrolladas para avanzar en la satisfacción de las expectativas legítimas de cada uno de estos grupos. Comunicación y transparencia son de nuevo las claves para hacer públicos los resultados.

En este punto, entendemos que sería interesante para las universidades que deseen realizar un ejercicio de reporting de su responsabilidad seguir los modelos de memorias de RSE abordados en el sexto capítulo de la tesis, como el GRI, el Pacto Mundial, la AA1000 AccountAbility, la SA 8000, la Norma SGE 21 o la ISO 26000. En este sentido, cada centro debería estudiar el modelo que mejor responda a sus características y circunstancias. En cualquier caso, para Schomberg (2013) la adopción de normas, certificaciones y estándares resulta un requisito fundamental para permitir el desarrollo responsable y constituye una nueva forma de gobernanza que juega un papel clave en la RRI.

Con independencia del sistema de evaluación, memoria o acreditación por el que se opte, vemos interesante de cara a su elaboración tener en cuenta los principios en los que se inspira el GRI, y que son referente en materia de Responsabilidad Social. Así, los principios de transparencia -ligado directamente a la necesidad de información públicaglobalidad y auditabilidad forman el marco de la memoria. A la hora de determinar qué aspectos deberían incluirse en la misma, los principios a tener en cuenta, siguiendo al GRI, serían los de exhaustividad, relevancia y contexto de sostenibilidad; mientras que la precisión, neutralidad y comparabilidad resultan necesarios para garantizar la calidad y la veracidad del documento.

En el ámbito de la comunicación, son especialmente relevantes los principios de claridad y periodicidad establecidos por el GRI y que afectan a las decisiones sobre el acceso a la memoria. En referencia a la claridad, desde esta guía se destaca que toda organización informante debería mantenerse al corriente de las distintas necesidades y 
experiencias de sus partes interesadas, y poner la información a disposición de los usuarios de manera que resulte inteligible para el mayor número posible de éstos, manteniendo un adecuado nivel de detalle. Este principio aparece estrechamente ligado a la necesidad de establecer diálogos con los stakeholders para conocer sus expectativas, llegar a acuerdos y comunicarles de forma adecuada y suficiente los resultados alcanzados sobre los mismos. Por lo que respecta la periodicidad, para el GRI este principio tiene que ver con la necesidad de que la memoria ofrezca información con una periodicidad que se adapte a las necesidades de los usuarios y a la naturaleza de los datos.

Como hemos visto, para que las memorias y evaluaciones de resultados, en cualquiera de sus formas, cumplan realmente su papel es necesario garantizar el acceso de los grupos de interés a las mismas con la claridad y la periodicidad suficientes y adecuadas. Siguiendo el modelo desarrollado, la comunicación juega un papel clave en la información pública de estos resultados. En este sentido, la publicidad de las memorias puede realizarse a través de los canales habituales de la universidad como webs y medios propios y también a través de la puesta en marcha de canales específicos, como las webs o revistas sobre RRI a las que hacíamos referencia en la etapa anterior. Otra opción ampliamente extendida en el ámbito de la Responsabilidad Social es la realización de presentaciones sobre resultados o su publicación a través de anuarios. Los correos, las redes sociales o las tradicionales notas de prensa son asimismo acciones de relaciones informativas que suelen realizar las universidades y que pueden ayudar a difundir los resultados alcanzados en el cumplimiento de los compromisos por la Universidad en materia de RRI. Como en las anteriores etapas, dependerá de cada universidad establecer los canales de comunicación que considere más adecuados en función de sus características y su relación con los stakeholders de la RRI.

Al igual que ocurría en el caso de la RSE, este proceso comunicativo es circular, de forma que la presentación de resultados debe dar pie a un nuevo proceso de negociación a través del que se redefinan las expectativas de los stakeholders y se establezcan nuevos compromisos por parte de la universidad. 


\section{- La comunicación de la ciencia como elemento central}

La comunicación de la ciencia supone un elemento central del modelo desarrollado ya que se sitúa como acción necesaria para, en primer lugar, dotar a los grupos de interés de los conocimientos necesarios para poder plantear sus expectativas en materia de investigación e innovación y poder participar en el diálogo y la negociación con la universidad en condiciones adecuadas. Además, la comunicación de la ciencia puede afectar y verse afectada por los compromisos en materia de responsabilidad social de la universidad, así como por los resultados de las acciones en este ámbito.

La inclusión de la comunicación de la ciencia como elemento central introduce una novedad respecto al modelo de comunicación de la RSE del que partimos (Fernández Beltrán, 2008), adaptándolo a las especificidades de la investigación y la innovación en su búsqueda de la responsabilidad. En este sentido, cabe introducir algunas reflexiones teóricas sobre la oportunidad de incluir en el modelo la función transmisora del conocimiento científico y de la innovación con el fin de formar a públicos capacitados para participar de forma autónoma en el diálogo. Siguiendo a De Semir, para que la relación entre ciencia y sociedad sea efectiva es necesario contar con interlocutores informados a través de la extensión de la cultura científica y el acceso a la información.

Para que esta relación entre la comunidad científica y los ciudadanos sea fructífera es imprescindible potenciar la extensión de la cultura científica, el acceso a la información científica y tecnológica y la participación de los ciudadanos en las decisiones científicas desde una perspectiva informada, habilitando para ello los marcos sociales y jurídicos adecuados (De Semir, 2011:51-52).

Por tanto, parece necesario que para que los grupos de interés puedan actuar y opinar de forma autónoma requieren de información. Para Sartori (1992) se encuentra en la base de la democracia que el consenso que soporta a los gobiernos parta de públicos con opiniones autónomas, para lo que es necesario que estén informados, entendiendo que la falta de información supone un problema de base. Cabe recordar aquí el concepto de umbral de conocimiento señalado por el autor, en referencia al nivel que es necesario alcanzar para reducir el coste de informarse, ya que, para quien no está informado, el coste de comprender y digerir la información se replantea todos los días y ya no se convierte en gratificante. Esto explica, para Sartori, por qué existe un salto que 
enfrenta a quien está informado y a quien no lo está, es decir, una distribución discontinua y, en segundo lugar, "por qué los límites entre las distintas zonas o especialidades de información son verdaderamente unos límites” (Sartori, 1992:173).

En el ámbito de la ciencia y la innovación, parece evidente que una vez alcanzado un cierto umbral de conocimiento, resulta mucho más asequible acceder a nuevas informaciones. Sin embargo, sin una base suficiente, las noticias sobre investigaciones pueden suponer un reto que puede descorazonar a una gran parte del público, así como la posibilidad de participar en la gestión de la RRI. En este sentido, es función de los profesionales de la comunicación de las universidades hacer la información accesible para la mayoría de la audiencia y contribuir, junto con los investigadores, a que cuente con una base de conocimiento científico que facilite su acceso a nuevas informaciones.

Autores como Sutcliffe ponen asimismo el acento en el hecho de que favorecer la participación supone partir de un público informado, con una comprensión básica de la ciencia y el proceso científico que le capacite para realizar "mejor" los juicios. Entendemos que el papel de la Comunicación Pública de la Ciencia resulta básico como herramienta para contar con una opinión pública formada e informada. En este sentido, señala Sutcliffe que uno de los retos más importantes de la RRI es considerar cuidadosamente qué tipo de información y de participación quiere y necesita la gente para ayudarles a formarse una opinión informada, y entregársela con claridad y eficacia (Sutcliffe, 2011:12).

Cabe hacer referencia asimismo a la triple tarea señalada por Cortina como necesaria para alcanzar en la actualidad decisiones morales objetivas en materia de ciencia. Si pasan, como hemos visto, por la toma de decisiones responsables por parte de los afectados que han de optar teniendo en cuenta no sólo sus intereses individuales, sino los universalizables (Cortina, 1993:262), alcanzarlo exige la triple tarea de que los expertos comuniquen la ciencia y la innovación, los individuos entiendan que son ellos a los que corresponde decidir, y educarlos para que lo hagan teniendo en cuenta los intereses universalizables. El modelo de comunicación ética de la RRI desde las universidades debe contribuir por tanto a la consecución de decisiones morales fomentando la comunicación por parte de los expertos para que acerquen la investigación y la innovación al público, de modo que, siguiendo a Cortina (1993), "éste pueda codecidir de forma autónoma, contando con la información necesaria para ello". 
También desde el marco normativo europeo se establece la necesidad de mejorar la alfabetización científica de la ciudadanía para alcanzar un diálogo más fértil y favorecer la participación. De este modo, el informe Ciencia, sociedad y ciudadanos en Europa pone el acento en la alfabetización científica como condición necesaria para elevar la capacidad de la ciudadanía para debatir con conocimiento de causa las cuestiones relativas a "ciencia y sociedad", señalando que el diálogo será más fértil cuanto más profundos sean sus conocimientos y su comprensión de la ciencia y la tecnología, incluyendo los "hechos" de la ciencia, los resultados de la labor de investigación, el método científico y la forma en que funciona concretamente la investigación. "El objetivo no puede ni debe ser obtener de la población una actitud sistemáticamente favorable, sino crear las condiciones necesarias para un debate democrático con conocimiento de causa", se indica (European Commission, 2000:15).

El Plan de Acción Ciencia en Sociedad establece en este sentido la necesidad de fomentar una adecuada formación e información en materia de ciencia e innovación que favorezca a su vez la participación, aludiendo a la necesidad de instituir un marco de nivel comunitario "para lograr que los ciudadanos europeos puedan juzgar con mayor conocimiento de causa los grandes fenómenos científicos y tecnológicos de su tiempo, y para despertar sus deseos de participar en la aventura científica" (European Commission, 2002:7). De hecho, la promoción de la educación y la cultura científica en Europa se establece como un ámbito necesario de actuación para la estrategia "ciencia en sociedad", considerándose fundamental reforzar la presencia de la ciencia y la tecnología en los medios de comunicación y los ámbitos docentes europeos de cara a fomentar el diálogo entre la esfera de la ciencia y la de la sociedad. Así, el documento hace referencia a la necesaria sensibilización e información del público, destacando el papel especialmente relevante de las universidades en esta comunicación del conocimiento científico y de su contexto.

Para que los progresos de la ciencia y la tecnología respondan a las necesidades de los ciudadanos europeos y cuenten con su adhesión, es necesario que dispongan de una información comprensible y de calidad, así como de un acceso libre a esta cultura específica. Los medios de comunicación, los investigadores, los organismos de investigación -y, en particular, las universidades, y también las empresas, deben desempeñar plenamente su papel de información al público. Deben ser capaces de comunicar y dialogar sobre temas de carácter científico de una forma profesional, a la vez rigurosa y atractiva, así como de exponer, en mayor grado que hasta el momento, en qué consiste la labor científica, con todo rigor y especificando sus límites (European Commission, 2002:9). 
También documentos más recientes, como la convocatoria Horizonte 2020 hablan de la necesidad de favorecer una participación informada de los ciudadanos y de la sociedad civil en las cuestiones relacionadas con la investigación y la innovación, mediante el fomento de la educación científica, haciendo más accesibles los conocimientos científicos, elaborando unas agendas de investigación e innovación responsables que atiendan las expectativas y preocupaciones de los ciudadanos y de la sociedad civil, y facilitando su participación en las actividades de Horizonte 2020 (Mesas, 2015).

La comunicación de la ciencia como elemento central se relaciona no sólo con la necesaria alfabetización científica de los grupos de interés para alcanzar esta participación informada. Tiene que ver también con todas las fases del modelo de comunicación de la RRI planteado, dado que el establecimiento de la agenda informativa puede afectar también a los compromisos alcanzados por las universidades y al rendimiento de cuentas y, a su vez, puede verse afectado por los mismos. En este sentido, desde el marco normativo, cabe recordar que el Plan de Acción Ciencia en Sociedad recoge cómo los medios de comunicación tradicionales siguen siendo el medio más importante para la definición de la agenda en materia de ciencia e innovación, elevando el conocimiento e implicando a ciudadanos que no estén, de entrada, particularmente interesados en cuestiones de ciencia. El informe establece unos objetivos claros de la comunicación entre la ciencia y la sociedad, estableciendo que estos pasan por "informar al público en general acerca de los problemas relacionados con la ciencia y la tecnología, e informar a la ciencia sobre las percepciones y expectativas de la sociedad".

El Plan de Acción considera que la comunicación de la ciencia hace visible públicamente la experiencia científica, establece la agenda de la formulación de políticas, afecta la legitimidad de la investigación, y juega un papel importante en la gobernanza de la ciencia, la tecnología y el riesgo. Asimismo, se destaca cómo la comunicación puede ayudar a establecer una forma de relación bidireccional que contribuya a hacer más tranparentes las inversiones públicas en materia de ciencia, permita a los responsables políticos y a los investigadores conocer la percepción de la ciencia y favorezca el uso del conocimiento científico por parte de la sociedad. De este modo, la Unión Europea, establece la comunicación de la ciencia como un factor clave 
para el desarrollo de la RRI, justificando su inclusión como elemento central en el modelo comunicativo de la RRI propuesto.

Una vez expuesto el modelo de comunicación de la RRI para las universidades y analizadas cada una de sus diferentes fases, así como el papel de la comunicación como elemento central y facilitador de todo el proceso, en el siguiente capítulo nos centraremos en las respuestas que busca ofrecer el modelo desarrollado desde una perspectiva ética a algunos de los retos de la RRI y la comunicación de la ciencia.

\subsection{RESPUESTAS PARA LA RESPONSABILIDAD Y LA}

\section{COMUNICACIÓN DE LA CIENCIA}

Para completar el modelo de comunicación de la RRI propuesto para las universidades cabe abordar también los retos a los que busca dar respuesta y plantear soluciones desde el marco ético desarrollado. En este punto trataremos de abordar algunos de los aspectos de la RRI y la comunicación de la ciencia planteados a lo largo del trabajo y a los que el modelo desarrollado podría ofrecer respuesta.

El modelo planteado busca ofrecer una orientación hacia las acciones, decisiones y políticas que la universidad puede dar para responder a las demandas de sus grupos de interés, situándose en el plano de las conductas y de la responsabilidad social. Esta respuesta se vincula a la responsabilidad moral, entendida, siguiendo a García Marzá, como las condiciones procedimentales para el diálogo, que suponen que solo la inclusión de todos en condiciones de igualdad asegurará la justicia del acuerdo, situándose en el nivel procedimental para establecer un diálogo justo o moral.

El enfoque de la RRI planteado se convierte en un recurso moral para el logro de las condiciones óptimas para la generación y mantenimiento de la confianza. Y para ello la responsabilidad social ha de ir ligada a la comunicación ya que, como hemos visto, responsabilidad es responder. Para García Marzá la responsabilidad social consiste desde esta perspectiva en decir lo que se hace y en hacer lo que se dice (García Marzá, 2005). La publicación así entendida genera la confianza que, para el autor, será directamente proporcional a la capacidad de las organizaciones para hacer públicas y justificar discursivamente sus acciones, estrategias y políticas. "En definitiva, de hacer pública su responsabilidad” (García Marzá, 2006:93). 
El modelo comunicativo atiende asimismo a los principios para el desarrollo de una ética y una ciudadanía cordial planteados por Cortina y que han servido de marco a la definición de la RRI. Desde la perspectiva de la comunicación, la información adecuada y la transparencia son aspectos que contribuyen a garantizar el principio de no instrumentalizar a las personas. Así, la comunicación de la ciencia resulta clave para que las personas puedan actuar de forma informada y autónoma. Además, el modelo gira en torno al principio dialógico, que obliga a tomar como fuente de la obligación moral el reconocimiento recíproco, de forma que deben tenerse en cuenta los intereses de los afectados por las decisiones para que sean ellos quienes, en la medida de lo posible, expresen esos intereses a través del diálogo (Cortina, 2007). El modelo establece un ciclo comunicativo que busca favorecer el diálogo con los grupos de interés y, además, que sus consideraciones sean tenidas en cuenta y adecuadamente gestionadas, todo ello desde la publicidad y la transparencia. El marco ético del que parte el modelo tiene asimismo en consideración el principio de responsabilidad por los seres indefensos no humanos y el principio de justicia distributiva.

Por lo que respecta a la RRI, este modelo puede dar respuesta a la necesidad de una ciencia para y con la sociedad impulsada y demandada por la Unión Europea. En su desarrollo teórico de la ciencia "para" la sociedad, Owen, Macnaghten y Stilgoe (2012) señalan que se trata de la decisión de qué se quiere que se haga. Los autores destacan éste como un punto de partida importante para la RRI, que plantea cómo identificar los objetivos de forma ética, incluyente, de manera democrática y equitativa. Se pide la deliberación inclusiva en relación con la dirección en la que ha de avanzar la ciencia y la innovación con el fin de que se oriente desde un principio hacia fines socialmente deseables. Para los autores, la RRI requiere de procesos de reflexión inclusiva y de democracia deliberativa.

La ciencia “con" la sociedad guarda relación con la integración e institucionalización de los mecanismos establecidos de anticipación, reflexión y deliberación inclusiva alrededor de los procesos de investigación e innovación. Así, esta dimensión recoge en primer lugar la necesidad de anticipar las posibles consecuencias $\mathrm{y}$, en segundo, el tener que reflexionar sobre los propósitos subyacentes, las motivaciones, los impactos potenciales, las incertidumbres asociadas, los riesgos, las preguntas y los dilemas éticos. En tercer lugar, la ciencia "con" la sociedad conlleva la necesidad de abrir esta reflexión a la deliberación colectiva a través de procesos de 
diálogo con las diferentes partes interesadas (Owen et al, 2012:754). El modelo de comunicación planteado responde por tanto al desarrollo de la ciencia para y con la sociedad, de forma que sean las personas afectadas las que muestren sus intereses y expectativas en las reflexiones en materia de ciencia e innovación por parte de las universidades.

Por su parte, Carsten vincula la RRI al concepto de democracia, destacando la necesaria participación de todas las partes interesadas, algo que se busca fomentar a través del modelo comunicativo planteado. El autor destaca entre los aspectos claves de la RRI, además de la participación pública, el principio de rendición de cuentas vinculándolo a la necesidad de transparencia, un aspecto recogido asimismo en el modelo a través de la publicidad.

El modelo de comunicación de la RRI planteado se ajusta asimismo al marco normativo europeo, tanto desde una visión general como desde las perspectivas de “ciencia y sociedad" y de RRI. Al respecto, cabe recordar que el Tratado de la Unión Europea establece en su Artículo 11 la necesidad de que las instituciones establezcan los cauces y mecanismos apropiados para la participación de ciudadanos y asociaciones, dándoles la "posibilidad de expresar e intercambiar públicamente sus opiniones en todos los ámbitos de actuación de la Unión". Se señala asimismo que "las instituciones mantendrán un diálogo abierto, transparente y regular con las asociaciones representativas y la sociedad civil" (Unión Europea, 2010). El modelo propuesto plantea un mecanismo circular que posibilita el desarrollo de un diálogo abierto, inclusivo y sometido a información pública en el ámbito de la investigación y de la innovación por parte de las universidades.

Desde la perspectiva de la "ciencia en sociedad", el modelo permite avanzar asimismo en los tres ámbitos establecidos por el Plan de Acción Ciencia y Sociedad, posibilitando, en primer lugar, favorecer la promoción de la educación y la cultura científica en Europa, al situar a la comunicación de la ciencia en el centro del proceso, como elemento indispensable para una participación informada por parte de los grupos de interés. En segundo lugar, el modelo favorece asimismo la elaboración de políticas científicas más cercanas a los ciudadanos, ayudando a replantear el contrato social con la ciencia, la tecnología y la innovación al establecer su planificación en función de las necesidades y aspiraciones legítimas de la ciudadanía. El tercer ámbito de actuación establecido en el Plan de Acción se centra en la incorporación de una ciencia 
responsable en las distintas políticas, entendiendo que la mayoría de las políticas cuenta con una dimensión científica y tecnológica, y sus decisiones deben apoyarse en dictámenes transparentes y responsables basados en investigaciones que tengan en cuenta imperativos éticos. Por ello, se señala que es necesario reforzar la base ética de las actividades científicas y tecnológicas, así como detectar y evaluar los riesgos inherentes al progreso y encontrar soluciones responsables para éstos en función de experiencias pasadas. El marco ético en el que se basa el modelo comunicativo permite avanzar también en esta dirección.

Continuando con el marco normativo, cabe señalar que el modelo planteado responde a algunos de los riesgos de la comunicación basada en el modelo ciencia y sociedad planteados por los expertos del proyecto MASIS (Sinue et al, 2009). Entre ellos, los autores destacaban la vulnerabilidad a los malentendidos y los abusos, ante el riesgo de caer en modelos y conceptos excesivamente simplificados de cómo la ciencia y la sociedad se comunican. En este sentido, el modelo de comunicación de la ciencia desde las universidades propuesto parte de modelos aplicados con éxito en el campo de la Responsabilidad Social, adaptándolo a las especificidades de la RRI desde una visión que tiene en cuenta la complejidad de la relación con los diferentes grupos de interés y los mecanismos necesarios para alcanzar compromisos reales por parte de las universidades.

En el apartado de conclusiones, los expertos señalan que el reto de la comunicación para una ciencia en sociedad no pasa tanto por ofrecer más información como por proporcionar formas adecuadas para la comunicación y el diálogo. En este sentido, advierten de que la ideología que puede estar escondida detrás de un modelo limitado a la transmisión de información desde la ciencia a la sociedad es que la sociedad debe aceptar la ciencia, la tecnología y la innovación, y a su vez dar respuesta a la necesidad de aumentar las vocaciones para contar con los ingenieros y científicos que requiere una economía basada en el conocimiento. A través de este modelo, entienden que "la ciencia y la sociedad no se comunican (la comunicación es un proceso de dos canales), sino que la ciencia habla a la sociedad". El modelo planteado permite dar respuestas a esta situación, proponiendo nuevas formas de comunicación y diálogo que vayan más allá de la transferencia de información sin renunciar a ésta.

Además, el modelo responde a algunos de los retos planteados por los autores del informe MASIS. Entre ellos se encuentra la necesidad de desechar el mito de un 
público singular ya que las audiencias, las razones para implicarse, las voces y los tipos de intermediarios son múltiples. La propuesta comunicativa con diferentes stakeholders, que cada universidad debe concretar en perfiles más específicos, obliga a establecer acciones de comunicación que tengan en cuenta las características e intereses de cada uno de estos grupos.

La puesta en marcha de este modelo también debería contribuir a romper las reticencias de los científicos hacia la sociedad. Los científicos en muchas ocasiones ven las consideraciones éticas como un obstáculo, por lo que es necesario avanzar en una visión en la que sociedad y ética aportan valor. Las acciones de diálogo propuestas con los diferentes grupos de interés, incluida la sociedad civil, ayudaría a que la comunidad científica tuviera un mejor conocimiento sobre la misma y sobre la importancia de su contribución.

Otro de los retos planteados por el informe MASIS alude a las responsabilidades tanto de la ciencia como de la sociedad, al deber de comunicar de la primera y al derecho de participar de la segunda. Para que la implicación de la ciudadanía en la ciencia sea eficaz, se considera que debe producirse una mayor comprensión de todas las partes acerca de la naturaleza de la ciencia como actividad evolutiva. En este sentido, para que haya una implicación pública efectiva, entiende que debe prestarse más atención a las decisiones que es preciso adoptar, a los recursos que hay que asignar y al trabajo y método realizado por científicos individuales y centros de investigación. La participación a través del diálogo en los asuntos de ciencia e innovación de las universidades, sin duda contribuiría a avanzar en este sentido, de forma que los centros de investigación tomaran conciencia de su deber de comunicar en un sentido amplio y los grupos de interés hicieran valer su derecho a participar.

El modelo ofrece asimismo respuesta al reto de la construcción de futuros potenciales, al no limitar la comunicación a la trasmisión de resultados e incorporarla desde el inicio del proceso, favoreciendo una participación que permita una mejor deliberación y evaluación de esos futuros. Por lo que respecta al aprovechamiento de las tecnologías de la web 2.0 y su incorporación para el desarrollo de la Comprensión Pública de la Ciencia y sobre todo del Compromiso Público con la Ciencia, resulta evidente que, en la actual galaxia mediática, los canales y herramientas de comunicación que permitirán llevar a cabo el modelo de comunicación planteado descansarán en gran medida en las Nuevas Tecnologías de la Información y la web 2.0. 
Avanzando en los documentos europeos que establecen el marco normativo, cabe detenerse asimismo en el informe que sienta la bases de la RRI, A report on Responsible Research \& Innovation (Sutcliffe, 2011), en el que se señala como uno de los retos de la RRI la necesidad de ser más innovadora e inclusiva a la hora de alcanzar la participación efectiva de la ciudadanía en todas las etapas de la investigación y la innovación, determinando la manera más eficaz de articular el proceso. En este sentido, se indica la necesidad de transmitir a los participantes que su aportación se va a gestionar de forma rigurosa y profesional, y que su voz va a ser considerada y tenida en cuenta. El informen lamenta la notable ausencia de una retroalimentación con los participantes y la sociedad en general acerca de cómo se utilizan las aportaciones, cómo influyen en el proceso en discusión y las razones de las decisiones finalmente adoptadas, sobre todo si son contrarias a las opiniones suscitadas a través del proceso de participación. El modelo de comunicación de la RRI desarrollado da respuesta a estas críticas, garantizando la publicidad en todas las fases del proceso, tanto a la hora de concretar los compromisos por parte de las universidades como a la de dar cuenta de los resultados alcanzados, publicaciones que permitirán continuar el ciclo comunicativo, con el planteamiento de nuevas expectativas por parte de los stakeholders. De este modo, se garantiza una adecuada retroalimentación y una información suficiente y transparente durante todo el proceso. Se ofrece por tanto una forma eficaz para la articulación del proceso de cara a garantizar una participación efectiva.

Más allá de la adecuación de la propuesta de modelo comunicativo al marco ético y normativo, se trata de un modelo que puede ofrecer respuestas de interés a algunos de los retos y críticas planteados también desde el ámbito académico y profesional en materia de comunicación de la ciencia y la innovación. En este sentido, cabe recordar que una de las principales críticas que se plantea al enfoque de la comunicación basado en el modelo ciencia y sociedad hace referencia al hecho de que muchos programas y acciones que dicen fomentar la participación ciudadana no llegan finalmente a cumplir su propósito, puesto que las opiniones y demandas de la ciudadanía no son tenidas en cuenta en los niveles de decisión. En este sentido, se critica que no llega a tratarse de un modelo realmente bidireccional (De Semir, 2014). El modelo planteado busca superar estas críticas al contemplar la necesidad de que la universidad negocie y adquiera compromisos públicos a la hora de satisfacer las expectativas de cada uno de los stakeholders. Dando un paso más, no resulta suficiente 
con adquirir estos compromisos, sino que además debe dar cuenta de los resultados alcanzados. De esta forma, se garantiza que las opiniones y demandas sean tenidas en cuenta, estableciéndose una verdadera comunicación bidireccional.

La apuesta por un modelo comunicativo que tenga en cuenta la bidireccionalidad viene a complementar la función comunicativa que en muchas ocasiones se ha atribuido a las universidades y que, como hemos visto, sigue siendo la predominante, basada en la transmisión de los resultados de investigación. En este sentido, el Libro Blanco de las UCC+i entiende la función comunicativa de estas universidades como la difusión de informaciones y contenidos que cumplen determinados criterios de noticiabilidad. En concreto, "que sean novedosos y de actualidad, y que estén asociados directamente a resultados producidos en los centros de investigación a los que pertenece la UCC+i" (FECYT; 2012). En la propuesta planteada estas acciones de comunicación, así como las vinculadas a la divulgación de la ciencia, siguen siendo fundamentales. De ahí la importancia de incluir en el modelo la necesaria formación de la ciudadanía y el desarrollo de la cultura científica a través de acciones de comunicación de la ciencia y la innovación.

En el modelo ético de comunicación de la RRI, la propia participación de los grupos de interés contribuye además a incrementar el conocimiento científico de sus miembros. En este sentido, se trata de un modelo que responde a la necesidad señalada por López Cerezo (2005) de que los procesos de participación pública generen aprendizaje social en relación con la ciencia y la tecnología, y por lo tanto, cultura científica en la ciudadanía.

El interés de un modelo que favorezca la comunicación entre la ciencia y los grupos de interés como el desarrollado permite, siguiendo a De Semir; informar a los stakeholders sobre cuestiones relacionadas con la ciencia y la tecnología; informar a la ciencia acerca de las percepciones y expectativas sociales; poner la experiencia científica a disposición del público; llegar a tener un impacto en el diseño de políticas y en la creación de programas por parte, en este caso, de las universidades; mejorar la legitimidad de la investigación desarrollada en los campus y desempeñar una función destacada en el gobierno de la ciencia, la tecnología y el riesgo potencial. Entendemos que se trata por tanto de un modelo que persigue el principal objetivo que para De Semir debe tener de la comunicación de la ciencia: 
(...) ser útil para establecer una forma de interrelación transparente y abierta que contribuya a definir la función de la ciencia en la sociedad, y fundamentalmente para posibilitar que la sociedad haga el mejor uso posible del conocimiento científico (De Semir, 2014:109).

Finalmente, cabe señalar que el planteamiento de un modelo de comunicación de la RRI desde las universidades da también respuesta a la creciente demanda social de participación en cuestiones de ciencia y tecnología. Así, cabe recordar que en la última Encuesta de Percepción Social de la Ciencia (FECYT, 2015a) por primera vez son mayoría los ciudadanos que consideran que deberían desempeñar un papel más importante en las decisiones sobre ciencia y tecnología que les afectan. Un 53,1\% de los ciudadanos estaban muy o bastante de acuerdo en 2014 con tener un papel más importante en la ciencia frente al 40,4\% de 2012.

El modelo de comunicación de la RRI para las universidades planteado desde la perspectiva dialógica y la teoría de los stakeholders busca ser una contribución para avanzar desde el campo de la comunicación en el desarrollo de una investigación y una innovación más responsables. El modelo supone una propuesta hacia un modelo de comunicación bidereccional, que responda al enfoque ciencia y sociedad. Esta búsqueda de un diálogo entre la ciencia y los grupos de interés vendría a complementar la visión más tradicional de la comunicación de la ciencia y la innovación como trasferencia del conocimientos desde las universidades hacia los diferentes públicos, una función que entendemos que sigue siendo fundamental para formar a públicos capacitados para participar con autonomía en las deliberaciones.

En el siguiente bloque trataremos de validar este modelo de comunicación de la RRI para las universidades, para lo que utilizaremos las técnicas descritas en el apartado de metodologías con el fin de conocer la realidad actual de la comunicación de la ciencia por parte de las universidades y dar voz a los grupos de interés y a los expertos. 


\section{PRESENTE Y FUTURO DE LA COMUNICACIÓN DE LA RRI EN LA UNIVERSIDAD}





\section{La comunicación de la ciencia en la universidad. El}

\section{caso de las universidades valencianas}

El análisis de los aspectos éticos de la comunicación de las RRI en las universidades requiere de una mirada a la realidad de la comunicación pública de la ciencia por parte de las universidades. Para ello, se optó por determinar una muestra representativa en base a las universidades valencianas públicas y privadas que forman parte de la Red de Universidades Valencianas para el fomento de la Investigación, la Innovación y el Desarrollo (RUVID). Tal y como se ha explicado al principio de la tesis, en el capítulo dedicado a la Metodología, de las siete universidades a las que se delimitó la muestra, finalmente contestaron seis al cuestionario, no obteniendo respuesta por parte de la Universidad de Alicante.

En el presente capítulo recogemos, en un primer apartado, las respuestas de los encuestados para, en un segundo, extraer las principales conclusiones de las mismas y ponerlas en relación con la propuesta de comunicación ética de la RRI planteada en la presente tesis.

\subsection{ANÁLISIS DE LAS ACCIONES DE COMUNICACIÓN DE LA}

\section{CIENCIA DE LAS UNIVERSIDADES VALENCIANAS}

Las respuestas ofrecidas por las universidades valencianas participantes en el estudio ofrecen una interesante visión de la situación de la comunicación de la ciencia y el papel de la ética y la responsabilidad en la misma. Las respuestas se han estructurado en tres puntos con el fin de favorecer su análisis. El primero de ellos aborda la estructura con la que cuanta cada universidad para la gestión de la comunicación de la ciencia, incluidas las personas que trabajan en la misma, los órganos de los que dependen y los servicios con los que colaboran. En este apartado se trata también la importancia que conceden las universidades a la comunicación de la ciencia y las razones de la misma. En un segundo punto se incluyen todas las cuestiones relacionadas con el proceso comunicativo, desde las acciones desarrolladas, los públicos destinatarios, los canales de interacción con ellos y los tiempos de la comunicación respecto al proceso de investigación. Finalmente, el tercer apartado aborda cuestiones directamente relacionadas con la ética y la responsabilidad en la gestión de la investigación y la innovación y en su comunicación. 


\subsubsection{Estructura y valoración de la comunicación de la ciencia}

En este primer punto recogeremos en primer lugar los datos del cuestionario referidos a la estructura de la comunicación de la ciencia de cada una de las universidades participantes y la valoración de la importancia que otorgan a la misma. Así, se incluyen las respuestas a los siguientes apartados del cuestionario:

- Universidad.

- Nombre y cargo/función de la persona que responda este cuestionario.

- Valore la importancia que otorga su Universidad a la comunicación de la ciencia. Siendo 0-nada, 1-poca, 2-algo, 3-bastante y 4-mucha.

- Indique los motivos de esa importancia otorgada a la comunicación de la ciencia en su Universidad.

- ¿Qué servicio/s o unidad/es gestiona/n la comunicación de la ciencia y la innovación?

- Otras unidades u oficinas que colaboran/apoyan la gestión de la comunicación de la ciencia y la innovación.

- ¿Cuál es su organigrama y/o dependencia orgánica dentro de la Universidad?

- Número de personas dedicadas exclusivamente a comunicación de la ciencia y la innovación.

- Número de personas dedicadas parcialmente a comunicación de la ciencia y la innovación.

\section{- Estructura y composición}

- Universitat de València. La periodista Maria Josep Picó responde el cuestionario, señalando que existen dos personas con dedicación exclusiva a la comunicación de la ciencia y dos con dedicación parcial. La comunicación de la ciencia se gestiona desde el Gabinete de Prensa de la Universidad en colaboración con la UCC+i, unidad que depende del Vicerrectorado de Investigación. Otras entidades que colaboran en la comunicación de la ciencia son el Parc Científic y MediaUni.

- Universitat Politécnica de València. Luis Zurano Conches, periodista de la UCC+i, es la persona que responde el cuestionario de la UPV, explicando que la comunicación de la ciencia y la innovación está coordinada por la Unidad de Comunicación Científica y de la Innovación (UCC+i), que depende del Vicerrectorado de Investigación, Innovación y Transferencia. En cuanto a la colaboración con otros servicios o unidades, señala que todo el trabajo de difusión de la ciencia y la innovación se hace en colaboración con el Área de Comunicación de la UPV. Externamente, destaca también 
la colaboración con RUVID. En cuanto al número de personas dedicadas a la comunicación de la ciencia, se indica que cuenta con una persona con dedicación exclusiva.

- Universitat Jaume I. La persona que respondió el cuestionario fue Mari Luz Blanco Burgueño, de la Unidad de Cultura Científica y de la Innovación, quien indica que la gestión de la comunicación de la ciencia depende de la Unidad de Cultura Científica y de la Innovación integrada en el Servicio de Comunicación y Publicaciones de la UJI (UCC+i UJI), servicio que depende orgánicamente del Rectorado. La UCC+i UJI cuenta con el apoyo y la colaboración de las áreas y unidades del Servicio de Comunicación de la UJI (relaciones informativas, Vox UJI Ràdio, audiovisuales, diseño, administración, publicaciones y corporate). Además trabaja en colaboración con la Oficina de Cooperación en Investigación y Desarrollo Tecnológico (OCIT). Según los datos aportados, la Jaume I cuenta con una persona con dedicación completa a la comunicación de la ciencia y tres con dedicación parcial.

- Universidad Miguel Hernández de Elche. La persona que respondió por vía telefónica el cuestionario es Juan José López, Director de Comunicación de la Universidad y profesor contratado Doctor de Lenguajes y Sistemas Informáticos. La institución cuenta con varias personas con dedicación parcial a la comunicación de la ciencia. Esta se gestiona desde la Oficina de Comunicación de la Universidad formada por tres miembros del Personal de Administración y Servicios (una periodista, una técnico de marketing y un especialista en telecomunicaciones y traducción), una auxiliar y el Director de Comunicación, además de becarios y colaboradores. La Oficina de Comunicación depende del Vicerrectorado de Relaciones Institucionales, mientras que el cargo de Director de Comunicación lo hace del Rector. La Oficina de Comunicación cuenta con diversos servicios que respaldan la comunicación de la ciencia como son la radio universitaria y el servicio de apoyo a la transferencia de la investigación, la innovación y la docencia.

- CEU Cardenal Herrera. Responde al cuestionario Elisa Marco Crespo, periodista de la Unidad de Comunicación Científica. Esta UCC+i pertenece al Servicio de Comunicación Corporativa de la Universidad, siendo el organismo que gestiona las acciones de comunicación de la ciencia. La periodista es la encargada de estas acciones con dedicación parcial, no existiendo ninguna persona con dedicación completa para las mismas. El Servicio de Comunicación Corporativa depende de la Gerencia de la 
Universidad CEU-UCH. En cuanto a otros organismos que colaboran en la comunicación de la ciencia, señala el Vicerrectorado de Investigación y Relaciones Internacionales.

- Universidad Católica de Valencia San Vicente Mártir. El DirCom de la Universidad, David Prada Moreno, responde el cuestionario. La institución cuenta con cuatro personas con dedicación parcial a la comunicación de la ciencia que se gestiona desde el Servicio de Comunicación dependiente del Rector.

\section{- Importancia otorgada a la comunicación de la ciencia}

Las respuestas sobre la importancia otorgada a la comunicación de la ciencia y las razones de la misma se abordan, al igual que las del resto del cuestionario, de modo genérico y anónimo. Los profesionales de la comunicación de la ciencia valoran mayoritariamente, en un $66,7 \%$ de los casos, como bastante la importancia que sus universidades otorgan a la comunicación de la ciencia. En dos casos elevaron esta consideración a mucha.

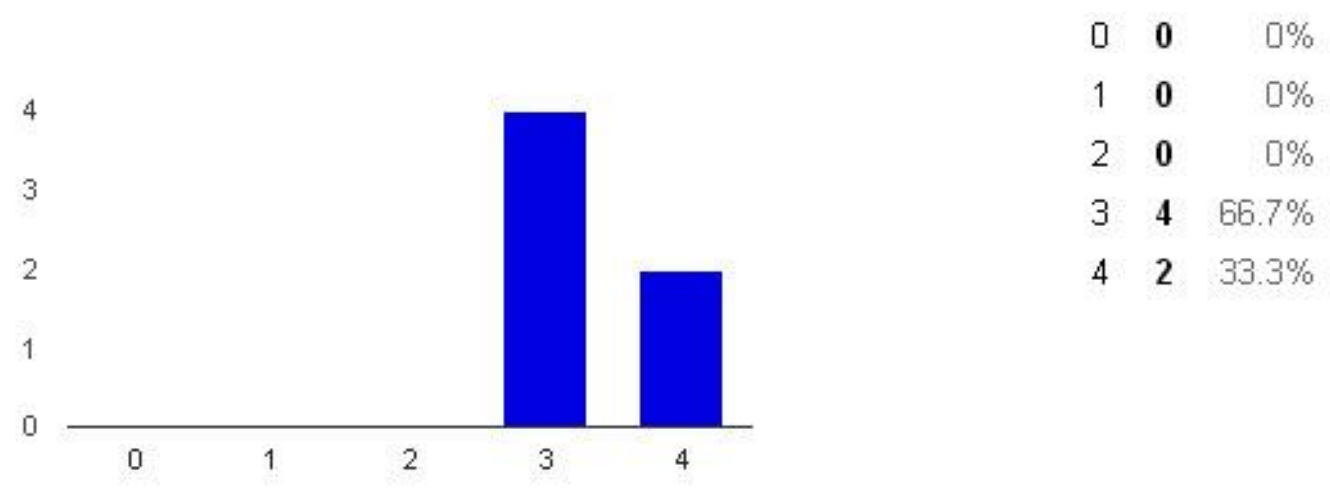

Las personas que contestaron al cuestionario expusieron las siguientes razones de la importancia otorgada a la comunicación de la ciencia por las Universidades:

- Una de las finalidades de la universidad pública de Castellón es participar en el progreso y desarrollo de la sociedad mediante la difusión del saber científico y sus aplicaciones. La comunidad científica es cada vez más consciente de que es necesario compartir los resultados de sus investigaciones con la ciudadanía para que pueda formarse una opinión y participar en las decisiones públicas con argumentos basados en la experimentación y el conocimiento científico.

- Mayor visibilidad de la institución; nuevas oportunidades de transferencia; contribuye a mejorar la cultura científica de la sociedad

- Existencia UCC+i. 
- Se ha designado a una persona del Servicio de Comunicación Corporativa para la difusión de la investigación.

- Es uno de los pilares de nuestra razón de ser.

- Somos una entidad generadora de ciencia y nuestra obligación es llevarla a la sociedad. Somos una entidad que tiene que crear y divulgar.

\subsubsection{El proceso comunicativo: acciones, públicos, canales y tiempos}

Este segundo punto recoge las cuestiones relacionadas con los procesos de la comunicación de la investigación y la innovación por parte de las universidades valencianas, incluyendo las acciones de comunicación más frecuentes y la importancia otorgada a cada una de ellas; los públicos prioritarios y la importancia de los mismos; los canales de retroalimentación utilizados y su grado de respuesta, y los tiempos de la investigación y la innovación que marcan la comunicación.

Detallaremos en las siguientes páginas cada una de las preguntas relacionadas con estos temas así como las respuestas planteadas por las universidades.

\section{- Acciones de comunicación}

En este apartado se planteaban las siguientes dos cuestiones, la primera de ella sobre la frecuencia de las diferentes acciones y, la segunda, sobre la importancia otorgada a cada una de ellas.

-¿Qué tipos de acciones de comunicación de la ciencia y la innovación son las que se realizan principalmente en su Universidad? Valore la frecuencia de las mismas.

\begin{tabular}{|c|c|c|c|c|c|c|}
\hline & Nada & Poca & Algo & Bastante & Mucha & $\begin{array}{c}\text { No sabe / } \\
\text { No } \\
\text { contesta }\end{array}$ \\
\hline $\begin{array}{l}\text { Elaboración de } \\
\text { productos } \\
\text { informativos para } \\
\text { su envío a medios } \\
\text { de comunicación } \\
\text { (notas de prensa, } \\
\text { vídeos, etc...) }\end{array}$ & $r$ & $C$ & $r$ & $r$ & $r$ & $C$ \\
\hline $\begin{array}{l}\text { Convocatoria de } \\
\text { ruedas de prensa }\end{array}$ & $r$ & $r$ & $r$ & $r$ & $r$ & $r$ \\
\hline $\begin{array}{l}\text { Atención a las } \\
\text { peticiones de los } \\
\text { medios }\end{array}$ & $r$ & $r$ & $r$ & $C$ & $r$ & $r$ \\
\hline Elaboración de & $r$ & $C$ & $r$ & $r$ & $r$ & $r$ \\
\hline
\end{tabular}




\begin{tabular}{|c|c|c|c|c|c|c|}
\hline & Nada & Poca & Algo & Bastante & Mucha & $\begin{array}{c}\text { No sabe / } \\
\text { No } \\
\text { contesta }\end{array}$ \\
\hline $\begin{array}{l}\text { contenidos para la } \\
\text { web de la } \\
\text { Universidad }\end{array}$ & & & & & & \\
\hline $\begin{array}{l}\text { Elaboración de } \\
\text { contenidos para } \\
\text { revista de la } \\
\text { Universidad } \\
\text { (impresa o digital) }\end{array}$ & $r$ & $r$ & $r$ & $C$ & $r$ & $r$ \\
\hline $\begin{array}{l}\text { Elaboración de } \\
\text { contenidos para la } \\
\text { radio de la } \\
\text { Universidad }\end{array}$ & $r$ & $C$ & $r$ & $r$ & $r$ & $r$ \\
\hline $\begin{array}{l}\text { Elaboración de } \\
\text { contenidos para la } \\
\text { televisión de la } \\
\text { Universidad }\end{array}$ & $r$ & $r$ & $r$ & $r$ & $r$ & $r$ \\
\hline $\begin{array}{l}\text { Gestión de blogs } \\
\text { de la Universidad } \\
\text { sobre } \\
\text { ciencia/innovación }\end{array}$ & $r$ & $r$ & $r$ & $C$ & $C$ & $C$ \\
\hline $\begin{array}{l}\text { Relaciones con } \\
\text { blogs externos } \\
\text { especializados en } \\
\text { ciencia }\end{array}$ & $C$ & $r$ & $r$ & $C$ & $r$ & $C$ \\
\hline Otras & $r$ & $r$ & $r$ & $C$ & $r$ & $r$ \\
\hline
\end{tabular}

- Valore la importancia que considera que tienen para la Universidad las acciones de comunicación anteriores.

\begin{tabular}{|c|c|c|c|c|c|c|}
\hline & Nada & Poca & Algo & Bastante & Mucha & $\begin{array}{c}\text { No sabe / } \\
\text { No } \\
\text { contesta }\end{array}$ \\
\hline $\begin{array}{l}\text { Elaboración de } \\
\text { productos } \\
\text { informativos para } \\
\text { su envío a medios } \\
\text { de comunicación } \\
\text { (notas de prensa, } \\
\text { vídeos, etc...) }\end{array}$ & $C$ & $r$ & $r$ & $r$ & $r$ & $r$ \\
\hline $\begin{array}{l}\text { Convocatoria de } \\
\text { ruedas de prensa }\end{array}$ & $r$ & $r$ & $r$ & $r$ & $r$ & $r$ \\
\hline $\begin{array}{l}\text { Atención a las } \\
\text { peticiones de los } \\
\text { medios }\end{array}$ & $C$ & $r$ & $C$ & $C$ & $r$ & $r$ \\
\hline
\end{tabular}




\begin{tabular}{|c|c|c|c|c|c|c|}
\hline & Nada & Poca & Algo & Bastante & Mucha & $\begin{array}{c}\text { No sabe / } \\
\text { No } \\
\text { contesta }\end{array}$ \\
\hline $\begin{array}{l}\text { Elaboración de } \\
\text { contenidos para la } \\
\text { web de la } \\
\text { Universidad }\end{array}$ & $r$ & $r$ & $C$ & $C$ & $r$ & $r$ \\
\hline $\begin{array}{l}\text { Elaboración de } \\
\text { contenidos para la } \\
\text { revista de la } \\
\text { Universidad } \\
\text { (impresa o digital) }\end{array}$ & $C$ & $r$ & $C$ & $C$ & $C$ & $C$ \\
\hline $\begin{array}{l}\text { Elaboración de } \\
\text { contenidos para la } \\
\text { radio de la } \\
\text { Universidad }\end{array}$ & $C$ & $r$ & $r$ & $C$ & $C$ & $C$ \\
\hline $\begin{array}{l}\text { Elaboración de } \\
\text { contenidos para la } \\
\text { televisión de la } \\
\text { Universidad }\end{array}$ & $C$ & $C$ & $C$ & $C$ & $C$ & $C$ \\
\hline $\begin{array}{l}\text { Gestión de blogs } \\
\text { de la Universidad } \\
\text { sobre } \\
\text { ciencia/innovación }\end{array}$ & $C$ & $r$ & $r$ & $C$ & $r$ & $r$ \\
\hline $\begin{array}{l}\text { Relaciones con } \\
\text { blogs externos } \\
\text { especializados en } \\
\text { ciencia }\end{array}$ & $r$ & $r$ & $r$ & $C$ & $r$ & $r$ \\
\hline Otras & $r$ & $r$ & $r$ & $r$ & $r$ & $C$ \\
\hline
\end{tabular}

- En el caso de que exista alguna acción que a pesar de tener una importancia alta se realice con poca frecuencia ¿puede explicar las causas?

A continuación analizaremos las respuestas planteadas para cada una de las acciones, incluyendo los gráficos extraídos del programa de formularios de Google Drive utilizado para la realización de la encuesta.

- Elaboración de productos informativos para su envío a medios de comunicación (notas de prensa, vídeos, etc...). Las universidades utilizan esta acción de forma muy frecuente, otorgándole bastante o mucha importancia, como se desprende de los siguientes gráficos. 


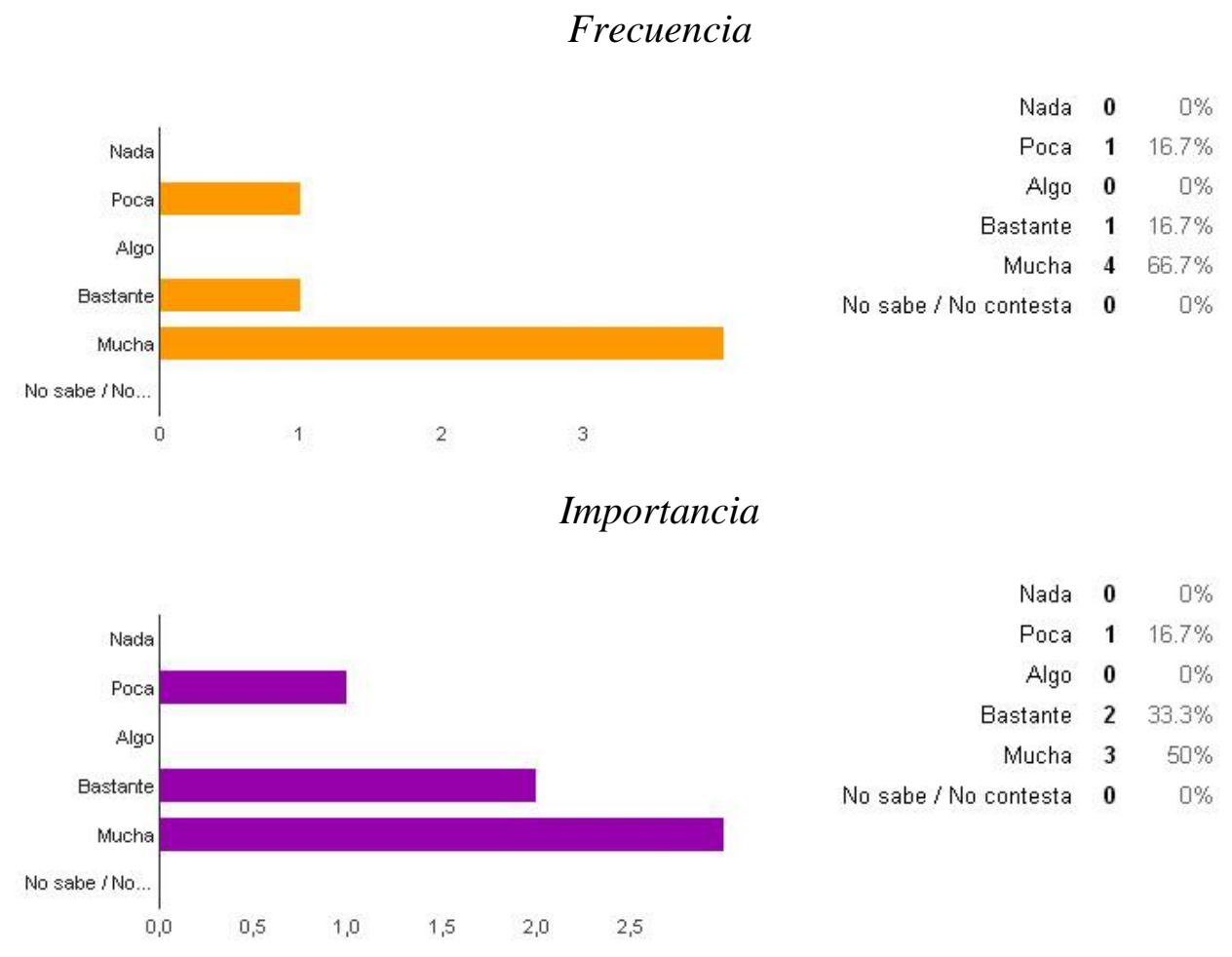

- Convocatoria de ruedas de prensa. La mitad de las universidades otorgan poca o ninguna importancia a este recurso, mientras que otras dos universidades lo sitúan como algo importante y sólo una como bastante. En el caso de la frecuencia, las cifras son todavía más reducidas, señalando la mitad de los encuestados que nunca realizan ruedas de prensa sobre ciencia. Uno de los encuestados explicaba así las posibles razones de esta reducida frecuencia.

Las ruedas de prensa pueden considerarse más importantes pero son menos frecuentes, porque los medios de comunicación disponen cada vez de menos redactores especializados en educación, ciencia y tecnología (al menos en el ámbito provincial) debido a la situación económica que ha reducido el número de redactores y ha obligado a los que han quedado a ocuparse de más temas. Esta razón también ha influido en el número de peticiones de los medios de comunicación, y sobre todo, en la petición de temas originales o de investigación periodística.

\section{Frecuencia}
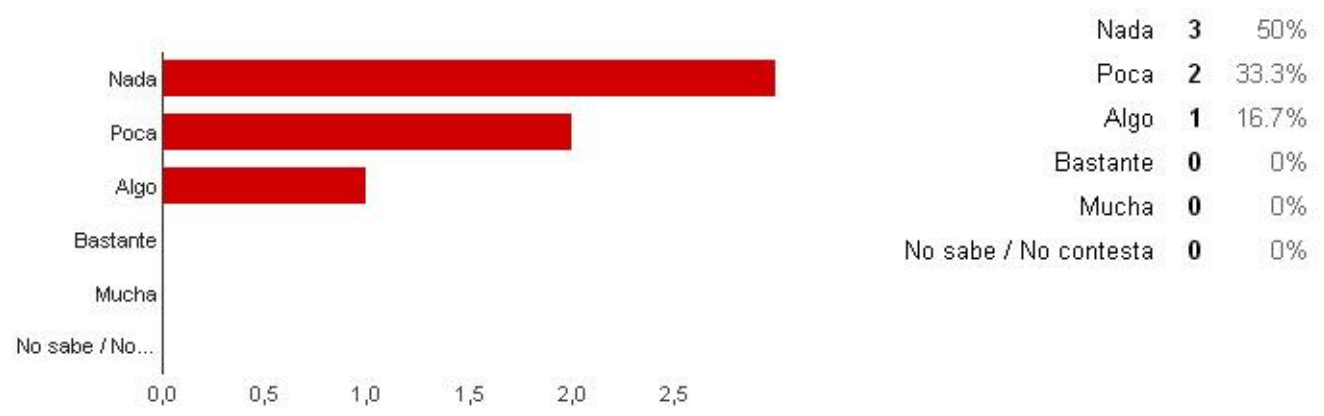

No sabe / No contesta $\mathbf{0} \quad 0 \%$ 


\section{Importancia}
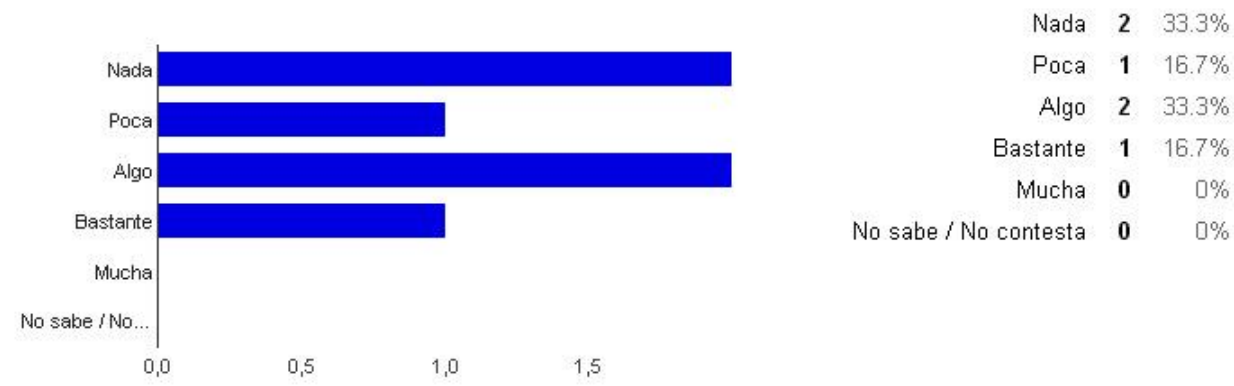

- Atención a las peticiones de los medios. La mayoría de universidades realizan con mucha o bastante frecuencia acciones de atención a las peticiones y consultas de los medios de comunicación en materia de investigación o innovación, otorgándoles a las mismas mucha importancia.

\section{Frecuencia}
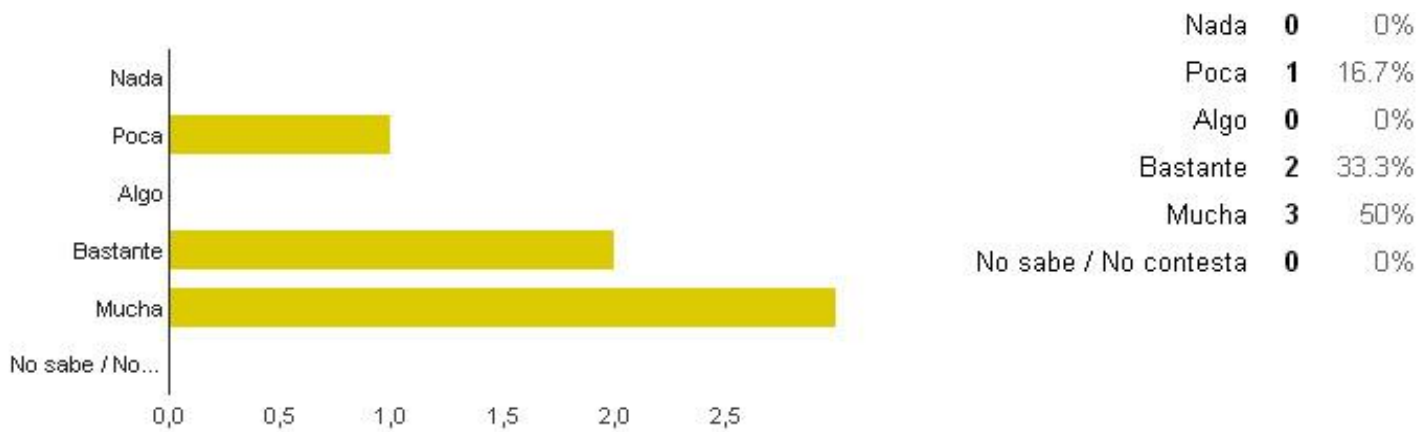

Importancia
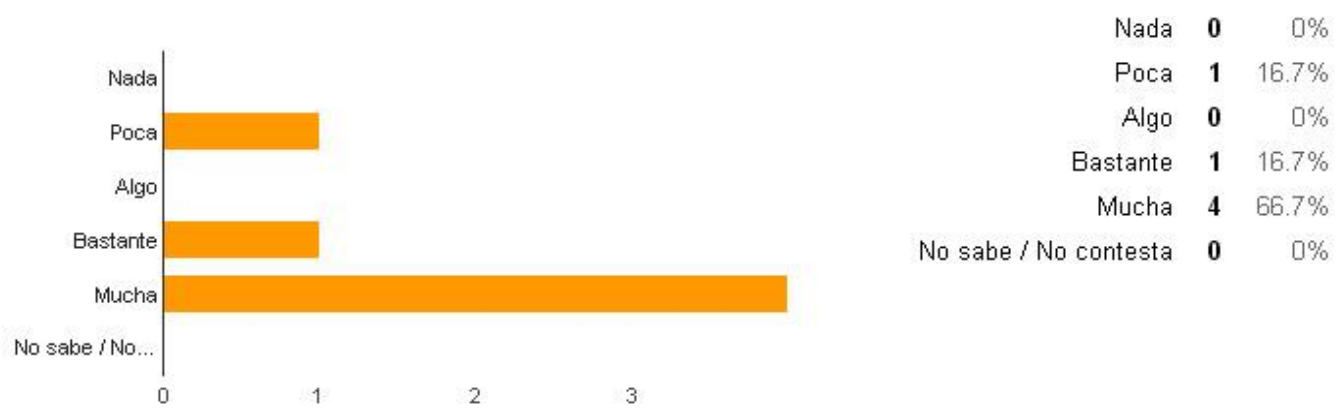

- Elaboración de contenidos para la web de la Universidad. Por las respuestas de los encuestados, la creación de contenidos para la web de la universidad centra gran parte de la labor de los gestores de la comunicación de la ciencia, señalando el 83,3\% que realizan esta acción con mucha frecuencia y el 16,7\% con bastante. En este caso existe unanimidad a la hora de conceder mucha importancia a esta acción. 


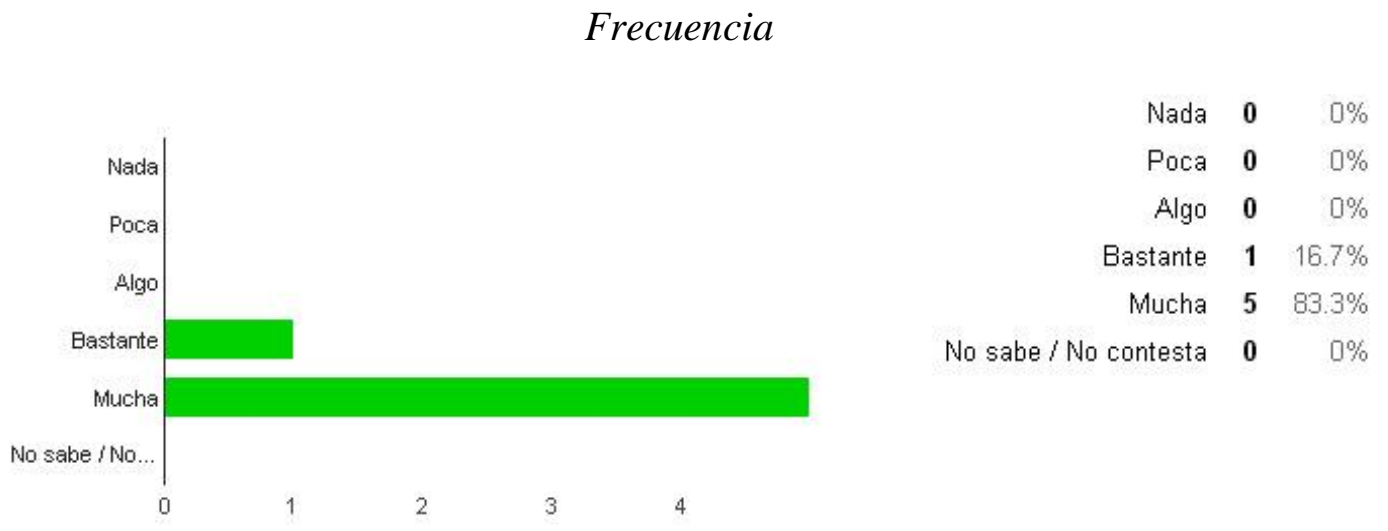

Importancia
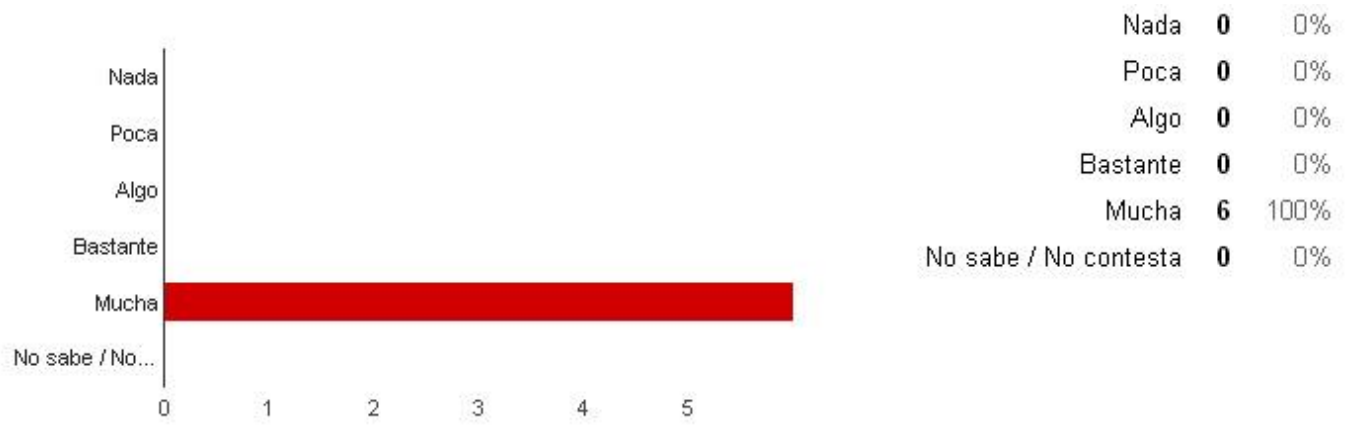

- Elaboración de contenidos para la revista de la Universidad (impresa o digital). En este caso existen dos universidades que señalan no realizar ningún tipo de contenidos para la revista de la universidad mientras que tres realizan muchos y una, algunos. También existen diferencias de criterio a la hora de valorar este tipo de acción ya que dos no la consideran nada importante mientras que las cuatro restantes valoran la importancia como bastante o mucha.

\section{Frecuencia}
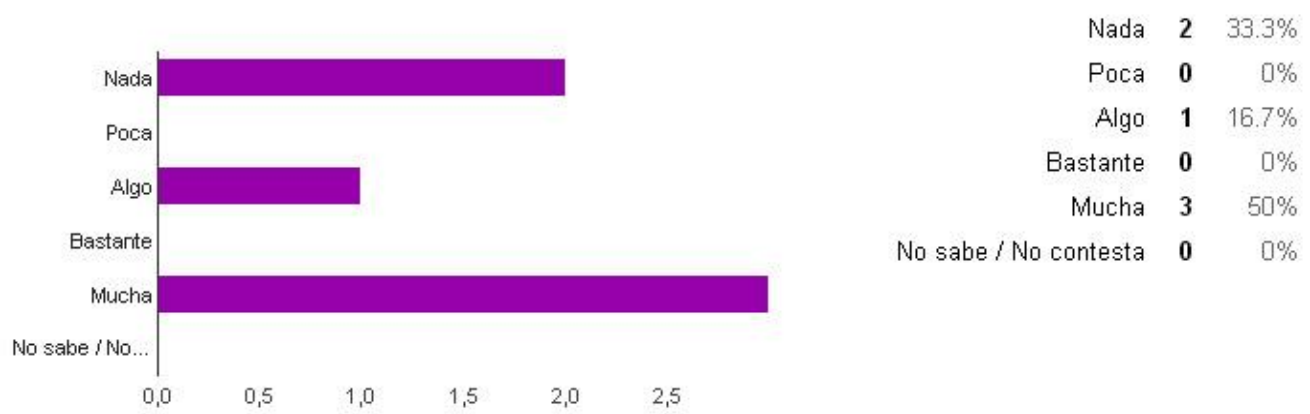


\section{Importancia}
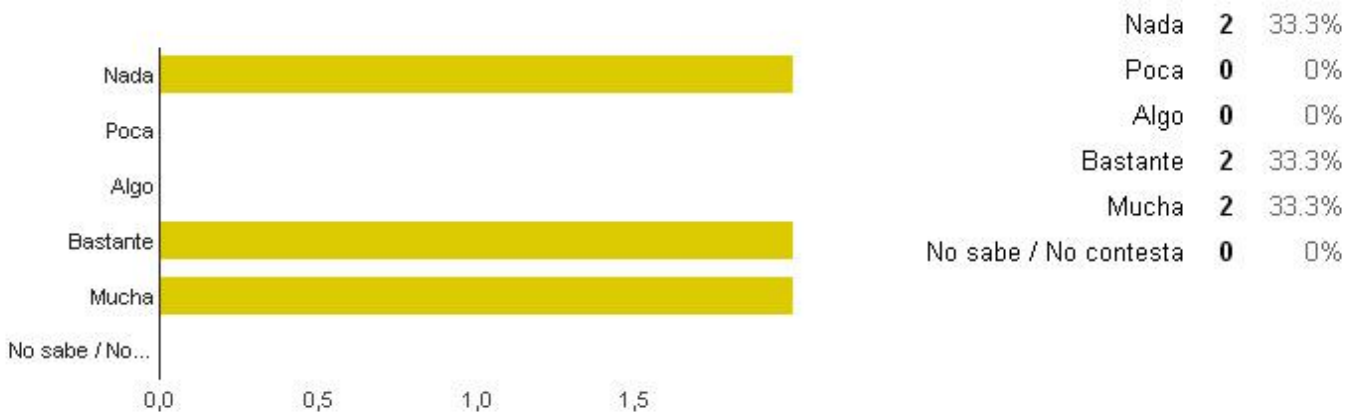

- Elaboración de contenidos para la radio de la Universidad. La frecuencia con la que los gestores de la comunicación científica realizan contenidos para las radios universitarias es muy variada, yendo desde ninguna a mucha, pasando por algo y bastante. En cuanto a la importancia, la mitad consideran esta acción como muy importante mientras que las restantes oscilan a la hora de valorarla entre nada y bastante importante.

\section{Frecuencia}
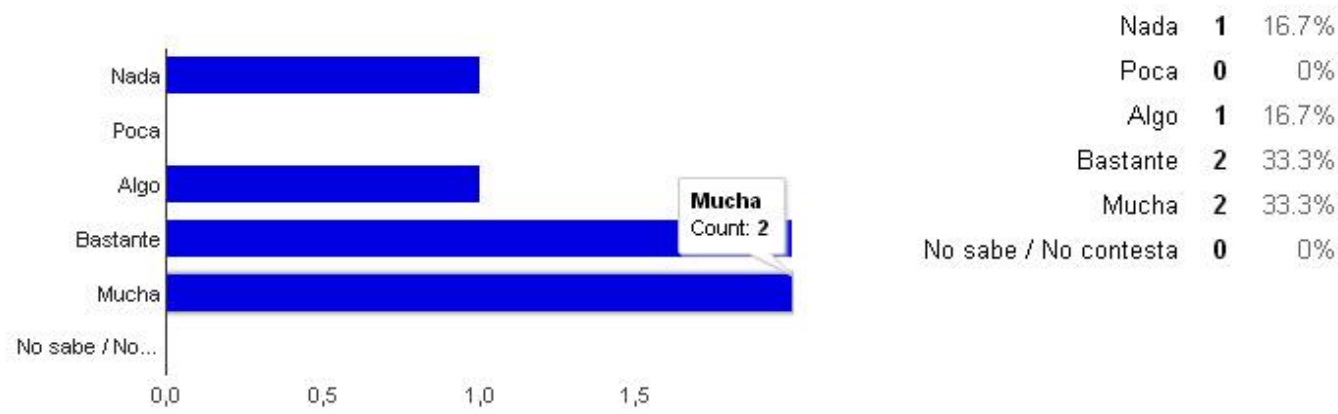

\section{Importancia}
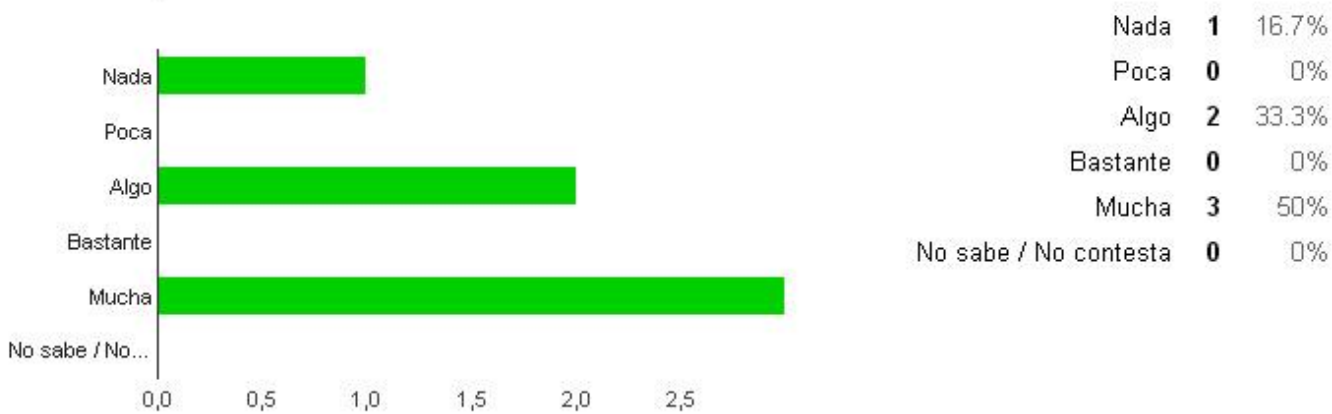
- Elaboración de contenidos para la televisión de la Universidad. Al igual que en el caso de la elaboración de contenidos para las revistas y las radios, en el caso de la televisión las respuestas son también muy variadas, yendo la frecuencia de las mismas desde nada a mucho. Cabe tener en cuenta en este sentido que algunas universidades no cuentan con canal de televisión, lo que podría explicar también la respuesta de "no sabe/no contesta". En cualquier caso, la importancia concedida a esta acción es mayor que la frecuencia con la que se realiza.

\section{Frecuencia}
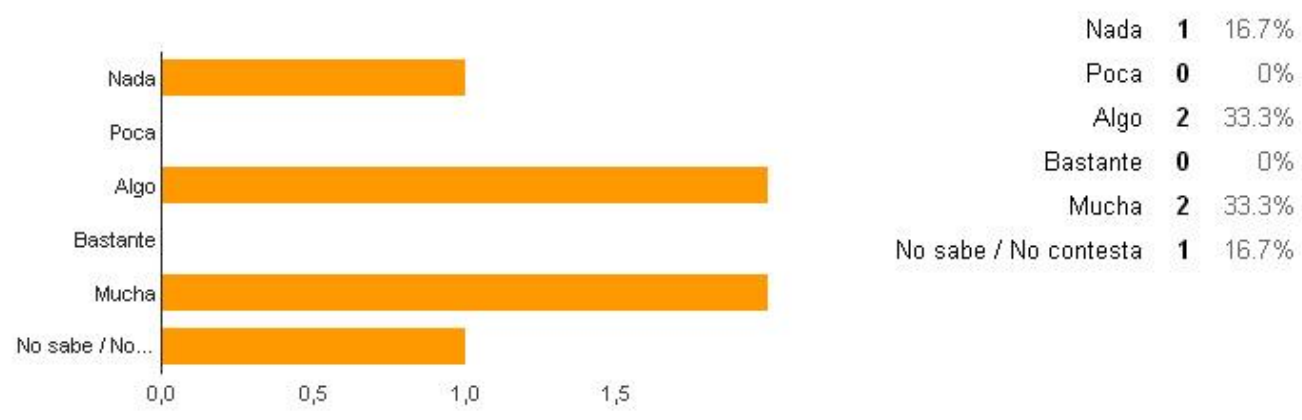

Importancia
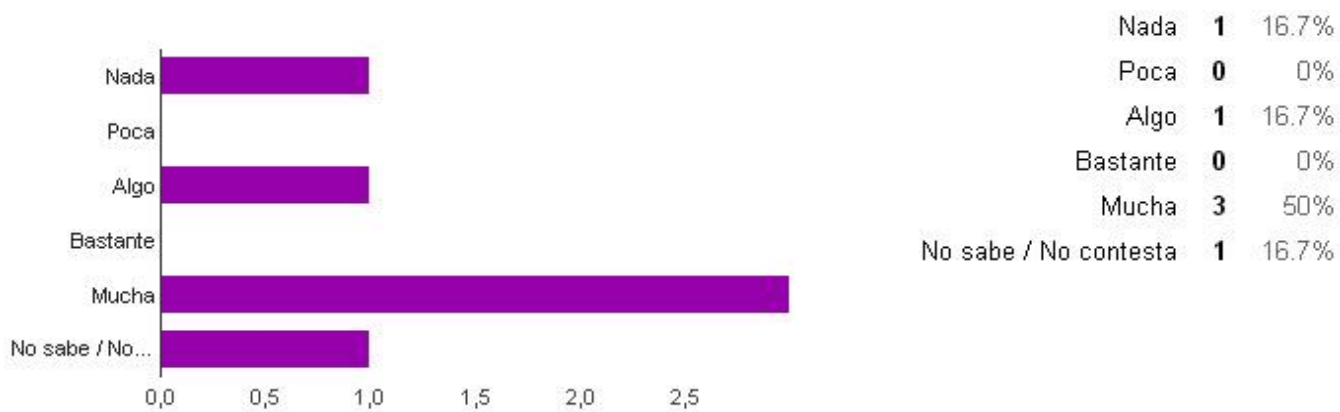

- Gestión de blogs de la Universidad sobre ciencia/innovación. Cinco de las seis universidades que contestaron a la encuesta señalaron que realizan la gestión de blogs dedicados a ciencia e innovación con mucha frecuencia, mientras que tan sólo una señaló que no realiza este tipo de acción, lo que hace pensar en la falta de existencia de este tipo de canal. La importancia concedida a los mismos varía respecto a la frecuencia, ya que en este caso fueron tres las que lo consideraron muy importante y las tres restantes redujeron la valoración a nada, algo o bastante. 


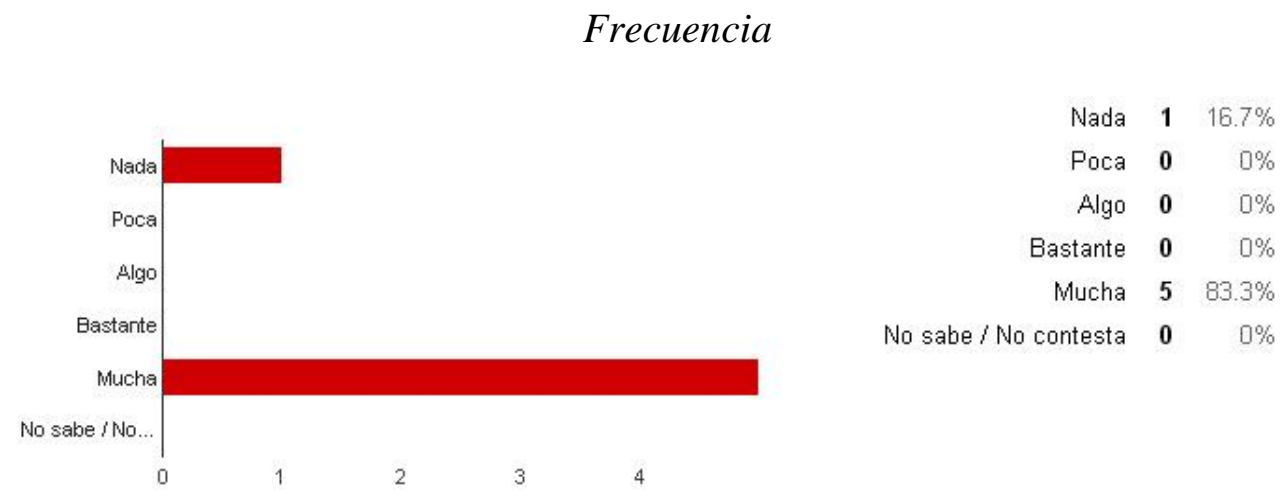

Importancia

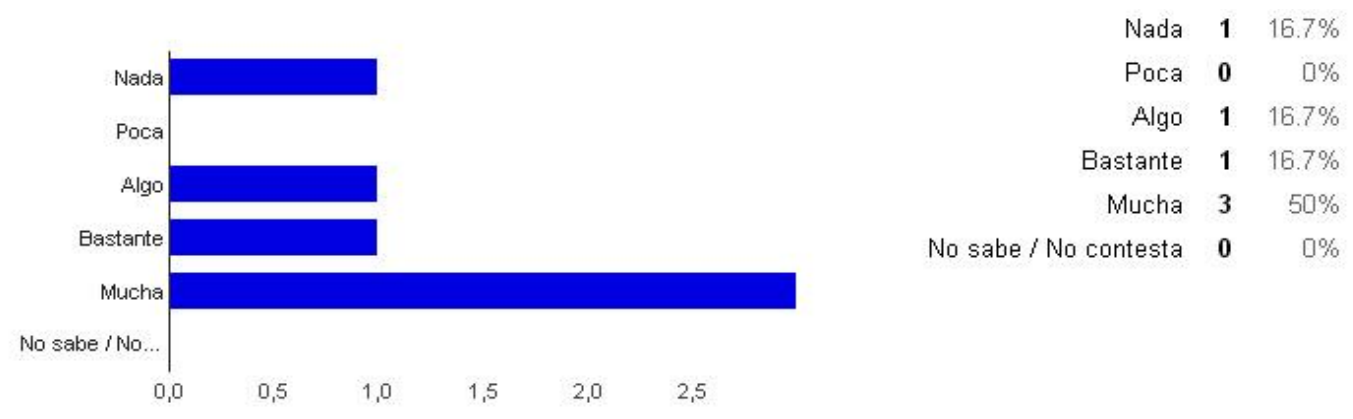

- Relaciones con blogs externos especializados en ciencia. En este caso tan sólo existe una universidad que mantienen relaciones con blogs externos de ciencia con mucha frecuencia, mientras que las cinco restante oscilan entre nada, poco y, en un caso, algo. La importancia concedida a esta acción es muy variable, yendo del "no sabe/no contesta" a aquellos que entienden que no tiene ninguna importancia y los que piensan que tiene bastante. Sobre esta acción uno de los encuestados comentó que se trata de un ámbito en el que consideran que se debe avanzar:

Tenemos más desarrollada la relación con medios de comunicación que con blogs especializados en ciencia, un ámbito en el que debemos avanzar (lo hacemos poco pero es importante).

\section{Frecuencia}
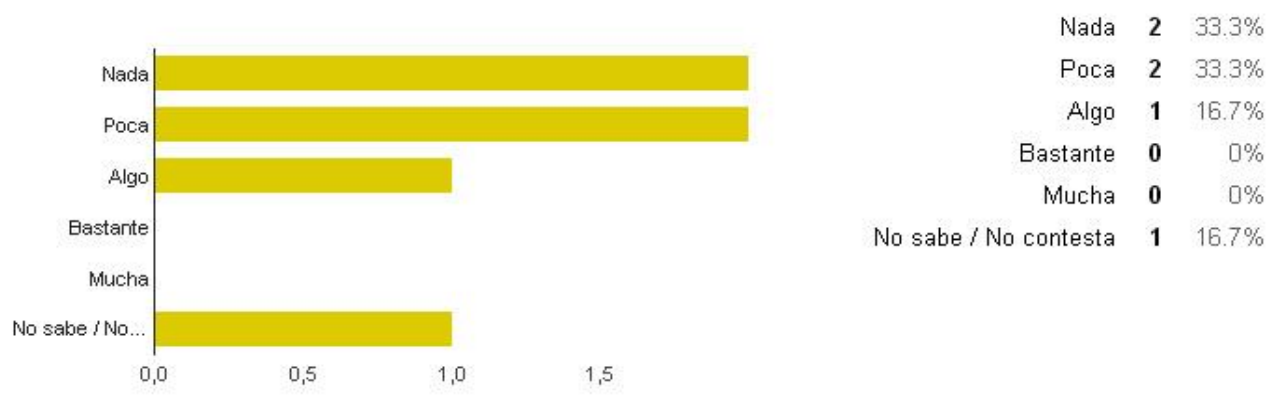


\section{Importancia}

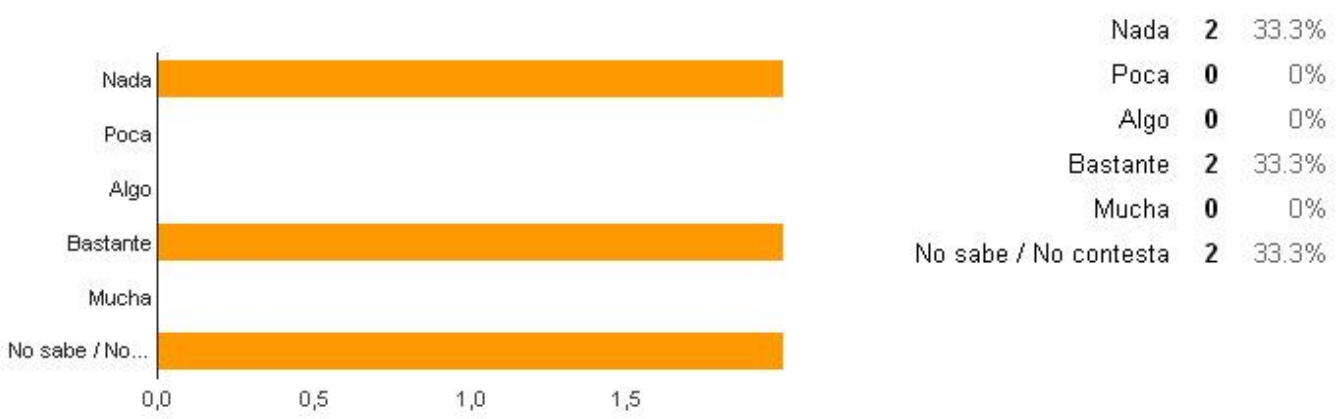

- Otras. La mayoría de encuestados marcó en este apartado la casilla de "no sabe/no contesta" mientras que una universidad indicó que no realiza con ninguna frecuencia ni considera importantes otro tipo de acciones. Tan sólo una señaló como bastante la frecuencia e importancia de otras acciones, relacionándolo con el siguiente comentario sobre la gestión de redes sociales:

Difusión en redes sociales de la Universidad y perfil específico en Twitter.

En este sentido, cabe señalar que se incluye una pregunta específica sobre redes sociales a la hora de abordar las herramientas y canales de interacción con los públicos.

\section{Frecuencia}
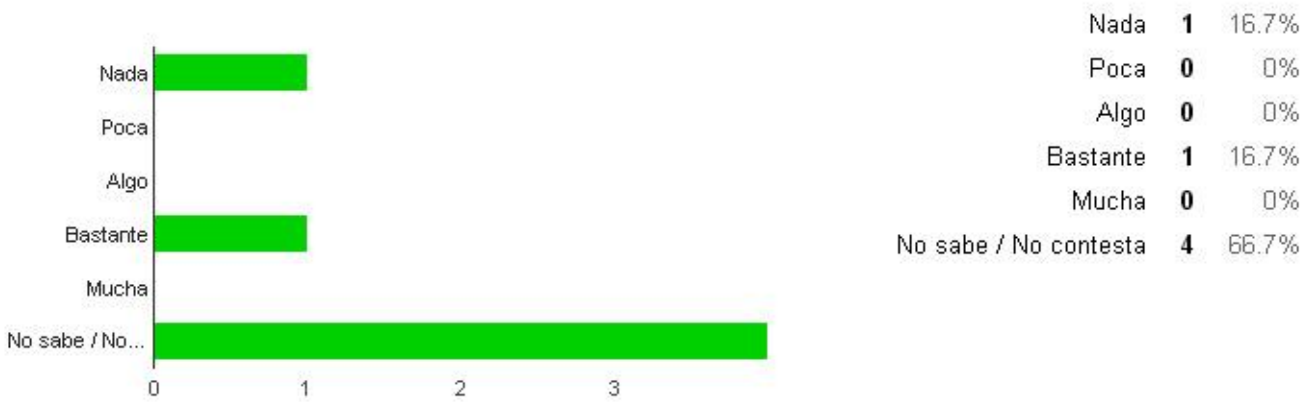

Importancia
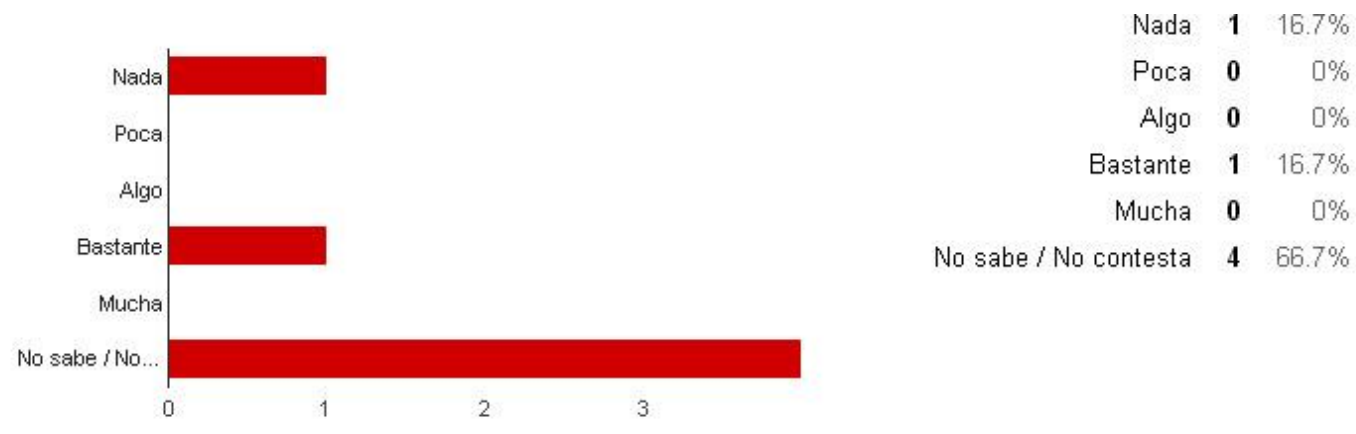


\section{COMPARATIVAS}

Con el fin de poner en relación unas respuestas con otras, se han elaborado gráficos en los que se recoge la frecuencia y la importancia concedida por cada una de las universidades a los diferentes recursos. Asimismo, se ha extraído la media de las respuestas con el fin de favorecer la comparación. Para la elaboración de estos gráficos se ha establecido una relación numérica, de forma que a las respuestas "nunca" y "no sabe/no contesta" se les ha atribuido el 0 al entender que en ninguno de los casos se realizan o se da importancia a esas acciones. Las restantes respuestas se han valorado del 1 al 4 (1-poco, 2-algo, 3-bastante y 4-mucho).

En el caso de la frecuencia, los gráficos evidencian cómo la elaboración de contenidos para la web de la universidad es la acción que realizan con mayor frecuencia los profesionales de la comunicación de la ciencia, seguida de la elaboración de productos informativos para su envío a medios y la gestión de blogs de ciencia propios de la universidad, lo que hace pensar que gran parte de los centros encuestados cuentan con este tipo de canales y dedican a su gestión una parte importante de sus recursos. La atención a las peticiones de los medios es la cuarta acción más frecuente para las universidades.

Por el contrario, entre las menos frecuentes se encuentra la convocatoria de ruedas de prensa, lo que puede deberse, tal y cómo señalaban en sus comentarios, a la disminución de periodistas en las redacciones. Resulta igualmente baja la frecuencia de las relaciones con blogs externos de ciencia e innovación. En un lugar intermedio se sitúa la elaboración de contenidos para revistas, radios y televisiones universitarias. En este sentido, cabe destacar la disparidad de respuestas entre universidades, lo que podría deberse al hecho de que cada universidad cuente o no con cada uno de estos medios.

\section{Frecuencia}

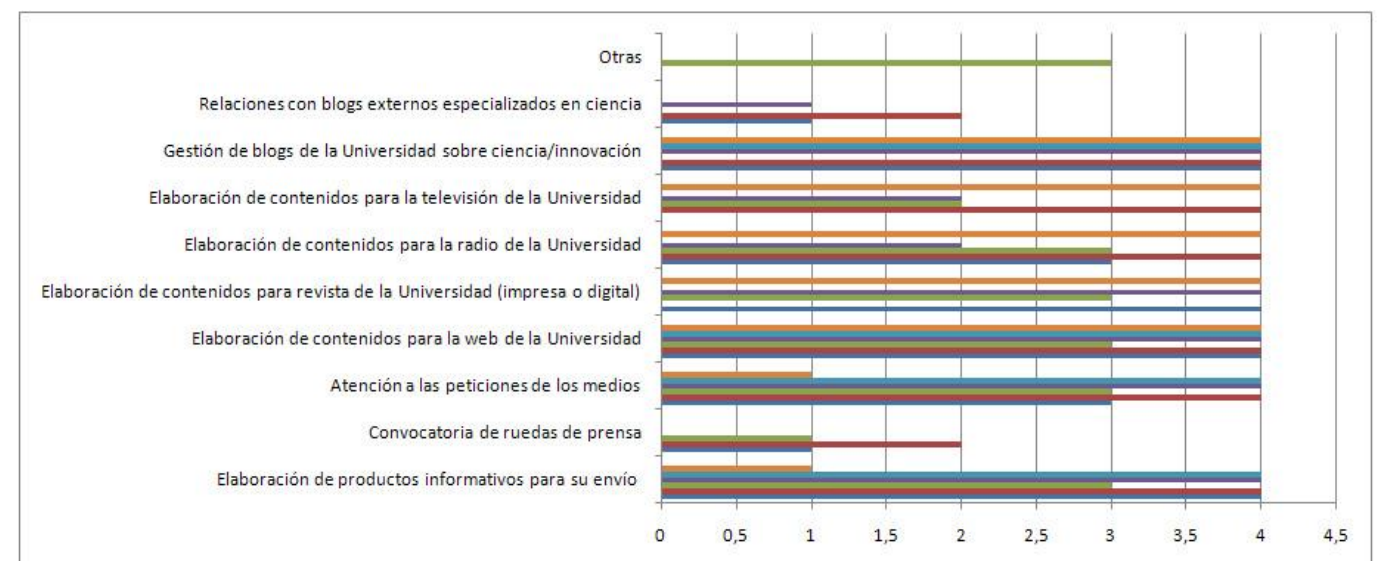




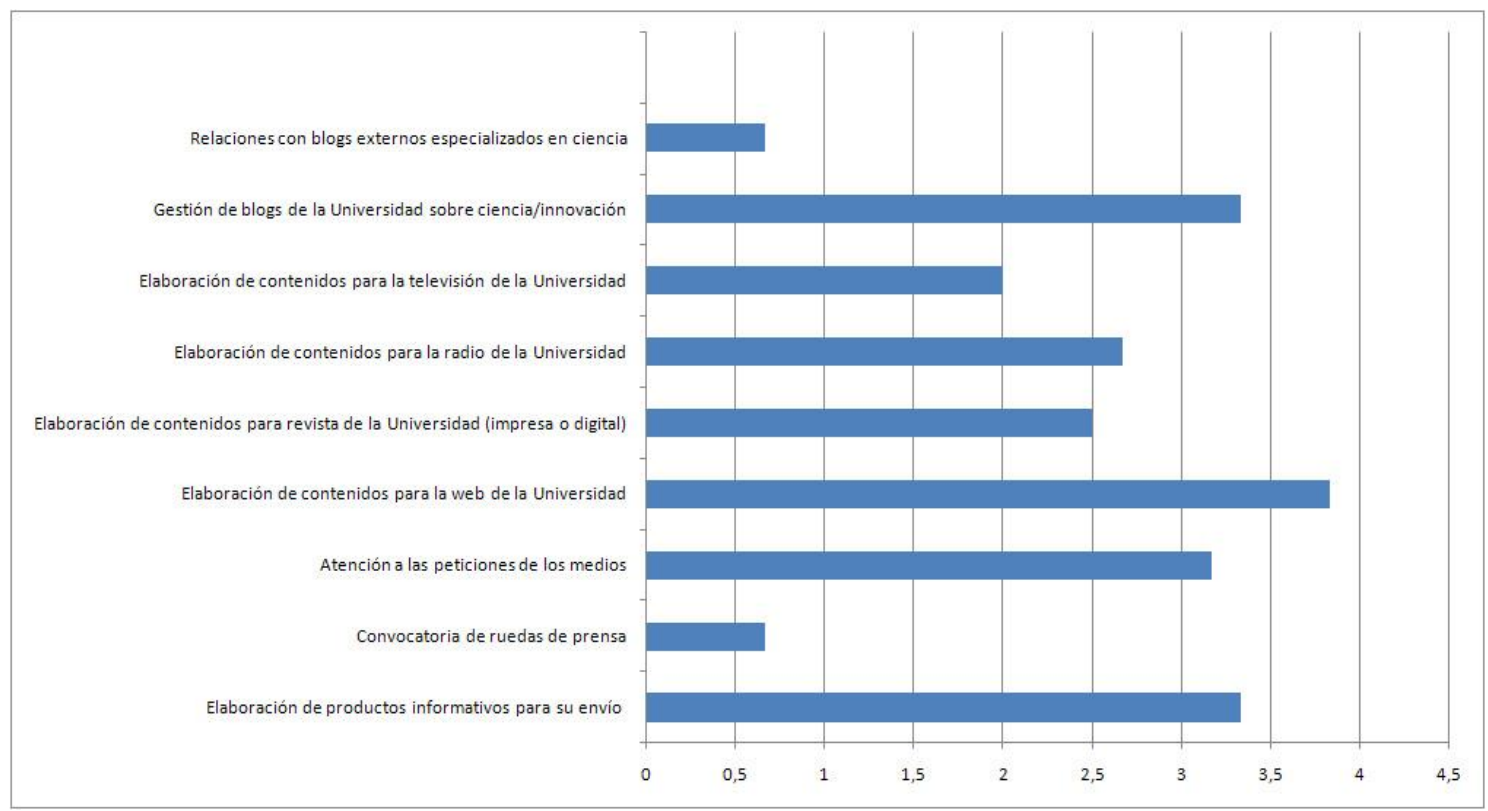

Por lo que respecta a la importancia concedida a cada una de estas acciones o recursos comunicativos en materia de investigación e innovación, existe unanimidad a la hora de otorgar mucha importancia a la elaboración de contenidos para la web. A continuación aparecen, con igual puntuación, la elaboración de contenidos para su envío a medios y la atención a las peticiones de los mismos. Esto viene a ratificar el peso que siguen teniendo los medios de comunicación tradicionales en la gestión de la comunicación de la ciencia de las universidades. Como ocurría en el caso de la frecuencia, la relación con blogs externos y la realización de ruedas de prensa son las acciones consideradas menos importantes. En cuanto a la elaboración y gestión de medios propios de las universidades, los encuestados han puntuado de forma más elevada los blogs sobre ciencia seguidos de la radio y, a continuación, las revistas y televisiones.

\section{Importancia}

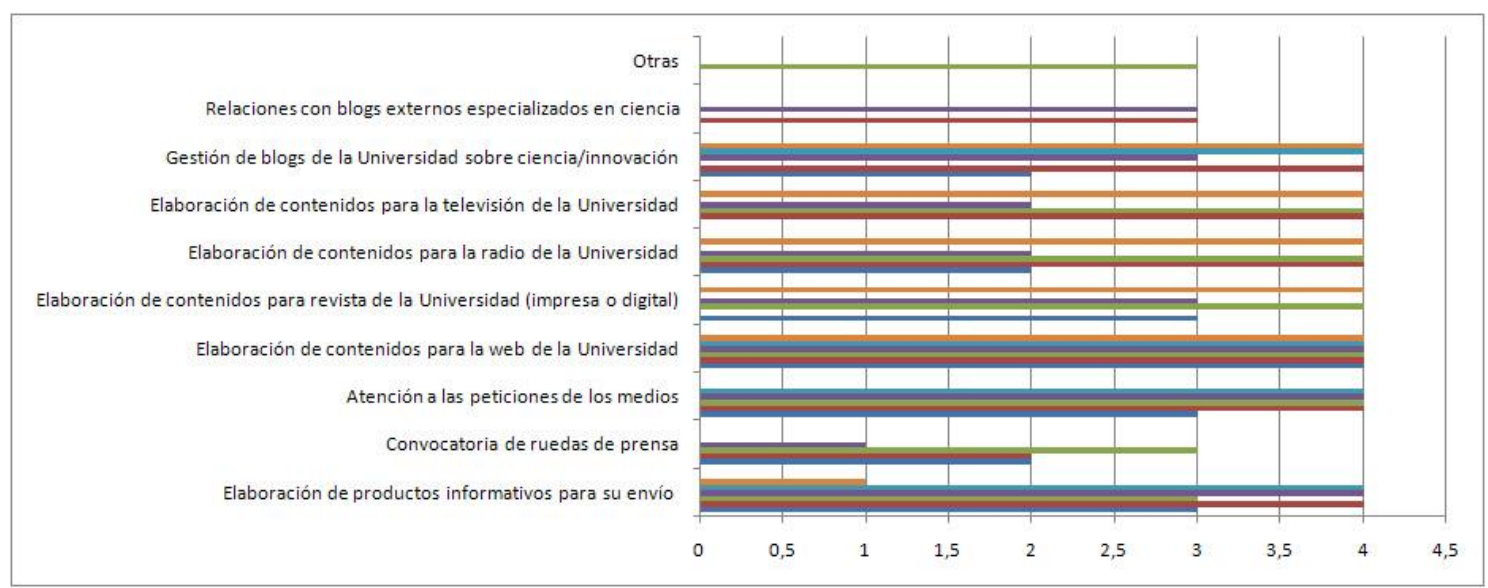




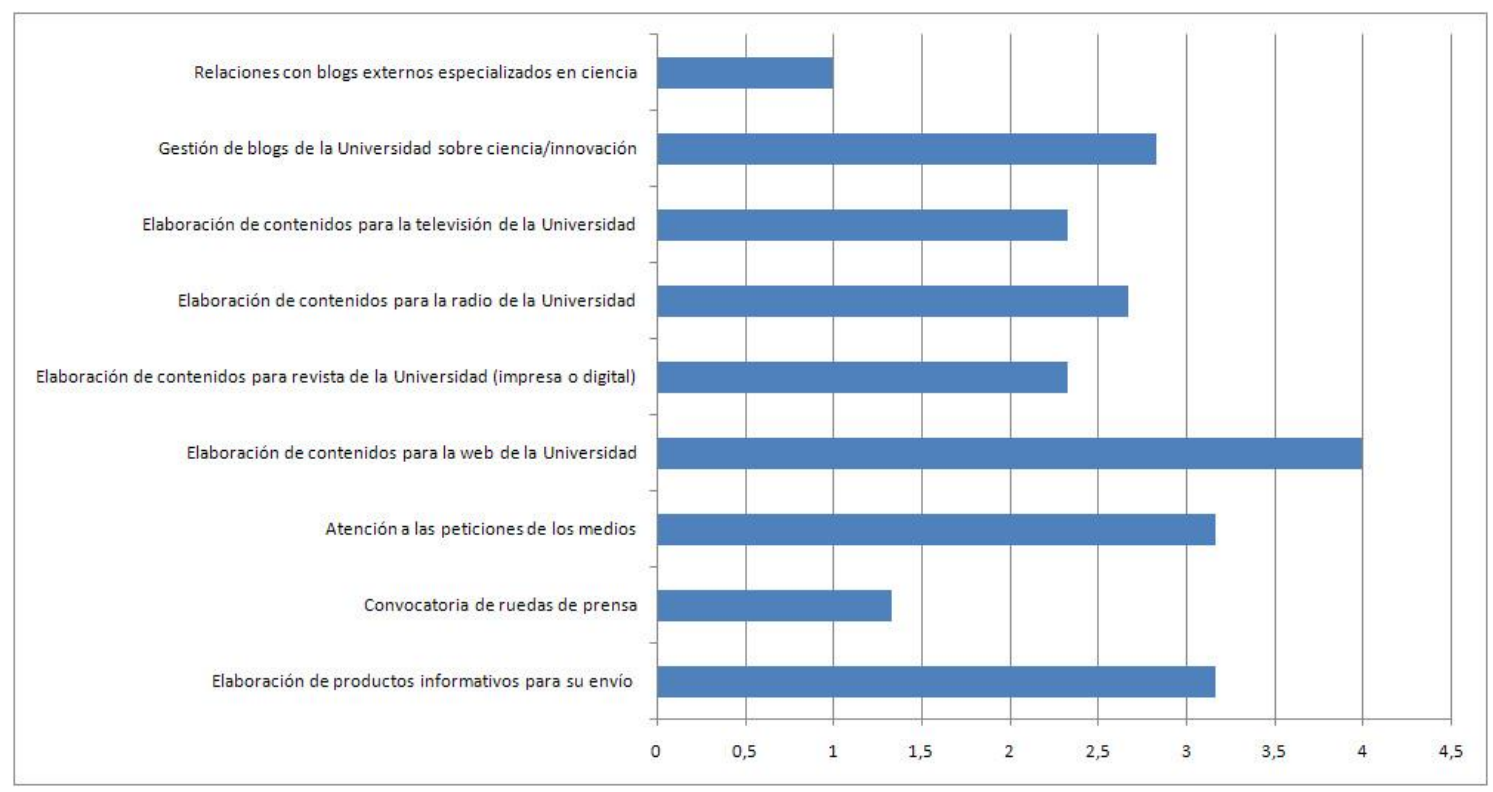

Finalmente, se han puesto en relación las valoraciones medias de frecuencia e importancia para poder compararlas. Tan sólo coinciden ambas en el caso de la atención a las peticiones de los medios y la elaboración de contenidos para las radios universitarias. En las restantes acciones, las puntuaciones varían, de forma que en cuatro de ellas se considera mayor la importancia que tienen que la frecuencia con la que se realizan. Es el caso de las relaciones con blogs externos especializados en ciencia, la convocatoria de ruedas de prensa y la elaboración de contenidos para la televisión y la web universitarias. En los restantes tres casos ocurre lo contrario, siendo acciones a las que se otorga menos importancia que la frecuencia con la que se realizan. Se encuentran en esta situación la gestión de blogs de la universidad sobre ciencia, la elaboración de contenidos para la revista universitaria y la elaboración de productos informativos para medios. Cabe señalar que una de las universidades encuestadas otorgó los mismos valores de frecuencia e importancia a cada una de las acciones argumentando que "las acciones que se realizan son las que consideramos más importantes”.

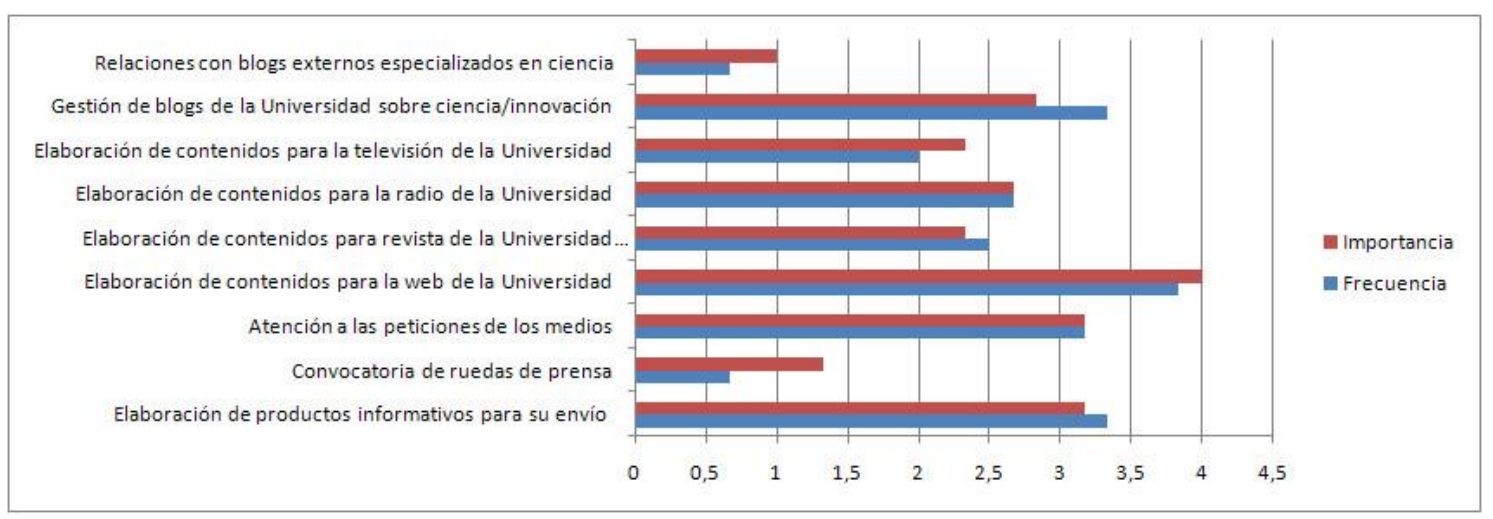




\section{- Públicos destinatarios}

El cuestionario incluyó dos preguntas relacionadas directamente con los públicos de la comunicación de la ciencia con el fin de conocer los más frecuentes y la importancia otorgada desde el ámbito de la comunicación de la ciencia a cada uno de ellos. En concreto, se plantearon las siguientes dos cuestiones:

- Respecto a los públicos destinatarios de las acciones de comunicación, valore cuáles de los siguientes son los más frecuentes.

\begin{tabular}{|c|c|c|c|c|c|c|}
\hline & Nunca & Poco & Algo & Bastante & Mucho & $\begin{array}{c}\text { No sabe / } \\
\text { No } \\
\text { contesta }\end{array}$ \\
\hline $\begin{array}{l}\text { Sociedad del } \\
\text { entorno de la } \\
\text { Universidad }\end{array}$ & $C$ & $C$ & $r$ & $r$ & $C$ & $r$ \\
\hline $\begin{array}{l}\text { Sociedad a } \\
\text { nivel global }\end{array}$ & $C$ & $r$ & $r$ & $r$ & $r$ & $r$ \\
\hline $\begin{array}{l}\text { Administración } \\
\text { pública } \\
\text { local/provincial }\end{array}$ & $r$ & $r$ & $r$ & $r$ & $C$ & $C$ \\
\hline $\begin{array}{l}\text { Administración } \\
\text { pública } \\
\text { autonómica }\end{array}$ & $r$ & $r$ & $r$ & $C$ & $r$ & $r$ \\
\hline $\begin{array}{l}\text { Administración } \\
\text { pública } \\
\text { nacional }\end{array}$ & $C$ & $r$ & $r$ & $r$ & $r$ & $r$ \\
\hline $\begin{array}{l}\text { Administración } \\
\text { pública europea }\end{array}$ & $r$ & $r$ & $r$ & $r$ & $r$ & $r$ \\
\hline $\begin{array}{l}\text { Comunidad } \\
\text { científica } \\
\text { interna de la } \\
\text { Universidad }\end{array}$ & $r$ & $r$ & 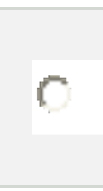 & $r$ & $r$ & $r$ \\
\hline $\begin{array}{l}\text { Comunidad } \\
\text { científica } \\
\text { externa }\end{array}$ & $r$ & $r$ & $r$ & $r$ & $C$ & $C$ \\
\hline $\begin{array}{l}\text { Medios de } \\
\text { comunicación a } \\
\text { nivel } \\
\text { local/regional }\end{array}$ & $r$ & $r$ & $r$ & $r$ & $r$ & $C$ \\
\hline $\begin{array}{l}\text { Medios de } \\
\text { comunicación a } \\
\text { nivel nacional }\end{array}$ & $C$ & $C$ & $r$ & $r$ & $C$ & $r$ \\
\hline $\begin{array}{l}\text { Medios de } \\
\text { comunicación a } \\
\text { nivel } \\
\text { internacional }\end{array}$ & $C$ & $r$ & $r$ & $r$ & $r$ & $r$ \\
\hline
\end{tabular}


- ¿Qué importancia considera que tienen para la comunicación de la ciencia de la Universidad cada uno de estos públicos?

\begin{tabular}{|c|c|c|c|c|c|c|}
\hline & Nada & Poca & Algo & Bastante & Mucha & $\begin{array}{c}\text { No sabe / } \\
\text { No } \\
\text { contesta }\end{array}$ \\
\hline $\begin{array}{l}\text { Sociedad del } \\
\text { entorno de la } \\
\text { Universidad }\end{array}$ & $r$ & $C$ & $r$ & $r$ & $r$ & $r$ \\
\hline $\begin{array}{l}\text { Sociedad a } \\
\text { nivel global }\end{array}$ & $r$ & $r$ & $r$ & $r$ & $r$ & $r$ \\
\hline $\begin{array}{l}\text { Administración } \\
\text { pública } \\
\text { local/provincial }\end{array}$ & $r$ & $r$ & C & $C$ & $r$ & $C$ \\
\hline $\begin{array}{l}\text { Administración } \\
\text { pública } \\
\text { autonómica }\end{array}$ & $r$ & $r$ & $r$ & $r$ & $r$ & $r$ \\
\hline $\begin{array}{l}\text { Administración } \\
\text { pública } \\
\text { nacional }\end{array}$ & $r$ & $r$ & $r$ & $r$ & $r$ & $r$ \\
\hline $\begin{array}{l}\text { Administración } \\
\text { pública europea }\end{array}$ & $C$ & $r$ & $r$ & $r$ & $r$ & $r$ \\
\hline $\begin{array}{l}\text { Comunidad } \\
\text { científica } \\
\text { interna de la } \\
\text { Universidad }\end{array}$ & $C$ & $C$ & $C$ & $C$ & $r$ & $r$ \\
\hline $\begin{array}{l}\text { Comunidad } \\
\text { científica } \\
\text { externa }\end{array}$ & $r$ & $C$ & $C$ & $C$ & $r$ & $C$ \\
\hline $\begin{array}{l}\text { Medios de } \\
\text { comunicación a } \\
\text { nivel } \\
\text { local/regional }\end{array}$ & $r$ & $r$ & $r$ & $r$ & $r$ & C \\
\hline $\begin{array}{l}\text { Medios de } \\
\text { comunicación a } \\
\text { nivel nacional }\end{array}$ & $r$ & $C$ & $C$ & $r$ & $r$ & $r$ \\
\hline $\begin{array}{l}\text { Medios de } \\
\text { comunicación a } \\
\text { nivel } \\
\text { internacional }\end{array}$ & $r$ & $r$ & $r$ & $C$ & $r$ & C \\
\hline
\end{tabular}

Recogemos a continuación la valoración mostrada por las universidades valencianas respecto a cada uno de estos públicos.

- Sociedad del entorno de la universidad. Para la mayoría de universidades la sociedad del entorno es un púbico prioritario, calificándolo todas ellas como un público muy importante, lo que explica que para cinco de las seis sea un público al que se dirigen sus acciones de comunicación con mucha frecuencia. 
Frecuencia
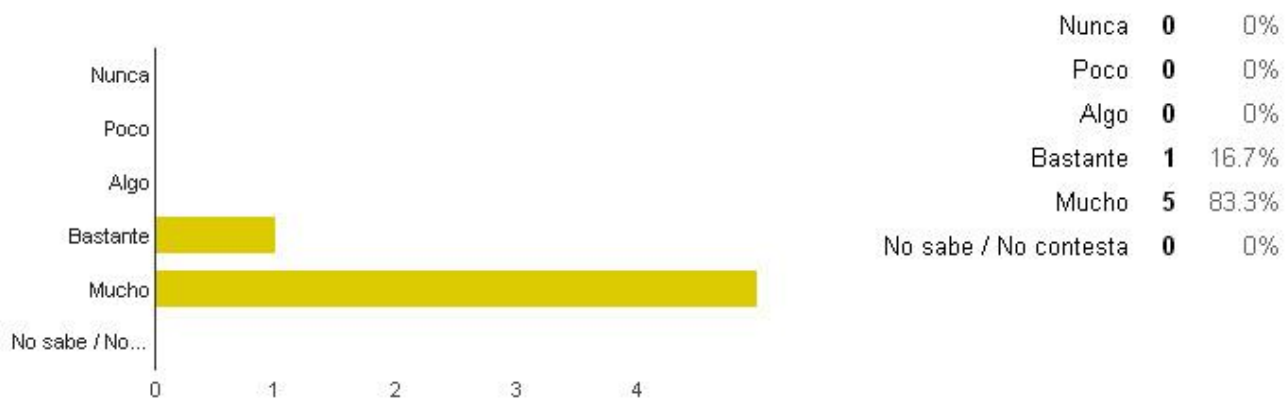

Importancia
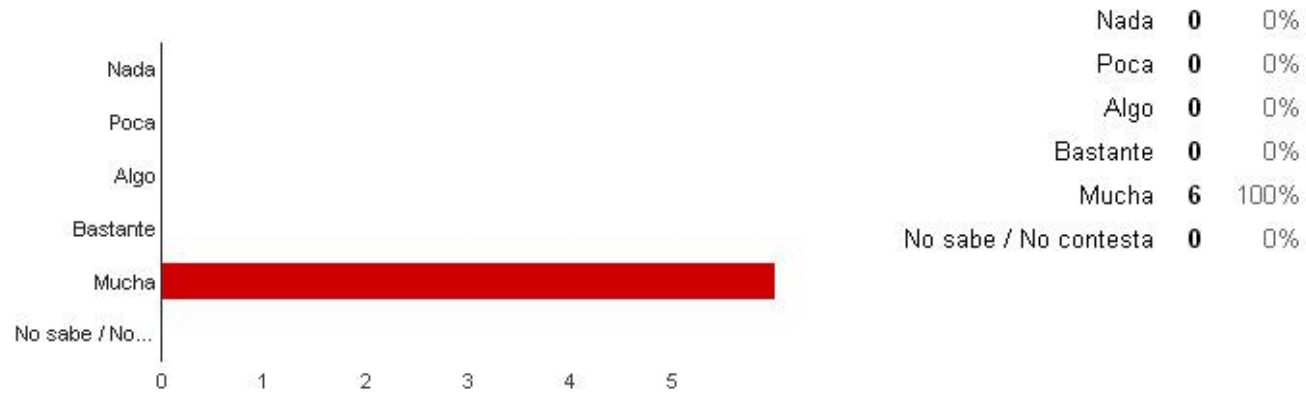

- Sociedad a nivel global. La sociedad en términos generales es un público importante para las universidades pero algo menos que la del entorno, ya que cuatro de ellas lo consideran muy importante y dos bastante. La frecuencia de las acciones de comunicación en este caso también se reduce respecto a la sociedad del entorno, oscilando la misma entre algo, bastante y mucho.

\section{Frecuencia}
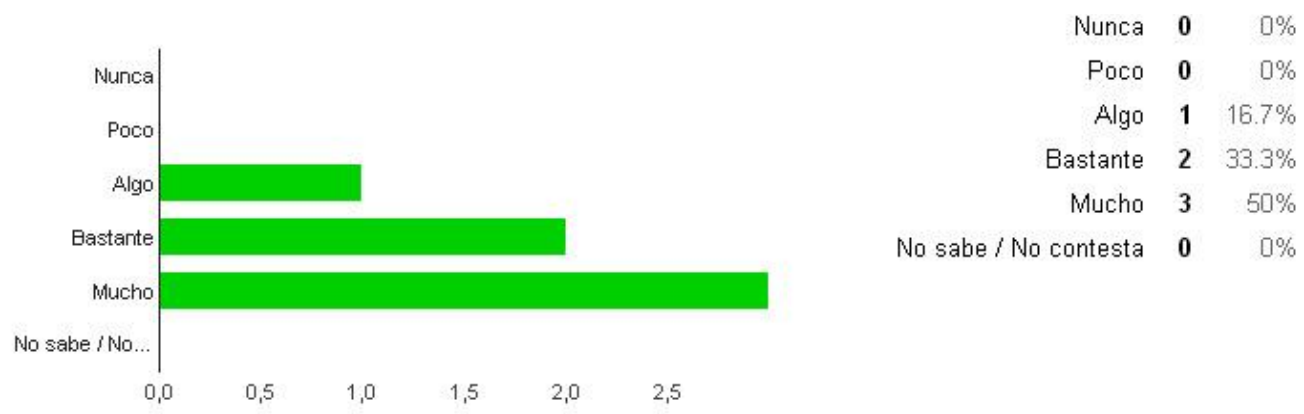


\section{Importancia}
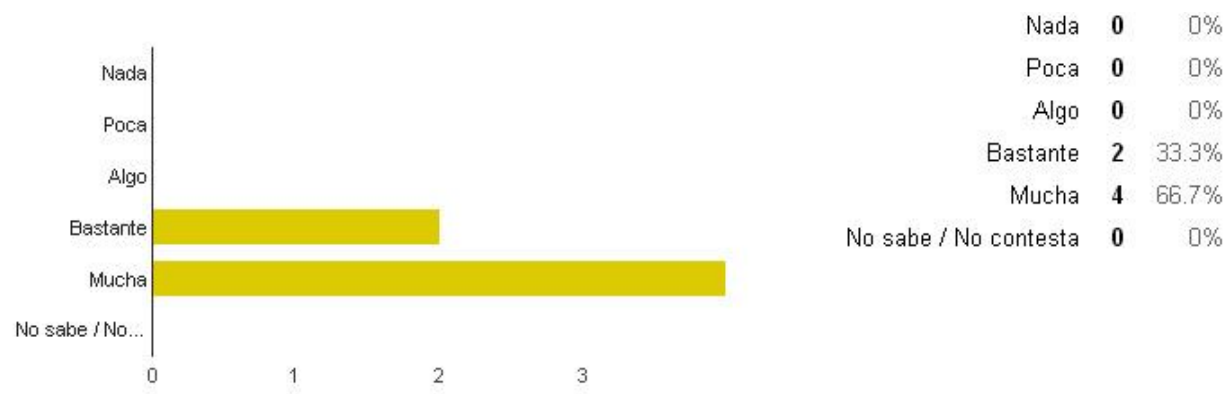

- Administración Pública local/provincial. La frecuencia con la que las acciones de comunicación se dirigen a las administraciones más próximas es más reducida que la importancia que se otorga a las mismas. No obstante, para una universidad se trata de un público nada importante y para otra de ellas tan sólo algo. Las cuatro restantes lo consideran bastante y muy importante. En cuanto a la frecuencia, dos de ellas señalan que nunca se dirigen a ellas mientras que otras dos sólo lo hacen algo. Tan sólo dos universidades señalan que dirigen acciones de comunicación a esta administración con bastante o mucha frecuencia.
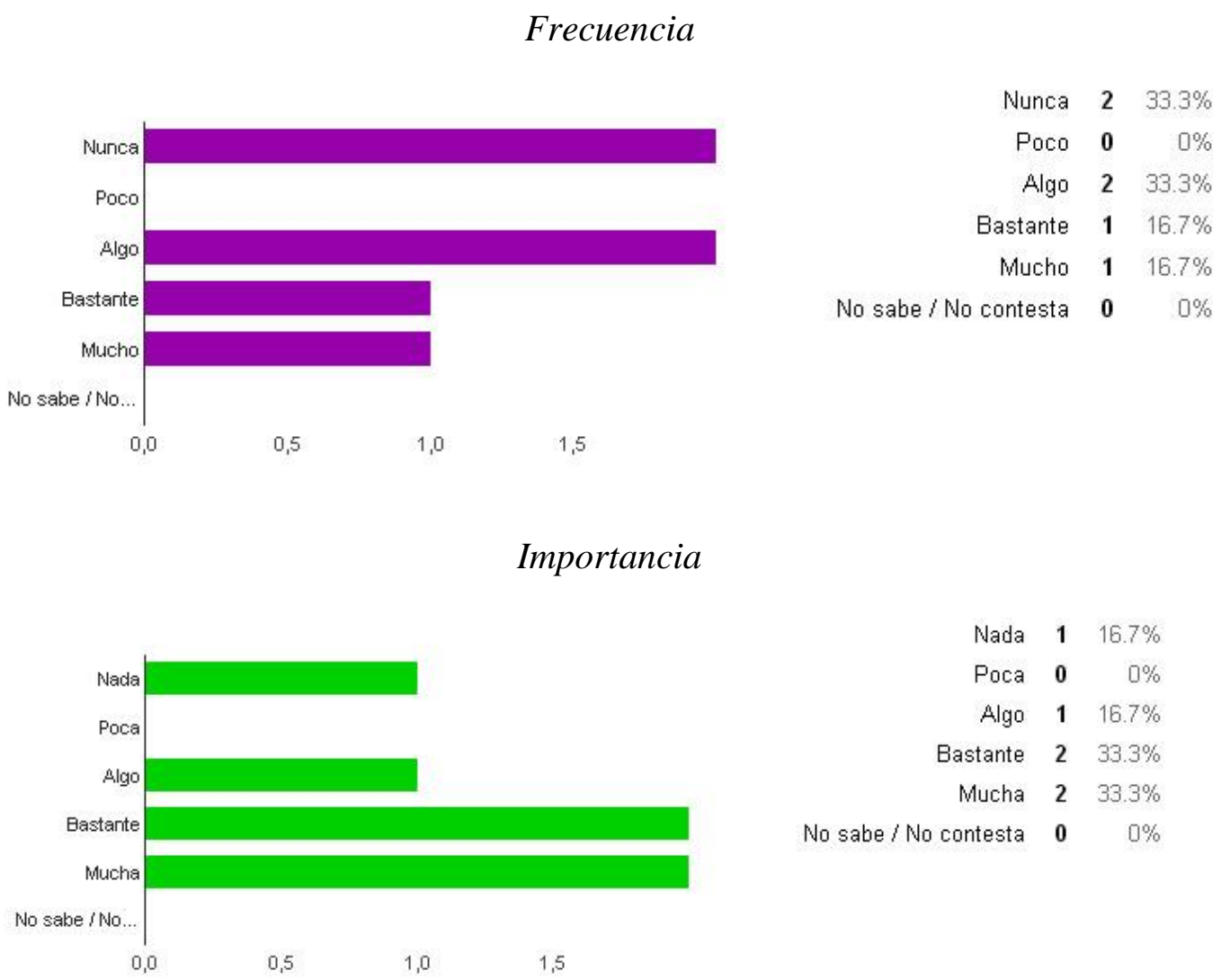

- Administración Pública autonómica. La importancia que otorgan las universidades a la administración autonómica como público destinatario es muy diversa, yendo desde 
nada hasta mucho. La frecuencia de la comunicación con la misma es igualmente variada, siendo el $50 \%$ las que la valoran como bastante.

\section{Frecuencia}
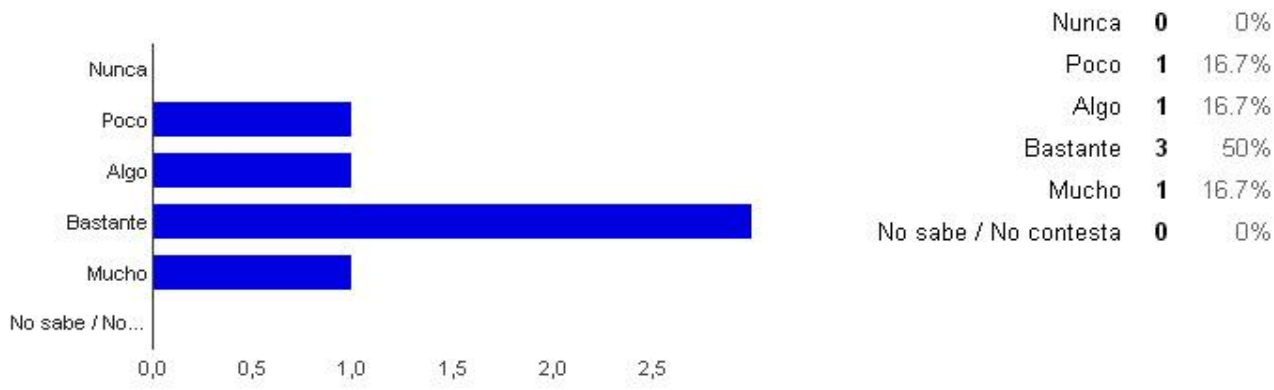

No sabe / No contesta $\mathbf{0} \quad 0 \%$

\section{Importancia}
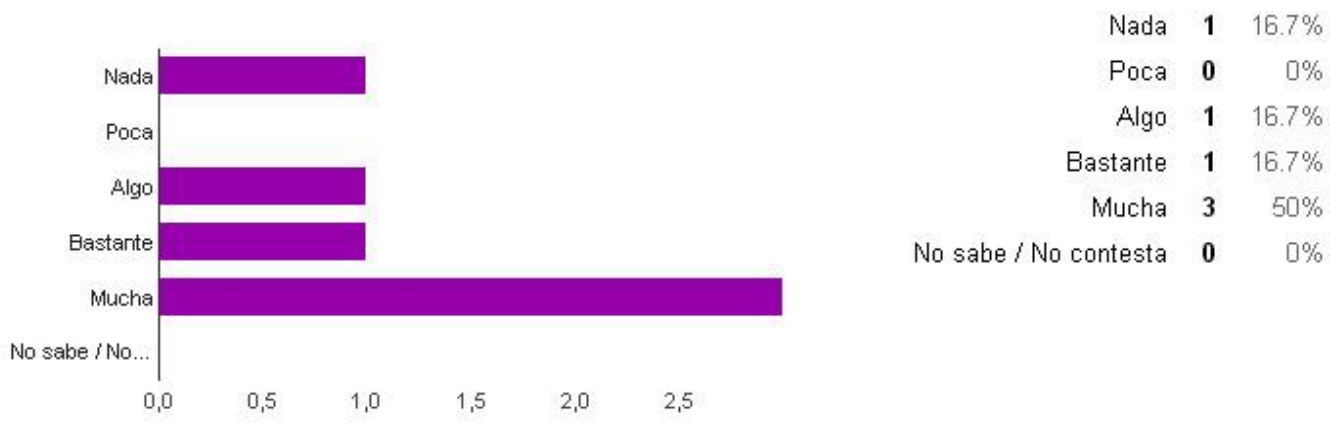

- Administración Pública nacional. Respecto a las administraciones anteriores, cabe destacar como en el caso de la frecuencia de las acciones de comunicación con las administraciones nacionales desciende notablemente, de forma que cinco de las seis universidades las mantienen poco o nunca y tan sólo una, bastante. Esta baja frecuencia contrasta con la importancia que se le otorga que en cuatro de los seis casos en bastante o mucha. Tan sólo una universidad entiende que no tiene importancia como público.

\section{Frecuencia}
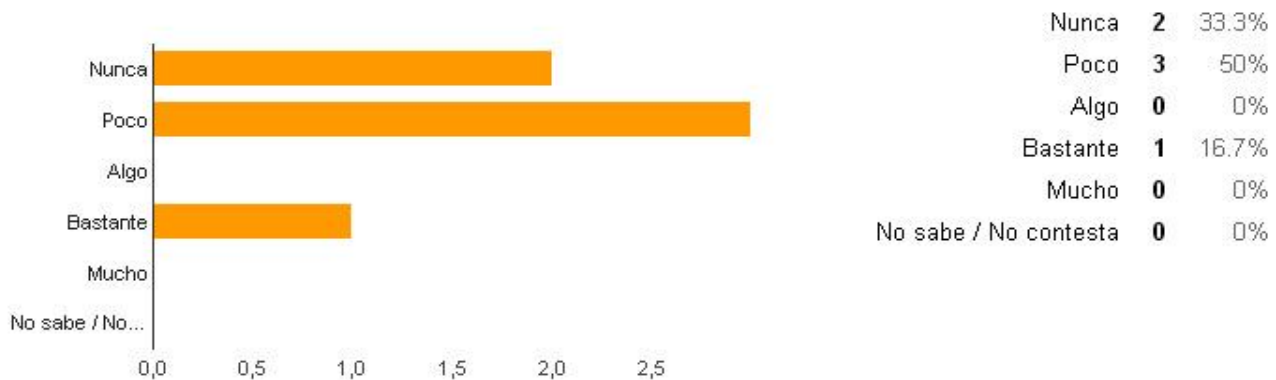


\section{Importancia}

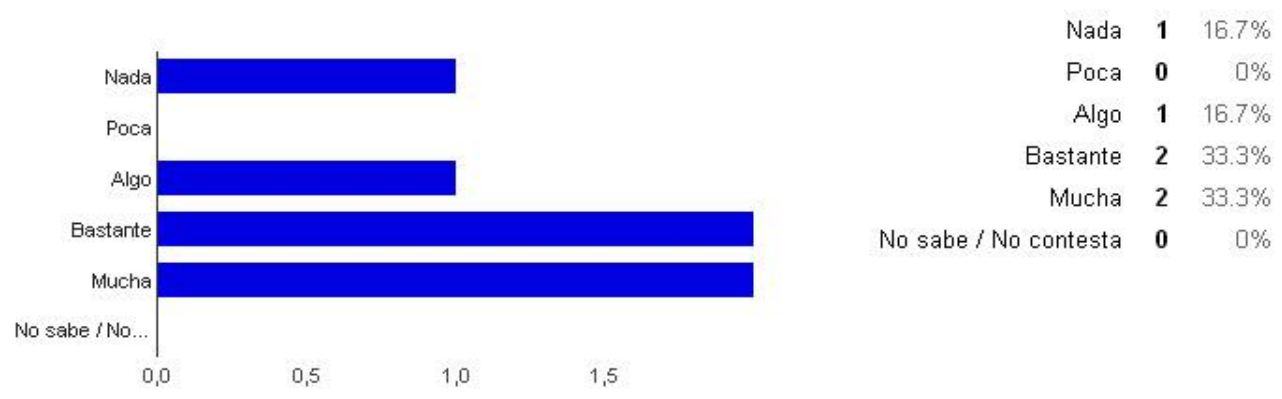

- Administración Pública europea. Del mismo modo, las universidades mantienen una baja frecuencia de comunicación con las administraciones europeas a pesar de considerarlo un público importante, aunque algo menos que las administraciones nacionales.

\section{Frecuencia}
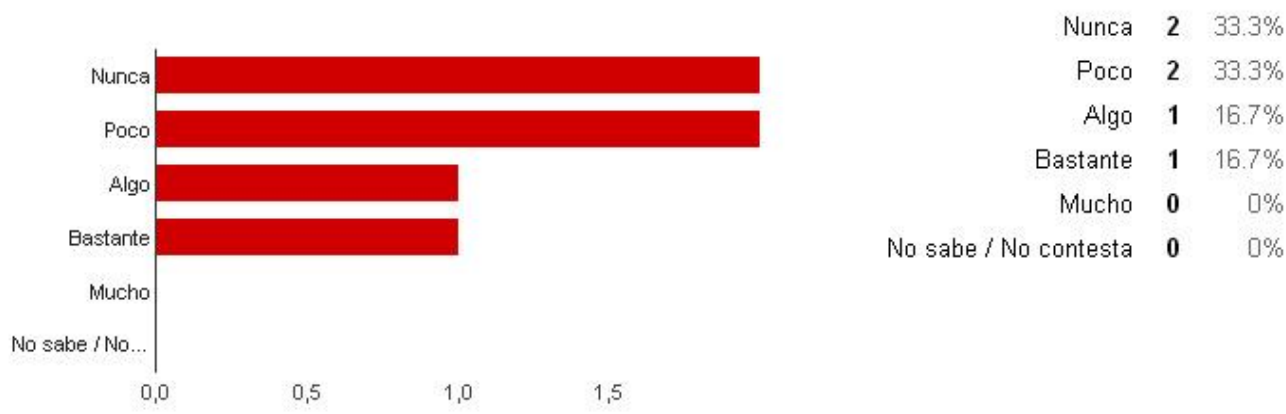

Importancia
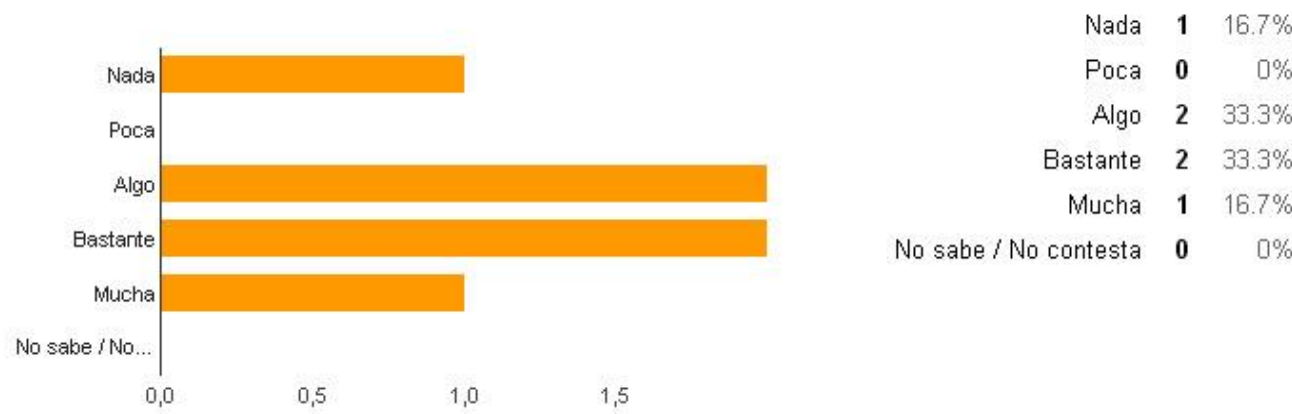

- Comunidad científica interna de la universidad. Al igual que en el caso de la sociedad del entorno, existe unanimidad entre las universidades a la hora de considerar a la comunidad científica interna como un público prioritario, calificándolo todas ellas como muy importante. Dada esta importancia, la frecuencia de las acciones dirigidas a este público es muy elevada en cuatro de las cinco universidades y bastante en las dos restantes. 
Frecuencia
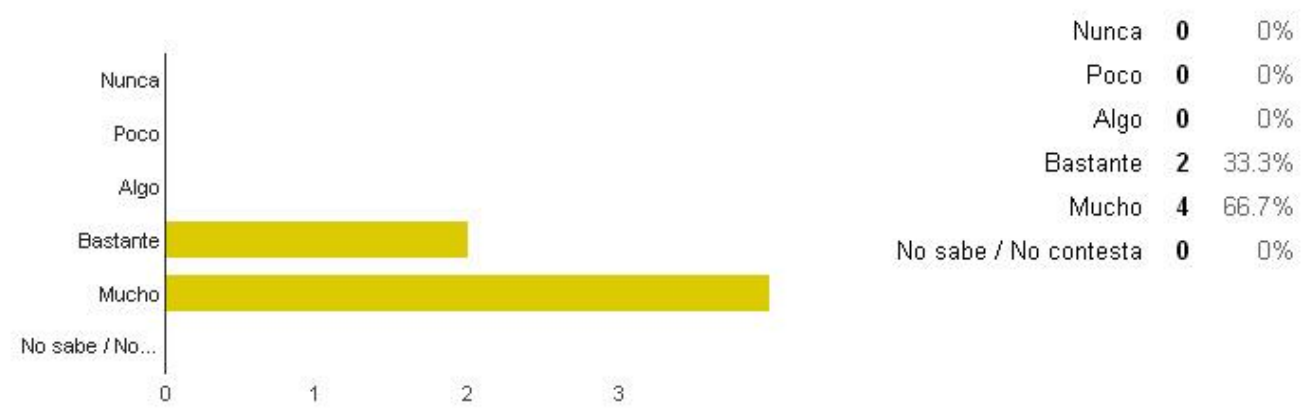

Importancia
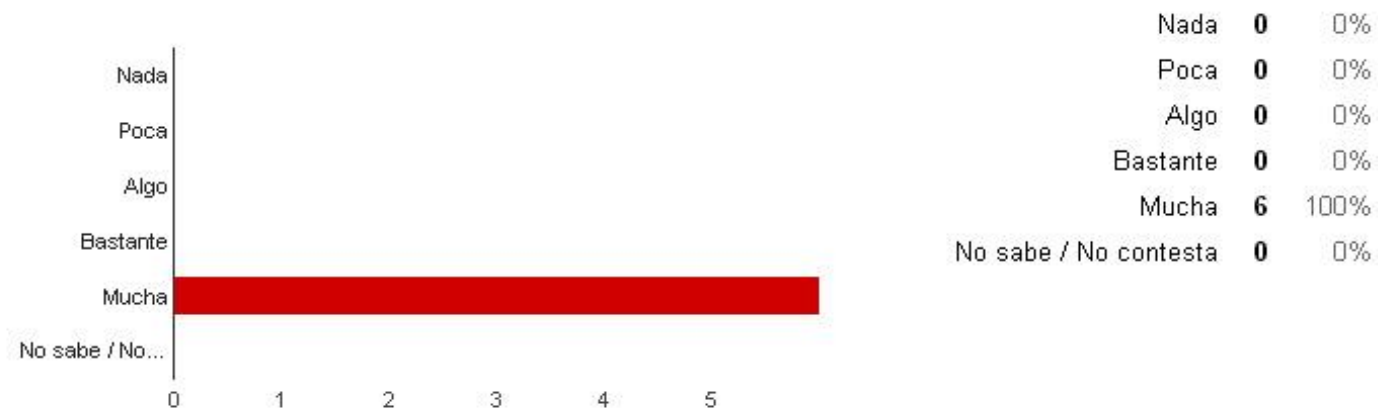

- Comunidad científica externa. A pesar de no mantenerse la unanimidad a la hora de considerarla como el público más prioritario, para todas las universidades es importante, oscilando la valoración entre bastante y mucho. En cuanto a la frecuencia de las acciones de comunicación dirigidas a este público, desciende respecto a la comunidad científica interna, oscilando entre algo y bastante y, sólo en un caso, mucho.

\section{Frecuencia}
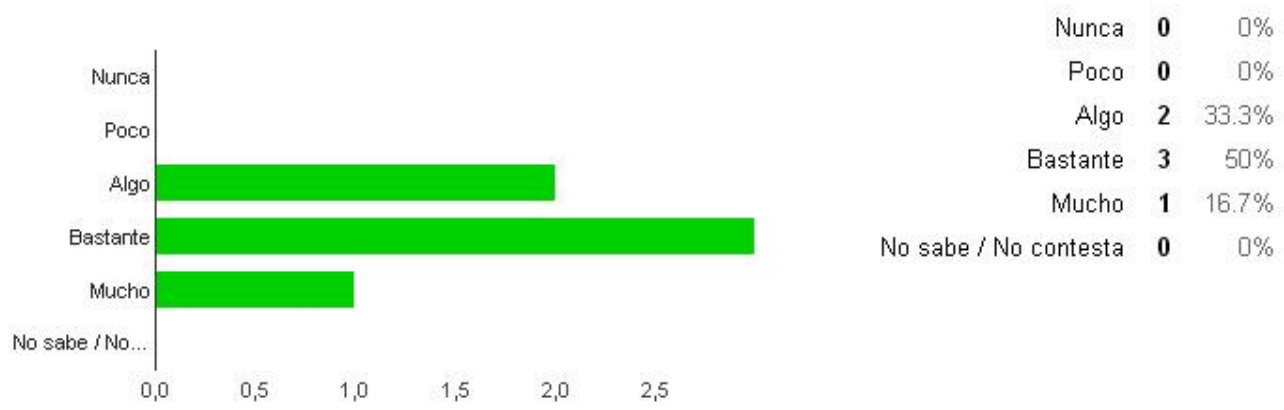


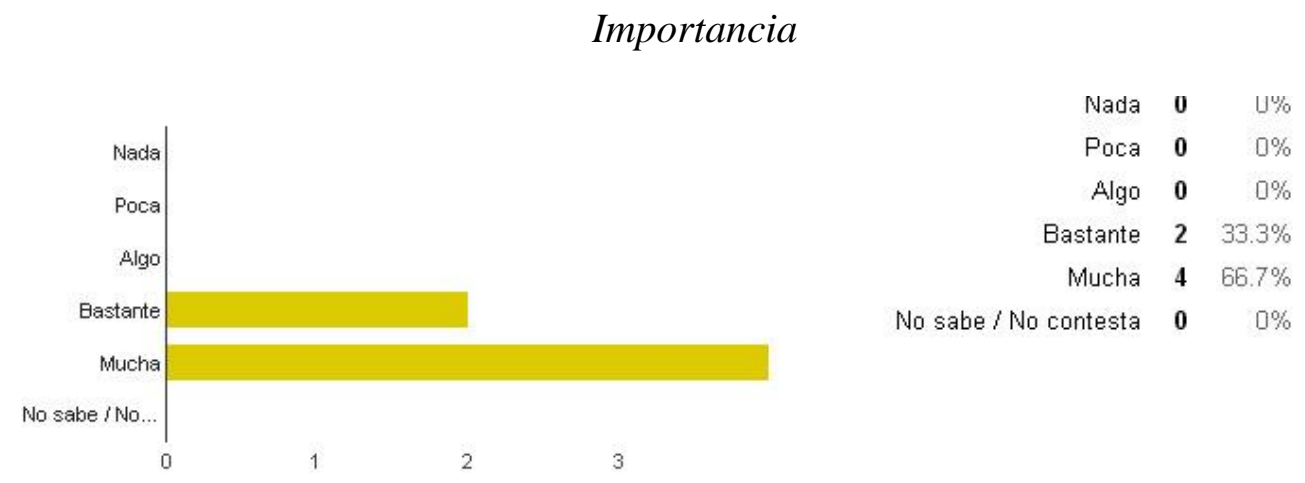

- Medios de comunicación a nivel local/regional. Los medios de comunicación del entorno parecen también un público prioritario, considerándolos muy importantes cinco de las seis universidades que afirmaron dirigir a los mismos acciones de comunicación de manera muy frecuente. En el apartado de medios, cabe señalar que una de las universidades mantuvo una posición diferenciada, valorando como baja tanto la frecuencia como la importancia de los mismos a nivel local, nacional y europeo.

Frecuencia
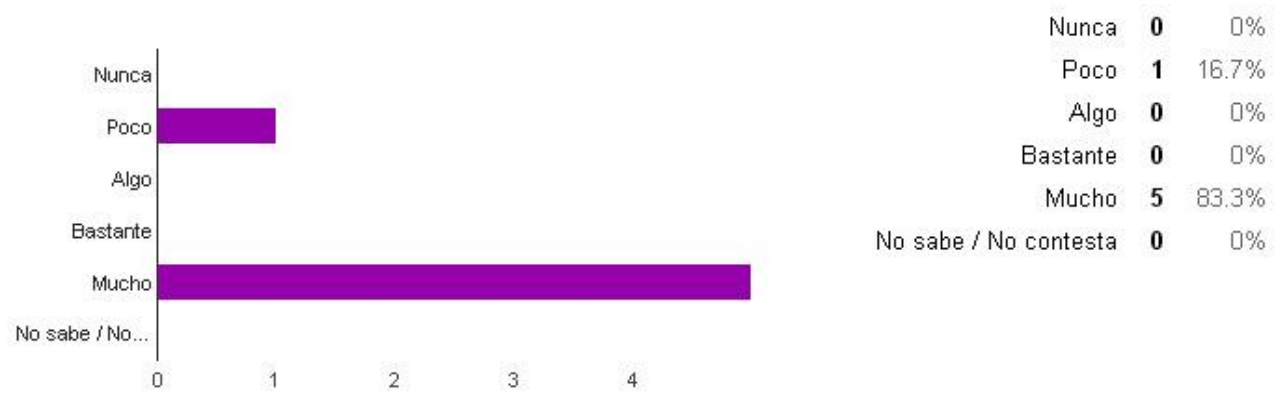

Importancia
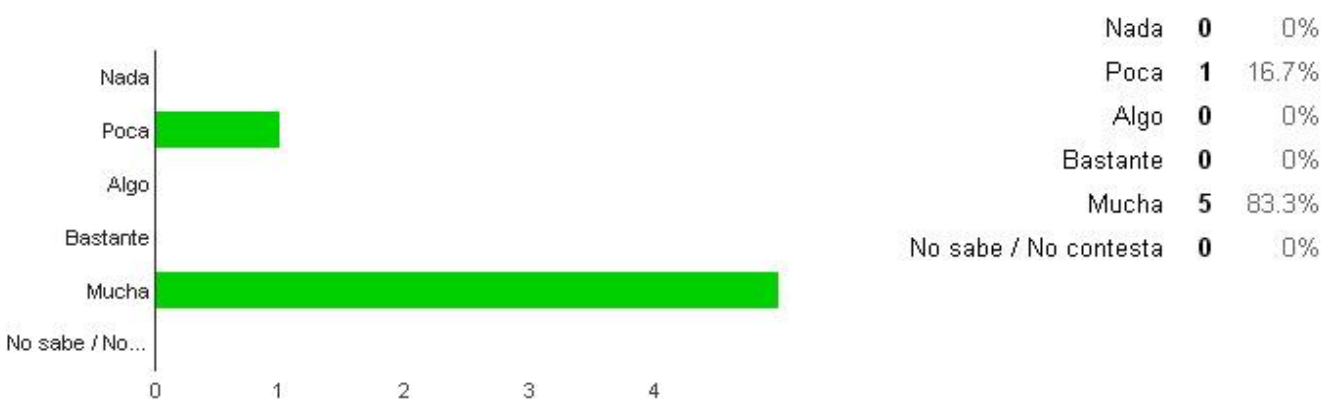

- Medios de comunicación a nivel nacional. Entre las cinco universidades que sí otorgaban importancia a los medios de proximidad, cuatro de ellas consideran que los medios nacionales son igualmente importantes, mientras que una entiende que la importancia desciende en este caso. La frecuencia de la comunicación es menor que en 
los de proximidad, de forma que tan sólo una universidad mantiene relaciones con mucha frecuencia y las cuatro restantes descienden a bastante, en tres de los casos, y a algo, en uno.

\section{Frecuencia}
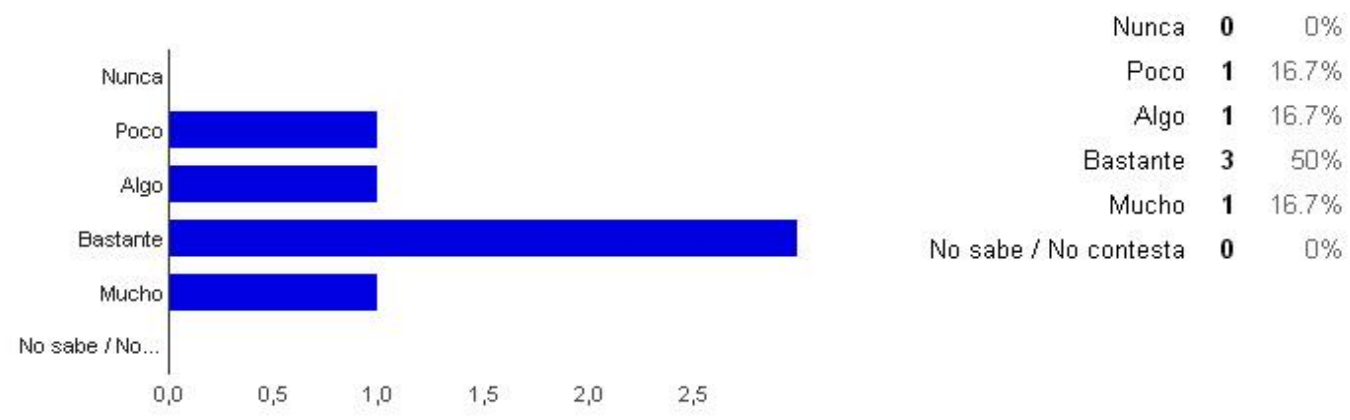

Importancia
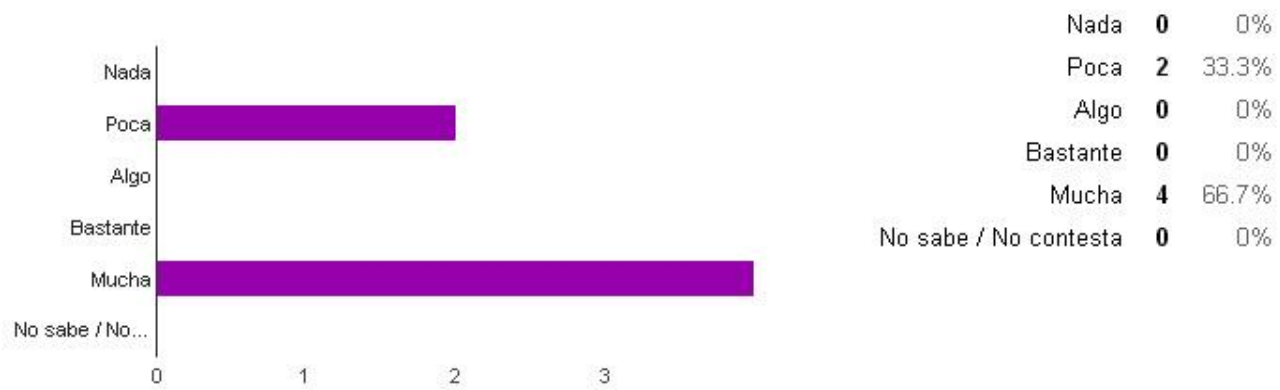

- Medios de comunicación a nivel internacional. La frecuencia de las acciones de comunicación con los medios internacionales es la que presenta mayor disparidad, yendo las respuestas desde nada y poco en tres de los casos a algo, bastante y mucho en los tres restantes. Existe mayor coincidencia a la hora de valorar su importancia, siendo mayoría las universidades que los consideran un público muy importante. Sin embargo, para las dos universidades restantes los medios internacionales no son nada importantes como público destinatario.

\section{Frecuencia}
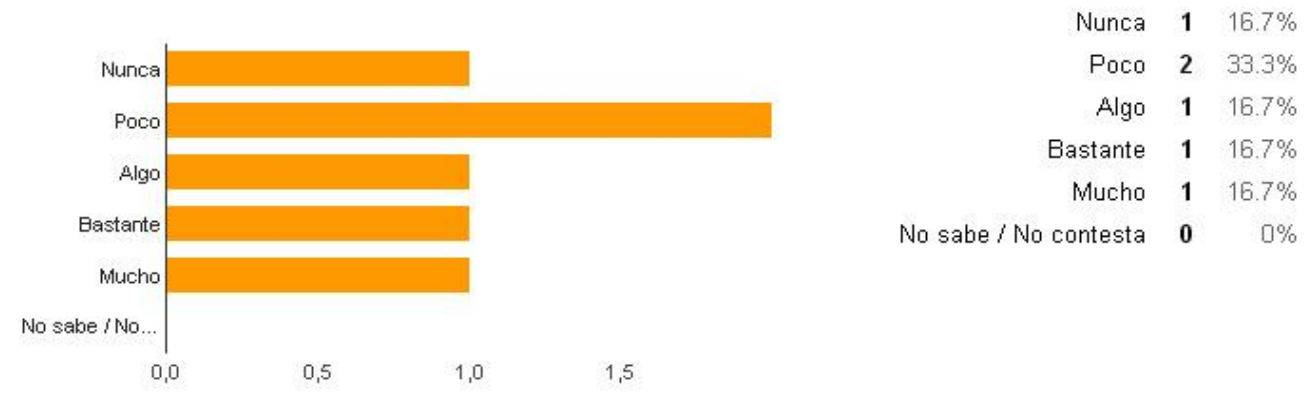


\section{Importancia}

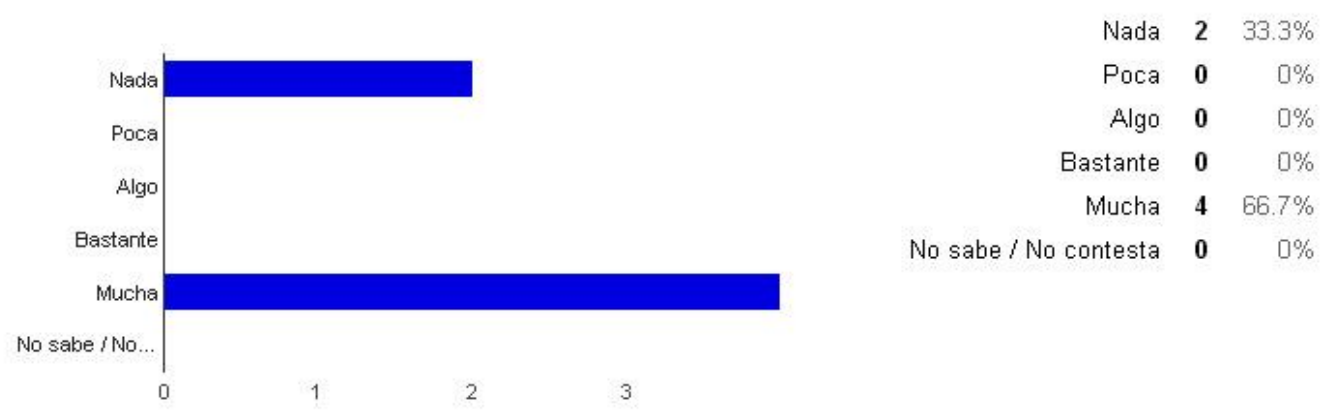

\section{COMPARATIVAS}

Como en el caso de las acciones de comunicación, se han elaborado gráficos que ponen en relación todas las respuestas de las universidades respecto a la frecuencia y la importancia de los públicos, así como las medias de estas respuestas.

A la hora de valorar la frecuencia con la que las universidades dirigen acciones de comunicación de la ciencia a sus diferentes públicos, resulta evidente como la principal actividad se dirige a los públicos más próximos, situándose en primer lugar la sociedad del entorno, seguida de la comunidad científica interna y los medios de comunicación de proximidad.

Por tipo de públicos, los gráficos muestran como las acciones de comunicación se dirigen con mayor frecuencia a la sociedad, especialmente a la del entorno y algo menos a la general. También se muestran como públicos muy frecuentes tanto la comunidad científica como los medios. En ambos casos, la frecuencia es también mayor con los más próximos a la universidad y algo menor con los restantes. Las administraciones son, con diferencia, los públicos a los que menos acciones de comunicación dirigen las universidades. En cualquier caso, de nuevo, se mantiene más relación con las más próximas: local, provincial y autonómica. Respecto a las dos administraciones restante, la frecuencia de la comunicación es mayor con la Administración europea que con la nacional. 


\section{Frecuencia}

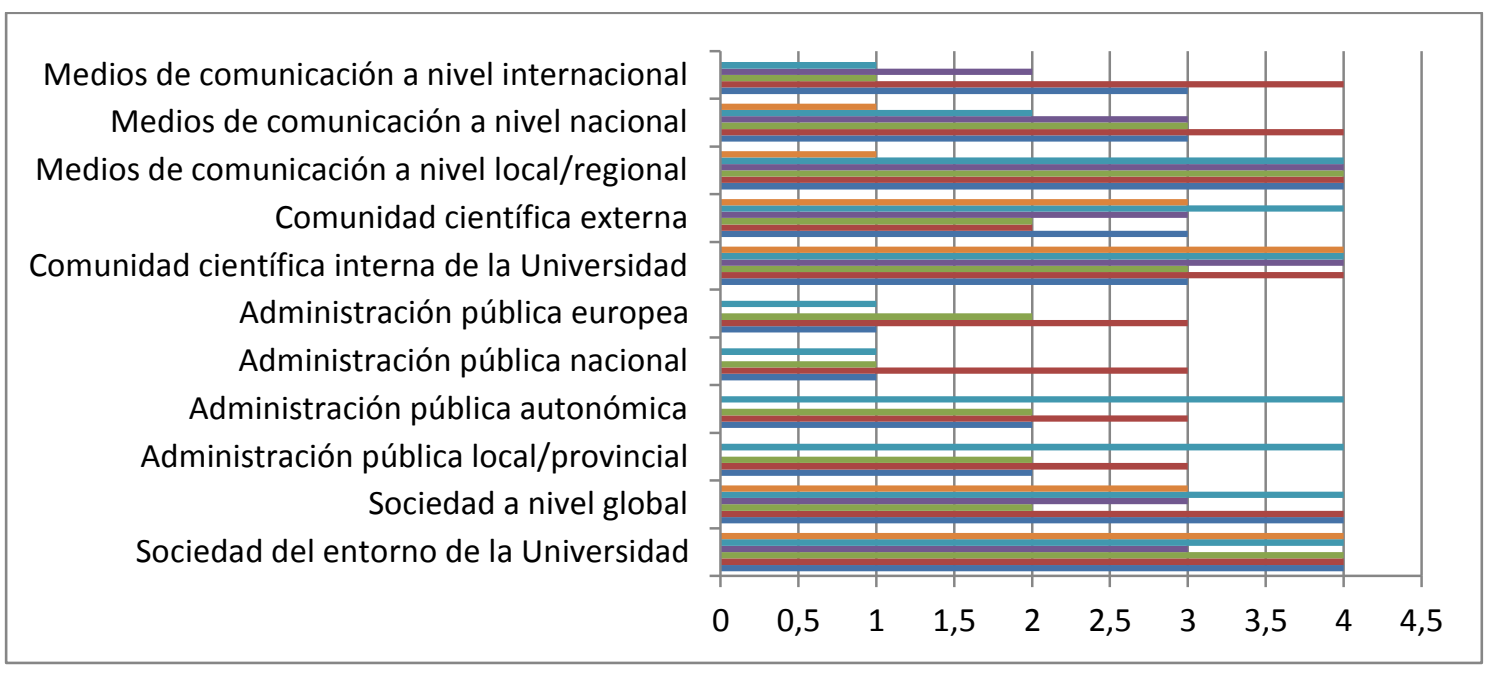

Medios de comunicación a nivel internacional

Medios de comunicación a nivel nacional Medios de comunicación a nivel local/regional Comunidad científica externa Comunidad científica interna de la Universidad Administración pública europea Administración pública nacional Administración pública autonómica Administración pública local/provincial Sociedad a nivel global Sociedad del entorno de la Universidad

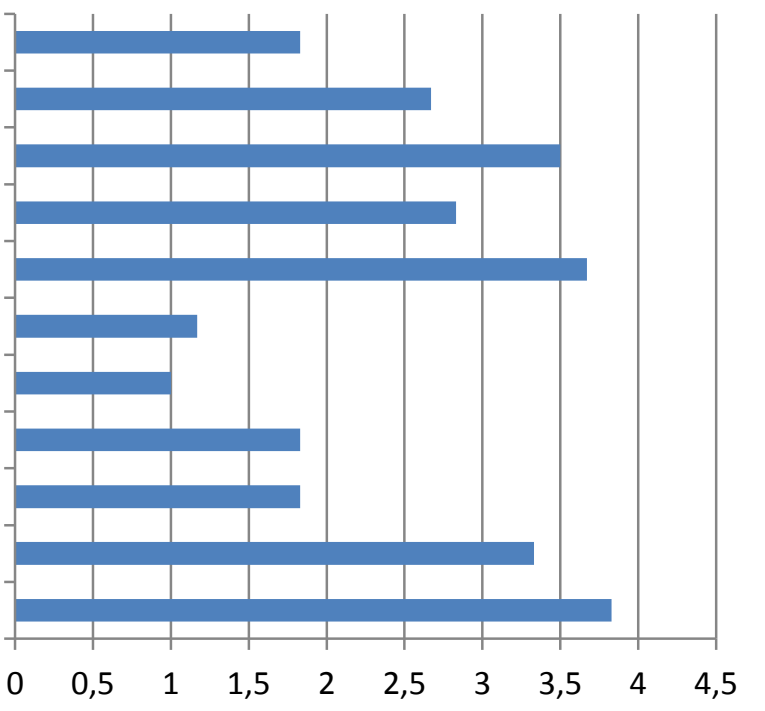

La importancia otorgada a los diferentes públicos destinatarios muestra una gráfica similar a la de la frecuencia pero con algunas diferencias interesantes. En este sentido, cabe señalar que las universidades otorgan la máxima importancia de forma unánime a la sociedad del entorno y a la comunidad científica interna, siendo sus dos públicos prioritarios. Le siguen la sociedad a nivel general y la comunidad científica externa, públicos a los que consideran más importantes a pesar de que no son tan frecuentes como los medios de proximidad. Estos son los siguientes en importancia, seguidos de los medios nacionales y los internacionales. En cuanto a las administraciones, son los públicos considerados como menos importantes por los profesionales de comunicación de la ciencia de las universidades encuestadas. De entre ellas, la considerada algo más importante es la autonómica y la menos, la europea. 


\section{Importancia}

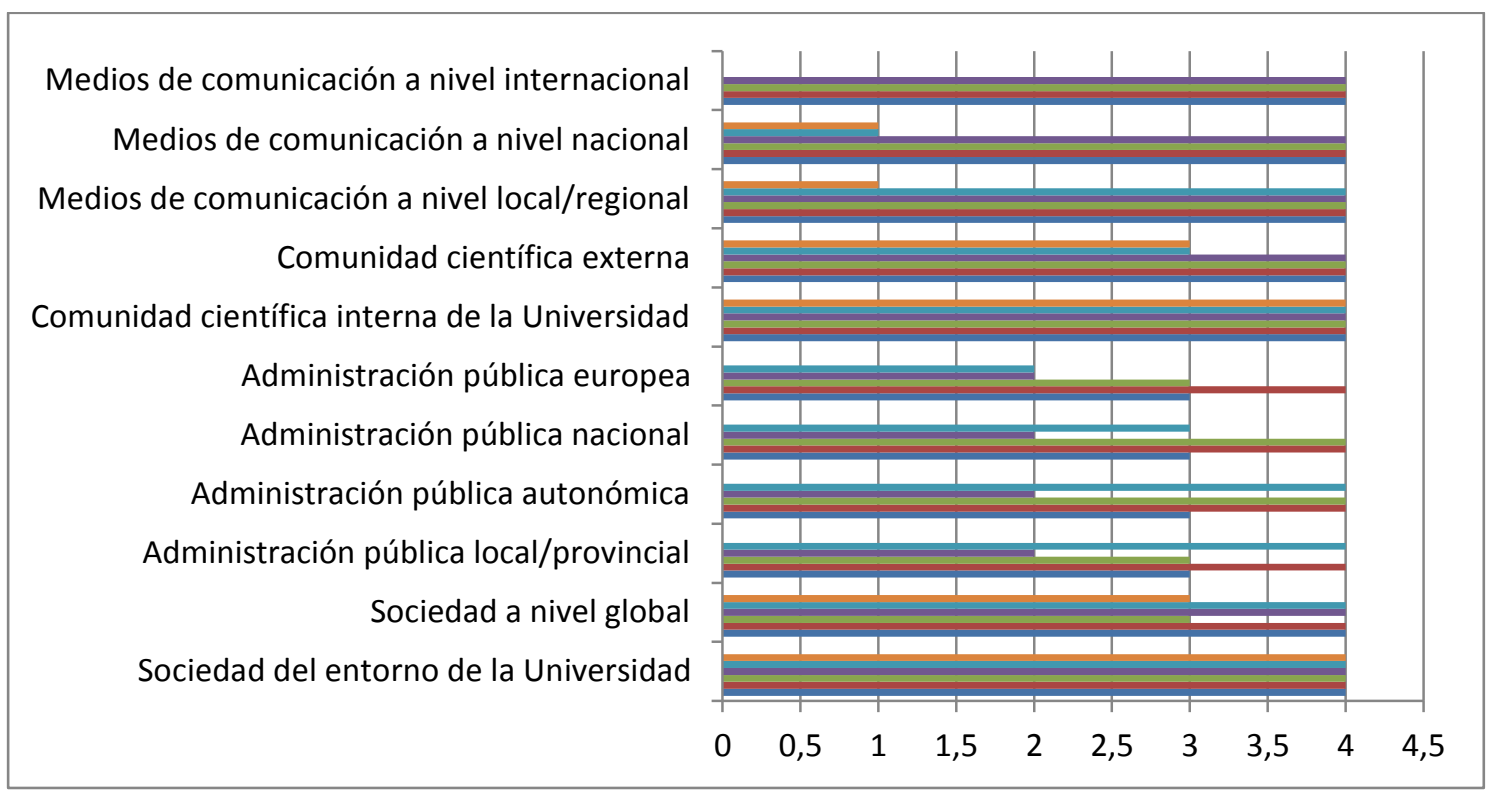

Medios de comunicación a nivel internacional

Medios de comunicación a nivel nacional Medios de comunicación a nivel local/regional Comunidad científica externa Comunidad científica interna de la Universidad Administración pública europea Administración pública nacional Administración pública autonómica Administración pública local/provincial Sociedad a nivel global Sociedad del entorno de la Universidad

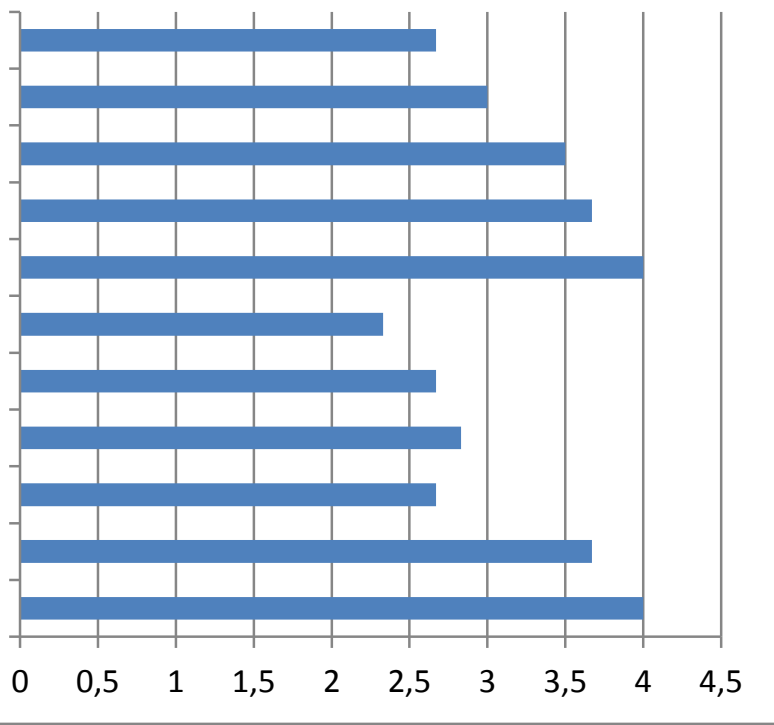

Finalmente, poniendo en relación las valoraciones concedidas a la frecuencia de la comunicación con la importancia de cada uno de estos públicos llama la atención que en todos los casos, menos uno, las universidades valoran por encima la importancia de los públicos respecto a la frecuencia de la comunicación. La única excepción son los medios de comunicación locales y regionales en los que ambos parámetros se igualan, de lo que se deduce que las universidades realizan las acciones de comunicación que creen necesarias dada la importancia de los mismos. En todos los demás casos cabe pensar que los responsables de comunicación entienden que la frecuencia es menor de la que debería en función de la importancia otorgada. Entre los públicos en los que esta diferencia es mayor se encuentran los más alejados del entorno de la universidad, como 
es el caso de los medios internacionales, la comunidad científica externa y las administraciones nacional y europea. La diferencia entre la importancia concedida y la frecuencia de la comunicación es también significativa en el caso de las administraciones autonómicas, locales y provinciales.

Frente a la frecuencia e importancia otorgada a los públicos más próximos, en el apartado de comentarios uno de los encuestados destacaba el reto que supone para las universidades el internacionalizar la comunicación:

Nuestro reto de crecimiento está en la internacionalización de la difusión, para abarcar tanto a la comunidad científica internacional, como a la sociedad en su conjunto.

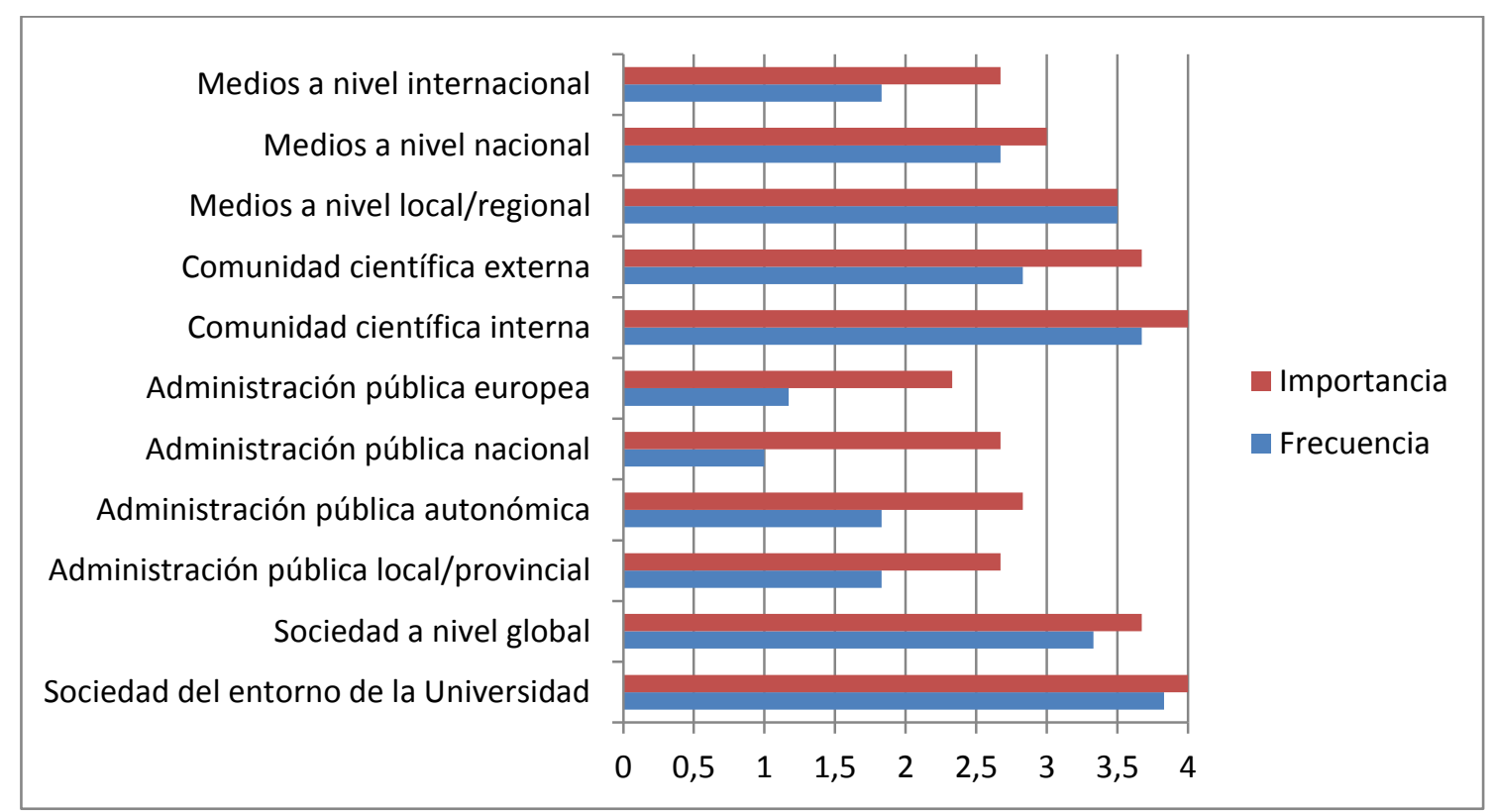

\section{- Canales para la interacción}

Las siguientes dos preguntas del cuestionario hacían referencia a los canales y mecanismos establecidos por las universidades de cara a favorecer la interacción y al nivel de respuesta de la universidad a los mismos.

- Valore la promoción por parte de la Universidad de los siguientes canales/acciones para conocer los intereses y expectativas sobre la ciencia y la innovación de sus públicos. *

\section{Nada Poco Algo Bastante Mucho No} contesta

\begin{tabular}{|c|c|c|c|c|c|c|}
\hline Correo electrónico & $r$ & $C$ & $r$ & $C$ & $C$ & $r$ \\
\hline Redes sociales & $r$ & $r$ & $r$ & $C$ & $r$ & $r$ \\
\hline
\end{tabular}




\begin{tabular}{|c|c|c|c|c|c|c|}
\hline & Nada & Poco & Algo & Bastante & Mucho & $\begin{array}{c}\text { No sabe / } \\
\text { No } \\
\text { contesta }\end{array}$ \\
\hline $\begin{array}{l}\text { Buzón de } \\
\text { sugerencias }\end{array}$ & $r$ & $r$ & $r$ & C & $r$ & $r$ \\
\hline $\begin{array}{l}\text { Peticiones directas } \\
\text { vía registro }\end{array}$ & $r$ & $r$ & $r$ & $C$ & $r$ & $C$ \\
\hline Consultas/encuestas & $r$ & $r$ & $C$ & $C$ & $C$ & $r$ \\
\hline $\begin{array}{l}\text { Grupos de } \\
\text { discusión }\end{array}$ & $r$ & $\mathrm{C}$ & $r$ & $\mathrm{C}$ & $r$ & $\mathrm{C}$ \\
\hline Otros & $r$ & $r$ & $r$ & $C$ & $r$ & $r$ \\
\hline
\end{tabular}

- Valore el nivel de respuesta de la Universidad a las peticiones/intereses en materia de ciencia que le llagan a través de estos canales/acciones

\begin{tabular}{|c|c|c|c|c|c|c|}
\hline & Ninguno & Poco & Algo & Bastante & Mucho & $\begin{array}{c}\text { No sabe / } \\
\text { No } \\
\text { contesta }\end{array}$ \\
\hline Correo electrónico & $r$ & $C$ & $r$ & $r$ & $r$ & $C$ \\
\hline Redes sociales & $r$ & $C$ & $r$ & $r$ & $r$ & $C$ \\
\hline $\begin{array}{l}\text { Buzón de } \\
\text { sugerencias }\end{array}$ & $r$ & $r$ & $C$ & $r$ & $C$ & $r$ \\
\hline $\begin{array}{l}\text { Peticiones directas } \\
\text { vía registro }\end{array}$ & $C$ & $r$ & $C$ & $C$ & $r$ & $r$ \\
\hline Consultas/encuestas & $C$ & $r$ & $C$ & $C$ & $r$ & $C$ \\
\hline $\begin{array}{l}\text { Grupos de } \\
\text { discusión }\end{array}$ & $r$ & $r$ & $C$ & $r$ & $r$ & $r$ \\
\hline Otros & $r$ & $r$ & $C$ & $r$ & $r$ & $r$ \\
\hline
\end{tabular}

- Correo electrónico. El grado de promoción de las universidades del correo electrónico como canal para conocer los intereses y expectativas de sus públicos en materia de ciencia e innovación se sitúa en una valoración intermedia, que va de poco a bastante, mientras que el nivel de respuesta varía ligeramente al señalar una de las universidades que es mucho, otra bastante y otra "no sabe/no contesta", manteniéndose únicamente invariable la puntuación de poco, señalada por dos de los encuestados. 

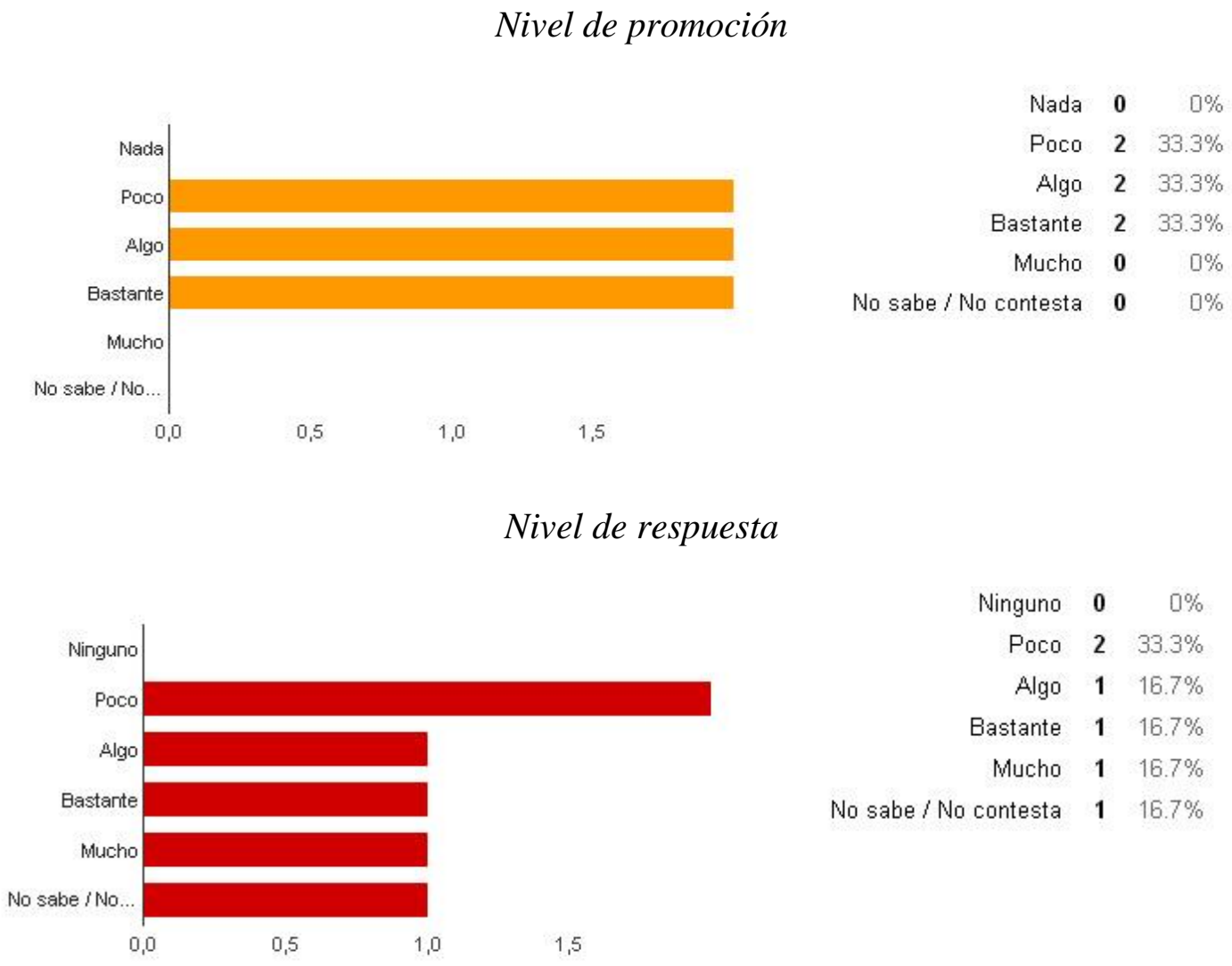

- Redes sociales. La promoción de las redes sociales es más elevada que la del correo, afirmando cuatro de las seis universidades que promueven mucho este canal de cara a interactuar con sus públicos. Por lo que respecta al nivel de respuesta, únicamente dos de las cuatro universidades que afirman promoverlo mucho mantienen también una respuesta muy elevada. En el apartado de comentarios del cuestionario, uno de los encuestados hacía la siguiente referencia a la importancia de las redes sociales:

Además de las relaciones habituales con los medios de comunicación, también damos importancia a la divulgación de nuestra actividad investigadora a través de las redes sociales.

\section{Nivel de promoción}
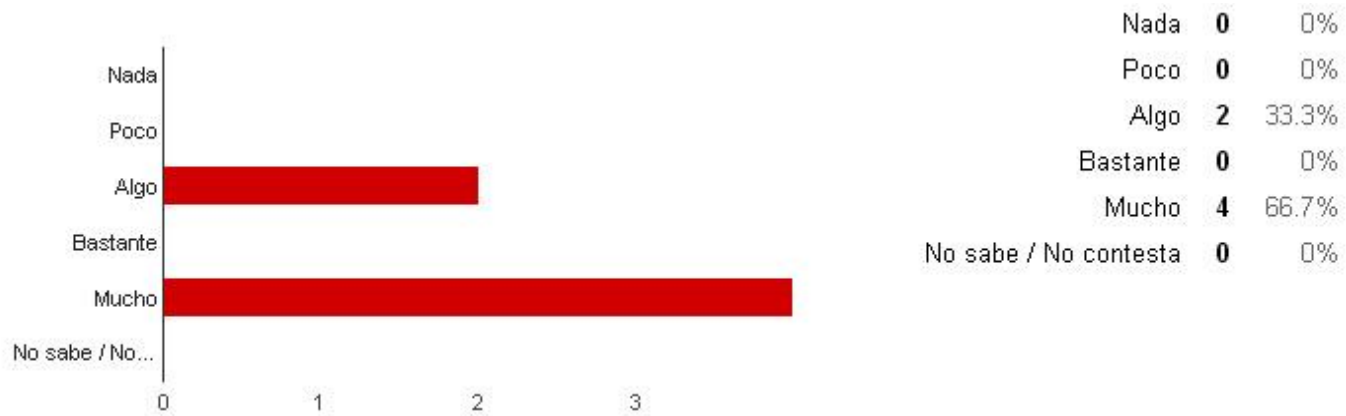
Nivel de respuesta
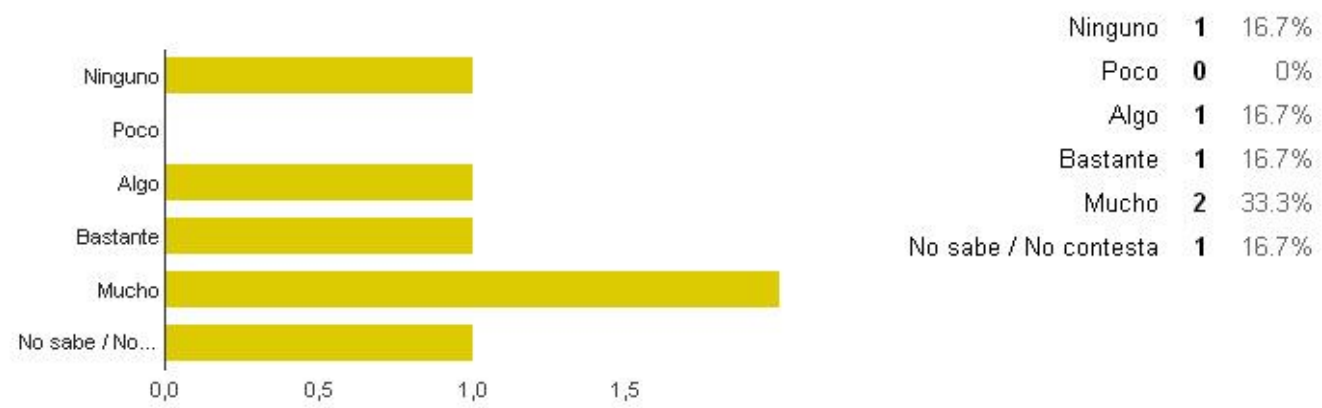

- Buzón de sugerencias. Los encuestados otorgan a este canal una valoración inferior por lo que respecta a su promoción que al nivel de respuesta, lo que hace pensar que se trata de un canal que, a pesar de promocionarse poco, cuando los públicos lo utilizan reciben un nivel de respuesta elevado. No obstante, dos de las universidades responden que se trata de un canal que no se promociona nada y al que no ofrecen ninguna respuesta.

\section{Nivel de promoción}
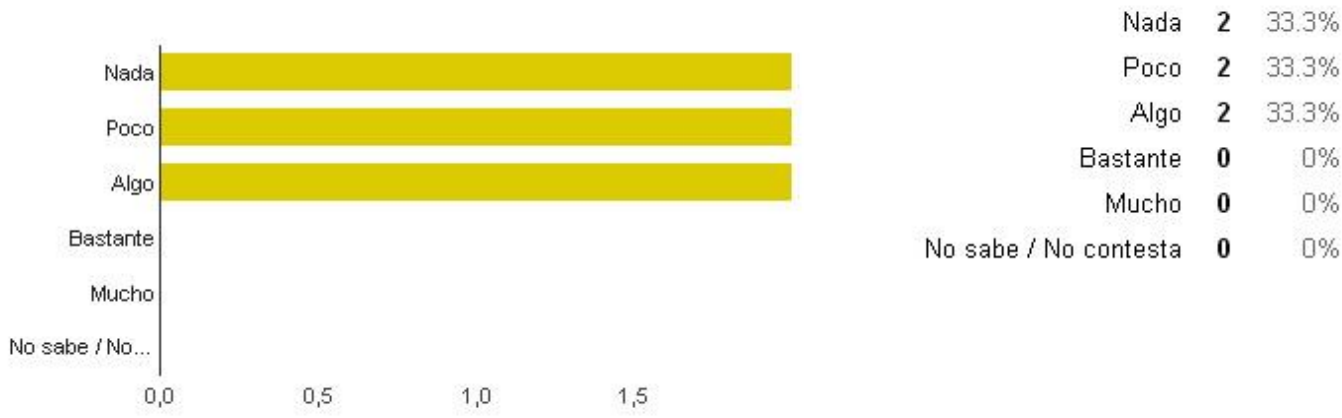

Nivel de respuesta
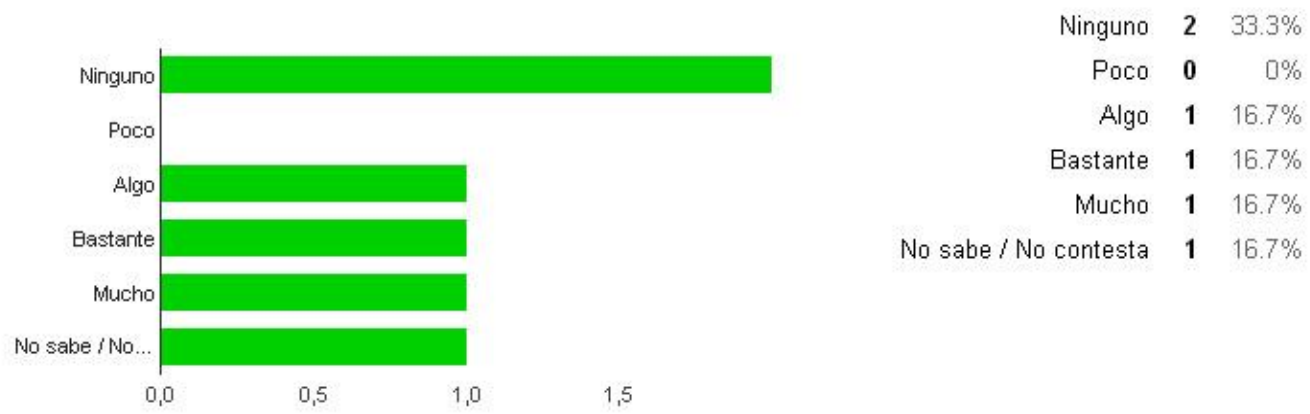

- Peticiones directas vía registro. Ninguna de las universidades promociona de forma activa las peticiones vía registro, señalando tres de ellas que se difunde poco, dos indican que nada y una "no sabe/no contesta". Tampoco consideran elevado el nivel de 
respuesta a las peticiones que puedan llegar a través de este canal ya que únicamente una valora el nivel de respuesta como bastante y las otras lo reducen a nada o poco.

Nivel de promoción
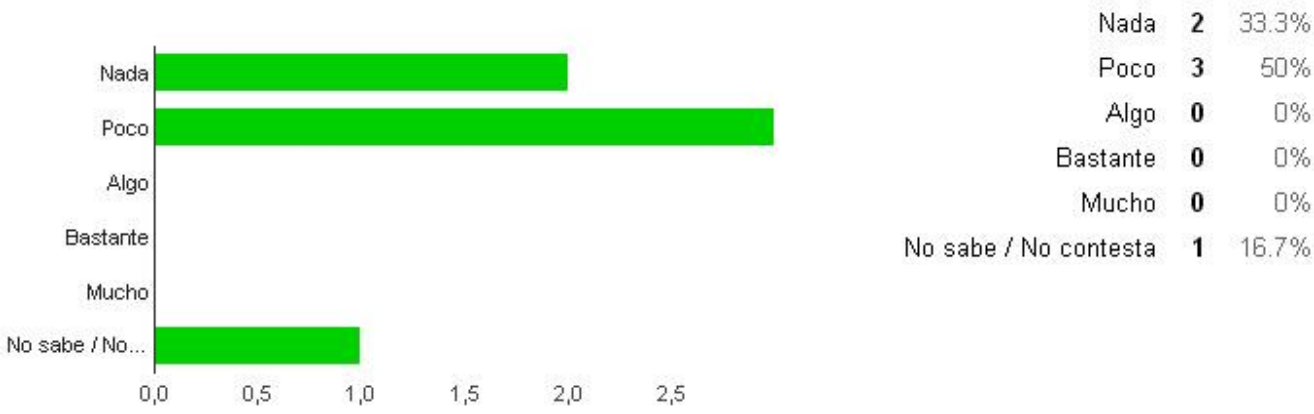

Nivel de respuesta
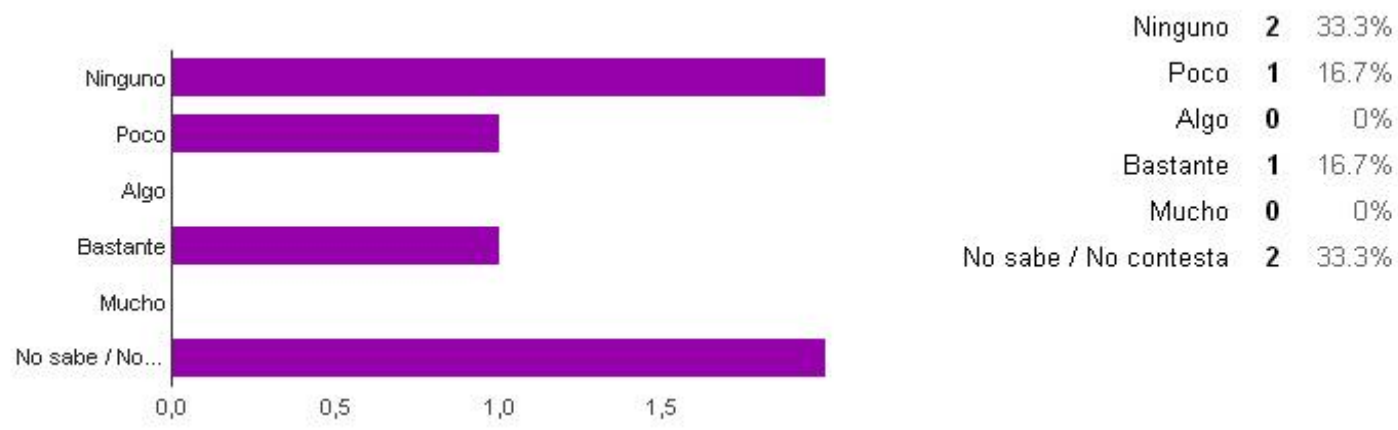

- Consultas/encuestas. La realización de consultas y encuestas es un canal utilizado poco por la mitad de las universidades encuestadas y algo por la otra mitad, de cara a conocer los intereses y expectativas de sus públicos en materia de investigación e innovación. El nivel de respuesta es asimismo reducido, menos en el caso de una universidad que lo valora como mucho.

Nivel de promoción
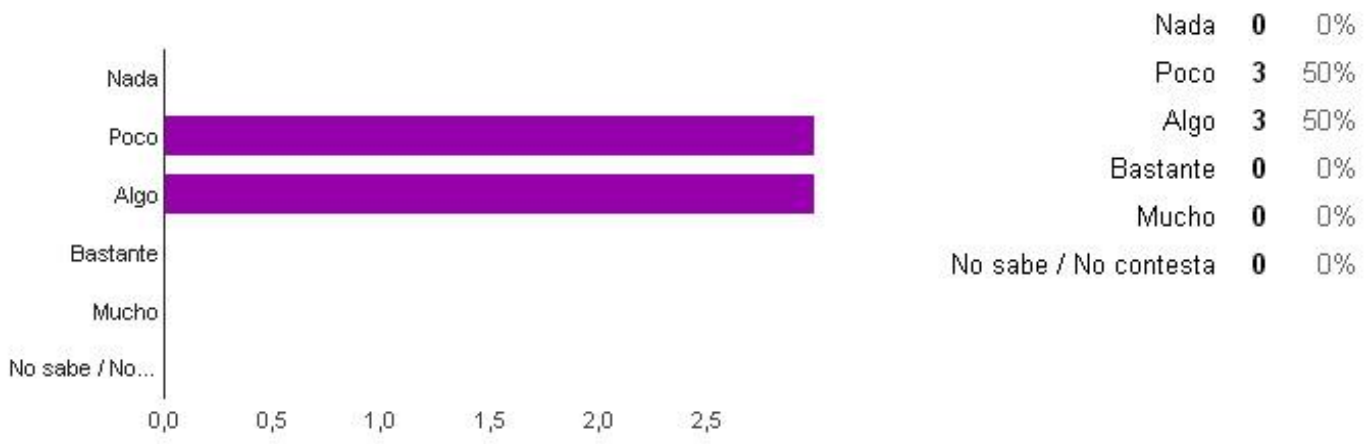

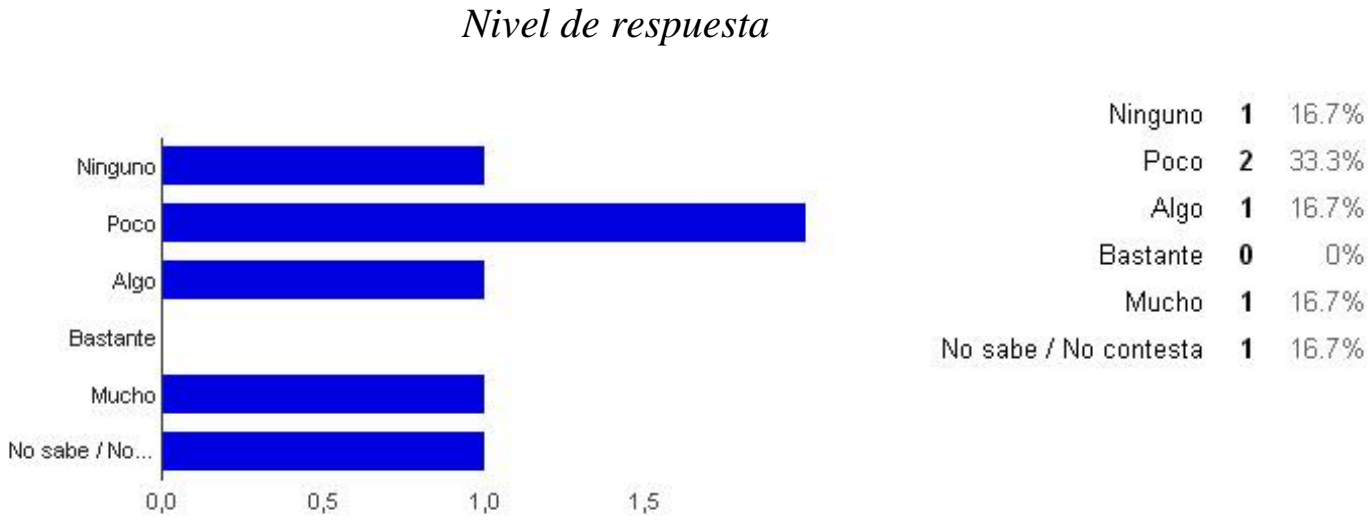

- Grupos de discusión. Se trata de un mecanismo para conocer los intereses de los públicos utilizado de forma muy minoritaria, siendo su promoción poca o ninguna. También la respuesta a los mismos es igualmente reducida, incrementándose en este caso el número de encuestados que señalan la opción de "no sabe/no contesta".

Nivel de promoción
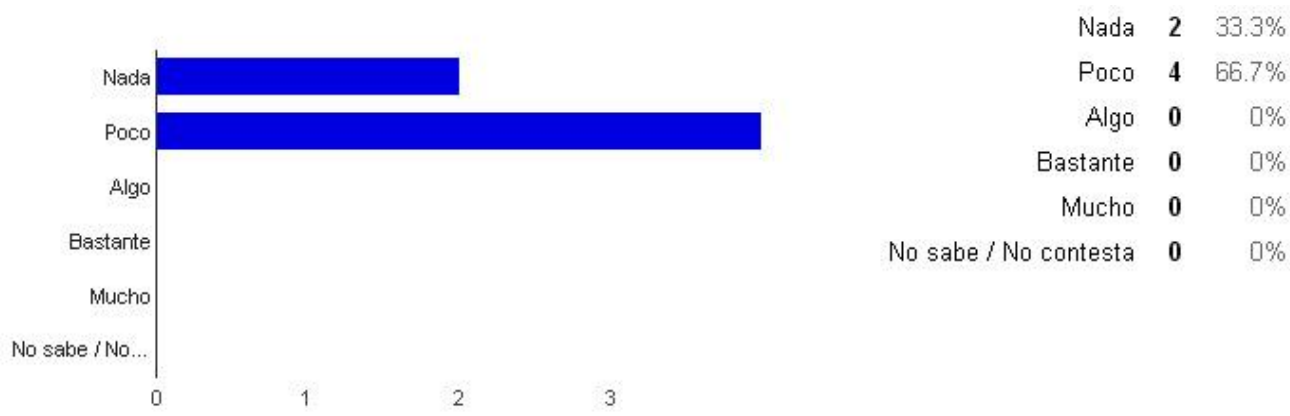

Nivel de respuesta
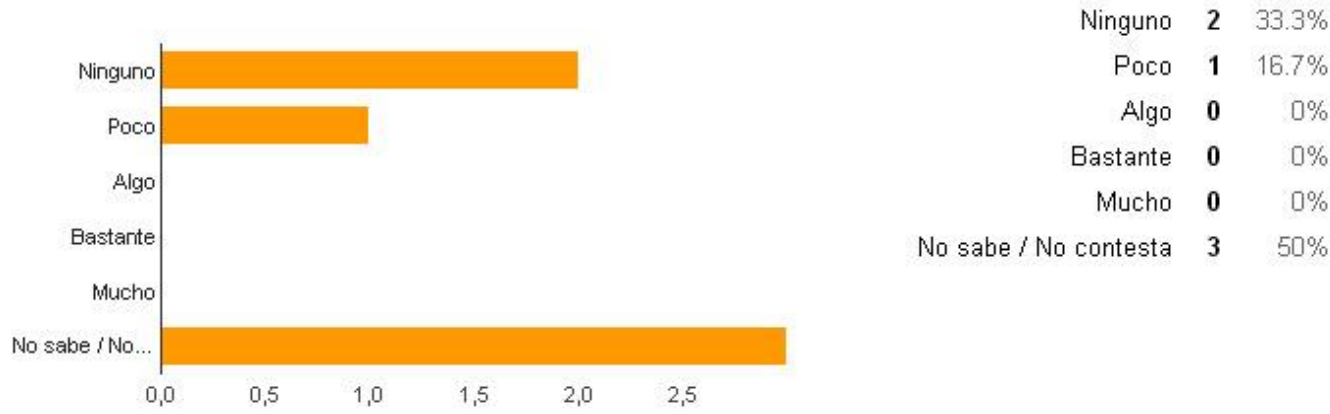

- Otros. En el caso de otros canales o acciones para conocer los intereses de los públicos las respuestas son iguales a la hora de valorar el nivel de promoción y la respuesta a las mismas, optando la mayoría de encuestados por señalar la opción de "no sabe/no contesta". 

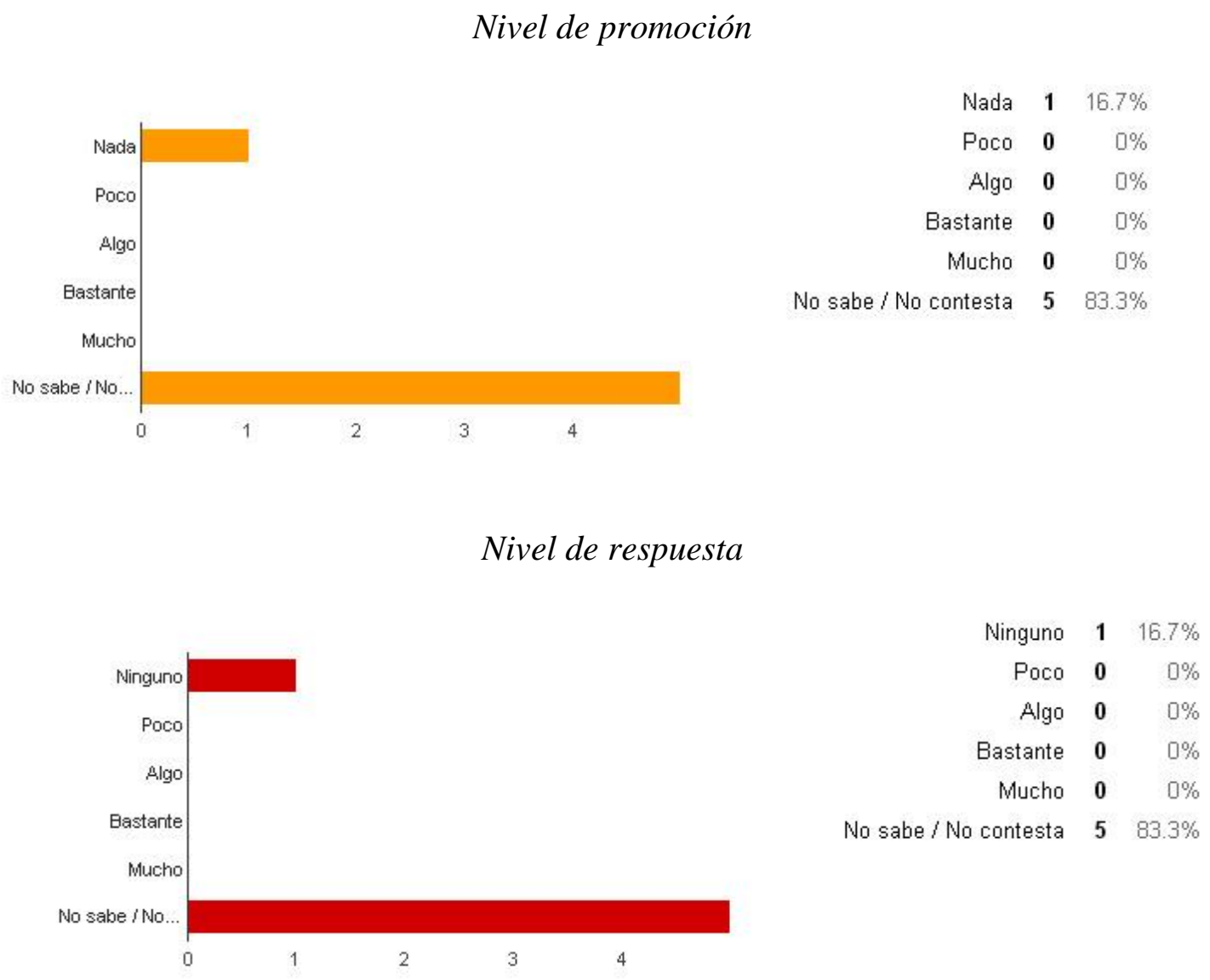

\section{COMPARATIVAS}

De cara a establecer una comparativa entre los diferentes canales utilizados por las universidades para conocer las expectativas e intereses de sus públicos, los gráficos elaborados comparan, en primer lugar, la promoción de los mismos y, en segundo, el nivel de respuesta. Como en las anteriores tablas, se extrae la valoración numérica considerando 0-nada y no sabe/no contesta, 1-poco, 2-algo, 3-bastante y 4-mucho. Finalmente, se comparan ambos parámetros a través de la media de las respuestas.

Los gráficos evidencian como el principal canal para conocer los intereses de los públicos son las redes sociales, cuya promoción es muy elevada por parte de la mayoría de universidades. Esto viene a reforzar la importancia de estas redes como canal para la interactuación de las universidades con sus públicos. El correo electrónico es el siguiente canal más utilizado, siendo variable su uso por parte de las diferentes universidades. Los otros tres canales planteados resultan totalmente minoritarios. De entre ellos resultan algo más frecuentes la realización de consultas y encuestas y el uso 
de un buzón de sugerencias. Finalmente, la promoción de grupos de discusión y las peticiones directas vía registro pueden considerarse prácticamente inexistente.

\section{Promoción}
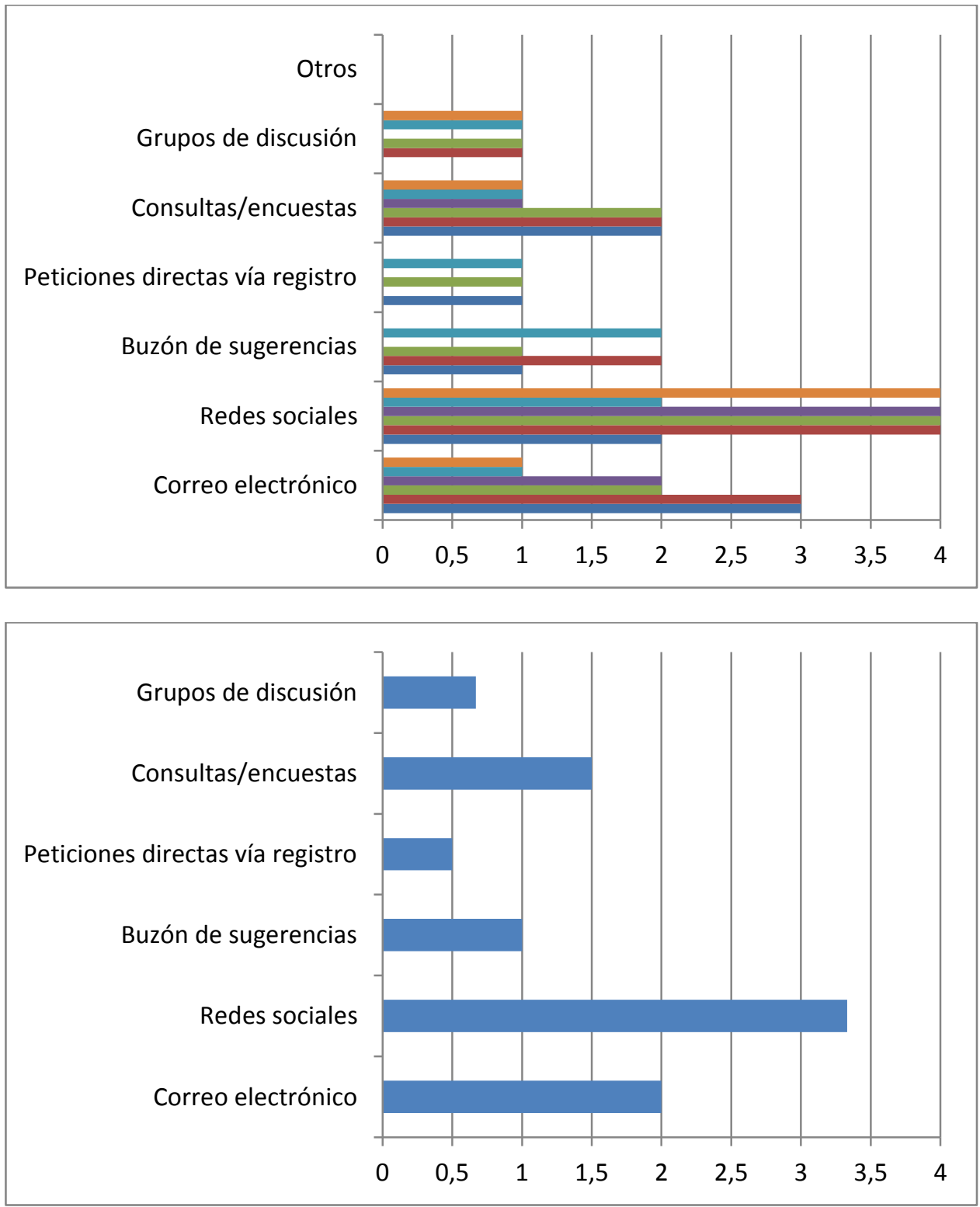

Por lo que respecta al nivel de respuesta, se repiten las redes sociales, seguidas del correo electrónico, como los canales a través de los que se ofrece una mayor respuesta a los intereses y expectativas de los públicos. A pesar de la baja promoción del buzón de sugerencias, las universidades lo valoran como el tercer canal por nivel de respuesta, seguido de las encuestas y consultas. También la respuesta a las peticiones vía registro es mayor que la promoción de este mecanismo. Finalmente, en el caso de los grupos de discusión, la respuesta pude considerarse también prácticamente inexistente, como ocurría con su promoción. 
Nivel de respuesta
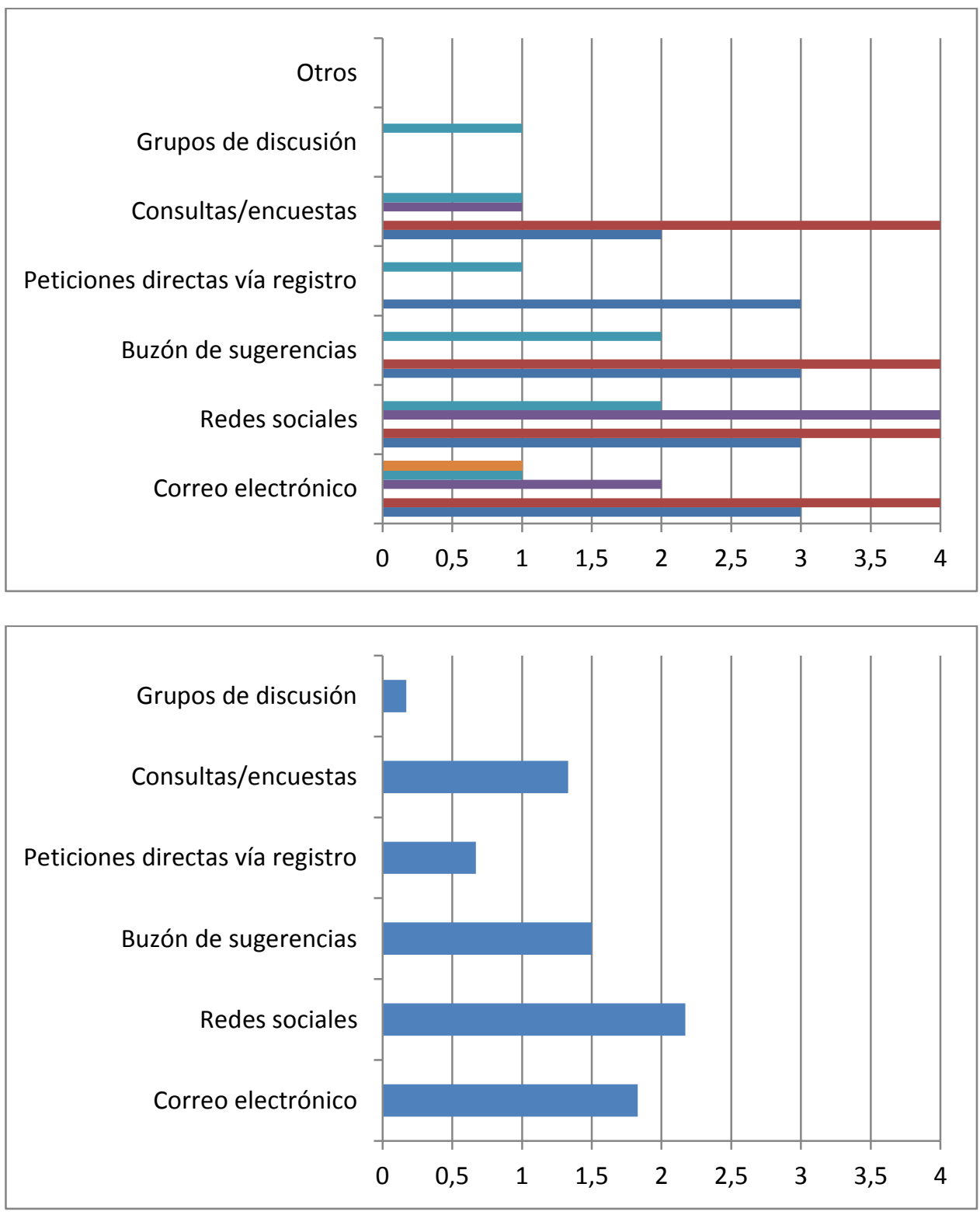

A la hora de establecer una comparativa entre ambos parámetros, se evidencia cómo los canales más utilizados para interactuar con los públicos y conocer sus intereses, basados ambos en las TIC, tienen un nivel de respuesta menor respecto a su promoción, según las respuestas de los encuestados. Sin embargo, ocurre lo contrario en dos canales que apenas se promocionan pero que, cuando son utilizados por los públicos, reciben un nivel de respuesta elevado. Se trata de dos mecanismos utilizados tradicionalmente por las universidades para conocer los intereses de sus públicos internos o externos como son el buzón de sugerencias o las peticiones directas presentadas a través de registro, teniendo esta última una presencia minoritaria. Más reducida todavía es la realización de grupos de discusión, mientras que las consultas y 
encuestas reciben una valoración algo mayor, siendo un poco más elevada su promoción que el nivel de respuesta.

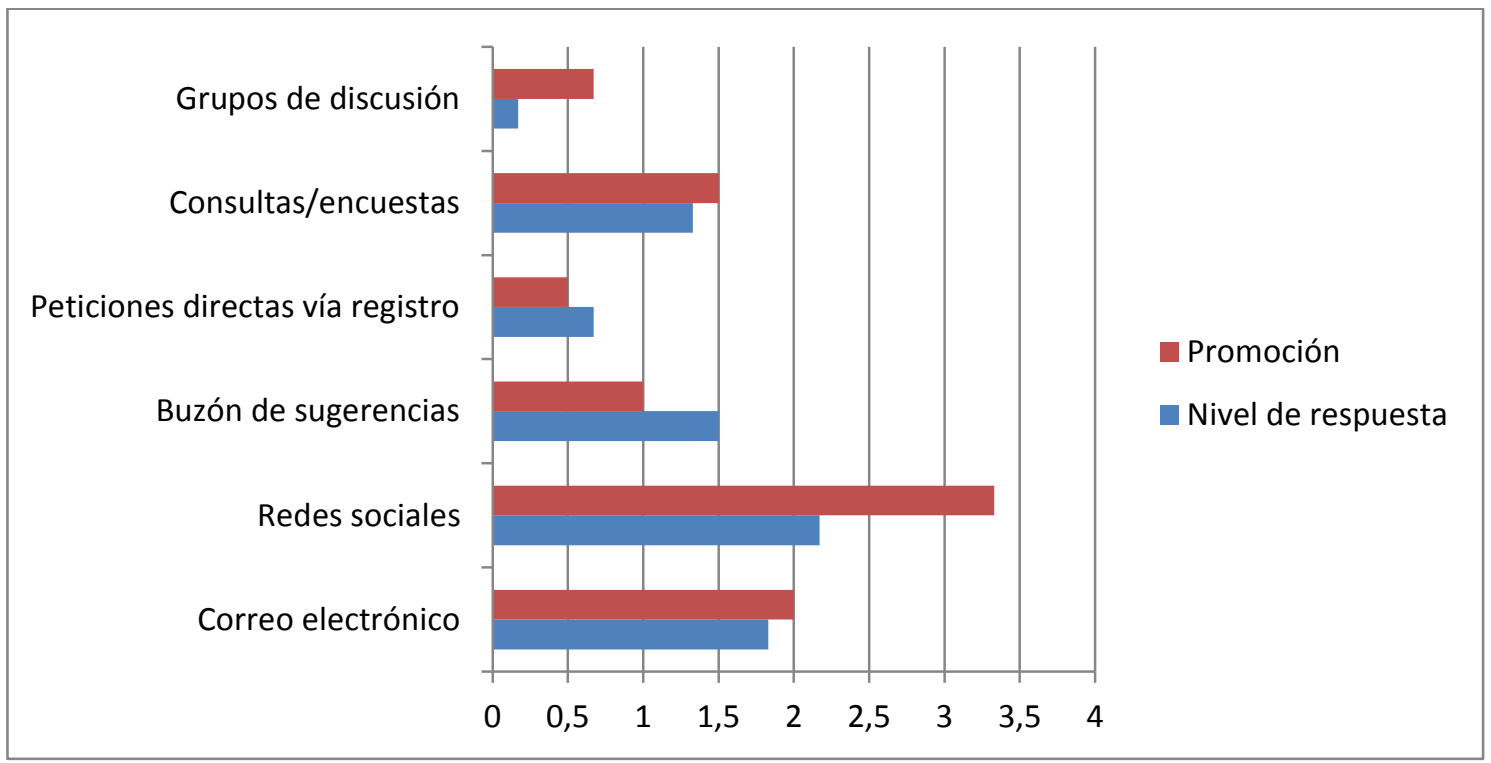

\section{- Los tiempos de la comunicación}

El presente punto se completa con el análisis de los tiempos de la comunicación. En concreto, se planteó a los responsables de la comunicación de la ciencia de las universidades valencianas en qué momento se informa habitualmente sobre los proyectos de innovación e investigación.

- ¿En qué momento suele realizarse la comunicación de las investigaciones e innovaciones?

\begin{tabular}{|c|c|c|c|c|}
\hline Nunca & $\begin{array}{l}\text { Pocas } \\
\text { veces }\end{array}$ & $\begin{array}{c}\text { Algunas } \\
\text { veces }\end{array}$ & $\begin{array}{c}\text { Bastantes } \\
\text { veces }\end{array}$ & Siempre \\
\hline
\end{tabular}

\begin{tabular}{|c|c|c|c|c|c|c|}
\hline $\begin{array}{l}\text { En el inicio de la } \\
\text { investigación/innovación }\end{array}$ & $r$ & $r$ & $r$ & $r$ & $r$ & $r$ \\
\hline $\begin{array}{l}\text { En el desarrollo de la } \\
\text { investigación/innovación }\end{array}$ & $r$ & $r$ & $r$ & $r$ & $r$ & $r$ \\
\hline $\begin{array}{l}\text { En el momento de la } \\
\text { obtención de resultados }\end{array}$ & $r$ & $r$ & $r$ & $r$ & $r$ & $r$ \\
\hline $\begin{array}{l}\text { Tras la publicación de } \\
\text { resultados/patente de } \\
\text { innovación }\end{array}$ & $r$ & $r$ & $r$ & $r$ & $r$ & $r$ \\
\hline
\end{tabular}

- En el inicio de la investigación/innovación. La comunicación de las investigaciones o innovaciones se produce de forma minoritaria en el inicio del proceso, asegurando la mitad de los encuestados que nunca o muy pocas veces se informa en este punto. Otras 
dos universidades informan algunas veces en esta fase, mientras que otra lo hace bastantes veces.
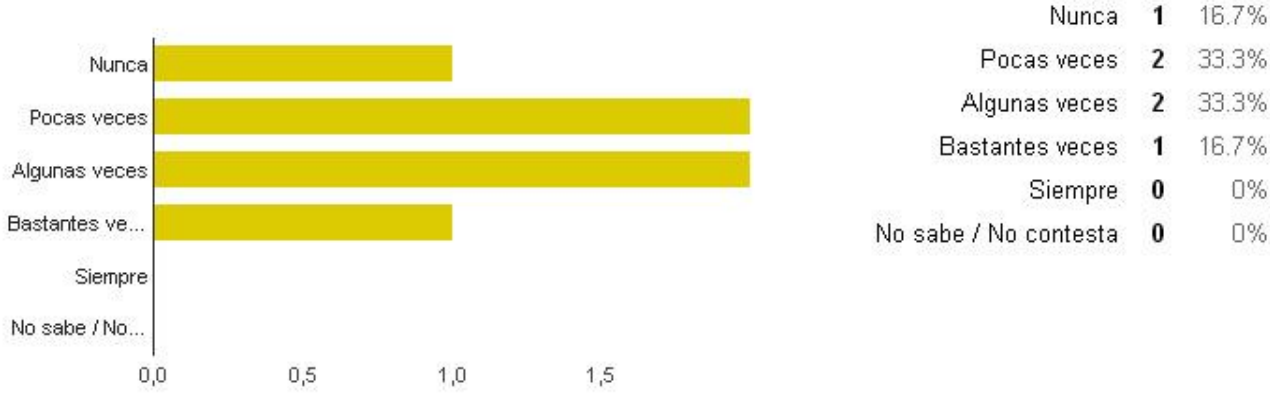

- En el desarrollo de la investigación/innovación. La comunicación durante el desarrollo de los procesos de investigación e innovación resulta menor incluso que en el inicio, afirmando tres de las seis universidades que nunca informan en esta fase.
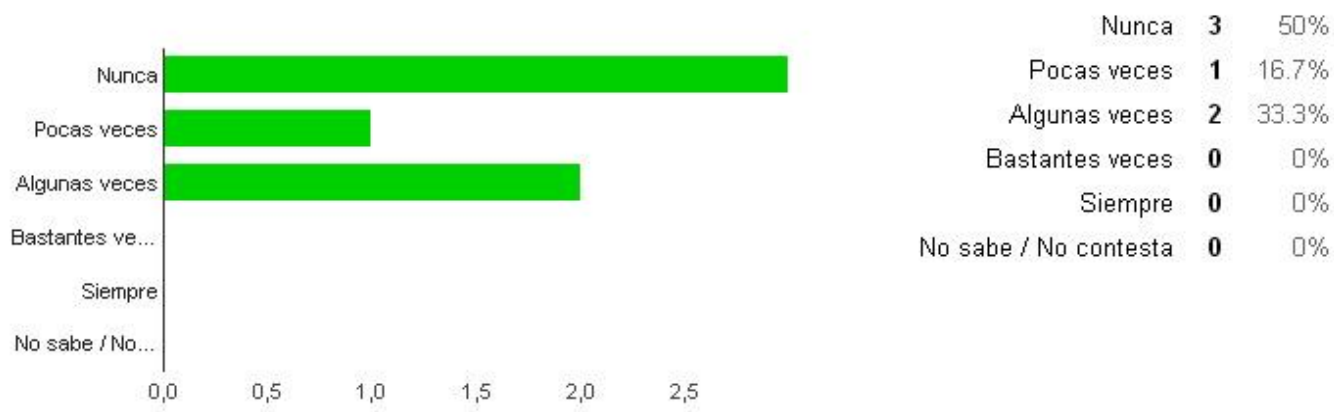

No sabe / No contesta $\mathbf{0} \quad 0 \%$

- En el momento de la obtención de resultados. La comunicación se incrementa notablemente en el momento en el que los procesos alcanzan resultados, momento en el que dos universidades señalan que informan algunas veces, otra señala que bastantes veces y otra que siempre. No obstante, existen dos centros que afirman que tampoco comunican nunca en este momento.
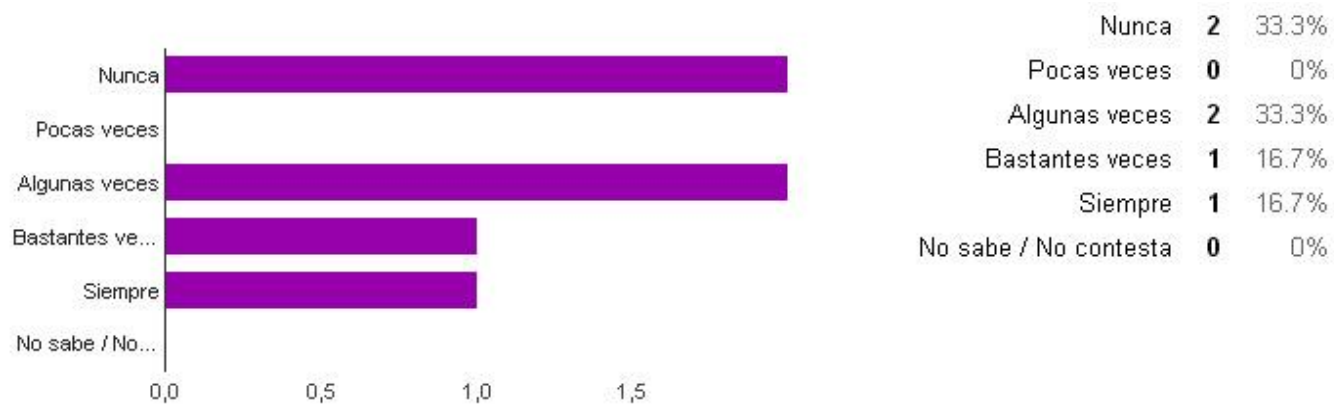

- Tras la publicación de resultados/patentes de innovación. La comunicación de la ciencia se produce de forma claramente mayoritaria en el momento de la publicación de 
resultados en las revistas de investigación o tras patentar las innovaciones. Cuatro de los encuestados afirman que siempre realizan la comunicación en este punto.

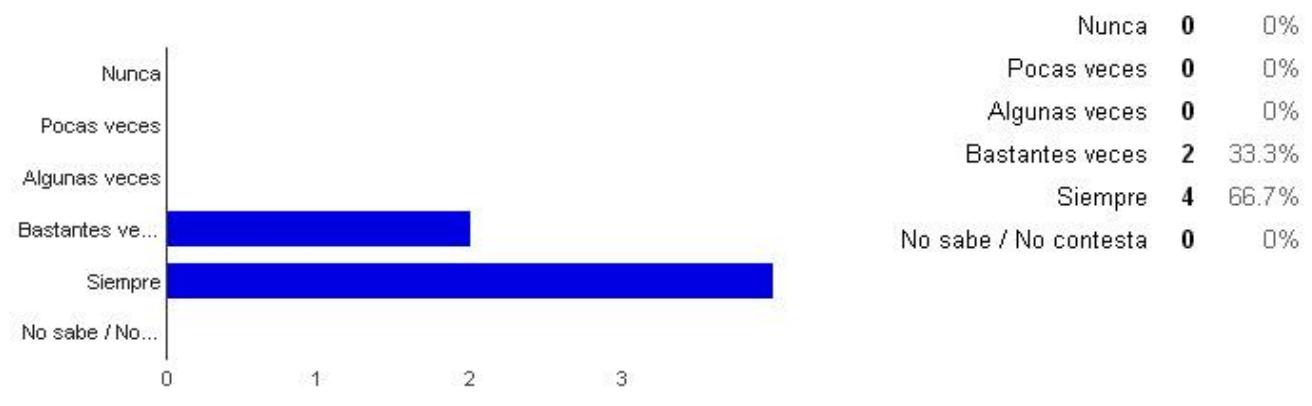

\section{COMPARATIVAS}

La comparativa de las respuestas realizadas por las diferentes universidades y la media de estas valoraciones permiten observar, en primer lugar, las diferencias de criterio utilizadas por las diferentes universidades sobre los momentos en los que se difunden las investigaciones e innovaciones. No obstante, existe un consenso general en realizar la información de forma mayoritaria una vez los resultados obtenidos han sido publicados o patentados, siendo este el momento elegido en la mayor parte de ocasiones para comunicar los proyectos.

La comunicación durante las demás fases de la investigación es mucho menor, siendo bastante similar la realizada en la fase de obtención de resultados y en la de inicio de los proyectos. Durante el desarrollo del proyecto es la fase en la que la comunicación es menor.

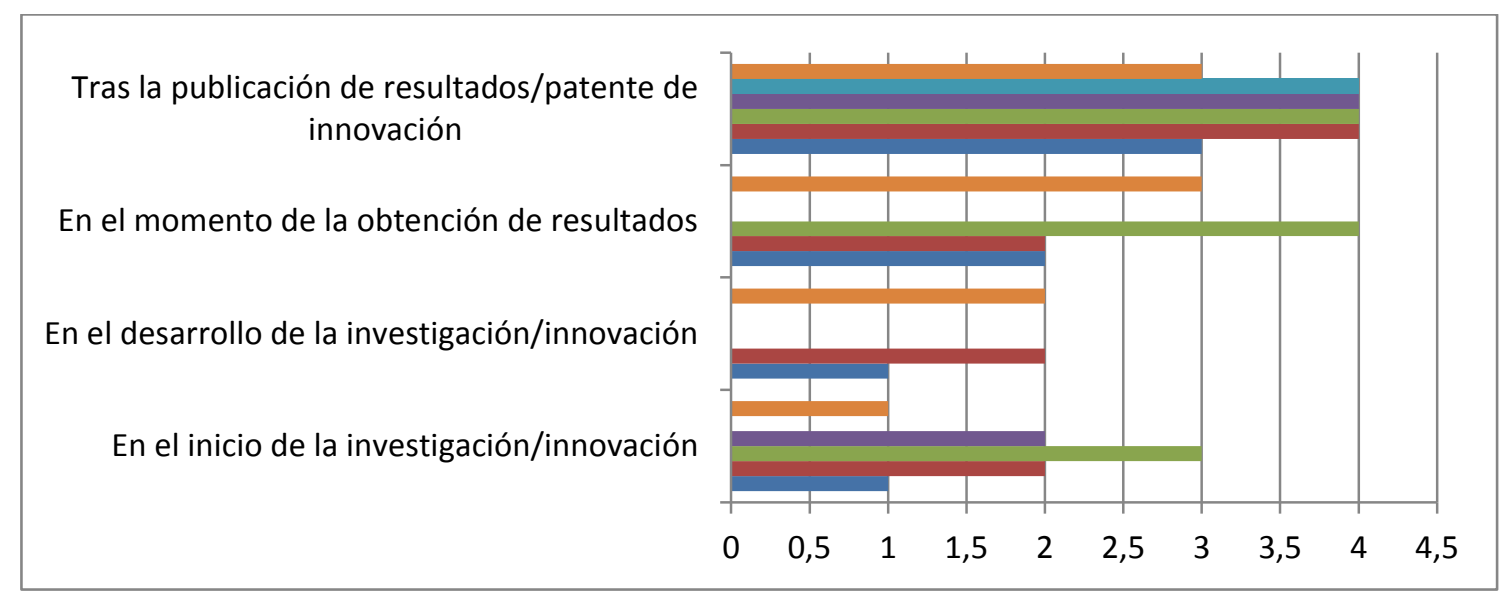




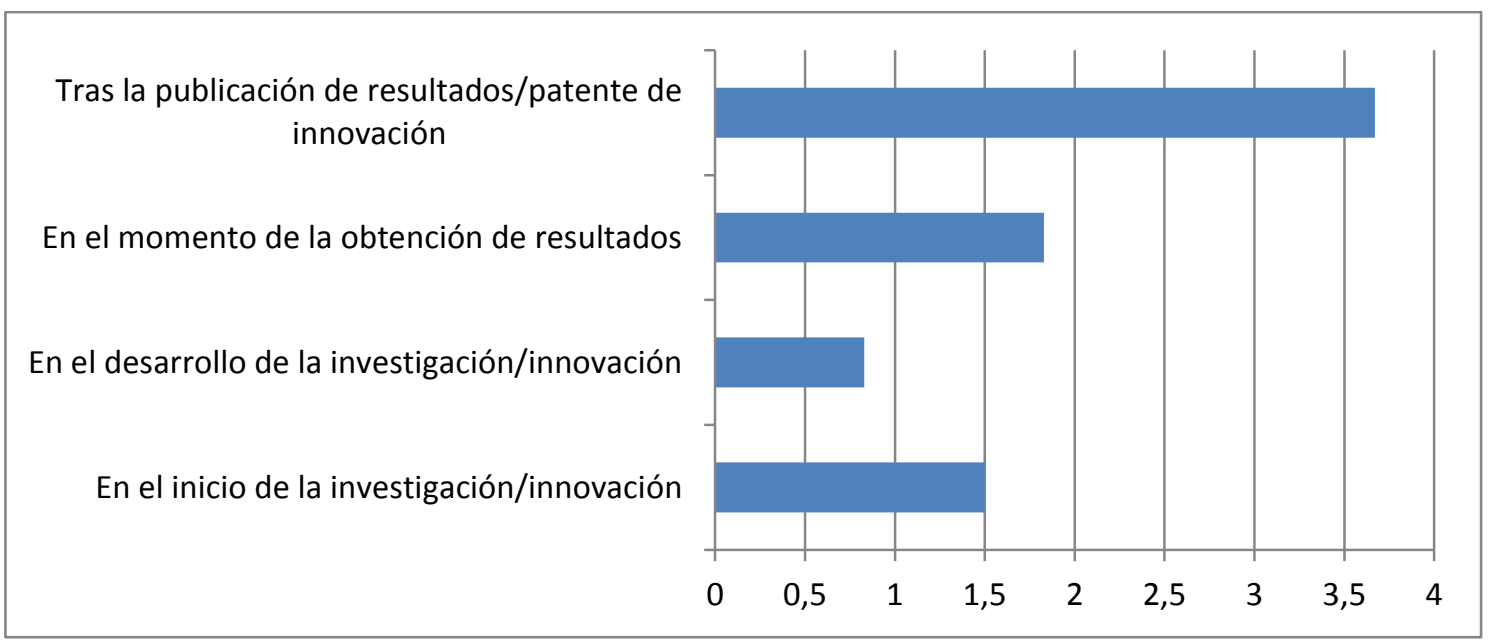

\subsection{3. Ética y responsabilidad en la comunicación de la ciencia}

El último apartado recoge las preguntas directamente relacionadas con la ética y la responsabilidad, comenzando por las fases planteadas en el modelo de comunicación de la RRI desarrollado, para continuar con la valoración sobre la aplicación de criterios éticos tanto en la gestión de la investigación y la innovación como en la comunicación de la misma. Como en los puntos anteriores, desglosamos a continuación cada una de las preguntas y las respuestas obtenidas.

\section{- Acciones relacionadas con el modelo de comunicación de la RRI}

En la primera de las preguntas de este bloque se explicaban de forma esquemática las tres fases específicas del modelo comunicativo planteado con el objetivo de conocer con qué frecuencia realizan las universidades valencianas acciones en cada uno de estos ámbitos.

- La presente investigación entiende la función ética de la comunicación en el ámbito de la ciencia y la innovación como un medio para conocer las expectativas de los públicos, negociar con ellos los compromisos de la Universidad e informar del grado de cumplimiento de los mismos. En este sentido, indique con qué frecuencia considera que realiza su Universidad acciones en cada uno de estos ámbitos.

$$
\begin{array}{ccccc}
\text { Nunca } & \begin{array}{c}
\text { Pocas } \\
\text { veces }
\end{array} & \begin{array}{c}
\text { Algunas } \\
\text { veces }
\end{array} & \begin{array}{c}
\text { Bastantes } \\
\text { veces }
\end{array} \text { Siempre } & \begin{array}{c}
\text { No sabe / } \\
\text { No } \\
\text { contesta }
\end{array}
\end{array}
$$

\begin{tabular}{|c|c|c|c|c|c|c|}
\hline $\begin{array}{l}\text { Conocer las } \\
\text { expectativas/intereses } \\
\text { de los públicos }\end{array}$ & $C$ & $r$ & $r$ & $r$ & $r$ & $r$ \\
\hline $\begin{array}{l}\text { Negociar } \\
\text { compromisos con los } \\
\text { públicos }\end{array}$ & $C$ & $r$ & $r$ & $C$ & $C$ & $r$ \\
\hline
\end{tabular}




$\begin{array}{cccccc}\text { Nunca } & \begin{array}{c}\text { Pocas } \\ \text { veces }\end{array} & \begin{array}{c}\text { Algunas } \\ \text { veces }\end{array} & \begin{array}{c}\text { Bastantes } \\ \text { veces }\end{array} & \text { Siempre } & \begin{array}{c}\text { No sabe / } \\ \text { No } \\ \text { contesta }\end{array}\end{array}$

Informar sobre el cumplimiento de los compromisos

- Conocer las expectativas/intereses de los públicos. El 50\% de los encuestados señalaron que su universidad realiza algunas veces acciones para conocer las expectativas de sus públicos, elevando únicamente una universidad la valoración a bastantes veces. Las otras dos lo situaron por debajo al considerar que realizan acciones con este fin nunca o pocas veces.
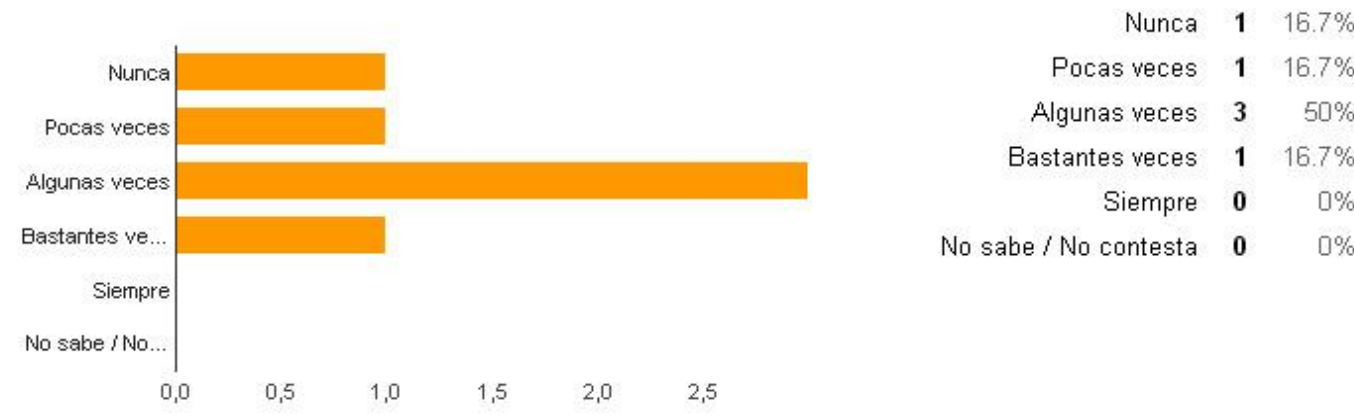

- Negociar compromisos con los públicos. Las acciones de negociación de compromisos con los públicos en materia de ciencia e innovación se producen nunca o pocas veces en la mayoría de los casos. Tan sólo uno de los encuestados considera que su universidad realiza este tipo de acciones algunas veces y otro eleva la respuesta a bastantes veces.
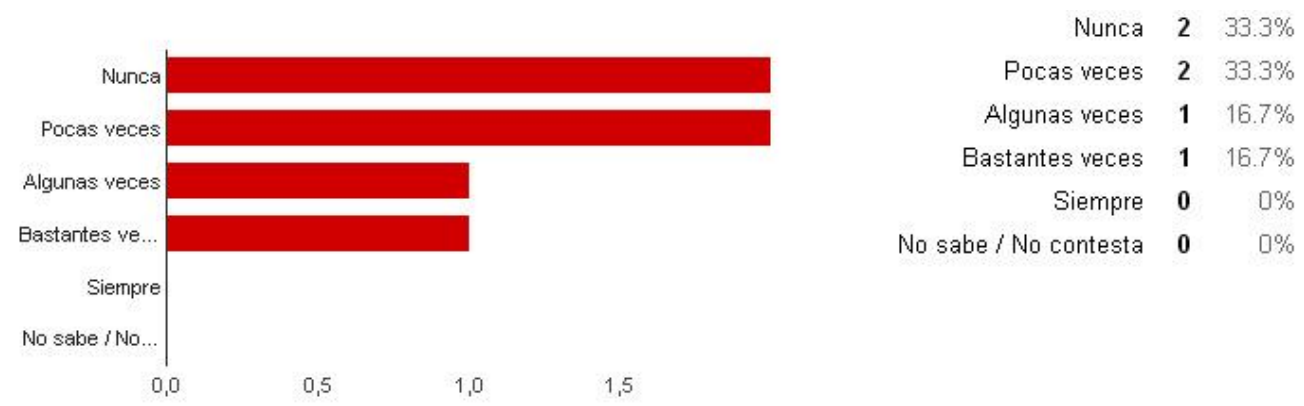

- Informar sobre el cumplimiento de los compromisos. Finalmente, el 50\% de los encuestados considera que su universidad no realiza nunca acciones través de las que 
informar a sus públicos del grado de cumplimiento de los compromisos, dos de ellas lo sitúan en algunas veces y una tercera en bastantes veces.
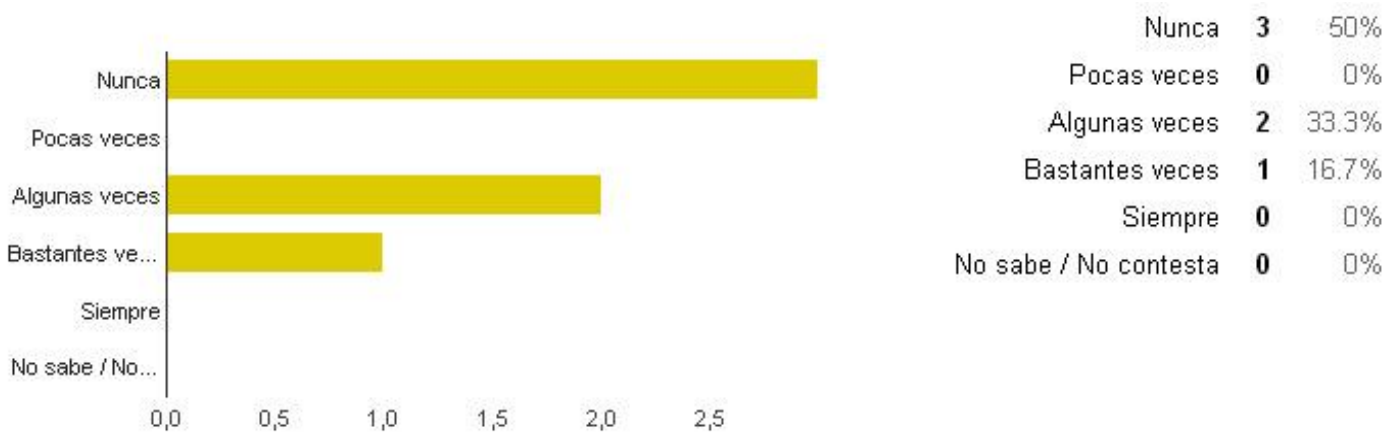

\section{COMPARATIVA}

La comparativa muestra la diferencia entre las respuestas de las universidades, señalando uno de los encuestados que su universidad realiza las tres acciones señaladas bastantes veces, mientras que las cinco restantes sitúan las puntuaciones por debajo, oscilando entre nada y algo. Analizando la media de estas valoraciones, vemos como los profesionales de la comunicación de la ciencia consideran que las acciones dirigidas a conocer las expectativas e intereses de los públicos son las más realizadas por las universidades, por encima de aquellas encaminadas a negociar compromisos e informar del cumplimiento de los mismos. No obstante, a pesar de ser más elevada, se sitúa en una respuesta media de 1,6, que evidencia que se trata, en cualquier caso, de acciones poco significativas.

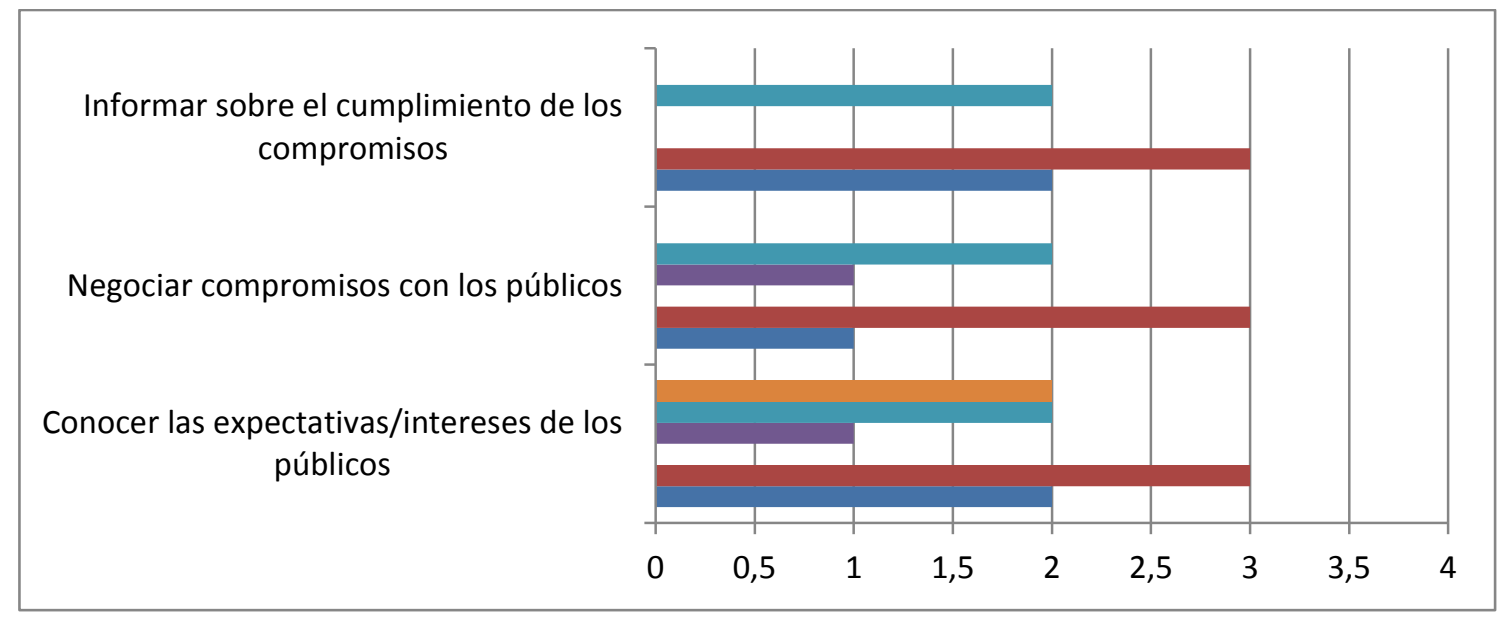




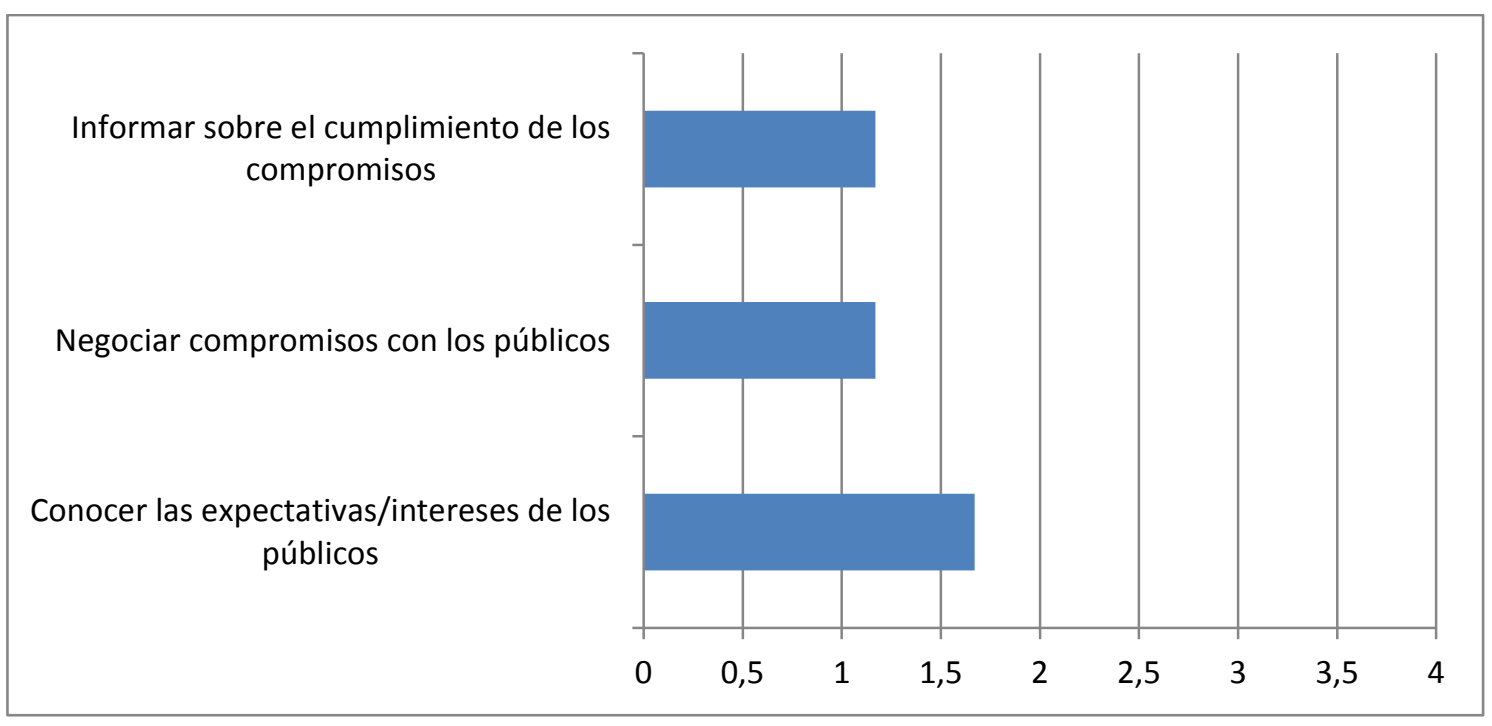

- Criterios éticos y de responsabilidad

Las siguientes cuestiones pedían la opinión de los profesionales de la comunicación de la ciencia sobre la consideración de criterios éticos y de responsabilidad social por parte de la universidad en la gestión de la investigación y la innovación y si los mismos aparecían recogidos en algún documento oficial. Finalmente, se solicitó a los participantes que valoraran la consideración de criterios de ética y de responsabilidad social en la gestión de la comunicación de la investigación y la innovación.

- ¿Cree que su Universidad tiene en cuenta criterios de ética y responsabilidad social en la gestión de la investigación y la innovación (compromiso social, atención a las necesidades sociales, transparencia en sus acciones, igualdad, etc.)?

Valore la respuesta en una escala de 0-nada, 1-poco, 2-algo, 3-bastante y 4-mucho.

\begin{tabular}{l|l|l|l|l}
0 & 1 & 2 & 3 & 4 \\
\hline & 6 & $C$ & 6 & 6 \\
\hline
\end{tabular}

- ¿Están estos criterios éticos o de responsabilidad en la gestión de la investigación y la innovación recogidos en algún documento oficial (Estatutos, Código Ético, comisión deontológica, etc.)? En caso afirmativo, indique en cuál/es.

- ¿Considera que en la gestión de la comunicación de la investigación y la innovación se tienen en cuenta aspectos de ética y responsabilidad social (atención a las expectativas ciudadanas, transparencia, participación, etc.)?

Valore la respuesta en una escala de 0-nada, 1-poco, 2-algo, 3-bastante y 4-mucho.

\begin{tabular}{l|l|l|l|l}
0 & 1 & 2 & 3 & 4 \\
\hline & 5 & 6 & 5 & 6 \\
\hline
\end{tabular}


- Criterios éticos en la gestión de la investigación y la innovación. La valoración de los participantes fue que los criterios de ética y responsabilidad social en la gestión de la investigación y la innovación de sus respectivas universidades se aplicaban de forma muy elevada en el $83,3 \%$ de los casos y algo en el $16,7 \%$ restante.

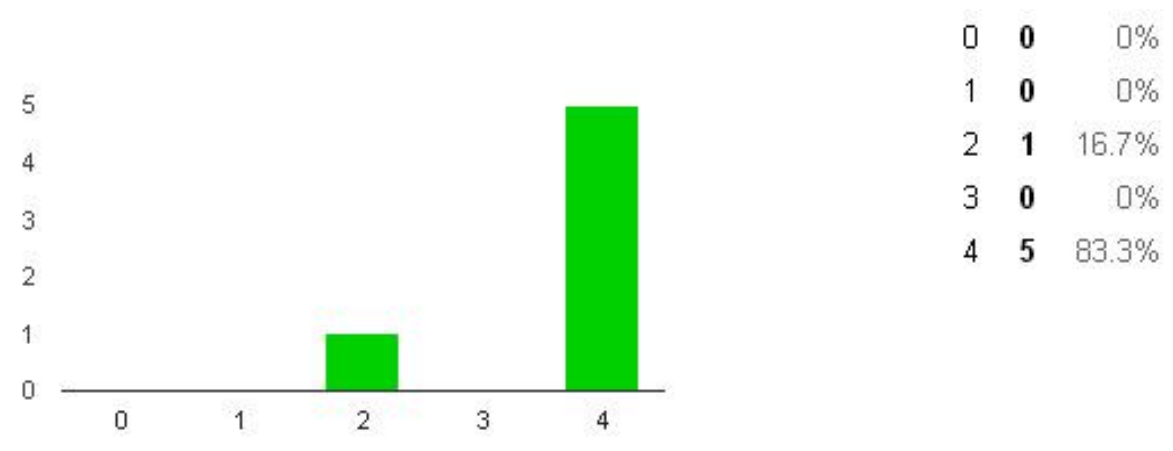

- Plasmación en documentos oficiales. Sobre los documentos que recogen estos criterios éticos, estas fueron las repuestas planteadas:

- Plan Estratégico

- Desconozco que exista un documento sobre criterios éticos o de responsabilidad. Sí que existe un protocolo en el caso de la investigación con animales. Es posible que en los Estatutos de la Universitat existan algunas ideas o propuestas que pudieran relacionarse.

- No que yo sepa

- Plan Estratégico, Plan transversal Campus Sostenible

- De este ámbito se encarga la Comisión de Investigación y Ética de la CEU-UCH. Cuenta con el apoyo de los tres institutos de investigación de la CEU-UCH: Instituto de Ciencias Biomédicas (ICB), Instituto de Disciplinas Económicas, Ambientales y Sociales (IDEAS) e Instituto de Innovación, Diseño y Tecnología (IDIT). Las directrices de la investigación en la CEU-UCH están recogidas en el Plan de Apoyo a la Actividad Investigadora.

- Estatutos

- Criterios éticos en la comunicación de la ciencia. En este punto, las valoraciones de los participantes fueron algo menores que en el caso de la aplicación de los criterios de ética y responsabilidad a la gestión de la investigación y la innovación. Así, sólo uno de los encuestados entiende que estos criterios se aplican también con mucha frecuencia a la comunicación y otros dos reducen a bastante su aplicación. Dos universidades mantienen la valoración en algo. 


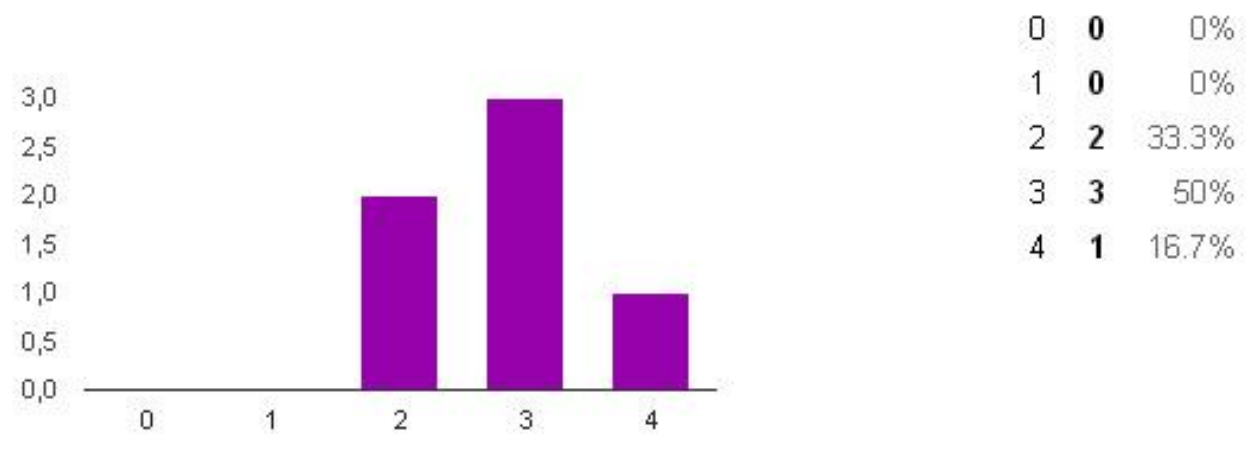

\section{COMPARATIVAS}

Estableciendo una comparativa entre las respuestas de las seis universidades a ambas preguntas se ve cómo dos de los encuestados mantienen la misma consideración respecto a la aplicación de criterios de ética y responsabilidad en la gestión de la investigación y la innovación que en la gestión de su comunicación: uno de ellos entiende que es mucha en ambos casos y el otro, que es algo. Las restantes respuestas varían, indicando que se atienen más a criterios éticos a la hora de gestionar la investigación y la innovación que en el momento de comunicarla. La suma de las puntuaciones muestra por tanto cómo es más elevada la percepción de la gestión ética de la ciencia, con una media de 3,6, entre bastante y mucho; frente a la media de 2,8 , que no llega a alcanzar el bastante, en el caso de la consideración de criterios éticos y de responsabilidad en la comunicación de la ciencia.

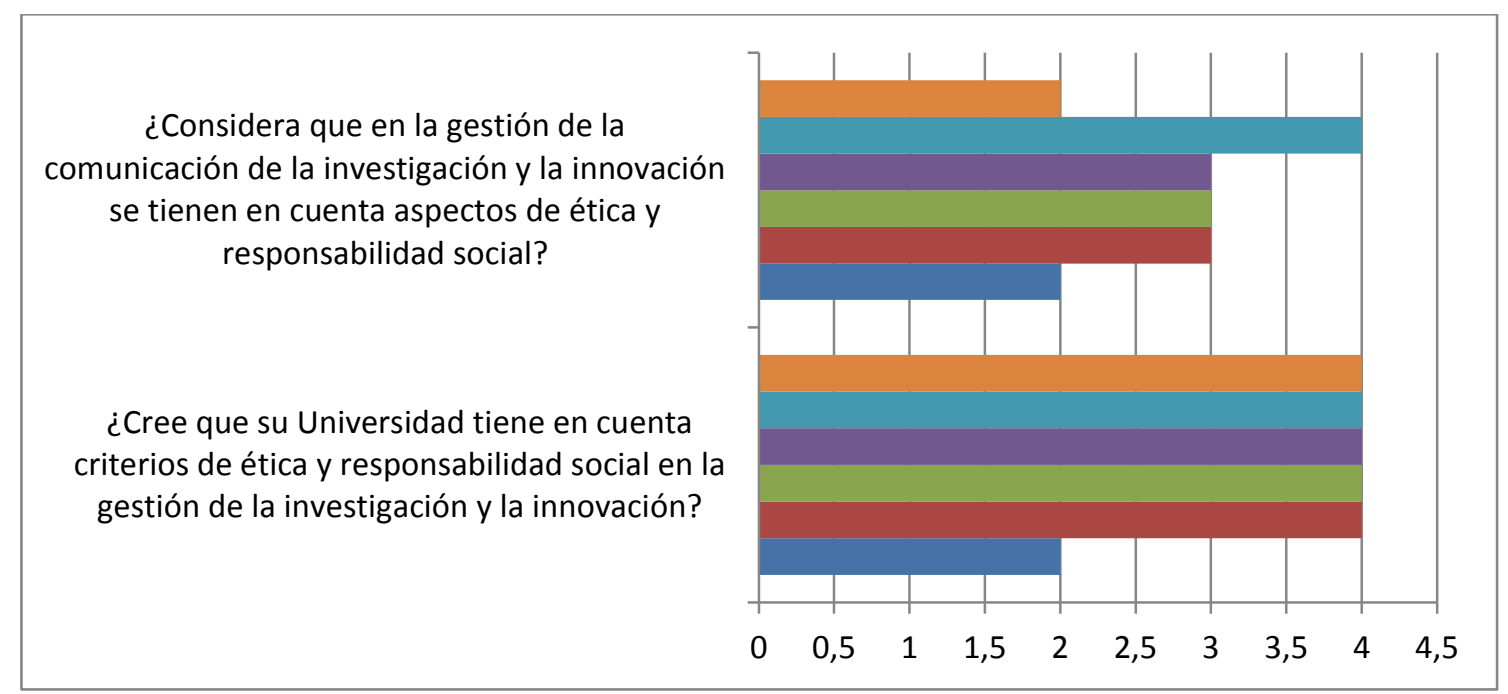


¿Considera que en la gestión de la comunicación de la investigación y la innovación se tienen en cuenta aspectos de ética y responsabilidad social?

¿Cree que su Universidad tiene en cuenta criterios de ética y responsabilidad social en la gestión de la investigación y la innovación?

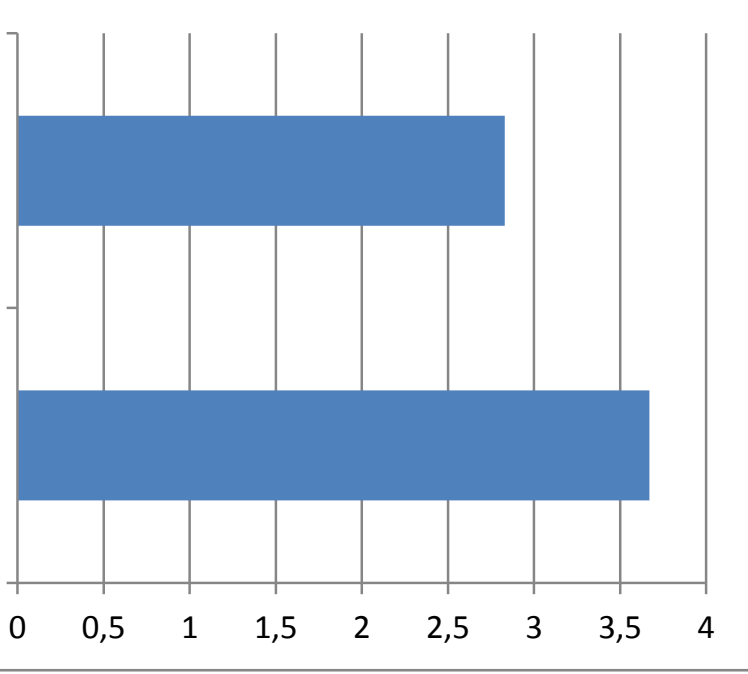

Una vez expuestas las respuestas de los encuestados, en el siguiente capítulo analizaremos las principales conclusiones, así como las consideraciones a tener en cuenta respecto al modelo ético de comunicación de la RRI planteado.

\subsection{CONSIDERACIONES SOBRE LA COMUNICACIÓN ACTUAL DE}

\section{LA CIENCIA RESPECTO AL MODELO PROPUESTO}

Recogemos a continuación las conclusiones extraídas de las respuestas de los profesionales de la comunicación de la ciencia encuestados, con el fin de realizar una aproximación a algunas características de la situación en la que se encuentra la comunicación de la investigación y la innovación en las universidades. Esto nos permitirá poner en relación esta situación con el modelo de comunicación ética de la RRI planteado.

- Diversidad en la estructura de la comunicación de la ciencia. El modo de gestionar la comunicación de la ciencia y la estructura con la que cuenta cada universidad para este fin es muy diversa, empezando por el número de persona dedicadas a la misma, que va desde universidades que cuentan con una única persona con dedicación parcial hasta centros que disponen de dos personas con dedicación completa y dos con dedicación parcial. No obstante, también presentan algunos rasgos comunes como es el hecho de realizarse desde los servicios de comunicación o gabinetes de prensa de las universidades, siendo así en cinco de los seis casos. 
- Alta valoración de la importancia de la comunicación de la ciencia. Todos los encuestados coinciden en que sus respectivas universidades le conceden mucha importancia a la comunicación de la ciencia. Entre las razones argumentadas, varios señalan que se trata de una función de la universidad, aludiendo a su obligación de divulgar. También se señalan como razones la necesidad de contribuir a un incremento de la cultura científica y una mejor formación de la opinión pública con el fin de empoderarla a la hora de tomar decisiones. La visibilidad institucional y la importancia de la transferencia son otras de las razones por las que se considera que es importante la comunicación pública de la ciencia.

- La web y los medios de comunicación de masas centran las acciones. La acción que realizan con mayor frecuencia y a la que conceden más importancia es la elaboración de contenidos para la web de la universidad lo que parece consolidar este medio como principal vehículo para la difusión de la información sobre ciencia e innovación universitaria. Sin embargo, los medios de comunicación de masas siguen teniendo un gran peso ya que a continuación aparecen como más frecuentes e importantes la elaboración de contenidos para los mismos y la atención a sus peticiones.

- El blog se posiciona como medio de comunicación propio de comunicación científica. El desarrollo de blogs propios sobre ciencia de las universidades tiene un peso muy importante, situándose su gestión entre las tres acciones que realizan con mayor frecuencia los responsables de la comunicación de la investigación e innovación. Este medio se sitúa como el primero por frecuencia e importancia entre los medios propios de las universidades, por delante de la televisión, la radio y las revistas.

- Las relaciones con blogs externos como objetivo. La convocatoria de ruedas de prensa y las relaciones con blogs externos de ciencia e innovación son las acciones que las universidades valencianas encuestadas realizan con menor frecuencia. En ambos casos la importancia que le otorgan los responsables de comunicación es mayor que la frecuencia con la que se utilizan, aunque por debajo de la concedida a las demás acciones. En el apartado de comentarios, los encuestados explican que la reducción de las ruedas de prensa responde a factores externos, como es la reducción de las redacciones 
de los medios. En el caso de las relaciones con blogs externos lo plantean como un objetivo de mejora.

- Primacía de la comunicación con el entorno. Los públicos más frecuentes e importantes son los más próximos a la universidad: sociedad del entorno, comunidad científica interna y medios de comunicación de proximidad.

- Sociedad y comunidad científica, públicos prioritarios. La sociedad es el público más importante y frecuente para las universidades en materia de ciencia, seguido de la comunidad científica. Casi al mismo nivel que ésta se encuentran los medios de comunicación. Los públicos que las universidades consideran menos importantes y con los que se relacionan en menor medida son, con diferencia, las administraciones. Dentro de estas cabe destacar que las relaciones son más frecuente con las administraciones europeas que con las nacionales.

- El reto de la internacionalización. En todos los casos los profesionales que contestaron la encuesta consideran que es mayor la importancia de los públicos que la frecuencia de la relación con los mismos, a excepción de los medios de proximidad en la que ambas se igualan. Sin embargo, la diferencia entre la importancia otorgada y la frecuencia es mayor en los públicos más alejados del entorno como son la sociedad en general, la comunidad científica externa y los medios nacionales y, especialmente, internacionales. Esto hace pensar en que, a pesar de que son conscientes de su importancia, entienden que todavía no se les dedican los recursos que consideran adecuados, señalando uno de los encuestados que la internacionalización es un reto necesario para la comunicación de la ciencia por parte de las universidades.

- Las TIC como herramientas para la interacción. Las redes sociales y, en menor medida, el correo electrónico, son los canales más utilizados por las universidades para conocer las expectativas y necesidades de los grupos de interés en materia de ciencia e innovación, lo que confirma la utilidad de las TIC para interactuar con los públicos. Las respuestas de los encuestados evidencian la falta de promoción de otros canales y mecanismos para conocer las expectativas de los stakeholders, limitándose a poca la 
realización de encuestas y consultas y la promoción del buzón de sugerencias y a prácticamente nada la difusión de peticiones vía registro y la realización de focus groups.

- Desequilibrios en las respuestas a los stakeholders. En ninguno de los canales de interacción con los stakeholders se encuentra equilibrado el nivel de promoción con el de respuesta. En este sentido, cabe señalar que los dos a los que se da mayor difusión, como son las redes sociales y el correo electrónico, tienen un nivel de respuesta inferior, siendo mayor este desequilibrio en el caso de las redes sociales. Por el contrario, el nivel de respuesta es superior a la promoción en el caso de las consultas o peticiones que llegan por vías más institucionales pero poco difundidas como son el buzón de sugerencias o las peticiones directas vía registro.

- La información, tras la publicación de resultados. Las universidades comunican públicamente sus investigaciones de forma mayoritaria tras haberse publicado los resultados en revistas de investigación o después de patentar las innovaciones. Esto concuerda con una visión de la comunicación pública de la ciencia basada en la transmisión de resultados finales y viene a evidenciar la falta de información y diálogo sobre las investigaciones a lo largo de todo el proceso que reivindican diferentes aproximaciones a la RRI (Sutcliffe, 2011; Laroche, 2011; European Comission, 2012).

- Elevada percepción sobre la aplicación de criterios éticos. Los encuestados tienen una elevada percepción de la aplicación de criterios de ética y responsabilidad social en la gestión de la investigación y la innovación por parte de sus universidades, afirmando en la mayoría de los casos que se tienen muy en cuenta. Las respuestas sobre los documentos que recogen estos criterios son bastante diversas, haciendo referencia en dos casos a los estatutos y en otros dos a los planes estratégicos, mientras que una universidad señala la existencia de una comisión específica de ética e investigación. También es bastante elevada, aunque algo menos, la consideración de que los criterios de ética y responsabilidad se aplican a la comunicación de la ciencia. 
- Pero ausencia de acciones vinculadas al modelo propuesto. A pesar de esta elevada percepción, poniendo en relación las acciones de comunicación de la ciencia realizadas por las universidades con el modelo de comunicación de la RRI propuesto, se evidencia cómo ninguna de las fases establecidas tienen un peso importante en las acciones de comunicación realizadas en la actualidad. Así, señalan que se realizan pocas acciones encaminadas a negociar compromisos con los públicos o a informar sobre el cumplimiento de los mismos, y tan solo algunas a conocer los intereses y necesidades de los stakeholderes.

En resumen, parece que la comunicación de la ciencia y la innovación realizada por las universidades tiene poca relación con el modelo comunicativo propuesto para el fomento de una investigación e innovación más responsables. Las respuestas evidencian la importancia otorgada por las universidades a la comunicación de la ciencia, a pesar de que los recursos destinados a la misma difieren bastante entre unas y otras.

En cuanto a los mecanismos y canales de comunicación, las TIC se sitúan como una herramienta primordial de cara tanto a informar sobre ciencia, mediante los portales web de las universidades y los blogs de ciencia propios, como para interactuar con los grupos de interés, mediante las redes sociales y el correo electrónico. Sobre estos últimos, en base a las contestaciones de los encuestados, cabría elevar el nivel de respuesta que ofrecen las universidades a las peticiones y demandas que les llegan a través de estos canales. En cualquier caso, parece que cualquier modelo comunicativo que busque potenciar la RRI debe tener en cuenta la utilidad de la web social y las TIC.

Más allá del uso de las nuevas tecnologías, los medios de comunicación tradicionales siguen jugando un papel importante, que también debería tenerse en cuenta en la comunicación de la RRI. Así, las universidades consideran a los medios de comunicación como un público destinatario importante, destinando a los mismos gran parte de sus acciones comunicativas.

Por otra parte, parece positivo de cara al desarrollo de una investigación e innovación que responda a los intereses y expectativas de los stakeholderes, el gran peso otorgado por los profesionales de la comunicación a los públicos más próximos a las universidades, como son la sociedad del entorno, la comunidad científica propia y los medios de comunicación locales y regionales. En este mismo apartado, cabe destacar 
la importancia dada a dos de los grupos de interés incluidos en el mapa de stakeholders como son la sociedad civil y la comunidad científica. Por contra, la Administración tiene un peso mucho más reducido como público destinatario.

Finalmente, cabe señalar que las universidades entienden que no realizan prácticamente ningún tipo de acción de cara a conocer las expectativas de los grupos de interés, a negociar compromisos para atenderlas y a difundir sus resultados. Tampoco se tiene en cuenta la posibilidad de desarrollar acciones de comunicación a lo largo de todo el proceso, sino que la información se ofrece mayoritariamente tras la publicación de resultados o el desarrollo de patentes. A pesar de ello, los encuestados perciben que sus respectivas universidades tienen muy en cuenta criterios de ética y responsabilidad social en la gestión de la ciencia. La visión también es muy positiva al valorar la aplicación de estos criterios a la comunicación de la ciencia. Estas respuestas dan a entender que la aplicación del modelo ético de comunicación de la RRI supondría un cambio sustancial en la forma de entender la comunicación de la ciencia. Un cambio que las universidades pueden, de entrada, no considerar necesario al entender que las cosas se están haciendo bien desde el punto de vista de la ética y la responsabilidad social por lo que respecta a la gestión de la investigación y la innovación y a su comunicación. 



\section{La visión de los stakeholders sobre la comunicación}

\section{ética de la RRI en la universidad}

Con el fin de validad y recopilar opiniones sobre el modelo ético de comunicación de la RRI para las universidades planteado se optó por realizar dos focus groups entre diferentes stakeholders, de forma que el debate suscitado permitiera a los participantes modificar y contrastar sus opiniones a partir de los diferentes puntos de vista expuestos. En el presente capítulo recogemos en primer lugar los informes sobre los dos focus groups realizados para, en un segundo capítulo, analizar las principales conclusiones y aportaciones planteadas por los stakeholders durante los debates y revisar el modelo en función de las mismas.

\subsection{FOCUS GROUPS STAKEHOLDERS}

Los stakeholders participantes en los focus groups fueron los establecidos en el mapa de stakeholders de la RRI planteado en el bloque anterior. Para la realización de los mismos, se decidió agruparlos en dos focus groups, reuniendo en el primero de ellos a los grupos de interés que habitualmente han sido receptores de la comunicación científica, mientras que en el segundo se convocó a representantes de la comunidad científica, incluyendo profesionales de la comunicación de la ciencia de las universidades y parques científicos. En ambos casos se buscó contar con un perfil variado y representativo de los diferentes grupos de interés con el fin de enriquecer el debate y las aportaciones al modelo. A continuación incluimos los informes correspondientes a cada uno de los focus groups.

\subsubsection{Receptores de la comunicación de la ciencia}

El focus group centrado en los receptores de la comunicación de la ciencia reunió a representantes de los stakeholders de la sociedad civil, empresas y administración pública. El hecho de que algunos de los mismos fueran además profesores e investigadores universitarios permitió enriquecer el debate, al introducir también su visión como personal investigador. Para este primer debate se contó con dos responsables de empresas, una de ellas una multinacional con experiencia en la gestión de la RSC y la otra una compañía azulejera, al entender que el sector cerámico debía 
estar presente por su gran peso en la provincial de Castellón. También participaron cuatro representantes de la sociedad civil al entender que es un grupo muy amplio que engloba a diferentes perfiles, incluyéndose en el focus group a responsables de asociaciones, profesorado preuniversitario y fundaciones. En este último caso se optó por una fundación dedicada a la lucha por la igualdad de género, dada la importancia que otorga a esta cuestión la Unión Europea en el marco de la RRI. Finalmente, como representantes de la administración pública se convocó a una política especializada en temas de ciencia y universidad y a una técnica de la Dirección General de Universidades, Estudios Superiores y Ciencia de la Generalitat Valenciana. Esta última disculpó en el último momento su presencia por un problema de agenda, por lo que no se pudo contar con sus aportaciones.

El informe del focus group desarrollada a continuación incluye los datos de realización del mismo y los principales puntos de debate agrupados en torno a tres ejes.

\section{Datos del Focus Group Receptores}

Fecha: 9 de junio de 2015

Hora: 12.30 a 14:00h

Lugar: Sala de Reuniones RR0322RU, edificio de Rectorado y Servicios Centrales de la Universitat Jaume I

Dinamizador: Francisco Fernández Beltrán, director del Servicio de Comunicación y Publicaciones de la UJI y codirector de la tesis.

Asistente: Rosana Sanahuja, autora de la tesis.

\section{Participantes:}

- Sociedad civil:

- Carlos Laguna, Presidente de la Confederación Española de Personas con Discapacidad Física y Orgánica (COCEMFE) de la Comunidad Valenciana.

- Carmen Ferrete, profesora de Educación Secundaria y profesora asociada del Departamento de Filosofía y Sociología de la UJI. 
- Sixto Barberá, vicepresidente de la Asociación Contra el Cáncer de Castellón.

- Gemma Escrig Gil, técnica de la Fundación Isonomía para la promoción de la igualdad de género.

- Empresas:

- Pablo Cruz, Corporate Manager UBE España.

- Carlos Cabrera, gerente Cerámicas Cabrera.

- Administración pública:

- Eva Alcón, diputada de las Cortes Valencianas por el PSPV-PSOE y catedrática de Filología Inglesa de la UJI.

\section{$\underline{\text { La comunicación de la ciencia como elemento central }}$}

La comunicación de la ciencia se sitúa a lo largo de todo el debate como un tema central, coincidiendo los participantes en la necesidad de la misma. Una idea que podría sintetizarse en la siguiente reflexión.

El conocimiento, la ciencia, si no se expande, ¿qué razón tiene de ser?

- Déficits en la Comunicación Pública de la Ciencia. La consideración de que la comunicación de la investigación que se realiza en el campus no llega de forma suficiente a la sociedad y queda limitada al ámbito científico y académico es ampliamente respaldada por los participantes. Se señala cómo el personal investigador se limita mayoritariamente a difundir sus resultados a través de revistas científicas y congresos de cara a otros investigadores, pero no de cara a la sociedad.

Parece que sólo se investigue para futuros investigadores pero si sólo nos centramos en ese aspecto todo aquello que estamos viendo aquí se queda fuera.

Mis compañeros o mis amigos no se enteran de lo que se investiga en el campus. La UJI es muy potente y tiene investigaciones muy interesantes pero no llegan.

- Propuesta de canales alternativos. Se repite la idea de que es necesario comunicar a la sociedad la investigación y la innovación que se desarrolla. En este sentido, a lo largo del debate se plantean una serie de propuestas para fomentar y mejorar la comunicación de la ciencia por parte de las universidades. 
- Inclusión de la comunicación en convocatorias. Se plantea, por un lado, la posibilidad de incluir la comunicación como un requisito en las convocatorias de investigación realizadas por la propia universidad. Por otra, se indica la conveniencia de que las universidades presionen para que las convocatorias públicas contemplen una comunicación más amplia, especialmente de cara a los "grupos meta" destinatarios de la investigación con el objetivo de realizar una transferencia focalizada.

En las convocatorias se tendría que valorar que los campos de comunicación fueran más abiertos y no tan endogámicos en el campo de la ciencia.

En este sentido, destacan cómo la inclusión de objetivos de comunicación en convocatorias como los proyectos Convenius de la Unión Europea consigue impulsar la difusión de proyectos y resultados.

Las acciones de comunicación que realizábamos a nivel local, nacional y europeo luego llegaban más o menos pero es verdad que hacíamos ese esfuerzo y luego eso daba puntos para poder participar en nuevas convocatorias.

- Medios especializados y propios de las organizaciones. Se apunta el interés de utilizar canales y medios especializados y propios de las organizaciones para llegar a grupos y colectivos concretos como es el caso de las personas con discapacidad, de cara a dar a conocer investigaciones que sean de su interés.

La universidad tendría que tener una bolsa de datos de esas revistas y enviar las informaciones que les afecten.

- Formación en comunicación de la ciencia. A lo largo del debate se reiteró por varios de los participantes la importancia de una mayor formación, especialmente entre el personal investigador, pero también por parte de los periodistas. Como propuestas de cara a mejorar esta formación, se incide en la necesidad de que la universidad incorpore la formación en comunicación de los investigadores como un interés real, apuntándose la posibilidad de que se pudiera incluir como materia en los cursos para profesorado. 
Habría que pasar a formar a los investigadores en la importancia de esa comunicación y ahí las universidades sí que tienen un papel importante, a través de sus servicios de comunicación o incluso de lanzar convocatorias específicas que incluyan la comunicación.

Todo y que pensamos que la comunicación es clave, en las universidades comunicar la ciencia se ha hecho un poco de manera voluntaria, no hemos tenido formación los investigadores y tampoco hemos tenido recursos y a lo mejor ese es un paso que se debería dar.

Una investigación puede ser de cientos de páginas y se necesita gente con capacidad de síntesis para llevar el grano a la sociedad, que puede ser el propio investigador si se le ha formado.

En el ámbito de la formación se habla también de abarcar a los medios y al estudiantado universitario.

Dar recursos también a los medios que son los que procesan la información.

A los alumnos en las universidades se les debería formar en comunicación también.

- La comunicación como motor de conocimiento. El focus group reflejó el consenso entre los diferentes stakeholders sobre la importancia de la comunicación como motor de conocimiento, cultura y participación, destacándose los beneficios “infinitos" de la misma. Durante el debate también se reiteró la necesidad de comunicar de forma eficiente la ciencia, mediante los canales y lenguajes adecuados.

La comunicación sabemos que hoy en día es una de las principales fuentes de generación de pensamiento y cultura.

La comunicación es la manera en la que se aproxima la ciencia pero también supone traducir los resultados a los que estamos llegando a un lenguaje asequible y que además sea de utilidad.

Es cierto que la comunicación es un elemento central y es ese mecanismo que puede acercar y traducir y hacer dinámico. Las investigaciones no llegan a mucha gente y es muy triste con los recursos que se están utilizando y la gente que está trabajando que los resultados se queden luego solo en la biblioteca.

Es que los beneficios son infinitos si llegan al gran público.

- La comunicación responsable. La responsabilidad de la comunicación de la ciencia salió también a relucir, poniendo el acento algunos de los participantes en la dificultad que supone mantener una información rigurosa y responsable ante los intereses generados alrededor de la investigación y la ciencia.

Incorporar la responsabilidad de los procesos comunicativos es fundamental. 
En comunicación y ética nos encontramos con el problema de los intereses que hay detrás de la investigación. Es muy complejo. En muchas ocasiones una universidad ha querido ponerse una medalla y se ha equivocado y ha equivocado a los grupos de interés y ha generado una frustración terrible. Se han de hacer las cosas bien, no despertar expectativas falsas.

\section{$\underline{\text { Aportaciones al modelo ético de comunicación de la RRI }}$}

- Atención a las expectativas. Existe un consenso general sobre la importancia de conocer las demandas de los grupos de interés y responder a sus necesidades, abarcando este punto diversos aspectos.

- Determinación de las investigaciones. Se entiende que los grupos de interés del entorno de la universidad deberían influir en la determinación de los temas que se investigan, considerándose que esto contribuiría a mejorar los resultados finales. En este sentido, también se critica que en ocasiones se lanzan proyectos, ayudas o investigaciones que no responden a necesidades reales.

Creo que cuando la universidad empieza a hacer un proyecto que es demandado por un colectivo al final eso tiene que generar una serie de beneficios.

Muchas veces hay esfuerzos que no tienen resultado porque no son los que se necesitan (...) Y es muy fácil, pregúnteme lo que necesito, preguntemos a la sociedad qué es lo que necesita a la hora de gastar unos recursos que son escasos.

La oferta no produce la demanda, en un ámbito próximo las necesidades están ahí y consiste en llamar a la puerta para averiguarlas y priorizarlas, a parte de la base que puedan ser las prioridades europeas o nacionales.

Y una vez desarrollada la investigación, destacan desde el ámbito empresarial la necesidad de que la innovación sea aplicable, para lo que también es necesario establecer canales de colaboración entre diferentes grupos, por ejemplo, para que en la adjudicación de construcciones se valore la utilización de baldosas cerámicas capaces de limpiar el aire, un avance investigador que para el consumidor final de azulejos puede no resultar de interés pero sí para la sociedad en su conjunto, de forma que resulta necesario ver la forma de favorecer su implantación.

- Detección de las necesidades. Se señala la dificultad para conocer las expectativas y necesidades de la sociedad. 
Es cierto que hay que detectar las necesidades si no la sociedad piensa que estamos ahí en una élite intelectual muy alejados, y creo que hay que hacerlo, pero es perverso porque la sociedad muchas veces tampoco se da cuenta de lo que necesita, siempre son dos o tres líneas de lo que se está acostumbrado por los medios de comunicación porque es un círculo perverso. Pero que es interesante, yo creo que sí.

En este punto, otros participantes discrepan, señalando que existen colectivos muy organizados y con años de historia que sí saben muy bien lo que quieren, a lo que se responde señalando que es posible que en algunos aspectos los intereses estén claros, pero en otros igual no. Como ejemplo, se indica cómo las cuestiones de género han sido introducidas en la sociedad a través de una labor activa y ahora sí se perciben ya como una necesidad.

Sí que hay necesidades, pero a veces conocemos las presentes y no nos damos cuenta de las futuras.

Otras voces apuntan la utilidad de la investigación aplicada para detectar las necesidades, así como a través de las acciones y proyectos puestos en marcha desde las Administraciones públicas para dar respuesta a las necesidades de una sociedad cada vez más cambiante.

- Actores implicados. Existe una amplia coincidencia en considerar que el diálogo y la participación debe abarcar a todos.

Se ha de interactuar con todos. Cada uno tiene sus ideas y necesidades. Detectemos lo que queremos y lo que tenemos.

Hay que dar participación a los grupos desde la propia universidad.

Hay que dar a conocer, la gente que entra y participa abrirá nuevos caminos.

Hay que abrir el diálogo a todos, porque las funciones son diferentes, las de las empresas, sociedad, administradores, cada uno cumplimos una función y sería un error que la universidad se centrara en un uno solo, tendría que establecer esa interacción con cada uno.

- Actitud proactiva por parte de la universidad. Se pone de manifiesto el interés de que la universidad adopte una actitud proactiva a la hora de recabar las expectativas y demandas de los grupos de interés. Se destaca además la necesidad de que en un primer momento la universidad se implique también a la hora de comunicar y dar a 
conocer a los grupos de interés las oportunidades que podría brindarle y las necesidades que podría cubrir.

Hay dos canales, uno explicarle lo que tengo y otro dar a conocer lo que no conoce y yo puedo tener. Si no conozco el teléfono no puedo demandarlo, hay cosas que tengo que explicar, hay que informar si existen herramientas que usted puede aplicar.

Para impulsar la actitud proactiva de la universidad de cara a los grupos de interés, uno de los participantes apunta también la optimización del tiempo que se requiere la participación de los grupos de interés, así como la capacidad de las universidades para suministrar recursos a los grupos de interés.

Lo ideal sería venir aquí y que los medios de la universidad vengan a mí. Yo traigo mi problema y que vengan los especialistas No tener que ir de departamento en departamento. Es tema de aprovechamiento y productividad. Yo vengo aquí, me siento con cinco y hablamos y resolvemos.

En este sentido, se demanda una actitud más proactiva de la universidad, que busque de forma activa aportar valor a sus grupos de interés ya que todos se necesitan mutuamente.

- $\quad$ Puente entre intereses de los stakeholders. El debate suscitado pone de manifiesto el interés de que la Universidad, más allá de conocer y satisfacer los intereses de los grupos de interés, contribuya en la medida de sus posibilidades a ejercer de puente entre los intereses de los diferentes grupos de investigación. En este sentido, como conocedora de los intereses, por ejemplo, de la sociedad, puede trasladar los mismos a las empresas o a la Administración, además de incorporarlos a su gestión de la ciencia y la innovación.

Hay un recurso muy importante que tiene la universidad que es el tiempo y materia gris. Poner recursos ahí me parece algo muy útil.

- Interacción y diálogo. Algunas de las reflexiones planteadas aludieron a la necesidad de establecer un diálogo eficaz y en condiciones de igualdad. En este ámbito, se destacó además la necesidad de que la universidad encuentre la forma de revertir en la sociedad lo que de ella recibe, reportando los beneficios de la investigación financiada con fondos públicos. 
Buscar canales, formativos, participativos, dar la voz durante todo el proceso, no solo bidireccional, sino de forma interactiva.

Se podría publicitar mucho más, porque quizá no llega suficientemente, lo que se hace o lo que se podría hacer y que haya un diálogo para que esos compromisos se basen en demandas concretas.

Ha de haber una consideración de universidad y sociedad al mismo nivel. Se ha mejorado pero algo hay que corregir, hay que buscar que ambas partes se beneficien (...) Si la universidad recibe dinero público deberá justificar en qué se gasta y, más allá de un balance, también aportando a la sociedad nuevas ideas, nueva información que le permitan desarrollarse.

- La presencia de la ética en el modelo. La presencia de participantes con conocimientos en el ámbito de la ética favoreció la aparición de reflexiones en torno a la dimensión ética del modelo de comunicación de la RRI planteado y la responsabilidad de la universidad como organismo social. También se señaló la validez del modelo a la hora de marcar un horizonte regulativo hacia el que se debe avanzar. En este sentido, cabe destacar el consenso general entre los participantes sobre la importancia a la hora de avanzar hacia una mayor atención a las expectativas de los grupos de interés, situando a la comunicación como elemento fundamental para alcanzarlo

La universidad es una entidad social y por eso debe de responder ante la sociedad y por eso el modelo tiene una dimensión ética. El hecho de estar representados todos los sectores eso es pura dimensión ética.

Una de las partes más importantes de la ética, como decía Kant, es el ideal regulativo, dónde vamos, hacia dónde nos dirigimos, porque desde ahí estamos proponiendo mejoras para la realidad. Ese horizonte también ha salido, y yo creo que estábamos de acuerdo de hacia dónde queríamos ir, el cómo igual no lo tenemos muy claro, pero el horizonte parece que sí.

En este sentido, se destaca cómo la dimensión ética ha estado presente en el lenguaje y en las aportaciones realizadas por los participantes a lo largo del focus group.

\section{$\underline{\text { Elementos transversales }}$}

- Localización geográfica. Un aspecto que surgió de forma reiterada a lo largo del debate fue la necesidad de la localización geográfica a la hora de abordar la gestión 
de la investigación y la innovación, así como la interacción con los grupos de interés. Al realizarse el focus group en la UJI, las referencias en este sentido se centraron en el ámbito de Castellón.

Estamos en Castellón, en la Comunidad Valenciana, con unas necesidades, con un tejido industrial equis y una tasa de paro equis, con una fortalezas muy importantes, y por tanto la investigación que se desarrolla desde la Universidad debería decidirse en base a estos elementos base.

Creo que hay material muy bueno y la dimensión es suficientemente pequeña para que pueda juntarse más Castellón con lo que se está haciendo en el campus.

¿Hay alguien que diga qué quiere Castellón?, ¿alguien lo está estudiando para dar una respuesta? Y luego, lo que yo tengo, ¿de qué me sirve?, ¿a qué colectivo lo tengo que hacer llegar?

Es importante que sea una investigación que repercuta en el ámbito económico primario, y luego al resto, no vamos a hacer una burbuja que no tenga nada que ver con otros sitios.

- Papel de los Consejos Sociales. Dos de los participantes destacaron las posibilidades que abren los Consejos Sociales de las universidades que pueden canalizar la relación entre ciencia y sociedad en materia de investigación e innovación. En concreto, se señaló la posibilidad de utilizar estos organismos como elemento dinamizador de la relación entre universidad y empresas; y se aludió a su posible papel a la hora de velar para que la universidad ofrezca a la sociedad el retorno adecuado.

Los Consejos Sociales representan a la sociedad pero en el ámbito de investigación podríamos ir un poco más allá y desde ellos se podría intentar captar a aquellas empresas que quisieran contribuir económicamente a la investigación y captar a los mejores grupos para que hicieran investigación a tenor de la demanda de la sociedad.

El Consejo Social tiene una labor de vigilancia de que lo que la sociedad le da a la universidad, la universidad se lo devuelva a ella.

- Paralelismos. En el debate se mostró el paralelismo del modelo desarrollado tanto con la forma de funcionar de algunas empresas y de algunas asociaciones, así como con los propios procesos de investigación. Así, desde la perspectiva empresarial se destacó la similitud entre el modelo y el círculo de mejora continua del sector privado basado en plan, desarrollo, comprobación y acción. 
No estamos tan lejos en cuanto a lo que debería ser, otra cosa son los resultados que se consigan y cómo llegan efectivamente a la sociedad.

También en el campo de la investigación se destacó cómo en los proyectos hay expectativas, compromisos y resultados.

\subsubsection{Emisores de la comunicación de la ciencia}

El segundo focus group se realizó en la Universitat de València contando para su organización con la colaboración de RUVID, de forma que el encuentro se celebró en el edificio en el que se encuentra la sede de esta red universitaria valenciana, que también ayudó en la propuesta de participantes de diferentes perfiles. En este caso se buscó la participación de investigadores e investigadoras de diferentes áreas de conocimientos con el fin de ampliar los puntos de vista. También se convocó a ex responsables de órganos de gobierno y a representantes de parques científicos, delegando estos en periodistas encargados de la comunicación de los mismos. La representación de expertos en comunicación científica contó también con periodistas universitarios y de la red RUVID. Por otra parte, la variedad también se buscó en lo referente a procedencia universitaria, de forma que se contó con participantes de tres universidades diferentes.

Como en el punto anterior, tras los datos del focus group, agruparemos los principales asuntos abordados durante el mismo en torno a tres ejes.

\section{Datos del Focus Group Emisores}

Fecha: 17 de junio de 2015

Hora: 12.30 a $14: 00 h$

Lugar: Sala de Juntas del Instituto INTRAS, Campus de Tarongers Universidad de Valencia (sede de RUVID)

Dinamizadora: Rosana Sanahuja, autora de la tesis.

Asistente: Patrici Calvo, investigador del grupo GERSE.

\section{Participantes:}

- Comunidad científica / ámbito investigador: 
- Pedro Carrasco, ex vicerrector de Investigación de la Universitat de València (UV) y Titular Universidad de Bioquímica y Biología Molecular.

- Sandra Boni, investigadora del área Humanidades del Departamento de Proyectos de Ingeniería de la Universitat Politècnica de València (UPV).

- José Antonio Solves Almela, investigador del Departamento de Comunicación e Información Periodística de la Universidad Cardenal Herrera CEU.

- Sergio Alejandro / Francisco Alonso, investigador y director de Instituto INTRAS de Tráfico y Seguridad Vial perteneciente al área de Psicología de la UV. En principio se solicitó la participación de Francisco Alonso, director de INTRAS, pero finalmente ante la dificultad de ajustar agendas, se acordó que asistiría Sergio Alejandro. Para tener la visión de ambos, se les envió una presentación del contenido del focus group y las preguntas que se plantearían, de forma que pudieron abordarlas y consensuar el contenido de la participación antes de la celebración del debate, enriqueciendo así las aportaciones.

- Sara García Gil-Perotín, médico e investigadora de la Unidad Mixta del Hospital Universitario La Fe-Universitat de València.

- Comunidad científica, ámbito comunicativo:

- Luis Zurano, periodista UCC+i y Parque Científico de la Universitat Politècnica de València (UPV).

- Olga Denia, periodista del Parque Científico Universitat de València (UV).

- Lauren Wickman, periodista de RUVID, Red de Universidades Valencianas para la Investigación, Innovación y Tecnología.

\section{$\underline{\text { La comunicación de la ciencia en la universidad }}$}

La presencia de profesionales de la comunicación científica de universidades, parques científicos y redes universitarias propicio diferentes debates en torno al modo en que se 
comunica la ciencia desde estos organismos, las nuevas formas de comunicar y los retos y problemas a los que se enfrenta.

- Incremento de la comunicación científica y cambio de paradigma. A pesar de que se indicó que existe cada vez una mayor apuesta por parte de las universidades por la comunicación de la ciencia, ésta se enfrenta a un cambio en el paradigma comunicativo resultado de la crisis de los medios tradicionales de comunicación y la irrupción de las TIC. En este sentido, algunos de los participantes apuntaron que los medios tradicionales son cada vez menos el objetivo de la comunicación de la ciencia ante la capacidad de llegar a la sociedad directamente a través de internet.

Vemos que sí que hay una apuesta decidida por la comunicación de la ciencia desde las universidades valencianas, cada vez se destinan más recursos y sí que hemos observado que cada vez hay más comunicación, además de los canales tradicionales, se apuesta más por los medios audiovisuales y redes sociales. En cuanto a respuesta, los medios tradicionales han caído en picado, muchos medios y periodistas especializados han desaparecido y esto dificulta que las investigaciones de las universidades salgan en los medios. Pero a la vez las redes sociales facilitan a las universidades el difundir directamente las investigaciones.

Es cierto que cada vez hay menos medios pero cada vez el objetivo es menos ese. La encuesta de FECYT lo decía, conforme vamos bajando de franja de edad el consumo de ciencia es a través de Facebook, de Twitter, de redes sociales, de vídeos. El marco en el que nos movemos es ese (...) Los públicos y formatos a los que nos dirigimos no es ya Levante, Las Provincias, El País o cualquier cabecera de toda la vida, ni siquiera estas cabeceras en internet, sino que son consumidores y usuarios directos cada uno con su perfil en las redes sociales.

... nos encontramos con medios atiborrados de informaciones de todo tipo, ¿qué seleccionan?, si les has dado un titular fuerte a lo mejor con muchas suerte lo tuyo. Ahora los periodistas especializados han desaparecido y quien se encarga de los medios son becarios mal pagados que sólo hacen copia y pega.

Durante el debate también se explicaron las diferentes formas de funcionar por parte de los profesionales de comunicación de la ciencia que, en líneas generales, pasan por conocer las publicaciones científicas bien a través de alertas de las revistas o bien mediante el aviso por parte de los propios investigadores, realizar un trabajo conjunto con el investigador o investigadora en la redacción de la información y consensuar la nota final para su difusión. 
- Nuevas formas de comunicar y avances hacia la bidireccionalidad. Además del modelo más tradicional de la comunicación de la ciencia entendida como la transmisión de los resultados de las investigaciones, durante el debate se destacaron otras acciones de comunicación y divulgación que están realizando las universidades o los propios grupos de investigación y que favorecen la interacción, la conexión con la sociedad y la bidireccionalidad.

Creo que las universidades sí que están jugando un papel importante en conectar más con la sociedad, están organizando ferias de ciencia, de inventos, realizando jornadas con empresas,... yo creo que eso también es comunicación y creo que a partir de esas acciones están cogiendo feedback de lo que realmente a la sociedad le puede interesar.

El Hospital la Fe tiene un programa, "Investiga para ti”, en el que se exponen a la sociedad las investigaciones que se están realizando sobre temas como la esclerosis múltiple, pueden ir e interesarse sobre cómo están trabajando los grupos de investigación, los medios que hay, etc. Esto creo que es muy interesante, no te venden la cabra del resultado, te están comunicando los ensayos clínicos que hay.

La importancia de establecer una comunicación bidireccional con la sociedad y los beneficiarios finales de las investigaciones fue abordada por uno de los participantes, señalando los esfuerzos realizados desde su ámbito de investigación de cara a generar debates sobre la investigación y sus resultados como modo de acercarlos a la sociedad, considerando muy positiva la experiencia.

Tratamos de fomentar el debate social como una forma de bidireccionalidad de la información, como una forma de traer de vuelta esa pregunta a la que tratamos de responder con nuestra investigación, generando debate social utilizando la radio, la prensa, las redes sociales.

Para nosotros el usuario final es cualquiera, siempre y cuando haya de por medio una forma de comunicar, desde el usuario que está más arriba de la pirámide, que lee revistas científicas, al usuario al que llega la información sencillamente a través de una campaña. Para nosotros esta es una forma de entender la bidireccionalidad, más allá es muy difícil (...) Creo que la mejor forma de establecer la bidireccionalidad es fomentar el debate social y fomentar la conciencia y hacerlo de una manera responsable.

- Retos y problemas a los que se enfrenta. Los participantes plantearon diferentes retos y problemas a los que consideran que se enfrenta la comunicación de la ciencia desde las universidades. Entre ellos, la dificultad de medir resultados, la 
visión sesgada de los contenidos que se publican o la diferencia a la hora de gestionarla por parte de las diferentes universidades.

Para mí lo más complicado es la medición. FECYT insiste en la medición de resultados y cómo se hace. Cuáles son nuestras expectativas lo tenemos claro, pero cómo mido el impacto, cómo medimos el impacto de nuestro trabajo es a mí lo que más me cuesta.

La falta de unas políticas claras, efectivas y compartidas por todas las universidades en materia de comunicación de la ciencia fue otro de los problemas que apareció de forma reiterada.

Otra cuestión es quién tiene que comunicar la ciencia en la universidad. Hay veinte formas de comunicar que luego no terminan en un cauce único, en un criterio único, ahí tenemos un problema interno. Cada universidad utiliza un sistema.

Malinterpretarse se va a malinterpretar y más como están los medios de comunicación y las universidades. Aquí o nos sentamos a trabajar sobre cómo hacemos una política de comunicación desde las universidades en general, y concretamente científica, o es que todo es un desbarajuste como lo está siendo porque es una tarea muy difícil.

Los contenidos de la comunicación científica se plantearon también como un aspecto a mejorar y tener en cuenta. En este sentido, tanto investigadores como profesionales de la comunicación coincidieron en señalar que existen investigaciones muy importantes que es muy difícil que sean comunicadas ya que las lógicas científicas y periodísticas son muy diferentes.

La lógica de la ciencia no puede ser la lógica periodística. Podemos intentar que casen mínimamente, pero a veces lo más aburrido suele ser lo más importante y eso para un periodista es inasumible. Es una paradoja, le estamos pidiendo al periodismo que difunda conocimiento científico que en realidad casa muy mal con las características de su discurso.

Se ofrece una visión muy sesgada, hay cosas que están más de moda que otras que a veces tienen más calidad pero no se publican.

Hay trabajos que no puedes contar porque a nadie le interesa, a veces nos obcecamos en intentar contar cómo es una investigación cuando a veces eso no interesa a la sociedad. El científico eres tú, yo confío en que lo harás bien, cuéntame el sentido de tu investigación, a lo mejor ahora no sirve directamente para nada pero en un futuro sí.

Dentro de los contenidos abordados en las informaciones sobre ciencia, se indicó el interés de realizar un seguimiento de las investigaciones, respondiendo algunos de los especialistas en comunicación que este seguimiento no es posible por el volumen de información y las lógicas periodísticas. 
El seguimiento no se hace. Se publica una investigación y después hay 20 artículos que lo contradicen pero luego eso no sale. El seguimiento es algo que nunca nos lo planteamos.

Se ha planteado pero eso no es posible, hay tantísima información que no es posible.

¿Por qué no se siguen las noticias? porqué ya fueron noticias y si no hay nada nuevo no se sigue porque no cabe en la lógica periodística.

Entre los problemas a los que se enfrenta la comunicación científica, los participantes señalaron también las presiones a las que están sometidos los periodistas de los medios de comunicación.

Los periodistas viven con presiones absolutamente alucinantes todos los días. Les pedimos que sepan absolutamente de todo, que trabajen deprisa, cosa que es incoherente con saber de todo, que atiendan los posibles intereses de todos sus lectores, oyentes,...

\section{$\underline{\text { Aportaciones al modelo ético de la comunicación de la RRI }}$}

El modelo de comunicación de la RRI propuesto generó un intenso debate, cuestionándose desde los planteamientos hacia una investigación e innovación más responsable que tenga en cuenta la participación más activa y las expectativas de la sociedad hasta el papel de los comunicadores en estos procesos. Esta visión contrastó con la de otros participantes que consideraron que la responsabilidad y la comunicación dialógica son horizontes hacia los que se debería tender, realizando diferentes aportaciones y reflexiones sobre el modo de llegar a ellos.

- Expectativas y fines de la investigación. El modelo plantado generó un gran debate en torno a quien debe determinar los fines de la investigación, considerando algunos de los asistentes que los grupos de interés no deben intervenir en estas cuestiones al entender que corresponden únicamente a los científicos; mientras que otros de los participantes consideraban que es conveniente introducir un cambio en el enfoque que tenga en cuenta la perspectiva dialógica y la participación de los afectados. Desde la visión más crítica con el modelo y los planteamientos de la RRI, expresada tanto por investigadores como por profesionales de la comunicación, se considera que la sociedad y los grupos de interés no deben determinar los fines de la investigación, argumentando aspectos como que no tienen la suficiente 
información o no son capaces de prever los beneficios futuros de una investigación básica.

Es delicado pensar que tenemos que estar a la demande de las expectativas de la sociedad. (...) Por ejemplo, ahora la biomedicina está sobredimensionada en financiación porque socialmente se demanda, no digo que no haya que hacerlo pero digo que eso conduce a modelos conflictivos. Entended esa reserva, muchas veces la gente que no tiene esa información no está preparada ni siquiera para pedir.

Hay una parte de la ciencia más oculta, la que no recibe ese impacto social, porque no es de interés social, como cuestiones sobre animales, mucha ciencia interesante queda olvidada durante el proceso, hasta que con el resultado no se publica en Nature. Igual cómo se comporte un lagarto no les interesa y queda al margen. Mucha de la ciencia que va a contracorriente es la más interesante, Darwin iba a contracorriente... Si está relacionándose con grupos de interés, empresas y lo que puede interesar a la sociedad igual ese tipo de investigación se saldría fuera. Que la sociedad influya pero no determine lo que se investiga.

Otros de los participantes, a pesar de considerar que el horizonte debería ser el dialógico, ponían el foco en la importancia de respectar el criterio de autoridad de los investigadores a la hora de establecer los fines.

Todos buscamos idealmente una comunicación dialógica en la que todo el mundo pueda participar (...) Bidireccionalidad obviamente sí, pero ¿entonces qué pasa con el criterio de autoridad? No se supone que aquí los que saben son unos. Al final no podemos hacer lo que dice un determinado grupo de interés, incluso diría yo por mayoritario que sea, porque si un determinado grupo de interés, y esto está ocurriendo, impone que se investiguen determinadas cuestiones porque tiene el poder económico o político, esto no puede ser (...) Yo creo que hay que partir de la idea de multidireccionalidad en los discursos pero al final la ciencia es un tipo de conocimiento y responde a una lógica y esa lógica no se puede perder porque entonces dejará de ser ciencia, y esa lógica termina en lo que podríamos llamar un criterio de autoridad. Entonces bidireccionalidad sí pero tampoco absolutamente. Buscamos la bidireccionalidad pero alguien tiene que ser la autoridad y el que sabe.

Algunos de los participantes discreparon sobre este principio de autoridad a la hora de abordar los fines y procesos de la ciencia.

Ahí discrepo del principio de autoridad, creo que se puede producir ciencia utilizando quizás otros planteamientos no tan extendidos en el campo científico que son válidos y se puede coproducir ciencia con la ciudadanía. 
También se habló de los riesgos de asociar la responsabilidad a los intereses inmediatos y actuales a la hora de determinar los fines

Interesante no significa responsable. Hay tipos de investigaciones que hasta dentro de 30 años no tendrán aplicación y que un empresario no sería capaz de ver y por tanto no entra en el concepto de responsable que se maneja. Se confunde la utilidad con la responsabilidad (...) No creo que sea buena idea asociar ética a responsabilidad.

Para mí una parte de la innovación, que esté asociada a responsabilidad hoy, inmediata, eso me parece bien. Pero la gente que tenemos alrededor, sobre todo los empresarios, no están preparados para ver los problemas de aquí a unos años (...) Estrechar demasiado la relación responsabilidad social-investigador como un motor para la investigación no lo acabo de ver.

Dentro de esta visión que relaciona la responsabilidad con la utilidad inmediata de la ciencia se señala como ejemplo el caso de la resonancia nuclear magnética.

El fundamento físico de la resonancia nuclear magnética no hay dios que lo relacione con una aplicación médica, para llegar a la aplicación pasaron 40 años. Hay que tener en cuenta esa dualidad, la responsabilidad social obedece a demandas próximas.

La búsqueda de la utilidad en la investigación y las expectativas generadas, señalaron que llega a introducir presión y a condicionar la investigación en un sentido negativo.

En la investigación yo me siento un poco presionada a veces por buscar cosas que sean útiles, sobre todo si interviene una empresa. Te influyen las expectativas que tenga la empresa

Por su parte, algunos de los profesionales de comunicación de la ciencia cuestionaron que ésta tenga que jugar cualquier papel en la determinación de los fines de la ciencia, señalando que su función puede ser generar una opinión pública formada y con capacidad crítica pero no determinar los fines. Asimismo, cuestionaron que los periodistas o la sociedad deban influir en lo que se investiga.

¿Para qué sirve la comunicación de la ciencia? ¿Para que los individuos decidan lo que hay que investigar? No, creo que esa no es la función, solo faltaría que esa fuera responsabilidad de los periodistas, cómo lo comunicas porque en función de eso van a decidir qué es lo que hay que investigar. Pero sí es función comunicar para que la sociedad adquiera unos conocimientos que le den criterio para saber de qué va esto y para poder decidir en muchas ocasiones, pero no para dictar las líneas de investigación, eso sería explosivo, para eso están los expertos, ellos son los que han de decidir. La 
sociedad sí podemos tener un criterio para tomar decisiones y poder influir en las políticas pero ellos son los que han de decidir.

Tu investiga sobre lo que tengas que investigar, solo faltaría que el periodista tuviera que entrar en lo que se debe de investigar, o la sociedad.

En un momento posterior, se indició la necesidad de incrementar la cultura científica de la sociedad para que la comunicación de la ciencia pueda tener algo positivo que aportar en la priorización de los fines a investigar.

Para que la comunicación tenga algo positivo que aportar a la hora de establecer las prioridades de investigación bajo el paraguas de la ética, creo que hay un primer paso complicadísimo que es elevar la ciencia a la cultura, que las personas tengamos un criterio.

Durante el debate también se planteó cómo se determinan los fines actualmente en la Unión Europea bajo la presión de los lobbies.

La Unión Europea lo implanta por decreto, sí se procede a comunicación y diálogo pero no entre todos, con universidades, investigadores y empresas. Perciben que es necesario trabajar en cambio climático, igualdad,..., lo ponen porque socialmente lo han percibido y luego dicen que se ha de hacer participar a empresas, etc. (...) Se decide pero no como consecuencia del modelo de comunicación de la ciencia, son unos señores los que deciden qué proyectos van a potenciar y a los que se va a dar dinero. Un proyecto de investigación al final es el resultado de un lobby.

- Visiones y aportaciones al modelo. Diversas voces ratificaron la importancia de la comunicación de cara a favorecer el desarrollo de la RRI, destacando el papel de la misma a lo largo de todo el proceso y no únicamente en la transmisión de resultados.

La comunicación no tiene que centrarse en el resultado, sino en el proceso. Todo tiene que ser comunicativo. Puede ser empezar discutiendo qué vamos a investigar y sentar a diferentes afectados en esa mesa.

Se parecería más al modelo de comunicación dialógica, al final caemos en el modelo de comunicación al que estamos acostumbrados de ya tengo estos resultados y lo comunico. Si fuera dialógico tendríamos que dialogar desde el principio y tendrían que discutirse los medios pero también los fines desde el principio.

Por otra parte, destacaron cómo la introducción de la comunicación y la participación pueden llevar a otras formas de medir los impactos. 
Si consideramos que una investigación responsable fuera una investigación en la que distintos actores participan en la investigación, podríamos medir también el proceso. Creo que hay diferentes maneras de involucrar a diferentes stakeholders en diferentes procesos y ahí puedo medir cómo se participa (...) No es la comunicación a la que estáis acostumbrados pero es una comunicación también.

Asimismo, ratificaron el interés de tender hacia la introducción de más agentes a lo largo de todo el proceso, señalando que esto es algo que choca con las lógicas desde las que ahora se trabaja de forma aislada.

Cada agente en el proceso de comunicación funciona de forma autónoma, con su propia lógica, en el caso de la periodística producen una comunicación a partir de los papers que prevén que va a tener éxito. Los científicos y los periodistas funcionan desde su lógica. El modelo al que deberíamos tender, que ya sé que es muy utópico, es que hubiera muchos más agentes en todos los momentos y que cada agente no estuviera aislado. Decís, nosotros no tenemos que ver con eso, nosotros somos periodistas. La lógica periodística impide que ningún otro agente, a no ser a la fuerza, incorpore nuevas dinámicas. (...) La lógica me refiero a todo, los periodistas trabajan en un mundo simbólico, temporal, espacial que es el del periodismo. Lo que se está proponiendo es un cambio de lógicas, que incluya a más agentes, agentes que sean contrapoderes, la propia lógica general es la del poder, entonces no hay otra lógica que se pueda sostener que no sea la de los contrapoderes.

A este respecto, desde el ámbito de la comunicación científica universitaria se destacó cómo su trabajo no se centra en la lógica de los medios, sino en el papel de intermediación entre científicos y periodistas, a lo que se respondió señalando:

Trabajáis con dos lógicas y al final hacéis una, tenéis esta responsabilidad de que lo que llegue sea vendible pero que hable realmente de lo que se ha producido científicamente. Yo lo que creo que se está buscando aquí es un proceso comunicativo que sí que incluyera a otros agentes.

Los participantes apuntaron además algunas propuestas de mejora o aspectos de interés de cara al desarrollo del modelo.

Faltan cosas sustantivas. Una aproximación ética a la investigación responsable no es solo los cauces, es también sobre qué temas estamos hablando y quién produce ciencia, y también los fines y los intereses (...) No sé hasta qué punto este modelo puede responder a estas cuestiones, sobre quienes son los que hacen ciencia, para qué se hace ciencia. La Unión Europea no se queda solo en una cuestión de procedimiento, es también sustantivo, están metiendo ya sobre qué temas estamos hablando, sostenibilidad, igualdad, etc. 
A lo mejor sería interesante hacer el mapeo de todo el proceso de investigación científica, desde el mapeado hasta los resultados, pensar en todo el proceso. Ir viendo también los momentos comunicativos que son mucho más que la comunicación final, quizás lo que está haciendo más la universidad es la comunicación final, pero hay mucho más que influye y ahí tiene cabida la comunicación y la ética.

Uno de los profesionales de la comunicación participantes señala que en ese proceso el periodista se queda fuera, a lo que otro de los asistentes responde indicando que en el proceso están los investigadores y los afectados, pero quizá en algún momento también puedan estar los periodistas que podrían ser los que tomaran la voz.

\section{$\underline{\text { Elementos transversales }}$}

Durante el focus group se abordaron conceptos relacionados con el modelo como ética y responsabilidad social, evidenciando las diferentes visiones que de los mismos tenían algunos asistentes.

- Presencia del componente ético. El concepto de ética apareció en diversos momentos del focus group ligado a diferentes aspectos y desde diferentes visiones, empezando por la ética a la hora de realizar la comunicación de resultados científicos por parte de los periodistas.

Para una comunicación ética de la ciencia, se puede ver desde diferentes aspectos, primero desde la elaboración de un contenido para su transmisión a la sociedad (titular, enfoque, etc.). Hasta el tipo de difusión que haces: si eres pesado, si llamas, si les pagas a los medios por publicar. Desde la parte emisora ya hay una ralla para que pueda ser ético.

Sí hay un aspecto ético de cómo un investigador y la propia institución se plantea la comunicación, de cómo hacemos este trabajo, pero siempre hay maneras éticas de contarlo.

Desde el ámbito de la investigación, varios de los asistentes incidieron en la necesidad de establecer de forma correcta el alcance de la investigación para no generar falsas expectativas, ni a la hora de comunicar ni a la hora de plantear los proyectos. 
Hay que tener cuidado con las expectativas que se generan. Si lo pensamos, el alzhéimer y el cáncer con todas las noticias que se generan deberían estar ya curados hace años.

Cuando haces un proyecto hay un apartado de interés social y ahí llega la ética, en ese pequeño párrafo, que es el que luego sale en la televisión, hay que tener en cuenta que lo que estás diciendo sea mínimamente razonable, el investigador ha de saber ahí dónde está el límite (...) El periodista debería tener la capacidad de filtrarlo, pero el problema viene de la fuente.

Para mi ética es no generar expectativas excesivas sobre la investigación. Para mi ético es fundamentalmente no mentir sobre una investigación. Eso es lo que hacemos, lo hacemos así y hoy sirve para esto y dentro de 20 años dios dirá. Y convencer a la sociedad que eso es lo que estamos haciendo y que vale la pena.

Por otra parte, algunos de los asistentes relacionaron la ética con la necesidad de conocer las necesidades de los usuarios e incidir positivamente en los mismos.

Todo lo que hacemos nosotros a nivel de investigación está mediado por una ética comunicativa que está alineada a su vez con saber cuáles son las necesidades del usuario y las formas de intervenir con un ejercicio de honestidad y seriedad (...) Además del gusto y el interés de investigar, tenemos la responsabilidad de incidir positivamente sobre el usuario.

- El concepto de responsabilidad social. El concepto de responsabilidad social, y en concreto de Responsabilidad Social Corporativa (RSC), fue abordado por algunos de los participantes, evidenciando que en algunos casos existe una visión negativa de la RSC que la limita a una operación de marketing.

Cuando hablamos de RSC entra el marketing en medio porque al fin y al cabo la RSC tiene mucho que ver con la venta. Nos metemos aquí en un terreno pantanoso.

El 90\% de lo que llamamos RSC es marketing. Las empresas ya no pueden invertir en fincas e invierten en RSC que les renta más.

Sin embargo, entre los investigadores también hubo quien relacionó el concepto de RSC con una mayor involucración con los usuarios y una mejor comunicación por parte de las universidades.

Desde nuestra experiencia en proyectos de RSC, de alguna manera se podría decir que existe una necesidad de que la universidad esté más directamente involucrada con la comunicación de los resultados de la investigación. Con el prototipo de comunicación actual, esos resultados son difícilmente bien direccionados al público que los necesita. 
Si la universidad se comprometiera a mejorar la comunicación con los diferentes grupos de interés, debería involucrarse más también con el seguimiento de los proyectos, de qué pasa después. Muchas veces la investigación no sale del laboratorio.

\subsection{APORTACIONES DE LOS STAKEHOLDERS}

Las aportaciones y visiones recogidas a través de los dos focus groups resultan de gran interés para la investigación, por lo que recogemos en este capítulo las principales conclusiones que nos llevarán a replantear y mejorar el modelo ético de comunicación de la RRI para las universidades y determinar algunos de los problemas a los que deberá hacer frente. En primer lugar abordaremos los aspectos referentes a la comunicación de la ciencia desde las universidades ya que estos han sido objeto de diferentes debates en ambos focus groups. En el segundo apartado nos centraremos en las aportaciones específicas al modelo de comunicación de la RRI.

\subsubsection{Visión de los stakeholders de la comunicación de la ciencia en las universidades}

A pesar de que desde el campo de los profesionales de la comunicación de la ciencia se destacó la apuesta cada vez mayor por la comunicación de la ciencia realizada por las universidades, en concreto del ámbito de la Comunidad Valenciana, fueron muchas las voces que consideraron deficitaria la comunicación de las investigaciones que se realiza desde los campus. Tanto investigadores como algunos de los periodistas de comunicación científica destacaron la necesidad de establecer políticas más claras y efectivas por parte de las universidades de cara a mejorar la Comunicación Pública de la Ciencia.

En este sentido, se constató cómo la visión sobre la comunicación de la ciencia que realizan las universidades mantiene mayoritariamente una perspectiva de comunicación unidireccional de transmisión de resultados, un tipo de comunicación que se considera necesaria para aumentar la cultura científica y la capacidad crítica de la sociedad. De cara a mejorar este tipo de comunicación de la ciencia se plantearon algunas propuestas que vienen a corroborar las recomendaciones de los expertos que veíamos en el capítulo sobre Comunicación Pública de la Ciencia. Así, se plantean 
como propuestas de mejora la formación en materia de comunicación de la ciencia tanto de los periodistas como, especialmente, de los investigadores.

También se alude a la conveniencia de introducir en las diferentes convocatorias de proyectos de investigación acciones de comunicación, confirmándose los buenos resultados de este tipo de requisitos en los proyectos europeos. Como propuesta que puede resultar más novedosa, se concreta que las acciones de comunicación contempladas en los proyectos deberían hacer referencia explícita a los canales y mecanismos de comunicación con los "grupos meta" de las investigaciones como destinatarios directamente afectados por las mismas.

Los focus groups ratificaron asimismo el cambio de paradigma comunicativo que han supuesto las Tecnologías de la Información y la Comunicación (TIC), especialmente por la posibilidad que ofrecen a las universidades y a los investigadores para comunicarse directamente con los públicos. Esto aparece además relacionado con la crisis de los medios tradicionales de comunicación, y el descenso de periodistas especializados en ciencia debido a la precariedad económica. En este sentido, se apunta que los medios de comunicación son cada vez menos los objetivos de la comunicación de la ciencia.

Algunas voces hablan también de una tendencia hacia formas de comunicar la ciencia más participativas y bidireccionales, que podríamos situar más en la línea del modelo comunicativo "ciencia y sociedad". Se trata, por ejemplo, de acciones realizadas por los grupos y centros de investigaciones encaminadas a generar un debate social, ferias de investigación y de innovación, etc., acciones que favorecen el feedback con la sociedad.

En materia de comunicación de la ciencia, cabe señalar asimismo como durante los grupos de discusión se puso de manifiesto las dificultades que entraña debido a las diferencias existentes entre la lógica científica y la periodística, lo que lleva a que investigaciones de gran interés resulten prácticamente imposibles de comunicar de forma atractiva a través del periodismo tradicional.

A modo de resumen, en el siguiente cuadro extraemos de forma sintética los principales resultados de los focus groups realizados en lo referente a comunicación de la ciencia. 


\section{CONCLUSIONES}

- Se confirma el predominio de una visión unidireccional de la comunicación de la ciencia entendida como transferencia de resultados y se destaca su utilidad para incrementar la capacidad crítica de la sociedad, pero se apunta también al impulso cada vez mayor de iniciativas que buscan la bidireccionalidad y que permiten obtener un retorno de la sociedad.

- A pesar de la mayor apuesta de las universidades por la comunicación científica se entiende que existe todavía un importante déficit y que es necesario mejorar las políticas de comunicación de la investigación y la innovación.

- Se constata el cambio de paradigma en comunicación de la ciencia ante la aparición de las TIC y la crisis de los medios tradicionales. Esto lleva a considerar que los destinatarios de la comunicación de la ciencia son cada vez menos los medios tradicionales.

- La comunicación de la investigación y la innovación debe enfrentarse a la dificultad de aunar la lógica de la ciencia y del periodismo, especialmente en el caso de aquellas investigaciones que puedan no resultar atractivas desde la perspectiva de los medios.

A partir de estas conclusiones, cabe señalar que el modelo de comunicación de la RRI que planteamos puede suponer una aportación hacia una relación más participativa y bidireccional de los públicos, lo que no evita que siga siendo necesaria la comunicación de la ciencia entendida como transferencia de resultados de cara a aumentar la cultura científica y la capacidad crítica de los grupos de interés. En este sentido, se confirma el interés de haber incluido esta perspectiva en el modelo comunicativo y la importancia de que las universidades refuercen aún más estas acciones de comunicación a través de acciones formación, inclusión de requisitos de comunicación en las convocatorias, etc.

Por otra parte, las reflexiones evidencian también la importancia de las TIC y las redes sociales en la comunicación de la ciencia, por lo que entendemos que estas deben jugar también un papel importante en el desarrollo del modelo. Asimismo, cabe señalar 
que la introducción de nuevas dinámicas comunicativas como el modelo de comunicación de la RRI planteado pueden favorecer la transmisión de la información sobre la investigación e innovación de forma diferente a la tradicional transmisión de resultados, favoreciendo nuevas lógicas comunicativas que den cabida a contenidos e informaciones que queden fuera de los criterios de noticiabilidad de los medios.

\subsubsection{Aportaciones al modelo de comunicación de la RRI}

Durante los dos focus group surgieron cuestiones de gran interés de cara a mejorar el modelo y considerar algunos de sus riesgos. En este sentido, desde los stakeholders tradicionalmente receptores de la comunicación científica se apuntó la importancia de que en un primer momento la universidad adopte una actitud proactiva de cara a informar a los grupos de interés sobre las opciones que puede ofrecerles en materia de investigación e innovación. También cabe valorar la conveniencia de que la universidad actúe como puente y correa de transmisión entre los intereses de los diferentes grupos. De cara a hacer efectiva la implantación del modelo, resulta asimismo de interés la opción planteada por los participantes de contar con los Consejos Sociales como organismos ya consolidados representantes de diferentes stakeholders. La necesidad de tener en cuenta la localización geográfica de las universidades fue asimismo una de las cuestiones reiteradas por los stakeholders de la sociedad civil, el campo de la empresa y la Administración Pública.

Por lo que respecta al focus group realizado con los stakeholders situados tradicionalmente como emisores de la comunicación de la ciencia, resulta especialmente significativo el debate generado en torno al concepto mismo de RRI en el sentido de abrir la puerta a una mayor participación a la hora de determinar los fines de la investigación. En este sentido, se constató como tanto investigadores como profesionales de la comunicación de la ciencia se mostraron reticentes ante la posibilidad de que la sociedad pueda influir a la hora de determinar qué se investiga. En este sentido, aludieron al criterio de autoridad de los expertos a la hora de decidir y la falta de preparación de la ciudadanía para abordar esta cuestión. En este sentido, cabe recordar con Adela Cortina que, a pesar de que pueda tenderse a pensar que son los expertos los que deben determinar los fines en materia de investigación, no existen los expertos en fines. Para la autora hay expertos en medios pero los fines sólo pueden 
determinarlos los afectados por la puesta en marcha de una ciencia, porque son ellos los que mejor conocen en qué consiste ese bien. Por ello, desde el marco ético desarrollado, son los afectados los que deben tomar decisiones morales objetivas en materia de ciencia e innovación, con el debido asesoramiento de los expertos y teniendo en cuenta no sólo sus intereses individuales sino los universalizables (Cortina, 1993). Asimismo, la Unión Europea considera que la RRI supone alinear mejor los procesos y resultados de la investigación y la innovación con los intereses y expectativas de la sociedad.

Las voces más críticas con la participación de la sociedad en la determinación de los fines de la investigación tuvieron también su contrarréplica, con investigadores que mostraron el interés de avanzar hacia un modelo más participativo tanto en la determinación de los fines como en los procesos de investigación e innovación. Del mismo modo, el grupo de debate con los receptores de la comunicación de la ciencia evidenció que empresas y sociedad civil reclaman que se tengan en cuenta sus necesidades y expectativas en materia de investigación e innovación.

Respecto al papel de la comunicación en la gestión de la RRI, la mayoría de los participantes en ambos focus groups coincidieron en el papel central de la misma, así como en su importancia en diferentes momentos del proceso. No obstante, se puso de manifiesto cómo las acciones de comunicación planteadas para la gestión de la RRI suponen una ruptura total con el modo de entender la comunicación de la ciencia de los profesionales responsables de la misma en las universidades. "No es la comunicación a la que estamos acostumbrados pero es comunicación también”, apuntaba una de las investigadoras participantes. En este sentido, sería interesante plantear cómo se integraría el desarrollo del modelo de RRI en las políticas de comunicación de la ciencia que ya llevan a cabo las universidades ya que se trata de un planteamiento que rompe con las formas de entender la comunicación de la ciencia que mantienen en la actualidad las universidades.

Por otra parte, cabe señalar que desde las voces más expertas en materia de Ética se valoró positivamente el modelo y su apuesta por un marco dialógico, apuntando asimismo el interés de concretar aspectos sustantivos y especificar pasos concretos en función de los procesos de investigación. Entendemos que estas son aportaciones de gran interés de cara al desarrollo del modelo o su traslación a un proyecto de investigación específico. Respecto a las referencias a la Ética surgidas a lo largo del debate, algunos de los participantes la relacionan con la actitud ética de los 
profesionales de la comunicación a la hora de elaborar y difundir los contenidos, así como con la actitud de los investigadores en la generación de expectativas. En ambos casos se alude a la necesidad de la ética en el desarrollo de las profesiones señalada por Cortina (1997), una actitud moral que no puede imponerse sino que debe ser asumida desde dentro. También podemos relacionar estas diferentes percepciones de la ética surgidas desde el planteamiento de Carsten (2013) de la RRI como una "metaresponsabilidad" que agrupa responsabilidades ya definidas previamente.

Señalamos a continuación de forma esquemática algunas de las conclusiones extraídas de ambos focus groups para ver posteriormente cómo pueden afectar al modelo de comunicación de la RRI propuesto.

\section{CONCLUSIONES}

- Necesidad de establecer una fase proactiva por parte de la universidad en la que se informe a los grupos de interés sobre las opciones que se les ofrece en materia de investigación e innovación.

- A la hora de implantar el modelo, se señala el interés de considerar el papel de la universidad como puente entre los intereses de diferentes stakeholders, así como de valorar el papel de los Consejos Sociales como organismos ya consolidados de representación de stakeholders. También se evidencia el interés de mejorar la localización geográfica mediante la gestión de la RRI.

- Se constatan las reticencias de algunos investigadores a la participación de los grupos de interés en la determinación de los fines de la investigación, lo que viene a chocar con la demanda de una mayor participación por parte de sociedad civil, Administración y empresas que exigen que sus necesidades sean tenidas en cuenta.

- La participación de profesionales de la comunicación de la ciencia de universidades y parques científicos deja patente la ruptura que supone el modelo de comunicación de la RRI propuesto respecto a la forma de entender la comunicación de la ciencia desde las universidades.

- La mayoría de los stakeholders ratifican la importancia de situar la comunicación en el centro del modelo y establecer acciones comunicativas en diferentes fases de proceso. 
- Se considera que la ética está presente en el modelo desarrollado y se destaca que debe estarlo también en el ejercicio de las profesiones, especialmente por parte de investigadores y comunicadores de ciencia.

A partir de estas conclusiones, podemos señalar que resulta de interés introducir algunas modificaciones en el modelo de comunicación de RRI propuesto. Entre ellas, la introducción de una fase previa a las tres establecidas que permita que la universidad informe a los grupos de interés sobre las opciones que le ofrece en materia de investigación e innovación. Como señalaron los participantes, si los stakeholders no conocen qué les puede ofrecer la universidad, esto les limitaría a la hora de plantear sus necesidades y expectativas. Por ello, planteamos una modificación del modelo que incluya esta primera fase:

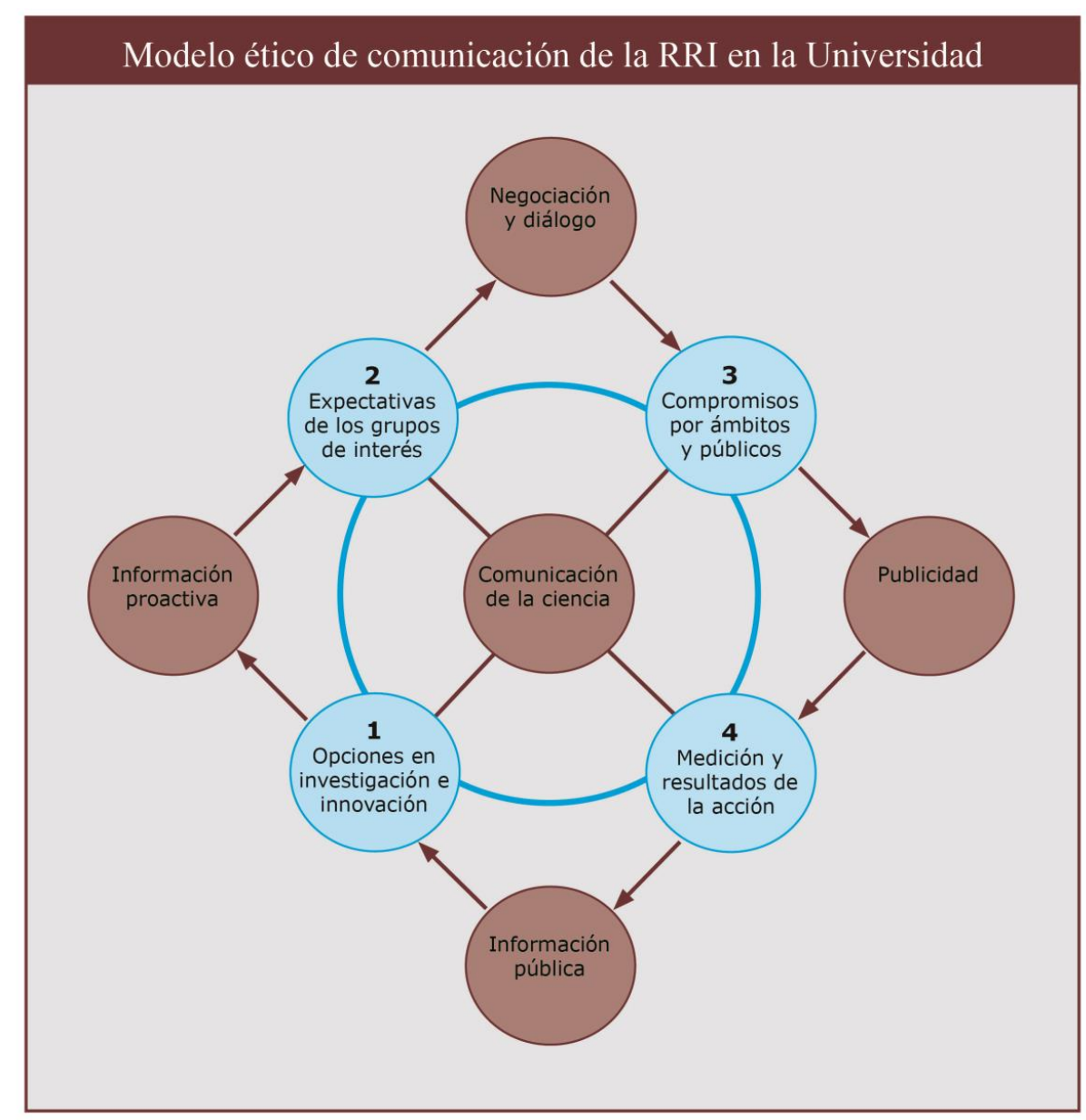

Por otra parte, de cara al desarrollo e implantación del modelo entendemos que resulta interesante tener presente la posibilidad que abre a la universidad de ejercer de correa de transmisión de las necesidades e intereses de los stakeholders, así como el 
papel que pueden jugar los Consejos Sociales. Por lo que respecta a la localización geográfica, el modelo supone establecer un diálogo con los grupos de interés del entorno de la universidad, lo que sin duda contribuiría a avanzar en la misa.

En cuanto a los riegos a los que se enfrenta el modelo, los focus groups han evidenciado la posibilidad de que para su implantación se tenga que hacer frente a las reticencias de muchos investigadores e incluso de los profesionales de la comunicación de la ciencia. En este sentido, cabría plantearse cómo favorecer el desarrollo del modelo de comunicación de la RRI de forma compatible con las acciones de comunicación de la ciencia desarrolladas de forma mayoritaria. Al tratarse de dinámicas comunicativas tan diferentes valdría la pena reflexionar sobre si son los propios profesionales de la comunicación de la ciencia desde las universidades los que deben llevarlo a cabo o se requiere un perfil diferente. En cualquier caso, consideramos que el desarrollo de una comunicación ética de la RRI necesita de la comunicación de la ciencia realizada tradicionalmente por las universidades, que permite incrementar la cultura científica y capacitar a los stakeholders para una participación informada.

Finalmente, entendemos que los focus groups han validado el marco ético del modelo de comunicación de la RRI para las universidades, aportando además diferentes consideraciones sobre la ética de las profesiones.

Las conclusiones obtenidas a través de estos focus groups, junto a las planteadas a través de los cuestionarios sobre comunicación de la ciencia por parte de las universidades valencianas, nos permitió modificar y mejorar el modelo ético de comunicación de la RRI que planteamos a diversos expertos mediante el panel Delphi que abordamos en el siguiente capítulo. 


\section{La visión de los expertos sobre la comunicación}

\section{ética de la RRI en la universidad}

Contar con la visión de expertos en las dos disciplinas que centran la presente tesis, Ética y Comunicación, resultaba fundamental a la hora de validar el modelo de comunicación ética de la RRI propuesto. Para conocer su visión, se optó por la metodología del panel Delphi, seleccionándose a los participantes por su saber y experiencia en los campos de la Ética y la Responsabilidad Social, la Comunicación de la Ciencia, la Comunicación Universitaria y en el emergente concepto de Investigación e Innovación Responsable.

Recogemos a continuación los perfiles de los cuatro expertos y expertas participantes en el panel Delphi, unos perfiles que evidencian la idoneidad de cada uno de ellos de cara a la valoración del modelo propuesto y a la realización de aportaciones al mismo. Los participantes en el Panel Delphi fueron:

- Jesús Conill. Catedrático de Filosofía Moral y Política en la Universidad de Valencia y Patrono fundador de la Fundación ÉTNOR para la ética de los negocios y las organizaciones con sede en Valencia, de la que es también asesor técnico. Estudió en las Universidad de Valencia y ha desarrollado proyectos de investigación en las universidades alemanas de München, Bonn y Frankfurta.M., en la Universidad de St. Gallen (Suiza) y en la Universidad de Notre Dame (EEUU). Es miembro de la Asociación EBEN-España (Ética, Economía y Dirección), del Seminario de Investigación Xavier Zubiri y de la Junta de gobierno de la Real Sociedad Económica de Amigos del País de Valencia. Entre sus numerosas publicaciones destacan obras como Democracia participativa y sociedad civil. Una ética empresarial; Educar en la ciudadanía; Republicanismo y educación cívica ¿Más allá del liberalismo?; Glosario para una sociedad intercultural; Horizontes de economía ética. Aristóteles, Adam Smith, Amartya Sen y Ética hermenéutica, entre otras.

- Antonio Marín. Licenciado y DEA en Filosofía por la Universidad de Granada y Máster en Comunicación en las Organizaciones, Comunicación y RRPP por la Universidad de Barcelona, es desde 2014 director de Mecenazgo de la Universidad de Granada, en la que durante más de cinco años ocupó el cargo de 
director de Comunicación. Ha dirigido proyectos nacionales, como el Plan Estratégico para el Desarrollo de la Sociedad de la Información en Extremadura, Infodex, impulsado por la Junta de Extremadura; e internacionales, como la Agencia Universitaria de Noticias Diálogo Iberoamericano (AUNDI). Ha participado en diversas publicaciones que abordan la comunicación de la ciencia y la comunicación universitaria como Universidad, comunicación y ciencia: contrastes; Mass media y universidad: el reto de la comunicación en las universidades; Crisis, Universidad y Comunicación Social de la Ciencia, y Retos de los servicios de comunicación ante la Universidad 2.0, entre otras.

- Gema Revuelta. Licenciada en Medicina, Máster en Comunicación Científica y miembro del comité de expertos en RRI de la Unión Europea. Desde 1998 es profesora asociada del Departamento de Comunicación de la Universitat Pompeu Fabra de Barcelona, en la que es también subdirectora del Observatorio de la Comunicación Científica y coordinadora del Máster en Comunicación Científica, Médica y Ambiental y del Postgrado de Comunicación Científica semipresencial de IDEC-UPF Argentina. Su investigación ha sido publicada, entre otras revistas, en Nature Biotechnology, Science Communication, JAMA, Medicina Clínica, Gaceta Sanitaria Periodística, Trípodos, etc. Es autora, entre otros libros e informes, de Dilemas y acuerdos éticos en comunicación médica, Retos éticos de la e-salud y Medicina y salud en la prensa diaria. Cuanta además con una amplia experiencia en el desarrollo de proyectos europeos, varios de ellos relacionados con cuestiones de RRI.

- Guillermo Santamaría. Licenciado en Bioquímica y máster en Comunicación Científica, con estudios relevantes en biología molecular, historia de la ciencia, psicobiología, filantropía y acción social y conducción de actividades de cocreación. Acumula más de 10 años de experiencia en comunicación de la ciencia bajo muy diferentes formatos (televisión, actividades presenciales, comunicación escrita, evaluación de proyectos de divulgación...). Desde 2008 trabaja en el departamento de Ciencia y Medio Ambiente de Fundación "la Caixa", como coordinador de actividades, y desde 2012 trabaja en el proyecto RRI Tools, dedicado a la creación y difusión de un conjunto de recursos que ayuden a implementar la RRI a nivel europeo. 
Una vez expuesto el perfil de los participantes, pasamos en el próximo apartado a recoger sus respuestas a las dos oleadas del panel Delphi. En un segundo apartado, abordaremos las principales conclusiones extraídas del panel y las aportaciones realizadas por los expertos y expertas al modelo ético de comunicación de la RRI propuesto.

\subsection{PANEL DELPHI DE EXPERTOS}

En una primera oleada se remitió a los cuatro expertos un informe que incluía, en primer lugar, información sobre el proyecto de investigación y un gráfico con el modelo desarrollado de comunicación ética de la RRI para las universidades. Este primer apartado se completaba con una pregunta abierta recabando la opinión de los expertos sobre el modelo. En segundo lugar, se incorporaron al cuestionario varias preguntas valorativas relacionadas con la importancia de la comunicación en la gestión de la RRI, el papel de los stakeholders en la determinación de los fines de la investigación y la aplicación de criterios éticos en la gestión de la investigación y su comunicación por parte de las universidades. El cuestionario completo remitido en la primera oleada aparece recogido al principio de la tesis, en el apartado sobre Metodología.

En las próximas páginas se recogen, en un primer punto, las respuestas de los expertos al cuestionario, así como el informe final elaborado a partir de las mismas que fue enviado en la segunda oleada. Las contestaciones a este nuevo envío se abordan en un segundo punto.

\subsubsection{Primera oleada del panel Delphi}

Los participantes en el panel Delphi valoraron desde sus respectivas disciplinas el modelo ético de comunicación de la Investigación e Innovación Responsable propuesto para las universidades, así como las oportunidades y riesgos que consideraban que presentaba. Recogemos a continuación las respuestas.

- Jesús Conill:

Sólo puedo valorar el modelo que se presenta aquí, porque no conozco ninguna otra propuesta, ni en la teoría ni en la práctica. Y tal como queda expuesto el modelo me parece excelente tanto en 
su propósito, como en su diseño y configuración. Considero que ofrece oportunidades realmente innovadoras y fecundas. El único "riesgo" que veo es su difícil aplicación a través de procesos efectivos, precisamente porque es de verdad innovador, ya que va contra las inercias más arraigas de la vida universitaria, que tienden a lo contrario, es decir, a la fragmentación y a la incomunicación.

\section{- Antonio Marín:}

Estimo que la propuesta plantea una línea de trabajo más que oportuna... necesaria, en tanto que:

- ayudaría a comprender socialmente el trabajo que realizan las universidades en investigación e innovación,

- contribuiría a orientar parte de ese trabajo en diálogo con empresas e instituciones y

- redundaría en un muy probable beneficio para la propia universidad a corto y medio plazo y para la sociedad en general a medio y largo plazo; en tanto que sería mayor la relación entre necesidad de sociedad y empresas y capacidad de investigación e innovación de las universidades.

Ahora bien, sugiero que el concepto de comunicación que se maneje se afine en la relación con los públicos, para su mejor comprensión. Comunicación como divulgación periodística, como traslado a los "iguales” de los resultados de investigación (artículos en revistas científicas, p. ej.), como información con un nivel medio de especialización... Sugiero tomar en consideración algo que ya publiqué hace más de 10 años, por si fuera de utilidad

“(...) hemos de aclarar a qué tipo de actividad nos referimos cuando hablamos de comunicación de la ciencia. Suele hablarse de esta actividad en, al menos, ocho casos:

1. Científicos: difusión de la ciencia inter pares.

2. Científicos divulgadores: maestros y/o técnicos.

3. Filósofos de la ciencia, investigadores del pensamiento científico.

4. Divulgadores científicos, no científicos: investigadores de los fenómenos de la difusión y de la divulgación.

5. Formadores de futuros profesores de ciencias (“didáctica de la ciencia”, enseñantes).

6. Teóricos del periodismo científico.

7. Periodistas científicos.

8. Informadores que hacen la labor de mediación entre científicos y periodistas de los medios de comunicación (servicios de comunicación).

(http://www.periodismoudec.cl/estudiosdeperiodismo/index2.php?option=com_content\&do_pdf $=1 \& \mathrm{id}=61)$ 
El "modelo" RRI va más allá, obviamente, a la hora de abordar investigación e innovación ligadas al concepto "responsabilidad", pero entiendo que quizá pueda ayudar la reflexión que les planteo. Mi experiencia tanto en divulgación como en captación de recursos es ésa.

\section{- Gema Revuelta:}

El modelo que se propone en el texto de este documento tiene sin duda un elemento muy interesante, el hecho de enmarcar conceptualmente la comunicación científica en la ética dialógica por una parte, en la teoría de los stakeholders y en el concepto de RSC.

Sin embargo, hay dos elementos que particularmente no me han parecido adecuados:

El título "Modelo de Comunicación de la RRI" es confuso. La Investigación e Innovación pueden llegar a ser descritas como "responsables" - en el sentido que atribuye la UE a este concepto en su programa H2020 - cuando, entre otras coas, establece mecanismos de comunicación basados en el diálogo y participación de diferentes stakeholders. Es decir, en mi opinión, no se presenta un modelo de comunicación de la RRI, sino un "Modelo de Comunicación que contribuya a la RRI".

El gráfico no se acaba de explicar en el texto y no me parece autoinformativo, o al menos, a mí en particular, no me resulta fácil comprenderlo. Por otra parte, de los cuatro enunciados que giran en torno al círculo central sólo uno parece que tiene que ver con el planteamiento de comunicación multidireccional propio de la RRI (negociación y diálogo), mientras que los 3 restantes (publicidad, información e información proactiva) son claramente representantes de acciones unidireccionales tradicionales. Coincido con la propuesta en que tanto la información unidireccional como las acciones de diálogo bidireccional son positivas y necesarias, pero quizá el énfasis en el diálogo debería estar bien representado visualmente, puesto que en el gráfico actual parece algo marginal.

\section{- Guillermo Santamaría:}

Como consideración general, y desde el punto de vista en el que actualmente me manejo, el modelo tal y como está propuesto corre el riesgo de quedar desactualizado antes de ser formulado. En primer lugar, ha pasado a sustituir el conjunto "research and innovation" por "responsable research and innovation", cuando en realidad la característica de "responsable" es adquirida por la investigación y la innovación a través de acciones que refuercen los aspectos positivos y disminuyan los negativos de las mismas. Concretando, en mi parecer no tiene sentido hablar de un modelo de comunicación de la RRI, si no que trabajar bajo nuevas perspectivas la comunicación de la I+i es lo que puede hacer que adquieran nuevos niveles de responsabilidad. Esto me lleva a pensar que el modelo está considerando una mera sustitución de un concepto por otro, conservando el resto de variables prácticamente inmóviles (a partir de un modelo de RSC?), mientras que esta sustitución implica una completa reordenación de todos los elementos y variables asociados a la I+i y su comunicación. Por ejemplo, bajo un paradigma de RRI, la transición de 3 a 4 (en su diagrama) no podría ser mediada por "publicidad", si no por 
“información pública transparente y relevante". Por ejemplo, en un paradigma RRI, los pasos 1 y 2 estarían intercambiados: la universidad se sumerge activamente en la búsqueda de las necesidades del resto de actores y seguidamente busca un diálogo al mismo nivel con ellos para ofrecer potenciales soluciones a sus necesidades.

Esto me lleva, en segundo lugar, a los dos modelos "complementarios" de comunicación que ofrece el modelo: unidireccional y bidireccional. A la luz de las nuevas corrientes movidas por el apoyo a la RRI desde la Comisión Europea (pero no sólo desde ahí), cabe suponer que nos estamos moviendo más allá de estos dos modelos hacia paradigmas donde la relación entre ciencia y sociedad es mucho más cercana e íntima, de manera que todos los actores relevantes participan en el proceso de $\mathrm{I}+\mathrm{i}$ en todos los niveles y etapas del mismo (diferentes actores tendrán diferente relevancia en unos u otros).

Por tanto:

- Oportunidades:

- El modelo ofrece la posibilidad de repensar la comunicación de la I+i desde los nuevos paradigmas de la RRI, y el papel de la universidad en estos procesos.

- De repensar el papel de la comunicación como puente entre universidad y resto de actores implicados en $\mathrm{I}+\mathrm{i}$.

- De repensar el papel de la universidad en la sociedad.

- Riesgos:

- Reescribir o reordenar lo existente sin cambiar nada.

- Perpetuar los modelos de relación entre ciencia y sociedad que han provocado la crisis que ha conducido a formular las opciones bajo los modelos de RRI (es decir, lo mismo que el punto anterior).

- Intentar trasladar a la I+i los modelos de RSC, incluyendo algunos de sus mayores defectos.

Una vez expuestas las aportaciones a la pregunta abierta sobre el modelo, recogemos a continuación las respuestas a las cuestiones cerradas en las que se pedía a los expertos que valoraran diversos aspectos en una serie en la que 0 era nada, 1-poco, 2-algo, 3-bastante y 4-mucho.

- Todos los expertos coincidieron en valorar como muy importante el papel de la comunicación en el desarrollo de una Investigación e Innovación Responsable en las universidades, otorgándole en todos los casos la máxima puntuación. 
- También dieron una elevada importancia al papel de las universidades como puente en la transmisión de intereses y necesidades de unos stakeholders a otros (por ejemplo, de la sociedad a la Administración o la empresa). En concreto, dos de los expertos entendieron que este papel tiene mucha importancia, mientras que otros dos le otorgaron bastante importancia.

- Los expertos consideran de forma prácticamente unánime que el diálogo con los stakeholders es muy importante a la hora de establecer los fines de la investigación y de la innovación. Así, tres de ellos lo señalaron como muy importante y, un cuarto, como bastante.

- La valoración es negativa a la hora de establecer en qué medida piensan que las universidades españolas tienen en cuenta criterios de ética y responsabilidad social en la gestión de la investigación y la innovación (compromiso social, atención a las necesidades sociales, transparencia en sus acciones, igualdad, etc.). Dos de los expertos consultados afirman que se tienen poco en cuenta estos criterios, frente a uno que dice que bastante. La respuesta de un cuarto se encuentra entre algo y bastante.

- Por lo que respecta a la pregunta sobre en qué medida consideran que en la gestión de la comunicación de la investigación y la innovación desde las universidades se tienen en cuenta aspectos de ética y responsabilidad social (atención a las expectativas ciudadanas, transparencia, participación, etc.), las respuestas son incluso más negativas. Uno de los encuestados cree que no se tienen en cuenta criterios éticos en esta comunicación nunca, mientras que otro entiendo que se consideran poco y, los dos restantes, opinan que se tienen tan sólo algo en cuenta.

Las respuestas planteadas por los expertos y expertas aparecen recogidas en dos tablas incluidas en el informe de la primera oleada realizado para su envío a los expertos y que recogemos más adelante. Antes, cabe hacer referencia a la pregunta que cerraba el cuestionario sobre "Otras cuestiones que considere de interés". En este punto se recogieron tres aportaciones: 


\section{- Jesús Conill:}

En las cuestiones 5 y $6^{5}$ he marcado la casilla de "Algo", porque no me atrevo a afirmar que no hay "Nada", confiando en que algo habrá, a pesar de que no tengo información fidedigna al respecto, entre otras cosas debido a que no hay comunicación eficaz al respecto, o, al menos, no con suficiente capacidad de superar la generalizada desinformación y la fragmentación.

- Antonio Marín:

Creo que a la hora de relacionarnos con empresas e instituciones hay que hacerlo con respuestas básicas a prejuicios con los que, en muchas ocasiones, se percibe a las universidades y se aborda la relación con ellas (en ocasiones no alejados de la realidad):

- qué es ciencia y qué es innovación más allá de la "torre de marfil" $\rightarrow$ qué función han de ocupar las universidades al manejar estos conceptos ante empresas e instituciones; y ello porque se han de poner ejemplos de buenas prácticas para romper tópicos,

○ qué prejuicios existen respecto a las universidades en cuanto a nuestro uso del tiempo y los excesos de controles (reuniones) y burocratización.

Presumo que en las conclusiones de su trabajo se planteará, entre otras, la propuesta de celebración de encuentros entre empresas y universitarios. Pongo esto en relación con las ideas de "ética" y "responsabilidad social" y la necesidad, creo, de diferenciar entre encuentros puntuales, ligados a proyectos de cooperación concretos (próximos a firma de convenios específicos), y encuentros más genéricos, en los que la reflexión tenga lugar, así como la presencia, por parte de la universidad, de un cierto grado de interdisciplinariedad. No abundo en esta cuestión por ya conocida.

\section{- Guillermo Santamaría:}

Desde mi humilde punto de vista, este modelo requiere una intensa reorganización si su fin es presentar un modelo novedoso y que vaya más allá del estado del arte (que, por otra parte, no es especialmente halagüeño, al menos en el entorno de la universidad española).

A partir de las respuestas planteadas por los expertos y expertas se elaboró el siguiente informe de la primera oleada que fue remitido a los cuatro participantes para que pudieran replantear sus respuestas a partir de las aportaciones realizadas por los demás expertos y de las matizaciones y aclaraciones que incluimos como autores de la investigación.

\footnotetext{
${ }^{5}$ Las cuestión 5 hace referencia a la consideración por parte de las universidades españolas de criterios de ética y responsabilidad social en la gestión de la investigación y la innovación, mientras que la 6 alude a la aplicación de estos criterios en la comunicación de la ciencia.
} 


\title{
Panel Delphi: Informe primera oleada
}

\author{
Aspectos éticos de la comunicación de la RRI
}

GERSE, Universitat Jaume I

Los expertos y expertas consultados han realizado valoraciones y aportaciones de gran interés sobre el modelo ético de comunicación de la RRI propuesto, ofreciendo perspectivas muy dispares y en algunos casos enfrentadas. A continuación recogemos agrupadas en cinco puntos las respuestas planteadas por expertos en ética, comunicación de la ciencia, comunicación universitaria y RRI, así como una valoración de las mismas y una revisión del modelo inicialmente planteado.

\section{- Oportunidad del modelo}

Uno de los expertos/as consultados considera que la propuesta plantea una línea de trabajo más que oportuna, necesaria, en tanto que entiende que:

- ayudaría a comprender socialmente el trabajo que realizan las universidades en investigación e innovación,

- contribuiría a orientar parte de ese trabajo en diálogo con empresas e instituciones $y$

- redundaría en un muy probable beneficio para la propia universidad a corto y medio plazo y para la sociedad en general a medio y largo plazo; en tanto que sería mayor la relación entre necesidad de sociedad y empresas y capacidad de investigación e innovación de las universidades.

Otro de los expertos/as consultados destaca lo innovador del modelo, señalando que no conoce ninguna otra propuesta en este sentido, ni en la teoría ni en la práctica. El experto considera excelente el modelo tanto en su propósito, como en su diseño y configuración: "Considero que ofrece oportunidades realmente innovadoras y fecundas. El único 'riesgo' que veo es su difícil aplicación a través de procesos efectivos, precisamente porque es de verdad innovador, ya que va contra las inercias más arraigas de la vida universitaria, que tienden a lo contrario, es decir, a la fragmentación y a la incomunicación".

Por su parte, un tercer experto/a considera que el modelo propuesto "tiene sin duda un elemento muy interesante, el hecho de enmarcar conceptualmente la 
comunicación científica en la ética dialógica por una parte, en la teoría de los stakeholders y en el concepto de RSC".

\section{- $\quad$ Sugerencias de mejora}

Entre las aportaciones de los expertos/as se encuentran algunas sugerencias de mejora en cuestiones como, por ejemplo, el título del modelo, al considerar que el hecho de aludir a un "Modelo de Comunicación de la RRI" resulta confuso. En este sentido, se señala que la Investigación e Innovación pueden llegar a ser descritas como "responsables" - en el sentido que atribuye la UE a este concepto en su programa H2020 - cuando, entre otras cosas, establece mecanismos de comunicación basados en el diálogo y participación de diferentes stakeholders. Por tanto, en opinión del experto/a no se presenta un modelo de comunicación de la RRI, sino un "Modelo de Comunicación que contribuya a la RRI". Como autores de la investigación entendemos que se trata de una reflexión muy oportuna, por lo que tendremos en cuenta la variación del título de cara a la propuesta definitiva del modelo. También referente al gráfico se señala que no se acaba de explicar en el texto, para que sea suficientemente autoinformativo. Este aspecto que se tratará asimismo de mejorar en el gráfico definitivo.

En cuanto al contenido del modelo, se señala que de los cuatro enunciados que giran en torno al círculo central sólo uno parece que tiene que ver con el planteamiento de comunicación multidireccional propio de la RRI (negociación y diálogo), mientras que los tres restantes (publicidad, información e información proactiva) son claramente representantes de acciones unidireccionales tradicionales. "Coincido con la propuesta en que tanto la información unidireccional como las acciones de diálogo bidireccional son positivas y necesarias, pero quizá el énfasis en el diálogo debería estar bien representado visualmente, puesto que en el gráfico actual parece algo marginal", se indica. Al respecto, desde la investigación se analizará el modo de incorporar y reflejar de manera visual una mayor comunicación bidireccional a lo largo de todo el proceso, dada la necesidad de la misma para alcanzar una investigación e innovación más responsable.

En otro orden de cosas, los expertos sugieren que el concepto de comunicación que se maneje se afine en la relación con los públicos, para su mejor comprensión. Comunicación como divulgación periodística, como traslado a los "iguales" de los resultados de investigación (artículos en revistas científicas, p. ej.), como información con un nivel medio de especialización. Así, recuerdan que suele hablarse de comunicación de la ciencia en, al menos, ocho casos: 
1. Científicos: difusión de la ciencia inter pares.

2. Científicos divulgadores: maestros y/o técnicos.

3. Filósofos de la ciencia, investigadores del pensamiento científico.

4. Divulgadores científicos, no científicos: investigadores de los fenómenos de la difusión y de la divulgación.

5. Formadores de futuros profesores de ciencias ("didáctica de la ciencia", enseñantes).

6. Teóricos del periodismo científico.

7. Periodistas científicos.

8. Informadores que hacen la labor de mediación entre científicos y periodistas de los medios de comunicación (servicios de comunicación).

(http://www.periodismoudec.cl/estudiosdeperiodismo/index2.php?option=co m_content\&do_pdf=1\&id=61)

\section{- $\quad$ Aportaciones críticas}

Entre los expertos consultados, algunos entienden que el modelo tal y como está propuesto corre el riesgo de quedar desactualizado antes de ser formulado: "En primer lugar, ha pasado a sustituir el conjunto 'research and innovation' por 'responsible research and innovation', cuando en realidad la característica de 'responsable' es adquirida por la investigación y la innovación a través de acciones que refuercen los aspectos positivos y disminuyan los negativos de las mismas. Concretando, en mi parecer no tiene sentido hablar de un modelo de comunicación de la RRI, si no que trabajar bajo nuevas perspectivas la comunicación de la I+i es lo que puede hacer que adquieran nuevos niveles de responsabilidad. Esto me lleva a pensar que el modelo está considerando una mera sustitución de un concepto por otro, conservando el resto de variables prácticamente inmóviles (a partir de un modelo de RSC?), mientras que esta sustitución implica una completa reordenación de todos los elementos y variables asociados a la I+i y su comunicación". Como ejemplo señala que, bajo un paradigma de RRI, la transición señalada en el gráfico entre la tercera y la cuarta fase del modelo no podría ser mediada por 'publicidad', si no por 'información pública transparente y relevante'. Desde la investigación, entendemos que estas reflexiones aparecen vinculadas a las incluidas en el apartado anterior, que plantean enfocar la propuestas como un modelo de comunicación que contribuya al desarrolla de la RRI y no tanto como un modelo de comunicación de la RRI. Valoramos asimismo de forma positiva la posibilidad de sustituir la denominación entre la fase de compromisos adquiridos y la de medición de resultados, como 'información pública relevante y transparente' al ser una denominación que ayuda a comprender mejor el sentido de la acción comunicativa. En este punto cabe señalar, no obstante, que el término 'publicidad' 
estaba utilizado originalmente no en el sentido de comunicación comercial o advertising sino en el sentido kantiano de hacer público, de dar a conocer a la opinión pública.

Por otra parte, el experto/a considera que en un paradigma de RRI los pasos señalados en el gráfico como 1 y 2 estarían intercambiados, de forma que la universidad se sumerge activamente en la búsqueda de las necesidades del resto de actores y seguidamente busca un diálogo al mismo nivel con ellos para ofrecer potenciales soluciones a sus necesidades. En este sentido, cabe explicar que si se incluyó esta primera fase como un paso previo al diálogo con los stakeholders fue porque en un focus group realizado con varios stakeholders, estos mostraron la necesidad de conocer previamente qué les podía ofrecer la universidad en materia de investigación e innovación para, así, ayudarles a determinar sus necesidades y expectativas respecto a las mismas.

Por otra parte, el experto/a consultado hace referencia a los dos modelos "complementarios" de comunicación que ofrece el modelo: unidireccional y bidireccional, señalando que "a la luz de las nuevas corrientes movidas por el apoyo a la RRI desde la Comisión Europea (pero no sólo desde ahí), cabe suponer que nos estamos moviendo más allá de estos dos modelos hacia paradigmas donde la relación entre ciencia y sociedad es mucho más cercana e íntima, de manera que todos los actores relevantes participan en el proceso de $\mathrm{I}+\mathrm{i}$ en todos los niveles y etapas del mismo (diferentes actores tendrán diferente relevancia en unos u otros)".

Desde esta perspectiva, entiende que el modelo comporta diferentes riesgos, entre los que destaca el de reescribir o reordenar lo existente sin cambiar nada, perpetuando los modelos de relación entre ciencia y sociedad que han provocado la crisis que ha conducido a formular las opciones bajo los modelos de RRI, así como de intentar trasladar a la I+i los modelos de RSC, incluyendo algunos de sus mayores defectos. No obstante, entiende que también ofrece algunas oportunidades, entre ellas, la posibilidad de repensar la comunicación de la l+i desde los nuevos paradigmas de la RRI, y el papel de la universidad en estos procesos, así como de repensar el papel de la comunicación como puente entre universidad y resto de actores implicados en I+i y el papel de la universidad en la sociedad.

\section{- $\quad$ Enfrentar prejuicios}

Entre los comentarios incluidos en el cuestionario, uno de los expertos/as participantes considera que a la hora de establecer relaciones con empresas e 
instituciones hay que hacerlo con respuestas básicas a prejuicios con los que, en muchas ocasiones, se percibe a las universidades y se aborda la relación con ellas (en ocasiones no alejados de la realidad):

- qué es ciencia y qué es innovación más allá de la "torre de marfil": qué función han de ocupar las universidades al manejar estos conceptos ante empresas e instituciones; y ello porque se han de poner ejemplos de buenas prácticas para romper tópicos,

- qué prejuicios existen respecto a las universidades en cuanto a su uso del tiempo y los excesos de controles (reuniones) y burocratización.

En cuanto a la celebración de encuentros entre empresas y universidades, se sugiere la necesidad de diferenciar entre encuentros puntuales, ligados a proyectos de cooperación concretos (próximos a firma de convenios específicos), y encuentros más genéricos, en los que la reflexión tenga lugar, así como la presencia, por parte de la universidad, de un cierto grado de interdisciplinariedad.

\section{- Gráficos de valoración}

Las respuestas de los expertos/as consultados a las preguntas de valoración se recogen en el siguiente gráfico:

Importancia de la comunicación en la gestión de la RRI en las universidades

Importancia del papel de las universidaden transmisión de intereses entre stakeholders

Importante del diálogo con los stakeholders para establecer los fines de la $\mathrm{l}+\mathrm{i}$

Consideración de criterios de ética y RS en la gestión de la I+i en las universidades

Consideración de criterios de ética y RS en la comunicación de la l+i en las universidades

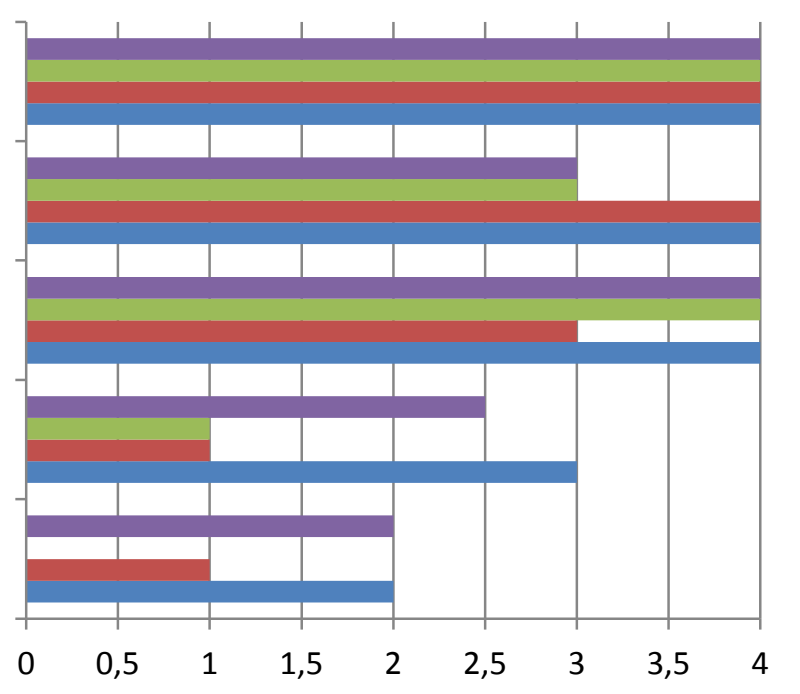


La media de todas las respuestas queda reflejada en el siguiente gráfico:

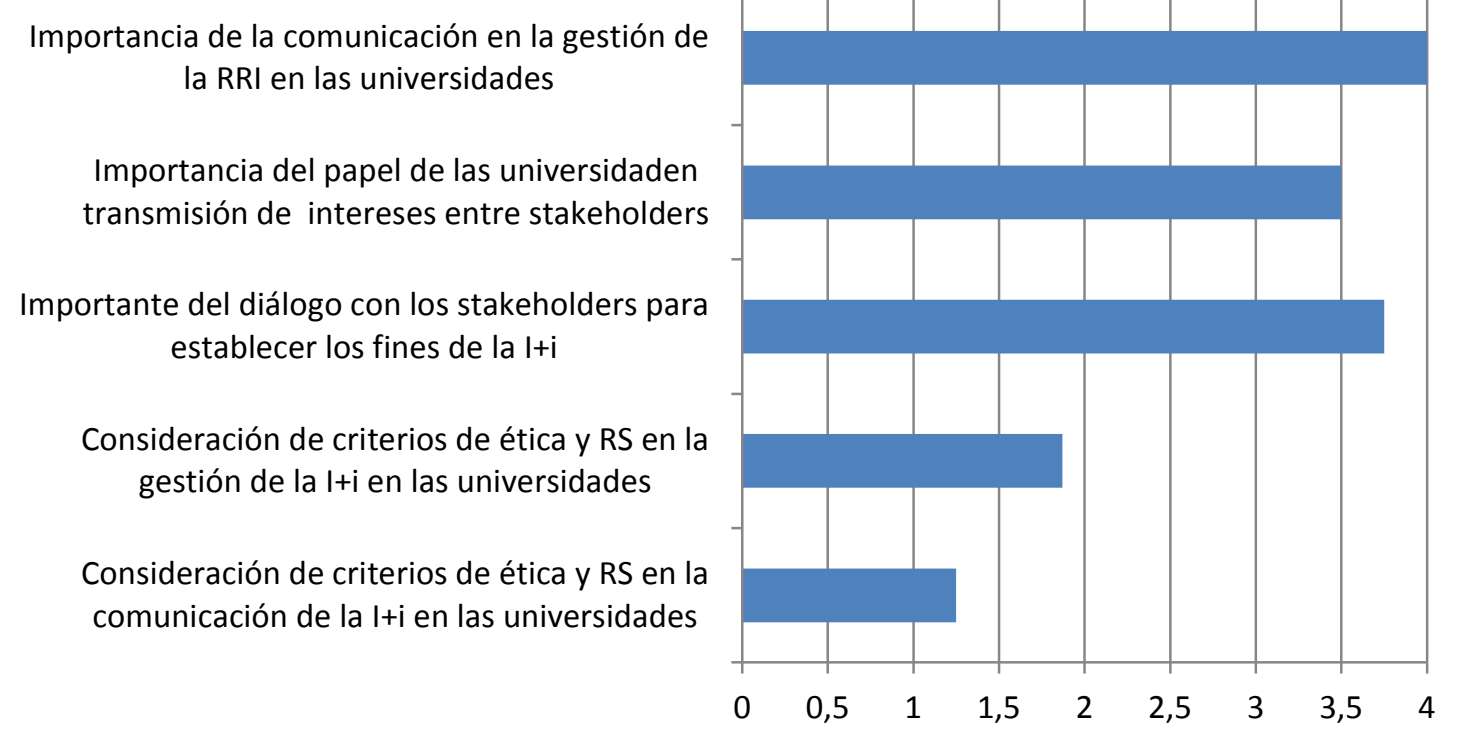

En líneas generales, los expertos/as valoran como muy importante la comunicación en la gestión de la RRI en las universidades, existiendo total unanimidad en este punto. Las respuestas oscilan entre muy y bastante importante al valorar el papel de las universidades a la hora de actuar de puente entre los intereses y necesidades de los diferentes stakeholders, así como en la importancia otorgada al diálogo con los grupos de interés para el establecimiento de los fines de la investigación.

Por el contrario, la puntuación ha sido negativa a la hora de valorar la realidad de las universidades españolas. Tan solo uno de los encuestados considera que se tienen bastante en cuenta los criterios éticos y de responsabilidad social en la gestión de la investigación y la innovación, mientras otros dos creen que se consideran poco. En el caso de la consideración de estos criterios en la comunicación de la investigación y la innovación, las opiniones son aún más negativas, valorándola uno de los expertos con un 'algo', otro como 'poco' y uno como 'nada'. Precisamente, respecto a estas dos preguntas uno de los expertos consultados explica que optó por marcar la casilla de 'algo', "porque no me atrevo a afirmar que no hay 'nada', confiando en que algo habrá, a pesar de que no tengo información fidedigna al respecto, entre otras cosas debido a que no hay comunicación eficaz al respecto, o, al menos, no con suficiente capacidad de superar la generalizada desinformación y la fragmentación”. 


\subsubsection{Segunda oleada del panel Delphi}

En la segunda oleada del panel Delphi, las aportaciones sobre el modelo de comunicación de la RRI para las universidades planteadas por los expertos y expertas, junto a las reflexiones y modificaciones que propusimos como autores del estudio, generaron las siguientes respuestas:

\section{- Jesús Conill:}

Me parecen adecuadas las mejoras con respecto a los términos que expresan el título y los objetivos de la investigación.

Por lo que se refiere al término "publicidad", también por mi parte lo había entendido el sentido kantiano, más que en el estrictamente comercial, por tanto, como espacio de transparencia y responsabilidad.

En cuanto a las diversas formas de comunicación de la ciencia (sea por científicos, filósofos, divulgadores, profesores, periodistas, $\mathrm{u}$ otros servicios), lo que me parece es que no hay diálogo alguno, sino que cada cual tiene su propia fuente, sin prestar atención al pluralismo existente y razonable.

Y, por otra parte, en la cuestión de la ciencia, no se transmite el proceso de la actividad científica y sus peculiaridades, sino que sólo se presentan los presuntos resultados con carácter de espectáculo y capacidad comercial ¿Es esa una buena comunicación? No se trata, pues, sólo de cantidad de información, sino que precisamente la universidad podría aportar un modo peculiar, más adecuado, de comunicación de la investigación científica.

- Antonio Marín:

Cuando en el informe inicial se presentaba el modelo de comunicación para la investigación e innovación responsable se afirmaba algo que -en mi experiencia- es clave: "la comunicación inicia y mejora la gestión de la RRI".

La lectura del informe "primera oleada":

1) me reafirma en las valoraciones numéricas,

2) enseña mucho al confrontar y conocer la opinión con otros y

3) me plantea unas reflexiones que, sinceramente, no sé si serán o no de utilidad, pero temo que mis opiniones se basen en experiencias y que mi capacidad de abstracción se haya terminado hace tiempo.

Decía un antiguo rector de mi Universidad ${ }^{6}$ que cuando dejó de serlo lo que más le sorprendió de su vuelta a investigador de "a pie" fue comprobar que para él seguía siendo igual de infierno

\footnotetext{
${ }^{6}$ Antonio Marín hace referencia a la Universidad de Granada en la que ha desarrollado mayoritariamente su trayectoria profesional.
} 
pensar en la gestión de la investigación: ante las necesidades de financiación local, autonómica, nacional, internacional, de empresas y las trabas y burocracia que no eran mitigadas por el rectorado (más bien todo lo contrario) --> dedicar más tiempo a tareas de gestión que a investigar... Temo que sea el de nuestro país un sistema administrado desde el principio de la desconfianza, que precisa de dosieres e informes, currículos extensos y amplias introducciones y justificaciones. En este sentido, si el investigador percibe que la RRI es más de lo mismo, mal vamos. En 25 años trabajando con investigadores he comprobado que aquéllos con más prestigio (medido en publicaciones científicas, no sólo en presencia en los fori) están encantados en comunicar la ciencia y se comprometen rápidamente a hacerlo, si se dan las condiciones obvias: que la interpretación de su trabajo no dé lugar a equívocos. En este sentido, los gabinetes de comunicación/prensa, los servicios de relaciones públicas y los medios de comunicación podemos ser la peste (universidades españolas, privadas, que no figuran en ningún ranking de prestigio mundial están muy, muy, muy sobrerrepresentadas en medios nacionales) o podemos contribuir a que los investigadores se tomen en serio la labor de comunicar socialmente su labor como parte de su quehacer... Y hablo ahora de comunicar en un sentido muy amplio (todos sus posibles stakeholers), incluidas la RSC y el concepto RRI.

En otras palabras: el investigador de prestigio (medido en publicaciones científicas) contribuirá a extender una idea y una práctica de RRI si entiende que el fin contribuye a difundir la ciencia sin comprometer la cientificidad de su labor y sin que el esfuerzo se convierta en una carga más. El momento es bueno, el dinero para investigar escasea, las fuentes de financiación se han de ampliar, se acepta mejor la idea de diálogo social para explicar en qué se trabaja y cómo se puede contribuir socialmente desde la innovación y la investigación responsables. Creo.

\section{- Gema Revuelta:}

No tengo nada más que aportar. En general estoy de acuerdo con las sugerencias de los expertos y las respuestas de los autores.

\section{- Guillermo Santamaría:}

Creo que ahora el modelo está mucho más completo, y atiende a varios criterios que antes podría haber pasado por alto. Diría que en general ha mejorado.

Como nota, no sé si realmente el modelo, a este nivel en que está, necesita tener tan en cuenta los diferentes tipos de "divulgación científica" que existen, porque además los roles propuestos siempre se dejarán algo fuera (existen infinitos roles de divulgadores y otros tantos modelos de divulgación). 


\subsection{APORTACIONES DE LOS EXPERTOS AL MODELO DE} COMUNICACIÓN DE LA RRI

La visión aportada por los expertos y expertas en Ética y Comunicación resulta de gran interés de cara a conocer las oportunidades y riesgos del modelo propuesto y a plantear algunas mejoras en el mismo.

Existe una notable coincidencia entre los profesionales consultados a la hora de valorar de forma positiva la oportunidad del modelo planteado. Expertos en Ética como Jesús Conill consideran que se trata de una propuesta que ofrece oportunidades innovadoras y fecundas a través de un modelo que califica de "excelente" en su propósito, diseño y configuración. También la especialista en Comunicación de la Ciencia Gema Revuelta destaca la aportación que supone enmarcar la comunicación de la ciencia en la ética del discurso, la teoría de los stakeholders y la RSC. Por su parte, Guillermo Santamaría, investigador del proyecto RRI Tools, señala la posibilidad que ofrece de repensar tanto la comunicación de la investigación y la innovación desde los nuevos paradigmas de la RRI como el papel de las universidades. Desde el ámbito de la Comunicación Universitaria, Antonio Marín considera que se trata de una propuesta no sólo oportuna, sino necesaria de cara a mejorar la comunicación del trabajo en investigación e innovación que realizan las universidades desde una perspectiva amplia y a favorecer la orientación de la investigación a través del diálogo. Estas mejoras presume que supondrían un beneficio para todos los actores implicados a corto, medio y largo plazo. En este mismo sentido, Conill destaca la oportunidad que ofrece de establecer una comunicación de la ciencia por parte de las universidades de un modo "más adecuado", que vaya más allá de la transmisión de información sobre resultados de investigación.

Con vistas al desarrollo del modelo, cabe tener en cuenta los riesgos sobre los que alertan los expertos. Jesús Conill estima que uno de ellos puede residir precisamente en lo innovador de la propuesta, al plantear un modelo que va contra las inercias más arraigadas de la universidad que, según la propia experiencia del filósofo valenciano, tienden hacia la incomunicación y la fragmentación en materia de investigación e innovación. Un punto de vista totalmente diferente presenta Guillermo Santamaría, quien entiende que el principal riesgo del modelo reside en que se reordene lo existente sin realmente llegar a cambiar nada. Cabe asimismo tener en cuenta los riesgos sobre los que advierte Antonio Marín con el fin de que la implantación del 
modelo no se convierta en una carga añadida para un personal investigador ya sobrecargado de tareas administrativas y burocráticas. En este sentido, el experto en Comunicación de la Ciencia y Universitaria argumenta que es clave facilitar la tarea de los investigadores y concienciarlos de que se trata de una contribución social de utilidad que no supone una pérdida de la cientificidad.

Entre las aportaciones de los expertos y expertas cabe destacar algunas sugerencias de mejora del modelo de comunicación de la RRI de gran interés. Entre ellas, la posibilidad de repensar el propio título, de forma que se presente un modelo de comunicación no tanto de la investigación y la innovación ya entendida como responsable, sino un modelo que contribuya a través de la comunicación a avanzar hacia una investigación e innovación más responsables. Si bien éste era desde un principio el objetivo de la propuesta, es cierto que no quedaba adecuadamente plasmado en el título, por lo que planteamos pasar a hablar de un "Modelo ético de comunicación para la RRI en la universidad".

Por otra parte, vemos igualmente acertada la sugerencia de concretar la expresión "comunicación de la ciencia" que ocupa el lugar central del modelo, pasando a hablar de "Comunicación Pública de la Ciencia" con el fin de evidenciar que se trata de una comunicación de la ciencia dirigida a los grupos de interés con un carácter informativo, divulgador y dialógico, y no tanto a la comunicación entre expertos o a otras acepciones de comunicación de la ciencia referenciadas por Antonio Marín. En este sentido, entendemos que el término CPC es lo suficientemente amplio para abarcar las diferentes formas de comunicar a diferentes públicos, tal y cómo apunta Guillermo Santamaría en la segunda oleada del panel.

Siguiendo con el gráfico del modelo, resultará asimismo de interés atender las sugerencias de los expertos de repensar las expresiones utilizadas con el fin de mejorar su comprensión, clarificar conceptos y evidenciar la presencia de la comunicación bidireccional en las diferentes fases, atendiendo así al planteamiento de comunicación dialógica señalado por Conill en la segunda oleada.

Las modificaciones del gráfico planteadas en el informe sobre la primera oleada fueron apreciadas de forma positiva por los expertos y expertas quienes, en la segunda oleada del panel, coincidieron en considerar que los cambios adoptados suponían una mejora del modelo. 
En el apartado referente a las preguntas cerradas, la opinión de los expertos muestra que desde los ámbitos de la Comunicación y la Ética se considera que la comunicación tiene un papel fundamental en el desarrollo de la RRI. También existe unanimidad entre los expertos a la hora de juzgar como muy importante el diálogo con los diferentes stakeholders de cara a la determinación de los fines de la investigación y la innovación. Estas valoraciones vienen a reforzar el interés de un modelo que gira alrededor de la comunicación y el diálogo con los grupos de interés para avanzar hacia una investigación e innovación más responsables en las universidades. Las respuestas de los expertos y expertas también apuntan el interés de abrir nuevas vías en el papel de la universidad, estimando adecuada la posibilidad de que ésta actúe como puente para la transmisión de intereses y necesidades entre los diferentes stakeholders.

Finalmente, las respuestas de los expertos ratifican la importancia de impulsar la RRI en las universidades y una comunicación de la ciencia que tenga más en cuenta criterios de ética y responsabilidad. En general, los especialistas consultados, conocedores desde diferentes ámbitos de la realidad universitaria, consideran muy reducida la aplicación de estos criterios en la gestión de la investigación y la innovación en las universidades. La percepción es todavía más negativa en el caso de la comunicación. Una situación a la que el modelo propuesto busca contribuir a hacer frente. 



\section{Validación del modelo, pautas para su desarrollo}

Los resultados obtenidos a partir del cuestionario sobre la comunicación de la ciencia en las universidades, los focus groups con los grupos de interés establecidos en el mapa de stakeholders y el panel Delphi de expertos, nos permiten validar y mejorar el modelo planteando y establecer algunas pautas para su desarrollo. En el presente capítulo recogeremos las principales aportaciones extraídas a partir de las tres técnicas puestas al servicio de la investigación, que nos posibilitan asimismo abordar las oportunidades y riesgos que plantea el modelo propuesto y los aspectos éticos de la comunicación de la ciencia para el fomento de la RRI en la universidad.

\section{- Aportaciones y validación del modelo}

Las aportaciones realizadas a partir de los focus groups con stakeholders dieron pie a una primera modificación del modelo inicialmente propuesto, incorporando una fase inicial de información proactiva por parte de las universidades sobre las posibilidades que pueden ofrecer a la sociedad civil, las empresas y la Administración Pública en materia de investigación e innovación. Las aportaciones realizadas posteriormente por diversos expertos a través del panel Delphi han permitido repensar el modelo con el fin de mejorarlo y clarificar determinados aspectos. Así, se ha considerado conveniente variar algunos de los enunciados, empezando por el propio título del gráfico. En este sentido, y atendiendo a los argumentos expuestos por expertos en Comunicación de la Ciencia y RRI, se modifica el título con el fin de clarificar que se trata de un modelo comunicativo que, desde la perspectiva de la ética dialógica, pretende contribuir al desarrollo de una investigación e innovación más responsable en las universidades a través de la comunicación y el diálogo.

Por otra parte, en el espacio central se sustituye el enunciado "Comunicación de la ciencia" por "Comunicación pública de la ciencia" con el fin de concretar que se trata de la difusión pública dirigida a los diferentes grupos de interés a través de diversos canales, dejando fuera otros tipos de comunicaciones de la ciencia como, por ejemplo, la que se produce entre pares a través de las revistas de investigación. También en el espacio central se introduce el diálogo como una forma de entender la comunicación desde la interacción y la relación entre todos los grupos de interés durante todas las 
fases del modelo. El modelo final mantiene así la "Comunicación pública de la ciencia" como centro del proceso, alrededor del cual circula el diálogo como elemento que impacta en las diferentes fases.

Finalmente, con el fin de lograr una mayor claridad en la interpretación del gráfico se sustituyen algunos de los términos empleados por otros que entendemos que pueden resultar más comprensivos. Recogemos a continuación el gráfico del modelo ético de comunicación de la ciencia para el fomento de la RRI en las universidades con los cambios introducidos.

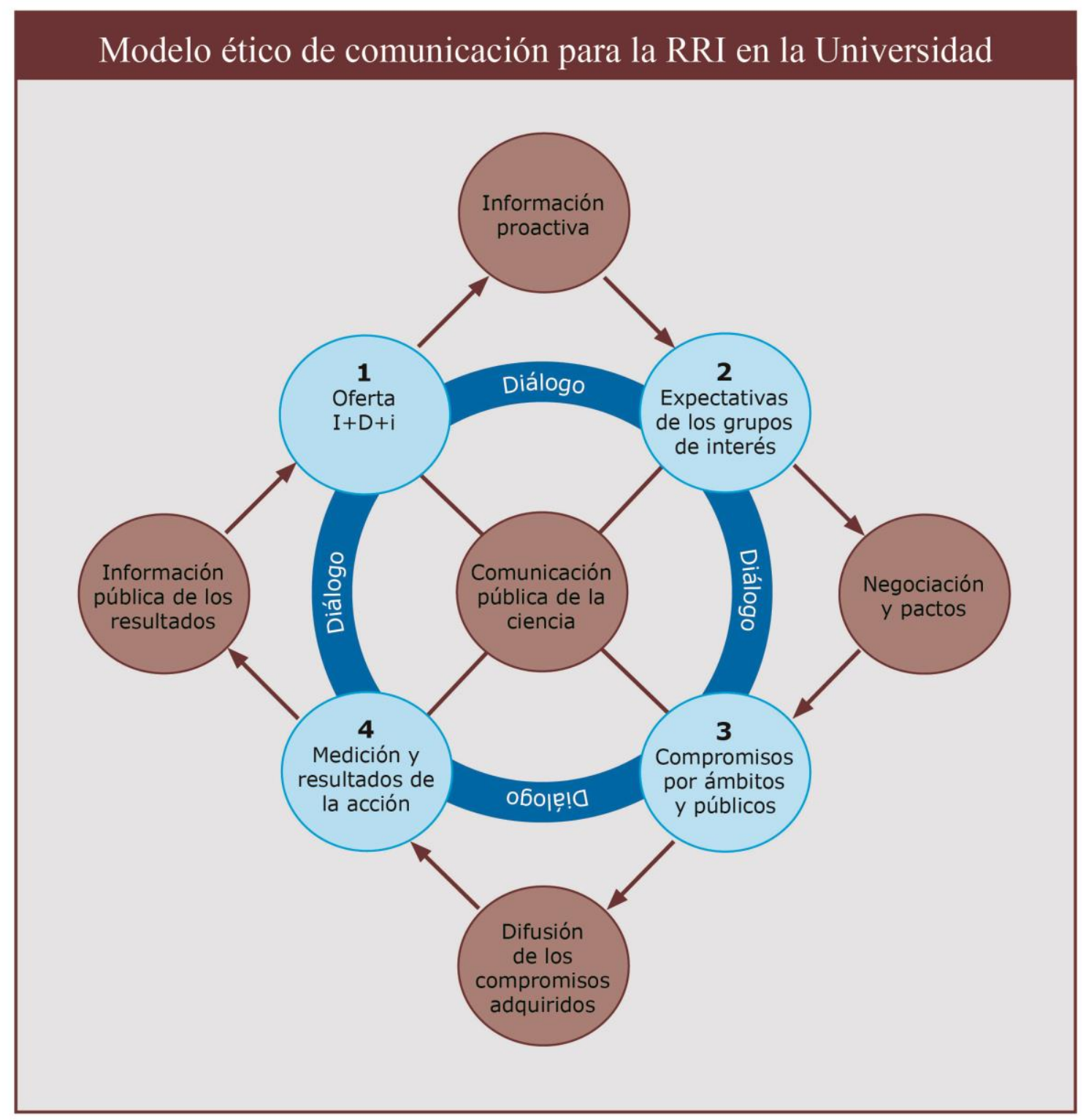

Además de para plantear algunas matizaciones y mejoras, las técnicas cualitativas y cuantitativas realizadas han servido para validar el modelo propuesto. Así lo han avalado diferentes expertos participantes en el panel Delphi. En concreto, desde 
el ámbito de la Ética han destacado la idoneidad del diseño, la configuración y el propósito del modelo, ratificando las opiniones expresadas ya por algunos de los participantes en los focus group provenientes asimismo del campo de la Filosofía. También desde los ámbitos de la Comunicación de la Ciencia y la Comunicación Universitaria se ha apreciado la aportación que supone el modelo a la hora de ofrecer un marco teórico a la comunicación científica a partir de la ética dialógica, la teoría de los stakeholders y la RSC, así como su contribución a una mejor difusión de la investigación y la innovación desde una perspectiva amplia a partir del diálogo.

Además, tanto los especialistas consultados como la mayoría de participantes en los focus groups, coincidieron en considerar fundamental el papel de la comunicación en el desarrollo de la RRI. En este sentido, algunos de los expertos ratificaron, según contempla el modelo, que tanto la información unidireccional como las acciones de diálogo bidireccional son positivas y necesarias, complementándose entre sí.

De este modo, en líneas generales los participantes en el panel y gran parte de los representantes de los stakeholders de la RRI que concurrieron en los grupos de discusión señalan la oportunidad, necesidad y adecuación del modelo, introduciendo algunas de las matizaciones recogidas y advirtiendo de algunos de los riesgos que abordamos a continuación.

\section{- Ruptura con el modelo actual de comunicación de la ciencia}

De los resultados de las encuestas, los focus groups y el panel Delphi cabe extraer que el modelo propuesto supone una ruptura respecto al sistema actual tanto de comunicación de la ciencia en las universidades como de gestión de la investigación y la innovación. Esta ruptura queda patente, en primer lugar, en las respuestas a los cuestionarios sobre la comunicación de la ciencia en las universidades que muestran cómo el actual sistema se basa principalmente en la información unidireccional y casi siempre en la fase final del proceso de investigación e innovación, una vez ya se han publicado en revistas científicas o se han patentado los resultados. Los cuestionarios pusieron además de manifiesto la escasa promoción y difusión de posibles canales y mecanismos para conocer los intereses de los stakeholders, y la aún menor respuesta ofrecida a través de los mismos. Las contestaciones de las universidades participantes evidencian igualmente la ausencia prácticamente completa de acciones vinculadas al 
modelo propuesto, como son el diálogo para conocer las expectativas legítimas de los grupos de interés, la negociación de compromisos por parte de la universidad para satisfacerlos o la rendición de cuentas sobre los resultados alcanzados.

Del mismo modo, los focus groups mostraron el alejamiento que supone el modelo propuesto respecto a la forma de entender y gestionar la investigación y su comunicación por parte de las universidades. Esta ruptura se puso especialmente de manifiesto en el focus group en el que participaron los emisores tradicionales de la ciencia, incluyendo a personal investigador y profesionales de la comunicación de la ciencia del ámbito universitario. Representantes de ambos colectivos mostraron reticencias a la hora de establecer una comunicación bidireccional que tenga como fin conocer las expectativas e intereses de los stakeholders en materia de investigación e innovación para orientar los fines de las mismas. Para justificar este rechazo, varias voces aludieron tanto al criterio de autoridad de los investigadores como a la falta de preparación de los grupos de interés a la hora de determinar los fines de la investigación. Asimismo, desde el ámbito de la comunicación, algunos de los participantes no consideraron que ésta pudiera ser una de sus funciones. Esto choca con los planteamientos de la RRI establecidos por la Unión Europea, así como con la visión de los expertos participantes en el panel Delphi quienes coincidieron de forma unánime en juzgar importante el diálogo con los stakeholders de cara a establecer los fines de la ciencia. También cabe señalar que, en el propio grupo de emisores de la comunicación científica hubo voces que coincidieron en estimar necesaria esta mayor participación de los grupos de interés a lo largo del proceso. En esta misma línea, la demanda para que la universidad tenga en cuenta las expectativas de los grupos de interés en materia de investigación e innovación fue prácticamente unánime en el focus group en el que participaron Administración Pública, empresas y sociedad civil, receptores tradicionales de la comunicación de la ciencia.

La diferencia de percepciones respecto a la aplicación de criterios de ética y de responsabilidad en la gestión de la ciencia y su comunicación muestra asimismo notables discrepancias. Mientras que por parte de los profesionales de la comunicación de la ciencia de las universidades que respondieron al cuestionario y de diferentes participantes en los focus group se valora como positiva la actual gestión de la investigación y de su comunicación desde el punto de vista ético; los expertos participantes en el panel Delphi tienen una percepción totalmente contraria, 
considerándola muy deficitaria, al igual que la mayoría de participantes en los focus groups, especialmente en el de receptores de la comunicación. De las respuestas de unos y otros se puede extraer que desde la comunidad científica y los profesionales de la comunicación de la ciencia se piense mayoritariamente que el modo en que se comunica y se gestiona la investigación y la innovación es el adecuado desde la perspectiva ética y responde a criterios de responsabilidad social. Sin embargo, expertos en Ética, en Comunicación de la Ciencia, Comunicación Universitaria y RRI coinciden en percibir como muy deficitaria la aplicación de estos criterios en las universidades.

\section{- Dificultades para el nuevo modelo}

Como hemos visto, la ruptura que supone el modelo propuesto comporta una serie de riesgos a los que se añaden otras cuestiones que pueden complicar su desarrollo. Entre estas dificultades a tener en cuenta se encontrarían:

- La diversidad en las estructuras de comunicación de la ciencia de las universidades y la falta de una política uniforme, aspectos puestos de manifiesto tanto a través de los cuestionarios como de los focus groups.

- La falta de canales y mecanismos para dialogar con los stakeholders y conocer sus intereses y expectativas, unida a una baja respuesta en el caso de que se haga uso de los mismos.

- El predominio de una comunicación de la ciencia de carácter unidireccional realizada mayoritariamente en la fase final de los procesos de investigación e innovación.

- La burocratización y los tiempos de la universidad fueron considerados como un problema a resolver de cara a entablar el diálogo con los restantes stakeholders, alertando de esta cuestión participantes en los focus groups y el panel Delphi. La carga de trabajo es asimismo un riesgo de cara a conseguir la participación del personal investigador.

- Las reticencias de la comunidad científica a que los grupos de interés incidan en la orientación de los fines de la investigación y la innovación.

- Las diferentes percepciones sobre la aplicación de criterios éticos en la gestión de la investigación y la innovación que hacen previsible que no se 
considere necesario introducir cambios por parte de los emisores de la comunicación de la ciencia.

\section{- Oportunidades del nuevo modelo}

No obstante, la situación analizada a través de los diferentes mecanismos pone de manifiesto también algunas circunstancias favorables, entre las que se encuentran:

- La elevada valoración de la importancia que otorgan las universidades a la comunicación de la ciencia y el incremento de políticas destinadas a su mejora.

- Una tendencia al incremento de acciones de divulgación de la ciencia que buscan la interacción con los públicos como ferias y cafés de ciencia.

- La importancia de las TIC en la comunicación de la ciencia con el predominio de las webs universitarias y los blogs de ciencia como canales de información y de las redes sociales como mecanismos de difusión abiertos a la interacción.

- El protagonismo de los medios tradicionales como intermediarios entre las universidades y la sociedad en su conjunto en la comunicación pública de la ciencia.

- La primacía entre los públicos destinatarios de la comunicación de la ciencia de los públicos del entorno, lo que aparece unido a una demanda de mayor localización de la investigación por parte de Administraciones Públicas, empresas y sociedad.

○ La relación con la sociedad y la comunidad científica como públicos prioritarios abre el camino a la comunicación con dos de los principales grupos de interés de la RRI.

\section{- Pautas y retos para su desarrollo}

El análisis de la información recogida, así como de las opciones y riesgos a los que puede enfrentarse el desarrollo del modelo, abre la puerta a establecer algunas 
pautas para su posible implantación y ayuda a establecer retos a los que cabría hacer frente en futuras investigaciones.

- El predominio de las TIC en la comunicación actual de la ciencia por pare de las universidades y su capacidad como mecanismo para la interacción hacen de las nuevas tecnologías una herramienta indispensable a tener en cuenta para el posible desarrollo del modelo.

- No obstante, a pesar del papel de internet y la web social, cabe considerar también la importancia que siguen teniendo los medios de comunicación de masas como destinatarios de gran parte de las acciones comunicativas en materia de ciencia realizadas por las universidades.

- La consideración de los públicos de proximidad de la universidad (sociedad del entorno, comunidad científica interna y medios locales y regionales) como prioritarios puede ser una base provechosa de cara a fomentar las relaciones con los mismos, atendiendo a la demanda de una mayor localización expresada por empresas, Administración Pública y sociedad civil.

- Dada la preponderancia de la sociedad y la comunidad científica como públicos destinatarios, cabría tener en cuenta de cara a la implantación del modelo, el interés de reforzar la comunicación con Administración y empresas, los otros dos grupos establecidos en el mapa de stakeholders.

- De cara a favorecer el diálogo en materia de investigación e innovación por parte de las universidades cabría valorar el interés de contar con los Consejos Sociales como organismos en los que están representados diferentes stakeholders.

- Además de avanzar hacia la comunicación bidireccional planteada en el modelo, cabría continuar mejorando la comunicación entendida como transmisión de información realizada por las universidades. Algunas propuestas planteadas pasan por la mejora de la formación de comunicadores e investigadores y la inclusión en las convocatorias de investigación de requisitos de difusión, en general, y a los "grupos meta", en particular. 
- La implantación del modelo ético de comunicación para la RRI propuesto puede favorecer un papel más activo de las universidades como puente de transmisión entre los intereses y necesidades entre stakeholders.

- El papel de los profesionales de la comunicación como transmisores es básico para que los investigadores entiendan la utilidad de divulgar la ciencia. En este sentido, una adecuada comunicación contribuye a que los investigadores tomen conciencia y jueguen un papel más proactivo, superándose las reticencias existentes en muchos casos.

- La ruptura que supone el modelo propuesto hace necesario plantear una amplia reflexión sobre cómo podría implantarse haciéndolo compatible y mejorando los actuales sistemas de comunicación de la ciencia de las universidades. Esta reflexión debería ahondar también en quiénes serían los actores más adecuados de cara a la implantación y desarrollo del modelo, actores que desde la perspectiva planteada deberían reunir una visión ética y comunicativa.

Como vemos, la investigación realizada a través de los cuestionarios a las universidades, los focus groups y el panel Delphi, nos ofrece interesantes planteamientos. Las conclusiones de esta investigación, junto con las extraídas del estudio documental, centrarán el próximo y último bloque de la tesis. 
V. CONCLUSIONES 



\section{Conclusiones de la investigación}

Una vez expuestos en las páginas precedentes los resultados del análisis teórico y las investigaciones cualitativas y cuantitativas, recogemos aquí, a modo de síntesis, las conclusiones extraídas de ambos procesos, todas ellas relacionadas directamente con los objetivos marcados al principio de la tesis.

Así, el objetivo general que nos planteábamos pasaba por definir una serie de aspectos normativos que guíen la comunicación de la ciencia realizada por las universidades hacia una comunicación ética que favorezca la Investigación y la Innovación Responsable. Para ello ha sido necesario cumplir una serie de objetivos específicos que incluyen la definición del concepto de Investigación e Innovación Responsable desde un marco ético que posibilite esta gestión responsable de la comunicación de la ciencia y el desarrollo de un modelo comunicativo. Retomamos aquí los cuatro grupos en los que dividimos los objetivos específicos y las conclusiones alcanzadas en cada uno de ellos, a raíz de las cuales se alcanza el objetivo general.

\section{Desarrollo del marco ético}

- Desarrollar un marco ético y político para la RRI. El primer objetivo pasaba por establecer un marco ético y político para la RRI que se asienta en la ética del discurso y la democracia deliberativa, tal y como recogemos en las siguientes conclusiones:

- La ética del discurso como marco. La RRI encuentra en la teoría ética del discurso desarrollada por Habermas un marco ético que marca un horizonte de actuación, un criterio de justicia y validez, al establecer que una norma, acción o decisión o una institución pueden ser consideradas correctas o justas cuando pudieran encontrar el consenso de todos los afectados, tras un cálculo de consecuencias, en un discurso práctico en condiciones de igualdad (Habermas, 2000). Este marco ético permite dotar de un valor moral la gestión de una investigación e innovación que quieran ser consideradas responsables, siempre que el discurso cumpla los principios de sinceridad, inclusión, reciprocidad y simetría.

- El principio ético-discursivo como ética aplicada. La gestión de la RRI requiere llevar al terreno de las éticas aplicadas el principio ético-discursivo. Siguiendo la 
propuesta de la Escuela de Valencia, la RRI encuentra en el principio de la ética discursiva un procedimiento para garantizar la imparcialidad del juicio moral y un punto normativo de referencia para la formación de la voluntad tanto individual como colectiva, representando un criterio de corrección para la decisión posible sobre la justicia de una acción, norma o institución (García Marzá, 1992:29). Por tanto, a partir de la aplicación de la ética del discurso se pueden alcanzar normas con validez moral, encontrando una orientación de la acción.

- Legitimidad para determinar los fines de la investigación. De cara al desarrollo de la RRI en el marco de la ética discursiva resulta de especial interés tener en cuenta las reflexiones de Adela Cortina (1993) sobre cuáles son los fines últimos de la investigación y quienes están legitimados para tomar decisiones sobre estos asuntos. Sobre la primera cuestión, señala que no existe un fin dado de antemano, ya que "el fin nos lo damos a nosotros mismos" (Cortina, 1993:258). Por tanto, lo realmente relevante es el sujeto ético de la decisión. En este sentido, la filósofa entiende que las decisiones en materia de ciencia, tecnología e innovación no se pueden dejar en manos de los países ricos, de las industrias o de los políticos, pero tampoco de los expertos porque no hay expertos en fines: "hay expertos en medios pero los fines sólo pueden determinarlos los afectados por la puesta en marcha de una ciencia, porque son ellos quienes mejor conocen en qué consiste ese bien" (Cortina, 1993: 260). El papel de los expertos consiste entonces en asesorar y la decisión recae en manos de los afectados. Para alcanzar estas decisiones resulta necesario:

- Lograr que los expertos comuniquen sus investigaciones a la sociedad para que pueda codecidir de forma autónoma, contando con la información necesaria.

- Concienciar a los individuos de que son ellos quienes han de decidir.

- Educar moralmente a los individuos en la responsabilidad a la hora de tomar decisiones que pueden implicar incluso a la especie.

- Democracia deliberativa como marco político. La gestión de la RRI desde el marco de la ética dialógica aparece vinculada al modelo de democracia deliberativa como marco político, de forma que todos los procesos políticos de decisión, incluidos los relacionados con la ciencia y la tecnología, deben estar sometidos a la consideración de todos los afectados. Así, la perspectiva crítica y la participación se 
constituyen cómo núcleo de la democracia, de forma que el principio democrático es que todos aquellos que puedan sufrir las consecuencias tengan capacidad de decidir (Habermas, 1998). La democracia de doble vía establecida por el filósofo alemán permite alcanzar resoluciones a través de la vía de los procesos formales, que corresponden a la dimensión política, y generar procesos de deliberación mediante la vía de los procesos informales, de la sociedad civil. Tanto estas dos vías como la tercera añadida por Cortina (2010a:90), que da cabida a las instancias éticas intermedias que favorecen la toma de decisiones racionalmente justificadas, resultan de interés para el desarrollo de políticas de investigación e innovación que busquen una validez moral y en las que los ciudadanos ejerzan su autonomía política tomando parte activa en las decisiones a través de la deliberación.

- Democracia monitorizada. La democracia deliberativa encuentra en la propuesta de democracia monitorizada de John Keane (2009) una propuesta complementaria que favorece el escrutinio de todos los campos de la vida política y social, incluida la ciencia y la tecnología, ampliando las posibilidades de participación política. En esta propuesta es fundamental el papel de la nueva galaxia mediática de carácter global, multimedia y accesible.

- El conocimiento como requisito para la participación. El "ideal de participación" planteado en la ética discursiva y en el modelo de democracia deliberativa requiere del conocimiento para que los diferentes afectados puedan actuar autónomamente. Así, cabe deducir que en el caso de la ciencia y la innovación, los afectados requieren de un conocimiento que les capacite para el diálogo y, para lograrlo, la comunicación juega un papel fundamental. Siguiendo a Cortina, la participación requiere de una ciudadanía activa, y para alcanzarla es necesario el conocimiento, ya que "contar con información fiable es imprescindible para formarse un juicio moral, para lo que se necesitan expertos que dispuestos a llevar sus conocimientos y opiniones a la esfera de la opinión pública” (Cortina, 2007:256).

- Principios para una ética cordial. Adela Cortina plantea lo que califica como una "versión cálida" de la ética del discurso a través de la ética cordial, preocupada no sólo por los aspectos epistémicos del vínculo comunicativo, sino también por los aspectos cordiales que lo convierten en una auténtica comunicación (Cortina, 2007). La autora fija cinco principios de la ética cordial, en los cuales encontramos aspectos normativos que pueden ayudar a guiar la comunicación ética de la ciencia 
para avanzar hacia la RRI como son no instrumentalizar a las personas y empoderarlas dotándolas de las capacidades necesarias. Entre los principios de la ética cordial encontramos también el principio dialógico -directamente vinculado a los procesos comunicativos de la RRI-, el principio de justicia distributiva y el principio de responsabilidad por los seres indefensos no humanos.

- La ciencia ciudadana como ejemplo de participación. El emergente desarrollo de la ciencia ciudadana, en la que la investigación se lleva a cabo por investigadores y personas con una formación no especializada en ciencia que colaboran de forma voluntaria, supone un claro ejemplo de ciudadanía participativa en materia de ciencia. La ciencia ciudadana representa una interesante propuesta para crear un escenario abierto y transdisciplinar que favorezca una investigación más democrática, sentando las bases de un nuevo paradigma de la ciencia abierta (Socientize Consortium, 2013).

- Extraer las posibles aportaciones a la RRI del modelo de Responsabilidad Social Empresarial desarrollado por la Escuela de Valencia, incluida su propuesta en el campo de la comunicación. Las conclusiones alcanzadas a través de este objetivo confirman el interés de tomar la RSE como referente para el desarrollo de la RRI:

- La RSE como referente. La RRI puede encontrar en la experiencia acumulada por la Responsabilidad Social Empresarial una guía útil para su desarrollo, también desde una perspectiva ética. Siguiendo a Cortina, empresas y organizaciones mantienen un contrato moral con la sociedad que las legitima y les obliga a ser, además de responsables, "responsivas", en el sentido de dar respuesta a las expectativas de los afectados, alcanzando así un reconocimiento recíproco (Cortina, 2005:15). Desde este planteamiento, la ética de los centros de investigación trataría de la adquisición del carácter necesario para responder a las expectativas legítimas de los afectados por ella de manera excelente.

- El modelo de RSE de la Escuela de Valencia. Dado el marco ético y político propuesto para el desarrollo de la RRI, resulta de gran interés para la gestión de la misma el modelo de RSE de la Escuela de Valencia basado precisamente en la ética discursiva y en la teoría de los stakeholders, entendidos estos como "cualquier 
grupo o individuo que puede afectar o ser afectado por el logro de los objetivos" de una empresa u organización (Freeman, 1984). En concreto, su modelo de RSE se basa en definir la responsabilidad a partir del diálogo de una organización con todos sus stakeholders tratando de averiguar en tal diálogo qué intereses y valores son universalizables y por tanto legítimos. Según esta propuesta, una institución será responsable cuando las decisiones, acciones y políticas que adopta "pudieran ser aceptadas por todos los implicados y/o afectados presentes y futuros en un diálogo abierto en condiciones simétricas de participación” (García Marzá, 2006:91).

- La comunicación como principio y motor de la RSE. El modelo de RSE de la Escuela de Valencia plantea la comunicación como principio desde el que construir las políticas de Responsabilidad Social de las empresas y organizaciones, un papel extrapolable, desde la perspectiva ética planteada, al que juega en el caso de la RRI. Francisco Fernández Beltrán (2008) propone un modelo comunicativo de la RSC por el que la organización establece un proceso de diálogo para conocer las aspiraciones y expectativas legítimas de los grupos de interés, negocia compromisos públicos de satisfacción de los mismos e informa sobre su grado de cumplimiento. Participación, diálogo, comunicación y transparencia son aspectos claves en un modelo del que hemos extraído interesantes aportaciones de cara a definir un modelo comunicativo para el fomento de la RRI en las universidades.

- Herramientas para una gestión responsable. La larga experiencia teórica y práctica acumulada por la RSE ha generado diversas herramientas para la gestión de la responsabilidad social por parte de empresas y organizaciones, cuya utilidad cabe considerar de cara al desarrollo de la RRI. Es el caso, por ejemplo, de webs y publicaciones específicas, teléfonos de información para diferentes públicos (accionistas, clientes,...), encuentros y foros con stakeholders, códigos éticos o de conducta, comités de ética, memorias de sostenibilidad y auditorías éticas.

- Realizar una aproximación al estado de la Comunicación Pública de la Ciencia en España y a la misión de las universidades respecto a la misma. A partir de este objetivo se alcanzan las siguientes conclusiones:

- Importancia de las razones para comunicar ciencia. Entre los motivos esgrimidos por científicos, divulgadores, periodistas y académicos para comunicar la ciencia, 
recogidos a través del estudio documental, vemos algunos de interés para el desarrollo de la RRI. Es el caso de la importancia de aumentar el conocimiento y la comprensión ciudadana de la ciencia, vinculando este conocimiento a una mayor capacidad para la toma de decisiones. La transmisión del conocimiento aparece también relacionada con la mejora del bienestar de las personas, el desarrollo económico de las sociedades a través de la transferencia y la expansión del propio conocimiento. Entre las razones para comunicar la ciencia se halla también, directamente vinculada a la RRI, el conocer las expectativas en materia de ciencia de la sociedad. A esto se une la necesidad de rendir cuentas a una sociedad que exige cada vez mayores niveles de transparencia e información. Aparecen además razones vinculadas a los beneficios que supone para los propios investigadores como el aumento del prestigio y la confianza en la comunidad científica, la mayor legitimación y apoyo a la ciencia o el simple gozo de transmitir el entusiasmo por su trabajo.

- Dos modelos de comunicación complementarios para la RRI. El repaso realizado a la evolución de la comunicación de la ciencia nos ha permitido aproximarnos a dos modelos que presentan interés para una comunicación que busque promover la RRI como son el modelo más tradicional de la comunicación de la ciencia, basado fundamentalmente en informar a la sociedad sobre los resultados alcanzados, denominado desde una visión crítica como "modelo del déficit" (Bodman, 1985; Miller, 2001) y el modelo comunicativo de "ciencia y sociedad" (European Comission, 2002; Sinue et al, 2009) que busca promover el diálogo y la bidireccionalidad. Si bien se trata de dos tendencias que comportan acciones de comunicación diferentes, ambas han coexistido en el tiempo. Consideramos que las dos formas de entender la relación entre científicos y públicos y la comunicación de la ciencia se complementan y enriquecen ya que sin el primer modelo, más informativo, es difícil establecer un diálogo real como se plantea en el segundo. En este sentido, el desarrollo de la RRI requiere de una Comunicación Pública de la Ciencia que tenga en cuenta tanto la capacitación de la ciudadanía como el establecimiento de un diálogo entre ciencia y sociedad a lo largo del proceso.

- El desarrollo del periodismo científico en paralelo a la extensión de los medios online y la profesionalización del sector. El auge del periodismo científico ha venido acompañado en los últimos años por el cambio de paradigma comunicativo 
que han supuesto las TIC y la tendencia a la profesionalización de la comunicación de la ciencia. La web social abre las puertas a nuevas oportunidades y retos para la comunicación de la ciencia, haciendo necesaria a su vez una mayor capacitación de la ciudadanía para hacer frente a la sobreinformación. La explosión de la comunicación científica en el caso de España tiene que ver además con la profesionalización del sector en la que ha tenido un papel clave la Fundación Española para la Ciencia y la Tecnología (FECYT) a través de iniciativas como la Red de Unidades de Cultura Científica y de la Innovación (Red UCC+i), el congreso anual Comcired o la Agencia de Noticias Científicas SINC.

La comunicación como función de la universidad. La Ley Orgánica 6/2001 de Universidades (LOU) establece en su Título Preliminar como la primera función de la universidad "la creación, desarrollo, transmisión y crítica de la ciencia, de la técnica y de la cultura". A partir del análisis documental realizado y de la propia experiencia profesional cabe pensar que existen todavía muchos retos por superar en el cumplimiento de esta función. Por una parte, se observa como la comunicación de la ciencia entendida como transmisión de información, a pesar de los déficits que puedan seguir existiendo, ha vivido un notable avance con la consolidación de $\mathrm{UCC}+\mathrm{i}$, la labor de profesionales dedicados a este ámbito y el incremento de las informaciones sobre ciencia. Sin embargo, parece que el modelo de comunicación centrado en el diálogo ciencia y sociedad todavía queda distante del ámbito universitario. Ni las declaraciones de los expertos ni las voces de divulgadores y académicos del ámbito de la comunicación universitaria parecen poner el foco en la necesidad de establecer nuevos mecanismos de comunicación que favorezcan la bidireccionalidad y hagan llegar a la universidad las expectativas e intereses en materia de ciencia e innovación de los diferentes grupos de interés.

- Conocer el estado de la cuestión sobre la RRI, las diferentes aportaciones a la misma y la apuesta europea. La consecución de este objetivo nos ha permitido trazar un marco teórico general en torno al concepto de RRI.

- Puntos de encuentro sobre la RRI. La aproximación teórica a las diferentes definiciones surgidas alrededor de un concepto emergente como es la RRI nos ha 
mostrado algunos puntos en común entre las propuestas de autores como Laroche, Schomberg, Carsten, Shomberg, Stilgoe y de la propia Unión Europea. Así, vemos como la aceptabilidad y deseabilidad de la ciencia y la innovación, tanto en sus procesos como en sus resultados, es un aspecto reiterado. El papel de los afectados y actores sociales es otro de los puntos que se repite, así como la necesidad de la participación y la interacción de los mismos. Por lo que respecta la comunicación, se relaciona con la necesidad de transparencia y apertura.

- Aportaciones teóricas desde el estado de la cuestión. El estudio del estado de la cuestión ha revelado diferentes aproximaciones al concepto de RRI que resultan de interés para su desarrollo. Entre ellas, cabe destacar la planteada por Jack Stilgoe (2013) que aborda la RRI como un reto importante para la democracia, que enlaza con el concepto de democracia deliberativa. También desde una perspectiva política, Schomberg (2013) entiende que la RRI debe entenderse como una estrategia para que los interesados en materia de ciencia e innovación respondan mutuamente, compartiendo la responsabilidad ante las respuestas a los grandes retos de nuestro tiempo. Siguiendo esta línea, desde le proyecto RRI Tools se plantea la RRI como el cambio de pensar en términos de nociones individualistas y consecuencialistas de responsabilidad a pensar en términos de responsabilidad colectiva y distribuida. Por otra parte, la visión de Carsten (2013) del concepto de RRI como una metaresponsabilidad que engloba responsabilidades ya existentes junto a otras nuevas, permite vincularla la RRI con criterios éticos y de responsabilidad social establecidos en la propuesta de marco ético. Igualmente interesantes resultan las reflexiones de Owen, Macnaghten y Stilgoe (2012) sobre el paso de la ciencia en sociedad a la ciencia con y para la sociedad, una transición que les permite identificar ya algunas de las características distintivas de la RRI entre las que destacan la democratización de la gobernanza de la intención (para la sociedad), la institucionalización de la sensibilidad (con la sociedad) y el replanteamiento de la responsabilidad, entendiendo que la RRI confiere a los actores vinculados a la ciencia nuevas responsabilidades.

- Impulso clave de la Unión Europea. El auge de la RRI no puede entenderse sin el papel de la UE que, desde que pusiera en marca en 2001 el Plan de Acción "Ciencia y Sociedad" para establecer una estrategia común que mejorara la conexión entre la ciencia y los ciudadanos europeos, no ha dejado de impulsarla, llegando a 
incorporarla como un concepto transversal en la convocatoria Horizonte 2020 de 2014. Ese mismo año la UE creaba el Grupo Europeo de Expertos para el estudio de Indicadores Sociopolíticos de RRI y aprobaba la puesta en marcha del proyecto RRI Tools para el desarrollo de las herramientas formativas necesarias hacia una investigación e innovación responsables. La UE entiende que la RRI hace referencia a que los actores de la sociedad trabajen juntos durante todo el proceso de investigación e innovación con el fin de alinear mejor los procesos y sus resultados con los valores, necesidades y expectativas de la sociedad europea.

\section{- Analizar las actuales normativas en materia de comunicación de la RRI} en el ámbito de la Unión Europea. Los documentos europeos en torno a ciencia y sociedad y a RRI recogidos en el estudio marcan las directrices a seguir para su desarrollo, alcanzando también al ámbito de la comunicación.

- Derechos de información, expresión y participación. El movimiento de la RRI encuentra en la Carta de Derechos Fundamentales y el Tratado de la Unión Europea las directrices que marcan los valores y los fundamentos de la UE y que avalan la necesidad de avanzar hacia una investigación e innovación responsable, transparente y participativa. El derecho a la libertad de expresión, a la información y al acceso a la documentación pública, son aspectos recogidos en la Carta de Derechos Fundamentales que fundamentan la importancia de la RRI, junto a otros aspectos recogidos en el Tratado de la UE como el derecho de participación de la ciudadanía en la vida democrática de la Unión y la necesidad de que las instituciones establezcan los cauces y mecanismos apropiados para favorecerla, manteniendo un diálogo abierto, transparente y continuo con los representantes de la sociedad civil.

○ De "ciencia y sociedad" a "ciencia en sociedad". La publicación en el año 2000 del informe Ciencia, sociedad y ciudadanos europeos supone un avance hacia un modo de entender la ciencia más abierta y participativa, siendo el germen de lo que apenas una década después pasaría a denominarse RRI. Entre los objetivos de este documento, clave para entender el desarrollo y las directrices de la RRI en Europa, se encuentra abrir una reflexión sobre la relación entre ciencia y sociedad, poniendo en marcha un debate que se concretaría dos años después con el Plan de Acción Ciencia y Sociedad que proponía 38 actuaciones concretas encaminadas a la 
promoción de la educación y la cultura científica en Europa, la elaboración de políticas científicas más cercanas a los ciudadanos y la incorporación de una ciencia responsable en las distintas políticas. Encontramos así tres ámbitos de actuación que se encuentran en la base del surgimiento del fenómeno de la RRI, y en los que la comunicación y la participación juegan un papel clave. Posteriormente, el proyecto Monitoring Activities of Science in Society (MASIS), supuso la publicación en 2009 de un amplio informe sobre lo que pasó a denominarse "ciencia en sociedad", con el fin de aportar una visión colectiva de tendencias y establecer la estrategia a seguir. En lo referente a comunicación, el documento establece que el reto de la misma para una ciencia en sociedad no pasa tanto por ofrecer más información como por proporcionar formas adecuadas para la comunicación y el diálogo (Sinue, 2009:60).

- Directrices para la RRI a favor de la información y la educación. A partir del estudio documental realizado se extraen tres publicaciones que dibujan el marco normativo de la RRI en la Unión Europea. Se trata del primer informe sobre RRI (Sutcliffe, 2011) en el que, además de una primera aproximación al concepto de RRI, se ofrecen directrices relacionadas con su comunicación y la participación de los grupos de interés, aludiendo ya a la necesidad de involucrar a los stakeholders en el desarrollo de soluciones beneficiosas para el bien común (Sutcliffe, 2011:8). Tan sólo un año después la CE publica Responsible Research and Innovation. Europe's ability to respond to societal challenges, un documento muy breve, que recoge la definición de la UE del concepto de RRI y los seis aspectos claves en torno a los que determina que debe girar el desarrollo de una investigación y una innovación más responsable en el ámbito europeo (participación, igualdad de género, educación científica, acceso abierto a la información, ética y buen gobierno).

Finalmente, encontramos en el programa Horizonte 2020 las directrices más recientes de la UE respecto al desarrollo de la RRI a través del programa "Ciencia con y para la Sociedad". En concreto, la Propuesta del Reglamento del Parlamento y del Consejo por la que se establece Horizonte 2020 señala explícitamente que esta convocatoria debe favorecer una participación informada de los ciudadanos y de la sociedad civil en las cuestiones relacionadas con la investigación y la innovación. Para ello, destaca la importancia de "la educación, el acceso a los conocimientos científicos y la elaboración de agendas de investigación e innovación responsables 
que atiendan las expectativas y preocupaciones de los ciudadanos y de la sociedad civil” (Mesas, 2015).

\section{Elaboración de propuestas}

- Proponer una nueva definición de Investigación Responsable y del proceso de RRI que es necesario llevar a cabo para alcanzarla desde un marco ético. Entre los objetivos de la tesis se planteaba la contribución al desarrollo teórico de la RRI a través del planteamiento de propuestas concretas, siendo la primera de ellas una nueva definición.

- Propuesta de definición de la RRI desde la ética dialógica. El trabajo realizado para trazar el marco ético y político de la RRI, unido al estudio de las diferentes aproximaciones a este concepto, nos permite plantear una redefinición del mismo en base a la ética dialógica y a la teoría de los stakeholders, una redefinición que toma como referente el modelo de RSE de la Escuela de Valencia. A partir de estos planteamientos, se entiende que:

La Investigación y la Innovación serán Responsables cuando las decisiones sobre la aceptabilidad y deseabilidad de las mismas y sus resultados pudieran ser aceptadas por todas las personas afectadas y/o implicadas presentes y futuras en un diálogo abierto en condiciones simétricas de participación. El proceso de Investigación e Innovación Responsable (RRI) supone establecer las condiciones de comunicación interacción y participación, por parte de los diferentes grupos de interés (stakeholders) necesarias para alcanzar dicha aceptabilidad.

La definición pone el acento en el diálogo como base para llegar a decisiones sobre la aceptabilidad y deseabilidad de la ciencia y la innovación, tanto por lo que respecta a sus procesos como a sus resultados. Para que tenga un valor moral, en el diálogo deberían participar en condiciones simétricas los afectados presentes y futuros, lo que introduce la necesidad de valorar los riesgos y oportunidades que tendrán más adelante los procesos de investigación e innovación. Comunicación, interacción y participación por parte de los stakeholders -conceptos a los que aluden autores como Shomberg, Stilgoe, Sutcliff y la UE en sus definiciones de la RRI- quedan recogidos como las claves del proceso necesario para alcanzar la aceptabilidad requerida. 
- Trazar el mapa de stakeholders de la RRI, definiendo las expectativas comunicativas de cada uno de los grupos. La segunda contribución plantea establecer cuatro grandes grupos de interés en torno a la RRI.

- Mapa de stakeholders de la RRI. Entre las diferentes aproximaciones a la RRI recogidas en el estudio, existe una gran unanimidad a la hora de determinar los grupos de interés de la ciencia, a pesar de que puedan existir pequeños matices en la denominación. Así, se reiteran por parte de los diferentes autores y organismos cuatro grupos: investigadores, innovadores y comunidad científica en su conjunto; responsables políticos, autoridades políticas y Administración Pública; industrias, empresas y compañías privadas; y sociedad en un sentido amplio, que abarcaría desde el tercer sector hasta la ciudadanía. Estos cuatro grupos, en los que tienen cabida diferentes perfiles y que en ocasiones pueden estar interconectados, conforman nuestra propuesta de mapa de stakeholders de la RRI:

\section{Mapa de stakeholders RRI}

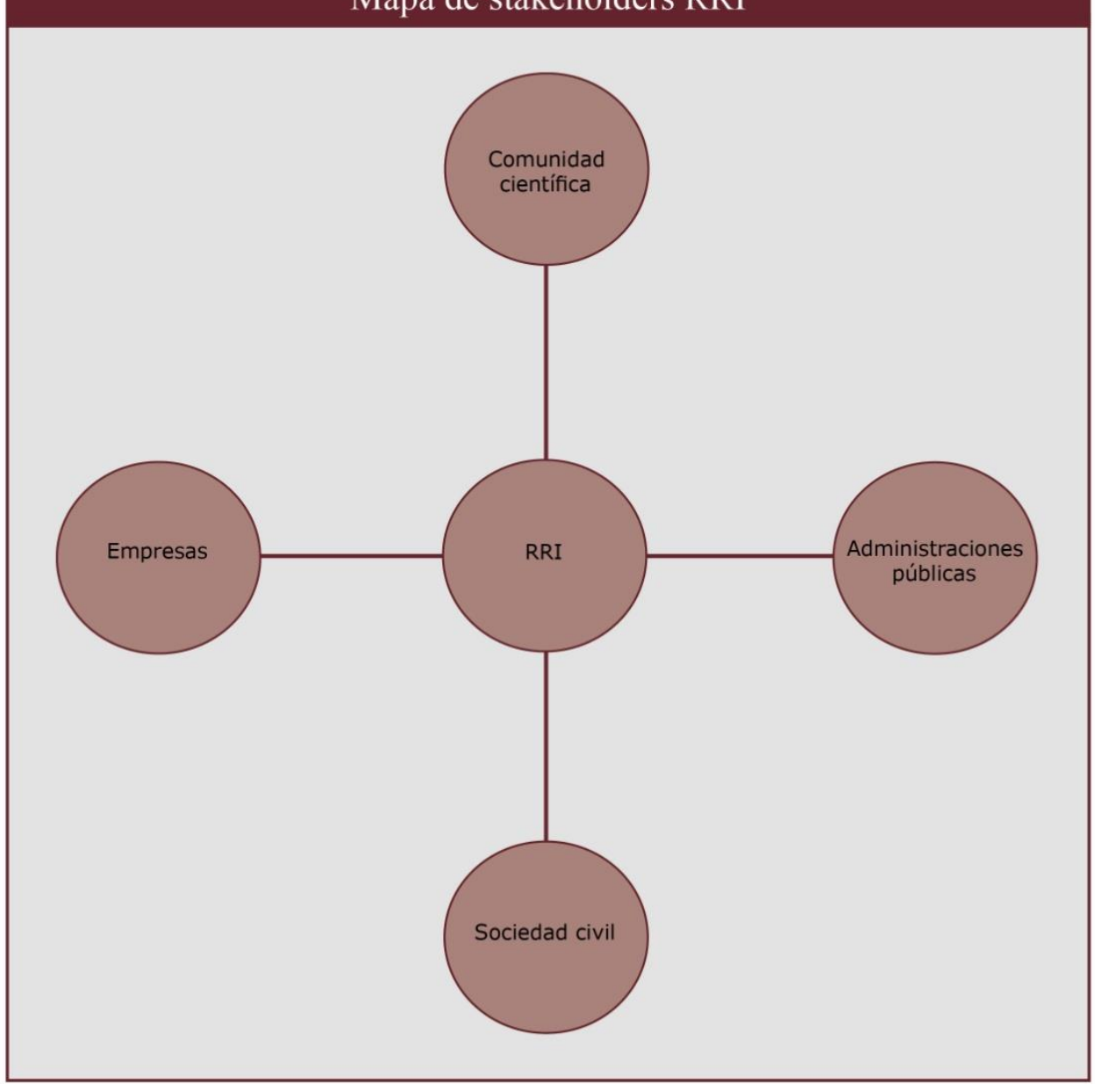


- Expectativas diferenciadas respecto a la comunicación de la ciencia. El mapa planteado define los stakeholders generales de la RRI, de forma que posteriormente cada universidad o centro de investigación e innovación debería desarrollarlos y concretarlos en función de sus características y estructuras específicas. Los cuatro grupos de interés en torno a la RRI presentan expectativas e intereses diferenciados respecto a la comunicación de la ciencia. Mientras que la comunidad científica, en la que incluimos a los profesionales de la comunicación de la ciencia, actúa habitualmente como emisora; el papel de receptores lo ocupan empresas, Administración Pública y sociedad civil. La RRI conlleva, desde la ética dialógica, una modificación de estos roles, favoreciendo la interacción y el diálogo entre ellos de cara a avanzar hacia una gestión de la investigación y la innovación que resulte aceptable y responda a los intereses legítimos de todos los stakeholders.

\section{- Desarrollar un modelo de comunicación ética de la Investigación e} Innovación Responsable en la universidad. La tercera contribución planteada pasa por el desarrollo de un modelo comunicativo que contribuya al desarrollo de la RRI.

- Un modelo de comunicación ética para la RRI en la universidad. La propuesta inicialmente desarrollada parte del modelo de comunicación de la RSE planteado por la Escuela de Valencia, adaptándolo a las características de la gestión de la investigación y la innovación. El esquema circular original situaba a la comunicación de la ciencia en el centro, como elemento necesario, y a su alrededor los objetivos a alcanzar por parte de la universidad como son conocer las expectativas, adquirir compromisos y evaluar resultados. En un tercer nivel se encuentran las acciones de comunicación específicas necesarias para lograr estos objetivos y dotarlos de validez como son la definición de los mecanismos de participación y diálogo y el desarrollo de acciones de comunicación pública y transparencia. El modelo sirvió como base para la investigación metodológica, utilizándose en la elaboración del cuestionario a las universidades, los focus groups y el panel Delphi, técnicas de las que surgieron planteamientos y propuestas de mejora que dan pie al modelo final que explicaremos ampliamente en el siguiente capítulo dedicado a las implicaciones del estudio. 


\section{Análisis de la realidad y validación}

- Conocer la situación de la ciencia en la universidad y sus debilidades y fortalezas respecto al modelo de comunicación de la RRI desarrollado.

El cuestionario realizado entre las universidades pertenecientes a RUVID nos ha ofrecido una visión de la situación de la comunicación de la investigación y la innovación en centros de diferentes perfiles.

- Elevada valoración de la comunicación de la ciencia. Las respuestas obtenidas de seis de las siete universidades que configuraban la muestra reflejan la importancia otorgada por las universidades a la comunicación de la ciencia, a pesar de que los recursos destinados a la misma difieren bastante entre unas y otras.

- Relevancia de las nuevas tecnologías. Las TIC se sitúan como una herramienta primordial de cara tanto a informar sobre ciencia, mediante los portales web de las universidades y los blogs propios de ciencia, como para interactuar con los grupos de interés, mediante las redes sociales y el correo electrónico. No obstante, la promoción y difusión de canales de interacción es escasa y reciben un bajo nivel de respuesta.

- El papel de los medios de comunicación de masas. Más allá del uso de las nuevas tecnologías, los medios de comunicación tradicionales, tanto en soporte clásico como online, siguen jugando un papel importante, estando considerados por los profesionales de la comunicación universitaria como un público destinatario fundamental. Las universidades destinan a los medios gran parte de sus acciones comunicativas.

- Prioridad de los públicos más próximos. Parece positivo de cara al desarrollo de la RRI, el gran peso otorgado por los profesionales de la comunicación a los públicos más próximos a las universidades (sociedad del entorno, comunidad científica interna y medios de comunicación locales y regionales). En lo referente a públicos cabe destacar asimismo la importancia dada a dos de los grupos de interés incluidos en el mapa de stakeholders como son la sociedad civil y la comunidad científica. Por contra, la Administración tiene un peso mucho más reducido como público destinatario. 
- Ausencia de acciones vinculadas al modelo de comunicación para la RRI. Las universidades participantes entienden que no realizan prácticamente ningún tipo de acción de cara a conocer las expectativas de los grupos de interés, a negociar compromisos para atenderlas y a difundir sus resultados.

- Prevalencia del modelo de comunicación unidireccional de resultados. El modelo comunicativo que revelan las encuestas se basa mayoritariamente en informar sobre los resultados de la investigación, siendo poco significativas las acciones de comunicación a lo largo del proceso y prácticamente nulas las encaminadas a generar diálogo e interacción con los públicos.

- Elevada percepción de la aplicación de criterios éticos. Los encuestados consideran que sus respectivas universidades tienen muy en cuenta criterios de ética y responsabilidad social en la gestión de la investigación y la innovación y también, aunque algo menos, en su comunicación.

\section{- Validar el modelo de comunicación de la RRI planteado mediante} diálogos con los stakeholders y con expertos en ética y en comunicación universitaria. La realización de dos focus groups con stakeholders y de un panel Delphi con expertos ha aportado interesantes reflexiones, algunas de las cuales han contribuido a la mejora del modelo.

- Aportaciones de los focus groups respecto a la comunicación de la ciencia. Los dos focus groups realizados mostraron importantes coincidencias entre la visión de los tradicionales emisores de la comunicación de la ciencia (comunidad científica y periodistas de universidades) y sus receptores (Administración, empresas y sociedad civil), coincidiendo de forma bastante generalizada en los siguientes aspectos:

- Predominio de una visión unidireccional de la comunicación de la ciencia pero con un impulso creciente de iniciativas que buscan la bidireccionalidad y la interacción con los públicos.

- A pesar de considerar que se ha incrementado la apuesta de las universidades por la comunicación científica se entiende que existe todavía un importante déficit y que es necesario mejorarla. 
- Se constata el cambio de paradigma en la comunicación de la ciencia ante la aparición de las TIC y la crisis de los medios tradicionales de comunicación de masas.

- La comunicación de la investigación y la innovación debe enfrentarse a la dificultad de aunar la lógica de la ciencia y del periodismo.

- Aportaciones de los focus groups respecto al modelo de comunicación de la RRI. Las posturas mostradas respecto al modelo presentaron posturas prácticamente opuestas en cada uno de los grupos de discusión. Mientras en el formado por receptores de la comunicación valoraron positivamente una mayor participación e implicación en la gestión de la investigación y la innovación, varios de los representantes de la comunidad científica y de los profesionales de la comunicación de la ciencia se mostraron reticentes. De ambos focus groups recuperamos además las siguientes conclusiones:

- Incorporación al modelo de una fase previa de información proactiva a los grupos de interés sobre las opciones y posibilidadaes que ofrece la universidad en materia de investigación e innovación.

- Interés de considerar el papel de las universidades como puente entre los intereses de diferentes stakeholders, de valorar la función de los Consejos Sociales en la implantación del modelo y de apostar por una I+i más centrada en el territorio más próximo.

- Se evidencia la ruptura que supone el modelo de comunicación de la RRI propuesto respecto a la forma actual de entender la comunicación de la ciencia desde las universidades.

- La mayoría de los stakeholders ratifican la importancia de situar la comunicación en el centro del modelo y establecer acciones comunicativas en las diferentes fases del proceso.

- Se considera que la ética está presente en el modelo desarrollado y se destaca que debe estarlo también en el ejercicio de las profesiones relacionadas con la investigación y la comunicación de la ciencia. 
- Aportaciones de los expertos/as participantes en el panel Delphi. De las respuestas planteadas por los especialistas en Ética y Comunicación a las dos oleadas del panel Delphi podemos extraer diversas aportaciones de interés:

- Coincidencia mayoritaria en destacar el interés, la oportunidad y la adecuación del modelo, así como su contribución para avanzar a una mejor y más adecuada comunicación de la ciencia por parte de las universidades.

- Desde la perspectiva Ética se considera un modelo excelente en su propósito y diseño.

- Los expertos destacan la aportación que supone al enmarcar la comunicación de la ciencia en la ética dialógica, la teoría de los stakeholders y la RSC, así como la oportunidad que ofrece de repensar el papel de la comunicación de la ciencia y de la universidad en la RRI.

- Entre los riesgos se destaca lo innovador de la propuesta y la ruptura que supone respecto a las inercias de la universidad. Otros expertos consideran que el riesgo reside en que se reordene lo existente sin realmente llegar a cambiar nada.

- Los expertos proponen mejoras en los enunciados que clarifiquen el modelo como concretar el titulo y especificar que el modelo se centra en la "Comunicación Pública de la Ciencia". Los cambios, que se recogen de forma amplia en el próximo apartado, son valorados positivamente por los participantes.

- Todos los expertos consideran muy importante el papel de la comunicación en el desarrollo de la RRI. También opinan que el diálogo con los stakeholders es fundamental de cara a determinar los fines de la investigación y la innovación.

- Los participantes coinciden mayoritariamente en el interés de que la universidad actúe como puente para la transmisión de intereses y necesidades entre los diferentes stakeholders.

- Los expertos consultados tienen una visión negativa de la aplicación de criterios éticos y de responsabilidad social en la gestión de la investigación y 
la innovación. Esta es incluso más negativa respecto a la aplicación de estos criterios en la comunicación de la ciencia en las universidades.

\section{Propuesta final}

- Confirmar la hipótesis de partida. La investigación desarrollada permite confirmar la hipótesis de la que partía esta tesis.

- La comunicación como requisito para la RRI en el marco de la ética dialógica. A partir de la investigación desarrollada hemos visto como la ética dialógica supone un marco para la RRI que ofrece un horizonte de validez moral en la gestión de la misma. El referente aportado por el modelo de RSE de la Escuela de Valencia nos permite asimismo vincular el desarrollo de una investigación e innovación más responsables a la teoría de los stakeholders, de forma que se actúe de forma "responsiva" respecto a los intereses legítimos de las personas afectadas. En la ética del discurso lo moral está en el diálogo y en la posibilidad de alcanzar el acuerdo, para lo que resulta necesaria la comunicación.

Desde este planteamiento, vemos como la comunicación ocupa un papel central en varios sentidos:

- Como capacitadora para el diálogo por parte de los stakeholders.

- Como herramienta indispensable para el propio diálogo en torno a los intereses legítimos de los afectados y afectadas y para la negociación de compromisos.

- Como mecanismos para dar publicidad, en el sentido de hacer públicos, los compromisos alcanzados y dar cuenta de los resultados finales.

En base a la definición de RRI propuesta, si entendemos que la investigación y la innovación podrán ser consideradas responsables cuando las decisiones sobre la aceptabilidad y deseabilidad del proceso y sus resultados pudieran ser aceptadas por todos los posibles afectados en un diálogo abierto en condiciones simétricas de participación, la comunicación se convierte en un requisito moralmente imprescindible de cara a alcanzar esta aceptabilidad.

Del mismo modo, el modelo de comunicación pública de la ciencia planteado de cara al desarrollo de la RRI en las universidades encuentra en la comunicación el 
principio y motor para contribuir al desarrollo de una investigación e innovación que puedan ser consideradas responsables.

A partir de los argumentos expuestos, entendemos que queda verificada nuestra hipótesis de partida que destaca el papel de la comunicación como elemento moralmente necesario en la gestión de una investigación e innovación que puedan ser consideradas responsables.

\section{CONFIRMACIÓN DE LA HIPÓTESIS}

La comunicación ética de la ciencia es un requisito moralmente imprescindible para el desarrollo de un modelo de gestión de la Investigación e Innovación Responsable en las universidades.

- Realizar una propuesta final de modelo ético de comunicación de la RRI para las universidades. El último de los objetivos que nos queda por abordar constituye la principal aportación del estudio, por lo que las conclusiones respecto al mismo se recogen de forma más amplia en el siguiente capítulo. 



\section{Implicaciones del estudio: un modelo de}

\section{comunicación para favorecer la RRI en la universidad}

La investigación realizada sobre los aspectos éticos de la comunicación de la ciencia para el desarrollo de la RRI en las universidades nos ha permitido desarrollar una propuesta de modelo comunicativo de la ciencia desde una perspectiva ética. La propuesta, derivada en un primer momento del análisis teórico, ha sido validada y mejorada posteriormente a través de la investigación empírica. Por tanto, las implicaciones del estudio desarrollado nos ofrecen como resultado final el siguiente modelo:

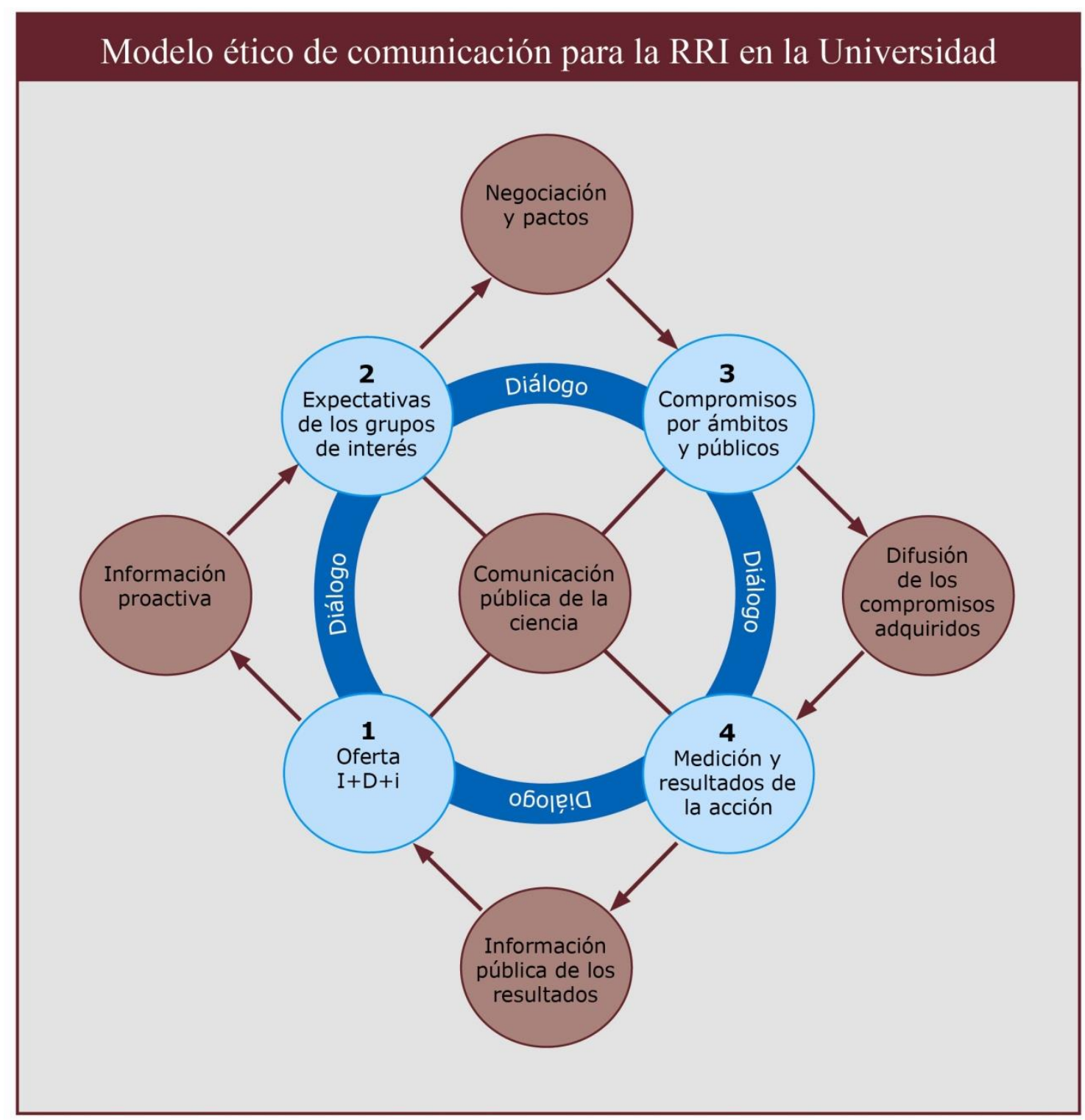


El modelo planteado busca contribuir desde el ámbito de la comunicación al desarrollo de la RRI en las universidades. Para ello sitúa a la Comunicación Pública de la Ciencia en el centro, como proceso necesario para alcanzar los objetivos de la RRI y, a su alrededor, se encuentra el diálogo, que abarca a todas las fases del modelo, favoreciendo una interacción continua entre la Universidad y los grupos de interés a los largo de todo el proceso. Alrededor de este núcleo formado por la comunicación y el diálogo se establecen los objetivos a alcanzar por la universidad en cuatro fases, interrelacionadas entre ellas a través de acciones de comunicación:

1. Poner en conocimiento de los stakeholders las posibilidades que ofrece la universidad en materia de investigación, innovación y desarrollo. Se considera que esta información resulta de interés de cara a que los grupos de interés determinen sus expectativas. En esta fase resulta necesaria una actitud proactiva por parte de la universidad a la hora de transmitir la información.

2. Conocer los intereses y expectativas de los stakeholders para lo que resulta necesario establecer un diálogo con cada uno de ellos a través de los mecanismos y canales que se consideren más oportunos. Una vez conocidas las expectativas legítimas, la negociación con los grupos de interés permite alcanzar acuerdos, llegando así a la siguiente fase.

3. Adquirir compromisos específicos por ámbitos y públicos para satisfacer los intereses legítimos. Estos compromisos deben ser puestos en conocimiento de la opinión pública a través de una información suficiente y transparente.

4. Evaluar los resultados alcanzados. La información pública de los mismos debe abarcar tanto las metas conseguidas como aquellos objetivos incumplidos, dando cuenta de las razones por las que no han sido satisfechos. Esta fase no cierra el proceso ya que se trata de un modelo circular en el que los resultados alcanzados alimentan de nuevo la información proactiva por parte de la universidad respecto a las opciones que ofrece a sus stakeholders en materia de investigación e innovación, generando así nuevas expectativas e intereses.

Las acciones de comunicación específicas establecidas en el último nivel se entienden como necesarias para alcanzar cada uno de los objetivos y dotarlos de validez. 
Los mecanismos de participación, negociación, comunicación pública y transparencia permiten avanzar entre las diferentes fases del proceso.

En definitiva, el modelo comunicativo propuesto para contribuir a la RRI en las universidades sitúa a la comunicación y el diálogo como principio y motor de una investigación e innovación que puedan ser consideras responsables.

Una vez expuesto el modelo, recogemos a modo de conclusiones algunas de las principales aportaciones que supone y diversas pautas para su desarrollo, incluidos los riesgos a los que puede tener que hacer frente para su implantación.

\section{- Aportaciones del modelo}

Entendemos que el modelo planteado se adecúa al marco de la ética dialógica y al marco normativo europeo de la RRI, ofreciendo además respuesta a algunos de los retos de la comunicación de la ciencia. Así, el modelo propuesto:

- Ofrece una orientación hacia las acciones, decisiones y políticas que la universidad puede implantar para responder a las demandas de sus grupos de interés, situándose en el plano de las conductas y de la responsabilidad social. El enfoque de la RRI presentado se convierte en un recurso moral para el logro de las condiciones óptimas para la generación y mantenimiento de la confianza.

- Atiende a los principios de la ética cordial establecidos por Cortina (2007), especialmente a los principios de no instrumentalizar a las personas, capacitarlas para que puedan actuar de forma informada y autónoma, y tener en cuenta los intereses de los afectados por las decisiones a través del diálogo en base al principio dialógico. En el cumplimiento de estos tres principios el papel de la comunicación resulta fundamental.

- Dar respuesta a la necesidad de una ciencia para y con la sociedad impulsada y demandada por la Unión Europea, afectando tanto a las decisiones sobre qué se quiere que se haga - para- como sobre quién ha de tomar parte en las mismas -con(Owen et al, 2012).

- Se vincula, a través de la ética dialógica, al modelo de democracia deliberativa. Siguiendo a Carsten (2013), el modelo atiende tanto a la necesidad de participación pública como a la rendición de cuentas a través de la transparencia comunicativa. 
- Se ajusta al marco normativo europeo:

- Favoreciendo un diálogo abierto, inclusivo y sometido a información pública en el ámbito de la investigación y de la innovación, siguiendo las directrices del Tratado de la UE.

- Avanzando en los tres ámbitos establecidos por el Plan de Acción Ciencia y Sociedad al favorecer:

- La promoción de la educación y la cultura científica al situar a la comunicación de la ciencia en el centro del proceso.

- La elaboración de políticas científicas más cercanas a los ciudadanos, ayudando a replantear el contrato social con la ciencia en función de las necesidades y aspiraciones legítimas de la ciudadanía.

- La incorporación de una ciencia responsable en las distintas políticas.

- Responde a algunos de los riesgos y retos de la comunicación basada en el modelo ciencia y sociedad planteados por los expertos del proyecto MASIS (Sinue et al, 2009).

- Evita caer en modelos y conceptos excesivamente simplificados de cómo la ciencia y la sociedad se comunican.

- Atiende al reto de plantear la ciencia en sociedad como el establecimiento de formas adecuadas para la comunicación y el diálogo.

- Desecha el mito de un público singular adaptando la comunicación a los diferentes stakeholders.

- Puede contribuir a través del diálogo a romper las reticencias de los científicos hacia la sociedad.

- Engloba la responsabilidad de comunicar por parte de la ciencia y de participar por parte de la sociedad.

- Contribuye a una mayor comprensión de todas las partes acerca de la naturaleza de la ciencia como actividad evolutiva y favorece la responsabilidad colectiva en la construcción de futuros potenciales. 
- La necesidad de comunicación y diálogo en el actual panorama comunicativo requieren del aprovechamiento de las tecnologías de la web 2.0.

- Atiende al reto establecido en el informe que sienta la bases de la RRI, A report on Responsible Research \& Innovation (Sutcliffe, 2011), de plantear una RRI innovadora e inclusiva a la hora de alcanzar la participación efectiva de la ciudadanía en todas las etapas de la investigación y la innovación, garantizándoles una adecuada retroalimentación.

- El modelo ofrece respuestas de interés a algunos de los retos y críticas planteados desde el ámbito académico y profesional en materia de comunicación de la ciencia y la innovación:

- Ofrece un planteamiento de la comunicación en base al modelo "ciencia y sociedad" que garantiza que la participación ciudadana sea tenida en cuenta, respondiendo a las críticas sobre la verdadera bidireccionalidad de este modelo (De Semir, 2014).

- Complementa la comunicación unidireccional de la ciencia realizada mayoritariamente por las universidades, manteniendo la relevancia de la misma.

- La propia participación de los grupos de interés contribuye a incrementar el conocimiento científico de sus miembros, generando aprendizaje social (López Cerezo, 2005).

- Permite, siguiendo a De Semir (2014), informar a los stakeholders sobre cuestiones relacionadas con la ciencia y la tecnología; informar a la ciencia acerca de las percepciones y expectativas sociales; poner la experiencia científica a disposición del público; llegar a tener un impacto en el diseño de políticas; mejorar la legitimidad de la investigación desarrollada en los campus y desempeñar una función destacada en el gobierno de la ciencia, la tecnología y el riesgo potencial.

- Responde a la creciente demanda social de participación en cuestiones de ciencia y tecnología reflejada en la última Encuesta de Percepción Social de la Ciencia (FECYT, 2015a) en la que por primera vez son mayoría -un 53,1\%- los ciudadanos que consideran que deberían desempeñar un papel más importante en las decisiones sobre ciencia y tecnología que les afectan. 


\section{- Pautas para su desarrollo}

Del estudio teórico y, especialmente, de los resultados de la investigación empírica, se desprenden algunas recomendaciones de interés para el desarrollo del modelo. La investigación ha puesto también de manifiesto algunas de las dificultades a las que podría tener que hacer frente. En este punto cabe destacar las siguientes consideraciones:

- Entender que la implantación de un modelo de comunicación requiere del respaldo de los órganos de gobierno de las universidades y de la dotación humana y material necesaria para su adecuado desarrollo en las mismas.

- Continuar mejorando la comunicación entendida como transmisión de información realizada por las universidades $-\mathrm{y}$ valorada por las mismas como muy importante- y potenciar la comunicación bidireccional menos desarrollada, pero con una tendencia creciente.

- Aprovechar el potencial y el predominio de las TIC para la comunicación e interacción con los stakeholders.

- Tener en cuenta el valor de los medios de comunicación de masas y su papel como público prioritario, destinatario de gran parte de las acciones de comunicación de la ciencia de las universidades.

- Incrementar la localización de proximidad de la RRI para lo que puede resultar provechosa la consideración de los públicos del entorno de la universidad como públicos prioritarios.

- Aprovechar la comunicación establecida desde las universidades con la sociedad civil y la comunidad científica como públicos principales y reforzar la comunicación con Administración y empresas, los otros dos grupos establecidos en el mapa de stakeholders.

- Valorar el interés de contar con los Consejos Sociales de las universidades como organismos en los que están representados diferentes stakeholders a la hora de promover el diálogo central del modelo.

- Considerar la utilidad de herramientas utilizadas en la RSC, adaptándolas, como webs y publicaciones específicas, teléfonos de información, encuentros y foros 
con stakeholders, códigos éticos o de conducta, comités de ética, memorias de sostenibilidad y auditorías éticas, entre otras.

- Tener en cuenta los riesgos que comporta la ruptura con el actual sistema de gestión de la investigación y la innovación y de comunicación de la ciencia que supone el modelo propuesto:

- Prever posibles reticencias por parte de la comunidad científica y los profesionales de la comunicación de la ciencia a la participación de los stakeholders en el establecimiento de los fines de la investigación.

- Predominio de la comunicación unidireccional realizada de forma mayoritaria al final de proceso científico.

- Ausencia de mecanismos de comunicación relacionados con las fases establecidas en el modelo vinculadas a expectativas, compromisos $\mathrm{y}$ rendición de cuentas.

- Posible falta de consideración de la necesidad de un cambio por parte de las universidades al entender que la aplicación de criterios éticos y de responsabilidad es ya la adecuada (en contra de la opinión de los expertos).

Una vez establecidas algunas de las aportaciones que puede suponer el modelo propuesto y planteadas una serie de pautas a tener en cuenta para su posible desarrollo, cerraremos la tesis doctoral abordando en un último capítulo algunas de las limitaciones a las que ha tenido que hacer frente y planteando posibles líneas de trabajo que, a la vista de los resultados alcanzados, podrían resultar de interés. 



\section{Limitaciones y futuras líneas de trabajo}

Si bien el presente trabajo, a partir tanto de la investigación teórica como empírica, ha conseguido alcanzar los objetivos planteados así como la verificación de la hipótesis, consideramos pertinente señalar algunas de las limitaciones con las que nos hemos encontrado.

Por una parte, a pesar de que en los últimos años se viene registrando un interesante aumento de la bibliografía en torno a la RRI, todavía se trata de un concepto incipiente y, por tanto, sin una sólida base teórica sobre el mismo. La presente tesis ha tratado de buscar los puntos en común entre las propuestas de diversos autores, aportando un enfoque propio desde la perspectiva de la ética dialógica.

Por otra parte, el planteamiento interdisciplinar de la presente tesis ha obligado a abordar la investigación desde una perspectiva amplia que abarca y pone en relación los ámbitos de la Ética y la Comunicación. No obstante, ésta doble aproximación ha permitido trazar, en primer lugar, un marco ético y político para la RRI y, en segundo, determinar a partir de este marco el papel de la comunicación como elemento moralmente necesario para el desarrollo de una investigación y una innovación que puedan ser consideradas responsables.

Entre las limitaciones a las que ha tenido que hacer frente el estudio se encuentra, además, la falta de experiencias en el desarrollo de acciones de RRI vinculadas a la comunicación de la ciencia desde las universidades. Si bien hemos visto algunos ejemplos de buenas prácticas de RRI, ninguna de ellas se centraba en las acciones de las universidades en materia de comunicación. Ante esta ausencia, la investigación planteó una aproximación a la realidad de la comunicación de la ciencia en la universidad, un análisis que ha evidenciado la distancia existente con el modelo comunicativo propuesto.

El estudio de una muestra de universidades a través de un cuestionario resultaba asimismo necesario ante el déficit de bibliografía que muestre la realidad de la comunicación y divulgación de la ciencia en los centros de investigación y universidades españolas. La publicación prevista por la FECYT para finales de 2015 sobre los datos recogidos a través de las encuesta sobre indicadores de la actividad en cultura científica realizadas desde 2011 hasta 2014 contribuirá, sin duda, a ampliar el 
conocimiento sobre esta realidad. Resultará asimismo de interés conocer el informe sobre las acciones y evolución de las UCC+i en España desde su nacimiento, hace siete años hasta la actualidad, puesto en marcha por la FECYT con el envío de un cuestionario a las UCC+i en agosto de 2015 y del que se desconoce en este momento su posible fecha de difusión.

Más allá del ámbito universitario o de las UCC+i, el papel de la comunicación como elemento central para el desarrollo de la RRI no cuenta tampoco con estudios específicos de referencia. En este sentido, cabe destacar el inicio en septiembre de 2015 del proyecto New Understanding of Communication, Learning and Engagement in Universities and Scientific Institutions (NUCLEUS) financiado a través del programa Horizonte 2020, que plantea precisamente el estudio de la comunicación como elemento clave en el proceso de RRI. Un consorcio internacional formado por 24 socios de Europa, Asia y África y coordinado por la Universidad de Ciencias Aplicadas de Cleves (Alemania) trabajará durante los próximos cuatros años en el estudio de la gobernanza y la cultura de los centros de investigación con el fin de promover un mayor diálogo entre ciencia y sociedad (Rhine-Waal University of Applied Sciences, 2015).

La puesta en marcha de un proyecto como NUCLEUS, pone de manifiesto la necesidad de avanzar hacia un mayor conocimiento del papel de la comunicación en la RRI. La presente tesis busca contribuir a este avance, aportando una visión de los aspectos éticos de la comunicación para contribuir a la RRI en las universidades. Se plantea por tanto como un punto de partida que aporta nuevos conocimiento y propuestas para abordar la RRI, abriendo nuevas vías de desarrollo e investigación.

Entre las futuras líneas de investigación posibles, entendemos que resultaría de interés avanzar en un procedimiento específico para la implantación del modelo comunicativo propuesto. Una implantación que requeriría de una amplia reflexión sobre la forma más adecuada para que el modelo fuera compatible con los actuales sistemas de comunicación de la ciencia de las universidades, contribuyendo a su mejora. Ante la ruptura que plantea el modelo propuesto respecto a los mecanismos actuales de comunicación de la ciencia en las universidades, resultaría imprescindible reflexionar sobre quiénes serían los actores más adecuados de cara a la gestión del modelo establecido.

El estudio realizado hace prever que la RRI seguirá ganando peso en los próximos años, al menos en el ámbito europeo de ciencia e innovación. La investigación 
desarrollada ha confirmado la hipótesis de que la comunicación ética de la ciencia es un requisito moralmente imprescindible para el desarrollo de un modelo de gestión de la Investigación e Innovación Responsable. Por tanto, y a partir de los resultados alcanzados, resulta fundamental continuar avanzando en el desarrollo de una Comunicación Pública de la Ciencia que contribuya, a través de la información y el diálogo con todos los grupos de interés, a alcanzar una investigación e innovación que responda a las expectativas legítimas de los diferentes stakeholders y pueda, por tanto, ser considerada responsable. 



\section{BIBLIOGRAFÍA}





\section{BIBLIOGRAFÍA}

- ACED, C. (2010), "La ética 2.0 de la comunicación científica” en La ética, esencia de la comunicación científica y médica, Cuadernos de la Fundació Víctor Grifols i Lucas, Barcelona.

- Agüeros SÁnchez F., Rodríguez García H.J. y Martínez Domínguez J.F. (2011), "Modelo de comunicación responsable para la responsabilidad social empresarial", Universidad Autónoma de Coahuila, Facultad de Contaduría y Administración en www.colparmex.org/Revista/Art18/78.pdf [Fecha de consulta 15 de abril de 2015].

- AlfayA, V. (2006), "Acountability: comunicación y reporting" en Gestión y comunicación de la Responsabilidad Social Empresarial, Colección Biblioteca Ciencias Sociales, Ediciones Cinca, Madrid.

- Anichini G. y Cheveigné S. (2012), “Overview of research related to science in society in Europe" en Science and Public Policy 39 (6): 701-709.

- APEL, K.O. (1985), La transformación de la filosofía, Taurus, Madrid.

- AriÑo Villarroya, A. (2014), “La comunicación científica hoy” en Los públicos de la ciencia, Cuadernos de la Fundación Dr. Antonio Esteve, Fundación Dr. Antonio Esteve, Barcelona.

- Barros del Rio, M. A. (Ed.) (2012), Comunicación Social de la Ciencia: Estrategias y Retos, Centro Nacional de Investigación sobre la Evolución Humana (CENIEH), Burgos.

- BECK, U. (1992), Risk Society: Towards Another Modernity, Sage, London.

- Bloch C. y MejlgaARd N. (2012), "Science in Society in Europe" en Science and Public Policy 39 (6): 695-700.

- BoDMER, W. (1985), The Public Understanding of Science, Royal Society, Londres.

- Bonfil Olivera, M. (2013), "La ciencia ciudadana" en Milenio Diario, 13 de noviembre de 2013, http://lacienciaporgusto.blogspot.com.es/2013/11/la-cienciaciudadana.html [Fecha de consulta 23 de febrero de 2014]. 
- Buil, P. y Medina, P. (2015), Dircom, comunciar para transformar, Pirámide, Madrid.

- Calvo Hernando, M. (2002), "El periodismo del tercer milenio: problemas de la divulgación científica en Iberoamérica” en Interciencia, v.27 n.2, Caracas.

----- (2005), "Desafíos del siglo XXI para la divulgación de la ciencia: globalidad, complejidad y expansión incontrolada del saber" en Universidad y comunicación social de la ciencia, Editorial Universidad de Granada, Granada.

- Cardona, P.J. (2014), "Públicos y ciencia" en Los públicos de la ciencia, Grupo de Estudios Avanzados de Comunicación Universidad Rey Juan Carlos, Cuadernos de la Fundación Dr. Antonio Esteve, Barcelona.

- CArroll A. B. (1993), Business and Society. Ethics and Stakeholder Management, South-Western Publishing, Cincinnati, Ohio.

- Carsten Stahl, B. (2012), "Morality, Ethics, and Reflection: A Categorization of Normative IS Research" en Journal of the association for information systems 13(8), 636-656.

- CARSTEn STAHL, B. (2013), "Responsible research and innovation: The role of privacy in an emerging framework" en Science and Public Policy 40 (6), 708-716, http://spp.oxfordjournals.org/content/40/6/708.full [Fecha de consulta 23 de abril de 2014].

- CASAJÚs, L. (2014), “Radios universitarias y redes sociales. Análisis de la gestión de contenidos de la radio universitaria española en las redes sociales", Tesis doctoral, Universitat Jaume I, Castellón.

- Casas, J., Repullo J. y Donado J. (2003), "La encuesta como técnica de investigación. Elaboración de cuestionarios y tratamiento estadístico de los datos" en Atención Primaria, 31(8):527-38.

- CASTElls, M. (1996), La era de la información, 3 vols, Alianza, Madrid.

- COMCIRED (2014), http://www.comcired.es/UCCi/Pages/UCCi_Home.aspx [Fecha de consulta 10 de agosto de 2014]. 
- COMisión Europea (2006), "Metodologías de evaluación Europe Aid, Focus Group”, http://ec.europa.eu/europeaid/evaluation/methodology/tools/too_fcg_res_es.htm [Fecha de consulta 9 de abril de 2015].

- ConiLl, J. (2004), Horizontes de economía ética, Tecnos, Madrid.

----- y GozÁlvez, V. (2010), Ética de los medios: una apuesta por la ciudadanía audiovisual, Gedisa, Barcelona.

- CóRdobA, S. O. (2011), “La comunicación en la gestión de la Responsabilidad Social Empresarial” en Correspondencias \& Análisis, (1), 137-156.

- Corraggio, J.L. (2001), Construir universidades en la adversidad. Desafíos de la educación superior en América Latina, OEA/OAS, Punta del Este.

- CortinA, A. (1993), Ética aplicada y democracia radical, Tecnos, Madrid.

----- y MARTíneZ E. (1996), Ética, Ediciones Akal, Madrid.

----- (1997a), "Presupuestos éticos del quehacer empresarial” en A. Cortina (dir.), Rentabilidad de la ética para la empresa, Visor, Madrid.

----- (1997b), Ciudadanos del mundo. Hacia una teoría de la ciudadanía, Alianza Editorial, Madrid.

----- (2001), Alianza y contrato. Política, ética y religión, Trotta, Madrid.

----- (2003), Razón pública y éticas aplicadas. Los caminos de la razón práctica en una sociedad pluralista, Editorial Technos, Madrid.

----- (2005), "Ética de la empresa: no sólo responsabilidad social” en Ética de la empresa: hacia un nuevo orden global, Fundación ÉTNOR, Valencia.

-----, CONILl, J. y García MARZÁ, D. (2005), Ética de la empresa. Claves para una nueva cultura empresarial, Trotta, Madrid.

----- (2007), Ética de la razón cordial. Educar en la ciudadanía en el siglo XXI, Ediciones Nobel, Oviedo.

----- (2009), Las fronteras de la persona. El valor de los animales, la dignidad de los humanos, Taurus, Madrid.

----- (2010a), Justicia cordial, Trotta, Madrid. 
----- (2010b), "Ciudadanía activa en una sociedad mediática" en Jesús Conill y Vicente

Gozálvez (coords.), Ética de los medios: una apuesta por la ciudadanía audiovisual, Gedisa, Barcelona.

----- (2013), ¿Para qué sirve realmente la ética?, Editorial Paidós, Barcelona.

- CRESA.CAT, http://www.cresa.cat/blogs/sociedad/es/el-cresa-amb-escolab-i-la-recercai-innovacio-responsables-rri/ [Fecha de consulta 23 de abril de 2014].

- Crovi DruetTA, D. (2005), "La articulación medios/universidad en la distribución social del conocimiento" en Mass media y Universidad. El reto de la comunicación en las universidades, Editorial Universidad de Granada, Granada.

- DAVIS, K. (1977), "Five propositions for social responsibility” en A.B. Carroll (ed.), Managing corporate social responsibility, Little, Brown and Company, pp. 46-51, Boston/Toronto.

- De SEMIR, V. (2011), Meta análisis: comunicación científica y periodismo científico, Fundación Española para la Ciencia y la Tecnología (FECYT), Madrid.

----- (2014), Decir la ciencia. Divulgación y periodismo científico de Galileo a Twiter, Publicacions i Edicions de la Universitat de Barcelona, Barcelona.

- Dewey (1927), Public Deliberation: Pluralism, Complexity, and Democracy, J. MIT Press, Bohman.

- EÑA, J. (2008), “El ideal de la democracia republicana” en A. Arteta, El saber del ciudadano, Alianza, Madrid.

- Enderle, G. (2003), “Competencia Global y Responsabilidad Corporativa de las pequeñas y medianas empresas" en A. Cortina (dir.), Construir confianza. Ética de la empresa en la sociedad de la información y las comunicaciones, pp.131-155, Trotta, Madrid.

- EPSRC. Enginnering and Physical Sciences Research Council, http://www. epsrc.ac.uk/ [Fecha de consulta 8 de julio de 2014]

- EsCÁMEZ, J. (2003), “La educación para la participación en la sociedad civil” en Revista de Educación, num. extraordinario "Ciudadanía y educación", Ministerio de Educación, Cultura y Deporte, Madrid. 
- ESConect (2009), ESConect modules, ESConet_Modules_CC-WordPress.com [Fecha de consulta 26 de abril de 2015].

- European COMmission (2000), Ciencia, sociedad y ciudadanos en Europa, Documento de trabajo de los servicios de la Comisión, Bruselas.

----- (2001), Libro verde. Fomentar un marco europeo para la responsabilidad social de las empresas, Publicaciones Oficiales UE, Bruselas.

----- (2002), Science and Society Action Plan, European Research Area, Bruselas.

----- (2011), "DG Research workshop on Responsible Research \& Innovation in Europe (16-17 May 2011 Brussels)", http://ec.europa.eu/research/sciencesociety/document _library/pdf_06/responsible-research-and-innovation-workshop-news letter_en.pdf [Fecha de consulta 1 de septiembre de 2012].

----- (2012), Responsible Research and Innovation. Europe's ability to respond to societal challenges, Publicaciones Oficiales UE, Bruselas.

----- (2013), "Horizon 2020. The EU Framework Programme for Research and Innovation", https://ec.europa.eu/programmes/horizon2020/en/h2020section/responsible-research-innovation [Fecha de consulta 227 de mayo de 2015].

---- (2015), “Horizon 2020, Work Programme 2014-2015. Science with and for Society. Revised", Unión Europea, Bruselas.

- FECYT (2010), Agenda ciudadana de Ciencia e Innovación, Fundación Española de Ciencia y Tecnología, Madrid.

----- (2012), Libro blanco de la Unidades Científicas y de la Innovación, Fundación Española de Ciencia y Tecnología, Madrid.

---- (2015a), VII Encuesta de Percepción Social de la Ciencia y la Tecnología, Fundación Española de Ciencia y Tecnología, Madrid.

----- (2015b), Convocatoria de ayudas para el fomento de la cultura científica, tecnológica y de la innovación 2015, Fundación Española de Ciencia y Tecnología, http://www.convocatoria.fecyt.es/Publico/Bases/Bases.aspx [Fecha de consulta 5 de mayo de 2015]. 
- Federación de Asociaciones de Periodistas Españoles, FAPE, (2013), Manifiesto FAPE en defensa del periodismo, http://www.fape.es/manifiesto-de-la-fape-en-defensadel-periodismo_fape-818799721464.htm [Fecha de consulta 5 de marzo de 2013]

- Feenstra, R. (2012), Democracia monitorizada en la era de la nueva galaxia mediática. La propuesta de John Keane, Icaria Editorial, Barcelona.

----- (2008), "Las memorias de la RSC, una comunicación tangible en la gestión de los intangibles", ponencia realizada en el Curso de Verano La elaboración de memorias de RSE: un instrumento para el diálogo empresarial, Universitat Jaume I, Benicàssim (Castellón).

----- (2011), Comunicación interna 2.0: La gestión de los portales corporativos y redes sociales, Editorial Ciencias Sociales.

----- et al. (2012), "El videoblog multilingüe como oportunidad ante los nuevos retos de la comunicación científica: el caso Ciència UJI TV”, www.uji.es/bin/noticies/ctv/p1.pdf [Fecha de consulta 29 de abril de 2015].

- Ferrer, A. (2005), "Una mina de oro puro: las universidades y su potencial informativo" en Universidad y comunicación social de la ciencia, Editorial Universidad de Granada, Granada.

- Fisher, E., Mahajan, R. y Mitcham, C. (2006), "Midstream modulation of technology: governance from within" en Bulletin of Science, Technology and Society, 2006; 26:485-96.

- FRANCESCUtTI, L.P. (2014), Los públicos de la ciencia, Grupo de Estudios Avanzados de Comunicación Universidad Rey Juan Carlos, Cuadernos de la Fundación Dr. Antonio Esteve, Barcelona.

- FreEmAn R.E. (1984), Strategic Management. A Stakeholder Approach, Pitman, Toronto.

- Friedman, M. (1979), “The Social Responsibility of Business is to Increase Its Profits" en T.L. Beauchamp y N.E. Bowie (eds.), Ethical Theory and Business, Prentice Hall, Englewood Cliffs, pp. 55-60. 
- FundaCIÓN BBVA (2012), Cultura científica: actitudes hacia la ciencia, http://www.fbbva.es/TLFU/tlfu/esp/investigacion/fichainves/index.jsp?codigo=381

[Fecha de consulta 28 de abril de 2015].

- Fundación COTEC (2006), Comunicar la ciencia, Fundación Cotec para la Innovación Tecnológica, Madrid.

- Fundació Víctor GRIfols i LuCAS (2010), La ética, esencia de la comunicación científica y médica, Cuadernos de la Fundació Víctor Grifols i Lucas, Barcelona.

- García MarzÁ, D. (1992), Ética de la justicia. J. Habermas y la ética discursiva, Tecnos, Madrid.

----- (1999), "La ética ante la responsabilidad ecológica" en La Laguna. Revista de Filosofía, Número extraordinario: Universalismos, 1999, pp.296-299.

----- (2003), Razón pública y éticas aplicadas. Los caminos de la razón práctica en una sociedad pluralista, Editorial Technos, Madrid.

----- (2004), Ética empresarial. Del diálogo a la confianza, Editorial Trotta, Madrid.

----- (2005), "Diálogo y responsabilidad: Bases éticas de la confianza en la empresa" en ICADE, Revista cuatrimestral de las Facultades de Derecho y Ciencias Económicas y Empresariales, $\mathrm{n}^{\circ}$ 64, enero-mayo, pp. 91-108.

----- (2006), "La responsabilidad social de la empresa: una definición desde la ética empresarial” en Revista Valenciana de Economía y Hacienda, nº12, III, pp.77-94.

----- (2008), "Sociedad civil: una concepción radical" en RECERCA. Revista de Pensament i Anàlisi, nº8, pp. 27-46.

- GARCía MolinA, E. (2012), "SINC, una agencia de noticias para la ciencia" en M" Amor Barros del Rio (Ed.), Comunicación Social de la Ciencia: Estrategias y Retos, Centro Nacional de Investigación sobre la Evolución Humana (CENIEH), Burgos.

---- (2014), "Los públicos de la agencia SINC" en Los públicos de la ciencia, Cuadernos de la Fundación Dr. Antonio Esteve, Barcelona.

- GeOghEAN-QuinN, M. (2012), "Science in Dialogue - Towards a European Model for Responsible Research and Innovation", Odense, Denmark, 23-25 April 2012, http://ec.europa.eu/research/science-society [Fecha de consulta 4 de abril 2013]. 
- Global RePORTING InITIATIVE (2015), https://www.globalreporting.org/ Pages/default.aspx [Fecha de consulta 15 de abril de 2015]

- GoldberG, N. (2010), "Responsible innovation: A pilot study with the U.K. Engineering and Physical Sciences Research Council" en Risk Analysis: An International Journal, 30:1699-707.

- Golombeck, D. (2015), "Entrevista a Diego Golombeck" en Revista Digital Cabal, http://www.revistacabal.coop/entrevista-diego-golombek [Fecha de consulta 22 de abril de 2015]

- GómEZ, O. (1996), La investigación en comunicación desde la perspectiva cualitativa, Instituto Mexicano para el Desarrollo Comunitario, Guadalajara (México).

- GonzÁlez Esteban, E. (2002), “Defining a Post-conventional Corporate Moral Responsibility" en Journal of Business Ethics, vol. 39, pp. 101-108.

----- y GARcía MARZÁ, D. (2006), “La responsabilidad social empresarial (RSE) en Europa: la apuesta por un nuevo modelo de empresa. Una revisión crítica desde la ética empresarial" en RECERCA. Revista de Pensament i Anàlisi, no 4, 2006, pp.157-171.

---- (2007), “La teoría de los stakeholders. Un puente para el desarrollo práctico de la ética empresarial y la responsabilidad social corporativa" en Veritas, Vol II, n 17, pp. 205-224.

----- (2012), "Elementos y estructura de la responsabilidad" en X Conferencia anual de Ética, Economía y Dirección "Responsabilidad social de las empresas", Universidad Pontificia Comillas, Madrid. www.eben-spain.org/docs/ Papeles/ X/lsa_Gonzalz.pdf [Fecha de consulta 3 de febrero de 2013].

- GozÁlvez V. (2013), Ciudadanía mediática. Una mirada educativa, Dykinson, Madrid.

- Gregory, J. y Miller, S. (1998), Science in Public Comunication, Culture and Credibility, Plenum Press, Cambridge, Massachussetts.

- Gutmann, A (2011), "The ethics of synthetic biology: Guiding principles for emerging technologies" en Hastings Center Report 2011; 41 (4):17-22.

- HABERMAS, J. (1998), Facticidad y Validez, Madrid, Trotta. 
----- (1999), La inclusión del otro. Estudios de teoría política, Paidós, Barcelona.

----- (2000), Aclaraciones a la éticas del discurso, Trotta, Madrid.

----- (2006), Entre naturalismo y religión, Paidós, Barcelona.

- Hernández Sampieri, R., Fernández Collado, C. y Baptista Lucio, P. (2003), Metodología de la investigación, McGraw-Hill, México.

- HeAther, D (1990), Citizenship, Longmann, Londres/Nueva York.

- HoRIZON 2020 (2014), Science with and for Society, http://ec.europa.eu/programmes/ horizon2020/en/h2020-section/science-and-society [Fecha de consulta 10 de julio de 2015].

- House of Lords Select Committee on Science And Technology (2000), Science and Society, Third Report of Session 1999-2000, http://www.publications. parliament.uk/pa/ld199900/ldselect/ldsctech/38/3802.htm [Fecha de consulta 20 de abril de 2015].

- JONAS, H. (1996), El principio de responsabilidad, Herder, Barcelona.

- KeAne, J. (2009), “DDemocracia monitorizada? La historia secreta de la democracia desde 1945", conferencia Universitat Jaume I, 5 de febrero de 2009, Castellón, http://eticaydemocracia-uji.blogspot.com.es/2009/11/conferencia-prof-john-keaneelfuturo.html [Fecha de consulta 14 de abril de 2014].

- Lafunte, A. y LombrañA, D. (2014), “Oficina Nacional de Ciencia Ciudadana” en Público.es, 13 de febrero de 2014, http://blogs.publico.es/el-cuarto-poder-enred/2014/02/13/oficina-nacional-de-ciencia-ciudadana/ [Fecha de consulta 5 abril 2014].

- LAROCHE (2011), "Franco-British workshop on responsible innovation. From concepts to practice" (23-24 May 2011), http://www.ambafrance-uk.org/Videos-andpresentations-from-the, 19118 [Fecha de consulta 1 de septiembre de 2012].

- LÓPEZ CEREzo, J.A. (2005), "Participación ciudadana y cultura científica", en ARBOR Ciencia, pensamiento y cultura, Septiembre-Octubre 2005, pp 351-362.

- LÓPEZ VERDEGUER, I (2014), “A visión for Responsible Research and Innovation” en Euroscientist http://euroscientist.com/2014/01/a-vision-for-responsible-research-andinnovation/ [Fecha de consulta 23 de abril de 2014]. 
----- y BANDA, E. (2014), "Ciencia con y para la sociedad: una perspectiva de la investigación y la innovación responsable" en Excelencia.org, http:// www.excelenciencia.org/articulo.asp $2 i d=10068 \&$ catgrupo $=29 \&$ tipocom $=20 \quad[$ Fecha de consulta 6 de mayo de 2014].

- LozAno, J.M. (1999), Ética y empresa, Trotta, Madrid.

----- (2007), "La retórica del poder: la RSE a debate" en Villafeñe, J., La comunicación empresarial y la gestión de los intangibles en España y Latinoamérica 2007, Pearson, Madrid.

- LOU (2001), “Ley Orgánica 6/2001, de 21 de diciembre, de Universidades”, Boletín Oficial del Estado, Agencia Estatal, Madrid.

- Luers, A. y Kroodsma, D. (2014), "Science Comunication in the Post-Expert Digital Age), en EOS, 95(24): 203-204.

- MARín, A. (2005), Mass media y Universidad. El reto de la comunicación en las universidades, Editorial Universidad de Granada, Granada.

----- (2005b), Universidad y comunicación social de la ciencia, Editorial Universidad de Granada, Granada.

----- (2009), “Crisis, Universidad y Comunicación Social de la Ciencia" en Estudios de Periodismo, Chile, http://www.periodismoudec.cl/estudiosdeperiodismo/index.php? option=com_content\&task=view\&id=61\&Itemid=1 [fecha de consulta 18 de abril de 2015].

- Martín Sempere, M.J., Garzón García, B. y Rey Rocha, J. (2008), "Scientists' Motivation to Communicate Science and Technology to the Public: Surveying Participants al the Madrid Science Fair" en Public Understanding $f$ Science, num.17, pag. 349.

- Medialab PRAdo (2014), Encuentro de Ciencia Ciudadana, http://medialabprado.es/article/cienciaciudadana [Fecha de consulta 6 de junio 2014].

- MeJlgaARD N. ET AL (2012), "Locating science in society across Europe: Clusters and consequences" en Science and Public Policy, 39 (6): 741-750. 
- Mesas, M. (2015), “Infoday sobre el programa 'Ciencia con y para la Sociedad'. Convocatorias 2015. Mar Mesas - NCP Programa SwafS, Oficina Europea", MUNCYT, Alcobendas (Madrid), http://www.eshorizonte2020.es/mas-europa/cienciacon-y-para-la-sociedad/noticias/disponibles-las-presentaciones-de-la-jornadainformativa -h2020-ciencia-con-y-para-la-sociedad-convocatorias-2015 [fecha de consulta 27 de mayo de 2015].

- Miller, J.D., Pardo, R. y Niwa, F. (1998), Percepciones del Público ante la Ciencia y la Tecnología, Fundación BBV, Madrid.

- Morgan, G. (1990), Imágenes de la organización, Ra-Ma, Madrid.

- MoORE, A. (2010), "Beyond participation: Opening up political theory in STS" en Social Studies of Science, 40:793-799.

- NERRI, Neuro-Enhancement Responsible Research and Innovation (2013), http://www.nerri.eu/eng/home.aspx [Fecha de consulta 20 de junio 2014].

- OBSERVATORI 2.0. (2013), "Se constituye el Comité Español de Apoyo a la RRI del proyecto NERRI", https://comunicacioncientifica.wordpress.com/2013/12/04/se-constituye-el-comite-espanol-de-apoyo-a-la-rri-del-proyecto-nerri/ [Fecha de consulta 8 de julio de 2014].

----- (2014) , “Gema Revuelta, miembro del Grupo Europeo de Expertos para el estudio de Indicadores Sociopolíticos de Investigación e Innovación Responsables", http://comunicacioncientifica.wordpress.com/2014/04/07/gema-revuelta -miembro-delgrupo-europeo-de-expertos-para-el-estudio-de-indicadores-sociopoliticos-deinvestigacion-e-innovacion-responsables/ [Fecha de consulta 4 de julio de 2014].

- Ortega y Gasset, J. (1976), “QQué es filosofía?” en Revista de Occidente, 9a ed., Alianza Editorial, Madrid.

- OWEn R., MACNAGHTEN P. y Stilgoe J. (2012), "Responsible research and innovation: From science in society to science for society, with society" en Science and Public Policy 39 (6): 751-760.

- Pulitzer, J. (1904), "The College of Journalism" en North American Review, 178(570), 641-680. 
- RAmonet, I. (2011), La explosión del periodismo. De los medios de masas a la masa de medios, Clave Intelectual, Madrid.

- Rask M., Maciukaite-Zviniene S. y Petrauskiene J. (2012), "Innovations in public engagement and participatory performance of the nations" en Science and Public Policy 39 (6): 710-721.

- RAVetz, J. R. y Funtowicz, S. (1993), "Science for the post-normal age" en Futures, vol. $25, n^{\circ} 7$.

- Renn, 0., Webler, T. y Wiedemann, P. (EDS.) (1995), Fairness and Competence in Citizen Participation, Kluwer.

- Revuelta, G. (2012), "Percepción social de la ciencia y acceso a la información” en Ma Amor Barros del Rio (Ed.), Comunicación Social de la Ciencia: Estrategias y Retos, Centro Nacional de Investigación sobre la Evolución Humana (CENIEH), Burgos.

- RIBAS, C. (2014), "Periodismo científico, presente y futuro", CristinaRibas.net, 28 de septiembre de 2014, http://www.cristinaribas.net/2014/09/28/periodismo-cientificopresente-y-futuro/ [Fecha de consulta 1 de mayo de 2015].

- Rhine-WaAl University of APPliEd ScIEnCEs (2015), “Communication is Key for Responsible Research and Innovation", Hochschule Rhein-Waal, Alemania, https://idwonline.de/de/news634596 [Fecha de consulta 28 de agosto de 2015].

- Rodríguez Gómez, G., Gil Flores, J. y García JimÉnez, E. (1999), Metodología de la investigación cualitativa, Ediciones Aljibe, Málaga.

- Roger, O. y BuIL, P. (2014), Manual de comunicación ambiental. Del greenwashing a la sostenibilidad, Ediciones Universidad de Navarra (EUNSA), Pamplona.

- Rowan, D. (2010), "How to sabe Science Jornalism", en Wired, http://www.wired.co.uk/news/archive/2010-09/27/how-to-save-science-journalism [Fecha de consulta 29 de abril de 2015]

- RRI TOOLS (2015), "RRI Tools: building a better relationship between science and society", http://www.rri-tools.eu/ [Fecha de consulta 1 de mayo de 2015]

- SABINO, C.A. (1996), El proceso de investigación, Editorial Lumen, Buenos Aires (Argentina). 
- SAgAn, C. (2000), El mundo y sus demonios. La ciencia como una luz en la oscuridad, Planeta, Barcelona.

- Santos, M. (1994), Técnica, Espaço, Tempo - Globalizaçao e Meio TécnicoCientífico Informacional, Hucitec, Sao Paulo.

- SARtori, G. (1992), Elementos de Teoría Política, Alianza, Madrid.

- Schomberg, R. Von (2011), "Prospects for technology assessment in a framework of responsible research and innovation" en R. Beecroft (Ed.), Technikfolgen abschätzen lehren, Methoden, Wiesbaden, Dusseldorp.

----- ( 2013), "A vision of responsible innovation" en R. Owen, M. Heintz y J. Bessant (Eds.), Responsible Innovation, John Wiley Forthcoming Books, Londres.

- SEN, A. (2000), Desarrollo y libertad, Planeta, Barcelona.

- Serrano, F. (2013), "Colaboración expertos amateurs" en Fundación Ibercivis, http://formacion.educalab.es/eva2013/pluginfile.php/3895/mod_resource/content/1/Fer m\%C3\%ADn\%20Serrano.pdf [Fecha de consulta 3 de febrero de 2014].

----- (2014a), “Towards increasing citizens' contribution to research" en Euroscientis, http://euroscientist.com/2014/02/towards-increasing-citizens-contribu- tion-to-research/ [Fecha de consulta 3 de febrero de 2014].

----- (2014b), "From RRI concept to toolkit-a defining Project launch" en Euroscientist, http://euroscientist.com/2014/01/from-rri-concept-to-toolkit-a-defining project-launch/ [Fecha de consulta 24 de abril de 2014].

- SINC (2014), Anuario SINC. La ciencia es noticia 2013, Fundación Española de Ciencia y Tecnología (FECYT), Madrid.

----- (2015), Anuario SINC. La ciencia es noticia 2014, Fundación Española de Ciencia y Tecnología (FECYT), Madrid.

- SinUE, K. ET AL. (2009), Challenging the Future of Science in Society. Emerging trends and cutting-edge issues. The Masis project, European Commission, Bruselas, www.ec.europa.eu/research/science-society/document_library/pdf_06/the-massisreport _en.pdf [Fecha de consulta 20 de abril de 2013]. 
- Socientize Consortium (2013), "Green Paper on Citizen Science: Citizen Science for Europe. Towards a better society of empowered citizens and enhanced research", http://www.csic.es/web/guest/libro-verde-de-la-ciencia-ciudadana [Fecha de consulta 20 de abril 2014].

- Stilgoe, J., Owen, R. y Macnaght, P. (2013), "Developing a framework for responsible innovation" en Research Policy, 42, 1568- 1580.

-----, LOCK S.J. y WILSDON, J. (2014), “¿Por qué debemos promover el compromiso público con la ciencia?” en Comprensión Pública de la Ciencia, 23: 4.

- Steinhaus N. (2014), "How the Science Shop model contributes to RRI" en Euroscientist, http://euroscientist.com/2014/01/how-the-science-shop-model-contributes -to-rri/ [Fecha de consulta 24 de abril de 2014].

- StiRling, A. (2008), “Opening up and closing down: Power, participation, and pluralism in the social appraisal of technology" en Science, Technology \& Human Values, 33: 262-294.

- Strandberg, L. (2010), La medición y la comunicación de la RSE: Indicadores y normas, Cuadernos $\mathrm{n}^{\circ} 9$ de la Cátedra "la Caixa" de Responsabilidad Social de la Empresa y Gobierno Corporativo, Navarra.

- Sutcliffe, H. (2011), A report on Responsible Research \& Innovation, European Commission, http://ec.europa.eu/research/science-society/document_library/pdf_06/rrireport-hilary-sutcliffe_en.pdf [Fecha de consulta 20 de abril 2014].

- TAYlor, S.J. y Bogdan, R. (1987), Introducción a los métodos cualitativos de investigación, Paidós, Barcelona.

- Thomas, G. y Durant, J. (1987), "Why should we promote the public understanding of science?” en M. Shortland (ed.), Scientific Literacy Papers, Oxford: Rewley House, pp. 1-14.

- Toledo FigueroA, D. (2010), "La participación social en las escuelas en los países de la OCDE” en Participación Educativa, 14, julio 2010, pp. 66-78.

- Trench B. y MiLler S. (2012), "Policies and practices in supporting scientists public communication through training" en Science and Public Policy, 39 (6): 722-731. 
- TSIPOURI L. (2012), “Comparing innovation performance and science in society in the European member states" en Science and Public Policy, 39 (6): 732-740.

- UlRiCh, P. (1993), Bases para una ética económica crítica, Universidad Alcalá de Henares, Alcalá de Henares (Madrid).

- Unión EuROPEA (2010), Tratados consolidados. Carta de los Derechos Fundamentales de la Unión Europea, Oficina de Publicaciones de la Unión Europea, Bélgica, http://europa.eu/eu-law/decision-making/treaties/index_es.htm [Fecha de consulta 10 de mayo de 2015].

- Vilanova, M.; Lozano, J. y Dinares, M. (2006). Accountability. Comunicación y Reporting en el ámbito de la RSE, Foroética, Madrid.

- Villafañe, J. (2004), La Buena Reputación: Claves del valor intangible de las empresas, Ediciones Pirámide, Madrid,

- VOICES FOR INNOVATION, http://www.voicesforinnovation.eu/ [Fecha de consulta 22 de abril de 2014]

- W. Stahel, A. (2004), “Investigación responsable. Límites y posibilidades" en Sostenible?, núm. 6.

- Yeo, S.K., Cacciatore, M.A., Brossard, D., Scheufele, A.A. y Xenos, M.A. (2014) "Science Gone Social" en The Scientist, October 1, http://www.thescientist.com/?articles.view/articleNo/40992/title/Science-Gone-Social/ [Fecha de consulta 25 de abril de 2015]. 
